\title{
THE NATURE OF ZEOLITE CATALYTIC SITES
}

\author{
by \\ Linda Margaret Parker
}

\begin{abstract}
A thesis
submitted to the Victoria University of Wellington in fulfilment of the requirements for the degree of Doctor of Philosophy

in Chemistry
\end{abstract}

Victoria University of Wellington

New Zealand

1989 


\section{ABSTRACT:}

The nature of zeolite catalytic sites was studied by observing their interactions with sorbants. In situ FTIR studies of a range of sorbants on H+ZSM-5, H+mordenite and $\mathrm{H}+\mathrm{Y}$ showed that the zeolite Bronsted proton was transferred towards the sorbant. Sorbants could be placed in three classes depending on the type of hydrogen bond formed. "Class A" sorbants were alcohols, alkanes, ammonia, amines and carboxylic acids and showed a single $v_{0-\mu}$ band shifted from the $\mathrm{v}_{\mathrm{O}-\mathrm{H}}$ of the zeolite. The shift in $\mathrm{v}_{\mathrm{O}-\mathrm{H}}$ increased with increasing proton affinity of the sorbant. "Class B" sorbants were alkenes and aromatics and showed a resultant broad, flat $\mathrm{v}_{\mathrm{O}-\mathrm{H}}$ due to bonding through the $\pi$ electrons of the double bond or aromatic ring. "Class C" sorbants included water, ethers, ketenes, aldehydes, nitriles and carboxylic acids (also class $A$ ). They showed extremely broad hydroxyl bands from -3700 to $-1200 \mathrm{~cm}^{-1}$ with several maxima. Bonding was through oxygen or nitrogen lone electron pairs.

A novel, low temperature $\left(\sim 400^{\circ} \mathrm{C}\right)$, reaction of acetic acid to ketene was observed over alkali-exchanged zeolites. Thermal desorption/mass spectrometry, mini-reactor mass spectrometry and in situ FTIR techniques were used to investigate the products obtained by varying the carboxylic acid and the catalyst, and the reaction mechanism. 
ii

DEDICATION:

To my daughter

Mary 


\section{SUMMARY:}

The nature of zeolite catalytic sites was studied by observing their interactions with sorbants. Thermal desorption/mass spectrometry, mini-reactor/mass spectrometry and in situ FTIR techniques were developed. A technique was also developed to determine the IR frequencies of the zeolite Bronsted hydroxyls, after bonding with a sorbant, by $H / D$ exchange.

Carboxylic acids sorbed on $\mathrm{H}+\mathrm{ZSM}-5$ were shown to be associated in a one-to-one ratio with zeolite acid sites. The acetic acid behaved as a base with the zeolite Bronsted protons partially transferred to the acetic acid molecules. $\mathrm{H}+\mathrm{ZSM}-5$ showed no basic behaviour.

Water sorbed on H+ZSM-5 shows broad IR bands, the origin of which had not previously been investigated. An FTIR study of the four combinations of $\mathrm{H}_{2} \mathrm{O}$ and $\mathrm{D}_{2} \mathrm{O}$ on $\mathrm{H}+\mathrm{ZSM}-5$ and $\mathrm{D}+\mathrm{ZSM}-5$ at $80^{\circ} \mathrm{C}$ showed that one band (at $\sim 3600 \mathrm{~cm}^{-1}$ ) was associated with sorbed $\mathrm{H}_{2} \mathrm{O}$. Others (at $3700, \sim 2900$ and $\sim 2470 \mathrm{~cm}^{-1}$ ) were associated with the zeolite Bronsted hydroxyl and only changed with H/D exchange of the Bronsted site. Exchange between the zeolite Bronsted hydroxyl and the sorbed water was slow, with distinct differences observed between the $\mathrm{H}+\mathrm{ZSM}-5+\mathrm{D}_{2} \mathrm{O}$ and $\mathrm{D}+\mathrm{ZSM}-5+\mathrm{H}_{2} \mathrm{O}$ cases.

Sorption of water on $\mathrm{H}+\mathrm{Y}$ resulted in FTIR spectra similar to those observed for $\mathrm{H}+\mathrm{ZSM}-5$. The amount of water sorbed was critical to the stability of $\mathrm{H}+\mathrm{Y}$. If less than one water molecule per framework Al was sorbed, the water desorbed at less than $100^{\circ} \mathrm{C}$ and the acid sites were fully restored. If greater than one water molecule per framework Al was sorbed, water only desorbed at higher temperatures with collapse of the zeolite structure. These results imply that water breaks Al-framework bonds. With more than one molecule of water sorbed per framework Al, more than one Al-framework bond may have broken, preventing reinsertion of Al into the framework upon desorption of water. 
An in situ FTIR study of a wide range of sorbants on $\mathrm{H}+\mathrm{ZSM}-5$ showed that they could be placed in three classes depending on the type of hydrogen bond formed. "Class A" sorbants were alcohols, alkanes, ammonia, amines and carboxylic acids and showed a single $\mathrm{v}_{\mathrm{O}-\mathrm{H}}$ band broadened and shifted from the $\mathrm{v}_{\mathrm{O}-\mathrm{H}}$ peak of $\mathrm{H}+\mathrm{ZSM}-5$. The shift in $\mathrm{v}_{0-\mathrm{H}}$ increased with increasing proton affinity of the sorbant. This correlation may be able to be used to obtain a quantitative measure of acid strength of $\mathrm{H}+\mathrm{ZSM}-5$. "Class B" sorbants were alkenes and aromatics and showed a resultant broad, flat $\mathrm{v}_{0-H}$ due to bonding through the $\pi$ electrons of the double bond or aromatic ring. "Class C" sorbants included water, ethers, ketenes, aldehydes, nitriles and carboxylic acids (also Class A). They showed extremely broad hydroxyl bands from $\sim 3700$ to $\sim 1200 \mathrm{~cm}^{-1}$ with several maxima. Bonding was through oxygen or nitrogen lone electron pairs.

Bases sorbed on $\mathrm{H}+$ mordenite showed similar behaviour to that observed for $\mathrm{H}+\mathrm{ZSM}-5$. Only methanol and ammonia bonded strongly with all the Bronsted sites. Steric limitations restricted larger sorbants to strong interactions with only some of the acid sites, with weak interactions observed for the remainder.

On $\mathrm{H}+\mathrm{Y}, \mathrm{Class} \mathrm{A}$ sorbants showed more complicated spectra with no single, shifted $\mathrm{v}_{0-H}$, because of the two types of Bronsted hydroxyls present. For pyridine sorbed on $\mathrm{H}+\mathrm{Y}$, major differences were observed in the ring bending and stretching region between physisorbed pyridine, pyridine sorbed on LF hydroxyls and pyridine sorbed on HF hydroxyls. Diffuse, broad bands were observed for the Class $C$ sorbant, DME. These were different in shape and position from those observed on $\mathrm{H}+\mathrm{ZSM}-5$ and H+mordenite, implying a different environment for the Bronsted protons associated with DME.

A novel reaction of acetic acid to ketene was observed over alkali-exchanged zeolites. The reaction occurred at low temperature $\left(-400^{\circ} \mathrm{C}\right)$ compared to conventional pyrolysis of acetic acid to ketene $\left(-750^{\circ} \mathrm{C}\right)$. This was a general reaction with other carboxylic acids reacting to their corresponding 
ketene. With increasing carboxylic acid chain length, the reaction became less effective with a ketene observed for iso-butyric acid but not for n-butyric acid.

In situ reactions of the ketene in the catalyst by adding reactant to the acetic acid feed were shown to be effective. Acetylation reactions of methanol to methylacetate, ethanol to ethylacetate and dimethylamine to dimethylacetate occurred readily.

A survey using the $t d / m s$ technique to determine the range of catalyst/cation combinations over which conversion of acetic acid to ketene occurred was carried out. The largest pore zeolites studied ( $\mathrm{X}$ and $\mathrm{Y}$ ) with the smallest cations ( $\mathrm{Li}^{+}$and $\mathrm{Na}^{+}$) were the most effective, as competing products (acetone and $\mathrm{CO}_{2}$ ) were minimised.

An investigation of the reaction mechanism showed that the reaction of acetic acid to ketene (at $\sim 400^{\circ} \mathrm{C}$ ) was catalysed by surfaces, and was not significant in the gas phase. Acetone and $\mathrm{CO}_{2}$ evolution was independent of ketene formation and occurred via decomposition of the acetate formed on the alkali cations. Ketene evolution was associated with a species that was not sorbed on alkali cation or Bronsted acid sites, but at weaker sorption sites. The "best" catalysts for producing ketene were therefore high surface area materials with weak sorption sites, but no strong Bronsted basic or acidic sites, such as silicalite or kao wool. 


\section{ACKNOWLEDGEMENTS :}

The help and encouragement of a large number of people has been essential in the completion of this thesis. I wish acknowledge the contribution of my supervisors Dr. Dave Bibby, Dr. Gary Burns and the late Dr. Alan Freeman, and thank Dr. Gordon Leary and Prof. Curtis for allowing me to undertake this study.

Invaluable help in development of experimental techniques and operation of equipment was given by Dr. John Patterson, Bob Sewell, Dr. Bob Buckley, Dr. Mike Staines and Chemistry Division's glassblowers. I would like to thank all members of the Inorganic Materials section, who provided a good working environment. Some analyses were carried out by Neville Baxter.

In the final processing of the thesis, encouragement and computer back up from John Patterson is greatly appreciated. I would also like to thank my husband, Michael, for his support and the time spent in evenings and weekends entertaining Mary so that I could finish this work. 


\section{CONTENTS:}

ABSTRACT ii

SUMMARY iv

ACKNOWLEDGEMENTS Vii

CHAPTER 1: INTRODUCTION 1

1.1 Zeolite structure 1

1.2 Definition of zeolite acid sites 5

1.3 Definition of zeolite basic sites 6

1.4 Techniques for studying catalytic sites 7

1.5 Historical summary 8

1.6 Summary of the current knowledge on acid sites 9

1.7 Summary of the current knowledge on basic sites 11

1.8 This thesis 13

1.9 REFERENCES 13

CHAPTER 2: EXPERIMENTAL

2.1 Thermogravimetric analysis (tga) 17

2.2 Thermal desorption mass spectrometry (td/ms) 17

2.2.2 Controlled sorption on to zeolite samples 21

2.2.3 Mini-reactor with on-line analysis by mass spectrometry 21

2.3 Fourier Transform Infra-red (FTIR) 22

2.3.2 The In situ FTIR cell 23

2.3.3 Sample Preparation 26

2.4 REFERENCES 26 
CHAPTER 3: SORPTION, DESORPTION AND REACTION OF CARBOXYLIC ACIDS OVER PROTONATED ZEOLITES.

3.1.1 Reasons for study 27

3.1.2 Reactions of carboxylic acids 28

3.2 RESULTS AND DISCUSSION 30

3.2.1 Tga results 30

3.2.2 Tdms results 30

3.2.3 Interaction/reaction of carboxylic acids with ammonia and amines over $\mathrm{H}+\mathrm{ZSM}-5$

3.2.3. A Sorption of acetic acid followed by sorption of ammonia at $150^{\circ} \mathrm{C}$

3.2.3.B Sorption of ammonia followed by sorption of acetic acid at $150^{\circ} \mathrm{C} \quad 35$

3.2.3.D Sorption of propionic acid followed by ammonia 38

3.2.4 NMR Results 40

3.2.5 FTIR Results 41

3.2.5. A Acetic acid on $\mathrm{H}+\mathrm{ZSM}-5 \quad 41$

3.5.2. C $\mathrm{CD}_{3} \mathrm{COOD}$ sorbed on $\mathrm{H} / \mathrm{D}+\mathrm{ZSM}-5 \quad 49$

3.2 .6 Formic Acid on $\mathrm{H}+\mathrm{ZSM}-5$

3.2.6. A Td/ms Results 52

3.2.6.B FTIR Results: Formic acid on $\mathrm{H}+\mathrm{ZSM}-5$

3.3 CONCLUSIONS 56

3.4 REFERENCES 57

CHAPTER 4: THE SORPTION OF WATER ON B+ZSM-5:

4.1 INTRODUCTION 59

4.2.1 H+ZSM-5 plus $\mathrm{H}_{2} \mathrm{O}$

4.2.2 D+ZSM-5 plus $\mathrm{H}_{2} \mathrm{O} \quad 64$

$4.2 .3 \mathrm{H}+\mathrm{ZSM}-5+\mathrm{D}_{2} \mathrm{O} \quad 66$

$4.2 .4 \mathrm{D}+\mathrm{ZSM}-5+\mathrm{D}_{2} \mathrm{O} \quad 68$

4.3 DISCUSSION 70

4.4 CONCLUSIONS 71

4.5 REFERENCES 72 
CHAPTER 5: INTERACTION OF WATER WITH THE ZEOLITE H+Y, STUDIED BY FTIR.

$\begin{array}{lll}5.1 & \text { INTRODUCTION } & 73 \\ 5.2 & \text { EXPERIMENTAL } & 74 \\ 5.3 & \text { RESULTS } & 75 \\ 5.3 .1 & \mathrm{H}+\mathrm{Y}+\mathrm{H}_{2} \mathrm{O} \text { at } 80^{\circ} \mathrm{C} & 76 \\ 5.3 .2 & \mathrm{H}+\mathrm{Y}+\mathrm{H}_{2} \mathrm{O} \text { at } 25^{\circ} \mathrm{C} & 77 \\ 5.4 & \text { DISCUSSION } & 80 \\ 5.5 & \text { CONCLUSIONS } & 83 \\ 5.6 & \text { REFERENCES } & 83\end{array}$

CHAPTER 6: SORPTION OF PYRIDINE ON H+Y

6.1 INTRODUCTION 85

6.1 .2 IR studies of pyridine on $\mathrm{H}+\mathrm{Y} \quad 86$

$\begin{array}{lll}6.2 & \text { RESULTS } & 87\end{array}$

$6.2 .1 \mathrm{H}+\mathrm{Y}+$ pyridine at $100^{\circ} \mathrm{C}$ and $150^{\circ} \mathrm{C} \quad 87$

$6.2 .2 \mathrm{H}+\mathrm{Y}+$ pyridine at $25^{\circ} \mathrm{C} \quad 92$

6.2.3 Thermal desorption of pyridine 95

6.3 DISCUSSION 97

6.4 .2 "Wrecked" H+Y + pyridine 98

6.5 CONCLUSIONS 99

$\begin{array}{lll}6.6 & \text { REFERENCES } & 100\end{array}$

CHAPTER 7: BASES SORBED ON H+ZSM-5 - A STUDY OF HYDROGEN BONDING.

7.1 INTRODUCTION 101

7.2 RESULTS and DISCUSSION: CLASS A SORBANTS 111

7.2.1 Alcohols 111

7.2.1A Introduction 111

7.2.1B Methanol 114

7.2.1C Conclusion 119

7.2.2 Propan-2-ol 119

7.2.3 Other Alcohols 120

7.3 Saturated Hydrocarbons 120

7.3.1 Methane 120

$\begin{array}{ll}7.3 .2 \text { n-Hexane } & 122\end{array}$ 
7.4 Nitrogenous bases 126

7.4 .1

Ammonia

$7.4 .1 \mathrm{~B}$

Results and Discussion

7.4 .2 Pyridine

$7.4 .2 \mathrm{~A}$

Introduction

7.4 .2

Results and Discussion

7.4 .3 n-Propylamine

$7.4 .3 \mathrm{~A}$

Introduction

$7.4 .3 \mathrm{~B}$

Results and Discussion

7.4 .4

1,3 diaminopropane

7.5 RESULTS and DISCUSSION - CLASS B SORBANTS

7.5

Alkenes

7.5 .1

Introduction

7.5 .2

Ethene

$7 \cdot 5 \cdot 3$

Propene

7.5 .4

Isobutene

7.5 .5

Benzene and Toluene

$7.5 .5 \mathrm{~A}$ Introduction

$7.5 .5 \mathrm{~B}$

Benzene

$7.5 .5 \mathrm{C}$

Toluene

$7.5 .5 \mathrm{D}$

conclusion

7.6 RESULTS and DISCUSSION - CLASS C SORBANTS

7.6 Ethers on $\mathrm{H}+\mathrm{ZSM}-5$

7.6 .1

Introduction

7.6 .2

Dimethylether

$7 \cdot 6 \cdot 3$

Diethylether

163

7.6 .4

Methylethylether

163

7.6 .5

Discussion

7.6 .6

Di-n-butylether

7.6 .7

Di-isopropylether

7.6 .8

Tetrahydrofuran (THF)

7.7

Acetone

7.7 .1

Introduction

7.7 .2

Results

7.8

n-Butraldehyde

7.9 Nitriles

7.9 .1

Introduction 
7.10 SUMMARY AND DISCUSSION

7.10.1 Class A - distinct, shifted hydroxyl band

7.10 .2 Class B - single flat broad band due to hydrogen bonding

7.10.3 Class C - Very broad, diffuse hydrogen bonding 188

7.10 .4 Is a correlation of ${ }_{0 . H}$ versus proton affinity possible?

7.10.5 Estimation of the proton affinity of H+ZSM-5 by comparison with $\mathrm{HCl}$ and $\mathrm{HBr}$ in a solid Ar matrix

7.10.6 Estimation of Proton Affinity by bracketing

7.10 .7 Bonding of physisorbed species

CHAPTER 8: BASES SORBED ON H+MORDENITE AND H+Y - A COMPARISON WITH H+ZSM-5:

8.1 Methanol on H+mordenite 195

8.2 Ammonia on H+mordenite 198

8.3 Pyridine on H+mordenite 200

8.4 Propene on H+mordenite 204

8.5 Toluene on H+mordenite 206

8.6 Dimethylether (DME) on H+mordenite 208

8.7 Acetone on H+mordenite 210

8.8 Ammonium $\mathrm{Y}$ (Ammonia on $\mathrm{H}+\mathrm{Y}$ ) 212

8.9 Dimethylether (DME) on $\mathrm{H}+\mathrm{Y} \quad 214$

$\begin{array}{ll}8.10 & \text { CONCLUSIONS } \\ & 216\end{array}$ 
CHAPTER 9: CARBOXYLIC ACIDS ON ALKALI EXCHANGED ZEOLITES:

9.1 INTRODUCTION

219

9.2 Reaction of acetic acid over $\mathrm{H}+\mathrm{ZSM}-5$

221

9.3 Reaction of formic acid over Na+ZSM-5

9.4 Reaction of propanoic acid over $\mathrm{Na}+\mathrm{ZSM}-5$

9.5 Reaction of iso-butyric acid on $\mathrm{Li}+\mathrm{Y}$

9.6 Reaction of n-butyric acid on $\mathrm{Li}+\mathrm{Y}$

9.7 Reaction of chloracetic acid on $\mathrm{Na}+\mathrm{X}$

9.8 Reaction of acetic acid over silicalite

9.9 Reaction of acetone over Na+ZSM-5

9.10 In situ reactions of ketenes

9.11 In situ reactions of carboxylic acids and alcohols

9.11.1 Reaction of acetic acid and methanol to methylacetate

9.11 .2

Acetic acid and Ethanol to give Ethylacetate

9.13 In situ reaction of acetic acid and

9.16 REFERENCES

CHAPTER 10: THE NATURE OF THE RETENE PRODUCING REACTION

10.1 Td/ms survey of possible catalysts for ketene production - Summary of results from Appendix II 243

10.2 The effect of catalyst composition on ketene production - a study using the mini-reactor technique

10.2.1 Na+ZSM-5

10.2.2 Na+Y (Sample A - as received Linde Y, SK40)

10.2.3 A comparison of two samples of $\mathrm{Na}+\mathrm{Y}$ (Sample A and Sample B)

10.2.4 Cs+Na+Y

10.3 In situ-FTIR - an investigation into the reactive species sorbed on the catalyst and gas phase products 
10.3.1 Background on IR spectra of acetic acid sorbed on similar surfaces

10.3.2 FTIR Results

10.3.2.1 Acetic acid sorbed on Li+ZSM-5 at $200^{\circ} \mathrm{C} \quad 256$

10.3.2.2 Acetic acid sorbed on $\mathrm{Li}+\mathrm{Y}$ at $150^{\circ} \mathrm{C} \quad 258$

10.3 .2 .3 Deuterated acetic acid on $\mathrm{Li}+\mathrm{Y}$ at $150^{\circ} \mathrm{C} \quad 260$

10.3 .2 .4 Sodium Acetate 262

10.3.2.5 Thermal desorption/FTIR (td/FTIR) 264

10.3.2.6 Td/FTIR of acetic acid on $\mathrm{Na}+\mathrm{Y}$ at atmospheric pressure 264

10.3.2.7 Td/FTIR of acetic acid on Na+Y under vacuum 267

10.3.2.8 Td/FTIR of acetic acid sorbed on $\mathrm{Na}+\mathrm{Y}$ diluted with Silicalite-1 270

10.3.2.9 Mini-reactor/FTIR of acetic acid over $\mathrm{Na}+\mathrm{Y}$ at $300^{\circ} \mathrm{C}$

$\begin{array}{lll}10.3 .2 .10 \quad \mathrm{Na}+\mathrm{Y} \text { at } 350^{\circ} \mathrm{C} & 278\end{array}$

$10.3 .2 .11 \mathrm{Na}+\mathrm{Y}$ at $400^{\circ} \mathrm{C} \quad 280$

10.3.3 SUMMARY Of FTIR RESULTS 283

10.3.4 DISCUSSION 284

10.4. Mini-reactor/ms experiment to determine if $\mathrm{Na}^{+}$ ions are catalysts for ketene production 285

10.5. Further investigation into the mechanism of ketene formation using the mini-reactor/ms

10.5.1 Effect of partial pressures of reactants and products on ketene formation

10.5.2 Is a catalyst required for ketene formation? 287

10.5.2.1 Catalytic effects of the reactor itself 287

10.5.2.2 Products observed with an empty mini-reactor 288

10.5.2.3 With kao wool in the reactive filter 289

10.5.2.4 With $\mathrm{Si}$ wool in the reactive filter 289

10.5.2.5 With Si wool and silicalite-1 (prep 737) 289

10.5.2.6 Reaction of acetone over Li+Y 292

10.6 DISCUSSION 293 
10.7 CONCLUSIONS: The Mechanism of ketene formation at low temperatures (less than $600^{\circ} \mathrm{C}$ )

10.8 Re-investigation of In situ-reactions acetylation of methanol to methylacetate

298

10.8.1. The empty mini-reactor 298

10.8.2. With $\mathrm{Si}$ wool in the reactive filter

10.8.3. With $\mathrm{Si}$ wool and silicalite-1

10.8.4. With LiY and kao wool

10.8.5. Reaction of methanol with sodium acetate

10.8.6 CONCLUSION: Acetylation of methanol

10.9 REFERENCES

APPENDIX II: SURVEY OF POSSIBLE CATALYSTS FOR RETENE PRODUCTION

11.1 INTRODUCTION

11.2 METHOD

11.3 Inorganic salts

11.3 .1

sodium carbonate 308

11.3 .2 Calcium carbonate

11.5 Mordenite

11.6 Chabazite

11.7 The Faujasites: Zeolites X, Y and Ultrastable Y

11.9 Aluminium phosphates 
CHAPTER 1: INTRODUCTION

\section{1 zeolite structure:}

Zeolites, as synthesised or formed in nature, are crystalline aluminosilicates. They have a structure based upon a three dimensional network of $\mathrm{SiO}_{4}$ and $\mathrm{AlO}_{4}$ tetrahedra linked through common oxygen atoms. This forms a framework which encloses cavities occupied by large ions and water molecules, both which have considerable freedom of movement, permitting ion exchange and reversible dehydration (1).

A wide range of zeolite structures is possible using a number of basic silicate cage structures as building blocks (2). Three zeolites with widely different structures were studied in this work - zeolite Y, ZSM-5 and mordenite.

Zeolite $Y$ is a synthetic version of the naturally occurring zeolite Faujasite. A schematic model of the Faujasite structure is shown in figure 1.1 (3). The Si or Al atoms are at the line intersections with the $O$ atoms between. This unit is repeated in three dimensions. A truncated octahedron (sodalite cage) is the basic building block, connected by hexagonal prismatic structures which gives rise to giant supercages $\sim 13 \AA$ diameter. The supercages are connected by 12 membered rings $\sim 8 \AA$ diameter. 


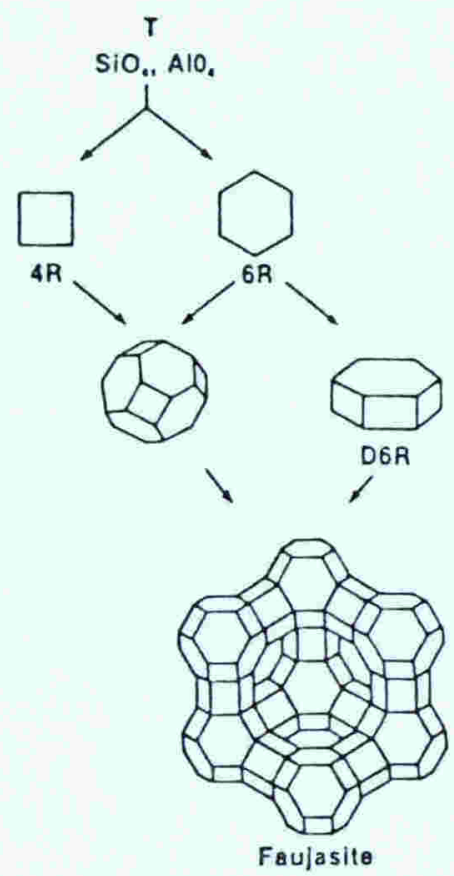

Figure 1.1 An illustration of the faujasite structure showing how it is built up from primary tetrahedra assembled into secondary building units. (From Thomas and Williams (3)).

The zeolite ZSM-5 has not been found in nature and was first synthesised by Mobil in 1972 (4). The framework structure contains a novel configuration of linked tetrahedra, shown in figure 1.2A, which are linked together to form chains (figure 1.2B) (5). The chains are connected to form sheets which link together forming a three dimensional structure (figure $1.2 \mathrm{c})$. The photograph of a model is shown in figure 1.3 with the brown balls representing $\mathrm{Al}$ or $\mathrm{Si}$ atoms and the red balls representing oxygen atoms. Two intersecting channel systems are formed - a straight channel system (5.4 x $5.6 \AA$ free diameter (6)) into the plane of the page, and a zig zag channel system $(5.1 \times 5.5 \AA$ free diameter (6)) shown by the blue marker. 


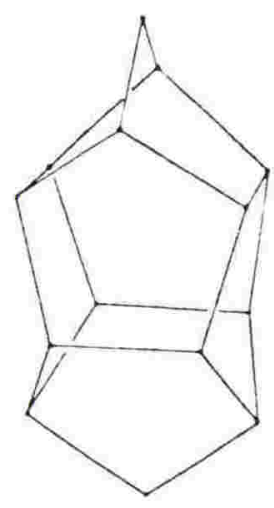

a

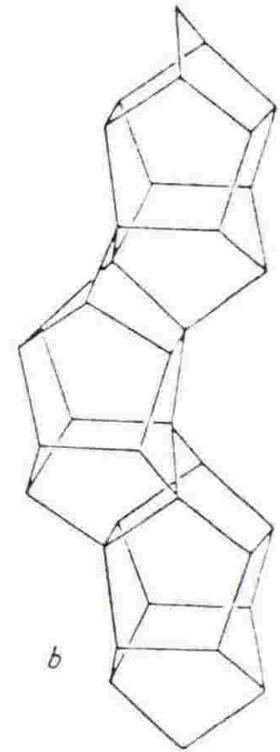

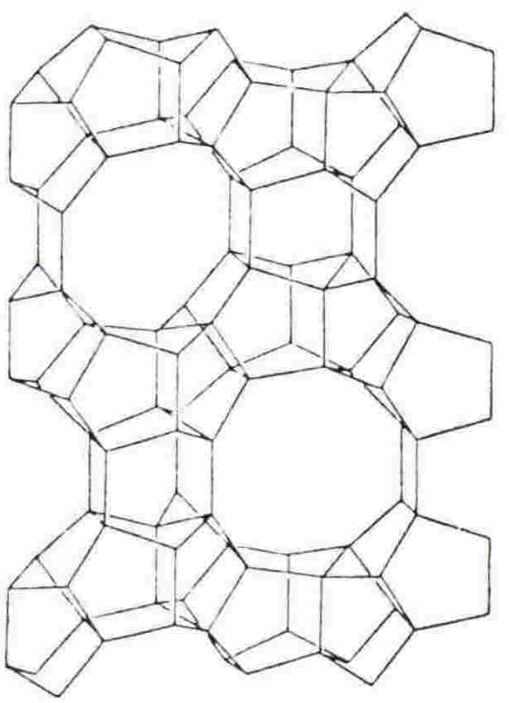

Figure 1.2 The structure of $2 \mathrm{SM}-5$ contains a novel configuration of tetrahedra (a), which are linked together to form chains (b). These are joined together to form a three dimensional structure (c). The 10-membered ring apertures shown in this orientation are the entrances to the zig-zag channels. (from Kokotailo et al. (5)).

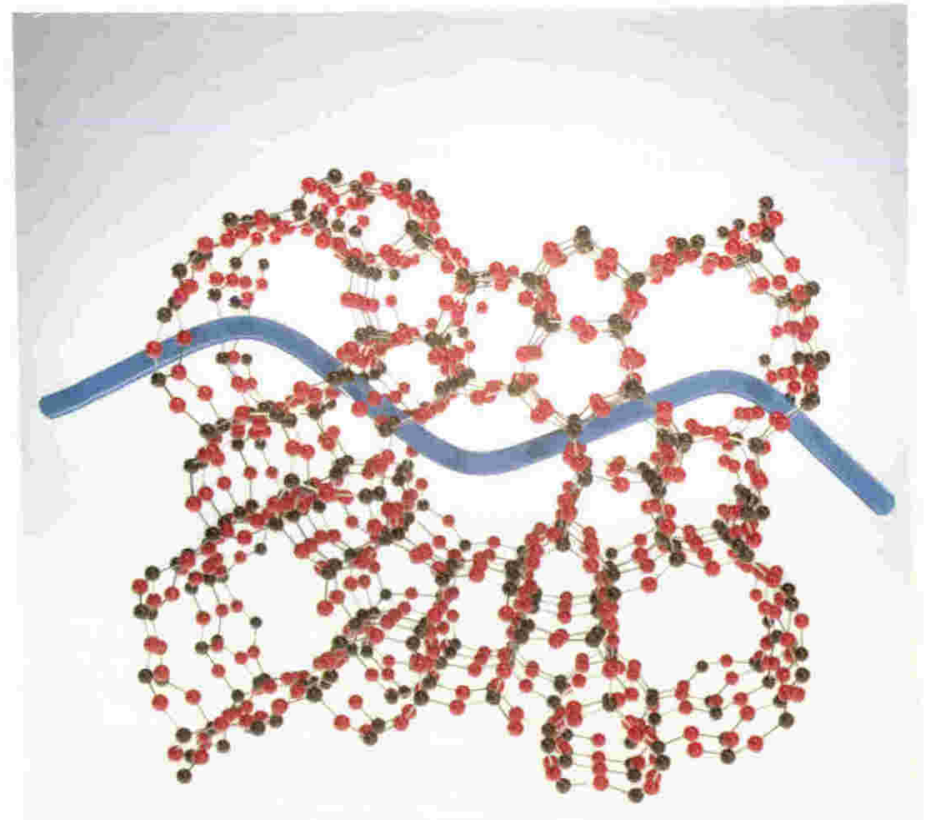

Figure 1.3 A model of the ZSM-5 structure. The brown ball represent $\mathrm{Al}$ of $\mathrm{Si}$ atoms and the red ball represent 0 atoms. The straight channel system is into the plane of the page and the zig-zag channel system is shown by the blue marker. 
Mordenite is found as the natural mineral or can be synthesised (2). The structure consists of chains of linked tetrahedra; the framework is shown in figure 1.4 (7). There is one $6.7 \AA$ diameter pore system, and a second at right angles to the first with 2.8 A restrictions. The small pore system is accessible only to small molecules (2), so that in practise mordenite can be regarded as having a one dimensional pore system.

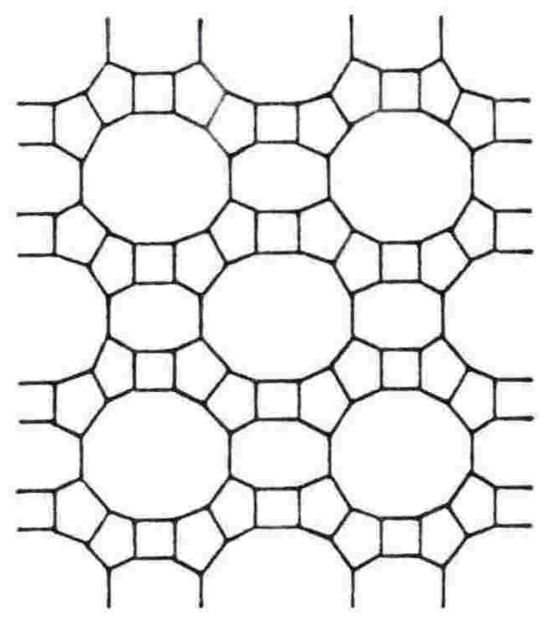

Figure 1.4 The structure of mordenite viewed along the $C$ axis. (from Ward (6)). 


\subsection{DEFINITION OF ZEOLITE ACID SITES:}

Ion exchange capability and catalytic activity are generated by substitution of $\mathrm{SiO}_{4}$ tetrahedra for $\mathrm{AlO}_{4}$. The zeolite lattice then gains a resultant negative charge, which must be compensated for by a cation. If the cation is a proton then a Bronsted acid (proton donating) site is generated:

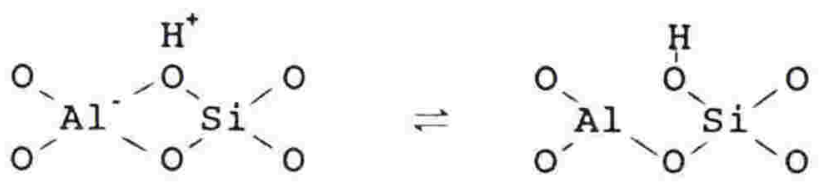

Bronsted acid site

The zeolite becomes an acid catalyst. Heating (to greater than $400^{\circ} \mathrm{C}$ ) results in the loss of water and the proposed $(8,9)$ formation of Lewis acid sites:

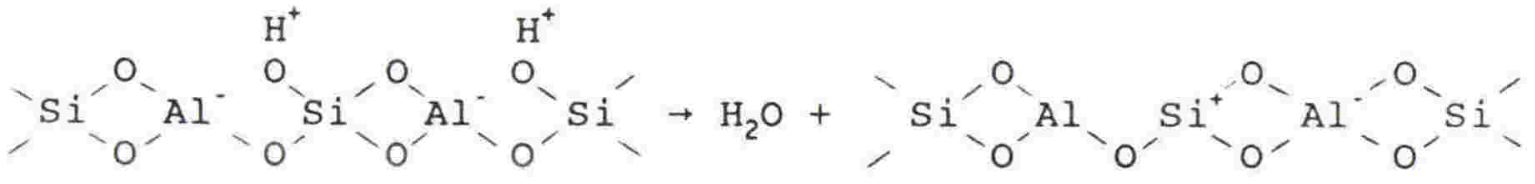

2 Bronsted acid sites $\rightarrow$ water + Lewis acid site

$$
+ \text { Lewis basic site (1.2) }
$$

Under conditions of high temperatures and water vapour pressure, aluminium is disloged and the structure can be healed to produce "true" Lewis sites (10):

$$
\text { "true" Lewis sites }
$$




\subsection{DEFINITION OF ZEOLITE BASIC 8ITE8:}

The role of the Lewis basic site (equation 1.2) is still uncertain, although they may act as reducing sites (11). It has also been proposed that adjacent acidic and basic sites can play an important mechanistic role in alcohol dehydration (12) .

zeolites exchanged with alkali metal and alkaline earth metal cations have been broadly termed "basic catalysts" (for example 13, 32). However, the cation itself behaves as a Lewis acid and the basicity arises from the creation of a negative charge on an oxygen atom. The basicity is dependent on the electronegativity of the cation (14):

$$
\begin{aligned}
& \mathrm{Mi}^{+}=\text {metal cation }
\end{aligned}
$$

\subsection{TECHNIQUES FOR STUDYING CATALYTIC SITES:}

combinations of a wide range of techniques are used to determine information of the number, type, strength, location (environment), catalytic activity and mean lifetime of the active sites. These are described in several reviews (1, 6, 15, 16) with the work of Meyers et al. (17) being an example. Each technique provides complementary information towards a complete description of the catalytic sites.

Physical techniques include elemental analysis, surface area measurements, surface analysis techniques (eg XPS and high resolution electron microscopy) and xray structural analysis.

Spectroscopic techniques include ESR, UV, Raman and visible spectroscopy with IR and NMR being most commonly used. spectroscopic techniques can ideally furnish information directly on the nature of surfaces and species sorbed on surfaces. They also provide information on the molecular level rather than on a total system level (18). 
IR spectroscopy is a powerful technique as the $0-\mathrm{H}$ stretch of the zeolite Bronsted hydroxyl can be directly observed and relative numbers of acid sites compared $(18,19)$.

Interactions of the hydroxyls with sorbed molecules can be observed, along with changes to the molecular vibrations of the sorbates. For example, different vibrations of sorbed pyridine are used to determine the relative numbers of Bronsted, Lewis and alkali metal cation sites $(15,20,21)$.

Solid state ${ }^{1} \mathrm{H},{ }^{27} \mathrm{Al}$ and ${ }^{29} \mathrm{Si}$ NMR are recent, powerful techniques. The chemical shift of the proton is not a measure of acidity (22), but the number of hydroxyl groups can be determined $(23,24)$ and relaxation and line width techniques give a measurement of proton mobility (25). ${ }^{29} \mathrm{Si}$ NMR enables a direct determination of the number of $\mathrm{Si}$ tetrahedra with $0,1,2,3$ and $4 \mathrm{Al}$ tetrahedra as nearest neighbours to be made as well as determining the Si/Al ratio of the framework (26). ${ }^{27}$ Al NMR gives a measurement of the relative amounts of tetrahedral (framework) and octahedral (non-framework) Al present (27).

Sorption of a base (eg ammonia) followed by tga (thermogravimetric analysis) or $t d / m s$ (thermal desorption/mass spectrometry) enables a quantitative determination of the number of acid sites to be made (28). A qualitative measurement of acid strengths is also obtained from the desorption temperature.

Calorimetry, measuring the heat of reaction as bases are sorbed, has the potential to determine zeolite acidity. However, only the average heat of unknown, perhaps diversely strong sites is obtained. A problem with this technique is that markedly different acid site strength distributions have been obtained on the same zeolite sample with probes of different base strength (eg ammonia, acetonitrile, dimethylether and water (22)).

The catalytic activity of a zeolite sample can be determined by carrying out a reaction and comparing reactivity to a 
standard. An example of a commonly used reaction is the alpha-test which measures the n-hexane cracking rate (29). This determines how the zeolite will behave under given reaction conditions but problems arise in characterising the active sites. A small number of very active sites may dominate the activity, and reactions may involve several kinetic features so that the overall rate does not provide the required information (33).

\subsection{Historical summary:}

The catalytic properties of zeolites in most systems are related to their acidic properties. The first reports of zeolite catalysis in the early 1960 s were soon followed by reports of acid sites (30). This was the start of many studies on the nature of acid sites.

Before 1970, IR spectroscopy was the exclusive method for studying zeolite acid sites and their interactions with basic molecules. This work has been reviewed by ward (31). The zeolites $\mathrm{X}$ and $\mathrm{Y}$ and Ultrastable $\mathrm{Y}$ were of major interest due to the importance of Ultrastable $\mathrm{Y}$ as a cracking catalyst.

Work carried out in the 1970 s used a greater range of techniques and has been reviewed by Jacobs (32). In the 1980 s, attention has been focused on the synthetic zeolite 2SM-5 due to its performance as a shape selective catalyst. Much improved experimental techniques such as FTIR, solid state nmr and surface analysis techiques have enabled further information to be obtained. 


\section{6 summary of the current knowledge on acid sites:}

The potential number of acid sites equals the number of $A 1$ atoms substituted in the zeolite structure (35). The number of acid sites in a sample may be lower due to factors such as loss of crystallinity, dehydroxylation or partial neutralisation with cations or bases (36).

Many methods have been developed to characterise acid strength, but none of them is able to give absolute values comparable to the scale of $\mathrm{pK}_{\mathrm{A}}$, for instance (36). Samples are usually ranked using one method, with care required in defining the experimental conditions used. A classical indicator is the infrared frequency of the Bronsted hydroxyl stretch. Also used is the thermal desorption temperature of bases such as ammonia or pyridine (20).

The strength of the acid sites depends upon the zeolite structure and aluminium density. Theoretical calculations have shown that different bond angles in the different structures, and different crystallographic positions within the same structure, result in acid sites of differing strengths $(15,37)$.

As the aluminium content of a zeolite decreases, the strength of acid sites increases until a limiting value is reached (33). This is deduced from a decrease in the IR frequency of the hydroxyl bond and an increase in the ${ }^{1} \mathrm{H}$ NMR chemical shift with increase in Si/Al (figure 1.5) $(33,38)$. A simple model is proposed (33) to account for these changes in which an acid site becomes stronger as the number of nearest neighbour Al atoms decreases until they become "isolated" at $S i / A l>7$. For faujasites these trends have also been correlated with catalytic activity (33). 


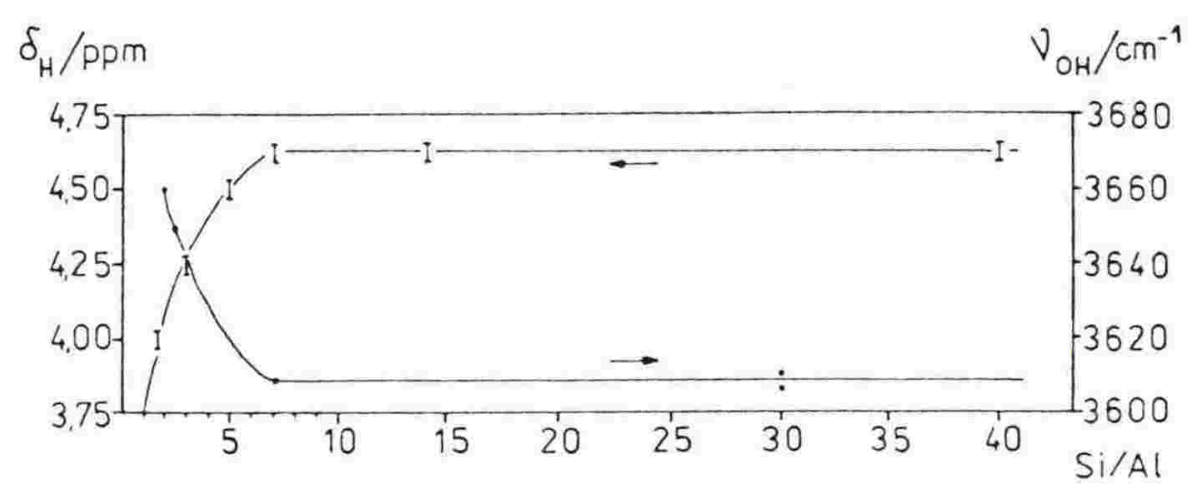

Figure 1.5 Comparison of ${ }^{1} \mathrm{H}$ MAS $\mathrm{nmr}$ chemical shifts (using $\mathrm{CH}_{4}$ internal standard) and changes in acid hydroxyl stretch for various zeolites (from Freude et al. (38)).

For ZSM-5, the available evidence shows that all the Bronsted acid sites are the same strength with a linear dependence of acidity (measured by IR, ${ }^{27} \mathrm{Al}$ NMR and catalytic activity) on aluminium concentration. IR spectra of carefully prepared ZSM-5 samples show a single hydroxyl band, centred at $3600 \mathrm{~cm}^{-1}$, assigned to Bronsted acid sites which has an intensity proportional to Al content (39). The catalytic activities of reactions such as paraffin cracking (40), dimethylether conversion to hydrocarbons and xylene isomerisation $(37,38)$ are proportional to the content of tetrahedrally coordinated Al. ${ }^{29} \mathrm{Si}$ NMR results for $2 \mathrm{SM}-5$ (43) showed the presence of $\mathrm{Si}(1 \mathrm{Al}), \mathrm{Si}(2 \mathrm{Al})$, and $\mathrm{Si}(3 \mathrm{Al})$ in addition to $\mathrm{Si}(\mathrm{OAl})$. This suggests that the number of nearest Al neighbours is not an important factor in determining the acid strength in $\mathrm{ZSM}-5$.

Lewis acid sites are not observed in carefully prepared ZSM-5 (39), but form during hydrothermal treatment. Lewis sites are most commonly determined by IR of sorbed pyridine, with a distinct shift of the resultant ion observed (15). NMR studies provide more information on the nature of these sites. So far there has been no direct evidence for tricoordinate framework Si or Al (33). Non-framework aluminium may provide the source of Lewis acidity. This may 
be $\mathrm{Al}^{3+}, \mathrm{AlOH}^{2+}, \mathrm{Al}(\mathrm{OH})_{2}^{+}$or $\mathrm{Al}_{2} \mathrm{O}_{3}$. Dehydroxylation can also result in a siliceous phase seen by ${ }^{29} \mathrm{Si}$ NMR (33) and this could also be a source of Lewis acidity. However NMR is a bulk technique and may not detect small numbers of tricoordinated sites which could still be catalytically significant (34).

An important feature of the zeolite acid sites is that they are dynamic and moving continuously in the structure, the lifetime of a proton on a site being between $10^{-2}$ and $10^{-7}$ seconds (30). The properties of the acid sites are therefore influenced by their intrinsic proton mobility as well as their chemical environment (30). The nmr technique is used to determine such 1 ifetimes. Most other techniques take longer than a "lifetime" for a measurement and show an averaged picture of the acid sites.

\section{7 summary of the current knowledge on basic sites:}

For basic zeolite catalysts, formed by alkali metal exchange, basicity can be measured by the change in the pyrrole IR stretch (14). The larger the cation, the lower its electronegativity and the larger the negative charge on the oxygen. This results in increase of basicity with the size of the cation. The basicity also increases with increasing aluminium content and also depends on the structure of the zeolite (14).

All the ZSM-5 cation exchanged forms (including $\mathrm{Cs}^{+}$) showed no significant pyrrole $\mathrm{N}-\mathrm{H}$ shift compared to non-basic oxides (eg. silica)(44). This was ascribed to the low aluminium density which results in hardly any change in the calculated negative charge for the oxygen when a Bronsted proton is exchanged for an alkali cation (45). LiY and NaY also showed only a slight $\mathrm{N}-\mathrm{H}$ shift, implying only slight basicity (14).

Lewis acidity, determined by temperature desorption of pyridine (45), decreases with increasing cation size. The acid/base sites are coupled, with the strength of one increasing as the other decreases. Therefore catalysts such 
as LiY and NaY are most effective as Lewis acids.

The behaviour of a catalyst as "acidic" or "basic" depends upon the sorbant molecule or catalytic reaction. For example, Lix shows basic behaviour upon sorption of pyrrole with a strong $\mathrm{N}-\mathrm{H}$ shift (14). However, for the alkylation of toluene, it behaves as an acid catalyst producing xylenes (46). This is in contrast to the styrenes that are produced by basic catalysts (47) as shown in figure 1.6. The larger alkali cation exchanged faujasites produced styrenes with activity increasing with size.

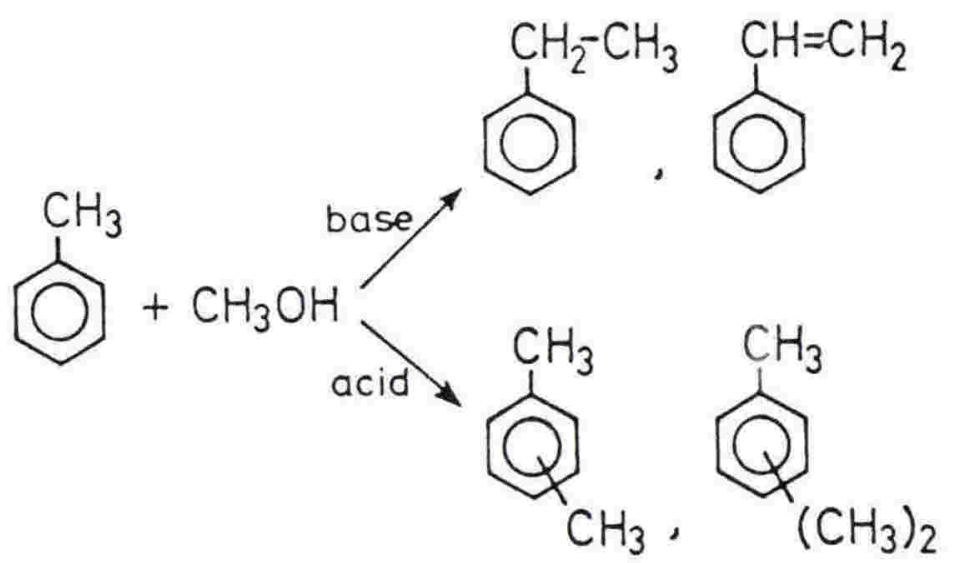

Figure 1.6 Alkylation of toluene with methanol over acid and base catalysts. (from Tanabe (40)).

Zeolites exchanged with polyvalent cations show acidic behaviour due to the creation of acidic centres by hydrolysis (15):

$\mathrm{M}^{\mathrm{n+}}+\mathrm{xH}_{2} \mathrm{O} \rightarrow \mathrm{M}(\mathrm{OH})_{x}^{(n-x)+}+\mathrm{xH}^{+}$ 


\subsection{THIS THESIS:}

As outlined above, there is a good basis for the understanding of zeolite catalytic sites. Research on this subject commenced about 30 years ago and has advanced rapidly over the last three years, while this thesis was in progress. This was mainly due to improved, computerised experimental techniques such as FTIR, solid state NMR, surface analysis and $\mathrm{td} / \mathrm{ms}$.

The work in this thesis investigated in detail how sorbants interact with the acid sites, and attempted to create a method for quantifying zeolite acid site strength. In addition, a novel reaction over alkali exchanged zeolites was investigated with regard to the interaction of the reactant with the catalytic sites to determine the reaction mechanism.

Each chapter of this thesis is prefaced by an introduction describing in more detail the background to the particular area of study.

\subsection{REFERENCES:}

1. Smith J.V. in "Zeolite Chemistry and Catalysis", Rabo J.A. Editor, American Chemical Society Monograph 171, 1976 , 3 .

2. Breck D.W., "Zeolite Molecular Sieves", Wiley-Interscience, New York, 1974.

3. Thomas J.M. and Williams C., "Chemical Reactions in organic and Inorganic Constrained Systems", Sutton R. (Editor), D. Reidel, 1986, 49.

4. Argauer R.J. and Landolt G.R. US patent $3702886,1972$.

5. Kokotailo G.T., Lawton S.L., Olson D.H. and Meier W.M., Nature, 1978, 272, 437.

6. Ward J.W., "Molecular Sieve Catalysts", Applied Industrial Catalysis, Academic Press, 1984, 3, 271.

7. Meier W.M., Z. Kristallogr., 1961, 115, 439. 
8. Skeels G.W. and Flank W.H.,"Intrazeolite Chemistry", ACS Symposium series, 1983.

9. Tanabe K., "Catalysis Science and Technology", Springer Verlag, 1981, 2, 232.

10. Jácobs P.A. and Beyer H.K., J. Phys. Chem., 1979, 83, 1174 .

11. Ono Y. "Catalysis by Zeolites", Elsevier, 1980, 19.

12. Santacesaria E. Gelosa D., Giorgi E. and Carra S. J. Catal., 1984, 90, 1.

13. Barthomeuf D. and Mallmann A., "Innovation in Zeolite Materials Science", Grobet P.J. et al. Editors, Elsevier, Amsterdam, 1988, 365.

14. Barthomeuf D., J. Phys. Chem., 1984, 88, 42 .

15. Barthomeuf D., "Zeolites: Science and Technology", NATO Asi Series E, Martinus Nijhoff, $1984,80,317$.

16. Austermann R.L., Denley D.R. Hart D.W., Himelfarb P.B., Irwin R.M., Narayana M., Szentirmay R., Tang S.C. and Yeates R.C,. Anal. Chem., 1987, 59, 68R.

17. Meyers B.L., Fleisch T.H., Ray G.J., Miller J.T. and Hall J.B., J. Catal., 1988, 110, 82.

18. Ward J.W. "Zeolite Chemistry and Catalysis", Am. Chem. Soc. Monograph 171, Rabo J.A. Editor, 1976, 118.

19. Ward J.W., Advances in Chemisty Series 101, Gould R.F. Editor, American Chemical Society, 1971, 381.

20. Datka J. and Piwowarska Z., Zeolites, $1988,8,30$.

21. Topsoe N.Y., Joensen F. and Derouane E.G., J. Catal., $1988,110,404$.

22. Auroux A., "Innovation in Zeolite Materials Science", Grobet P.J. et al Editors, Elsevier, Amsterdam, 1988, 385.

23. Hunger M., Freude D., Frohlich T., Pfeifer H. and Schwieger W., Zeolites, 1987, 7, 109.

24. Englehardt G., Jerschkewigtz H.G., Lohse U., Sarv P., Samoson A. and Lippmaa E., Zeolites, 1987, 7, 289.

25. Freude D., Oehme W., Schmiedel H. and Staude B., J. Catal., 1974, 32, 137.

26. Engelhardt G., Lohse U., J. Catal. 1984, 88, 513.

27. Fyfe C.A. Gobbi G.C., Klinowski J., Thomas J.M. and Ramdas S., Nature 1982, 296, 530.

28. Parker L.M., Bibby D.M. and Meinhold R.H., Zeolites, $1985,5,384$. 
29. Chang C.D., Hellring S.D., Miale J.N., Schmitt K.D., Brigandi P.W. and Wu E.L., J. Chem. Soc. Faraday Trans., $1985,81,2215$.

30. Barthomeuf D. "Molecular Sieves II", Katzer Ed., ACS Symposium Series 40, 1977, 453.

31. Ward J.W., Adv. Chem. Ser., 1970, 101, 380.

32. Jacobs P.A. "Carbiongenic Activity of Zeolites", Elsevier, Amsterdam, 1977.

33. Dwyer J., "Innovation in Zeolite Materials Science", Grobet P.J. et al. Editors, Elsevier, Amsterdam, 1988, 333.

34. Weisz P.B. Chemtech, 1987, June, 368.

35. Haag Wo., Lago R.M. and Weisz P.B., Nature, 1984, 309, 589 .

36. Barthomeuf D., Materials Chemistry and Physics, 1987, $17,49$.

37. Dempsey E.J., J. Catal., 1974, 33, 497.

38. Freude D., Hunger M., Pfeifer H. and Schwieger W., Chem. Phys. Lett., 1986, 128, 62 .

39. Jacobs P.A. and von Ballmoos R, J. Phys. Chem., 1982, 86,3050 .

40. Borade R.B., Hedge S.G., Kulkarni S.B. and Ratnasamy Z.P., Appl. Catal., 1984, 13, 27.

41. Guisnet M., Comerais F., Chen Y., Perot G. and Freund E., Zeolites, 1984, 4, 108 .

42. Babu G.P., Hedge S.G., Kulkarni S.B. and Ratnasamy P., J. Catal., 1983, 81, 471 .

43. Fyfe C.A., Gobi G.C. and Kennedy G.J. Chem Lett., $1983,1551$.

44. Scokart P.O. and Rouhet P.G., J. Chem. Soc., Faraday Trans 1, 1980, 76, 1476.

45. Derewinski M., Haber J., Ptaszynski J., Lercher J.A. and Rumplayr G., stud. Surf. Sci. Catal., 1986, 28, 957.

46. Garces J.M., Vrieland G.E., Bates S.I. and Scheidt F.M., "Catalysis by Acids and Bases", Imelik B. et al. Editors, Elsevier, Amsterdam, 1985, 67.

47. Tanabe K. in "Catalysis by Acids and Bases", Imelik B. et al. Editors, Elsevier, Amsterdam. 


\subsection{THERMOGRAVIMETRIC ANALYSIS (tga):}

Thermogravimetric analysis (tga) was carried out using a Stanton Redcroft tga model 770. Samples were heated at $10^{\circ} \mathrm{C}$

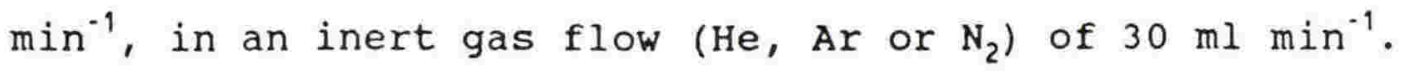
Adequate sensitivity was obtained with sample sizes of about $10 \mathrm{mg}$. The percentage weight losses were calculated on the basis of the zeolite weight at $600^{\circ} \mathrm{C}$ when there were no absorbed or occluded molecules present in the zeolite channel system.

\subsection{THERMAL DESORPTION MASS SPECTROMETRY ( $t d / \mathrm{ms})$ :}

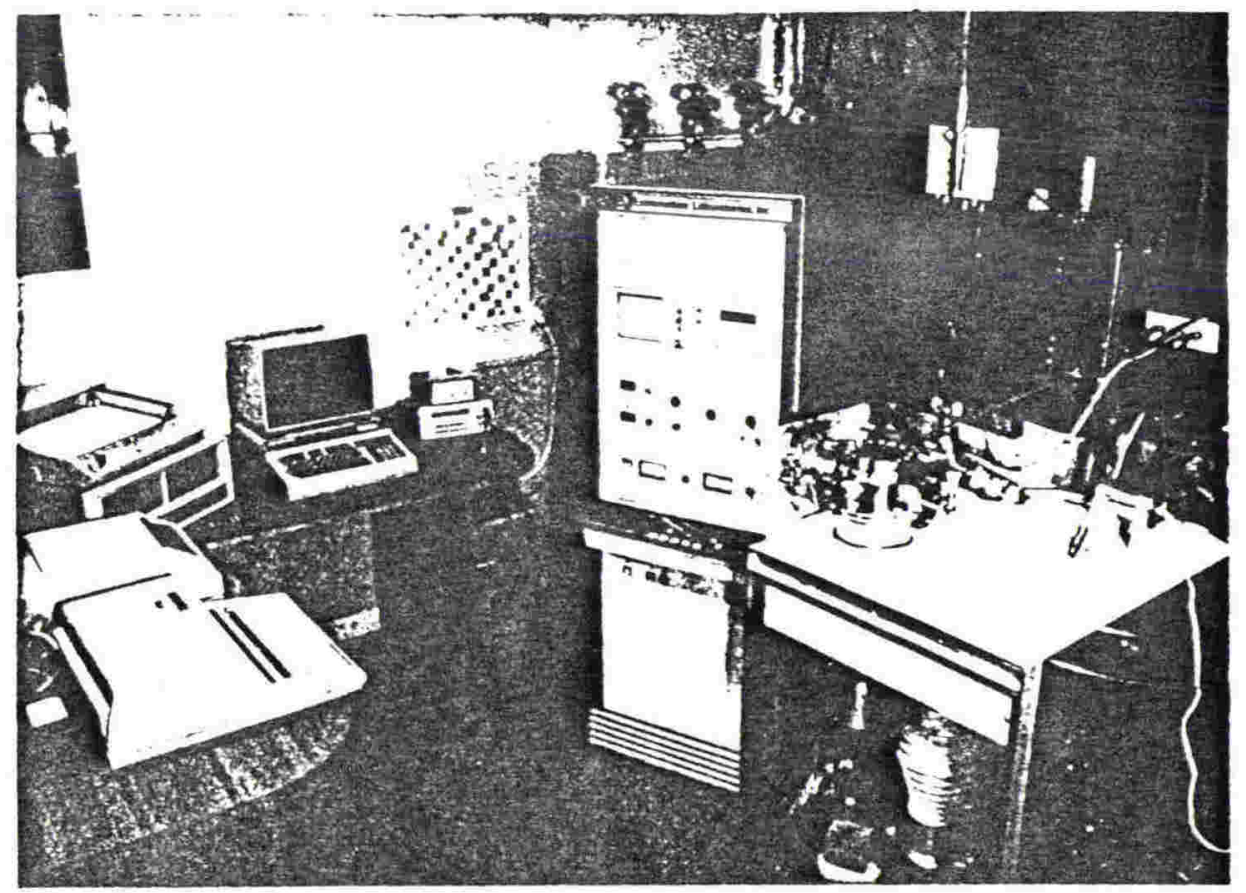

Figure 2.1. Evolved gas analysis mass spectrometer system. 
The gases that evolved as a sample was heated were analysed by mass spectrometry. The sample, accurately weighed ( 10 $\mathrm{mg})$, was placed in a silica $t \mathrm{~d} / \mathrm{ms}$ tube and heated at $10^{\circ} \mathrm{C} \min ^{-1}$. The temperature was controlled by an 8 step proportional current controller. The mass spectrometer system is pictured in figure 2.1 and the experimental layout is shown in figure 2.2 .

The td/ms apparatus was an original design and constructed by the glass blower at Chemistry Division. Argon carrier gas was controlled at a constant flow of $\sim 20 \mathrm{ml} \mathrm{min}^{-1}$ by a fixed glass capillary leak. The Ar flowed over the sample and swept the evolved gases past the mass spectrometer leak valve inlet. The carrier gas was either removed by a vacuum pump or vented to atmosphere. In the first case the pressure over the sample was only a few Torr, in the second case the pressure over the sample was just above atmospheric.

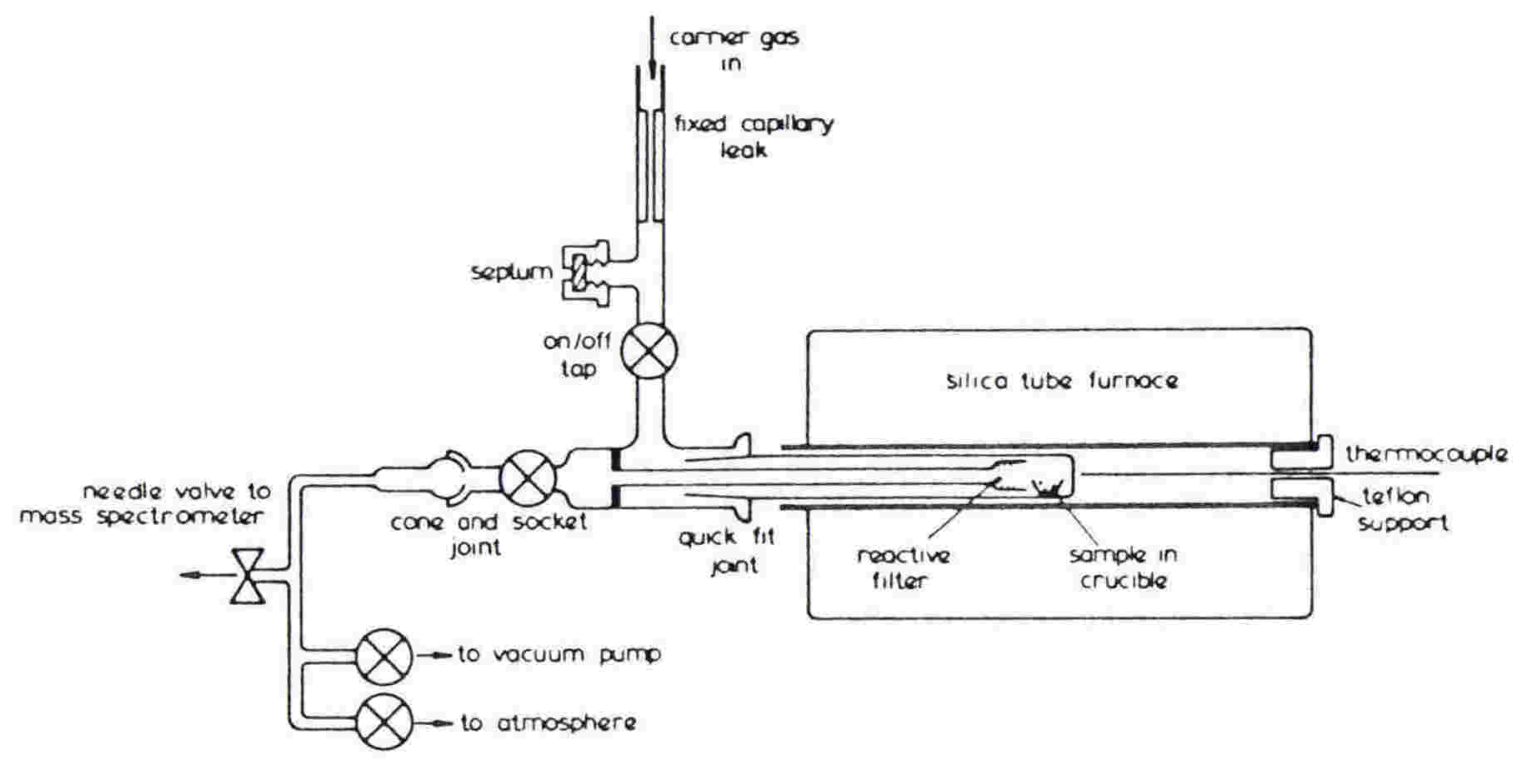

Figure 2.2. Experimental layout for thermal desorption/mass spectrometry. 
The gas stream was sampled through a leak valve into an Extranuclear spectrel system model 275-50 quadrupole mass spectrometer. The mass spectrometer was controlled by an HP9835A computer and was repeatedly scanned over a selected mass range. A typical scan between 1 and 80 amu took about $60 \mathrm{~s}$. The software was developed so that any ion signal intensity that had changed significantly from the previous scan was stored, along with the ion's mass-to-charge ratio $(\mathrm{m} / \mathrm{z})$ and the time or sample temperature. The software used has been described in detail by Parker and Patterson (1). The stored data from an experiment could be manipulated to give a plot of the ion signal for a particular $\mathrm{m} / \mathrm{z}$ as a function of time or sample temperature. In addition, the mass spectrum (in the mass range scanned) could be obtained at any particular time (or sample temperature). This allowed checking for any unexpected products evolved from the sample.

A technique was developed in which the constant argon flow (through the capillary leak) was used as an internal standard to enable quantitative comparisons to be made between different $t d / m s$ runs. The mass spectrometer sensitivity varied between runs, but scaling the experimental results to a constant argon ion signal for all the $t d / m s$ runs allowed this to be compensated for. The ion signal from the ${ }^{36} \mathrm{Ar}^{+}$ isotope was chosen as both the ${ }^{40} \mathrm{Ar}^{+}(\mathrm{m} / \mathrm{z} 40)$ and ${ }^{40} \mathrm{Ar}^{++}(\mathrm{m} / \mathrm{z}$ 20) ion signals were off-scale.

The amount of a given gas desorbed from a sample was determined by calibration. Tga was used to determine the percentage weight loss of a sample for which a single gas was evolved in a well defined weight loss step. Another sample of the same material was then analysed by $t d / m s$ and the integral under the ion signal versus temperature curve obtained. From the weight of the td/ms sample taken and the \% weight loss (from tga) the number of moles desorbed was calculated. The conversion factor between area and moles was then determined at a particular ${ }^{36} \mathrm{Ar}^{+}$ion signal.

Calibrations were carried out for a range of gases routinely analysed by mass spectrometry in order to determine their sensitivities in the mass spectrometer relative to argon. 
These sensitivities were determined by analysing gas mixtures of the gas with argon. The mixtures were prepared quantitatively on a vacuum gas handling rig using a barytron pressure gauge.

A strong ion signal from the mass spectrum of the gas to be calibrated was selected and the sensitivity factor calculated from:

sensitivity factor $=$

$\frac{\text { Ar partial pressure }}{\text { component partial pressure }} \times \quad \frac{\text { component ion signal }}{\text { Ar ion signal }}$

The sensitivity factors used in this work are shown in Table 2.1.

TABLE 2.1

$\begin{array}{lcc}\text { gas } & \text { ion signal }(\mathrm{m} / \mathrm{z}) & \text { sensitivity factor } \\ \text { methane } & 16 & 0.8 \\ \text { ammonia } & 16 & 0.5 \\ \text { water } & 17 & 0.3 \\ \text { ethene } & 27 & 0.52 \\ \text { argon } & 40 & 1.0 \\ \text { carbon dioxide } & 44 & 1.0 \\ \text { ketene } & 42 & 0.5 \\ \text { butene } & 41,56 & 1.1,0.44 \\ \text { acetone } & 58 & 0.3 \\ \text { acetic acid } & 60 & 0.28\end{array}$

A gas mixture for water could not be accurately prepared so the sensitivity factor for water was estimated from quantitative $t d / \mathrm{ms}$ of $\mathrm{CuSO}_{4} \cdot 5 \mathrm{H}_{2} \mathrm{O}$ and $\mathrm{CaCO}_{3}$. The $t d / \mathrm{ms}$ ion signal-temperature integrals for the same amounts of evolved water and $\mathrm{CO}_{2}$ were compared under constant mass spectrometer conditions. Since the sensitivity factor for $\mathrm{CO}_{2}$ was known, the sensitivity factor for water could be calculated. 
eg. from td/ms of $\mathrm{CuSO}_{4} \cdot 5 \mathrm{H}_{2} \mathrm{O}$

$1 \mathrm{mg} \mathrm{H}_{2} \mathrm{O}$ is equivalent to 23.6 area units (at $\mathrm{m} / \mathrm{z} 36=1000$ )

from $t d / m s$ of $\mathrm{CaCO}_{3}$

$1 \mathrm{mg} \mathrm{CO}_{2}$ is equivalent to 84 area units.

since the sensitivity factor for $\mathrm{CO}_{2}=1.0$

the sensitivity factor for $\mathrm{H}_{2} \mathrm{O}=1.0 \times 23.5 / 84=0.3$.

The sensitivity factor for ketene was estimated by comparison with other gases with similar mass spectra and molecular weights. The variation in sensitivity factors within this grouping is such that the sensitivity factor for ketene would be within the range of 0.3 to 0.7 .

Thus relative amounts of different desorbed gases could be obtained. The conversion of area to moles, as determined above for a particular gas, could be used for a range of gases by scaling with the appropriate sensitivity factors.

\subsubsection{Controlled sorption on to zeolite samples:}

Sorbants were sorbed on to zeolites prior to $t d / m s$ under controlled conditions. The zeolite sample was placed in the td/ms tube, connected to a vacuum gas handling rig, evacuated and dried by heating. The zeolite was then held at a desired temperature and the sorbate sorbed at its room temperature vapour pressure for 5 minutes. The excess sorbate was returned to the vacuum rig using a liquid nitrogen trap. The $t d / m s$ tube was then isolated and reconnected to the mass spectrometer for a $t d / m s$ run.

\subsubsection{Mini-reactor with on-line analysis by mass spectrometry:}

The $t d / m s$ setup was also used as a mini-reactor for catalytic experiments. The catalyst was placed in the reactive filter in the $t d / m s$ tube (see figure 2.2), and held in place with kao-wool. Reactant was introduced into the carrier gas stream either by injection through a septum for pulsed experiments, or by flowing the carrier gas through an impinger to absorb the vapour pressure of the liquid. Flow 
rates were controlled either by the fixed glass capillary or flow meters and the pressure was either a few Torr (pumped by a vacuum pump) or atmospheric (exhausted to atmosphere). The same $t d / m s$ software was used for gas stream analysis, with a fast scanning for selected masses available for the pulsed experiments.

\subsection{FOURIER TRANSFORM INFRA-RED (FTIR):}

The infra-red spectroscopy experiments were carried out using a Bomem DA3 FTIR spectrophotometer. The Fourier Transform technique offers the advantages of versatility and much greater speed and sensitivity for a given resolution compared to conventional scanning IR machines. The theory and instrumentation for FTIR has been described $(2,3,4)$. A choice of beam splitters and detectors enables a wavelength range from $10 \mathrm{~cm}^{-1}$ to the ultraviolet to be covered. In this work the MCT (mercury, cadmium, telluride), liquid $\mathrm{N}_{2}$ cooled, solid state detector was used with either a CaF 2 (1200 to 8000 $\mathrm{cm}^{-1}$ range) or a $\mathrm{KBr}$ (450 to $5000 \mathrm{~cm}^{-1}$ range) beamsplitter. The resolution could be varied down to $0.01 \mathrm{~cm}^{-1}$, with the time required to aquire a spectrum increasing with increasing resolution. A resolution of $4 \mathrm{~cm}^{-1}$ was normally chosen. The spectrophotometer has a large sample chamber $(56 \mathrm{~cm}$ x $28 \mathrm{~cm}$ x $24 \mathrm{~cm}$ ) which could either be evacuated or purged with a selected gas. The aperture controlling the infra-red beam could be varied so that the spot size focussed on the sample ranged from $10 \mathrm{~mm}$ to $1 \mathrm{~mm}$. The larger the spot size the greater the signal intensity at the detector.

Heating the zeolite resulted in thermal emission from the sample. This passed back through the beam splitter, becoming modulated, then detected. This effect was especially noticeable at small beam diameter. At $1.5 \mathrm{~mm}$ beam diameter complete overloading of the spectrum occurred when the sample was at $400^{\circ} \mathrm{C}$ but at $5 \mathrm{~mm}$ diameter only slight changes were observed in the spectrum recorded when the sample was at $600^{\circ} \mathrm{C}$. 
The operating conditions, data aquisition and treatment and spectral manipulations are software controlled. The main hardware consists of a high speed vector processor which performed all repetitive operations, and a minicomputer. The software was provided by Bomem.

Unless otherwise stated, spectra were scanned from 1200 to $4000 \mathrm{~cm}^{-1}$ at $4 \mathrm{~cm}^{-1}$ resolution, with 200 scans aquired for each spectrum. A $\mathrm{CaF}_{2}$ beamsplitter was used along with $\mathrm{CaF}_{2}$ windows on the FTIR cell

\subsubsection{The In situ FTIR cell:}

An in situ cell was designed and constructed in which a zeolite sample could be heated in a controlled atmosphere, with IR spectra being obtained at the same time. This was a modified version of an earlier cell (4) and is pictured in figure 2.3. A schematic diagram is shown in figure 2.4. The cell was constructed from silica which can withstand temperatures up to $800^{\circ} \mathrm{C}$. The furnace was wound with nichrome wire. Modified cajon fittings were used to hold the IR windows $\left(\mathrm{CaF}_{2}\right.$ or $\left.\mathrm{KBr}\right)$ with o-ring seals. These were water cooled to prevent the windows from cracking. The sample, in wafer form, fitted into a silica sample holder, which slipped into the cell. It was positioned in the cell by the thermocouple well. An Al foil heat shield was used in place of kao wool insulation which could have caused contamination of the vacuum chamber. The cell was suspended from a machined brass plate which replaced the top cover of the sample chamber and was o-ring sealed. Accurate mounting of the cell ensured the zeolite wafer was positioned in the focus point of the IR beam. The silica cell was connected to metal fittings via o-ring seals on the plate. The connections for the thermocouple and power were mounted on the plate. Swagelock fittings were used for gas and water connections and a septum was provided for injection of sorbants. The temperature was controlled by an 8 step proportional temperature controller. Gradual heating (10 to $20^{\circ} \mathrm{C}$ min-1) was required when the FTIR sample chamber was evacuated, as the windings were in a vacuum and therefore had 


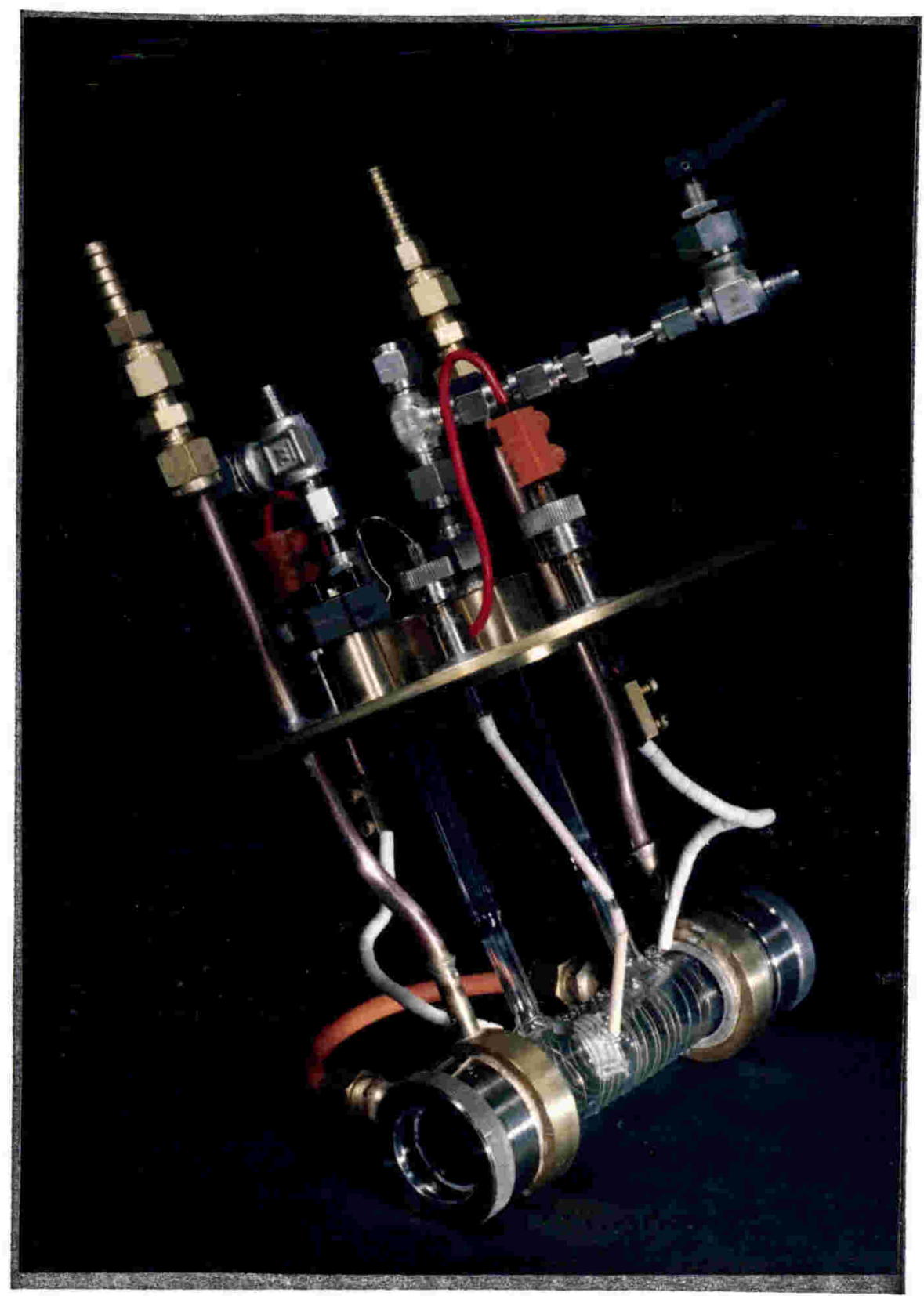

Figure 2.3. The in situ FTIR cell for temperature and atmosphere control of samples. 


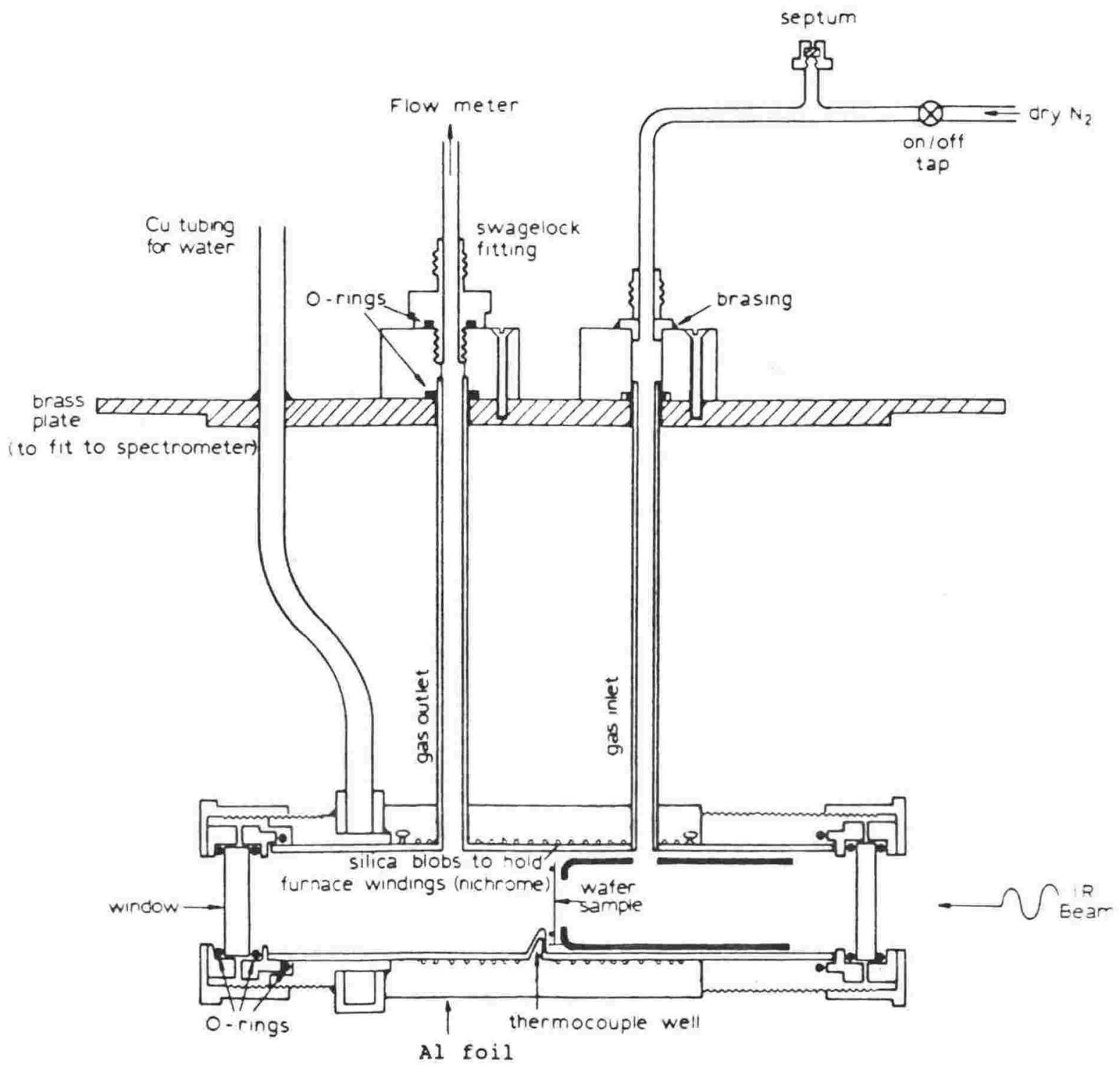

Silica Sample Holder

bars across

front to nold

sample water

uprignt

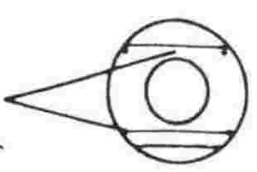

Figure 2.4. Schematic of the in situ FTIR cell. 
poor thermal contact with the cell. Too high a heating rate caused the windings to vaporise.

Sorbants were added to the cell by injection through the septum. These vapourised and were sorbed from the gas stream by the zeolite sample.

\subsubsection{Sample Preparation:}

Self supporting zeolite wafers were prepared by pressing dry finely ground powder between two polished metal dies at a pressure between 10 and 20 tonnes. A wafer size of about 1 $\mathrm{cm} \times 1.5 \mathrm{~cm}$ was required, which weighed $\sim 10 \mathrm{mg}$. Collapse of the zeolite structure was not observed as a result of this procedure. Samples could also be diluted by $\mathrm{KBr}$ and incorporated into thin $\mathrm{KBr}$ pellets which also fitted into the sample holder. These pellets could be successfully heated to $\sim 300^{\circ} \mathrm{C}$.

\subsection{REFERENCES:}

1. Parker L.M. and Patterson J.E. Chemistry Division Report No. CD 2330, Department of Industrial and Scientific Research, New Zealand, 1983.

2. Griffiths P.R., Chemical Infrared Fourier Transform Spectroscopy, John wiley and Sons, 1975.

3. Chamberlain J.," The Principles of Interferometric spectroscopy", Wiley and Sons, 1979.

4. Elving P.J. and Wineforder J.D. Editors, "Fourier Transform Infrared Spectrometry", Wiley-Interscience, 83, 1987.

5. Moon S.H., Windawi H. and Katzer J.R. Ind. Eng. Chem. Fundam., 1981, 20, 396. 
CHAPTER 3: Sorption, Desorption and Reaction of Carboxylic Acids over protonated zeolites.

\subsection{INTRODUCTION}

3.1.1 There were two reasons for studying the sorption of carboxylic acids on protonated zeolites.

1. Basic sites have been proposed, in addition to the acid sites, in $\mathrm{H}+\mathrm{ZSM}-5$. These have been invoked in some reaction mechanisms which explain the formation of the first carbon-carbon bond in the methanol-to-gasoline reaction (1). Alternative mechanisms not requiring the presence of basic sites have also been proposed $(2,3)$.

The sorption of a weak acid (carboxylic) followed by tga and $t d / m s$ should make possible the determination of the number of basic sites, if they are present. This method is analogous to the sorption of weak bases (eg ammonia and ethylamine) for the measurement of the number of acid sites (4).

2. The second reason was to determine whether the H+zeolite behaves as an acid or as a base towards carboxylic acids. It has been claimed by Bielanski and Datka (5) that the $-\mathrm{OH}^{+}$ zeolite sites in NaHY are amphiprotic and react with acid molecules such as acetic acid to form carboxylic anions and water:

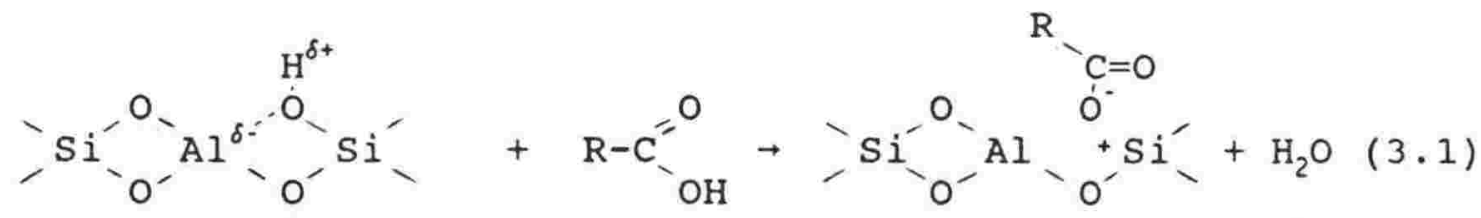

The zeolite $-\mathrm{OH}^{+}$groups therefore behave as Bronsted base centres towards acid molecules. The scheme also requires removal of an oxygen atom from the zeolite lattice which would result in irreversible loss of acid sites (dehydroxylation) and possible destruction of the zeolite lattice. This early (1974) infrared study (5) has often been quoted $(1,6,7,8,9,10)$ and only in one case questioned (10). However, the results could have been influenced by the $30 \% \mathrm{Na}^{+}$ ion occupation of the cation sites which would have given the zeolite additional basic properties (see Chapter 8 ). 
Since proton exchanged zeolites are known as strong acids and acetic acid is a weak acid, it would appear to be energetically more favourable for the acetic acid to be protonated by the zeolite:

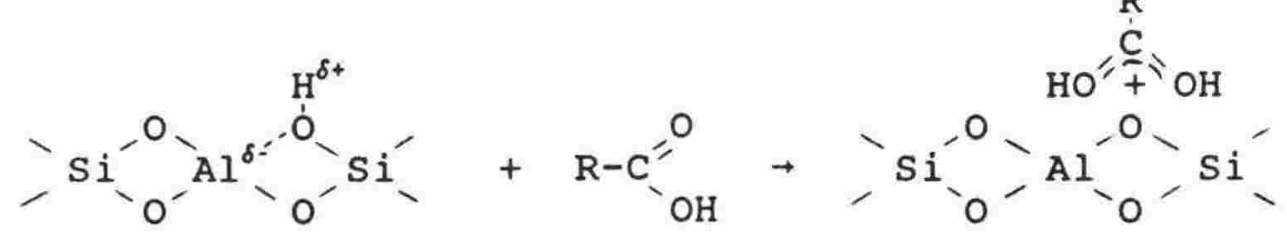

\subsubsection{Reactions of carboxylic acids over protonated zeolites:}

A study of the reaction products of a carboxylic acid over $\mathrm{H}+$ zeolites also leads to information about the nature of the sorbed acid. The products of acetic acid reaction over $\mathrm{H}+\mathrm{ZSM}-5$ have been investigated by several workers $(10,11)$. At $360^{\circ} \mathrm{C}$, the primary products are acetone, carbon dioxide and water:

$2 \mathrm{CH}_{3} \mathrm{COOH} \rightarrow\left(\mathrm{CH}_{3}\right)_{2} \mathrm{CO}+\mathrm{CO}_{2}+\mathrm{H}_{2} \mathrm{O}$

The acetone undergoes further condensation to produce isobutene and aromatics (10). Chang et al. (11) proposed a mechanism in which the acylium ion is generated:

$\mathrm{CH}_{3} \mathrm{COOH}+\mathrm{HO}$-zeolite $\rightarrow \mathrm{CH}_{3} \mathrm{C}^{+} \mathrm{O}-$ o-zeolite $+\mathrm{H}_{2} \mathrm{O}$

An acetate species is also formed (as reported in (5) and shown in equation 3.1). This is followed by a nucleophilic attack of the acylium ion by an acetate anion:

$\mathrm{CH}_{3} \mathrm{C}^{+} \mathrm{O}+\mathrm{CH}_{3}-\stackrel{\mathrm{C}}{\mathrm{C}}-\mathrm{O}^{-} \rightarrow\left(\mathrm{CH}_{3}\right)_{2} \mathrm{CO}+\mathrm{CO}_{2}$

This mechanism involves dehydroxylation of the zeolite (equation 3.1) and the zeolite should therefore loose acidity, as dehydroxylation has never been shown to be reversible (10). However, $\mathrm{H}+\mathrm{ZSM}-5$ cokes up rapidly when converting acetic acid, but is easily regenerable $(10,11)$. This implies that dehydroxylation is not occurring. Jacobs 
et al. (10) proposed an alternative transition state which does not involve dehydroxylation:

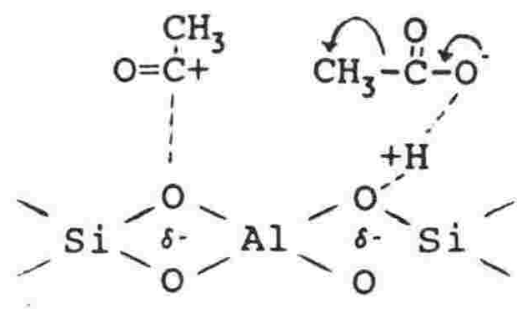

They propose that the acylium ion is formed the usual way, while the acetic acid is polarised by the diffuse negative charge. In this way acetate and acyl are formed close to each other and, upon reaction, leave the catalyst in its original state.

In this chapter td/ms, tga and FTIR techniques have been applied to determine the nature of the sorbed carboxylic acids and the information that can be obtained, indirectly, on the nature of the zeolite active sites. 


\subsection{RESULTS AND DISCUSSION:}

\subsubsection{TGA RESULT8:}

Acetic acid, in the vapour phase, was strongly sorbed on $\mathrm{H}+\mathrm{ZSM}-5$ held at $150^{\circ} \mathrm{C}$. (Sorption at $150^{\circ} \mathrm{C}$ avoids sorption of physisorbed acetic acid and results in a single high temperature weight loss). The amount sorbed was determined by tga for three $\mathrm{ZSM}-5$ samples with different aluminium contents (Table 3.1). The number of acetic acid molecules sorbed per zeolite unit cell (acetic acid molec./u.c.) was comparable to the chemically determined number of Al atoms per unit cell (Al/U.C.), and hence Bronsted acid sites per unit cell. The one-to-one relationship implies a direct association between Bronsted acid sites and acetic acid molecules.

\section{Table 3.1:}

$\begin{array}{lll}\begin{array}{l}\text { zeolite } \\ \text { prep. no. }\end{array} & \text { Al/u.c. } & \begin{array}{l}\text { acetic acid } \\ \text { molec/u.c. }\end{array} \\ \mathrm{H}+915 & 2.52 \pm .08 & 2.35 \pm 0.1 \\ \mathrm{H}+800 & 1.3 \pm .04 & 1.62 \pm 0.05 \\ \mathrm{H}+816 & 3.11 \pm .10 & 2.94 \pm 0.1\end{array}$

\subsubsection{TDMS RESULTS:}

$\mathrm{Td} / \mathrm{ms}$ showed the species that desorbed upon heating $\mathrm{H}+2 \mathrm{SM}-5$ after sorption of acetic acid at $150^{\circ} \mathrm{C}$ (figure 3.1). Initially, acetic acid desorbed unaltered and, as the temperature increased, products of thermal decomposition and further reaction were observed. There was a large $\mathrm{CO}_{2}$ peak, some ethene, methane, water and acetone. Some coke was also deposited, the zeolite having turned black. Integration of the desorption peaks, followed by scaling by their respective sensitivity factors, gave the following mole percentages of products desorbed $\mathrm{CO}_{2} 39$, ethene 15.4, $\mathrm{H}_{2} \mathrm{O} 25.8, \mathrm{CH}_{4} 9.9$ and acetone 9.9. Totalling up the $\mathrm{C}, \mathrm{O}$ and $\mathrm{H}$ atoms evolved, gave a ratio of $\mathrm{C}: \mathrm{O}: \mathrm{H}$ of $109: 114: 212$. This approximated the ratio for acetic acid of $2: 2: 4$, implying that the products desorbed were from the decomposition of acetic acid and did 
not include water from dehydroxylation of the zeolite. This also implies very little coke formation.

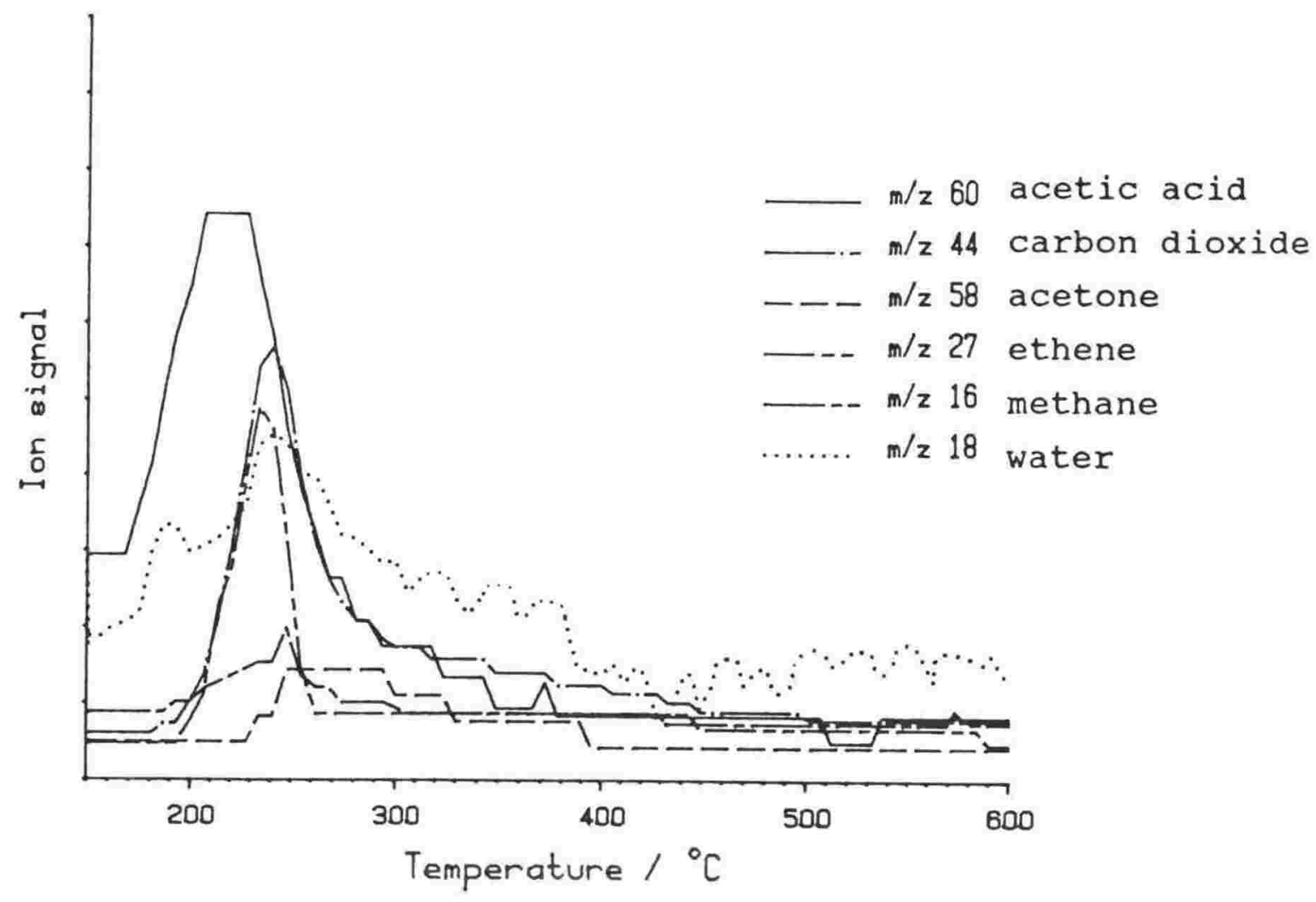

Figure 3.1. Td/ms of acetic acid sorbed on $\mathrm{H}+\mathrm{ZSM}-5$ at $150^{\circ} \mathrm{C}$ heated at $10^{\circ} \mathrm{C} \mathrm{min}^{-1}$.

Acetic acid that has been sorbed on a one-to-one-basis with the zeolite acid sites has been shown to desorb as acetic acid or its decomposition products, and this is strong evidence against equation (3.1). If water had been eliminated upon sorption on to an acid site then the desorption products could not include acetic acid. Any water evolved in (equation 3.1) would have rapidly desorbed from the zeolite held at $150^{\circ} \mathrm{C}$. 
Further evidence that the acid was sorbed intact was obtained by $t d / m s$ (figure 3.2 ).

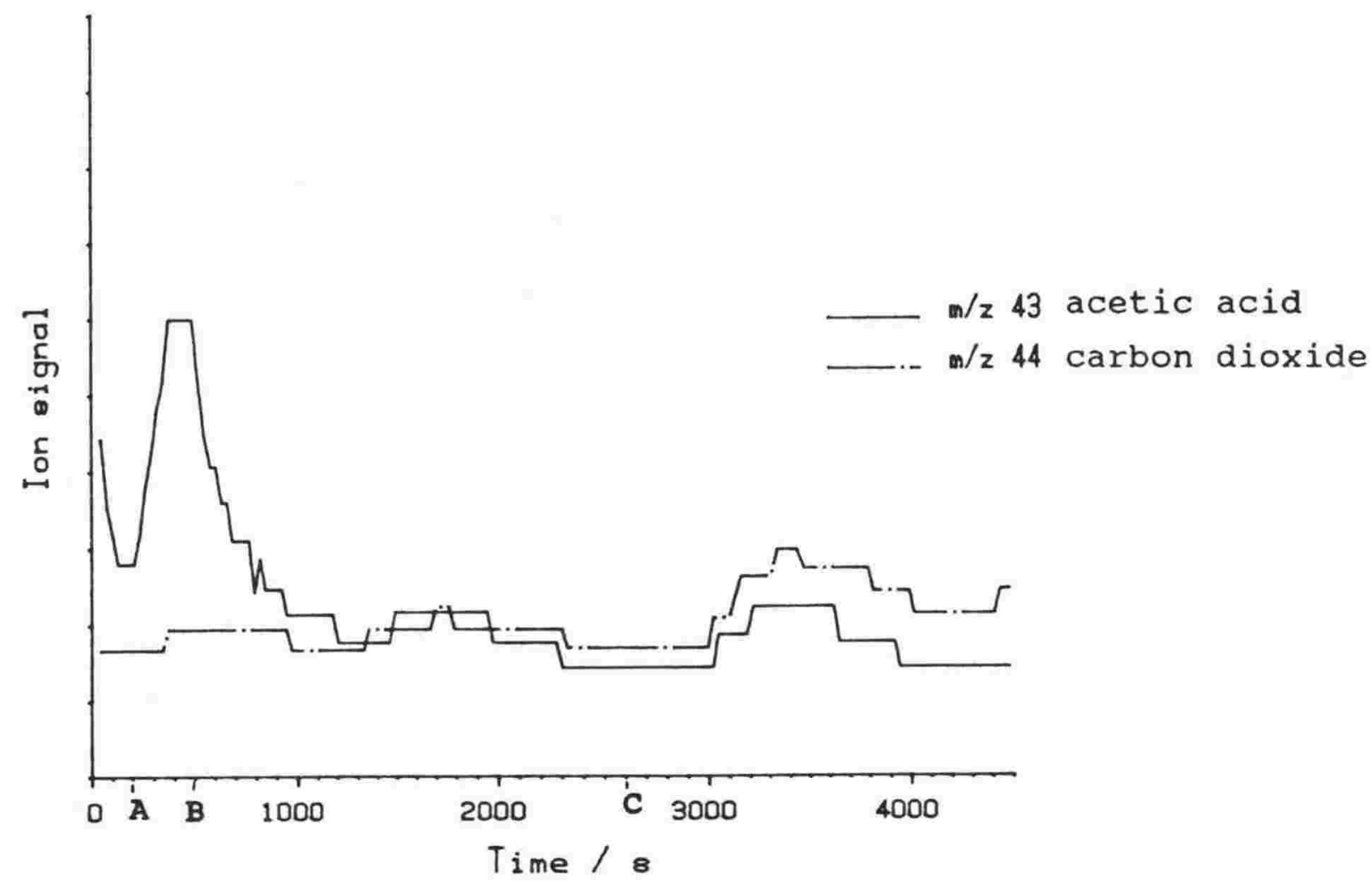

Figure 3.2. Td/ms of acetic acid sorbed on $\mathrm{H}+\mathrm{ZSM}-5$ at $150^{\circ} \mathrm{C}$, then heated to $200^{\circ} \mathrm{C}$ (from $\mathrm{A}$ to $\mathrm{B}$ ) and held for 40 minutes (until C).

Acetic acid was sorbed at $150^{\circ} \mathrm{C}$, then heated to $200^{\circ} \mathrm{C}$ (from $\mathrm{A}$ to $B$ ) and held for 40 minutes (until C). During this time, mass spectrometry showed only acetic acid desorption. The sample was then heated at $10^{\circ} \mathrm{C} / \mathrm{min}$ resulting in a very small acetic acid and a small $\mathrm{CO}_{2}$ desorption. Increasing the time for which the sample was held at $200^{\circ} \mathrm{C}$ to 213 minutes resulted in subsequent desorption, upon increasing the temperature, of no significant acetic acid and half the amount of $\mathrm{CO}_{2}$. The $\mathrm{CO}_{2}$ observed was probably due to the decomposition of a small amount of an acetic acid reaction product.

The $t d / m s$ results show that at $200^{\circ} \mathrm{C}$ very little, reaction of acetic acid occurs over H+ZSM5. The tga results show that acetic acid is sorbed on a one-to-one basis with the zeolite acid sites. 
3.2.3 INTERACTION/REACTION OF CARBOXYLIC ACIDS WITH AMMONIA AND AMINES OVER H+ZSM5.

These experiments were carried out to obtain further evidence that the sorbed acetic acid was protonated by the zeolite acid sites. If the acetic acid was protonated by the zeolite, and hence behaved as a weak base, then it should be displaced from the acid sites by a stronger base such as ammonia.

\subsubsection{A SORPTION OF ACETIC ACID FOLLOWED BY SORPTION OF AMMONIA AT $150^{\circ} \mathrm{C}$ :}

The sorption of acetic acid, followed by the sorption of ammonia on to $\mathrm{H}+\mathrm{ZSM} 5$ (prep 915) held at $150^{\circ} \mathrm{C}$ was studied by td/ms. Any excess acetic acid not strongly bound to the zeolite was removed by trapping into a liquid nitrogen cold finger before ammonia sorption. The results are shown in figure 3.3 . The amount of acetic acid desorbed was small compared to $t d / m s$ of sorbed acetic acid only, implying that very little acetic acid remained on the acid sites. The amount of ammonia desorbed, determined by quantitative $t d / m s$, was $2.4 \pm 0.1 \mathrm{NH}_{3}$ molecules per zeolite unit cell, the same as, within error, to the number of acid sites per unit cell $(2.52 \pm 0.08)$ for the zeolite sample used. This implies that the ammonia, being the strongest base, displaced acetic acid from the Bronsted sites. 


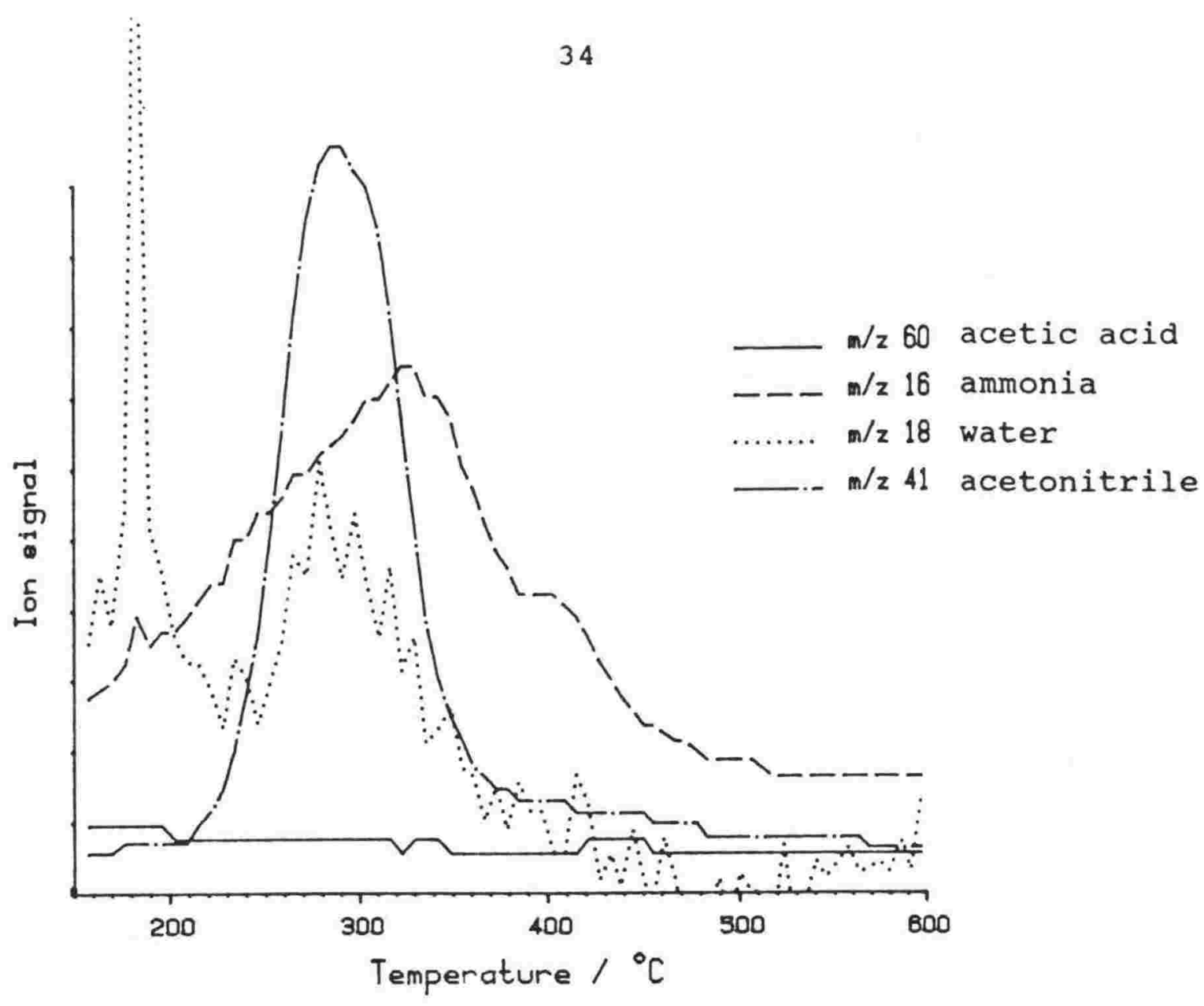

Figure 3.3. Td/ms of acetic acid, then ammonia sorbed on $\mathrm{H}+\mathrm{ZSM}-5$ at $150^{\circ} \mathrm{C}$.

However, this may not have been a simple displacement as the acetic acid and ammonia reacted together to form the salt:

$\mathrm{CH}_{3}-\underset{\mathrm{OH}}{\mathrm{C}_{\stackrel{\mathrm{O}}{\prime}+}^{\mathrm{OH}}}$ o-zeolite $+2 \mathrm{NH}_{3} \rightarrow \mathrm{CH}_{3}-\mathrm{C}_{\mathrm{ONH}_{4}}^{\prime \prime}+\mathrm{NH}_{4} \mathrm{O}$-zeolite (3.7)

Further reactions characteristic of the ammonium acetate (12) were observed as the sample was heated. Decomposition of the salt to give the amide and water was observed at $180^{\circ} \mathrm{C}$ with a sharp water loss:

$\mathrm{CH}_{3}-\stackrel{\mathrm{O}}{\mathrm{C}}-\mathrm{ONH}_{4} \stackrel{180^{\circ} \mathrm{C}}{\rightarrow} \stackrel{\mathrm{O}}{\mathrm{CH}_{3}-\stackrel{\mathrm{C}}{\mathrm{C}}-\mathrm{NH}_{2}}+\mathrm{H}_{2} \mathrm{O}$ 
Further dehydration resulted in the formation of acetonitrile:

$\stackrel{\mathrm{O}}{\mathrm{C} \mathrm{H}_{3}-\stackrel{\mathrm{C}}{\mathrm{C}}-\mathrm{NH}_{2}} \underset{-390^{\circ} \mathrm{C}}{\rightarrow} \mathrm{H}_{3} \mathrm{C}-\mathrm{C} \equiv \mathrm{N}+\mathrm{H}_{2} \mathrm{O}$

Acetonitrile and water desorption were observed between $220^{\circ} \mathrm{C}$ and $390^{\circ} \mathrm{C}$.

Reaction of ammonia with the acetic acid meant that the ammonia could have displaced ammonium acetate from the Bronsted sites, rather than the acetic acid. However, this interfering reaction provided further evidence that acetic acid was sorbed unreacted. The ammonium acetate could have been formed only by reaction of ammonia with acetic acid. The ammonium acetate could not have been formed by reaction of the acetate from equation 3.1 because the molecule of water lost in equation 3.1 is required for salt formation:

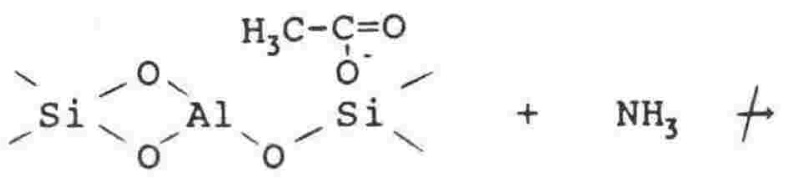

\subsubsection{B SORPTION OF AMMONIA FOLLOWED BY SORPTION OF ACETIC ACID AT $150^{\circ} \mathrm{C}$ :}

Figure 3.4 shows results from the td/ms experiment in which ammonia was sorbed first, followed by sorption of acetic acid (both at $150^{\circ} \mathrm{C}$ ). At $150^{\circ} \mathrm{C}$, after sorption of ammonia then evacuation, tga showed that one molecule of ammonia was sorbed per Bronsted site. Exposure to acetic acid resulted in the reaction of some of the sorbed ammonia with acetic acid to form ammonium acetate. Upon heating, decomposition to the amide and water (reaction 3.8) was again observed with the evolution of water. Further dehydration to acetonitrile and water was also observed. One third of the ammonia remained unreacted on the Bronsted sites and desorbed during $t d / m s$, but only a small amount of acetic acid desorbed. The acetic acid therefore did not displace the bulk of the ammonia from the Bronsted sites, but did react with some of 
the sorbed ammonia to form ammonium acetate. This implies that ammonia was more strongly bound than acetic acid, as would be expected if both ammonia and acetic acid were behaving as bases.

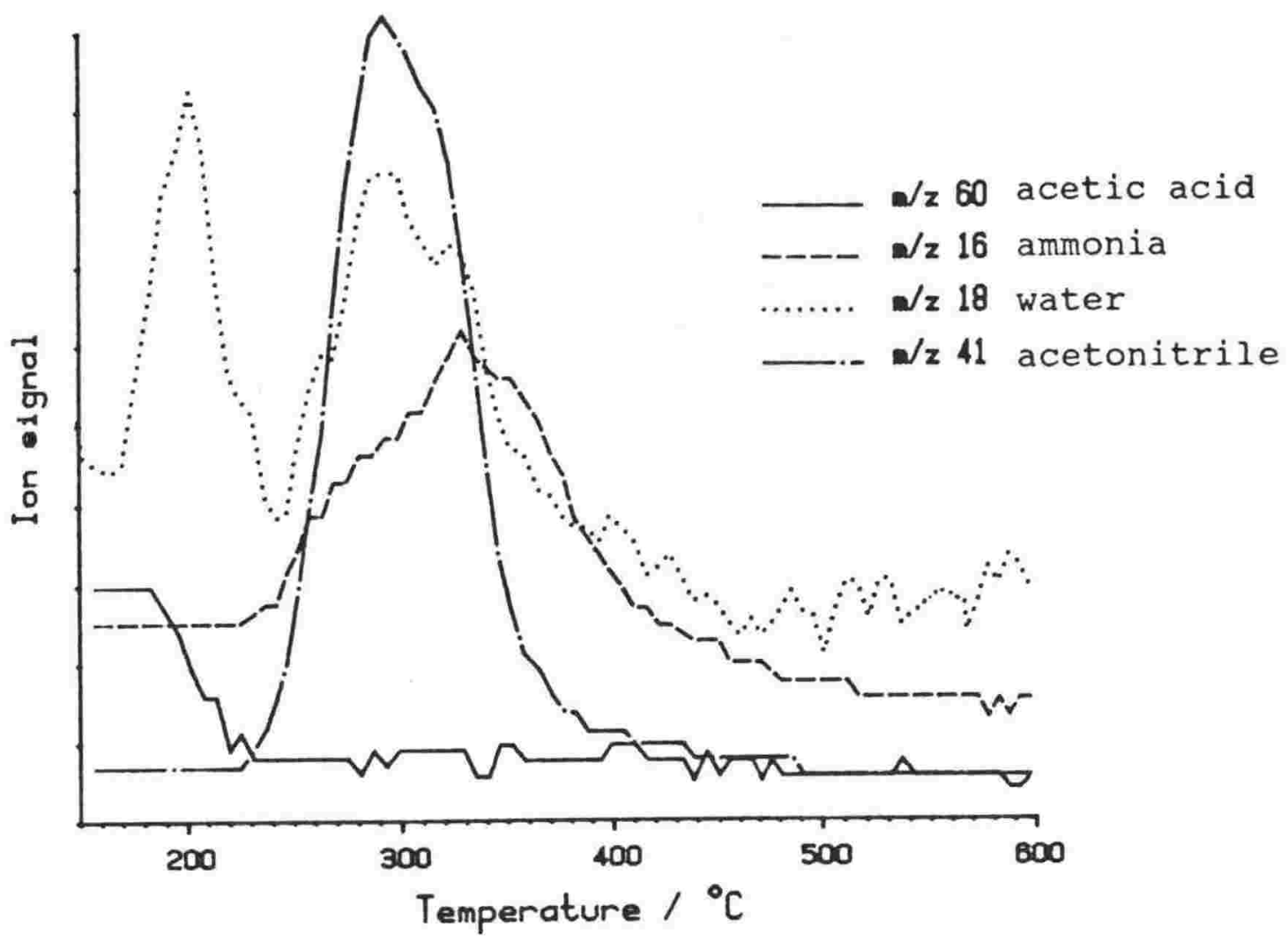

Figure 3.4. Td/ms of ammonia then acetic acid sorbed on $\mathrm{H}+\mathrm{ZSM}-5$ at $150^{\circ} \mathrm{C}$. 
3.2.3.C SORPTION OF ACETIC ACID FOLLOWED BY SORPTION OF ETHYLAMINE:

Acetic acid was sorbed on to $\mathrm{H}+\mathrm{ZSM}-5$ (prep 915) held at $150^{\circ} \mathrm{C}$, and the excess vapour was removed into a liquid nitrogen trap. Ethylamine was then sorbed similarly. The td/ms results are shown in figure 3.5. Physisorbed ethylamine desorbed between $150^{\circ} \mathrm{C}$ and $300^{\circ} \mathrm{C}$, along with a very small amount of acetic acid. The ethylamine reacted with the acetic acid, in the same manner as does ammonia with acetic acid, to form the salt:

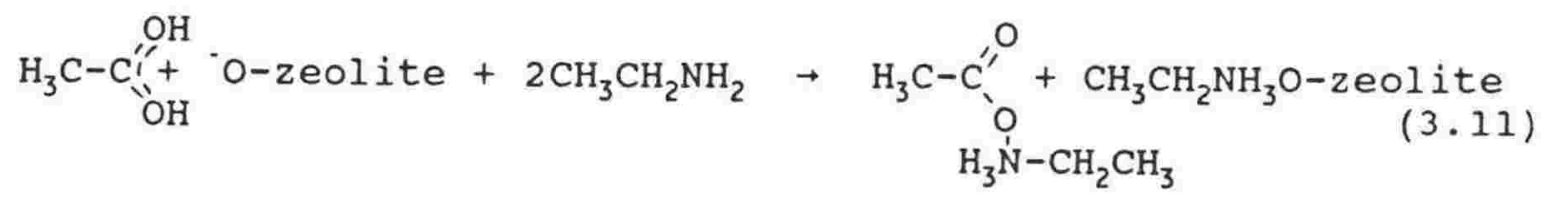

More ethylamine had sorbed on to the acid sites, having displaced either acetic acid or the salt. This was shown by the large desorption peak of ammonia and ethene between $330^{\circ} \mathrm{C}$ and $540^{\circ} \mathrm{C}$ due to decomposition of ethylamine bound to the acid sites (13). Decomposition of the salt to give the amide and water gave a sharp water loss at $230^{\circ} \mathrm{C}$ :

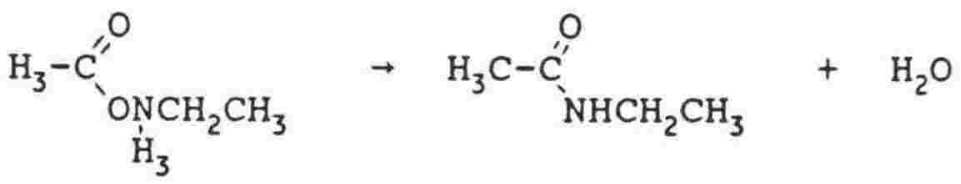

Further dehydration occurred between $250^{\circ} \mathrm{C}$ and $310^{\circ} \mathrm{C}$, but a temporarily stable complex must have formed as no other products evolved:

$\mathrm{H}_{3} \mathrm{C}-\mathrm{C}_{\mathrm{NHCH}_{2} \mathrm{CH}_{3}}^{\prime \prime} \rightarrow\left(\mathrm{H}_{3} \mathrm{C}-\mathrm{C}=\mathrm{CH}_{2}^{\prime} \mathrm{CH}_{2}\right) ?+\mathrm{H}_{2} \mathrm{O}$

After water had desorbed, this complex collapsed with acetonitrile and ethene being evolved between $300^{\circ} \mathrm{C}$ and $400^{\circ} \mathrm{C}$. Ethylamine sorbed on the acid sites decomposed to ethene and ammonia between $330^{\circ} \mathrm{C}$ and $540^{\circ} \mathrm{C}$. 


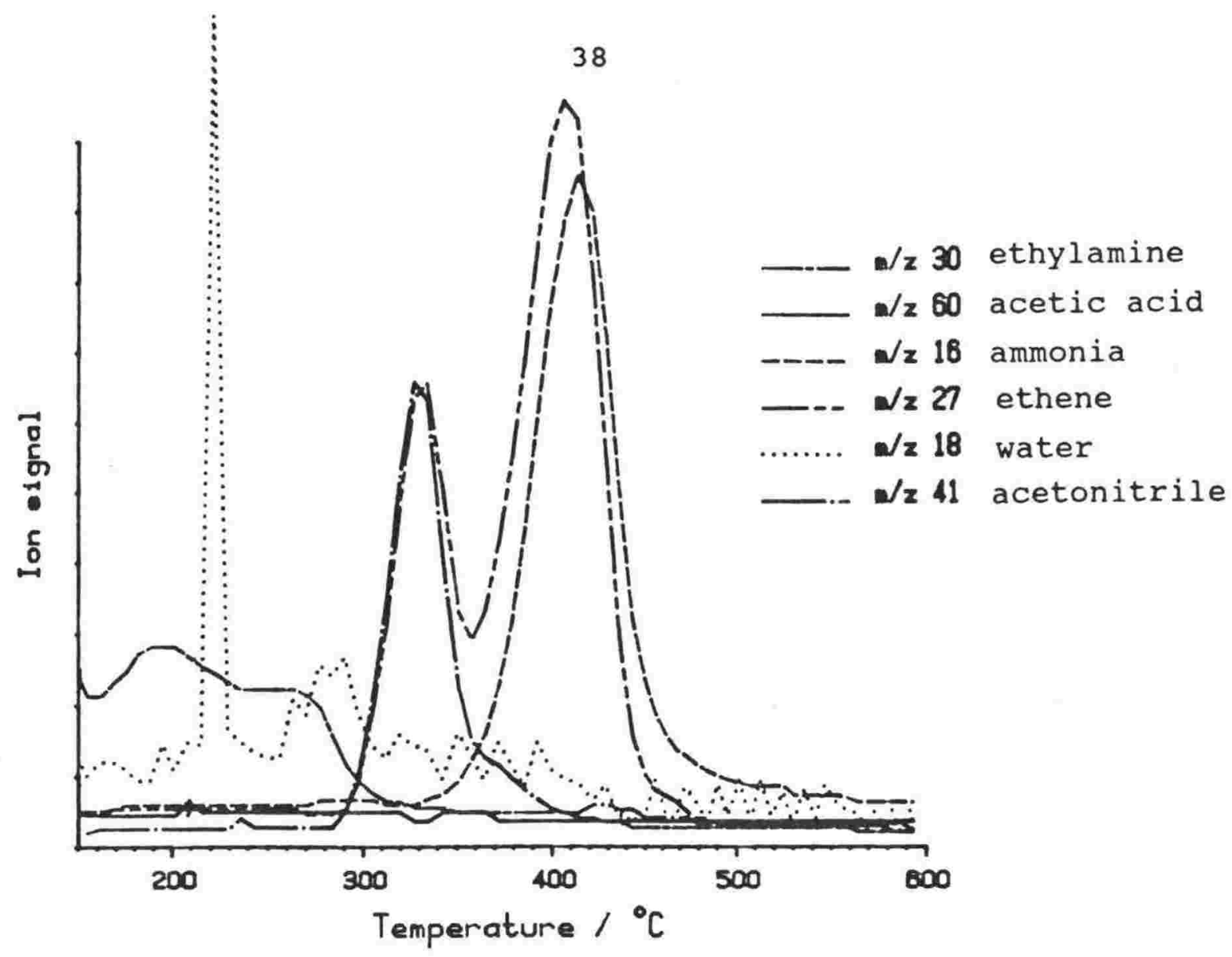

Figure 3.5. Td/ms of acetic acid, then ethylamine sorbed on $\mathrm{H}+\mathrm{ZSM}-5$ at $150^{\circ} \mathrm{C}$.

\subsubsection{SORPTION OF PROPIONIC ACID FOLLOWED BY AMMONIA:}

A drop of propionic acid was placed on $\mathrm{H}+\mathrm{ZSM}-5$ (prep 816) and the excess removed by evacuation at $150^{\circ} \mathrm{C}$. This was followed by sorption of $\mathrm{NH}_{3}$ at $150^{\circ} \mathrm{C}$. $\mathrm{Td} / \mathrm{ms}$ (figure 3.6) showed a very broad ammonia desorption from $150^{\circ} \mathrm{C}$ to $500^{\circ} \mathrm{C}$. Decomposition of the ammonium salt to give the amide and water (as in equation 3.8 ) must have occurred while the sample was held at $150^{\circ} \mathrm{C}$, as this was not observed by td/ms. Propionitrile and water desorbed between $215^{\circ} \mathrm{C}$ and $430^{\circ} \mathrm{C}$ probably from thermal decomposition of the amide:

$\mathrm{CH}_{3} \mathrm{CH}_{2}-\mathrm{C}_{\mathrm{NH}_{2}}^{\prime \prime \mathrm{O}} \rightarrow \mathrm{CH}_{3} \mathrm{CH}_{2}-\mathrm{C} \equiv \mathrm{N}+\mathrm{H}_{2} \mathrm{O}$

Reactions over zeolites of mixtures of formic acid with alcohols and amines to give mixtures of alkylnitriles have been patented (14). However, a study of the reactions of carboxylic acids and amines to give alkylnitriles, and 
details of the reaction sequences, as carried out here, have not previously been published.

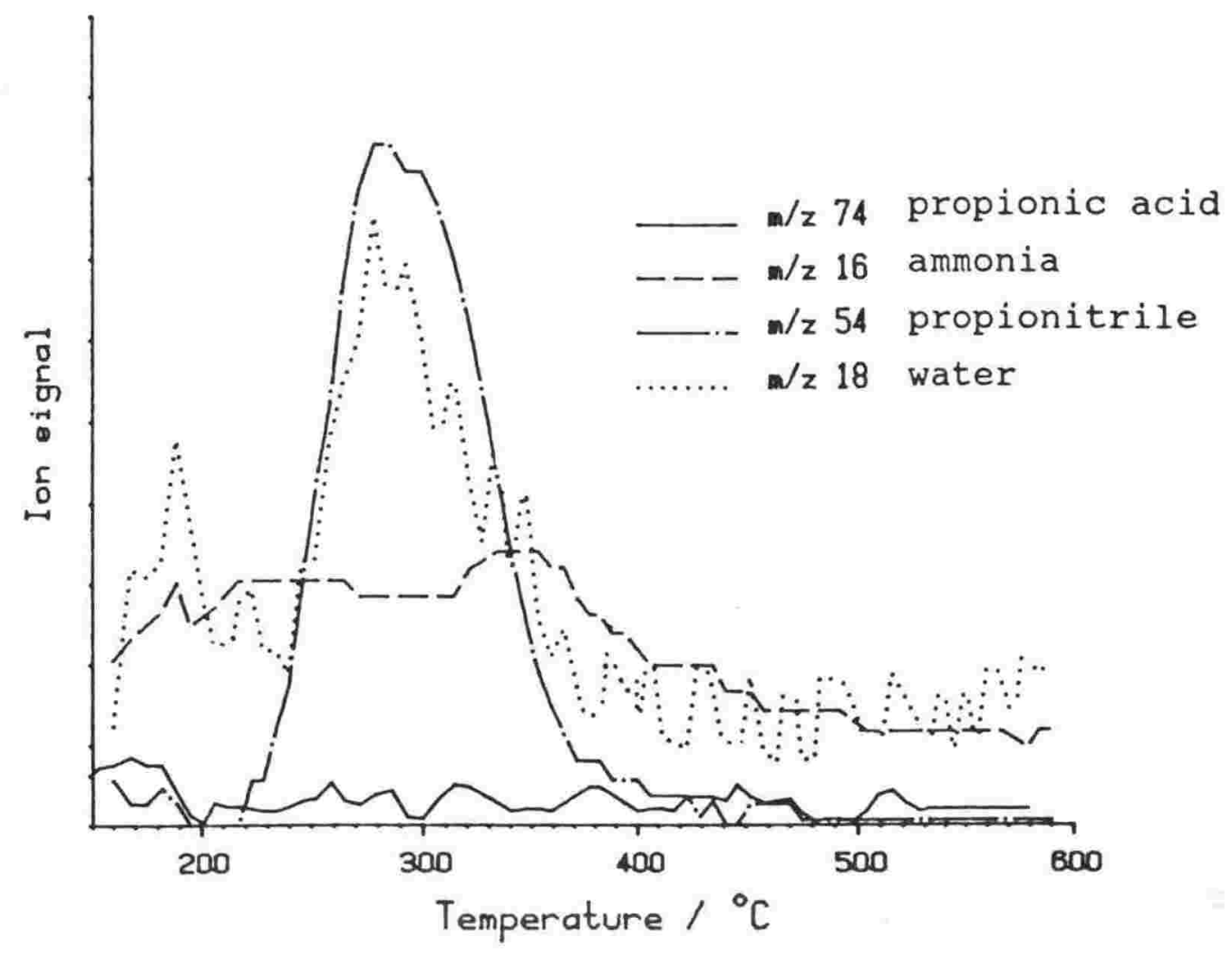

Figure 3.6. Td/ms of propionic acid then ammonia sorbed on $\mathrm{H}+\mathrm{ZSM}-5$ at $150^{\circ} \mathrm{C}$. 


\subsubsection{NMR RESULTS:}

${ }^{13} \mathrm{C}$ solid state $\mathrm{nmr}$ was carried out on $\mathrm{H}+\mathrm{ZSM}-5$ (prep 816) and $\mathrm{Na}^{+} \mathrm{Y}$ with acetic acid sorbed at $160^{\circ} \mathrm{C}$. A preliminary $\mathrm{nmr}$ experiment had shown no significant difference between acetic acid sorbed on the two zeolite samples, so care was taken to remove any physisorbed acid, the signal of which may have been swamping any small differences. After sorption of acetic acid for two minutes physisorbed acid was removed by evacuation of the sample for more than 30 minutes, while holding it at $160^{\circ} \mathrm{C}$. The nmr spectra are shown in figure 3.7. Again there were no major differences between the two samples. For acetic acid on $\mathrm{H}+\mathrm{ZSM}-5$ a small peak from the carboxylic acid carbon was observed at $179.3 \mathrm{ppm}$ with a shoulder (which may have been due to noise) at $181.0 \mathrm{ppm}$. The methyl carbons gave a much stronger signal at $19.7 \mathrm{ppm}$. For acetic acid on $\mathrm{Na}+\mathrm{Y}$, the carboxylic acid carbon gave a peak at $178.4 \mathrm{ppm}$, with the methyl carbons at $27.3 \mathrm{ppm}$. Acetic acid in the liquid phase has a peak at 177.27 ppm for the carboxylic acid carbon and at $21.1 \mathrm{ppm}$ for the methyl group (15). (The chemical shifts are relative to tetramethylsilane).

These are only small changes between very different environments for acetic acid, therefore the ${ }^{13} \mathrm{C} \mathrm{nmr}$ technique is too insensitive to obtain information on the different modes of bonding. 


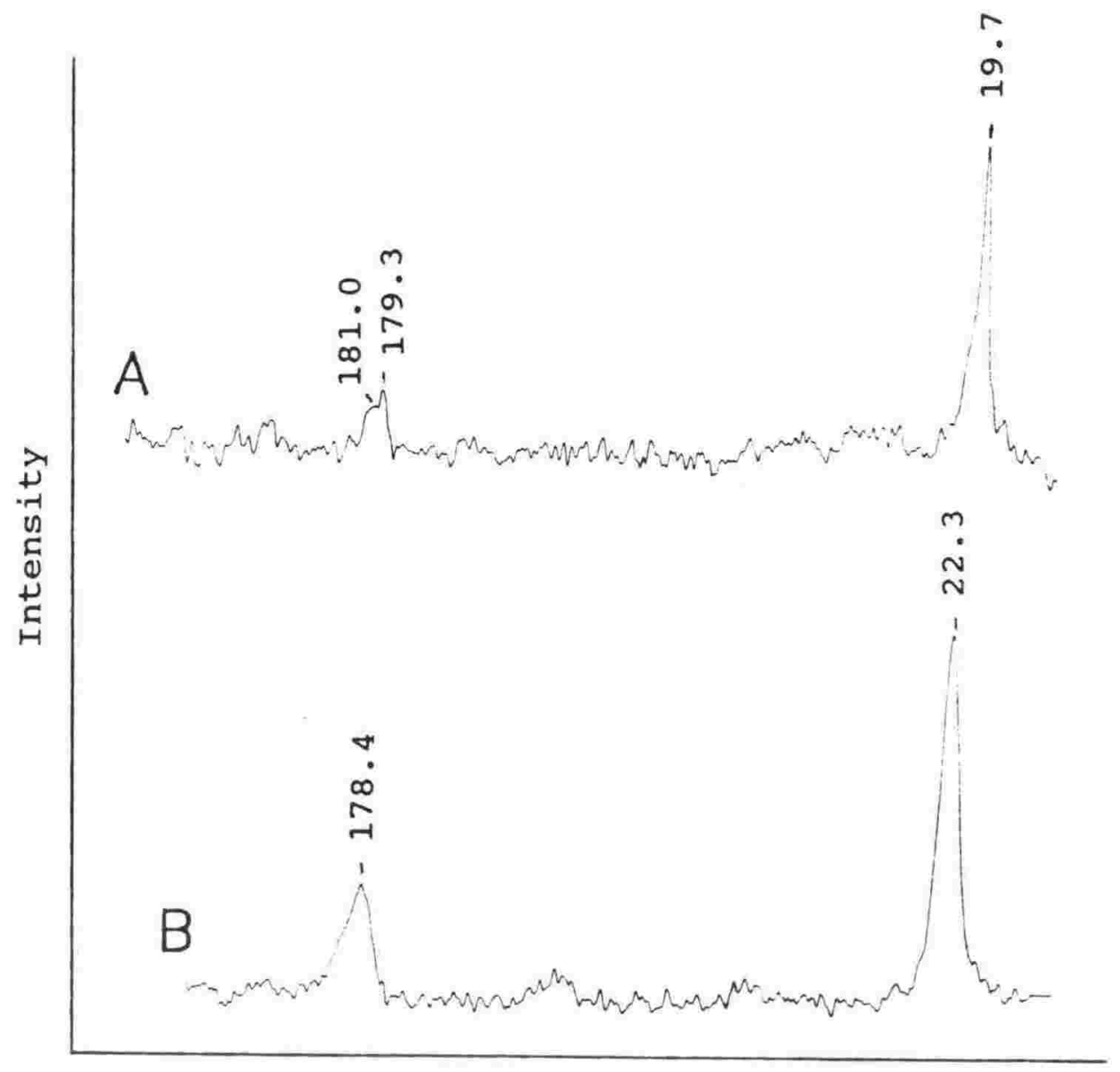

Chemical shift (ppm)

Figure 3.7. ${ }^{13} \mathrm{C}$ nmr of acetic acid sorbed on $\mathrm{A} . \mathrm{H}+\mathrm{ZSM}-5$ and B. $\mathrm{Na}+\mathrm{Y}$.

\subsubsection{FTIR RESULTS:}

\subsubsection{A ACETIC ACID ON H+ZSM5:}

The FTIR spectrum of vapour phase acetic acid in the FTIR cell is shown in figure $3.8 \mathrm{~A}$, with the spectrum of deuterated acetic acid $\left(\mathrm{CD}_{3} \mathrm{COOD}\right)$ vapour, along with some acetic acid vapour, shown in figure 3.8B. Acetic acid is present in the gas phase as a mixture of monomers and dimers (16) with the monomer $\mathrm{C}=0$ stretch at $1797 \mathrm{~cm}^{-1}$ and the dimer stretch at $1777 \mathrm{~cm}^{-1}$. The $0-\mathrm{H}$ stretch appears at $\sim 3584 \mathrm{~cm}^{-1}$ and the $\mathrm{O}-\mathrm{D}$ stretch at $\sim 2639 \mathrm{~cm}^{-1}$. The $\mathrm{O}-\mathrm{H}$ and $O-D$ stretches are split into three peaks due to the rotational bands ( $p, q$ and $r$ ). 


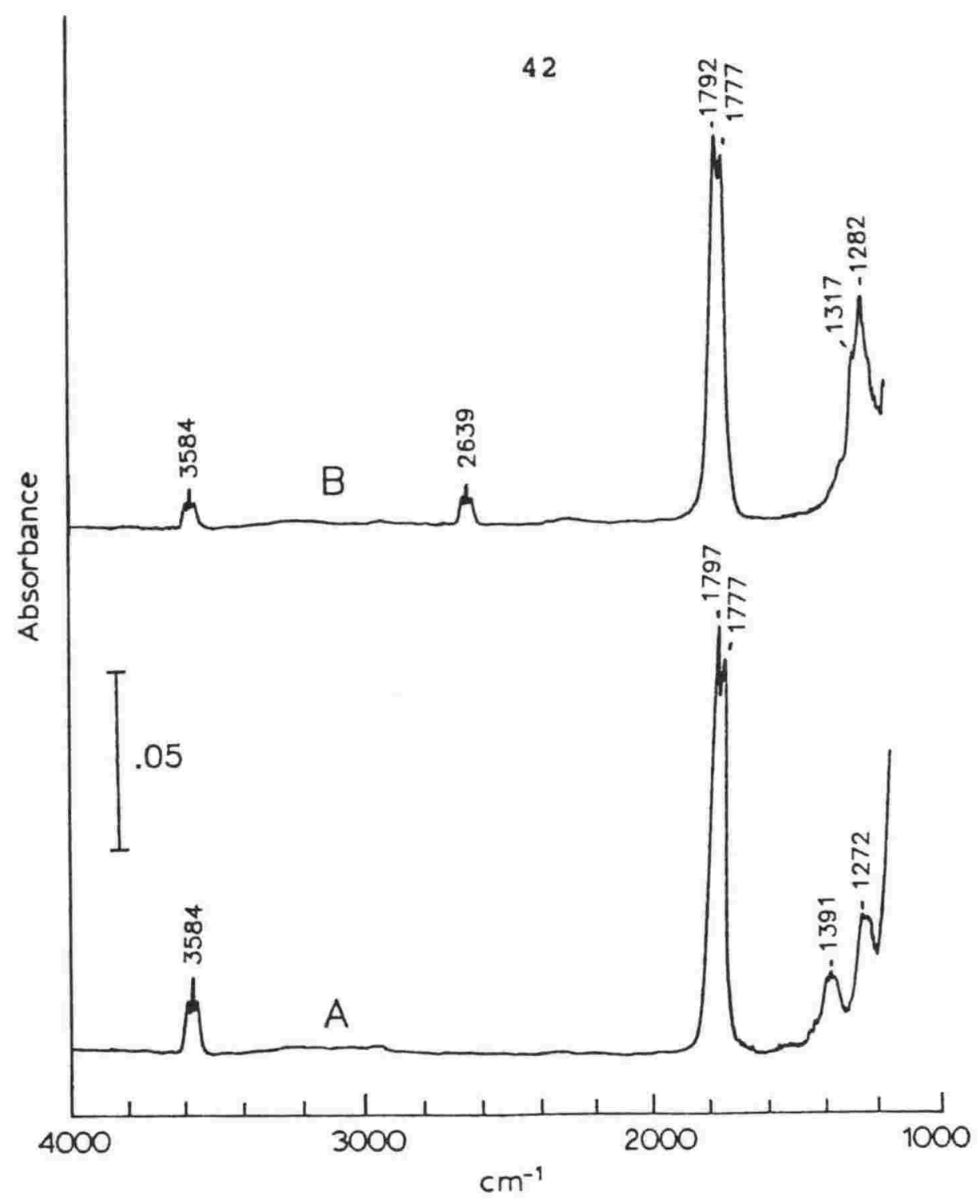

Figure 3.8. FTIR spectra of: A. vapour phase acetic acid and B. a mixture of fully deuterated acetic acid and acetic acid in the vapour phase.

A self supporting wafer of $\mathrm{H}+\mathrm{ZSM}-5$ (prep 816) was placed in the FTIR cell, heated to $140^{\circ} \mathrm{C}$, and flushed with nitrogen $\left(25 \mathrm{ml} \min ^{-1}\right.$ ) until dry (when no peaks due to sorbed water were observed). The FTIR spectrum of the dry zeolite at $140^{\circ} \mathrm{C}$ is shown in figure $3.9 \mathrm{~A}$. Sharp $\mathrm{O}-\mathrm{H}$ stretches were observed, with the peak at $3601 \mathrm{~cm}^{-1}$ due to Bronsted acid sites and the smaller peak at $3740 \mathrm{~cm}^{-1}$ ascribed to either internal and external hydroxyl groups (17) or impurities (18). The bands at 1975,1867 and $1638 \mathrm{~cm}^{-1}$ are overtone and combination bands of more intense lower frequency fundamental $\mathrm{SiO}_{4}$ or $\mathrm{AlO}_{4}$ stretches and deformations (19). 
Acetic acid $(2 \mu l)$ was injected into the FTIR cell and sorbed onto the wafer held at $140^{\circ} \mathrm{C}$. The resultant spectrum and subsequent spectra obtained after flushing the cell for $30 \mathrm{~s}$, $12 \mathrm{~min}$ and $2 \mathrm{~h}$ are shown in figure $3.9 \mathrm{~B}, \mathrm{C}$ and $\mathrm{D}$. Difference spectra (showing the changes that occurred to the original spectrum in figure 3.9A) are shown in figure 3.10 .

Small negative peaks at $\sim 2022$ and $\sim 1900 \mathrm{~cm}^{-1}$ in the difference spectra show changes in the tetrahedral overtone bands implying minor structural change as sorbants fill the zeolite channels. This effect was observed for all sorbants.

The strong doublet at 1800 and $1773 \mathrm{~cm}-1$ (see figure $3.10 \mathrm{~B}$ ) disappeared after 12 minutes (figure $3.10 \mathrm{C}$ ). This was due to loss of either gas phase or physisorbed acetic acid. The species that remained was/were more strongly sorbed. The loss of the Bronsted $\mathrm{O}-\mathrm{H}$ stretch, shown by the negative peak at $3601 \mathrm{~cm}^{-1}$ (figure $3.10 \mathrm{C}$ ), shows that this/these species was/were bonded to the acid sites.

The Bronsted proton had been transferred towards the acetic acid with three broad bands centred at $\sim 3500, \sim 2870$ and $\sim 2470 \mathrm{~cm}^{-1}$ observed. The first broad band is obscured by the large loss of the zeolite Bronsted hydroxyls in the difference spectra (figure 3.10). Similar broad bands are observed for water sorbed on $\mathrm{H}+\mathrm{ZSM}-5$ at $80^{\circ} \mathrm{C}$ (see chapter 4 ). The species observed was not water, as under the conditions in the FTIR cell $\left(140^{\circ} \mathrm{C}\right.$, dry nitrogen flowing) water was almost immediately desorbed. A wide range of energies was associated with the bonded Bronsted proton as the bands were broad and had no fine structure when observed at $0.1 \mathrm{~cm}^{-1}$ resolution. 


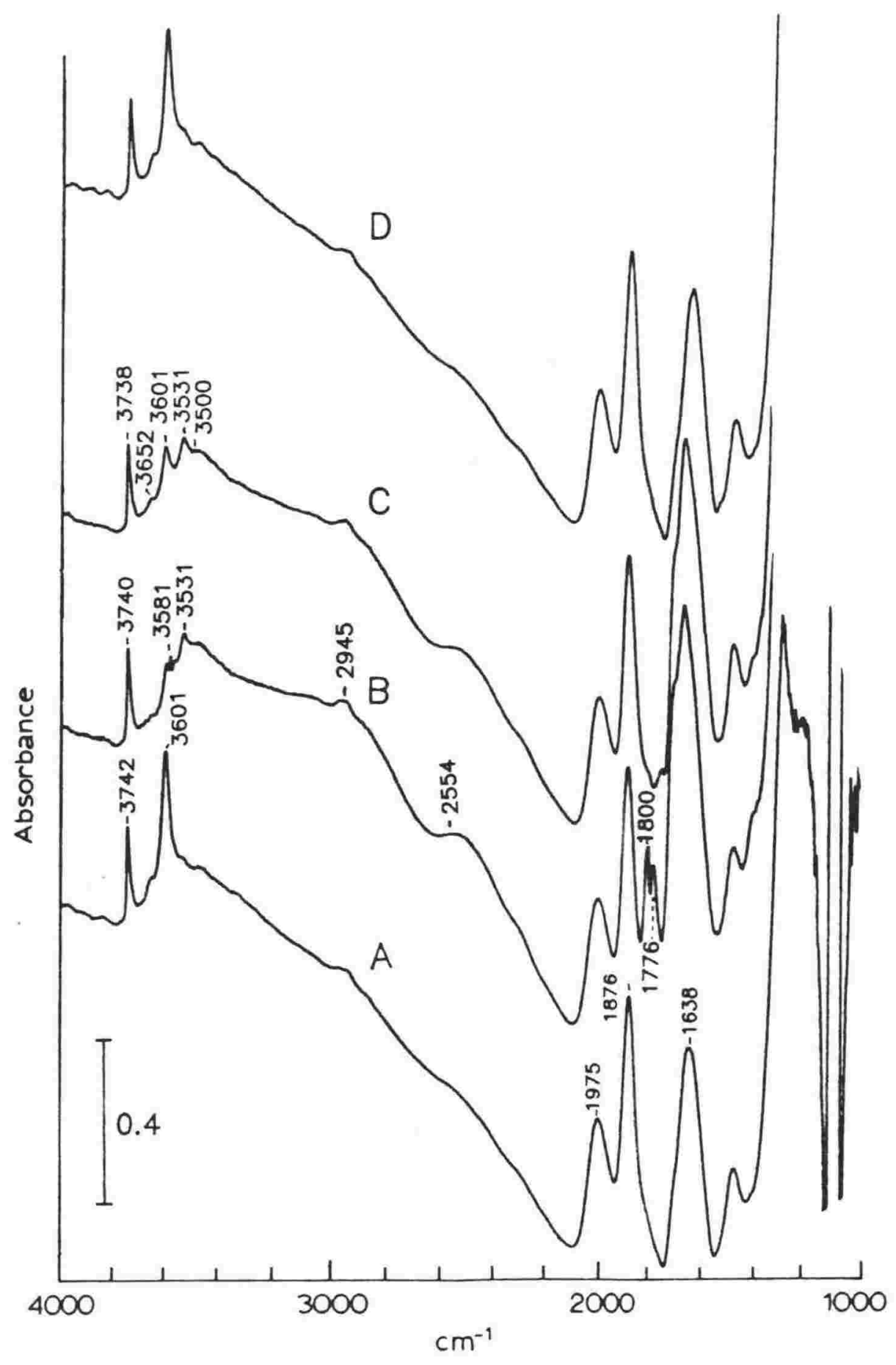

Figure 3.9. FTIR spectra of: A. Dry $\mathrm{H}+\mathrm{ZSM}-5$ held at $140^{\circ} \mathrm{C}$; B. $30 \mathrm{~s}$ after injection of $2 \mu \mathrm{l}$ acetic acid into the FTIR cell; C. 12 min later and D. $2 \mathrm{~h}$ later. 
Figure $3.9 \mathrm{C}$ shows sharper peaks upon the broad ${ }^{-} 3500 \mathrm{~cm}^{-1}$ band. The peak at $3601 \mathrm{~cm}^{-1}$ was due to unbonded Bronsted hydroxyls, with the other peaks at 3652,3531 and $3500 \mathrm{~cm}^{-1}$ unassigned. These may be due to hydroxyl species associated with the sorbed acetic acid. Similar peaks are investigated more fully for the case of sorbed water (see Chapter 4 ).

The wavenumber of the $\mathrm{C}=0$ stretching band varies with the degree of bonding of this group to other molecules. Table 3.2 summarises the $\mathrm{C}=\mathrm{O}$ and $\mathrm{C}-\mathrm{O}$ stretches for a range of acetic acid species.

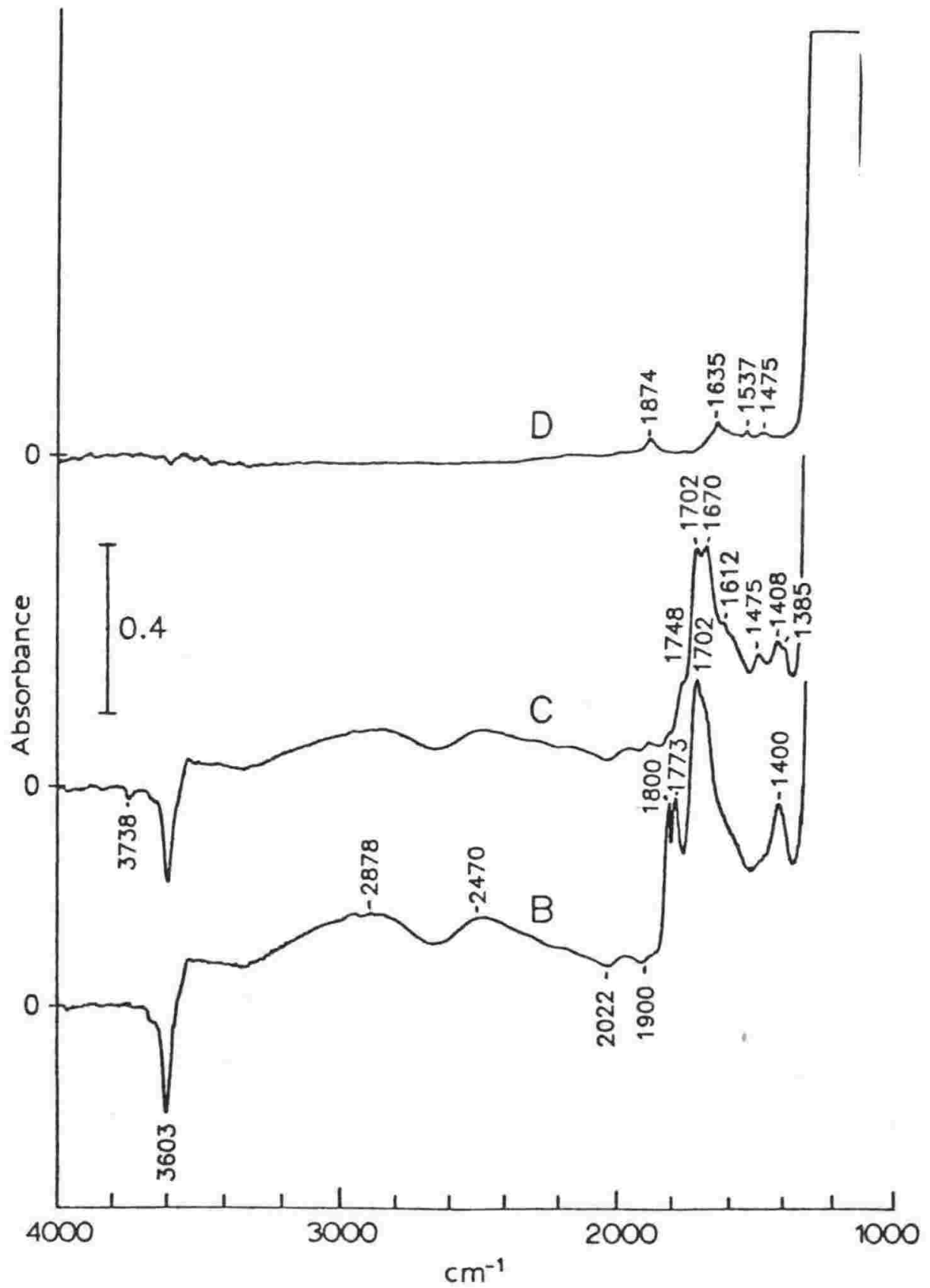

Figure 3.10. FTIR difference spectra (from original dry H+ZSM. 5 spectrum) of acetic acid sorbed on $\mathrm{H}+\mathrm{ZSM}-5$. B. $30 \mathrm{~s}$ after acetic acid addition; C. $12 \mathrm{~min}$ later and D. $2 \mathrm{~h}$ later. 
Table 3.2: IR C-O stretching frequencies for acetic acid species.

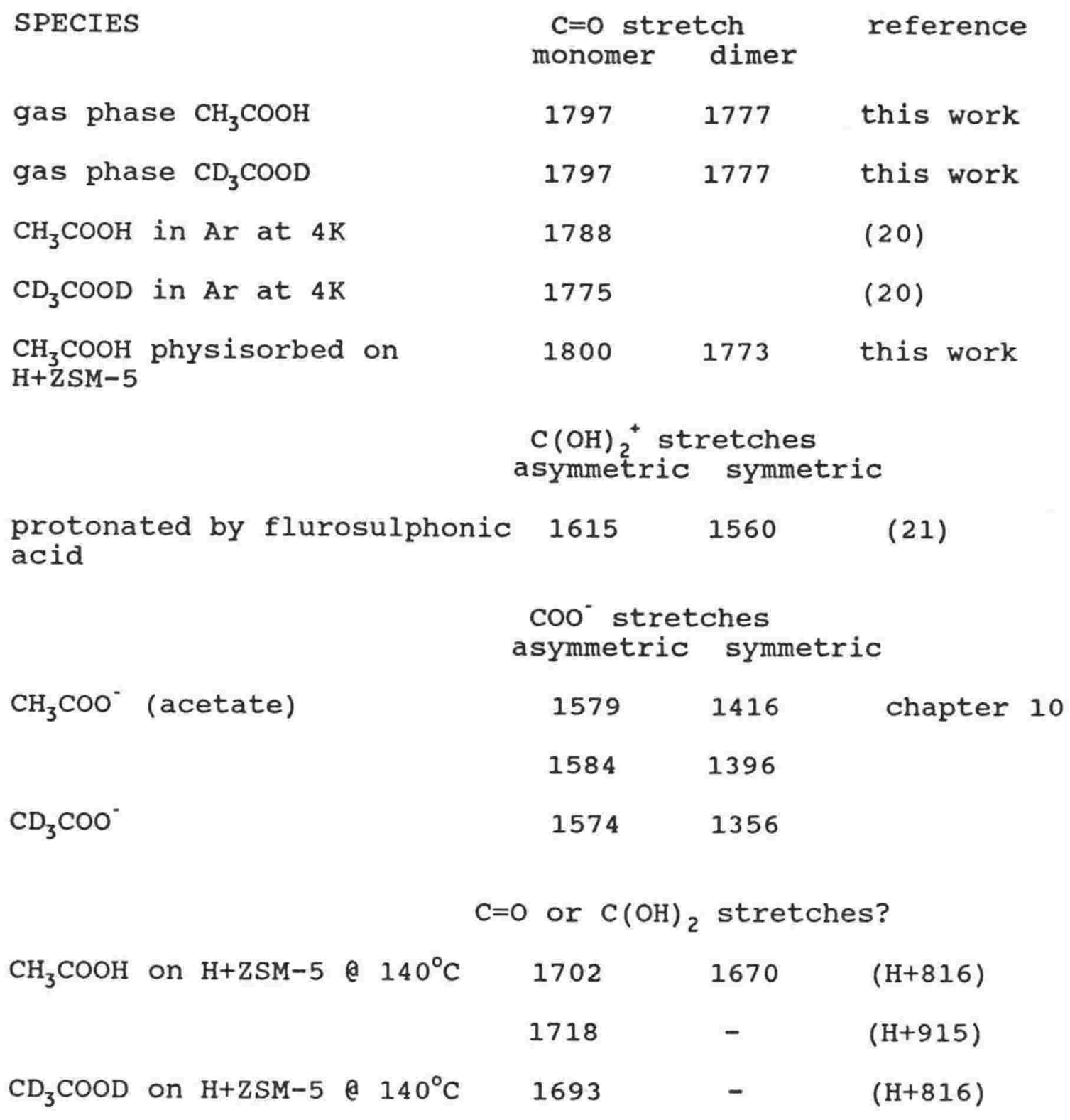


The large doublet at 1702 and $1670 \mathrm{~cm}^{-1}$ for the strongly sorbed acetic acid on $\mathrm{H}+\mathrm{ZSM}-5$ is at lower wavenumbers than the $\mathrm{C}=0$ stretch of the gas phase or physisorbed acetic acid species. Acetic acid fully protonated by flurorosulphonic acid in the crystalline state at $90 \mathrm{~K}$ produces a symmetrical species with symmetric and anti-symmetric C-O stretches at 1615 and $1560 \mathrm{~cm}^{-1}$ (21), which is a much greater shift than that observed on $\mathrm{H}+\mathrm{ZSM}-5$. Therefore partial proton transfer from the zeolite to acetic acid is proposed (figure 3.11B), intermediate between the extremes of no proton transfer (figure 3.11A) and complete proton transfer (figure 3.11C).

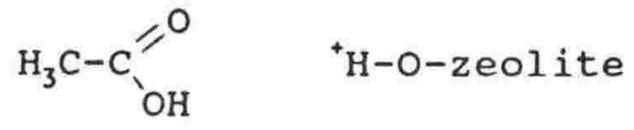

A. No proton transfer. transfer.<smiles>CC(=O)O[CH]OC(=O)O</smiles>

B. Partial proton<smiles>CC(=O)OS(=O)(=O)O</smiles>

C. Complete proton transfer.

Figure 3.11. Different possible degrees of proton transfer for acetic acid associated with a stronger acid.

The splitting of the $\mathrm{c}-\mathrm{O}$ stretch into a doublet for strongly sorbed acetic acid is not due to the presence of monomer and dimer species sorbed on the zeolite (as observed for the gas phase species) because tga showed that acetic acid is sorbed on a one-to-one basis with the zeolite acid sites. The splitting could arise from a symmetrical species showing asymmetric and symmetric stretches (as observed for the fully protonated acetic acid and for the acetate anion). Alternatively a species, as shown in figure 3.11B, would show splitting of the $\mathrm{C}-\mathrm{O}$ stretch if tunnelling of the $\mathrm{H}$ atom between the two oxygen atoms, as described by Berney et al. (20), occurred. 
After about two hours at $140^{\circ} \mathrm{C}$ the acetic acid almost completely desorbs, restoring the zeolite $0-\mathrm{H}$ stretches and resulting in an almost zero difference plot (figure 3.10.C). The small peaks remaining show that further reaction of the acetic acid occurred to a slight extent.

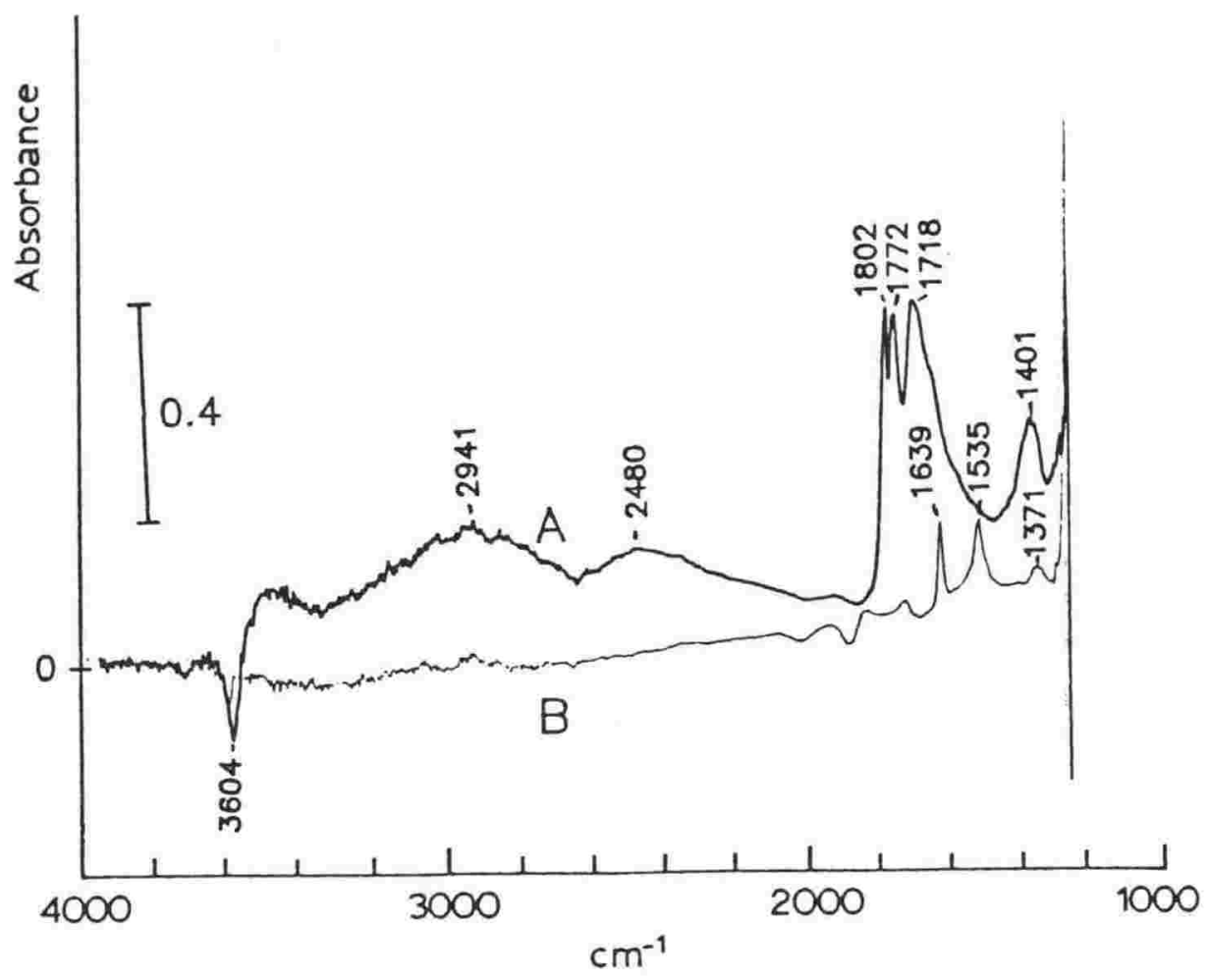

Figure 3.12. FTIR difference spectra of $2 \mu 1$ acetic acid sorbed on H+ZSM-5. A. 30 s after addition of acetic acid at $150^{\circ} \mathrm{C}$; $\quad$ B. After heating to $190^{\circ} \mathrm{C}$ in $10 \mathrm{~min}$.

At higher temperatures the extent of this reaction increases. This is shown by sorption of acetic acid on $\mathrm{H}+\mathrm{ZSM}-5$ (prep $\mathrm{H}+915$ ) held at $150^{\circ} \mathrm{C}$ (figure $3.12 \mathrm{~A}$ ), then heating to $190^{\circ} \mathrm{C}$ in $10 \mathrm{~min}$. (figure $3.12 \mathrm{~B}$ ). The peaks at 1639 and $1535 \mathrm{~cm}^{-1}$ were stronger, as, at the higher temperature, more reaction occurred before the acetic acid had time to desorb. Further heating to $350^{\circ} \mathrm{C}$ resulted in the loss of these peaks. The zeolite wafer had become dark brown. The reaction products of acetic acid over $\mathrm{H}+\mathrm{ZSM}-5$ were not investigated further. 


\subsubsection{C $\mathrm{CD}_{3} \mathrm{COOD}$ sorbed on $\mathrm{H} / \mathrm{D}+\mathrm{ZSM}-5$ :}

The FTIR experiment was repeated with fully deuterated acetic acid to obtain further information on the form of the strongly bound acetic acid. A wafer of H+ZSM-5, with some D+2SM-5 present from previous experiments, was dried and held at $140^{\circ} \mathrm{C}$. Its spectrum is shown in figure $3.13 \mathrm{~A}$. The Bronsted O-D stretch is at $2658 \mathrm{~cm}^{-1}$, with the silanol O-D at $2752 \mathrm{~cm}^{-1}$.

Immediately after addition of $2 \mu l$ deuterated acetic acid (figure 3.13B) the Bronsted O-Ds and O-Hs were bonded. This is shown by negative peaks in the difference spectrum (figure 3.14B). Some gas phase or physisorbed acetic acid was observed immediately after its addition (doublet at $\sim 1792 \mathrm{~cm}^{-1}$ (figure 3.14B)), but desorbed rapidly. The broad bands assigned to Bronsted hydroxyls were present in the O-D region and of ill-defined shape. Only one peak was present in the $\mathrm{C}=0$ region at $1693 \mathrm{~cm}^{-1}$, even after waiting $36 \mathrm{~min}$. (figure 3.14D).

The frequency of the $\mathrm{C}=0$ stretch is not significantly different from the $\mathrm{H}$ case, confirming its assignment. These results also show that the acetic acid was protonated/deuterated and that no significant reaction occurred at $140^{\circ} \mathrm{C}$. 


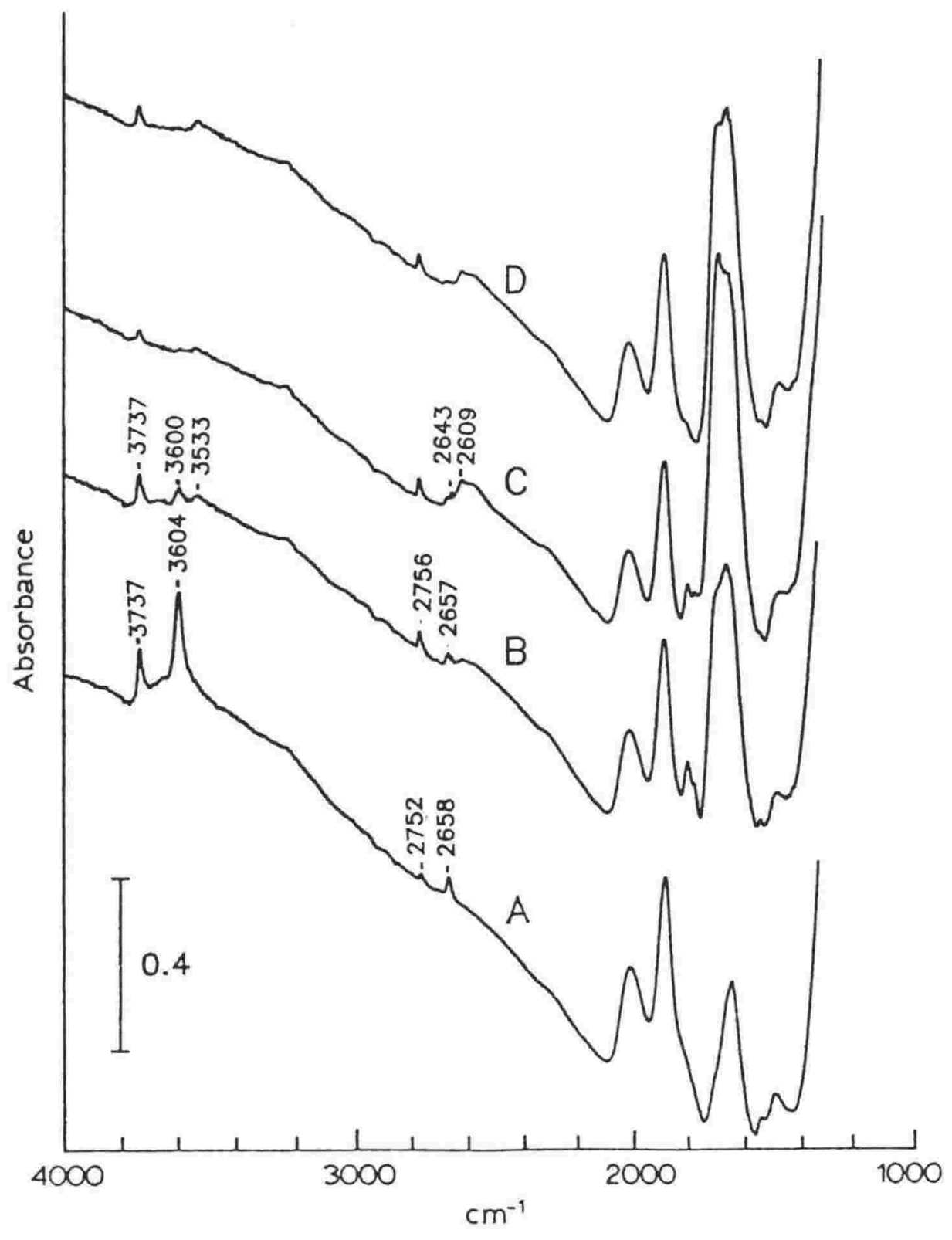

Figure 3.13. FTIR spectra of deuterated acetic acid sorbed on $\mathrm{H} / \mathrm{D}+\mathrm{ZSM}-5$ at $140^{\circ} \mathrm{C}$ : A. before; $\mathrm{B}$. immediately after addition of $2 \mu l$ of deuterated acetic acid; C. $12 \mathrm{~min}$ later and D. $36 \mathrm{~min}$ later. 


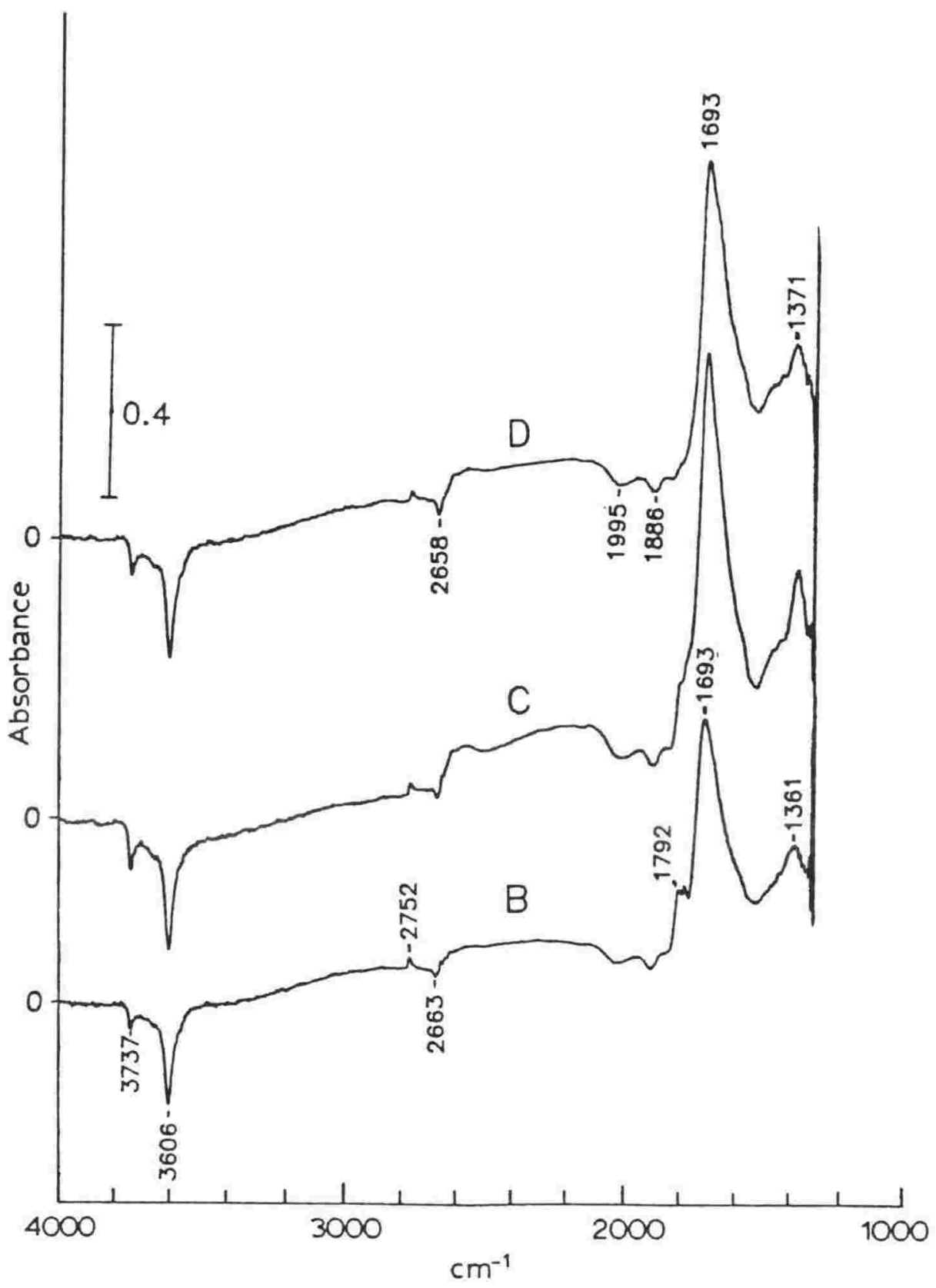

Figure 3.14. Difference FTIR spectra of deuterated acetic acid sorbed on $\mathrm{H} / \mathrm{D}+\mathrm{ZSM}-5$ at $140^{\circ} \mathrm{C}$. $\mathrm{B}, \mathrm{C}$ and $\mathrm{D}$ as in figure 3.13 . 


\subsubsection{FORMIC ACID:}

\subsubsection{A Td/ms RESULTS:}

Formic acid was sorbed on to $\mathrm{H}+\mathrm{ZSM}-5$ (prep 915) held at $30^{\circ} \mathrm{C}$. The $t d / m$ sesults (figure 3.15 ) showed desorption of formic acid. There was also a higher temperature loss of CO (Tmax at $150^{\circ} \mathrm{C}$ ) from thermal decomposition of formic acid:

$\mathrm{HC}_{\mathrm{OH}}^{\prime \prime} \rightarrow \mathrm{C} \equiv \mathrm{O}+\mathrm{H}_{2} \mathrm{O}$

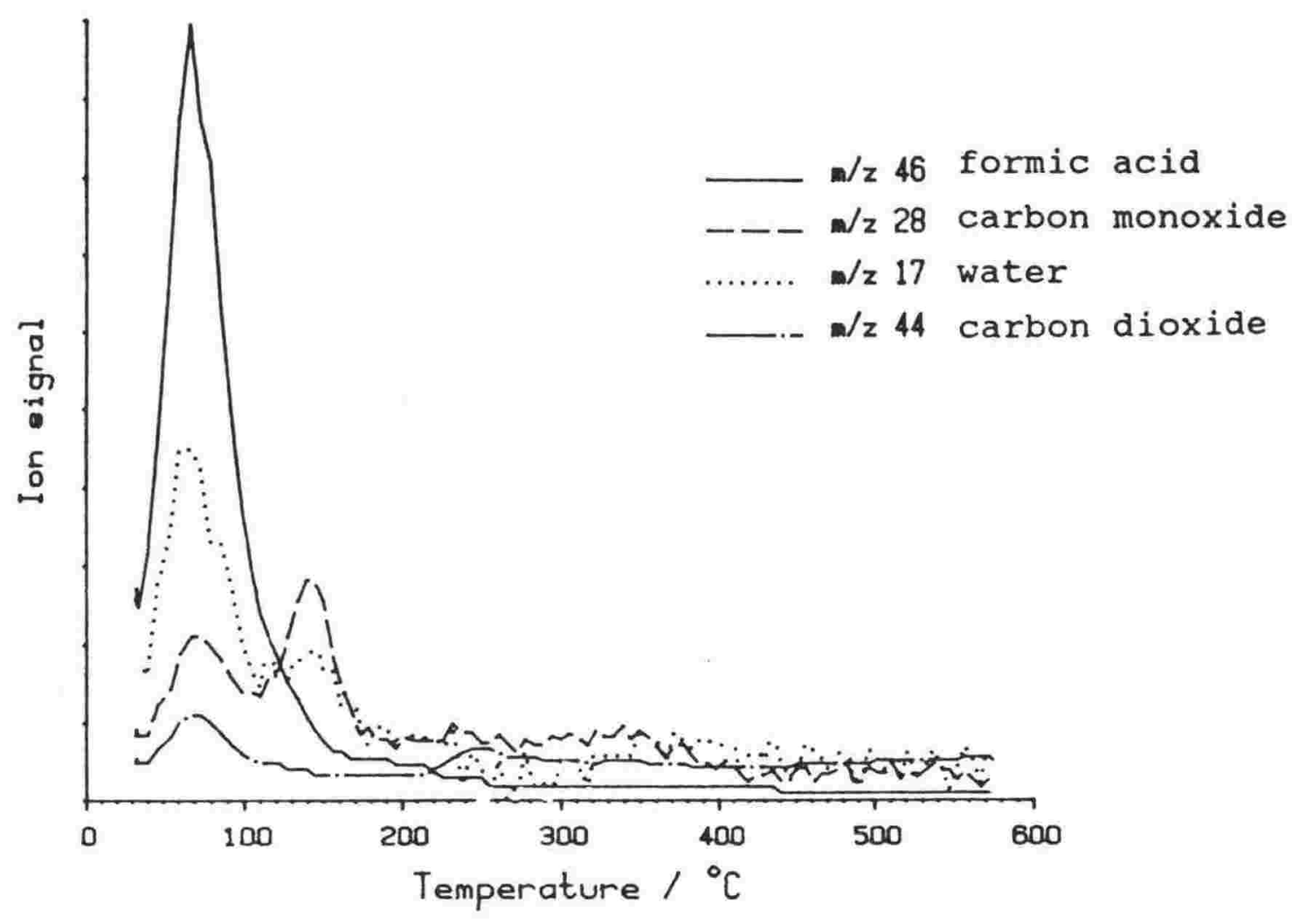

Figure 3.15. Td/ms of formic acid sorbed on $\mathrm{H}+\mathrm{ZSM}-5$ at $30^{\circ} \mathrm{C}$. 


\subsubsection{B FTIR RESULTS: Formic acid on H+ZSM-5:}

Formic acid vapour ( $\sim 60$ Torr) was added from the vacuum gas handling rig to the evacuated FTIR cell containing a dried wafer of $\mathrm{H}+\mathrm{ZSM}-5$ (prep 816) at room temperature. The spectrum obtained after flushing the cell for $10 \mathrm{~min}$ then heating to $80^{\circ} \mathrm{C}$ is shown in figure $3.16 \mathrm{~A}$. After heating to $110^{\circ} \mathrm{C}$ and flushing for a further $15 \mathrm{~min}$ (to remove any physisorbed formic acid) the spectrum shown in figure $3.16 \mathrm{~B}$ was obtained. After heating to $450^{\circ} \mathrm{C}$ and cooling to $110^{\circ} \mathrm{C}$, the spectrum in figure $3.16 \mathrm{C}$ was obtained. This showed that the formic acid had desorbed with a small amount of coke remaining (peaks in the $\mathrm{C}-\mathrm{H}$ stretching region at 2964 and $2933 \mathrm{~cm}^{-1}$ ). The difference spectrum between figure $3.16 \mathrm{C}$ and $3.16 \mathrm{~B}$ is shown in figure 3.17 .

Bonding of the formic acid to the zeolite Bronsted sites is shown by the loss of the $0-\mathrm{H}$ stretch at $3605 \mathrm{~cm}^{-1}$ and the appearance of broad bands at $\sim 2855$ and $\sim 2464 \mathrm{~cm}^{-1}$, similar to those observed for acetic acid. The $\mathrm{c}=0$ bands are also in a similar position to those of acetic acid, at 1700 and $1680 \mathrm{~cm}^{-1}$. Peaks at 1596,1480 and $1412 \mathrm{~cm}^{-1}$ in the $\mathrm{C}-\mathrm{H}$ bending region are also similar, but unassigned. 


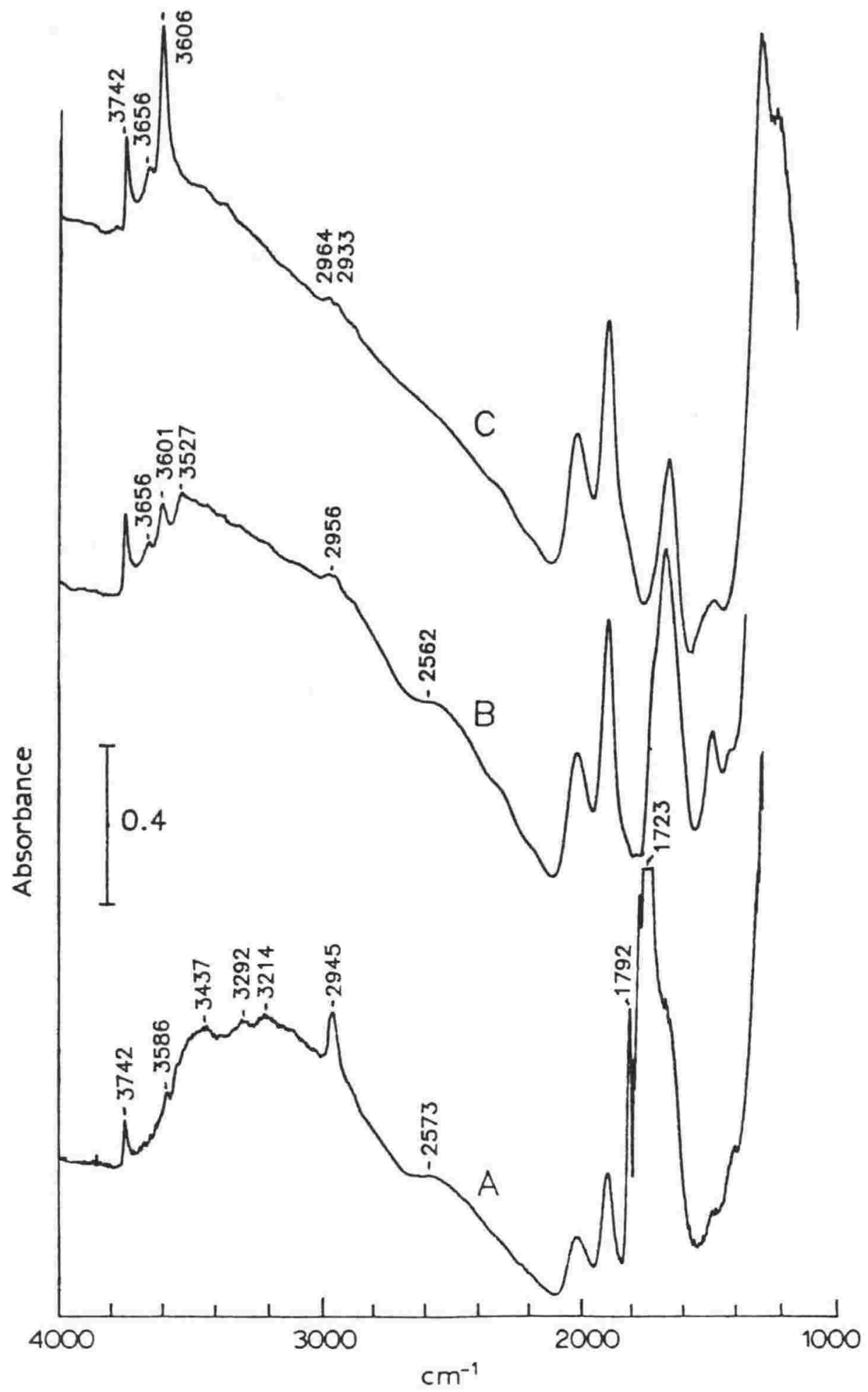

Figure 3.16. FTIR spectra of formic acid sorbed on H+ZSM-5 at $21^{\circ} \mathrm{C}$. A. after flushing for $10 \mathrm{~min}$ then heating to $80^{\circ} \mathrm{C} ; \mathrm{B}$. after flushing a further $15 \mathrm{~min}$ at $110^{\circ} \mathrm{C}$ and $\mathrm{C}$. after heating to $450^{\circ} \mathrm{C}$ then cooling to $110^{\circ} \mathrm{C}$. 


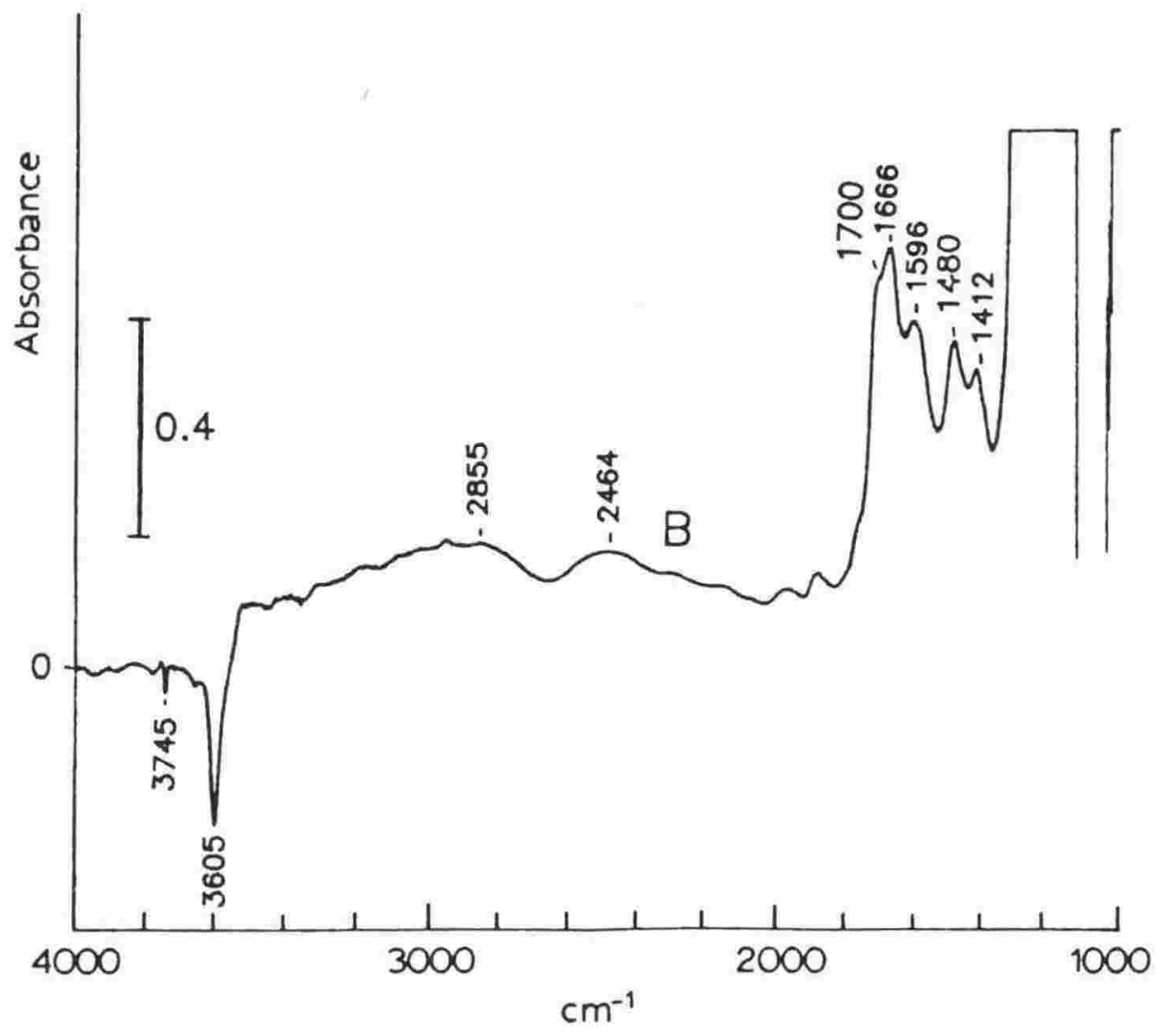

Figure 3.17. The difference between spectrum $B$ in figure 3.16 and the spectrum of dry $\mathrm{H}+2 \mathrm{SM}-5$ (figure $3.16 \mathrm{C}$ ).

There is a marked difference between the IR spectra obtained in this work from those published by Duncan et al. (8) for formic acid sorbed on Ultrastable HY zeolite (figure 3.18). Their spectrum showed two maxima at 1610 and $1385 \mathrm{~cm}^{-1}$ which are "within $10 \mathrm{~cm}^{-1}$ of a pair of peaks assigned to $\mathrm{C}=0$ and $\mathrm{C}-\mathrm{O}$ stretches of a formate species on $\mathrm{Al}_{2} \mathrm{O}_{3}$ ". Therefore they assigned their spectra to "surface bidentate formate, probably adsorbed at an Al site." This assignment could be correct if the formic acid was sorbing on extralattice Al (formed by the ultrastablisation process) rather than a Bronsted acid site. Alternatively physisorbed formic acid could have been present as the spectrum was recorded at room temperature. At a Bronsted site the formic acid should be (partially) protonated as it is the weaker acid. 


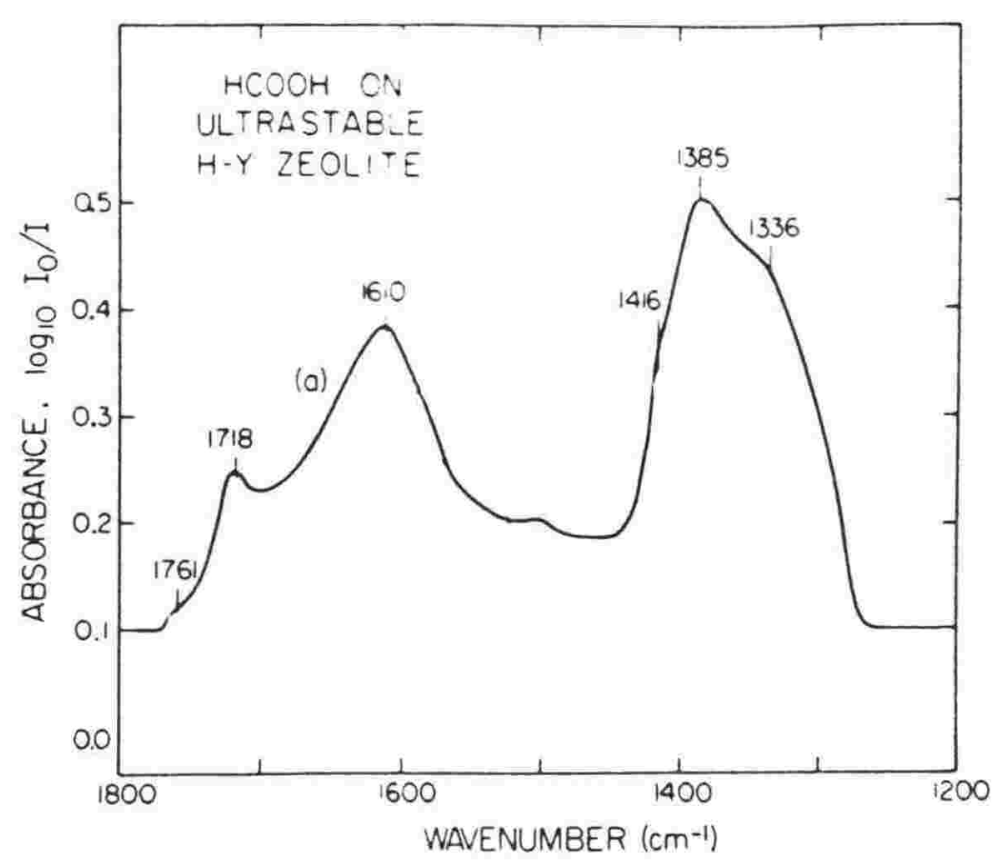

Figure 3.18. IR spectra of formic acid sorbed on an ultrastable $\mathrm{H}+\mathrm{Y}$ zeolite at $22^{\circ} \mathrm{C}$. (from Duncan et al.(8)).

\subsection{CONCLUSIONS :}

1. Tga, td/ms and FTIR techniques all provide evidence that the carboxylic acid is protonated by the H+zeolite. ${ }^{13} \mathrm{C} \mathrm{nmr}$ provided no significant information. Tga showed a one-to-one association of acetic acid with the zeolite acid sites at $150^{\circ} \mathrm{C}$. Td/ms showed that the acetic acid was absorbed intact with very little reaction occurring at $150^{\circ} \mathrm{C}$. FTIR showed the Bronsted protons are only partially transferred to the acetic acid molecules and that they occupy a wide range of energy states.

2. No behaviour was observed that could indicate the presence of basic sites in $\mathrm{H}+\mathrm{ZSM}-5$. 


\subsection{REFERENCES :}

1. Ono Y., "Catalysis by Zeolites", Imelik B. et al. Editors, Elsevier Amsterdam, 1980, 19.

2. Hunter R., Hutchings G.J. and Pickl W., J. Chem. Soc. Chem. Commun., 1987, 1369.

3. Chang C.D. "Methane Conversion", studies in Surface Science and Catalysis, 36, Bibby D.M., Chang C.D., Howe R.F. and Yurchak S. Editors, Elsevier, 1988, 127.

4. Lok B.M., Marcus B.K. and Angell, Zeolites, 1986, 6, 185.

5. Bielanski A., Datka J., J. Catal., 1974, 32, 183.

6. Ward J.W., "Zeolite Chemistry and Catalysis", Rabo J.A., Editor, 1976, 219.

7. Duncan T.M., Vaughan R.W., J Catal. 1981, 67, 49.

8. Duncan T.M., Vaughan R.W., J Catal. 1981, 67, 469.

9. Przystajko W., Fiedorow R., Dalla Lana I.G., Zeolites, $1987,7,477$

10. Servotte Y., Jacobs J. and Jacobs P.A. Acta Physica et Chemica, Hungary, 1985, 31, 609.

11. Chang C.D., Chen N., Koenig L.R. and Walsh D.E., Prep. A.C.S. Div. Fuel Chem., 1983, 28, 146.

12. Allinger N.L., Cava M.P., De Jongh D.C., Johnson C.R., Lebel N.A. and Stevens C.L., "Organic Chemistry", Worth publishers, New York, 1971.

13. Parker L.M., Bibby D.M. and Meinhold R.H., Zeolites, $1985,5,384$.

14. Chang C.D., Lang W.H. and Lapierre R.B., US Patent 4231955 , 1979 .

15. Strothers J.B. "Carbon-13 NMR Spectroscopy", Academic Press, New York, 1972, 147.

16. Bellamy L.J., "The Infra-red spectra of Complex Molecules", Chapman and Hall, London, 1968.

17. Dessau R.M., Schmitt K.D, Kerr G.T., Woolery G.L. and Alemany L.B., J. Catal. 1987, 104, 484.

18. Jacobs P.A., von Ballmoos R., J. Phys. Chem. 1982, 86, 3050 .

19. Flanigen E.M., Khatami H. and Szymanski H.A., Adv. Chem., Ser., 1971, 101, 201.

20. Berney C.V., Redington R.L. and Lin K.C., J. Chem. Phys., 1970, 53, 1713. 
21. Goypiron A., Villepin J. and Novak A, J. Chimie Physique $1978,75,414$. 


\subsection{INTRODUCTION:}

Water sorption on acid zeolites has been studied in order to improve understanding on the nature of the zeolite hydroxyl groups (Ward (1)) and the effect of the addition of water on catalytic reactions (Ison and Gorte (2)). Water is only weakly sorbed compared to bases such as ammonia, completely desorbing below $100^{\circ} \mathrm{C}$ in a dry atmosphere. However, it does interact with the zeolite acid sites producing marked changes in the infra-red spectra. Such spectra have been published before $(2,3)$, and show three strong, broad bands at approximately $3600 \mathrm{~cm}^{-1}, 2900 \mathrm{~cm}^{-1}$ and $2450 \mathrm{~cm}^{-1}$. However, the reasons for the occurance of these bands, and the nature of the water-zeolite interaction have not been discussed.

In this chapter, further experiments using the FTIR technique and interchanging $\mathrm{H}_{2} \mathrm{O}$ with $\mathrm{D}_{2} \mathrm{O}$ have been carried out in an attempt to understand the water-zeolite interaction.

\subsection{RESULTS:}

Figure 4.1 shows the FTIR spectrum of wet H+ZSM-5 (prep 816) as it is gradually dried in the in situ FTIR cell by heating at $10^{\circ} \mathrm{C}$ per minute in dry $\mathrm{N}_{2}$. At first no distinct peaks were observed (figure 4.1A) due to a broad sorption of the physisorbed water molecules, which have a wide range of positions relative to the zeolite acid sites and hence a wide range of IR vibrations. With heating, this broad absorption was removed and three broad bands uncovered (figure 4.1B). In an earlier work by Ison and Gorte (2) these corresponded to an coverage of 0.7 water molecules per zeolite acid site. Further heating above $80^{\circ} \mathrm{C}$ resulted in the disappearance of the broad bands and the formation of the sharp Bronsted $\mathrm{OH}$ peak associated with zeolite aluminium at $3606 \mathrm{~cm}^{-1}$ (figure 4.1C). There was a small peak at $3653 \mathrm{~cm}^{-1}$ which may be associated with extra-latttice Al. This increases at the 
expense of the Bronsted $\mathrm{OH}$ peak with high temperature heat treatment and steaming.

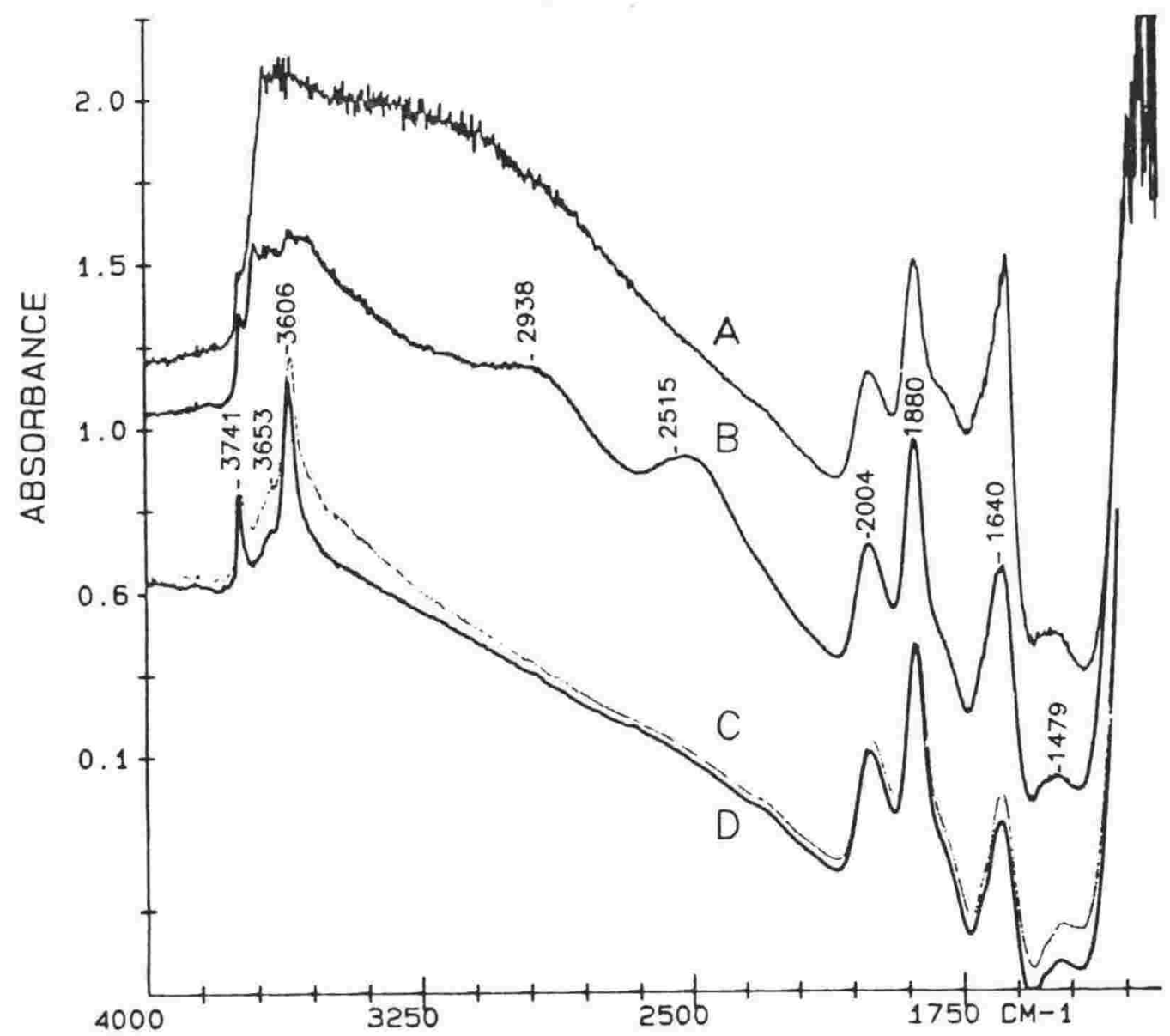

Figure 4.1. FTIR spectra of wet $\mathrm{H}+\mathrm{ZSM}-5$ heated at $10^{\circ} \mathrm{C} \mathrm{min}^{-1}$. A. wet, at $21^{\circ} \mathrm{C} ; \mathrm{B}$. at $80^{\circ} \mathrm{C} ; \mathrm{C}$. at $150^{\circ} \mathrm{C}$ and $\mathrm{D}$. at $100^{\circ} \mathrm{C}$ after heating to $550^{\circ} \mathrm{C}$, then cooling.

The peak at $3741 \mathrm{~cm}^{-1}$ is due to either extra-zeolitic material (4) or hydroxyls terminating the zeolite lattice at the surface (5) or lattice defects (6). There was a further broad band under the sharp hydroxyl peak, the bulk of which was removed by heating to $550^{\circ} \mathrm{C}$ as shown in figure $1 \mathrm{D}$. Upon cooling, this broad absorption returned only slowly over a period of days despite deliberate additions of water. This suggests that this broad band is not due to free or loosely bound $\mathrm{H}_{2} \mathrm{O}$ as this is lost before $100^{\circ} \mathrm{C}$, but to hydroxyls. Earlier work by Brunner (3) showed that this broad band was due to hydroxyls, as exchange with $\mathrm{D}_{2} \mathrm{O}$ occured to give a broad OD absorption. They proposed that water "dissolved" the lattice - breaking the si-O-si bond and creating two hydroxyls. Nmr work by Boxhorn et al. (7) supports this, showing breaking of the strained rings containing four tetrahedra. 
The four bands at 2004, 1880,1640 and $1479 \mathrm{~cm}^{-1}$ are overtone bands of the zeolite framework tetrahedral frequencies. Below approximately $1300 \mathrm{~cm}^{-1}$ very strong absorptions due to silica framework vibrations occur, effectively obscuring that region.

\subsubsection{H+ZSM-5 plus $\mathrm{H}_{2} \mathrm{O}$ :}

The three broad IR bands from water sorption may be due to the formation of water monomer, dimer and trimers. An alternative is that they are due to different vibrational modes of $\mathrm{H}_{2} \mathrm{O}$ protonated to some degree by the zeolite Bronsted site.

To investigate these options, the zeolite sample was dried at $150^{\circ} \mathrm{C}$, held at $80^{\circ} \mathrm{C}$, and controlled amounts of water (from an air/water mixture) injected into the FTIR cell. It was calculated that an $8 \mathrm{ml}$ injection would correspond to the addition of one $\mathrm{H}_{2} \mathrm{O}$ molecule per zeolite acid site. Figure 4.2A shows the FTIR spectrum of dry H+ZSM-5 (prep 816). The spectra after the addition of $4 \mathrm{ml}$ and $9 \mathrm{ml}$ of air/water are shown in figures $4.2 \mathrm{~B}$ and $4.2 \mathrm{C}$ respectively. The corresponding difference spectra (between the dry zeolite and the zeolite with water added) are shown in figure 4.3. Three bands increased intensity with increasing water content, along with an increase in the overall absorbance of the spectrum. (The plots have not been graphically displaced). The $\mathrm{OH}$ peak at $3747 \mathrm{~cm}^{-1}$ decreased only slightly, whereas most of the $3610 \mathrm{~cm}^{-1}$ peak was lost. This confirms bonding of the sorbed water to the Bronsted sites. Also, because all three bands increased together, it is not likely that they were due to monomer, dimer and trimer formation as these should have appeared consecutively as the layers built up. The bands are therefore a result of water bonded to the zeolite by partial transfer of the Bronsted proton.

Figure 4.2 shows that the hydroxyl peak at $3740 \mathrm{~cm}^{-1}$ did not change in intensity, implying that no bonding with water occured. A new peak in the hydroxyl region at $3700 \mathrm{~cm}^{-1}$ arose, along with an increase in the peak at $3653 \mathrm{~cm}^{-1}$. 
Desorption of water restored the spectrum in figure $4.2 \mathrm{~A}$. A more detailed, quantitative study was carried out on the origin of these peaks for the zeolite $H+Y$ and is described in chapter 5 .

A slight, but consistent, decrease occured in the zeolite overtone bands at $2015 \mathrm{~cm}^{-1}$ and $1886 \mathrm{~cm}^{-1}$. This implies an alteration in the zeolite structure as water is sorbed. This is not unexpected as sorbed molecules have been shown by nmr and XRD (FYfe (8)) to affect the zeolite structure. A peak increased at $1620 \mathrm{~cm}^{-1}$, probably due to the bending mode of $\mathrm{H}_{2} \mathrm{O}$ (normally at $1640 \mathrm{~cm}^{-1}$ ). 


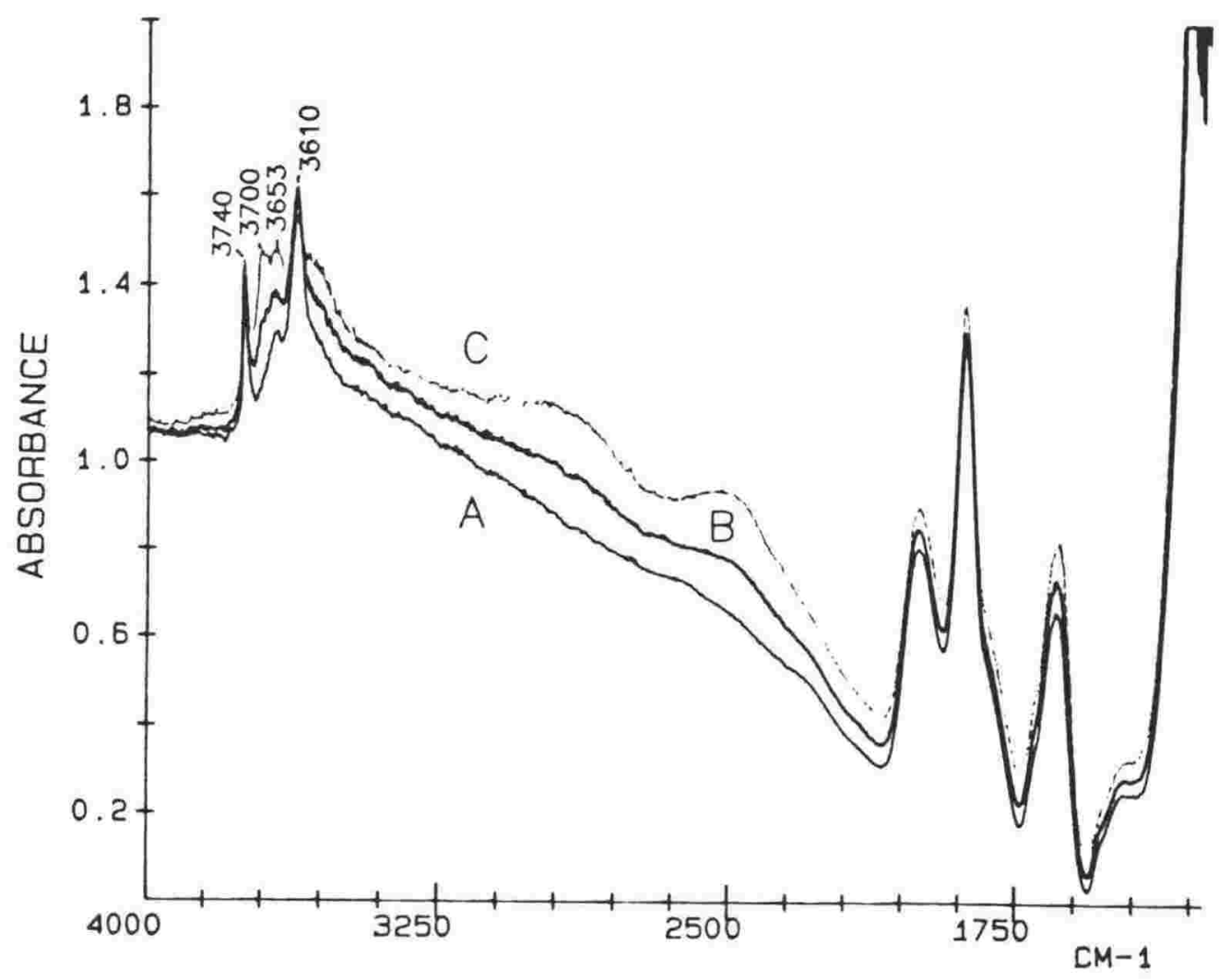

Figure 4.2. FTIR spectra of: A. dry $\mathrm{H}+\mathrm{ZSM}-5$ at $80^{\circ} \mathrm{C}$;

B. after addition of $4 \mathrm{ml}$ water saturated air and

C. after addition of a total of $9 \mathrm{ml}$ water/air.

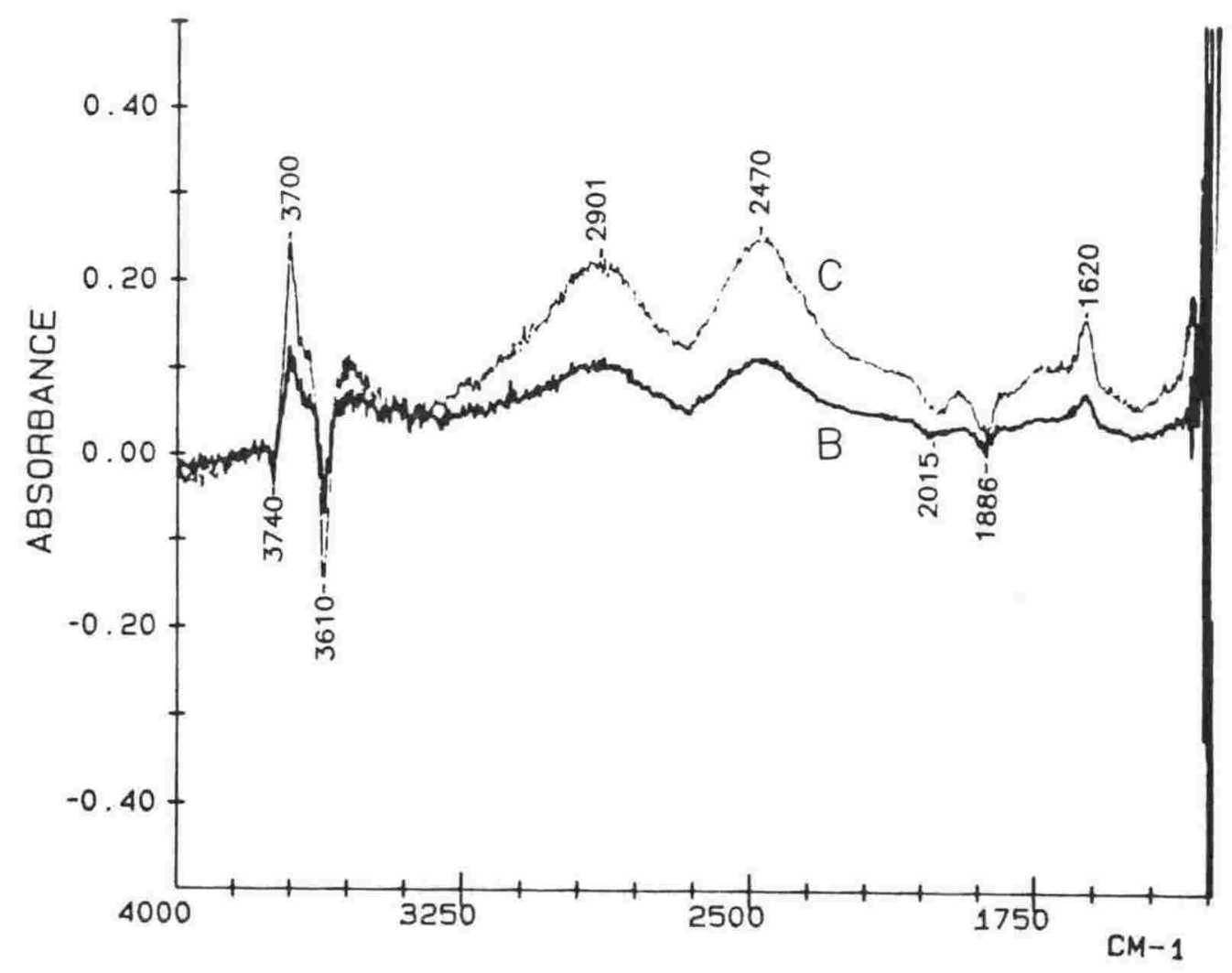

Figure 4.3. FTIR difference spectra after addition of $\mathrm{H}_{2} \mathrm{O}$ to dry $\mathrm{H}+\mathrm{ZSM}-5$ at $80^{\circ} \mathrm{C}$. B. $4 \mathrm{ml}$ water/air (fig. $4.2 \mathrm{~B}-\mathrm{fig}$. $4.2 \mathrm{~A}$ ) and C. $9 \mathrm{ml}$ water/air (fig. $4.2 \mathrm{C}$ - fig $4.2 \mathrm{~A}$ ). 


\subsubsection{D+ZSM-5 plus $\mathrm{H}_{2} \mathrm{O}$ :}

$\mathrm{H}+\mathrm{ZSM}-5$ was converted to $\mathrm{D}+\mathrm{ZSM}-5$ by heating the zeolite to $150^{\circ} \mathrm{C}$, then injecting pulses of $\mathrm{D}_{2} \mathrm{O}$. At this temperature, the $\mathrm{D}_{2} \mathrm{O}$ interacted with rapid exchange of $\mathrm{H}^{+}$to $\mathrm{D}^{+}$on the zeolite Bronsted sites, even though the $\mathrm{D}_{2} \mathrm{O}$ did not remain sorbed. The $3747 \mathrm{~cm}^{-1}$ hydroxyl peak exchanged much more slowly than the Bronsted hydroxyls. The sample was then cooled to $80^{\circ} \mathrm{C}$.

The FTIR results for addition of small amounts of $\mathrm{H}_{2} \mathrm{O}$ are shown in figure 4.4 with the difference spectra in figure 4.5. The spectrum before water addition showed a small Bronsted $\mathrm{OH}$ peak. This peak appeared not to have interacted with the $\mathrm{H}_{2} \mathrm{O}$ and sat on top of the broad peak rising beneath it. Because this peak did not change, it does not appear in the difference spectra. The $3747 \mathrm{~cm}^{-1}$ OH peak also did not interact with the $\mathrm{H}_{2} \mathrm{O}$ and is also not observed in the difference spectra.

The addition of small amounts of water resulted in the appearance of broad bands similar to the $\mathrm{H}+\mathrm{ZSM}-5+\mathrm{H}_{2} \mathrm{O}$ case. In the difference spectra, the shape of the higher wavelength band is not obscured (as is the case in figure 4.3) and can be clearly seen, although here the shape of the lower bands have been obscured by the loss of the Bronsted OD bands. In the non-difference spectrum (figure 4.4), the lower bands appear to be flat, having no defined maximum. The same changes as observed in the zeolite overtone region for $\mathrm{H}+\mathrm{ZSM}-5+\mathrm{H}_{2} \mathrm{O}$ (figure 4.3 ) occured here, except that a peak increasing at $1426 \mathrm{~cm}^{-1}$ was also observed. After the water was desorbed, by flushing with dry nitrogen for an hour at $80^{\circ} \mathrm{C}$, the Bronsted sites were a mixture of $\mathrm{OH}$ and $\mathrm{OD}$. 


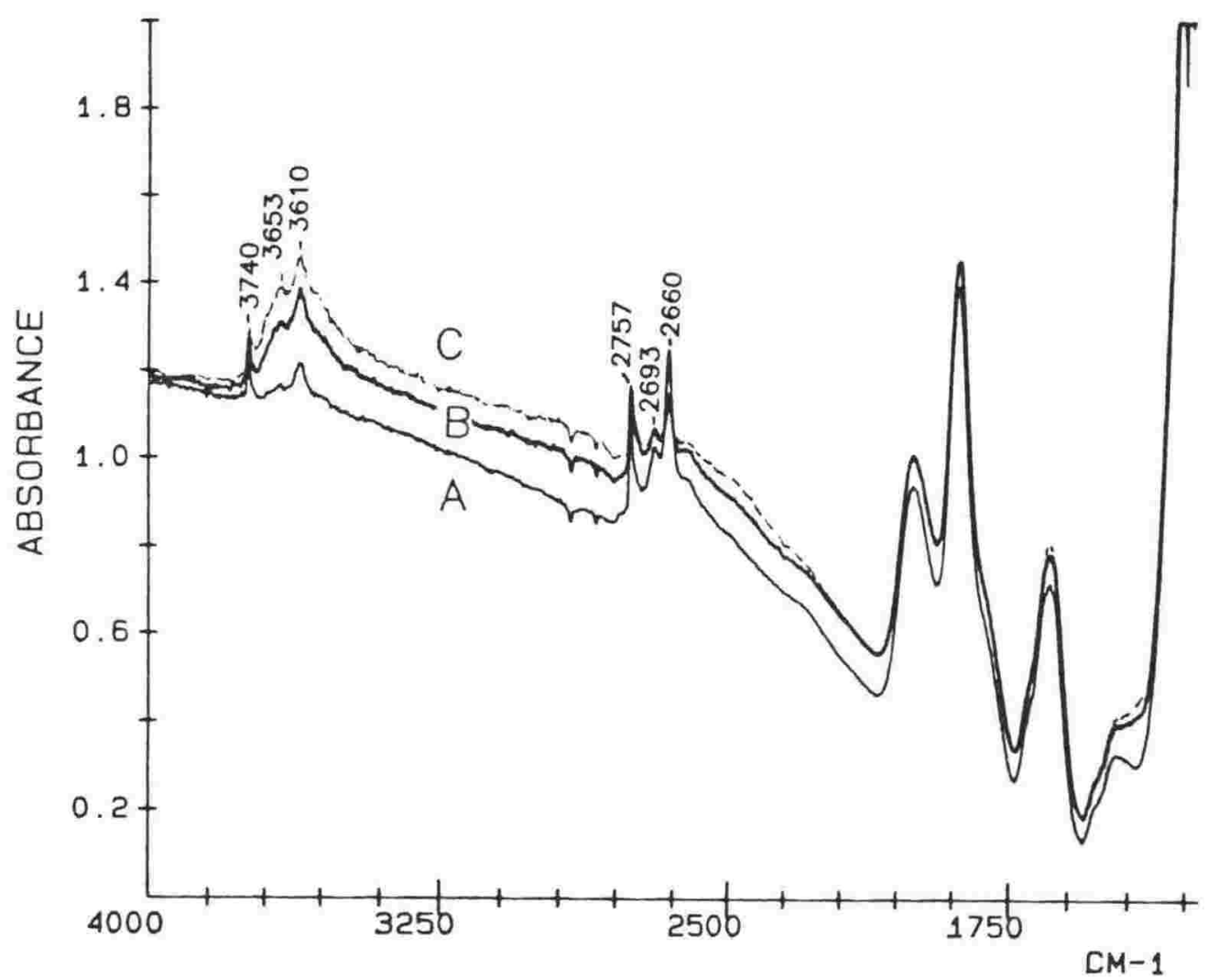

Figure 4.4. FTIR spectra of $\mathrm{D} / \mathrm{H}+\mathrm{ZSM}-5+\mathrm{H}_{2} \mathrm{O}$ at $80^{\circ} \mathrm{C}$.

A. before; B. after addition of $7 \mathrm{ml} \mathrm{H}_{2} \mathrm{O} / \mathrm{air}$ and

C. after addition of $12 \mathrm{ml} \mathrm{H}_{2} \mathrm{O} / \mathrm{air}$.

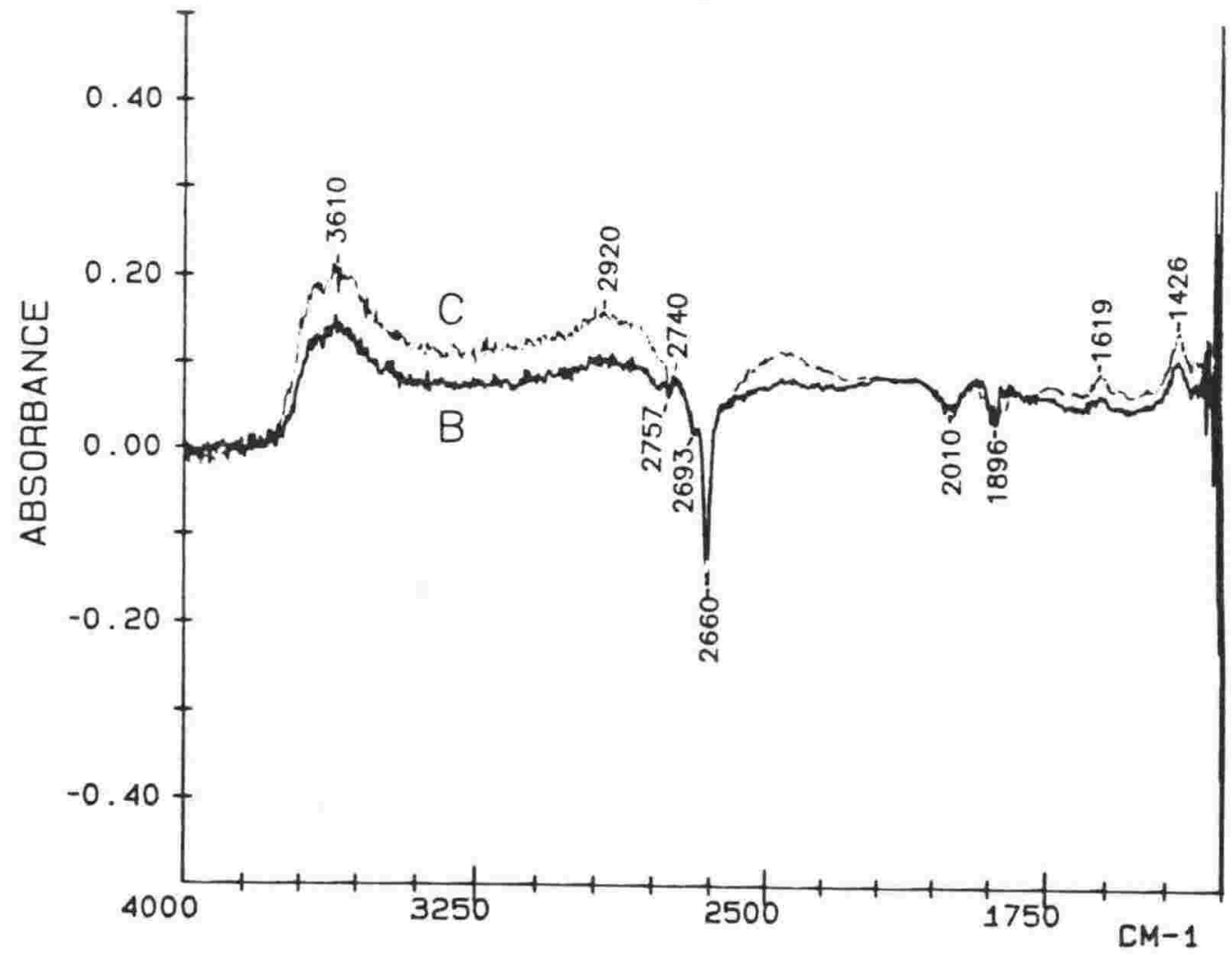

Figure 4.5. FTIR difference spectra of $\mathrm{D} / \mathrm{H}+\mathrm{ZSM}-5+\mathrm{H}_{2} \mathrm{O}$ at $80^{\circ} \mathrm{C}$. B. after addition of $7 \mathrm{ml} \mathrm{H} \mathrm{O} / \mathrm{air}$ ( $\mathrm{fig} .4 .4 \mathrm{~B}-4.4 \mathrm{~A}$ ) and $C$. after addition of $12 \mathrm{ml} \mathrm{H}_{2} \mathrm{O}$ air (fig. $4.4 \mathrm{C}-4.4 \mathrm{~A}$ ). 


\subsection{3 $\mathrm{H}+\mathrm{ZSM}-5+\mathrm{D}_{2} \mathrm{O}$ :}

The spectra after addition of small amounts of $\mathrm{D}_{2} \mathrm{O}$ to $\mathrm{H}+\mathrm{ZSM}-5$ at $80^{\circ} \mathrm{C}$ are shown in figure 4.6 , with the difference spectra in figure 4.7. Broad bands at $\sim 2900$ and $\sim 2470 \mathrm{~cm}^{-1}$ appeared in the infrared spectrum similar to those found for $\mathrm{H}+\mathrm{ZSM}-5+$ $\mathrm{H}_{2} \mathrm{O}$. No broad band in the $3600 \mathrm{~cm}^{-1}$ region (observed for $\mathrm{H}+\mathrm{ZSM}-5+\mathrm{H}_{2} \mathrm{O}$ and $\mathrm{D}+\mathrm{ZSM}-5+\mathrm{H}_{2} \mathrm{O}$ ) was observed in this case. As more $\mathrm{D}_{2} \mathrm{O}$ was added a small peak at $2660 \mathrm{~cm}^{-1}$ appeared as some of the zeolite Bronsted sites exchanged $\mathrm{H}+$ for $\mathrm{D}+$. (This exchange was alot slower at $80^{\circ} \mathrm{C}$ than at $150^{\circ} \mathrm{C}$ ). A peak at $\sim 3700 \mathrm{~cm}^{-1}$ increased (figure 4.7D), then decreased as the spectrum approached that of $\mathrm{D}+\mathrm{ZSM}-5+\mathrm{D}_{2} \mathrm{O}$ (figure $4.7 \mathrm{E}$ is similar to figure $4.9 \mathrm{C}$ ). The changes that occured in the lower wavenumber region were the same as for $\mathrm{D}+\mathrm{ZSM}-5+\mathrm{H}_{2} \mathrm{O}$. A peak at $1570 \mathrm{~cm}^{-1}$ also appeared as the spectrum approached that of $\mathrm{D}+\mathrm{ZSM}-5+\mathrm{D}_{2} \mathrm{O}$.

A broad band from $\sim 3600$ to $\sim 2900 \mathrm{~cm}^{-1}$ was lost. This may have been a result of exchange of the broad hydroxyl band described by Brunner (3).

To ensure that $\mathrm{H}_{2} \mathrm{O}$ had not been added inadvertantly these experiments were repeated several times with $\mathrm{D}_{2} \mathrm{O}$ from both a $\mathrm{D}_{2} \mathrm{O} / \mathrm{air}$ mixture and injection of $\mathrm{D}_{2} \mathrm{O}$ liquid. Consistent results were obtained. 


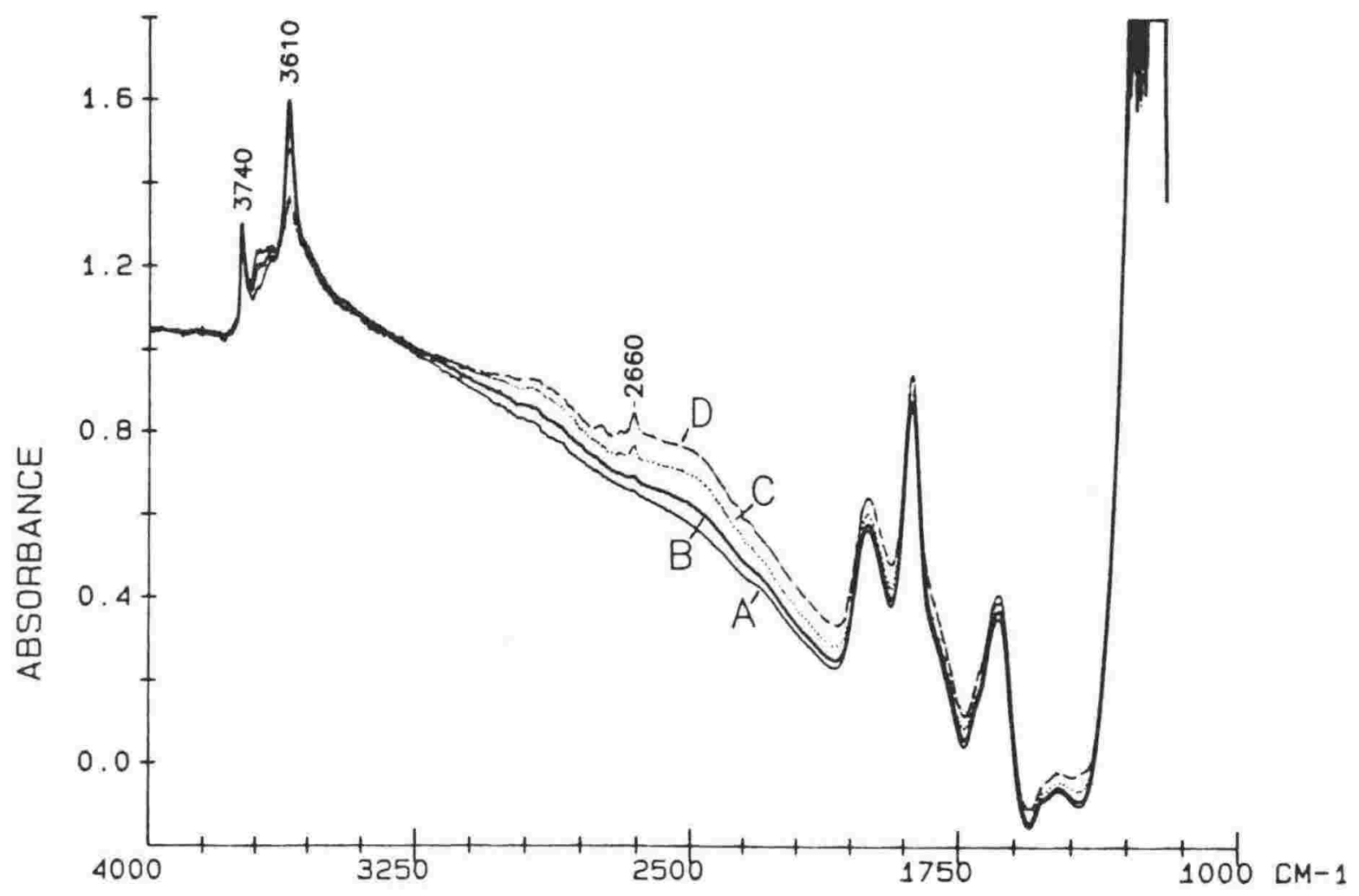

Figure 4.6. FTIR spectra of $\mathrm{D}_{2} \mathrm{O}$ sorbed on $\mathrm{H}+\mathrm{ZSM}-5$ at $80^{\circ} \mathrm{C}$. A. before; B. after addition of $1 \mathrm{ml} \mathrm{D}_{2} \mathrm{O} / \mathrm{air}$; $\mathrm{C}$. after addition of $4 \mathrm{ml} \mathrm{D}_{2} \mathrm{O} / \mathrm{a} i \mathrm{r}$ and $\mathrm{D}$. after addition of $11 \mathrm{ml}$ $\mathrm{D}_{2} \mathrm{O} / \mathrm{air}$.

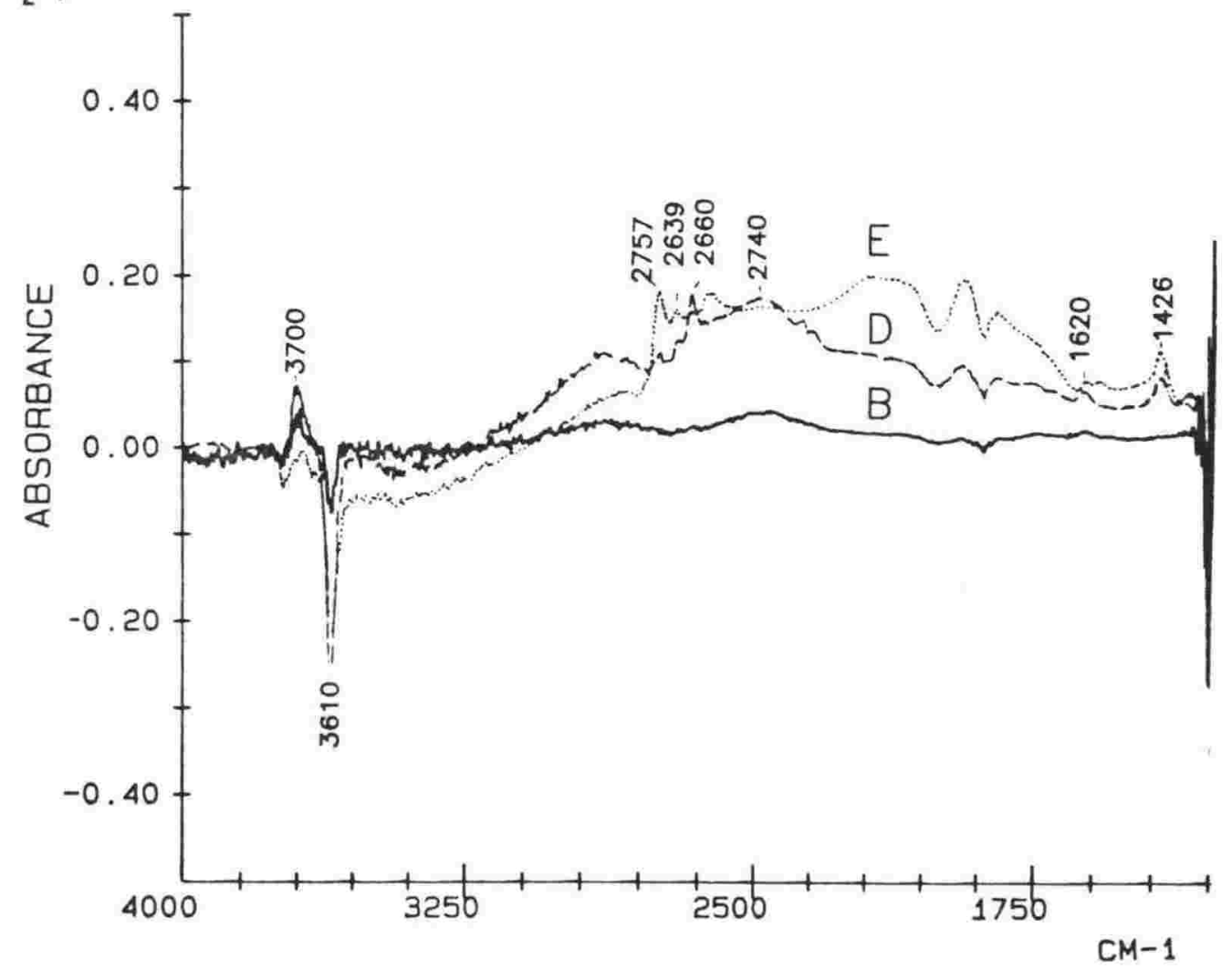

Figure 4.7. FTIR difference spectra of $\mathrm{D}_{2} \mathrm{O}$ sorbed on $\mathrm{H}+\mathrm{ZSM}-5$.

B. after addition of $1 \mathrm{ml} \mathrm{D}_{2} \mathrm{O} / \mathrm{air}$ (fig. $4.6 \mathrm{~B}-4.6 \mathrm{~A}$ );

D. " " " " 


\subsubsection{D+ZSM-5 + $\mathrm{D}_{2} \mathrm{O}:$}

The FTIR spectra of $\mathrm{D}_{2} \mathrm{O}$ sorbed on $\mathrm{D}+\mathrm{ZSM}-5$ at $80^{\circ} \mathrm{C}$ are shown in figure 4.8. The difference spectra (figure 4.9) show more clearly the changes in the lower wavenumber region. The resultant spectrum is shifted to lower wavenumbers, compared to the other cases, due to the isotope effect and appears more complicated than for $\mathrm{H}+\mathrm{ZSM}-5+\mathrm{H}_{2} \mathrm{O}$, with more features in a smaller wavelength range. The main features are again broad bands. Figure 4.8 shows that the highest wavelength band is split into two with maxima at $2741 \mathrm{~cm}^{-1}$ and $2617 \mathrm{~cm}^{-1}$. Figure 4.9 shows a broad band with a maximum $2150 \mathrm{~cm}^{-1}$ with negative peaks at 2004 and $1890 \mathrm{~cm}^{-1}$ due to changes in the zeolite overtone bands. At lower wavenumbers positive peaks at $1570 \mathrm{~cm}^{-1}$ and $1428 \mathrm{~cm}^{-1}$ were observed. The peak at $1428 \mathrm{~cm}^{-1}$ disappeared with increasing $\mathrm{D}_{2} \mathrm{O}$ addition and may have been due to interaction of $\mathrm{D}_{2} \mathrm{O}$ with the small amount of $\mathrm{H}+\mathrm{ZSM}-5$ originally present. 


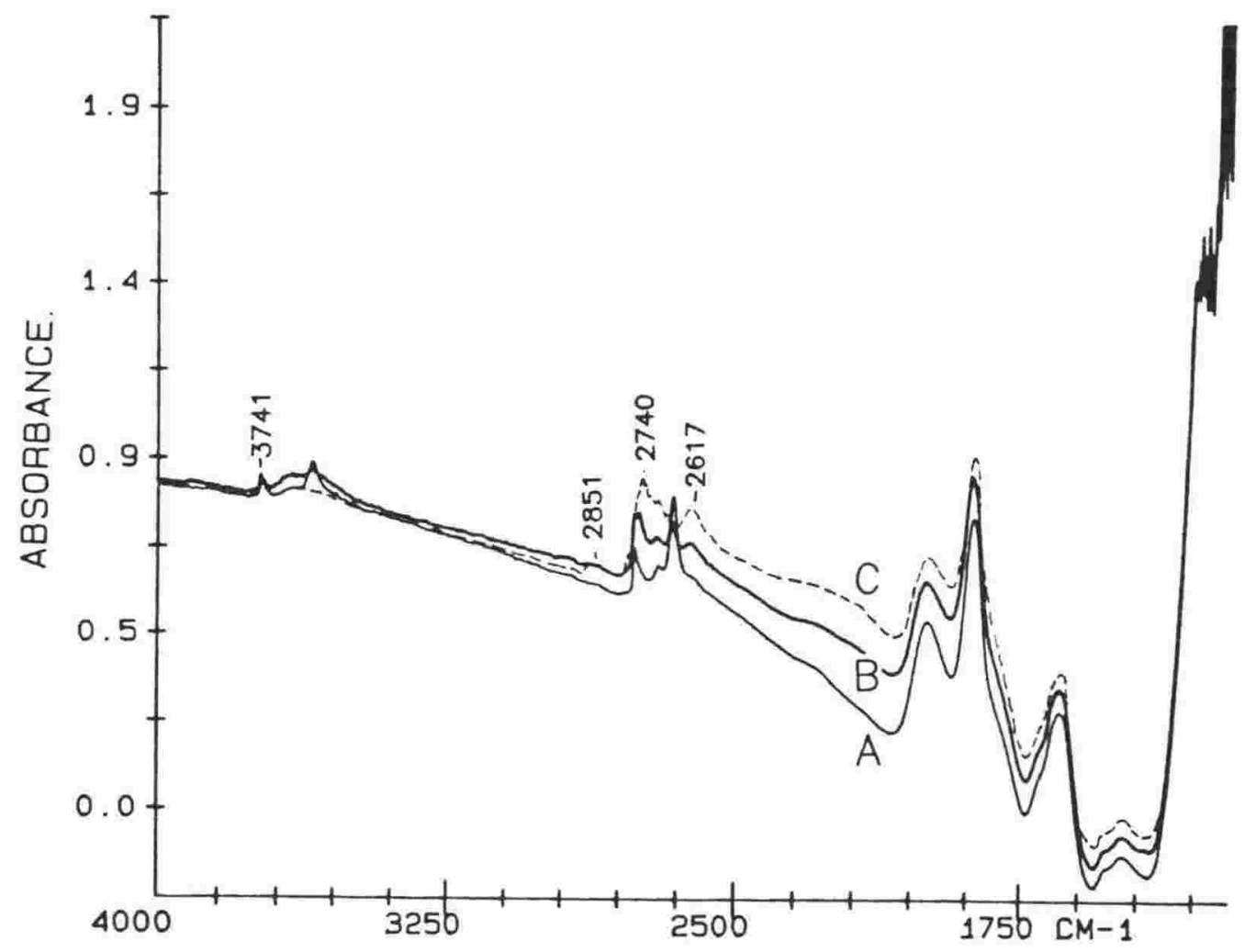

Figure 4.8. FTIR spectra of $\mathrm{D}_{2} \mathrm{O}$ sorbed on $\mathrm{D} / \mathrm{H}+\mathrm{ZSM}-5$. A. before; $B$. after sorption of $0.3 \mu 1 \mathrm{D}_{2} \mathrm{O} ; \mathrm{C}$. after sorption of $2.9 \mu \mathrm{l} \mathrm{D}_{2} \mathrm{O}$.

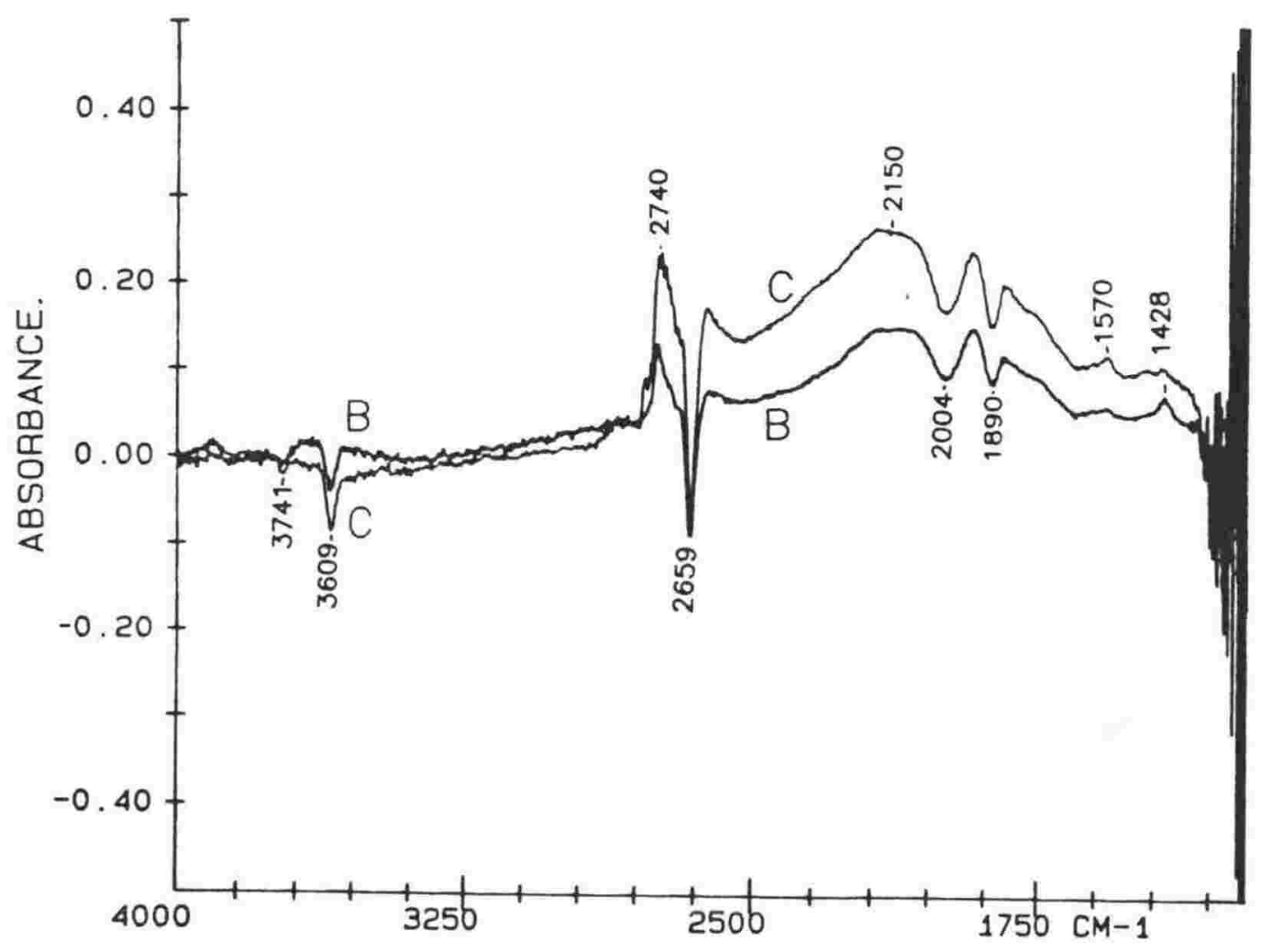

Figure 4.9. FTIR difference spectra of $D_{2} \mathrm{O}$ sorbed on $\mathrm{D} / \mathrm{H}+\mathrm{ZSM}-5$. B. after sorption of $0.3 \mu 1 \mathrm{D}_{2} \mathrm{O}$ (fig. $4.8 \mathrm{~B}-4.8 \mathrm{~A}$ ); C. " " $2.9 \mu 1 "$ " (fig. $4.8 \mathrm{C}-4.8 \mathrm{~A}$ ). 


\subsection{DISCUSSION:}

All the cases show three broad bands, with $\mathrm{H}+\mathrm{ZSM}-5+\mathrm{H}_{2} \mathrm{O}$, $\mathrm{H}+\mathrm{ZSM}-5+\mathrm{D}_{2} \mathrm{O}$ and $\mathrm{D}+\mathrm{ZSM}-5+\mathrm{H}_{2} \mathrm{O}$ all being similar, having maxima at approximately the same positions. For $\mathrm{D}+\mathrm{ZSM}-5+$ $\mathrm{D}_{2} \mathrm{O}$ broad bands are observed isotopically shifted by the amount expected for H/D exchange, and bunched up into a narrower wavelength range.

The spectra are most likely due to water being protonated to varying degrees by strong zeolite Bronsted acid sites. Complete proton transfer has not occured to give the symmetrical $\mathrm{H}_{3} \mathrm{O}^{+}$molecule, as its infrared spectrum (10) is significantly different from that observed. For the H+ZSM-5 $+\mathrm{H}_{2} \mathrm{O}$ case it is proposed here that the infrared spectrum observed is of the species:

$$
\mathrm{Z}-\mathrm{O}^{\delta-} \ldots \mathrm{H}^{\delta+} \ldots \mathrm{O}-\mathrm{H}
$$

$\mathrm{Z}$ represents the zeolite framework and can be considered as a rigid wall, and the degree of proton transfer is undetermined. The broadness of the bands implies a range of environments of the Bronsted proton.

A comparison of the bands observed for the different cases is given in Table 4.1 .

Table 4.1. The FTIR bands observed for different H/D combinations of water sorbed on acid ZSM-5. ( $\vee=$ band observed, $\mathrm{x}=$ band not observed, * = very small, ? = no defined maximum).

$\begin{array}{lrrrrrrrrr}\text { Band } \mathrm{cm}^{-1} & & \sim 3700 & \sim 3600 & \sim 2900 & \sim 2740 & \sim 2470 & \sim 1620 & \sim 1426 & \sim 1570 \\ \mathrm{H}+\mathrm{ZSM}-5 & +\mathrm{H}_{2} \mathrm{O} & \checkmark & \checkmark & \checkmark & \mathrm{x} & \checkmark & \checkmark & \mathrm{x} & \mathrm{x} \\ \mathrm{D}+\mathrm{ZSM}-5+\mathrm{H}_{2} \mathrm{O} & \mathrm{x} & \checkmark & ? & * & ? & \checkmark & \checkmark & \mathrm{x} \\ \mathrm{H}+\mathrm{ZSM}-5+\mathrm{D}_{2} \mathrm{O} & \checkmark & \mathrm{x} & \checkmark & \mathrm{x} & \checkmark & \checkmark & \checkmark & \mathrm{x} \\ \mathrm{D}+\mathrm{ZSM}-5+\mathrm{D}_{2} \mathrm{O} & \mathrm{x} & \mathrm{x} & \mathrm{x} & \checkmark & \mathrm{x} & \mathrm{x} & \checkmark & \checkmark\end{array}$


The peak at $\sim 3700$ and bands at $\sim 2900$ and $2470 \mathrm{~cm}^{-1}$ are observed only for the zeolite-OH cases. The band at $\sim 3600$ $\mathrm{cm}^{-1}$ is only observed for the cases with sorbed $\mathrm{H}_{2} \mathrm{O}$. These results imply that the bonded Bronsted hydroxyl has bands distinct from the sorbed water molecule's hydroxyl bands, confirming that symmetrical $\mathrm{H}_{3} \mathrm{O}^{+}$was not formed.

The significant differences between the $\mathrm{D}+\mathrm{ZSM}-5+\mathrm{H}_{2} \mathrm{O}$ and the $\mathrm{H}+\mathrm{ZSM}-5+\mathrm{D}_{2} \mathrm{O}$ cases implies that exchange between the Bronsted hydroxyl and sorbed water is slow at $80^{\circ} \mathrm{C}$. This is a surprising result as after water was sorbed, facile exchange was expected as is observed at $150^{\circ} \mathrm{C}$. The lower temperature was only expected to result in slower desorption of the water.

The small peaks at 1620,1426 and $1570 \mathrm{~cm}^{-1}$ may result from the $v_{2}$ mode of hydrogen bonded water molecules. For comparison, a study of the IR spectra of matrix isolated water dimers by Ayers and Pullin (11), gave $v_{2}$ for HoH... water at $1611.2 \mathrm{~cm}^{-1}, v_{2}$ for DOH... water at $1398.3 \mathrm{~cm}^{-1}$ and $v_{2}$ for DOD...water at $1189.1 \mathrm{~cm}^{-1}$.

\subsection{CONCLUSIONS:}

These experiments have shown that the sorption of water on $\mathrm{H}+\mathrm{ZSM}-5$ results in broad bands that are not due to the formation of water dimers and trimers.

A broad band at $\sim 3600 \mathrm{~cm}^{-1}$ is associated with sorbed $\mathrm{H}_{2} \mathrm{O}$. other broad bands observed at $\sim 3700, \sim 2900$ and $2470 \mathrm{~cm}^{-1}$ are associated with the bonded Bronsted hydroxyl, and only change upon $H / D$ exchange of the Bronsted sites. At $80^{\circ} \mathrm{C}$ proton exchange between the zeolite $\mathrm{O}-\mathrm{H}$ and water is slow, with distinct differences observed between the $\mathrm{H}+\mathrm{ZSM}-5+\mathrm{D}_{2} \mathrm{O}$ and $\mathrm{D}+\mathrm{ZSM}-5+\mathrm{H}_{2} \mathrm{O}$ cases.

The next step in understanding the nature of these broad bands was to determine whether they are a general feature, or specific to water on $\mathrm{H}+\mathrm{ZSM}-5$. The interaction of water on $\mathrm{H}+\mathrm{Y}$ was studied (Chapter 5 ) and a range of sorbants on H+ZSM- 
5 was also studied (Chapter 7). Broad bands were observed for water on $\mathrm{H}+\mathrm{Y}$ and also for some other sorbants on $\mathrm{H}+\mathrm{ZSM}-5$. These results showed that the broad bands are due to a wide range of vibrational frequencies for the Bronsted proton and are therefore not due to the different vibrational modes of water.

\subsection{REFERENCES:}

1. Ward J.W., Adv. Chem. Ser., 1970, 101, 380.

2. Ison A. and Gorte R.J., J. Catal., 1984, 89, 150.

3. Brunner G.0., Zeolites, 1987, 7, 9.

4. Jacobs P.A. and von Ballmoos R., J. Phys. Chem., 1982, 86,3050 .

5. Guanlin Qin, Ling zheng, Yuming Xie and Chuanchang Wu, J. Catal., 1985, 95, 609 .

6. Datka J. and Tuznik E., Zeolites, 1985, 5, 230.

7. Boxhoorn G., Korteek A.G.T.G., Hays G.R. and Alma N.C.M., Zeolites, 1984, 4, 15.

8. Fyfe C.A., Kennedy G.T., De Schutter C.T. and Kokotailo G.T., J. Chem. Soc. Chem. Commun., 1894, 541.

10. Colvin M.E., Gwedndolyn P.R, Schaefer H.F. and Dupuis M., J. Chem. Phys., 1983, 79, 1551.

11. Ayers G.P. and Pullin A.D.E., Spectrochimica Acta, $1976,32 \mathrm{~A}, 1641$.

12. Ward J.W., in "Zeolite Chemistry and Catalysis", Rabo J.A. Editor, ACS Monograph 171, 1976, 188. 
CHAPTER 5: Interaction of water with the zeolite $H+Y$, studied by FTIR.

\subsection{INTRODUCTION:}

The zeolite $\mathrm{H}+\mathrm{Y}$, formed by heating $\mathrm{NH}_{4}+\mathrm{Y}$ is unstable and hydrolyses rapidly in water with the loss of structural aluminium $(1,2)$. This material is therefore unsuitable for use as an industrial catalyst. However, heating $\mathrm{H}+\mathrm{Y}$ in the presence of water vapour at 700 to $800^{\circ} \mathrm{C}$ also results in removal of lattice alumiuium but has the additional effect of annealing the defects, forming a catalyst of high thermal stability called ultrastable $Y(3,4,5)$.

Because of its industrial significance, the interaction of $\mathrm{H}+\mathrm{Y}$ with steam at high temperatures to form ultrastable $\mathrm{Y}$ has been well studied (5). There are few studies of the interaction of water at lower temperatures. Chukin et al. (6) studied the interaction of water with $\mathrm{H}+Y$ at $450^{\circ} \mathrm{C}$ by IR. They found that for $\mathrm{H}+\mathrm{Y}$ held at $450^{\circ} \mathrm{C}$, contact with water vapour resulted in the formation of new hydroxyl peaks at $3740 \mathrm{~cm}^{-1}$ and $3690 \mathrm{~cm}^{-1}$ and assigned these peaks to $\mathrm{Si}-(\mathrm{OH})$ and $\mathrm{Al}-(\mathrm{OH})^{-}$groups respectively. The low temperature (less than $100^{\circ} \mathrm{C}$ ) interaction of water with Bronsted sites of $\mathrm{H}+\mathrm{Y}$ has not previously been studied. Using FTIR, we observed that even at temperatures less than $100^{\circ} \mathrm{C}$, water sorption can have a major effect on the acid sites and cause destruction of the crystal lattice. A more detailed study was then carried out to quantify this effect.

For the past 20 years infrared spectroscopy has been a major tool for studying the acid sites of zeolites $\mathrm{H}+\mathrm{Y}$ and ultrastable Y. Two distinctive Bronsted sites are observed, characterised by infrared absorbances at $\sim 3650 \mathrm{~cm}^{-1}$ (the high frequency, or $\mathrm{HF}$ peak) and at $\sim 3550 \mathrm{~cm}^{-1}$ (the low frequency, or LF peak). It is generally accepted $(7,8)$ that the proton associated with the HF band extends into the large super cage cavity, while the proton associated with the LF band extends into the small cavity of the sodalite cage. A third peak at $3745 \mathrm{~cm}^{-1}$ is observed due to $\mathrm{Si-OHs}$ terminating the crystal 
structure or at crystal defects. Dealumination of $\mathrm{NH} 4+\mathrm{Y}$ by deep bed calcination $\left(770^{\circ} \mathrm{C}\right.$ for $\left.20 \mathrm{~min}\right)$ or by steaming $\left(750^{\circ} \mathrm{C}\right.$ for $3 \mathrm{~h}$ ) results (9) in the appearance of additional bands at $\sim 3600 \mathrm{~cm}^{-1}$ and $\sim 3700 \mathrm{~cm}^{-1}$. As a result of solid state nmr studies (9) these IR peaks have been assigned to nonframework $\mathrm{AlOH}$ groups. Suggested $\mathrm{AlOH}$ species are hydroxyaluminium ions (eg $\mathrm{Al}(\mathrm{OH})^{2+}$ ) or boehmite-like aluminium clusters (10). However, hydroxy Al species partially bonded to the lattice or framework are also a possibility (11).

\subsection{EXPERIMENTAL:}

The zeolite used in this work was NaY (Linde SK40). This

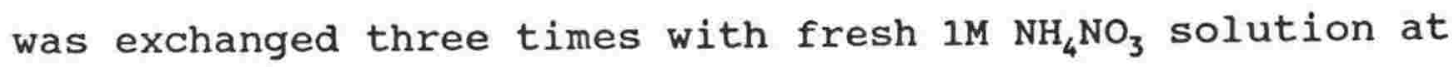
$80^{\circ} \mathrm{C}$. The powder XRD pattern showed no indication of peak broadening or impurities after this exchange procedure. Chemical analysis of the resultant $\mathrm{NH} 4+\mathrm{Y}$ showed $10.1 \% \mathrm{Al}$ and $0.64 \% \mathrm{Na}$. Thermogravimetric analysis showed a $21.3 \%$ weight loss of $\mathrm{H}_{2} \mathrm{O}$ and $\mathrm{NH}_{3}$ between room temperature and $500^{\circ} \mathrm{C}$, giving a final composition of $12.8 \% \mathrm{Al}$ and $0.81 \% \mathrm{Na}$ in the resultant $\mathrm{H}+\mathrm{Y}$.

Water was added quantitatively to the FTIR cell by injecting aliquots of air saturated in water vapour at $20^{\circ} \mathrm{C}$ into the $\mathrm{N}_{2}$ gas stream. The amount of water added to the cell per zeolite Al was calculated from the weight of the NH4+Y wafer and the results of the chemical and thermogravimetric analyses. 


\subsection{RESULTS:}

The FTIR spectrum of $H+Y$, as prepared in-situ from $N H 4+Y$, is shown in figure 5.1A. Bands due to Bronsted hydroxyls are observed at $3640 \mathrm{~cm}^{-1}$ and $3545 \mathrm{~cm}^{-1}$, with only a small peak due to terminating sioHs at $3745 \mathrm{~cm}^{-1}$. A spectrum of this sample after exposure to ambient air at room temperature for 10 minutes showed a broad water sorption over the hydroxyl stretching region and a peak at $1636 \mathrm{~cm}^{-1}$ due to the bending mode of water (figure 5.1B). Heating to $300^{\circ} \mathrm{C}$ was required to remove the bulk of this sorbed water, revealing that most of the acid sites had been destroyed (figure 5.1C). XRD of this material showed that the sample had become largely amorphous.

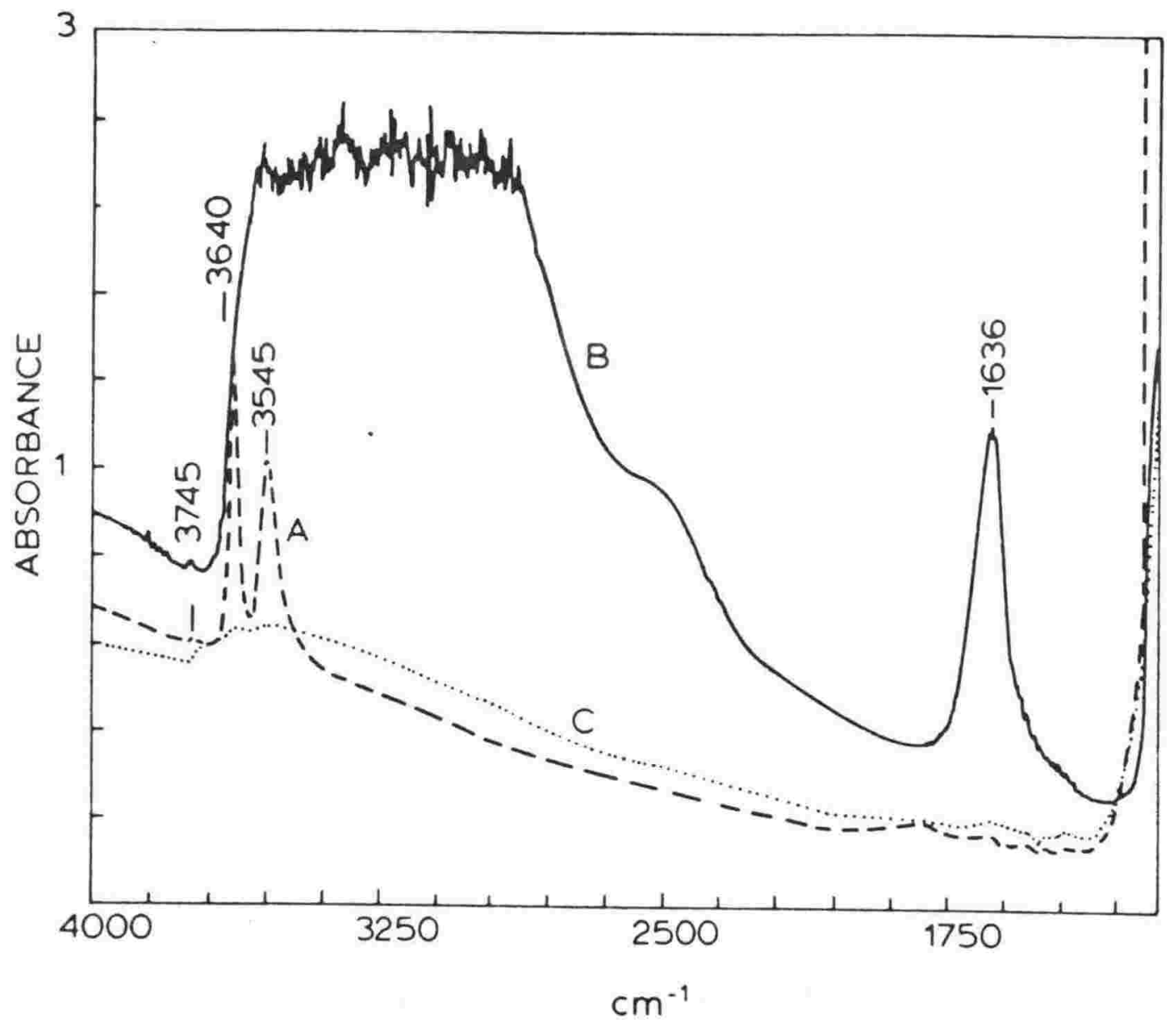

Figure 5.1. The effect on the H+Y FTIR spectrum of exposure to ambient air: $\mathrm{A}$. dry $\mathrm{H}+\mathrm{Y} ; \mathrm{B}$. after exposure to ambient air and $\mathrm{C}$. after heating to $300^{\circ} \mathrm{C}$. 


\section{$5.3 .1 \mathrm{H}+\mathrm{Y}+\mathrm{H}_{2} \mathrm{O}$ at $80^{\circ} \mathrm{C}$}

The interaction of small amounts of water with $\mathrm{H}+\mathrm{Y}$ was studied on a freshly prepared wafer of $\mathrm{H}+\mathrm{Y}$ held at $80^{\circ} \mathrm{C}$. Aliquots of air saturated in water vapour at $20^{\circ} \mathrm{C}$ were injected into the dry $\mathrm{N}_{2}$ gas stream. The spectra observed upon addition of increasing amounts of water are shown in figure 5.2. The HF and the LF hydroxyl peaks decreased showing sorption of water at both these these sites (figure 5.2B). The spectrum of $\mathrm{H}+\mathrm{Y}$ plus water showed three broad bands at $-3600 \mathrm{~cm}^{-1},-3000 \mathrm{~cm}^{-1}$ and $-2515 \mathrm{~cm}^{-1}$ and a peak at $1632 \mathrm{~cm}^{-1}$, similar to those observed for water sorbed on $\mathrm{H}+\mathrm{ZSM}-5$ (13). The broad band at $\sim 3600 \mathrm{~cm}^{-1}$ is difficult to observe as it is partially masked by the zeolite hydroxyl bands. The intensity of a new peak at $3710 \mathrm{~cm}^{-1}$ increased upon water sorption. The FTIR spectra showed that an equilibrium was reached at $2 \mathrm{H}_{2} \mathrm{O}$ molecules per zeolite $\mathrm{Al}$ after which further addition of water (up to $4 \mathrm{H}_{2} \mathrm{O}$ molecules per zeolite $A 1$ ) resulted in no significant changes to the spectra (figure 5.2C). About one fifth of the HF hydroxyls and one half of the LF hydroxyls remained unbonded.

Heating this sample to $110^{\circ} \mathrm{C}$ for 10 minutes in the dry $\mathrm{N}_{2}$ gas flow resulted in an IR spectrum identical to that obtained before water sorption (figure 5.2A). Repeating the water sorption at $80^{\circ} \mathrm{C}$ and desorption at $110^{\circ} \mathrm{C}$ three times produced no significant change in the IR spectrum of the dry $\mathrm{H}+\mathrm{Y}$. 


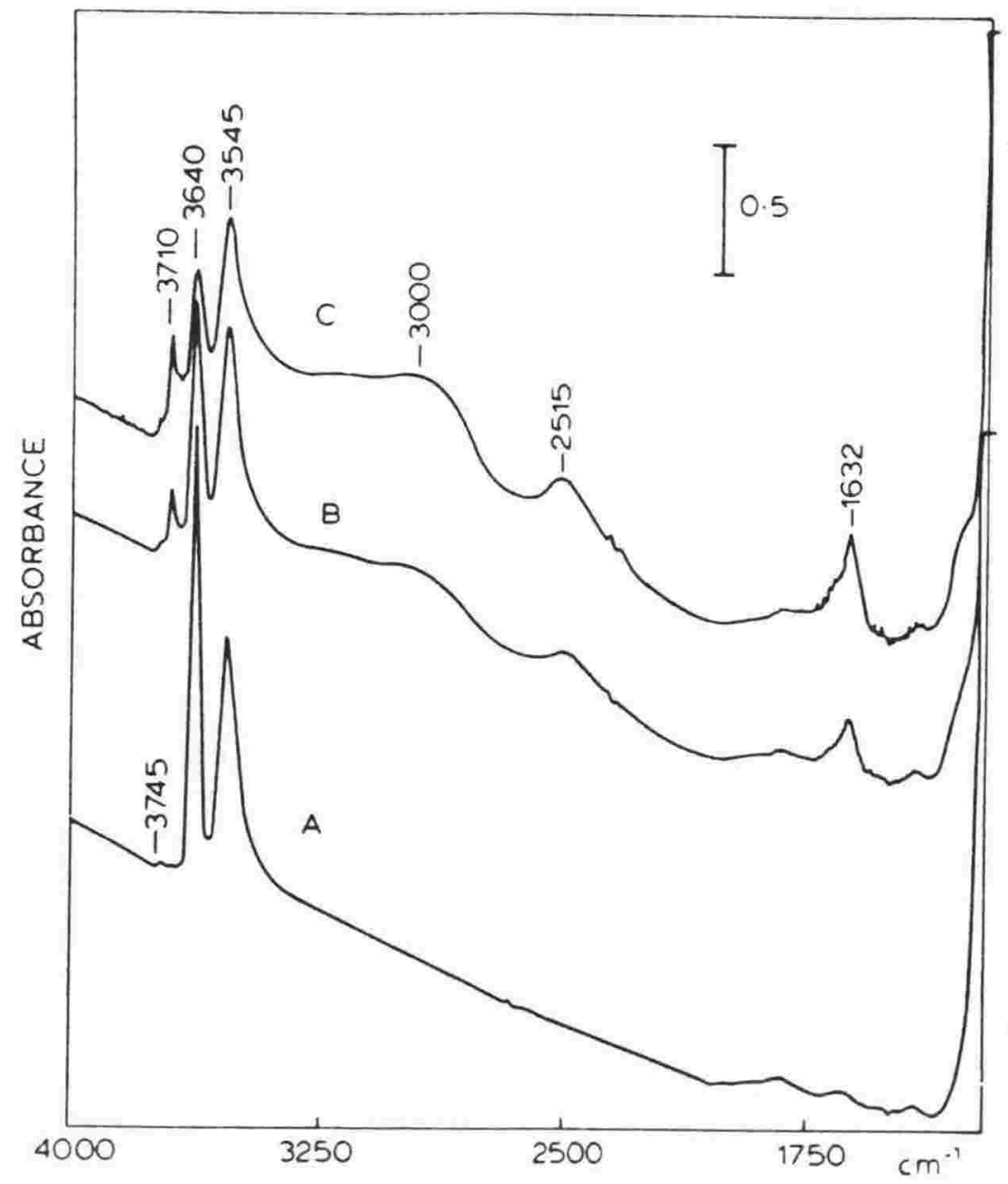

Figure 5.2. The FTIR spectra of: A. dry $\mathrm{H}+\mathrm{Y}$ held at $80^{\circ} \mathrm{C}$; $\mathrm{B}$. with 0.6 molecules of water sorbed per zeolite Al and C. with 4 water molecules sorbed per zeolite Al.

\section{$5.3 .2 \mathrm{H}+\mathrm{Y}+\mathrm{H}_{2} \mathrm{O}$ at $25^{\circ} \mathrm{C}$}

By reducing the temperature to $25^{\circ} \mathrm{C}$ more water could be sorbed on $\mathrm{H}+\mathrm{Y}$ and the amount required to cause irreversible framework collapse determined.

A fresh $\mathrm{H}+\mathrm{Y}$ pellet was prepared in-situ. The spectra obtained at $25^{\circ} \mathrm{C}$ as the amount of sorbed water was increased are shown in figure 5.3. The spectrum of the dry wafer was the same as that shown in figure 5.1A. Assuming that all the water injected was sorbed by the zeolite, figure 5.3A shows the spectrum obtained after sorption of 0.3 molecules of water per zeolite $A$. This spectrum was similar to that found at $80^{\circ} \mathrm{C}$, (figure 5.2) with the same band as before appearing in the $\mathrm{OH}$ region at $3710 \mathrm{~cm}^{-1}$ as the intensity of the HF and LF bands decreased. Upon sorption of 0.6 $\mathrm{H}_{2} \mathrm{O} /$ zeolite $\mathrm{Al}$ a new band at $3675 \mathrm{~cm}^{-1}$ was observed (figure 
5.3B). After sorption of $0.9 \mathrm{H}_{2} \mathrm{O} /$ zeolite $\mathrm{Al}$ this band had become the most prominent hydroxyl band, with some indication of another band at $3615 \mathrm{~cm}^{-1}$ (figure 5.3C). After a wait of 2.5 hours, the sample was heated to $150^{\circ} \mathrm{C}$ at $10^{\circ} \mathrm{C} \mathrm{min}^{-1}$ and held there for $20 \mathrm{~min}$. After the sample had been cooled to $25^{\circ} \mathrm{C}$ the spectrum showed very little difference from the original (figure 5.1A), except for a slight broadening around $3700 \mathrm{~cm}^{-1}$ with the terminal $\mathrm{siOH}$ peak becoming indistinct (figure 5.4A).

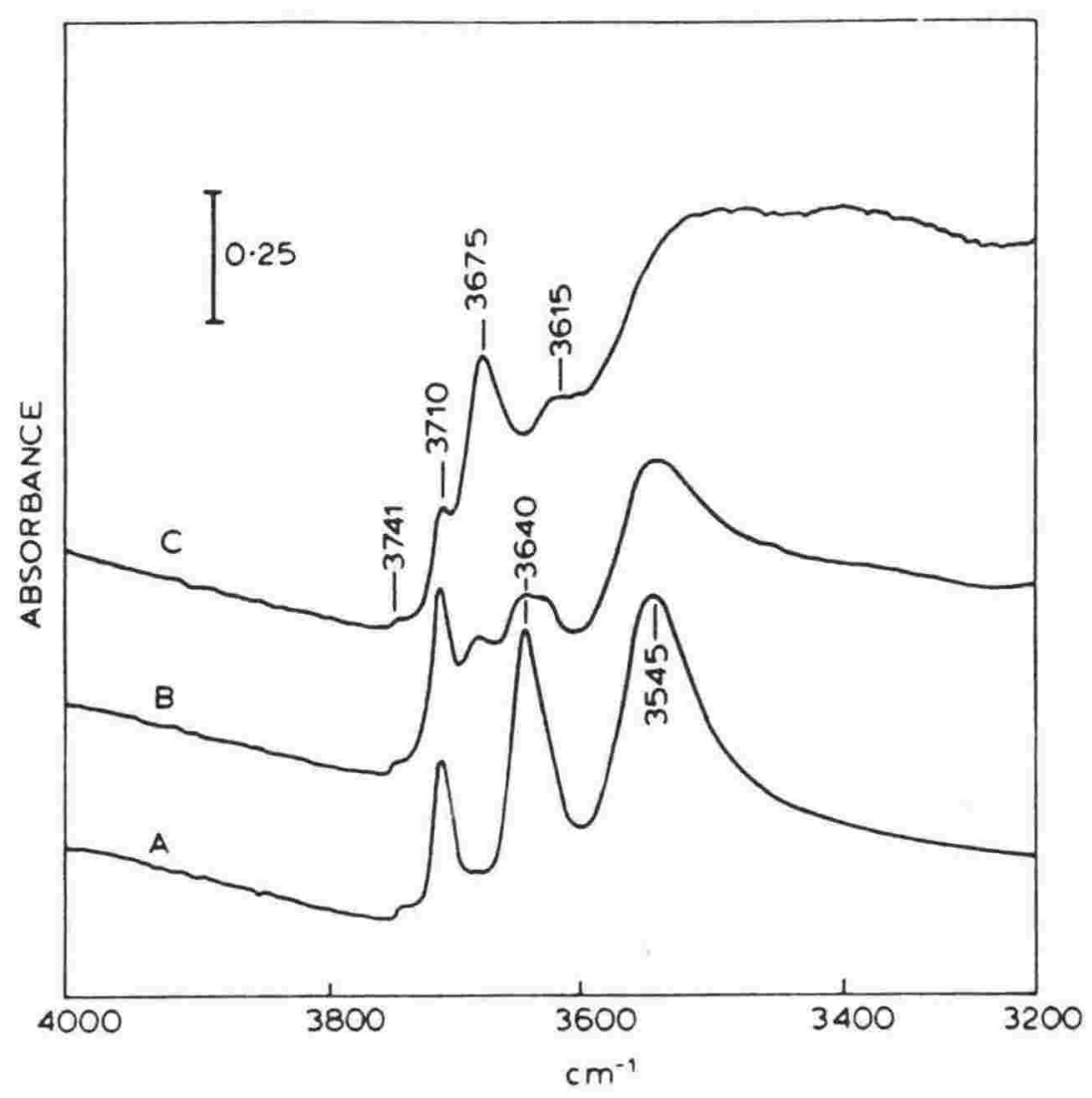

Figure 5.3. FTIR spectra of the hydroxyl region for water sorbed on dry $\mathrm{H}+\mathrm{Y}$ held at $25^{\circ} \mathrm{C}$. After sorption of 0.3 molecules of water per zeolite Al (A); after sorption of 0.6 molecules of water per zeolite Al (B) and after sorption of 0.9 water molecules per zeolite Al (C).

The dry sample used above was treated with $1.2 \mathrm{H}_{2} \mathrm{O}$ molecules per zeolite Al (figure 5.4B). The wafer was heated almost immediately to $150^{\circ} \mathrm{C}$ at $10^{\circ} \mathrm{C} / \mathrm{min}$ and held for $20 \mathrm{~min}$. The spectrum after cooling to $25^{\circ} \mathrm{C}$ (figure $5.4 \mathrm{C}$ ) showed a 
reduction of about $50 \%$ in the peak intensities due to the $\mathrm{HF}$ and LF hydroxyl stretching modes and a significant increase in the size of the broad band under these peaks.

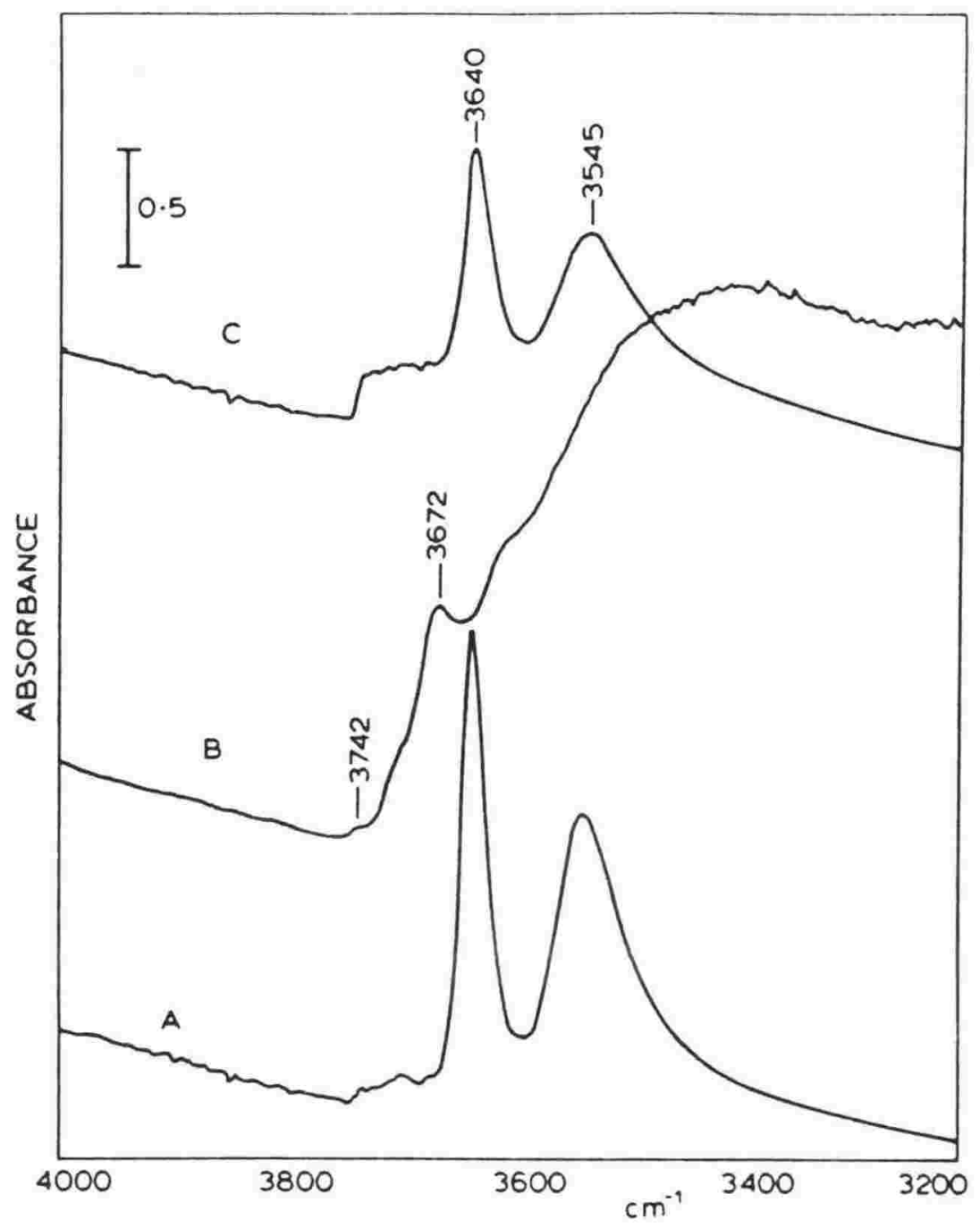

Figure 5.4. FTIR spectra of: A. H+Y dried after addition of 0.9 water molecules per zeolite Al (from figure 5.3C); B. after subsequent addition of 1.2 water molecules per zeolite $\mathrm{Al}$ at $25^{\circ} \mathrm{C}$ and $\mathrm{C}$. after water desorption.

A slightly larger amount of water $\left(1.45 \mathrm{H}_{2} \mathrm{O}\right.$ molecules per zeolite Al) was sorbed on a fresh wafer of $\mathrm{H}+\mathrm{Y}$ (figure $5.5 \mathrm{~A}$ ) and left for 5 hours, resulting in the spectrum shown in figure 5.5B. After desorption (by heating to $150^{\circ} \mathrm{C}$ at $5^{\circ} \mathrm{C} / \mathrm{min}$ ) the intensities of the LF and HF peaks were only about $20 \%$ of the original (figure $5.5 \mathrm{C}$ ). The HF peak had shifted in frequency by $5 \mathrm{~cm}^{-1}$ to $3635 \mathrm{~cm}^{-1}$. According to Lohse et al. (9), the HF band shifts to lower frequency as the $\mathrm{Si} / \mathrm{Al}$ ratio increases, implying that some dealumination had occurred. 


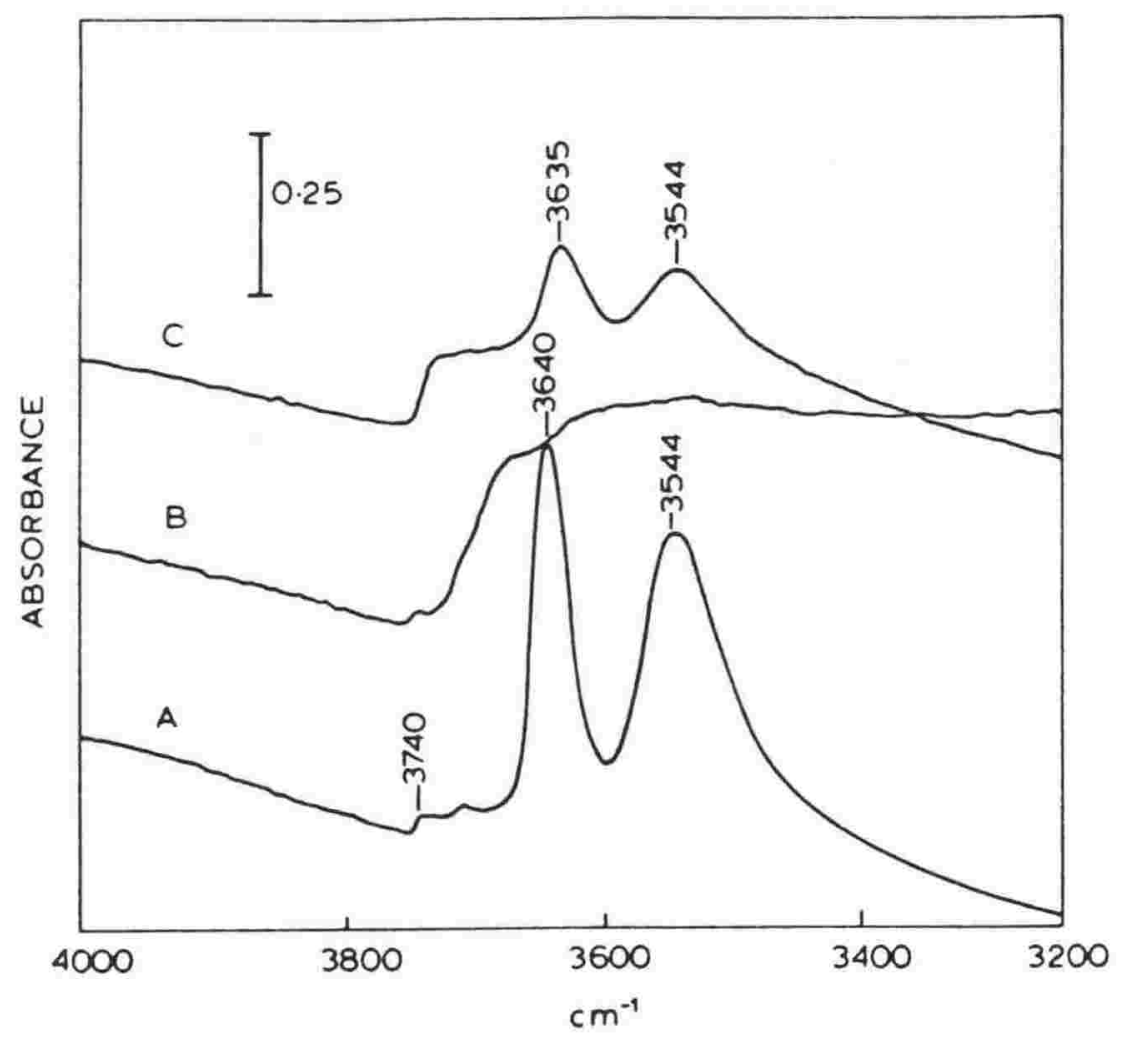

Figure 5.5. Dry $\mathrm{H}+\mathrm{Y}$ (A), after addition of 1.45 water molecules per zeolite $\mathrm{Al}$ and waiting $5 \mathrm{hr}$ at $25^{\circ} \mathrm{C}$ (B). After water desorption at $150^{\circ} \mathrm{C}$ (C).

A fresh wafer of $\mathrm{H}+\mathrm{Y}$ was prepared in the FTIR cell then exposed to ambient air. An XRD pattern was obtained which showed that, at this stage, the zeolite $Y$ structure was still intact. The FTIR spectrum showed a broad water absorption, as in figure 5.1C. To determine if removal of the sorbed water under mild conditions would prevent decomposition of the sample, it was heated to $80^{\circ} \mathrm{C}$ at $2^{\circ} \mathrm{C} \mathrm{min}{ }^{-1}$ in the FTIR cell, in a $\mathrm{N}_{2}$ flow, and held for 16 hours. The broad peaks associated with water absorption, although reduced in intensity, were still present, as was the band due to water at $1636 \mathrm{~cm}^{-1}$. No distinct hydroxyl bands were observed.

After heating from $80^{\circ} \mathrm{C}$ to $150^{\circ} \mathrm{C}$ at $4^{\circ} \mathrm{C} \mathrm{min}{ }^{-1}$, an IR spectrum similar to that shown in figure 5.1C was obtained, with no indication of any Bronsted hydroxyl sites remaining.

\subsection{DIscussION:}

These results show that the amount of water sorbed on dry $\mathrm{H}+\mathrm{Y}$ is critical to its stability. 
At increasing amounts, up to one $\mathrm{H}_{2} \mathrm{O}$ per zeolite $\mathrm{Al}$, new hydroxyl peaks are formed and the Bronsted sites reduce in intensity. The first peak observed is at $3710 \mathrm{~cm}^{-1}$, the second at $3675 \mathrm{~cm}^{-1}$ with perhaps a third at $3615 \mathrm{~cm}^{-1}$. Peaks at $\sim 3600 \mathrm{~cm}^{-1}$ and $\sim 3700 \mathrm{~cm}^{-1}$ have previously been assigned (9) to non-framework $\mathrm{AlOH}$ species in dealuminated $\mathrm{H}+\mathrm{Y}$.

The reversible nature of $\mathrm{H}_{2} \mathrm{O}$ sorption - that the Bronsted sites can be fully restored - implies that, at this stage, the $A l$ has been only partially removed from the framework. Possibly, the Al retains at least one bond to the framework then, as the water is removed, it reinserts into the framework. Recent solid state nmr results (11) also support the hypothesis of the production of $\mathrm{AlOH}$ species which are partially bonded to the framework.

The partial removal of Al from the lattice to produce $\mathrm{AlOH}$ species also implies the formation of internal silanols. One of the new peaks observed may therefore be due to these internal silanols, shifted to lower wavenumbers than those of the terminal silanols because of hydrogen bonding or framework interactions.

Sorption of more than about one $\mathrm{H}_{2} \mathrm{O}$ per zeolite $\mathrm{Al}$ results in an increasing irreversible loss of acid sites on subsequent desorption. Sorption of one water per Al may only break one Al-framework bond which is readily reformed upon desorption of water. With greater amounts of water, two or more Al-framework bonds may be broken so that on water desorption reinsertion is not possible and the Al moves irreversibly into the channels.

The subsequent loss of Bronsted acidity did not result in an increase in the distinct terminal sioH peak, but rather a broad band developed from $3745 \mathrm{~cm}^{-1}$ downwards. This band was probably due to the increasingly amorphous nature of the sample. 
When zeolite $\mathrm{H}+\mathrm{Y}$ was held at $80^{\circ} \mathrm{C}$ an equilibrium was reached at where less than one $\mathrm{H}_{2} \mathrm{O}$ per zeolite $\mathrm{Al}$ was sorbed. Only one new $\mathrm{OH}$ peak formed at $3710 \mathrm{~cm}^{-1}$. However, at $25^{\circ} \mathrm{C}$ all the acid sites interacted with water and at least two new hydroxyl peaks were observed. This implies that under these conditions water is only weakly sorbed and that the degree of sorption is controlled by thermal equilibrium.

Under the conditions used here, small amounts of sorbed water (less than $\sim 1 \mathrm{H}_{2} \mathrm{O} /$ zeolite $\mathrm{Al}$ ) are readily removed from $\mathrm{H}+\mathrm{Y}$ by heating to $100^{\circ} \mathrm{C}$ in dry $\mathrm{N}_{2}$. However, if large amounts of water are sorbed (eg. from exposure to ambient air) heating to $300^{\circ} \mathrm{C}$ is required to remove all of the sorbed water. The water is therefore desorbing from different species with different affinities for water.

The results from XRD of $\mathrm{H}+\mathrm{Y}$ exposed to ambient air showed that $\mathrm{H}+\mathrm{Y}$ can absorb large amounts of water and still retain its structural integrity. It is during the removal of this water that framework collapse occurs to form an amorphous material with few Bronsted hydroxyls detectable by IR. This collapse occurs below $300^{\circ} \mathrm{C}$.

Further studies, by temperature and atmosphere controlled XRD and solid state nmr and FTIR are required in order to determine how the interaction of water with the Bronsted acid sites leads to loss of Al from the framework and the eventual collapse of the zeolite framework. 


\subsection{CONCLUSIONS:}

Water interacts with the Bronsted acid sites of the zeolite $\mathrm{H}+\mathrm{Y}$ at low temperatures resulting in the formation of new hydroxyl peaks. This implies that water is breaking the Al-framework bonds, forming $\mathrm{AlOH}$ and SiOH species.

If less than one molecule of water is sorbed per framework Al the water can be desorbed at low temperature and the acid sites fully restored. This may be because only one Al-framework bond is hydrolysed and readily reformed. If more than about one molecule of water is sorbed, then water desorption occurs at higher temperatures and there is a permanent loss of Bronsted acidity, presumably with the formation of extra lattice Al species. This observation may be a consequence of two or more framework bonds hydrolysing for a given $A l$ atom, precluding its reinsertion into the framework.

\subsection{REFERENCES :}

1. Breck, D.W., 'Zeolite Molecular Sieves', John Wiley and Sons, New York, 1974.

2. Kerr, G.T., J. Catal. 1982, 77, 307.

3. McDaniel, C.V. and Maher, P.K. 'Molecular Sieves', Soc. Chem. Ind., London, 1968, 186.

4. Kerr, G.T. J. Phys. Chem. 1967, 71, 4155.

5. Marosi, L. Angew Chem. Int. Ed. Engl. 1980, 19, 743.

6. Chukin, G.D, Kulikov, A.S. and Sergienko, S.A., React. Kinet. Catal. Lett. 1985, 27, 287.

7. Lunsford, J.H., Rothwell, W.P. and Shen, W., J. Am. Chem. Soc. 1985, 107, 1540 .

8. Ward, J.W., Adv. Chem. Ser. Gould, R.F Editor. Am. Chem. Soc. 1971,380 .

9. Lohse, U., Loffler, E., Hunger, M., Stockner, J., and Patzelova, V., Zeolites 1987, 7, 11.

10. Shannon, R.D., Gardner, K.H., Staley, R.H., Bergeret, G., Gallezot P. and Auroux, A., J. Phys. Chem. 1985, 89, 4778 . 
11. Dwyer, J., 'Studies in Surface Science and Catalysis', Grobet, P.J., Mortier, W.J., Vansant, E.F. and SchulzEkloff, G. Editors, 37, Elsevier, Amsterdam, 1988, 333.

12. Moon, S.H., Windawi, H., and Katzer, J.R., Ind. Eng. Chem Fundam., 1981, 20, 396.

13. Parker, L.M., Bibby, D.M. and Burns, G.R. To be published. 
CHAPTER 6: SORPTION OF PYRIDINE ON H+Y:

6.1 INTRODUCTION: IR Spectroscopy of Pyridine on Sorbates:

Historically pyridine has been used as a probe in Infra-red studies to determine the presence of Bronsted (protonic) and Lewis (electron acceptor) acid sites. Infra-red characterisation of pyridine was carried out in the early 1960s. Table 1 shows the assignments of gas phase pyridine, and physisorbed and chemically (Bronsted and Lewis) sorbed pyridine on silica-alumina, as given by Basila et al. (1).

Table 1. Infra-red wavenumbers $\left(\mathrm{cm}^{-1}\right)$ for pyridine in the gas phase and physically and chemically sorbed on silica-alumina (1).

\begin{tabular}{lccccc}
\multicolumn{2}{c}{ type } & gas phase & physisorbed & Lewis & Bronsted \\
$7 \mathrm{a}$ & $\mathrm{vNH}$ & - & - & - & $3260 \& 3188$ \\
$20 \mathrm{~b}$ & $\mathrm{vCH}$ & 3083 & - & $(3147)$ & $(3147)$ \\
16 & $\mathrm{vCH}$ & 3054 & 3065 & $(3114)$ & $(3114)$ \\
$7 \mathrm{~b}$ & $\mathrm{vCH}$ & 3054 & 3043 & $(3087)$ & $(3087)$ \\
$8 \mathrm{a}$ & $\mathrm{VCC}(\mathrm{N})$ & 1580 & 1614 & 1620 & 1638 \\
$8 \mathrm{~b}$ & $\mathrm{VCC}(\mathrm{N})$ & 1572 & 1593 & 1577 & 1620 \\
$19 \mathrm{a}$ & $\mathrm{VCC}(\mathrm{N})$ & 1482 & 1490 & 1490 & 1490 \\
$19 \mathrm{~b}$ & $\mathrm{vCC}(\mathrm{N})$ & 1439 & 1438 & 1450 & 1545
\end{tabular}

The physisorbed pyridine, which is held on the surface by weak interactions is detected by characteristic 1593 and $1614 \mathrm{~cm}^{-1}$ bands. Protonated (Bronsted) pyridine is characterised by bands at 3260 and $3188 \mathrm{~cm}^{-1}$, which are due to the $\mathrm{NH}^{+}$stretching vibration and by the bands at 1638 and $1545 \mathrm{~cm}^{-1}$ which are due to the combined $\mathrm{C}-\mathrm{C}$ stretching and $\mathrm{NH}$ bending modes (Zerbi et al.(2)). Chemisorbed (Lewis bound) pyridine is characterised by bands at 1452 and $1577 \mathrm{~cm}^{-1}$ which are due to the combined $\mathrm{C}-\mathrm{C}$ stretching and in plane $\mathrm{C}-\mathrm{H}$ bending modes. The $\mathrm{C}-\mathrm{H}$ stretching vibrations of Bronsted and Lewis bound pyridine are indistinguishable on silica-alumina (1) and the assignments are tentative, as indicated by parentheses. Pyridine associated with $\mathrm{Na}^{+}$ions in zeolites (Lewis bound) shows characteristic bands at 1590 and $1445 \mathrm{~cm}^{-1}$ (Jacobs et al. (3)). 

Pyridine sorbed on $\mathrm{H}+\mathrm{Y}$ was studied (in this work) to test the correlation of proton affinity of sorbed base versus shift in the Bronsted $\mathrm{OH}$ stretch for this zeolite. In addition, an attempt was made to obtain further information on the nature of the acid sites of $\mathrm{H}+\mathrm{Y}$ using the much studied IR tool of pyridine sorption with the added versatility of FTIR. FTIR enables spectra to be scanned more rapidly and dynamic changes observed.

\subsection{RESULTS:}

\section{$6.2 .1 \mathrm{H}+\mathrm{Y}+$ pyridine at $100^{\circ} \mathrm{C}$ and $150^{\circ} \mathrm{C}$ :}

The two distinct Bronsted sites of $\mathrm{H}+\mathrm{Y}$, differing in acidity and accessability result in a more complicated interaction with pyridine than observed for $\mathrm{H}+2 \mathrm{SM}-5$. As previously described $(3,6)$, the LF hydroxyls have a much lower affinity for pyridine than the HF hydroxyls. The spectrum of dry $H+Y$ held at $100^{\circ} \mathrm{C}$ is shown in figure $6.1 \mathrm{~A}$ and the spectrum obtained after sorption of $\sim 0.7$ molecules of pyridine per zeolite $A l$ on $\mathrm{H}+\mathrm{Y}$ is shown in figure 6.1B. Only about one fifth of the HF hydroxyls, but most of the LF hydroxyls remain.

The spectrum obtained after heating the same sample to $350^{\circ} \mathrm{C}$ in $20 \mathrm{~min}$, then cooling to $150^{\circ} \mathrm{C}$ is shown in figure $6.2 \mathrm{~A}$. This ensured that no physisorbed pyridine remained. The LF hydroxyl peak increased and the HF peak decreased compared to figure $6.1 \mathrm{~B}$. 


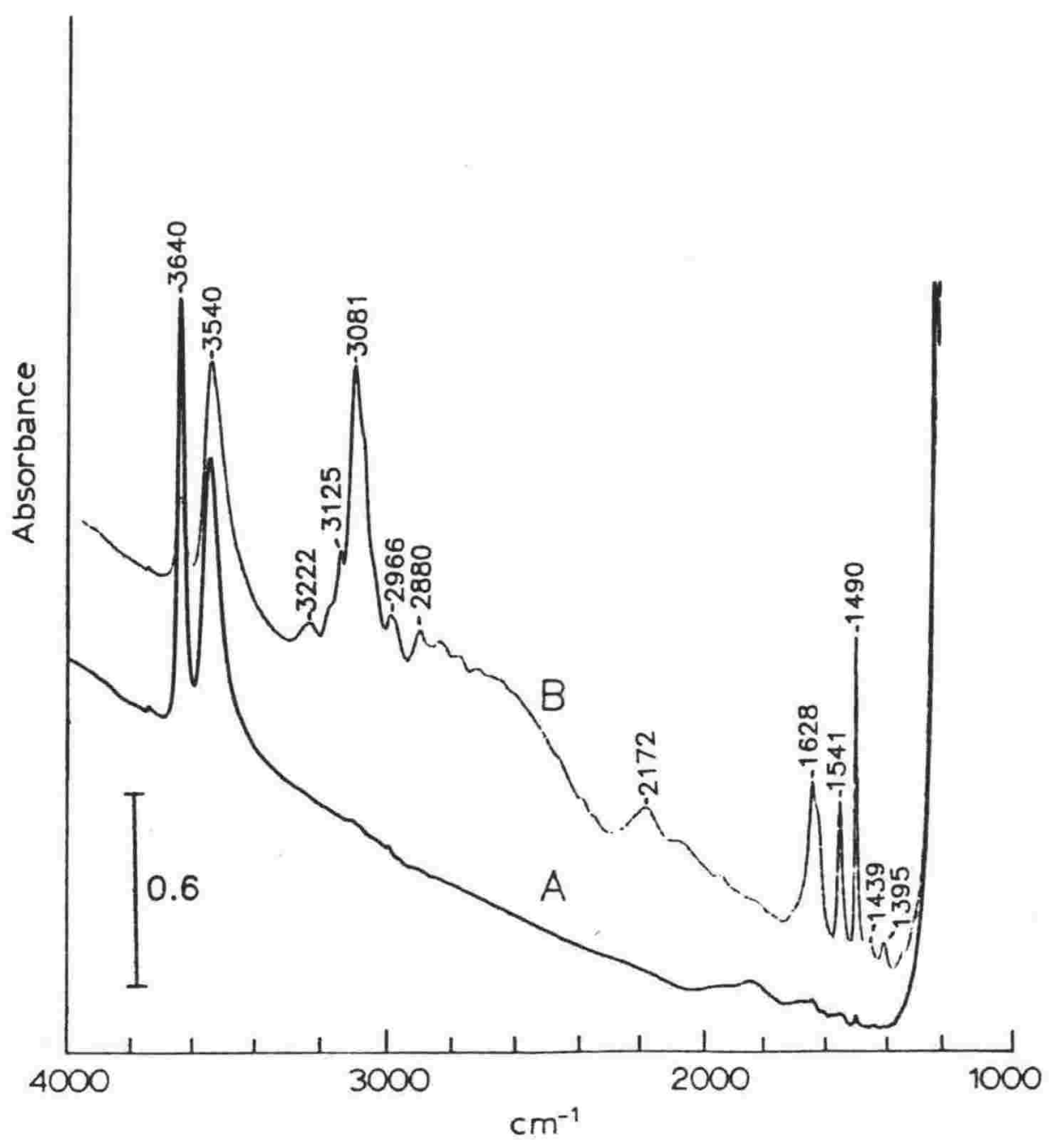

Figure 6.1. FTIR spectra of: A. Dry $\mathrm{H}+\mathrm{Y}$ held at $100^{\circ} \mathrm{C}$ and B. after sorption of $\sim 0.7$ pyridine molecules/zeolite Al at $100^{\circ} \mathrm{C}$. 


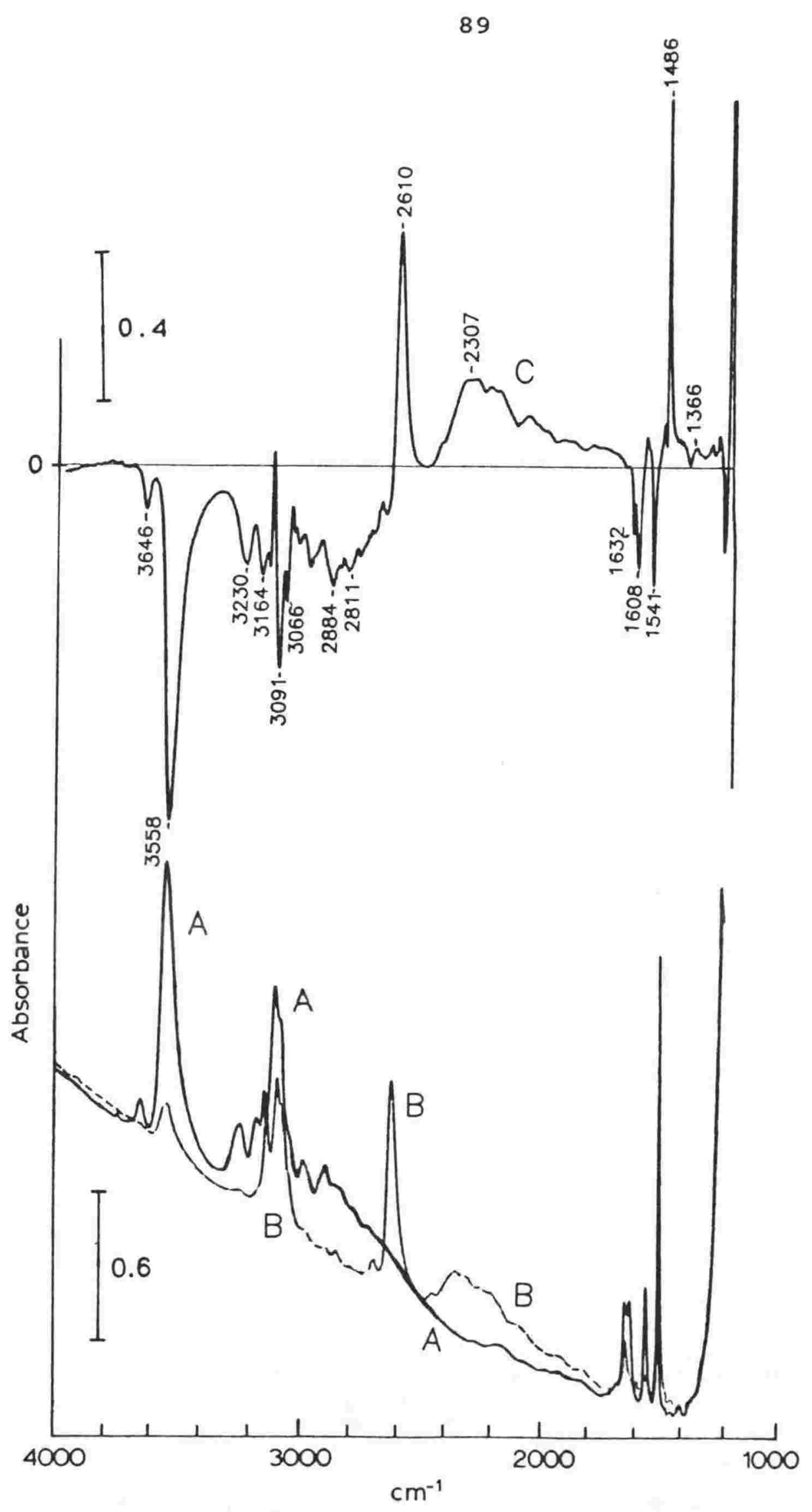

Figure 6.2. FTIR spectra of: A. pyridine sorbed at (mainly) HF hydroxyls at $150^{\circ} \mathrm{C}$; $\mathrm{B}$. after $\mathrm{H} / \mathrm{D}$ exchange by $\mathrm{D}_{2} \mathrm{O}$ and C. the difference spectrum B - A. 


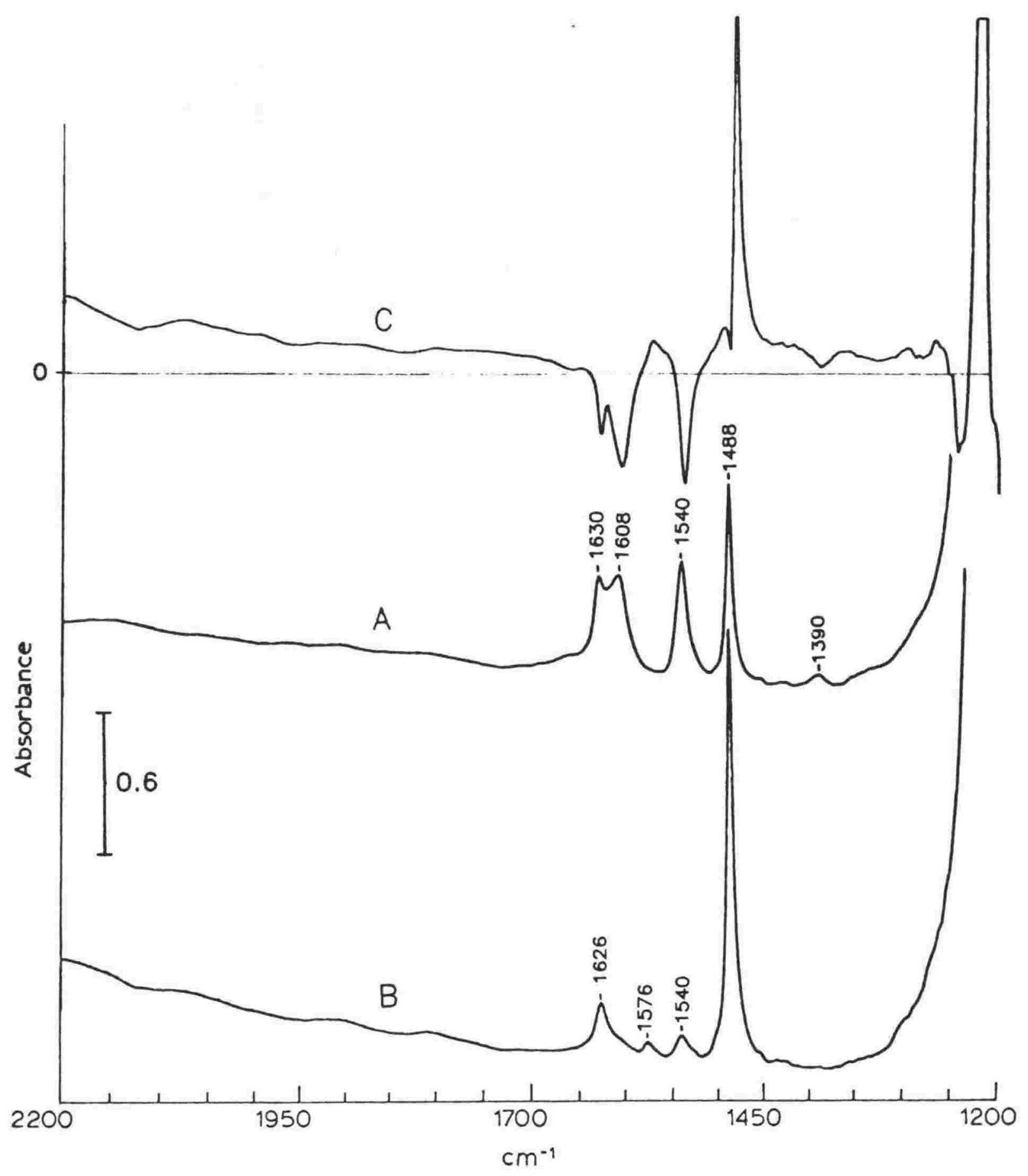

Figure 6.3. Expanded FTIR spectra of pyridine ring bending and stretching region corresponding to those in figure 6.2 . 
Injection of $\mathrm{D}_{2} \mathrm{O}$ into the gas stream results in an exchange of available $\mathrm{H}$ for $\mathrm{D}$ as the water interacts with the zeolite and desorbs again. The spectrum obtained after injection of $4 \mu \mathrm{l}$ of $\mathrm{D}_{2} \mathrm{O}$ over a $30 \mathrm{~min}$ period is shown in figure $6.2 \mathrm{~B}$. The difference spectrum (spectrum after $\mathrm{D}_{2} \mathrm{O}$ addition - spectrum before) is shown in figure 6.2C. The unassociated $O H$ peaks have been lost (negative peaks in figure 6.2C) and Bronsted OD peaks formed. A broad complex band from $\sim 3650 \mathrm{~cm}^{-1}$ to $\sim 2620 \mathrm{~cm}^{-1}$ was lost and reappeared between $\sim 2500 \mathrm{~cm}^{-1}$ and $\sim 1640 \mathrm{~cm}^{-1}$. This was due to exchange of $\mathrm{H}$ for $\mathrm{D}$, most likely the Bronsted protons from the HF hydroxyls associated with pyridine.

The wide range of energies of the Bronsted protons implies different degrees of association with the sorbed pyridine molecules. This may be due to varying degrees of accessability of pyridine to the HF acid sites. An alternative is that rapid motion of the pyridine molecules broadens the energy range of the Bronsted protons. Solid state ${ }^{1} \mathrm{H}$ nmr of proton spin relaxation times (Rausher et al. (8)) showed that sorbed pyridine was in a state of flux. After a mean time of $5 \times 10^{-7} \mathrm{~S}$ (at $40^{\circ} \mathrm{C}$ ) the protonated pyridine is desorbed as a pyridine molecule, hopping to another $\mathrm{OH}$ group. Less often, after a mean time of $10^{-5} \mathrm{~s}$, a jump as a pyridinium ion occurs which carries the proton of the $\mathrm{OH}$ group to another oxygen of the zeolite skeleton. These movements are slow compared to the IR time scale $\left(3000 \mathrm{~cm}^{-1}\right.$ is equivalent to $0.9 \times 10^{14} \mathrm{~s}^{-1}$ ) so a frozen image is obtained by FTIR. This would result in the observation of a broader energy range for the Bronsted protons than when there are no sorbants.

The ring bending and stretching region showed marked changes upon exchange of labile $\mathrm{H}$ for D. Figure 6.3 shows an expanded difference plot of this region corresponding to those in figure 6.2. Peaks at 1632,1608 and $1541 \mathrm{~cm}^{-1}$ decreased. According to zerbi et al. (2) these peaks are due to combined $\mathrm{C}-\mathrm{C}$ stretching and in plane $\mathrm{CH}$ and $\mathrm{NH}^{+}$bending modes. The peak at $1486 \mathrm{~cm}^{-1}$, assigned to $\mathrm{vCC}(\mathrm{N})$, increased 
markedly. These changes show that there are strong interactions of the NH/ND modes with the ring vibrations.

\section{$6.2 .2 \mathrm{H}+\mathrm{Y}+$ pyridine at $25^{\circ} \mathrm{C}$ :}

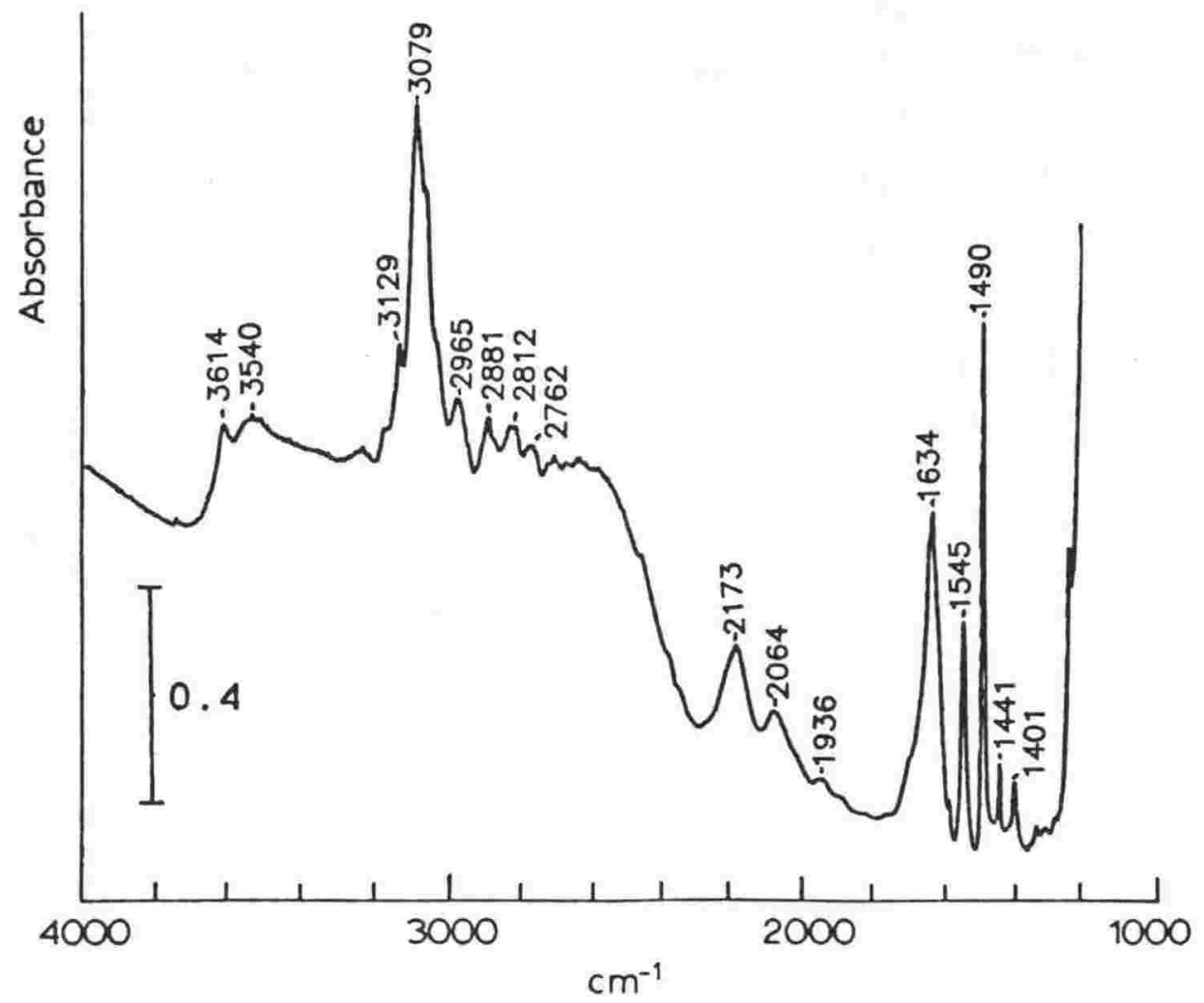

Figure 6.4. FTIR spectrum of pyridine sorbed on $\mathrm{H}+\mathrm{Y}$ at $25^{\circ} \mathrm{C}$.

As shown in figure 6.4, more pyridine is sorbed on $\mathrm{H}+\mathrm{Y}$ at $25^{\circ} \mathrm{C}$ than $100^{\circ} \mathrm{C}$. Both the HF and LF hydroxyl stretches have almost disappeared. There is a large broad band from $\sim 3700$ to $2200 \mathrm{~cm}^{-1}$ which is larger and covers a wider range than at higher temperatures when only the HF hydroxyls are bonded. It was not possible to determine the frequencies of the hydroxyl stretches by injecting $\mathrm{D}_{2} \mathrm{O}$ to exchange $\mathrm{H}$ for $\mathrm{D}$ as was done at $150^{\circ} \mathrm{C}$, as the sorption of $\mathrm{D}_{2} \mathrm{O}$ would occur at this temperature. However a comparison of figures 6.2A (no physisorbed pyridine) and figure 6.4 , shows a broader band implying the bonded LF hydroxyls have a wider energy range than the HF hydroxyls.

Additional peaks at 2173, 2064 and $1936 \mathrm{~cm}^{-1}$ were also observed. These disappeared as the LF hydroxyl band was restored upon heating. Earlier work (Jacobs (3)) scanned 
from 1300 to $1700 \mathrm{~cm}^{-1}$ and 2600 to $3800 \mathrm{~cm}^{-1}$ and so did not observe these peaks. No assignments have been given in the literature, so their assignment is uncertain.

The 1300 to $1700 \mathrm{~cm}^{-1}$ region has been well studied. Jacobs et al. (3) state that "for pyridine an important band at $1442 \mathrm{~cm}^{-1}$ develops as the $\mathrm{HF}$ band has disappeared and the LF band starts to decrease. This has always been assigned to hydrogen bonded pyridine". This $1442 \mathrm{~cm}^{-1}$ band is equivalent to the $19 \mathrm{~b}\left(1438 \mathrm{~cm}^{-1}\right)$ band for physisorbed pyridine given in Table 1 .

To obtain the spectrum of physisorbed pyridine under conditions used in these experiments, zeolite H+ZSM-5 (prep 816) was used, as its IR spectrum is not complicated by LF hydroxyls. The difference spectrum between $\mathrm{H}+\mathrm{ZSM}-5$ at $25^{\circ} \mathrm{C}$, containing physisorbed and Bronsted pyridine, and that with only Bronsted pyridine is shown in figure 6.5. The zeolite with only Bronsted sorbed pyridine was obtained by sorbing pyridine at $150^{\circ} \mathrm{C}$ so that all the Bronsted sites were bonded, flushing, then cooling to $25^{\circ} \mathrm{C}$. The difference spectrum in figure 6.5 therefore shows the spectrum due to physisorbed pyridine only. This has a strong band at $1440 \mathrm{~cm}^{-1}$.

The expanded spectrum of pyridine sorbed on $\mathrm{H}+\mathrm{Y}$ at $25^{\circ} \mathrm{C}$ from 2200 to $1200 \mathrm{~cm}^{-1}$ is shown in figure 6.6 . The spectrum was obtained with very little physisorbed pyridine, but most of the LF hydroxyls bonded, by sorbing pyridine on $\mathrm{H}+\mathrm{Y}$ held at $150^{\circ} \mathrm{C}$, flushing, then cooling the cell. The cell was then sealed and left overnight. Just enough pyridine was sorbed on the walls of the cell to interact with the LF hydroxyls. 


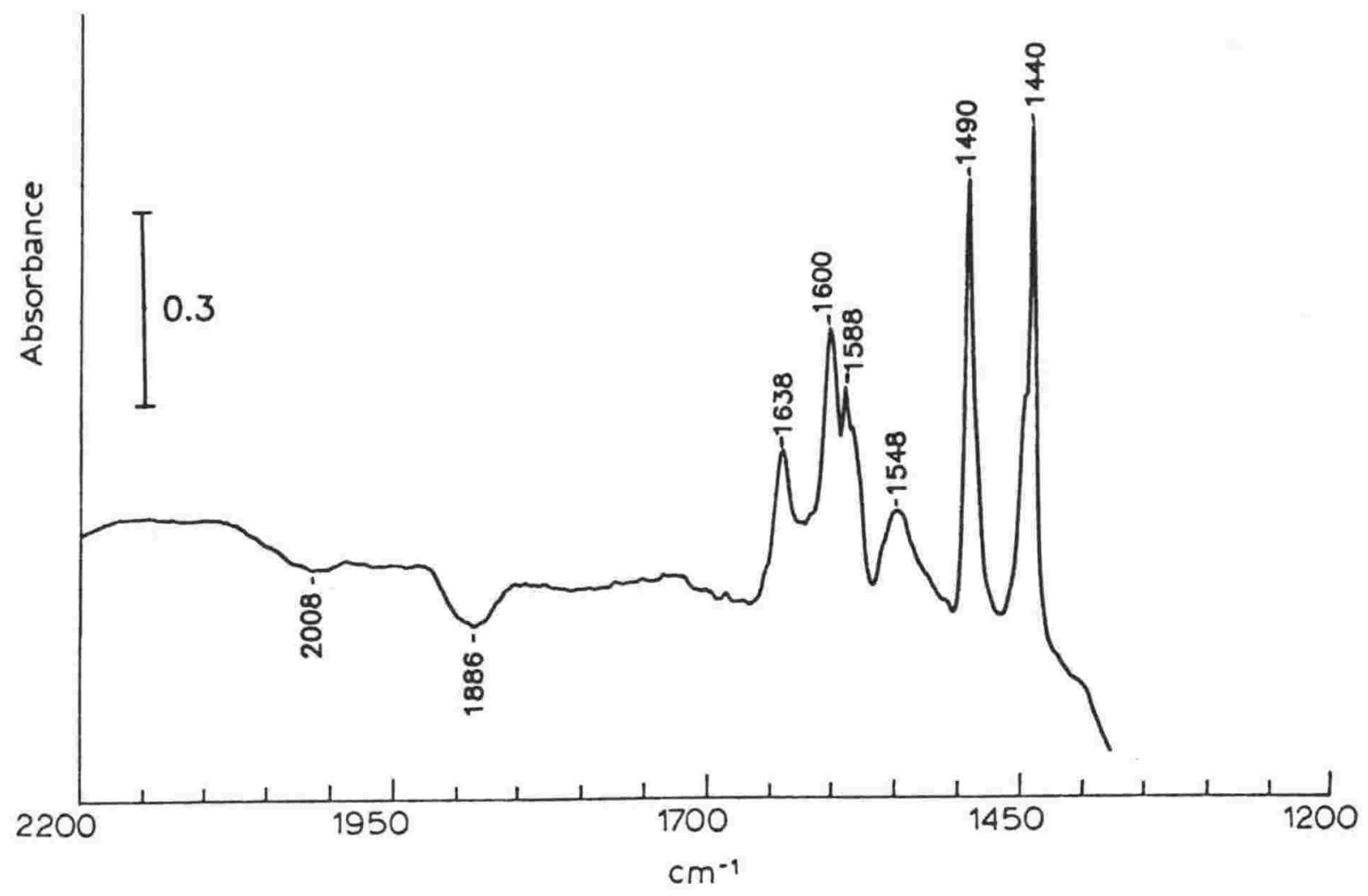

Figure 6.5. FTIR difference spectrum between $\mathrm{H}+\mathrm{ZSM}-5$ at $25^{\circ} \mathrm{C}$, containing physisorbed and Bronsted pyridine, and H+ZSM5 with only Bronsted pyridine. This shows the peaks that are due to physisorbed pyridine.

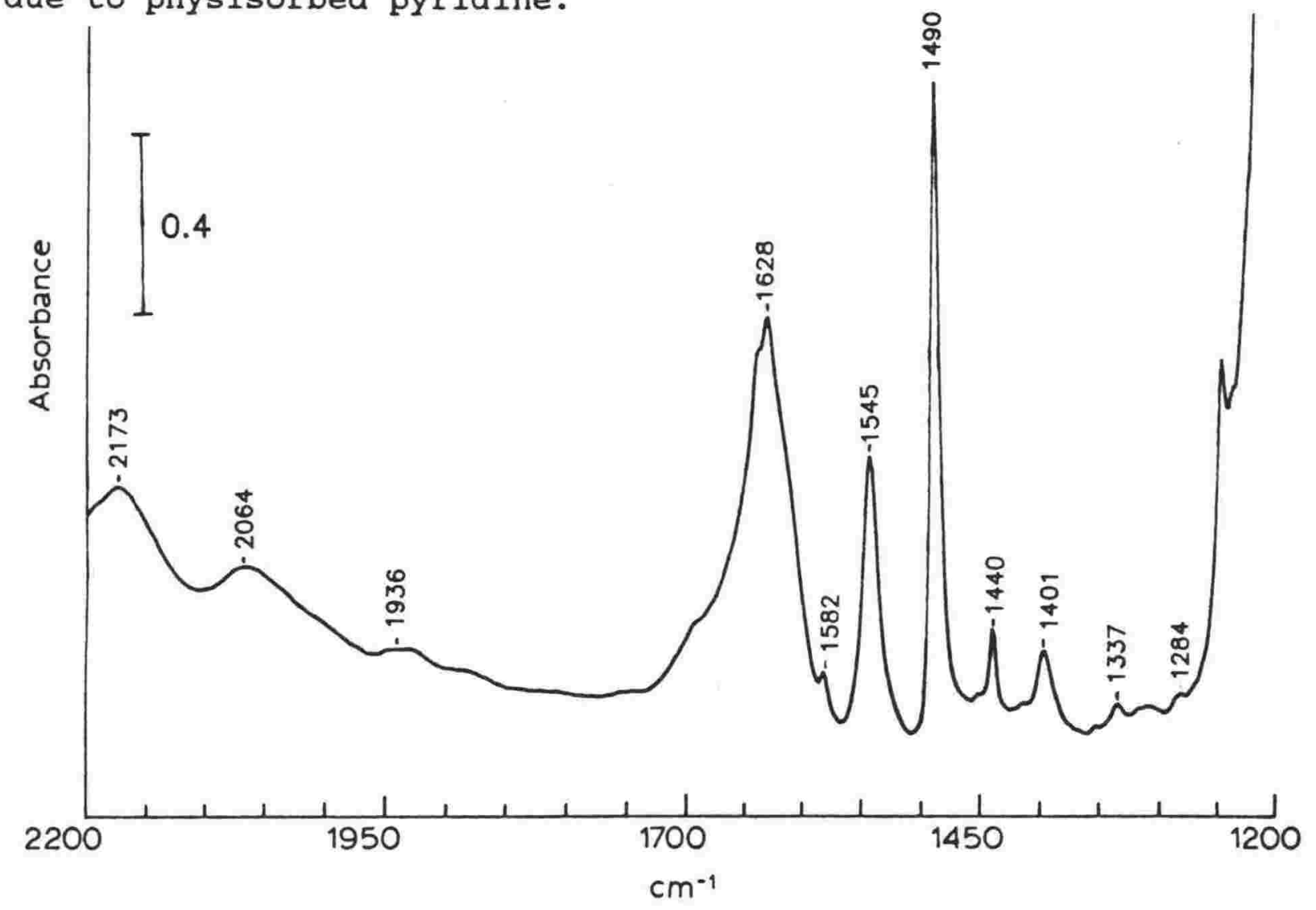

Figure 6.6. Pyridine sorbed on $\mathrm{H}+\mathrm{Y}$ at $25^{\circ} \mathrm{C}$, with the $\mathrm{LF}$ and HF hydroxyls bonded but little physisorbed pyridine present. 
There was only a small peak at $1440 \mathrm{~cm}^{-1}$ showing that very little physisorbed pyridine was present. As more pyridine was added the peaks at 1440 and $1582 \mathrm{~cm}^{-1}$ increased markedly due to the increase in physisorbed pyridine. Therefore pyridine sorbed at the LF hydroxyls is associated in a different manner from physisorbed pyridine. It is probably protonated to some degree. The difficulty in avoiding the presence of physisorbed pyridine was probably the reason for earlier conclusions that the pyridine bonded to the LF hydroxyls was physisorbed.

A comparison of the spectra in figures $6.3 \mathrm{~A}, 6.5$ and 6.6 shows major differences in the pyridine ring stretching and bending region between pyridine that is physisorbed, sorbed on LF hydroxyls and sorbed on HF hydroxyls. Information on the different modes of bonding is contained in these spectra, but a detailed analysis is required to obtain this.

\subsubsection{Thermal desorption of pyridine:}

Further pyridine was sorbed at $50^{\circ} \mathrm{C}$ on the sample after H/D exchange (figure $6.2 \mathrm{~B}$ ) to obtain the spectrum in figure $6.7 \mathrm{~A}$. This sample was then heated at $10^{\circ} \mathrm{C} / \mathrm{min}$. Pyridine desorbed from the LF hydroxyls (both $\mathrm{OH}$ and OD) by $200^{\circ} \mathrm{C}$, almost completely restoring their intensity (figure 6.7B). The HF hydroxyls were still almost completely bonded. When $400^{\circ} \mathrm{C}$ was reached (figure $6.7 \mathrm{C}$ ), the intensity of the HF hydroxyls was about half that of the LF hydroxyls, with some pyridine still sorbed. At $500^{\circ} \mathrm{C}$ (figure 6.7D) most of the pyridine had desorbed, but the intensities of the HF and LF hydroxyls were very much reduced to about one seventh of their original value. A peak of comparable size had also formed in the terminal $\mathrm{siOH}$ region (3738 $\left.\mathrm{cm}^{-1}\right)$, implying that dealumination and a loss of acid sites had occured with removal of the most strongly bound pyridine. 


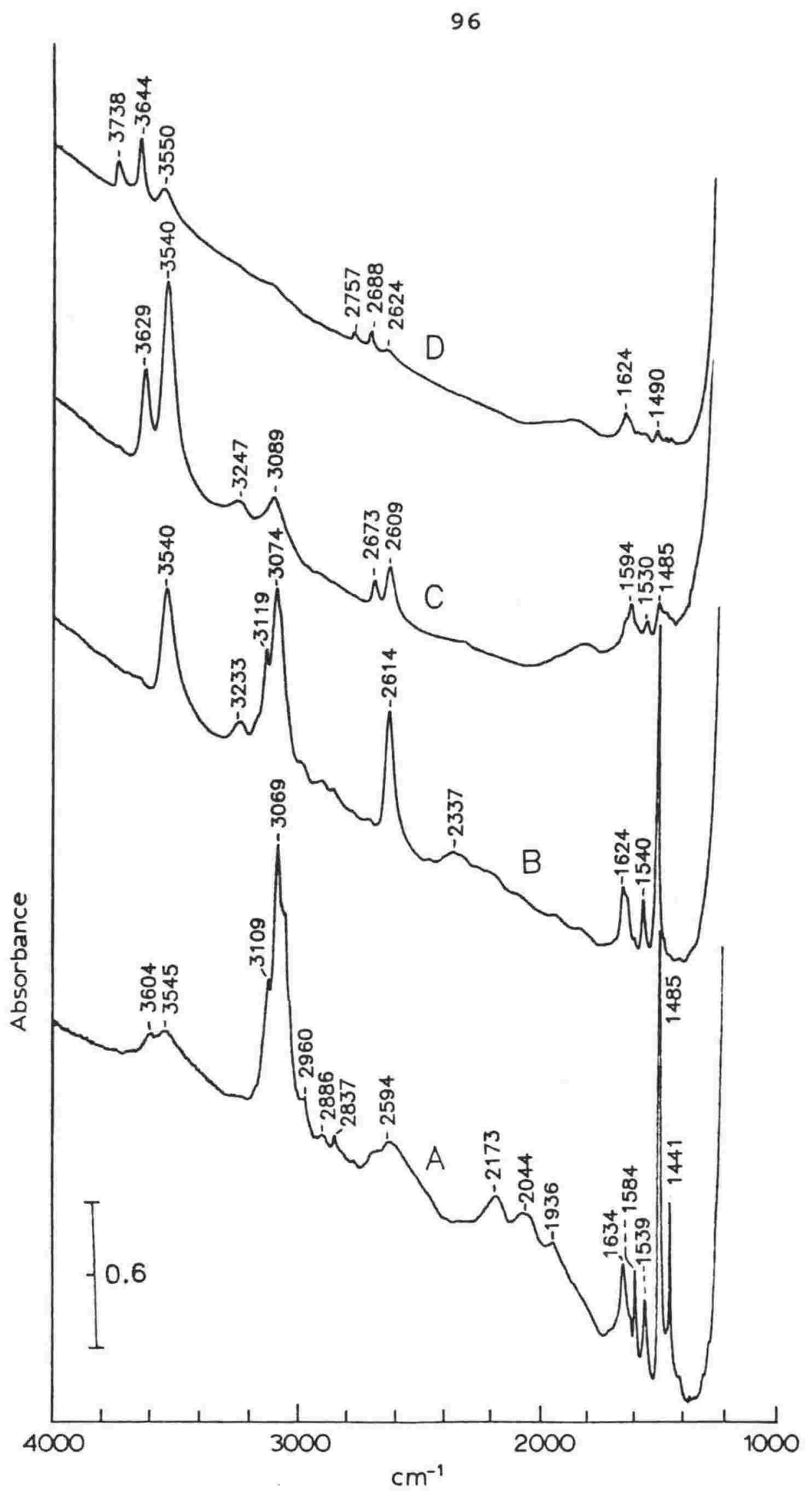

Figure 6.7. FTIR spectra of the thermal desorption of pyridine from $\mathrm{H} / \mathrm{D}+\mathrm{Y}$ heated at $10^{\circ} \mathrm{C} \mathrm{min}^{-1}$. A. at $50^{\circ} \mathrm{C} ; \mathrm{B}$. at $200^{\circ} \mathrm{C} ; \mathrm{C}$. at $400^{\circ} \mathrm{C}$ and $\mathrm{D}$. at $500^{\circ} \mathrm{C}$. 
If the appearance of the silanol hydroxyl indicates the loss of strong acid sites, then dehydroxylation only occured upon desorption of the most strongly bound pyridine from the HF hydroxyls. Sorption and desorption of pyridine from the LF and some HF hydroxyl sites is therefore reversible. This is in contrast to the results obtained by Jacobs et al. (3). Their attempt at quantifying the intensities of the $0-\mathrm{H}$ and $\mathrm{N}-\mathrm{H}$ peaks may have been affected by the appearance of the broad hydroxyl band upon pyridine sorption. This would have reduced the intensities of the $\mathrm{O}-\mathrm{H}$ and $\mathrm{N}-\mathrm{H}$ peaks and, if not accounted for, given the appearance that dehydroxylation had occured.

\subsection{Discussion:}

These results show that pyridine is protonated to some degree by both the HF and LF hydroxyls of $\mathrm{H}+\mathrm{Y}$. The LF hydroxyls have a much lower affinity for pyridine than the HF hydroxyls.

Interaction of pyridine with the LF hydroxyls, which are normally oriented into the sodalite cage, is difficult as it is a large molecule and cannot fit through the cage openings. This interaction may occur by pyridine interacting with the sodalite cage framework, (as does water (von Ballmoos (9))) temporarily creating an opening large enough for it to gain access into the cavity. Once inside, a more stable protonated pyridine complex would form than with the HF hydroxyls, as, from their frequency, LF hydroxyls have a higher acidity. This would mean that pyridine desorption from the LF hydroxyls should occur at higher temperatures than the HF hydroxyls, so this explanation does not appear to be feasible.

A possible alternative is that the LF hydroxyls reorient themselves into a position of higher energy facing outside the sodalite cage as the pyridine molecules approach. Protonation occurs, stabilising the complex. However, with increased temperature and thermal motion of the pyridine (hopping from one hydroxyl to another) the LF hydroxyls are 
not bonded for sufficient time to stabilise the complex and the LF hydroxyls reorientate themselves to the lower energy position, facing inside the sodalite cage. The pyridine has then effectively desorbed.

\subsection{2 "Wrecked" H+Y + pyridine:}

Pyridine was sorbed onto $\mathrm{H}+\mathrm{Y}$ which had undergone loss of Bronsted sites and structural collapse during desorption of water. The sample was that shown in figure 5.1C. Very little pyridine was sorbed onto the sample held at $100^{\circ} \mathrm{C}$, as shown in figure 6.8. An expanded version from 220 to 1200 $\mathrm{cm}^{-1}$ is shown in figure 6.9. There was a small amount of physisorbed pyridine (characterised by the peak at $1440 \mathrm{~cm}^{-1}$ ), a small amount of Lewis sorbed pyridine $\left(1452 \mathrm{~cm}^{-1}\right)$ and a smaller amount of Bronsted sorbed pyridine $\left(1542 \mathrm{~cm}^{-1}\right)$.

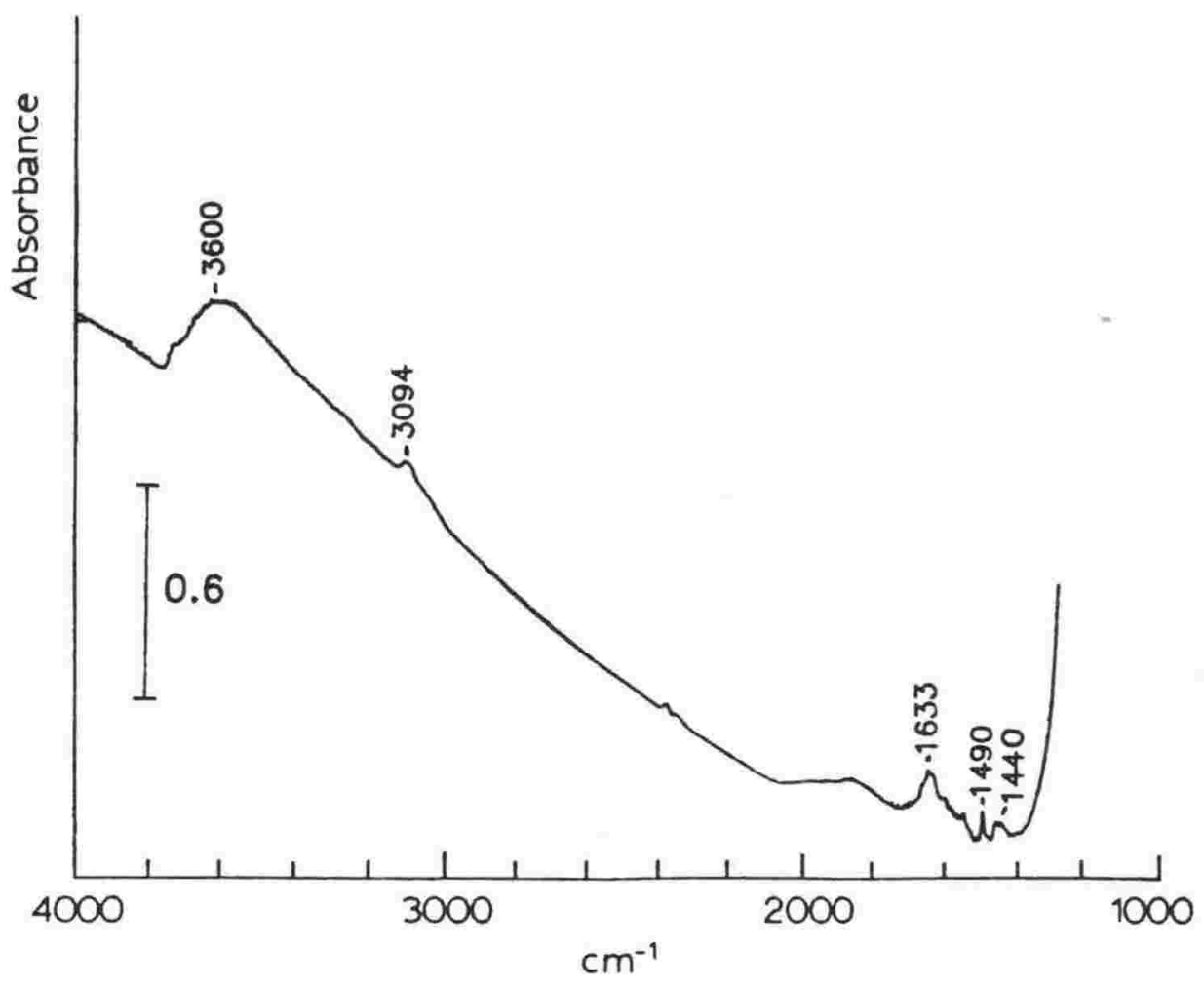

Figure 6.8. FTIR spectra of pyridine sorbed on "wrecked" $\mathrm{H}+\mathrm{Y}$ held at $100^{\circ} \mathrm{C}$. 


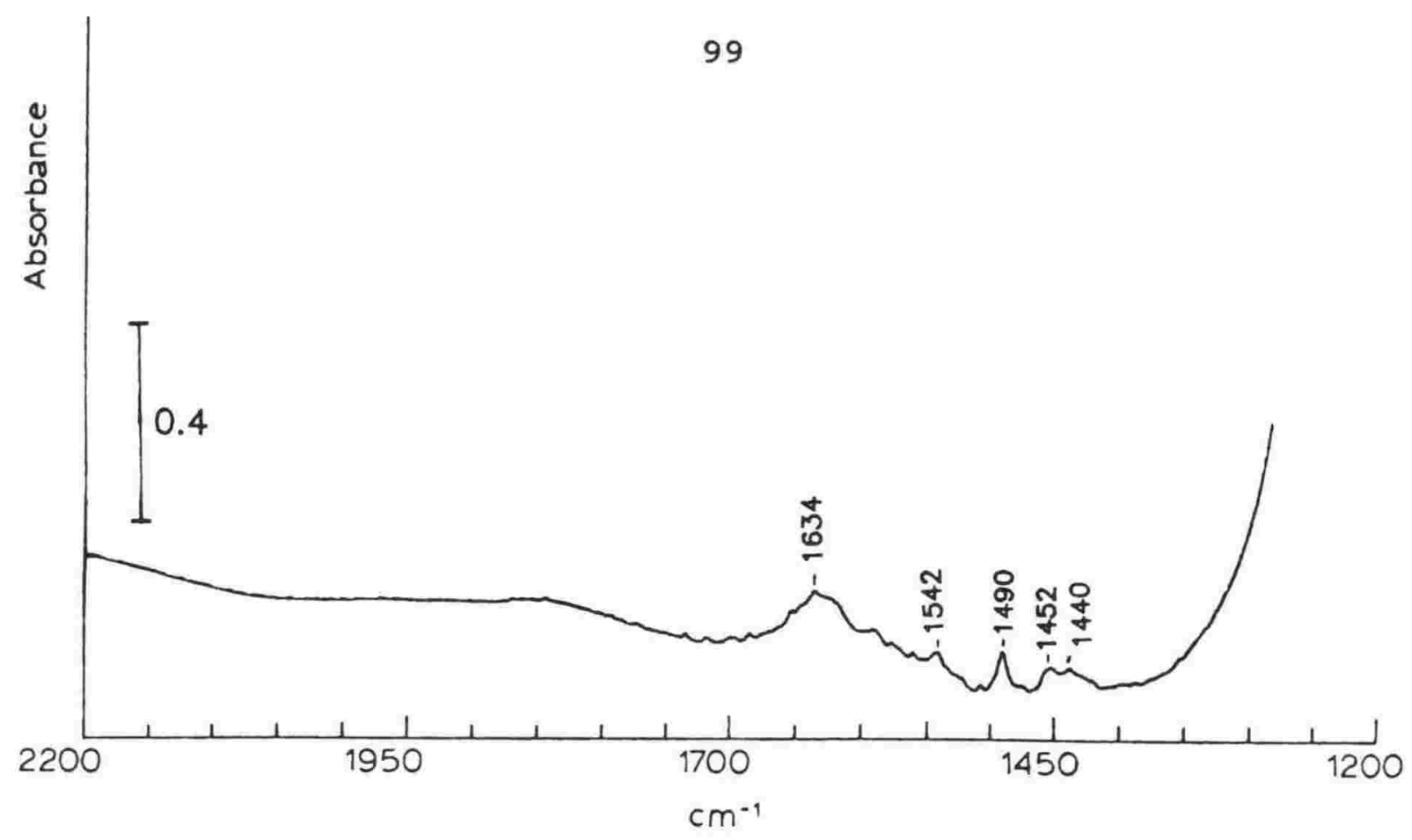

Figure 6.9. Expanded FTIR spectrum of pyridine sorbed on "wrecked" $\mathrm{H}+\mathrm{Y}$.

\subsection{CONCLUSIONS:}

Three modes of sorption were observed for pyridine on $\mathrm{H}+\mathrm{Y}$ physisorbed, sorbed on the LF hydroxyls and sorbed on the HF hydroxyls. Major differences between these species were observed in the ring bending and stretching region of the FTIR spectra.

Physisorbed pyridine was the most weakly sorbed, then pyridine bonded to the LF hydroxyls. Reversible sorption/ desorption of pyridine occured in both cases. Most strongly bound was pyridine associated with the HF hydroxyls. Complete desorption of the pyridine resulted in destruction of the zeolite.

It is proposed here that both the LF and HF hydroxyls protonate, to differing degrees, the pyridine. Reorientation of the LF hydroxyls to outside the sodalite cage is required for bonding to occur. The energy required to do this would result in a lower bond energy and a lower affinity for pyridine. H/D exchange showed that the Bronsted protons associated with HF hydroxyls had a broad band of energies from $\sim 3600$ to $\sim 2600 \mathrm{~cm}^{-1}$ with a maximum at $\sim 3090 \mathrm{~cm}^{-1}$. 


\section{6 REFERENCES:}

1. Basila M.R., Kantner T.R. and Rhee K.H., J. Phys. Chem., $1964,68,3197$.

2. Zerbi G., Crawford B. and overend J., J. Chem. Phys., $1963,38,127$.

3. Jacobs P.B., Theng B.K.G. and Uytterhoeven J.B., J. Catal., 1972, 26, 191.

4. Jacobs P.A. and Uytterhoeven J.B., J. Catal., 1972, 26, 175.

5. Ward .W., Advances in Chemistry Series 101, Gould R.F., Editor, ACS, 1971, 380.

6. Ward J.W., J. Catal., 1968, 11, 259.

7. Sohn J.R., DeCanio S.J., Fritz P.O. and Lunsford J.H,

J. Phys. Chem., 1986, 90, 4847.

8. Rauscher H.J., Michel D. and Pfeifer H., J. Molecular Catalysis, 1981, 12, 159.

9. von Ballmoos R., Meier W.M., J. Phys. Chem., 1982, 86, 2698. 


\section{CHAPTER 7: Bases sorbed on H+ZSM-5 - a study of hydrogen bonding.}

A correlation of the extent of hydrogen bonding with the proton affinity of the sorbed base.

\subsection{INTRODUCTION:}

Zeolites in which the compensating cation is a proton are known to be strong Bronsted acids, even though a quantitiative measurement of acid strength has not been obtained. Molecules which are strongly sorbed into the zeolite are therefore likely to be protonated. The extent of protonation will depend on the base strength of the sorbant and the acid strength of the zeolite. Figure 7.1 shows the range of cases possible.

$$
\mathrm{Z}-\mathrm{H} \ldots \mathrm{B} \quad \mathrm{Z}^{\delta-} \ldots \mathrm{H}^{\delta+} \ldots \mathrm{B} \quad \mathrm{Z}^{-} \ldots \mathrm{H}^{+}-\mathrm{B}
$$

Figure 7.1. Variations in the extent of proton transfer from an acid zeolite $(\mathrm{Z}-\mathrm{H})$ towards a base (B).

Proton transfer will vary from only slight transfer of the Bronsted proton to the base for weak bases on a zeolite (figure $7.1 \mathrm{I}$ ), to equal sharing of the proton (figure 7.1 II), to almost complete transfer of the proton to the base with the formation of an ion pair (figure 7.1 III), for very strong bases.

For a range of bases sorbed on a zeolite the acid strength of the zeolite is constant and the extent of proton transfer will depend on the proton affinity of the base. 
102 
"Protonation" as defined here is equivalent to the term "hydrogen bonding". Some authors define the term

"protonated" as complete proton transfer (figure 7.1 III), but its use here has been widened to cover the range of proton transfer possibilities.

A quantitive measure of base strength is the proton affinity (PA) which, for a molecule $B$, is defined as the negative enthalpy of the reaction (7.1):

$\mathrm{B}+\mathrm{H}^{+} \rightarrow \mathrm{BH}^{+}$

Proton affinities have been determined from gas phase equilibria:

$\mathrm{B}_{1} \mathrm{H}^{+}+\mathrm{B}_{2} \rightleftharpoons \mathrm{B}_{1}+\mathrm{B}_{2} \mathrm{H}^{+}$

in which the proton tends to be associated with the molecule which has the highest proton affinity. The advantage of using proton affinities is that they are determined in the gas phase and are therefore free from complicating solvation effects which are associated with the pKa scale.

The proton affinities used in this work were taken from a compiliation by Lias et al. (2) who attempted to give a complete, internally consistent set of values. They used the vast body of data generated by equilibrium constant measurements up to 1984, and assigned absolute values using primary standards such as ketene, water and carbon dioxide, whose proton affinities could be calculated from thermochemistry.

When bases are sorbed on $\mathrm{H}+2 \mathrm{SM}-5$ the IR Bronsted hydroxyl peak at $3610 \mathrm{~cm}^{-1}$ shifts to lower wavenumber and broadens. This is presumably due to proton transfer to the base, the extent of the shift depending on the strength of the base. Jacobs and Martens (3) state that the most promising 
technique to determine the strength of Bronsted acid sites "consists in the measurement of the oH frequency shifts upon interaction with hydrogen-bond acceptor molecules".

This technique has been used earlier by Rouhext and sempels in 1974 (4) to obtain an estimate of the hydroxyl acid strengths in silica-alumina. They compared the $0-\mathrm{H}$ frequency shifts, $\Delta v_{\mathrm{O}_{\mathrm{H}}}$, of two hydrogen bond donors $\mathrm{R}-\mathrm{XH}$ and $\mathrm{R}^{\prime}-\mathrm{X}^{\prime} \mathrm{H}$ interacting with various acceptors (eg $\mathrm{H}$ donors such as silica gel and phenol interacting with benzene and acetronitrile). A plot of $\Delta v / v_{0}$ for one donor versus $\left(\Delta v / v_{0}\right)$ ' for the other donor is linear with the slope (termed the "BHW slope") giving an estimate of the hydrogen bond strength of $\mathrm{R}-\mathrm{XH}$ compared to $\mathrm{R}^{\prime}-\mathrm{X}^{\prime} \mathrm{H}$. A wide range of data for (mainly) organic compounds was collected from the literature and a linear correlation of this slope versus the pKa of the proton donors obtained (figure 7.2).

The IR spectra (Rouxhet and Semples (4) obtained for benzene and acetonitrile sorbed on silica-alumina ( 0 - $50 \%$ alumina) are shown in figure 7.3 . Only one $0-\mathrm{H}$ peak was observed until sorbant was added. At "large amounts" of sorbant it was stated (4) that "two peaks were observed in the bonded hydroxyl region". This is clear for spectrum c for benzene sorption, but not for acetonitrile. The first peak was assigned (4) to sorbant bonded to $\mathrm{Si}-\mathrm{OH}$ and the second peak to sorbant on a stronger type of acid site, as it was not observed for the pure silica case. The correlation of BHW slope versus pKa was extrapolated to give an estimated pKa of between -4 to -8 for the stronger acid sites of silicaalumina.

The extrapolation of a log plot results in an inaccurate measure of the acid strength and the validity of the extrapolation has not been proven. There are two other faults with this work. The first is that the samples appeared to be contaminated with vacuum pump oil (IR band due 


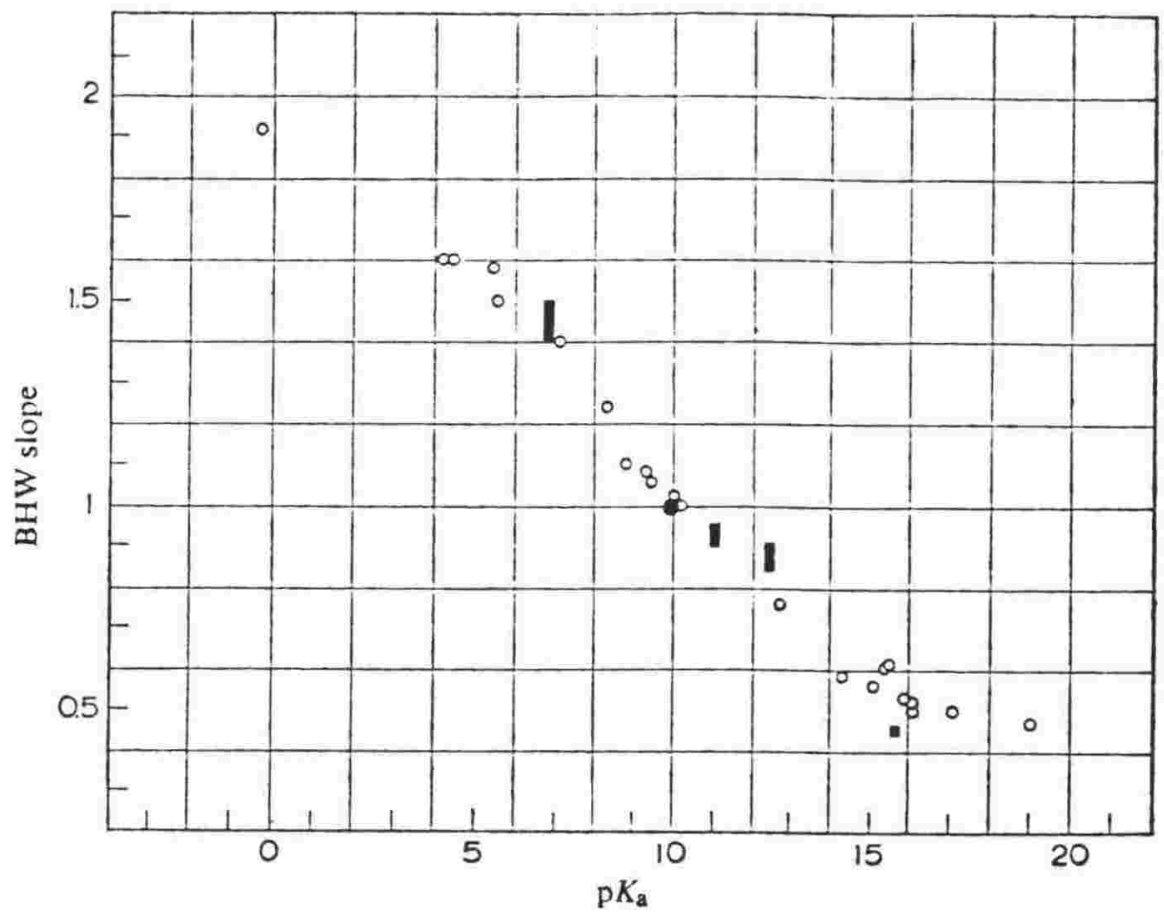

-Correlation between BHW slope and the $\mathrm{p} K_{\mathrm{a}}$ of various proton donors with $\mathrm{OH}$ as the active group. phenol and $p$-fluorophenol (references for the BHW slope); $O$, molecules with $\mathrm{OH}$ attached to a carbon atom (alcohols, phenols, organic acids); $\mathbf{\square}$, water, acetoxime, trimethylFigure 7.2 from (4). silanol, silica gel.

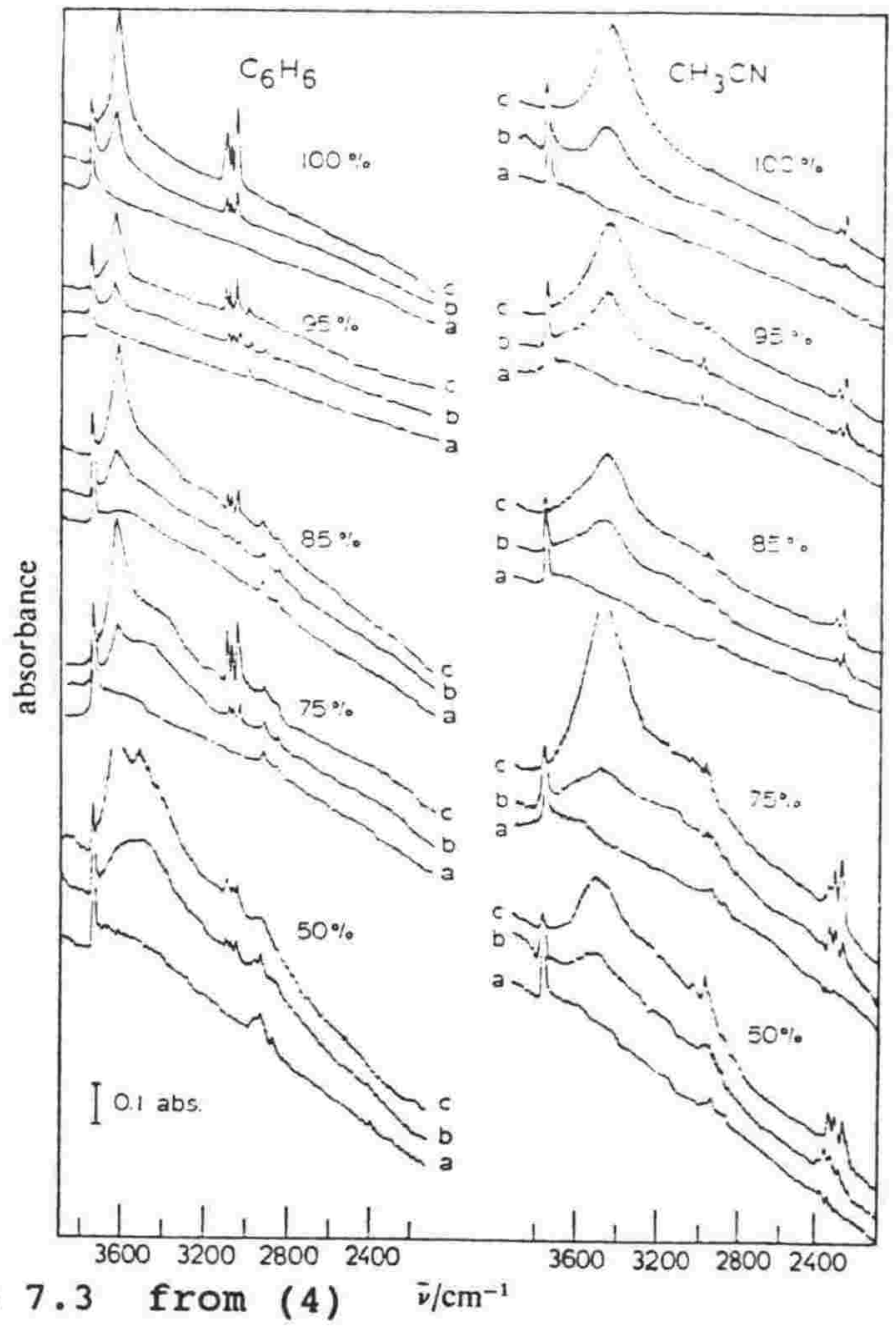

Figure 7.3 from (4) $\quad \bar{\nu} / \mathrm{cm}^{-1}$

-Spectra of silica-alumina gels containing approximately the indicated $\%$ of $\mathrm{SiO}_{2}: a$, before adsorption ; $b$, with a small amount of adsorbate; $c$, with a large amount of benzene or acetonitrile adsorbed. 
to $\mathrm{C}-\mathrm{H}$ stretching at $\sim 2900 \mathrm{~cm}^{-1}$ ) which may have interacted with the acid sites. The second is that the "stronger acid sites" only became apparent with "large amounts" (actual amount not stated) of sorbant. It is possible that the second peak may therefore be due to weakly bound sorbant, perhaps in a second coordination shell around the acid site. For example, similar second and even third peaks are observed for $\mathrm{NH}_{3}$ sorbed on $\mathrm{H}+\mathrm{ZSM}-5$ in amounts in excess of one $\mathrm{NH}_{3}$ per acid site (see 7.4.1). This $\mathrm{NH}_{3}$ is only weakly sorbed, desorbing by $100^{\circ} \mathrm{C}$. This means that their assignment (14) of the second bonded hydroxyl peak to sorbant on strong acid sites may not be correct and the correlation would therefore be invalid.

The work of Rouxhet and Sempels (4) was extended in 1983 to give an evaluation of the acidity of the hydroxyl groups in zeolites $\operatorname{HNaX}$ ( $80 \%$ decationized) and HNaY (49\% decationized) by Mailer et al. (5). The frequency shift of the zeolite hydroxyl upon sorption of various bases was compared to the corresponding frequency shift for silica gel, as shown in figure 7.4 .

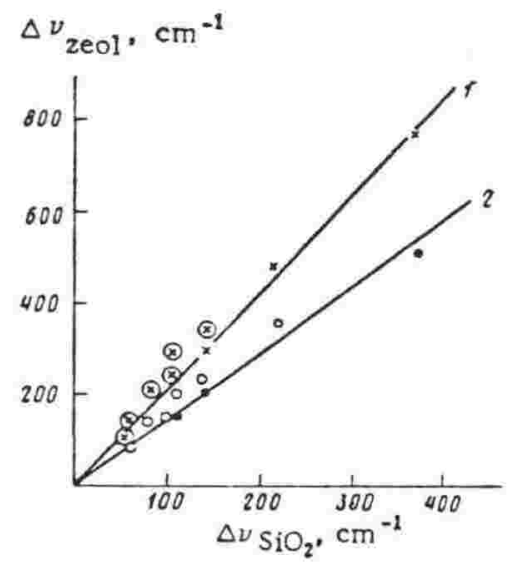

Frequency shift of OH group stretching vibrations in zeolites $Y(1)$ and $X(2)$ upon formation of H-complexes with adsorbed molecules, as a function of corresponding shift for $\mathrm{OH}$ groups of sillca gel.

Fig 7.4 from (5).

The lower slope of the line for HNaX is consistent with the theory (5) that the hydroxyl groups of this zeolite have a lower acidity than those of HNaY. Using the published 
correlation of BHW slope versus pKa (4) they obtained pKa values for the hydroxyl groups of the $X$ and $Y$ zeolites as 0 and -8 respectively. No discussion was given of the accuracy of these values or the possible errors.

An alternative, simpler correlation is proposed here. The extent of the hydroxyl shift upon sorption of a base should show a correlation with the proton affinity of the sorbed base. This could lead to a quantitative determination of zeolite acid strength by a comparison with similar work for simple, strong inorganic acids such as $\mathrm{HCl}$ and $\mathrm{HBr}$.

The extent of proton transfer from the acids $\mathrm{HCl}$ and $\mathrm{HBr}$ towards a range of bases has been studied by Pimentel et al. (6). One-to-one hydrogen bonded complexes were isolated in a nitrogen matrix at $15 \mathrm{~K}$. For each acid the shift in the proton stretching frequency $\left(v_{s}\right)$ depended systematically, though not linearly, on the proton affinity of the base. Figure 7.5 is taken from this work and shows that a minimum proton stretching frequency is obtained.

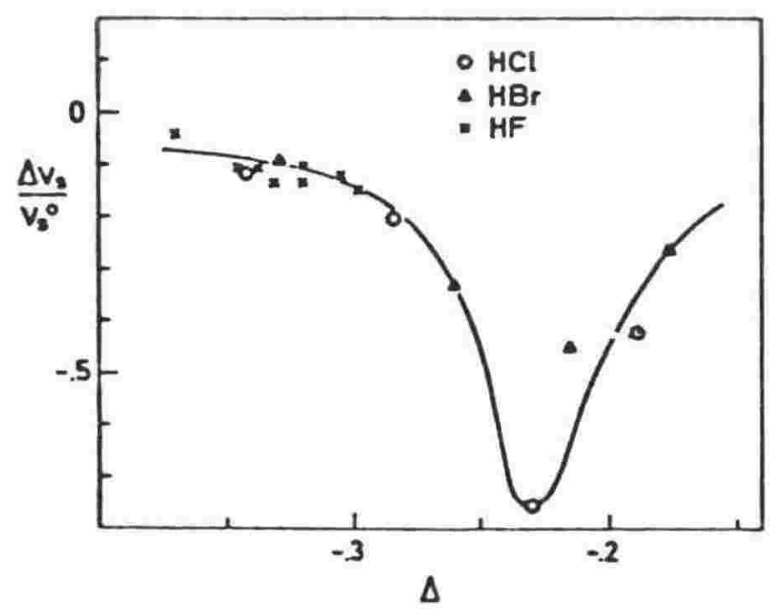

\footnotetext{
A plot of $\Delta v_{\mathrm{s}} / \nu_{\mathrm{s}}$ vs. $\Delta$ for a series of hydrogen bonds, $\Delta=$ $\left(\mathrm{PA}(\mathrm{B})-\mathrm{PA}\left(\mathrm{A}^{-}\right)\right) /\left(\mathrm{PA}(\mathrm{B})+\mathrm{PA}\left(\mathrm{A}^{-}\right)\right)$.
}

Figure 7.5 from (6).

This is explained in terms of the three types of hydrogen bonding situations (I, II and III in figure 7.1 where $z$ is now an acid (A)). "When an acid forms a hydrogen bond to a base $\mathrm{A}-\mathrm{H} \ldots \mathrm{B}, \mathrm{U}_{\mathrm{s}}$ is lowered and the $\mathrm{A}-\mathrm{H}$ distance increases relative to the isolated $\mathrm{A}-\mathrm{H}$ molecule. If the base strength is increased, the frequency continues to decrease and the $\mathrm{A}-\mathrm{H}$ 
distance to increase until the proton can no longer be said to be preferentially associated with A (a type II complex). Further increase of base strength, then, will draw the proton close enough to become strongly associated with $B$, causing $U_{s}$ to rise again, approaching the limiting frequency of the isolated ion $\mathrm{HB}^{+}$. Of course, the base strength (proton affinity) of $B$ needed for proton transfer from an acid $\mathrm{A}-\mathrm{H}$ will also depend upon the base strength of the conjugate base, $A^{-}$. Hence, proton transfer in a hydrogen bond should depend systematically upon the difference between the proton affinities of $B$ and $A^{-1}(6)$.

other IR studies of hydrogen bonding have been carried out on liquid and solid complexes of mainly organic acids and bases. In 1966 Hadzi and Kobilarov (7) studied the IR spectra of liquid adducts of carboxylic acids with sulphoxides, phosphine oxides and other bases to determine the effect of increasing strength of the hydrogen bond on the spectra. They found two distinct types of spectra:

(i) when the region 1800 to $3000 \mathrm{~cm}^{-1}$ contains three broad bands connected with $\mathrm{O}-\mathrm{H}$ vibration and

(ii) no bands in the 1800 to $3000 \mathrm{~cm}^{-1}$ region, but a strong, broad feature at lower frequencies. Intermediate cases between (i) and (ii) were also observed.

No completely satisfactory explanation was given for the three broad bands (type (i)), although it was suggested that an explanation may be obtained by the use of "a complex and very anharmonic potential surface, instead of vibrations in one dimension". Type (ii) spectra were ascribed to complexes in which the proton was equally shared (type II complex).

Zundel and co-workers $(8,9,10,11)$ have studied symmetrical hydrogen bonded complexes in detail. They showed that continuum (type (ii) spectra) are observed over a relatively large $\Delta \mathrm{pKa}$ (between acid and base) region of $\sim 2.5 \mathrm{pKa}$ units around the $\Delta \mathrm{pKa}$ required for $50 \%$ proton transfer. They ascribe this to the hydrogen bond becoming easily polarisable 
due to a potential energy curve for the proton having two minima, but a low barrier for proton transfer. The broad absorption arises from electric field fluctuations in the environment, leading to a broadening of tunnel transition levels.

Sobsyzk et al. studied (12) a series of crystalline pentachlorophenol-amine complexes and 2,6 dichlorophenols and oxygen bases (13). Figure 7.6 shows the variation in protonic absorption bands with increasing $\Delta \mathrm{pKa}$ (from (12)). They suggest that formation of a continuum may result from the "modulation of bridge length as a result of coupling by low frequency bridge vibrations", and emphasise the importance of the shape of the proton potential motion.

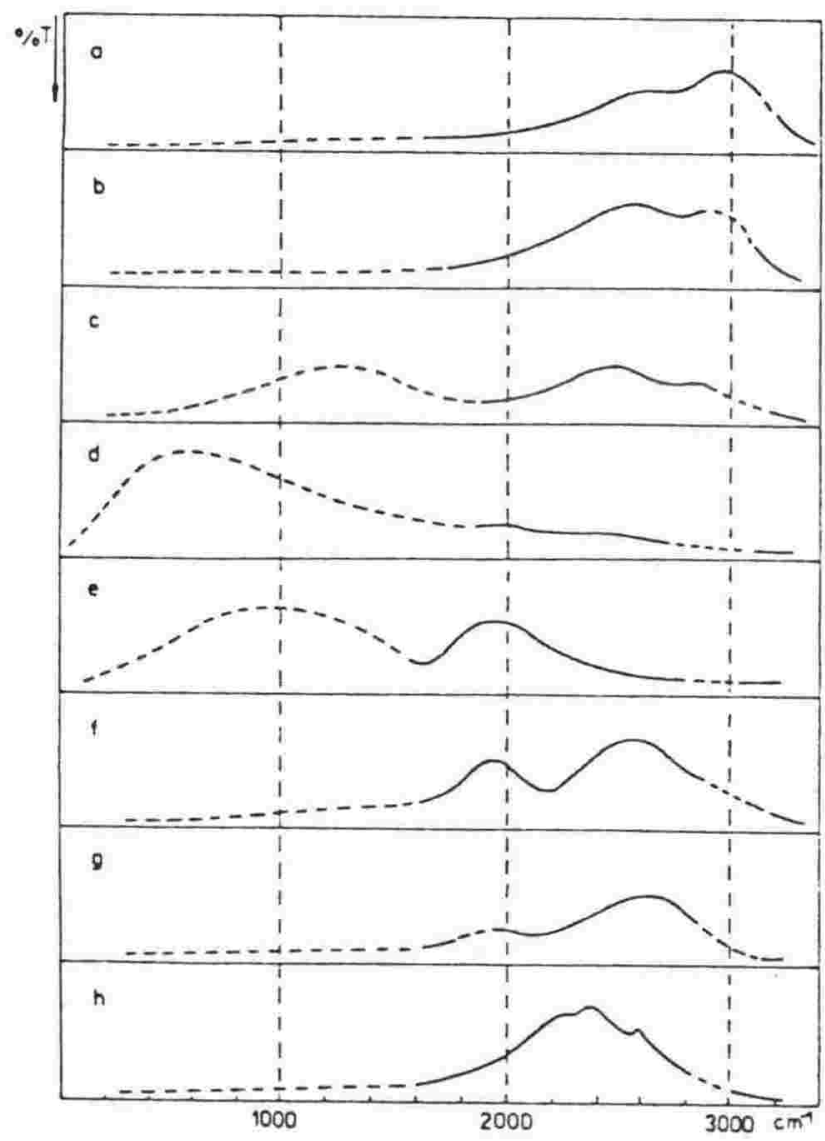

Evolution of protonic absorption bands on increasing the $\triangle \mathrm{pK}$ a value for pentachlorophenolates of (a) pyrazine, (b) 4-acetylpyridine, (c) isoquinoline, (d) 4-methylpyridine, (e) $\mathrm{N}$-methyimorpholine, (f) imidazole, (g) 4-(N,N-dimethylamino)pyridine, and (h) triethylamine, in $\mathrm{KBr}$.

Figure 7.6 from (12). 
A range of bases sorbed on $\mathrm{H}+2 \mathrm{SM}-5$ have been studied in an attempt to determine a correlation of $\Delta v_{O_{H}}$ with base proton affinity. It was found that different sorbants showed different hydrogen bonding characteristics. These were divided into three classes - A, B and C. Class A sorbants showed a single, shifted hydroxyl band with the possibility of a correlation of $\Delta v_{O-H}$ with proton affinity. Class $B$ sorbants showed a single, very flat, broad band. Class C sorbants showed broad, multiple hydroxyl bands similar to those observed in other hydrogen bonded complexes (references 7 to 12 ). Sorbants with a wide range of proton affinities were studied to determine the importance of the extent of proton transfer from acid to base on the type of hydrogen bonded spectrum observed. The results are presented with the sorbants grouped into these classes and not in the order in which they were studied. Summaries of previous literature results are included for each sorbant type. 


\subsection{CLASS A SORBANT8:}

\subsubsection{Alcohols sorbed on H+ZSM-5:}

\subsubsection{A Introduction:}

Gorte and coworkers have studied the sorption of alcohols on H+ZSM-5 over a number of years $(14,15,16,17)$ by tga, tpd and FTIR. This work is summarised and expanded in their most recent paper (17). Tga work (16) showed that after removal of physisorbed alcohol, the remaining alcohol is associated on a 1:1 basis with the number of Al sites. Methanol, ethanol and 1-propanol remain unreacted up to their desorption temperatures. FTIR spectra show that only the $\mathrm{O}-\mathrm{H}$ frequencies have been altered significantly upon sorption, the $\mathrm{C}-\mathrm{H}$ stretches are similar to that of the free alcohols. Addition of $\mathrm{D}_{2} \mathrm{O}$ to these sorbed species resulted in exchange of the $\mathrm{OH}$ to $\mathrm{OD}$ but no exchange of $\mathrm{CH}$ for $\mathrm{CD}$. This shows that only the hydroxyl group of the alcohol interacts with the zeolite acid sites. Gorte et al. (17) concluded that the primary interaction between the alcohols and the zeolite is due to proton transfer at the Al sites, and pictured the adsorbed species as ion pairs.

The work carried out for this thesis was carried out prior to publication of their 1987 paper (17) and the results found here are consistent with their conclusions, although only a partial transfer of the Bronsted proton to the alcohol is proposed.

In contrast with the above work, Forester and Howe (18) concluded from their insitu FTIR study of methanol on $\mathrm{H}+\mathrm{ZSM}-5$ that, above $100^{\circ} \mathrm{C}$, methanol was not protonated by the zeolite, but had reacted with the surface $\mathrm{SiOH}$ groups to form methoxy $\left(\mathrm{Si}-\mathrm{OCH}_{3}\right)$. At temperatures greater than $250^{\circ} \mathrm{C}$ additional peaks were observed and attributed to a second type of methoxy group formed at the Bronsted acid sites. The spectrum of sorbed methanol at $<250^{\circ} \mathrm{C}$ observed by Forester and Howe $(18,19)$ (peaks at 2959,2855 and $1470 \mathrm{~cm}^{-1}$ ) was very similar to that observed by Gorte et al. (17) (2960, 2860 and 
$1455 \mathrm{~cm}^{-1}$ ) assigned (17) to protonated methanol. However, Forester and Howe (18) concluded that the interaction did not involve hydrogen bonding as they had not observed a new $\mathrm{O}-\mathrm{H}$ band.

In this work a broad, shifted $\mathrm{O}-\mathrm{H}$ peak is observed in the spectrum of methanol sorbed on $\mathrm{H}+\mathrm{ZSM}-5$ (figure 7.8B). However, it is an artifact of the difference spectrum (spectrum of methanol on $\mathrm{H}+\mathrm{ZSM}-5$ - spectrum of $\mathrm{H}+\mathrm{ZSM}-5$ ) that sometimes this $\mathrm{O}-\mathrm{H}$ band is not apparent in the difference spectrum (figure $7.8 \mathrm{C}$ ). For this reason the difference spectrum presented by Forester (19) (figure 7.7) does not show a shifted $\mathrm{O}-\mathrm{H}$ peak. The difference spectrum of methanol on $\mathrm{H}+$ mordenite (figure 8.1 ) also shows no shifted $\mathrm{O}-\mathrm{H}$ peak. Forester and Howe showed only the difference spectrum, so the hydroxyl band was overlooked. It also seems unlikely that methanol would react first with the terminal $\mathrm{sioH}$ groups as these are significantly less reactive than the Bronsted sites, remaining unreacted after sorption of strong bases (for example pyridine).

Therefore the species observed at $<250^{\circ} \mathrm{C}$ is most likely methanol protonated, to some extent, by the Bronsted sites. The second species observed by Forester and Howe (18) at $>250^{\circ} \mathrm{C}$ may be a methoxy species as they showed it to be an active methylating agent and its appearance coincides with that of hydrocarbon reaction products. 


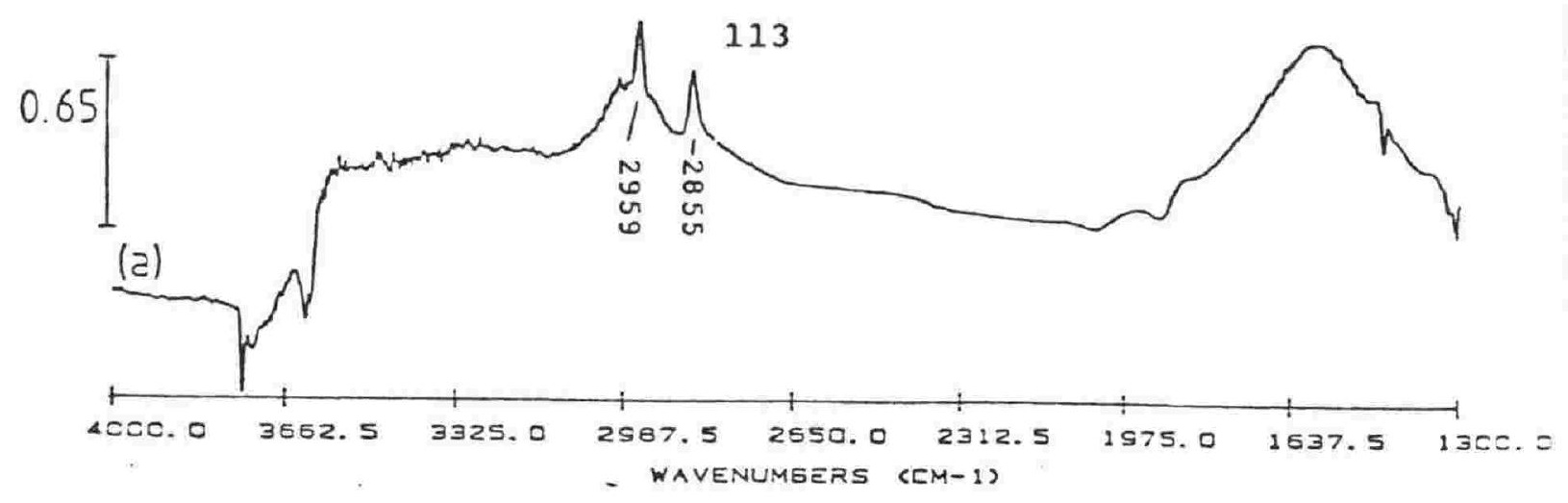

Figure 7.7 FTIR difference spectrum of methanol sorbed on $\mathrm{H}+\mathrm{ZSM}-5$ at $20^{\circ} \mathrm{C}$ from Forester (19).

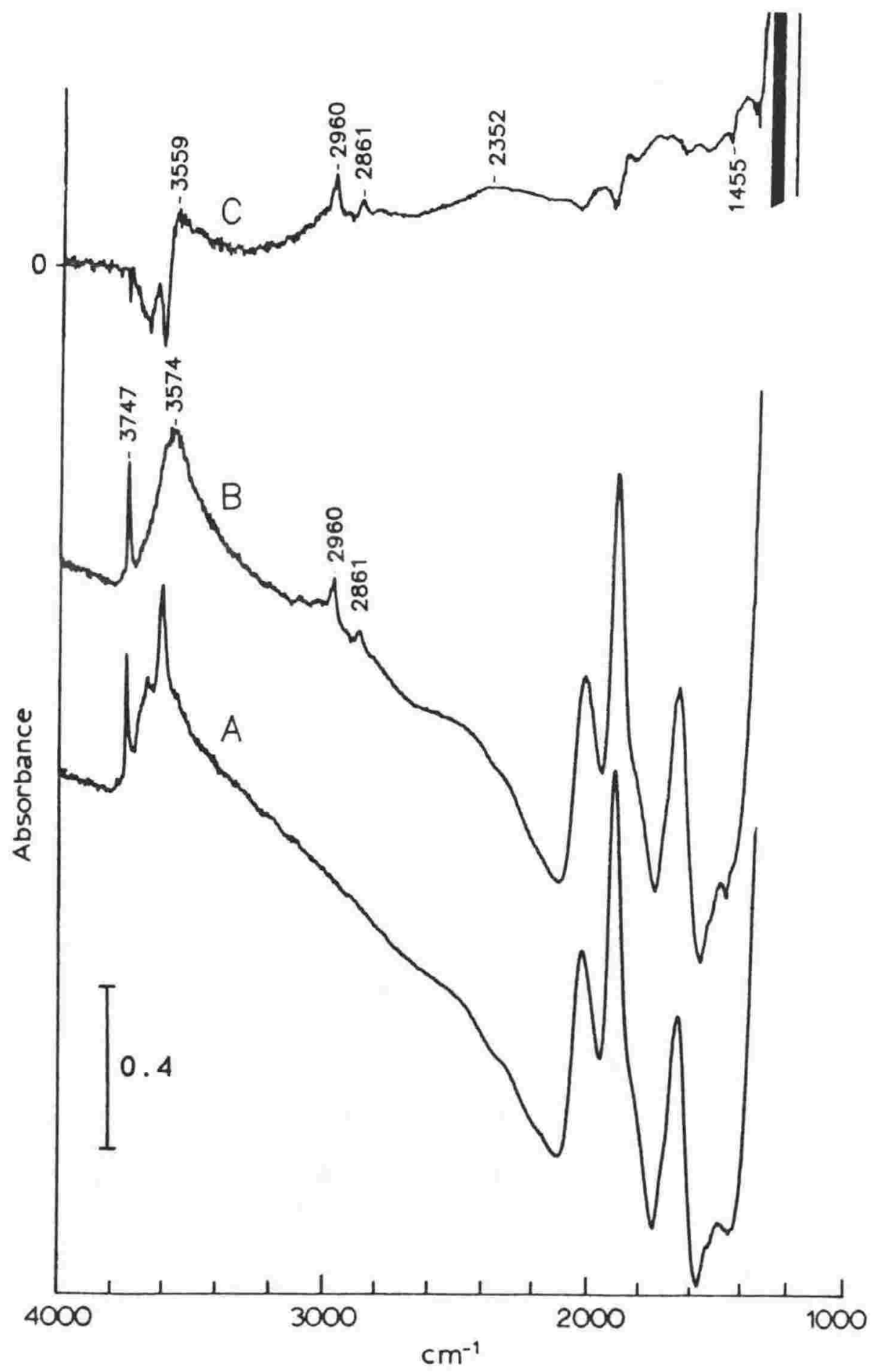

Figure 7.8 FTIR spectra of: A. dry $\mathrm{H}+\mathrm{ZSM}-5$ at $80^{\circ} \mathrm{C}$; $B$. after addition of $5 \mathrm{ml}$ methanol/air and $\mathrm{C}$. the difference spectrum $(B-A)$. 


\subsubsection{B Methanol:}

Source: Univar AR.

The FTIR spectrum of $5 \mathrm{ml}$ methanol/air sorbed on a wafer of dry $\mathrm{H}+\mathrm{ZSM}-5$ held at $80^{\circ} \mathrm{C}$ (figure $7.8 \mathrm{~A}$ ) is shown in figure 7.8B. The sharp Bronsted hydroxyl peak has shifted and broadened and two peaks at 2960 and $2861 \mathrm{~cm}^{-1}$ are apparent. The sioH peak $\left(3747 \mathrm{~cm}^{-1}\right)$ has only decreased slightly, showing a much lower reactivity. The difference spectrum (figure $7.8 \mathrm{C}$ ) shows a sharp negative peak due to loss of Bronsted hydroxyl which partially obscures the new broad hydroxyl peak. The broad bands at $\sim 2900$ and $\sim 2352 \mathrm{~cm}^{-1}$ are not due to sorbed water as no peak at $1620 \mathrm{~cm}^{-1}$ characteristic of sorbed water (see figure 4.3 ) is present. They are also not from sorbed DME as the sharp peak at $1460 \mathrm{~cm}^{-1}$ characteristic of sorbed DME (figure 7.38), is not present.

Sorption of methanol on $\mathrm{D}+\mathrm{ZSM}-5$ held at $100^{\circ} \mathrm{C}$ shows more clearly the increase in size of the shifted $\mathrm{O}-\mathrm{H}$ peak.

spectra obtained with increasing amounts of methanol are shown in figures $7.9 \mathrm{~A}, \mathrm{~B}, \mathrm{C}$ and $\mathrm{D}$ after addition of $0,1,5$, and $10 \mathrm{ml}$ of methanol/air mixture respectively. Methanol is injected into the $\mathrm{N}_{2}$ gas stream which flows through the wafer. Some methanol is only temporarily sorbed, exchanging an $\mathrm{H}$ for $D$ then desorbing. This is shown by the increase in the broad $\mathrm{O}-\mathrm{H}$ band $\left(\sim 3590 \mathrm{~cm}^{-1}\right)$ and decrease in the $\mathrm{O}-\mathrm{D}$ band $\left(\sim 2650 \mathrm{~cm}^{-1}\right)$ as more methanol is added to the cell. No C-D stretches were observed, therefore no H/D exchange into the methyl group occured.

The SiOD peak (at $2757 \mathrm{~cm}^{-1}$ ) exchanged with the methanol $\mathrm{O}-\mathrm{H}$, but at a much slower rate than the Bronsted O-Ds. After most of the Bronsted O-D had exchanged (figure 7.9D) about half the SiOD peak remained. The difference spectrum between figure $7.9 \mathrm{C}$ and $7.9 \mathrm{~A}$ (figure $7.9 \mathrm{E}$ ) shows clearly the loss in Bronsted $O-D$ (and some SiOD) and increase in bonded Bronsted $\mathrm{O}-\mathrm{H}$. 


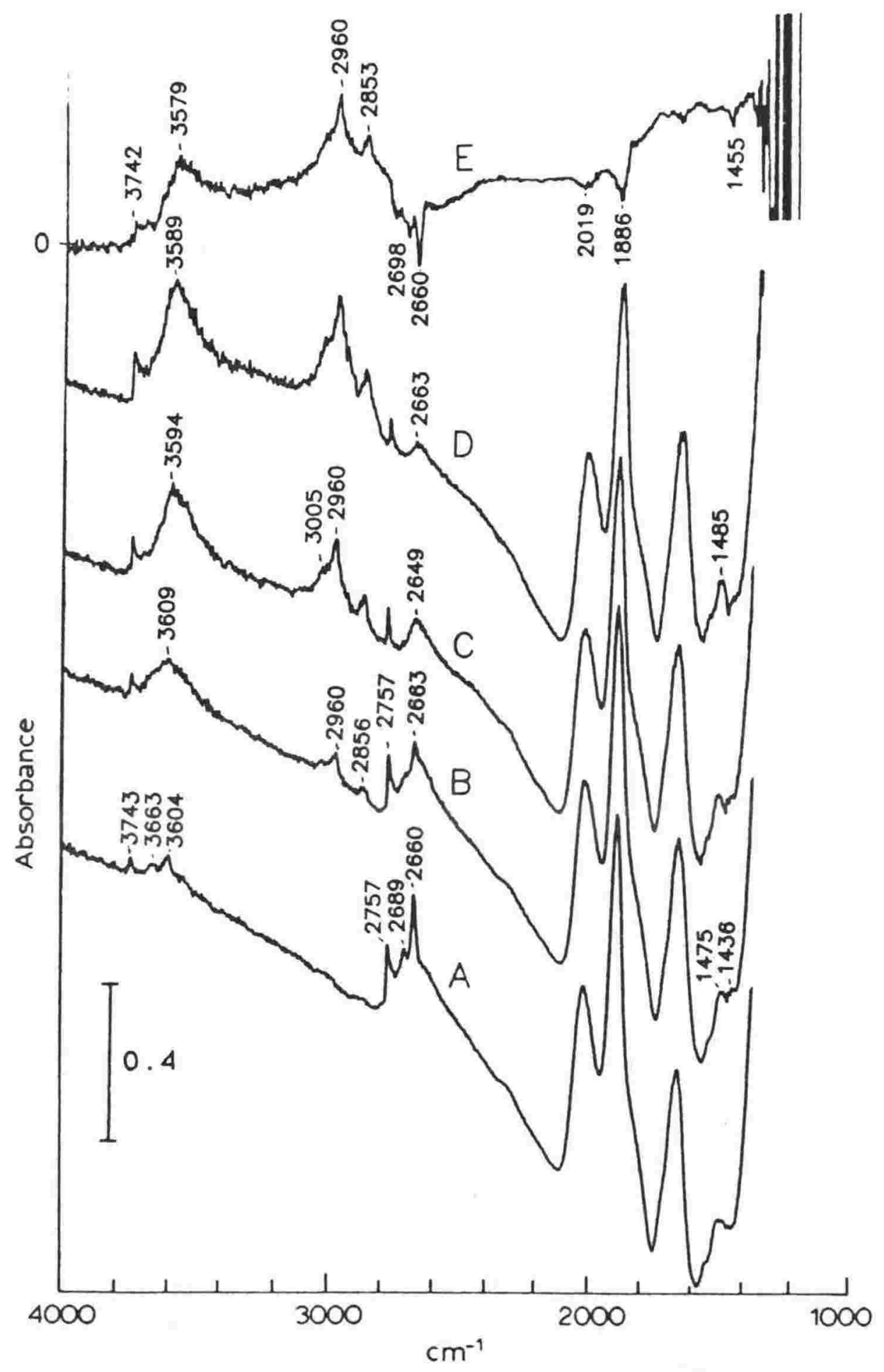

Figure 7.9 FTIR spectra of: A. D/H+ZSM-5 at $100^{\circ} \mathrm{C}$; $B, C$ and $D$ after addition of $1 \mathrm{ml}, 5 \mathrm{ml}$ and $10 \mathrm{ml}$ methanol/air respectively and $\mathrm{E}$. the difference spectrum (CA) . 


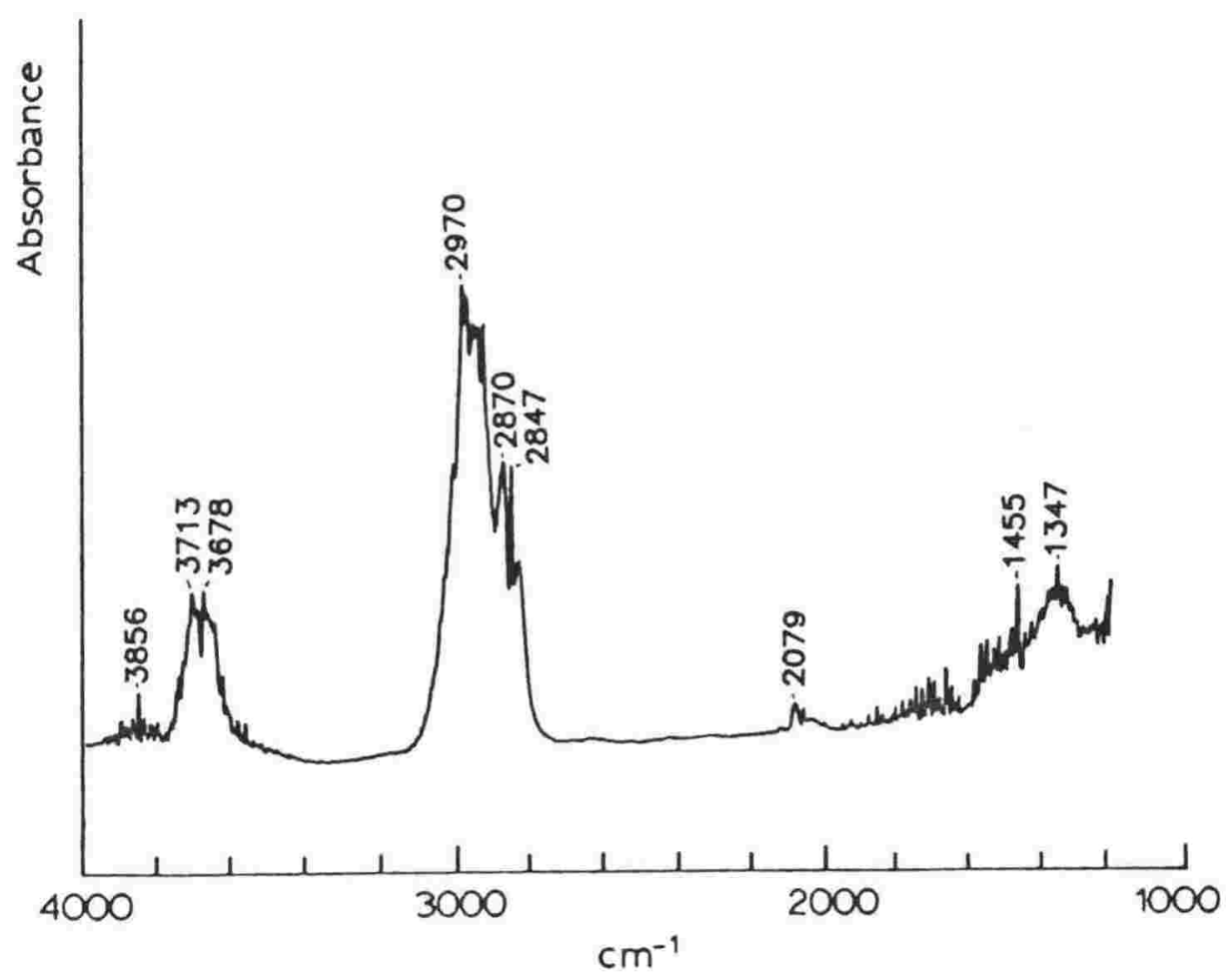

Figure 7.10 FTIR spectrum of gas phase methanol.

The peaks in the $\mathrm{C}-\mathrm{H}$ stretching region are the same (within 4 $\mathrm{cm}^{-1}$ resolution) as those shown by Gorte et al. (17) and Forester and Howe (18). The peaks are also similar, but less complicated than the gas phase spectrum (figure 7.10) with no rotational fine structure. The strongest peak in the gas phase spectrum at $2970 \mathrm{~cm}^{-1}$ is shifted to $2960 \mathrm{~cm}^{-1}$ upon sorption.

The $0-\mathrm{H}$ stretch of gas phase methanol (at $\sim 3680 \mathrm{~cm}^{-1}$ ) has disappeared. The resultant single broad band of the bonded methanol implies that the protons from the methanol and zeolite hydroxyls have become equivalent to perhaps form the following species:

$$
\mathrm{Z}-\mathrm{O} \underset{\mathrm{H}}{\stackrel{\mathrm{H}}{+} \mathrm{O}-\mathrm{CH}_{3}}
$$

An alternative is that the vibrations of one of the hydroxyls have become diffuse, resulting in the broad bands observed. A study of the different $H / D$ combinations of methanol and deuterated methanol over $\mathrm{H} / \mathrm{D}+\mathrm{ZSM}-5$, as carried out for water in chapter 4, may clarify this. 
A third alternative is that reaction of methanol had occured. To identify the sorbed species, the FTIR cell was connected to the mass spectrometer. After recording the spectrum shown in figure $7.9 \mathrm{D}$, the FTIR cell was held at $100^{\circ} \mathrm{C}$ and flushed with $\mathrm{N}_{2}\left(15 \mathrm{ml} \mathrm{min}^{-1}\right)$ for $30 \mathrm{~min}$. The FTIR cell was then sealed, transported to the mass spectrometer system and connected in the same manner as the $t d / m s$ furnace. The species evolved upon heating at $10^{\circ} \mathrm{C} \mathrm{min}^{-1}$ and flushing with $16 \mathrm{ml} \mathrm{min} \mathrm{m}^{-1}$ Ar are shown in figure 7.11. During connection of the FTIR cell to the mass spectrometer some water was sorbed by the sample. This desorbed first ( $\operatorname{Tmax}$ at $\sim 60^{\circ} \mathrm{C}$ ), followed by methanol $\left(\max\right.$ at $\left.\sim 135^{\circ} \mathrm{C}\right)$. This was mainly $\mathrm{CH}_{3} \mathrm{OH}(\mathrm{m} / \mathrm{z} 32$ ) with only a small amount of $\mathrm{CH}_{2} \mathrm{DOH}$ or $\mathrm{CH}_{3} \mathrm{OD}(\mathrm{m} / \mathrm{z} 33)$ observed. After $100^{\circ} \mathrm{C}$, dimethylether desorbed (Tmax at $\sim 170^{\circ} \mathrm{C}$ ) with no significant D incorporated. This was consistent with the FTIR results, showing no $\mathrm{H} / \mathrm{D}$ exchange of the $\mathrm{C}-\mathrm{H}$ bonds occured. No further reaction products were observed.

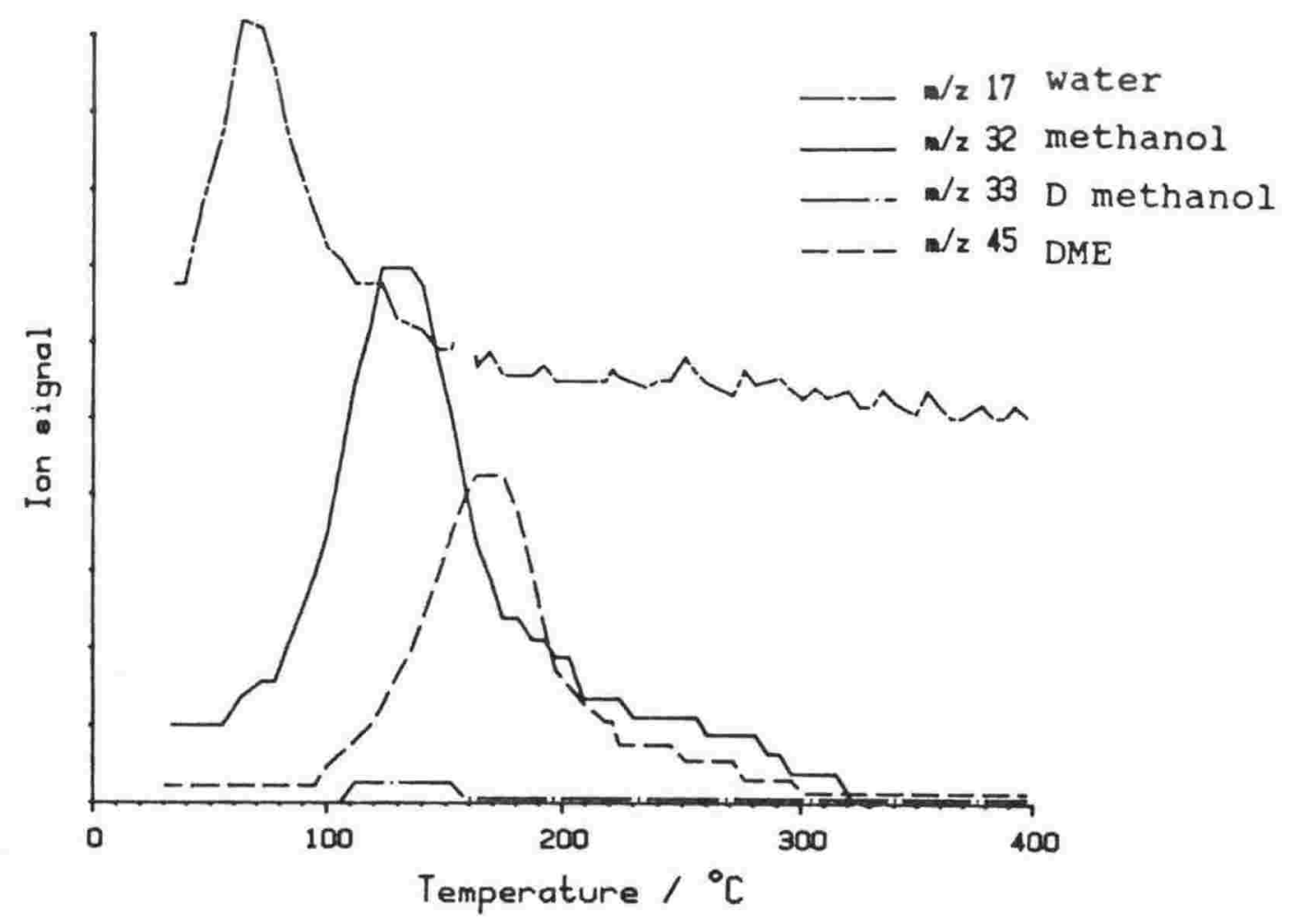

Figure $7.11 \mathrm{Td} / \mathrm{ms}$ of methanol sorbed on $\mathrm{D} / \mathrm{H}+\mathrm{ZSM}-5$. 
This experiment confirms that the bulk of the sorbed species observed in the FTIR spectra (figures 7.8 to 7.9 ) was methanol. The dimethylether observed was most likely a reaction product of methanol at higher temperatures. The alternative, that the sorbed species from the FTIR spectrum reacted with water, re-forming methanol, was discounted by Ison and Gorte (14) who showed that added water had no effect on the $t d / m s$ of methanol.

Ison and Gorte (14) studied the $t d / m s$ of methanol by leaking desorbed gases from a previously evacuated FTIR cell into the mass spectrometer, while the sample was heated at $30^{\circ} \mathrm{C} \mathrm{min} \mathrm{m}^{-1}$. They observed only methanol, with no reaction products, even though their second desorption maxima for methanol occured at $230^{\circ} \mathrm{C}$ (figure 7.12 ). Tga (14) showed that this second maxima corresponded to desorption of a single molecule of methanol from each cation site.

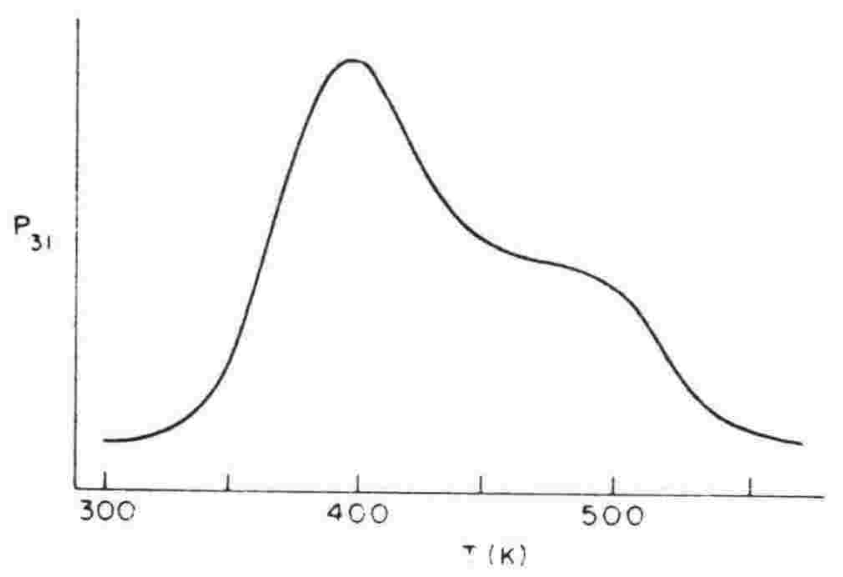

Figure 7.12. Td/ms of methanol on $\mathrm{H}+\mathrm{ZSM}-5$ heated at $30^{\circ} \mathrm{C} \mathrm{min}{ }^{-1}$ in an evacuated cell. Methanol was the only product observed during desorption. (from Ison and Gorte (14)).

There are major differences between the $t d / m s$ results obtained here and those of Ison and Gorte (14), especially in the temperatures of desorption. The main reason is probably because Ison and Gorte did not use a carrier gas to flush the desorbed species to the mass spectrometer, but relied on diffusion in a low pressure system. This, combined with the higher heating rate, would mean that by the time the desorbed methanol had reached the mass spectrometer the sample 
temperature would be much greater. This slow transfer from the cell to the mass spectrometer would also decrease the resolution, with desorption peaks overlapping. That only methanol was observed by Ison and Gorte (14) may have been due to desorption of methanol at a lower temperature under low pressure, desorbing before reaction occured, or alternatively a lack of mass spectrometer sensitivity.

\subsubsection{Conclusion:}

A combination of the experimental results presented here and literature results show that methanol sorbed at $100^{\circ} \mathrm{C}$ on $\mathrm{H}+\mathrm{ZSM}-5$ is protonated (to some extent) by the Bronsted acid sites.

\subsubsection{Propan-2-Ol on H+ZSM-5:}

source: BDH special for spectroscopy

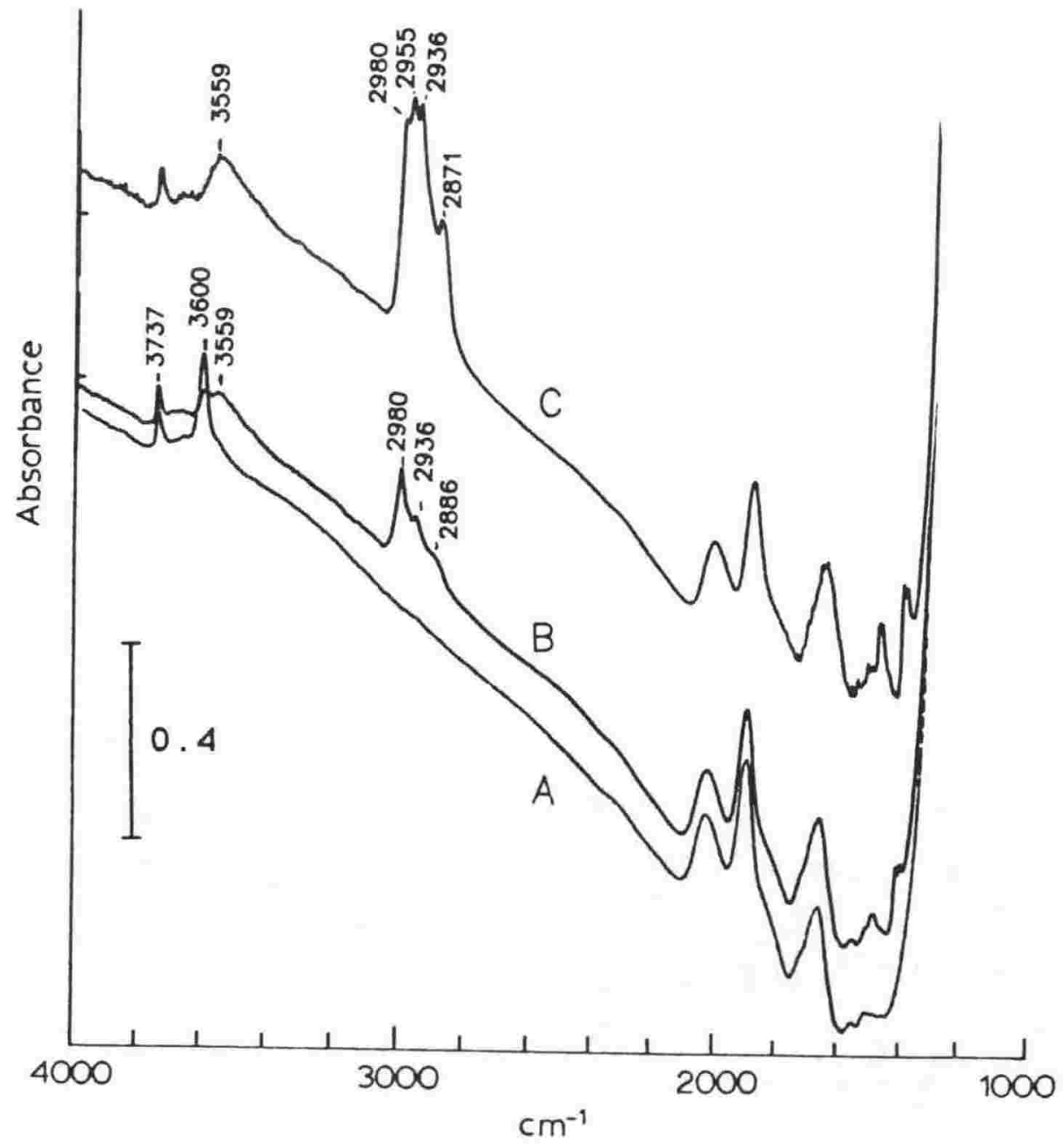

Figure 7.13. FTIR spectra of: A. H+ZSM-5 at $100^{\circ} \mathrm{C}$; B. after addition of $0.5 \mu \mathrm{l}$ propan-2-ol and C. after addition of $1.5 \mu 1$ propan-2-ol. 
Propan-2-ol sorption on $\mathrm{H}+\mathrm{ZSM}-5$ has been studied by Aronson et al. 1987 (17). The experiment was repeated to obtain a more accurate value for the position of the shifted $0-H$ peak after alcohol sorption. The spectrum of $0.5 \mu l$ propan-2-ol sorbed on $\mathrm{H}+\mathrm{ZSM}-5$ held at $100^{\circ} \mathrm{C}$ is shown in figure 7.13 . Further addition of propan-2-ol, at this temperature resulted in reaction to an alkene-like species, as was observed by Aronson et al.(17).

\subsubsection{Other Alcohols:}

These were studied by Aronson et al. (17). The positions of the shifted $\mathrm{O}-\mathrm{H}$ maxima were estimated from their figures and are shown in Table 7.4.

\subsection{Saturated Hydrocarbons:}

\subsubsection{Methane:}

Source: NZIG gas

No significant methane was sorbed onto $\mathrm{H}+\mathrm{ZSM}-5$ at room temperature in flowing $\mathrm{N}_{2}$. After injection of methane the gas phase spectrum of methane was observed, but no significant reduction in the concentration of zeolite acid sites occured.

At higher pressures of methane, some methane sorption has been observed. Papp et al. (20) studied the IR spectrum of 750 Torr of methane over $\mathrm{H}+\mathrm{ZSM}-5$ at $15^{\circ} \mathrm{C}$. A dual cell spectrometer was used with methane in the reference cell which effectively removed the gas phase methane from the spectrum. Their spectra before and after methane addition are shown in figure $7.14 \mathrm{~A}$, along with the difference spectrum (figure 7.14B). Only a very small Bronsted peak at $3605 \mathrm{~cm}^{-1}$ was observed, but this disappeared upon addition of methane. From the difference spectrum it was not possible to determine the maxima of the shifted hydroxyl due to the loss of Bronsted $\mathrm{O}-\mathrm{H}$. 


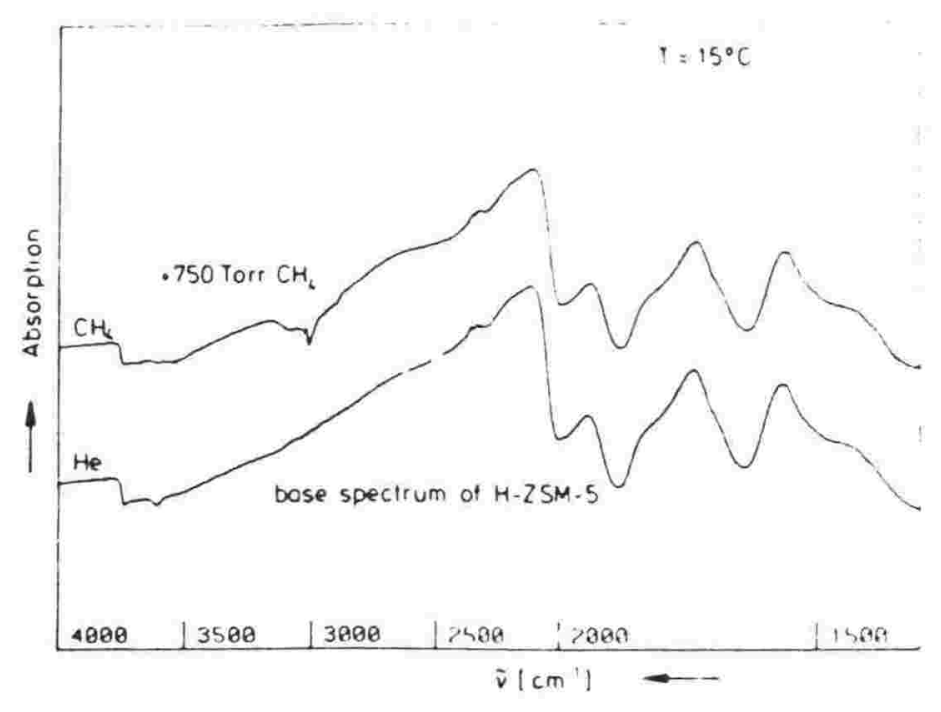

Ir-spectrum of clean $\mathrm{H}-2 \mathrm{SM}-5$ and after adsorption of methane at 750 Torr

Figure 7.14A, from Papp et al. (20).

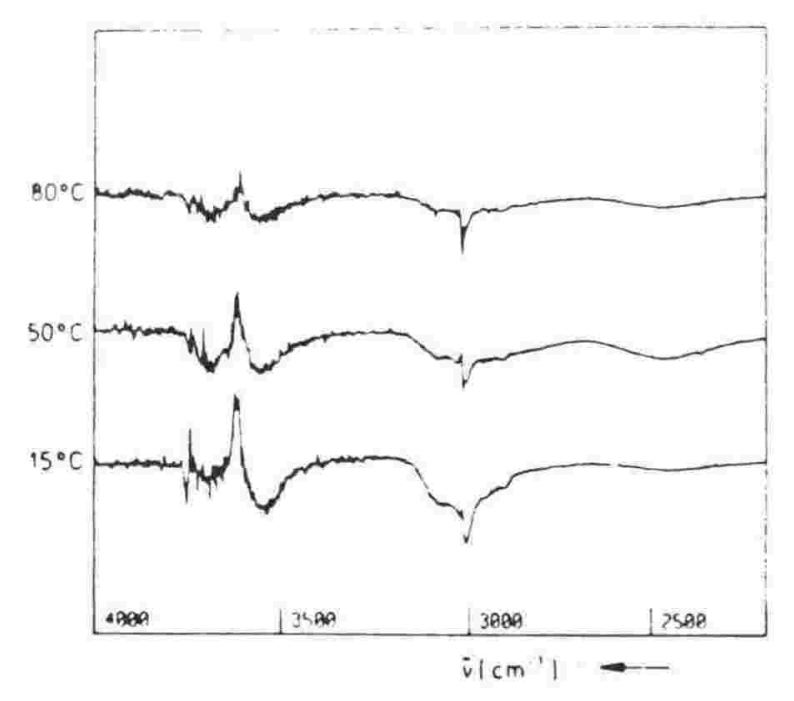

Difference spectra after methane adsorption on H-ZSM-5 (spectrum of the $\mathrm{CH}_{4}$ covered $\mathrm{H}-2 \mathrm{SM}-5$ /spectrum of the clean $\mathrm{H}-2 \mathrm{SM}-5$ )

Figure 7.14B, from Papp et al. (20). 


\subsection{2 n-Hexane:}

source:spectrosol for UV spectroscopy, Ajax Chemicals.

$\mathrm{n}$-Hexane was sorbed onto a wafer of $\mathrm{H}+\mathrm{ZSM}-5$ held at $80^{\circ} \mathrm{C}$ (figure $7.15 \mathrm{~A}$ ). The spectra after sorption of 0.25 and 1.25 $\mu 1$ of hexane are shown in figure $7.15 \mathrm{~B}$ and $\mathrm{C}$, and the corresponding difference spectra are shown in figure $7.16 \mathrm{~B}$ and c. (Initially the wafer contained sorbed water, as this experiment was also used to show displacement of water by hexane to provide information for a solid state nmr project). The hexane displaced water and bonded with the Bronsted hydroxyls, producing a broadened $0-\mathrm{H}$ peak with a maximum at $\sim 3480 \mathrm{~cm}^{-1}$. The hexane was sorbed unreacted - as shown by the similarity with gas phase hexane (figure $7.16 \mathrm{~A}$ ) and the lack of changes with addition of increasing amounts of hexane.

In a second experiment, $n$-hexane was sorbed onto a wafer that was mainly D+ZSM-5 held at $80^{\circ} \mathrm{C}$ (figure $7.17 \mathrm{~A}$ ). The spectrum in figure 7.17B and difference spectrum in figure $7.17 \mathrm{C}$ were recorded after sorption of $0.75 \mu \mathrm{l}$-hexane. The Bronsted O-D peak was lost, and a broadened, shifted O-D peak formed. The $\mathrm{C}-\mathrm{H}$ stretching and bonding regions were the same as for sorption of $\mathrm{H}+\mathrm{ZSM}-5$, with no $\mathrm{C}-\mathrm{D}$ vibrations observed.

After flushing the cell for $\sim 1 \mathrm{~h}$ at $80^{\circ} \mathrm{C}$ no significant desorption of hexane occured showing that the hexane was strongly sorbed. Heating to $200^{\circ} \mathrm{C}$ was required for hexane desorption. 


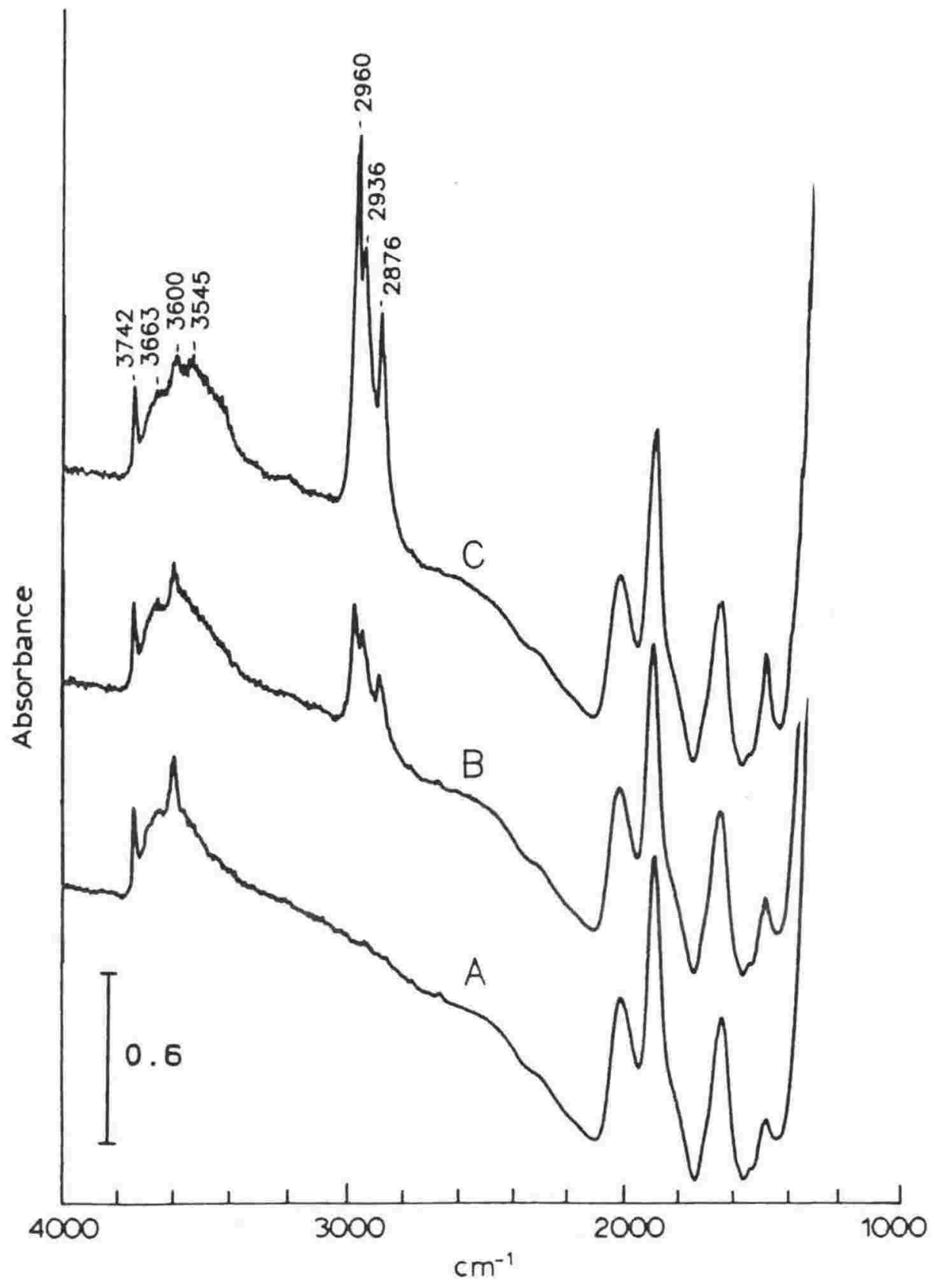

Figure 7.15 FTIR spectra of: A. H+ZSM-5 with a small amount of sorbed water held at $80^{\circ} \mathrm{C}$; $\mathrm{B}$. after addition of $0.25 \mu l$ hexane and $C$. after addition of $1.25 \mu 1$ hexane. 


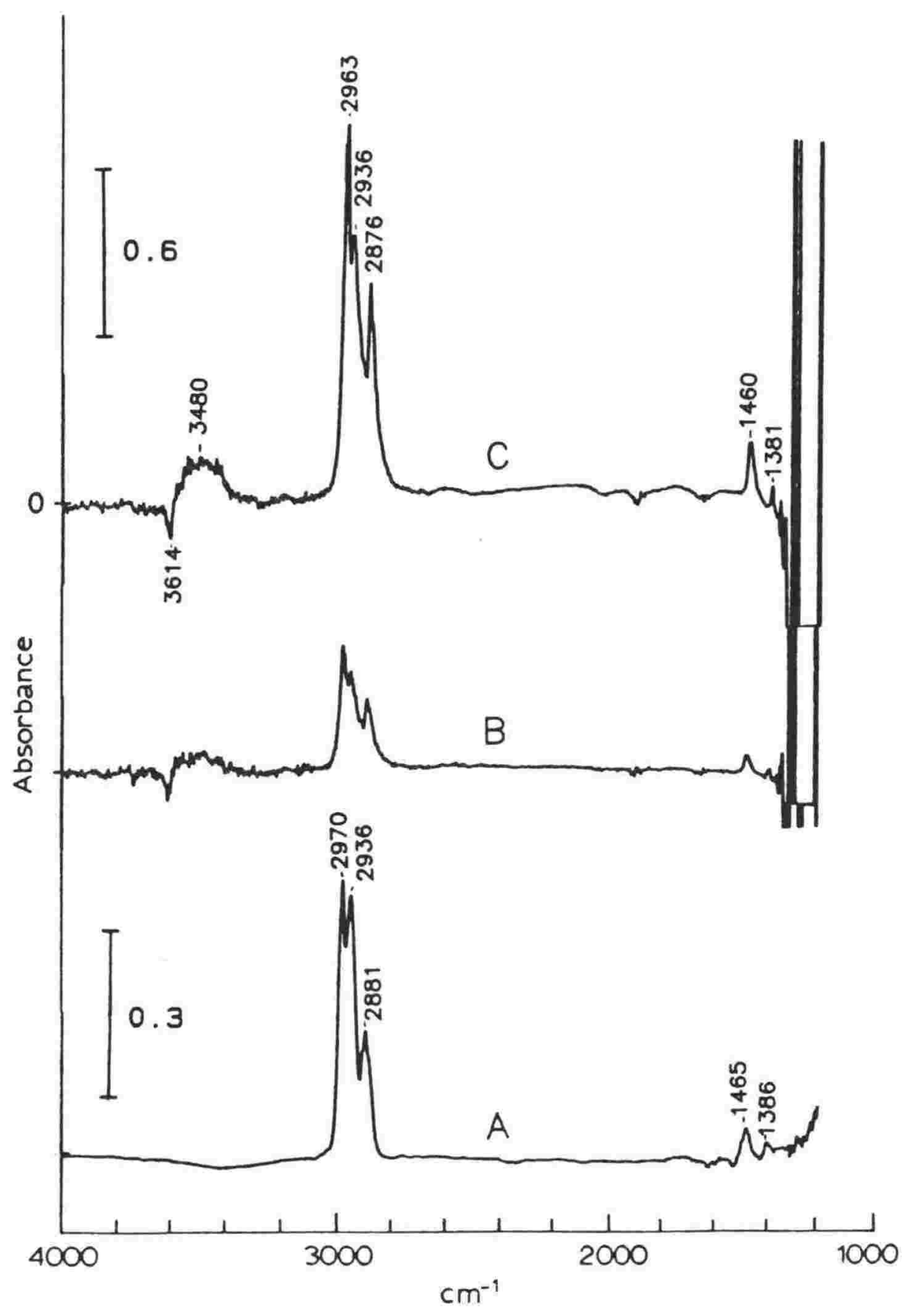

Figure 7.16 A. FTIR spectrum of gas phase hexane and FTIR difference spectra of: $B$. $0.25 \mu l$ sorbed hexane and $C$. 1.25 $\mu l$ sorbed hexane. 


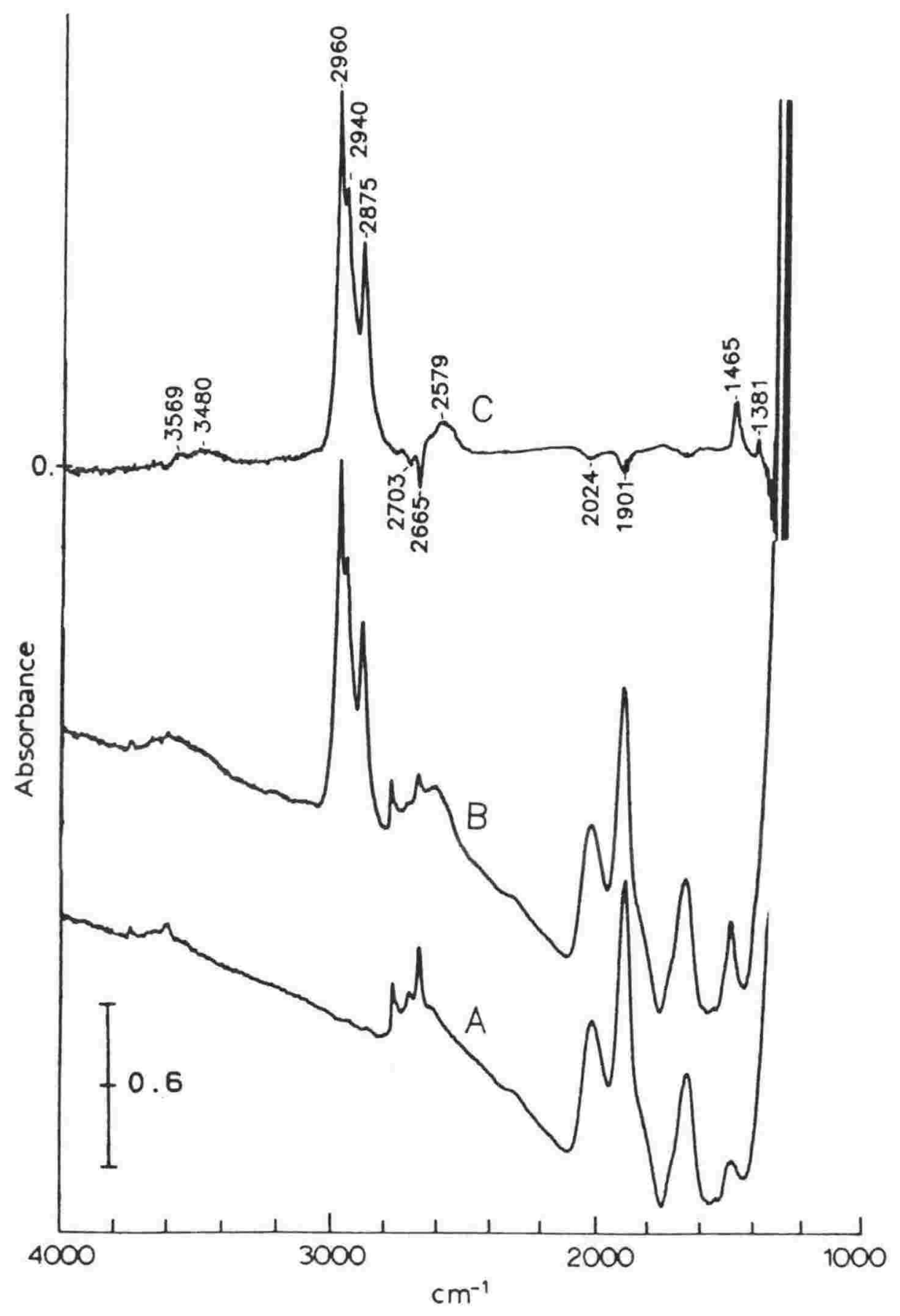

Figure 7.17 FTIR spectra of: A. D/H+ZSM-5 held at $80^{\circ} \mathrm{C}$; B. after addition of $0.75 \mu l$ hexane and the difference spectrum $(B-A)$. 


\subsection{FTIR of Nitrogenous bases on H+ZSM-5:}

\subsubsection{Ammonia:}

\subsubsection{A Introduction:}

Sorption of $\mathrm{NH}_{3}$ has long been used as a tool for studying zeolite acid sites in combination with techniques such as calorimetry (21), tpd $(22,23),{ }^{15} \mathrm{~N} \mathrm{nmr}(24)$ and $\operatorname{IR}(25,26)$. Ammonia is an appropriate molecule for these studies because its small size and high basicity means that it has access to and binds most acid sites.

The IR bands of $\mathrm{NH}_{3}$ sorbed on $\mathrm{X}$ and $\mathrm{Y}$ zeolites have been assigned by Uytterhoeven et al. (25) and are summarised in Table 7.1.

Table 7.1. The infrared absorption bands observed with decationated $X$ and $Y$ zeolites and their assignments (25).

Frequency $\left(\mathrm{cm}^{-1}\right)$ Assignment

\section{3}

3385

3320

$3275-3200$

3000-2950

1682

1650

1630

1505-1485

1435-1475 $v_{3}$ stretching $\mathrm{NH}_{4}^{+}$

$v_{3}$ stretching $\mathrm{NH}_{3}$ solid?

$v_{1}$ stretching $\mathrm{NH}_{3}$

$v_{3}$ stretching $\mathrm{NH}_{4+}^{+}$

$v_{3}$ stretching $\mathrm{NH}_{4}$

$\mathrm{NH}_{4}{ }^{+}$deformation

$\mathrm{H}_{2} \mathrm{O}$ deformation

$v_{4} \mathrm{NH}_{3}$ deformation

$v_{4}$ deformation $\mathrm{NH}_{4+}^{+}$

$v_{4}$ deformation $\mathrm{NH}_{4}^{+}$

The band commonly used to characterise sorbed $\mathrm{NH}_{4}{ }^{+}$is the asymmetric deformation at 1435 to $1475 \mathrm{~cm}^{-1}$. For sorption of $\mathrm{NH}_{3}$ on $\mathrm{H}+\mathrm{ZSM} 5$ this band occured at $1430 \mathrm{~cm}^{-1}$ (Datka et al. (27)). The bands at 3320 and $1630 \mathrm{~cm}^{-1}$ are assigned to Lewis bound $\mathrm{NH}_{3}$ (25) as they were only observed with samples that had been heated, prior to sorption, to greater than $300^{\circ} \mathrm{C}$ so that extensive dehydroxylation had occured. This assignment should be regarded with caution as another interpretation is possible because the $\mathrm{NH}_{3}$ sorption experiments were carried out 
at room temperature. These two bands were only significant for greater amounts of sorbed $\mathrm{NH}_{3}$, so they could have also been due to physisorbed $\mathrm{NH}_{3}$. The $1630 \mathrm{~cm}^{-1}$ band is also close to a strong band for sorbed water $\left(1650 \mathrm{~cm}^{-1}\right.$ (25) or $1620 \mathrm{~cm}^{-1}$ (chapter 4)) which could cause ambiguity.

The 1630 and $1430 \mathrm{~cm}^{-1}$ bands of sorbed $\mathrm{NH}_{3}$ are not normally used to determine relative amounts of Bronsted and Lewis sorbed $\mathrm{NH}_{3}$ as they are broad and diffuse, and accurate measurement of intensities difficult (28). Pyridine sorption is preferable.

\subsubsection{B Results and Discussion - Ammonia on H+ZSM-5:}

Source: Matheson dry $\mathrm{NH}_{3}$

With the FTIR cell connected to the vacuum gas handing rig, 30 Torr of $\mathrm{NH}_{3}$ was held over a wafer of $\mathrm{H}+\mathrm{ZSM}-5$ (at $21^{\circ} \mathrm{C}$ ) for 5 minutes. The $\mathrm{H}+\mathrm{ZSM}-5$ wafer had been previously heated in air at $500^{\circ} \mathrm{C}$ for 6 minutes. The resultant FTIR spectrum at $21^{\circ} \mathrm{C}$ is shown in figure $7.18 \mathrm{~A}$ and the difference spectrum (from the dry zeolite) in figure 7.19A. Earlier td/ms work (Parker et al.(23)) showed that both physisorbed and chemisorbed ammonia would be present after this treatment. The broad bands in the 3500 to $2500 \mathrm{~cm}^{-1}$ region are presumably due to physisorbed $\mathrm{NH}_{3}$ with different degrees of association with the Bronsted acid sites. This spectrum can be compared with the gas phase ammonia spectrum (figure 7.20). The peaks at 3402 and $1627 \mathrm{~cm}^{-1}$ (see difference spectrum figure 7.19A) may be due to a species similar to gas phase $\mathrm{NH}_{3}$ as they are at approximately the same wavenumbers, even though they are broadened and show no rotational fine structure. As the sample is heated in flowing $\mathrm{N}_{2}$ (30 $\left.\mathrm{ml} \mathrm{min}^{-1}\right)$, the physisorbed ammonia desorbs with the bands at lower wavenumber disappearing first. Figures $7.18 \mathrm{~B}$ and $7.19 \mathrm{~B}$ show the spectrum and difference spectrum at $70^{\circ} \mathrm{C}$. 


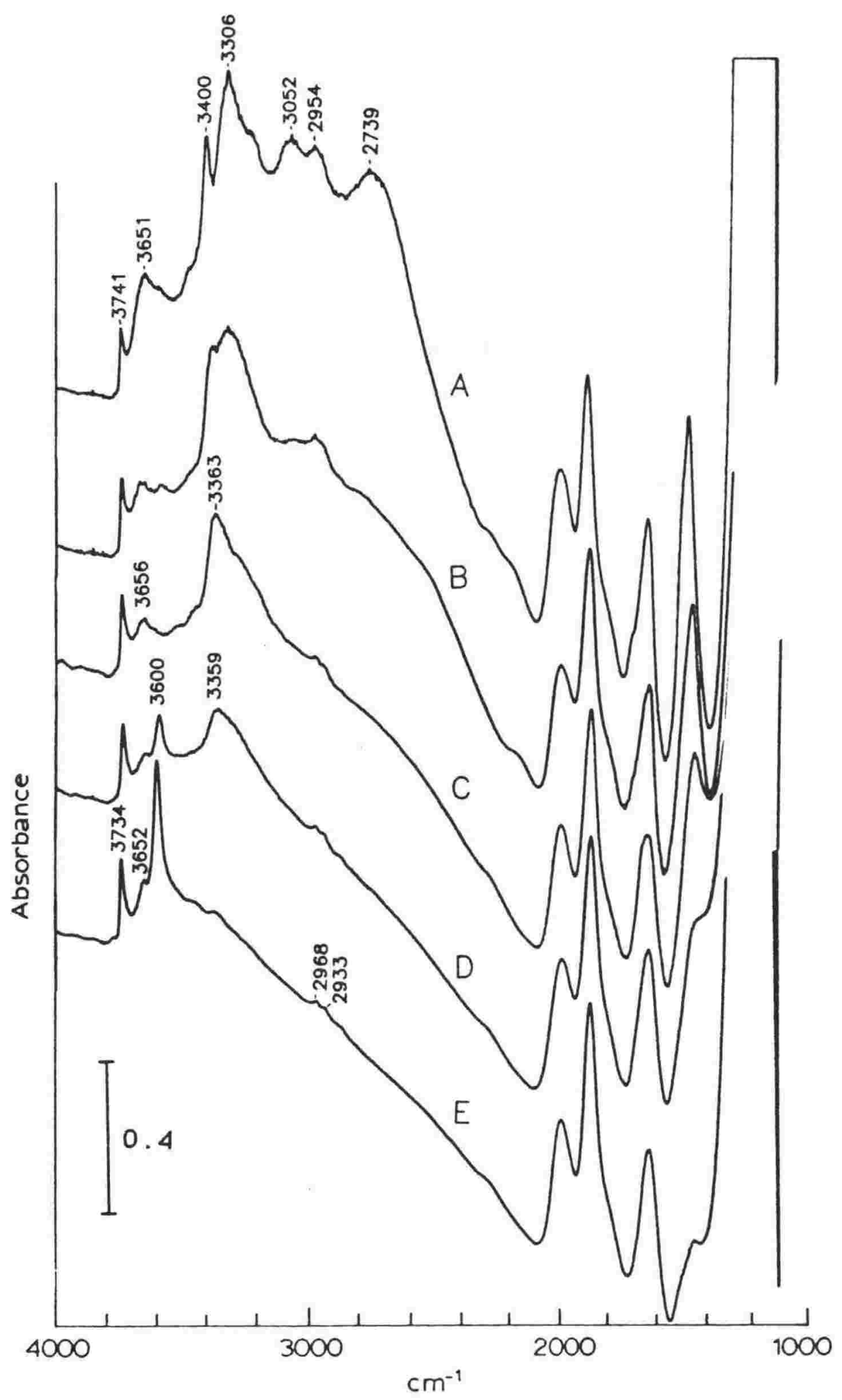

Figure 7.18 FTIR spectra of: A. ammonia sorbed on H+ZSM-5 at $21^{\circ} \mathrm{C} ; \quad$ B. after heating to $70^{\circ} \mathrm{C} ; \mathrm{C}$. after heating to $150^{\circ} \mathrm{C} ;$ D. at $200^{\circ} \mathrm{C}$ and $\mathrm{E}$. after heating to $400^{\circ} \mathrm{C}$ then cooling to $150^{\circ} \mathrm{C}$. 


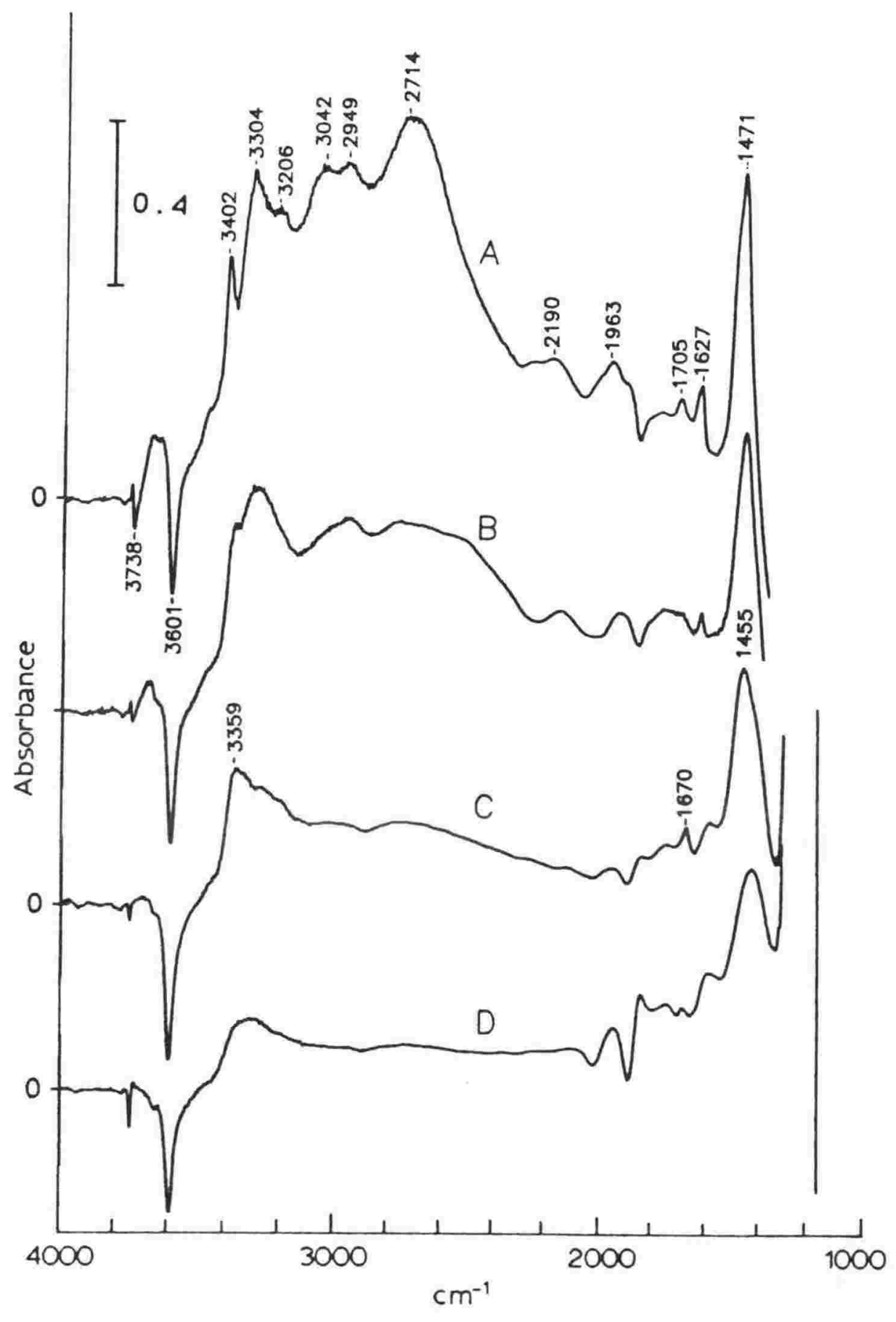

Figure 7.19 FTIR difference spectra corresponding to figure 7.18 . 


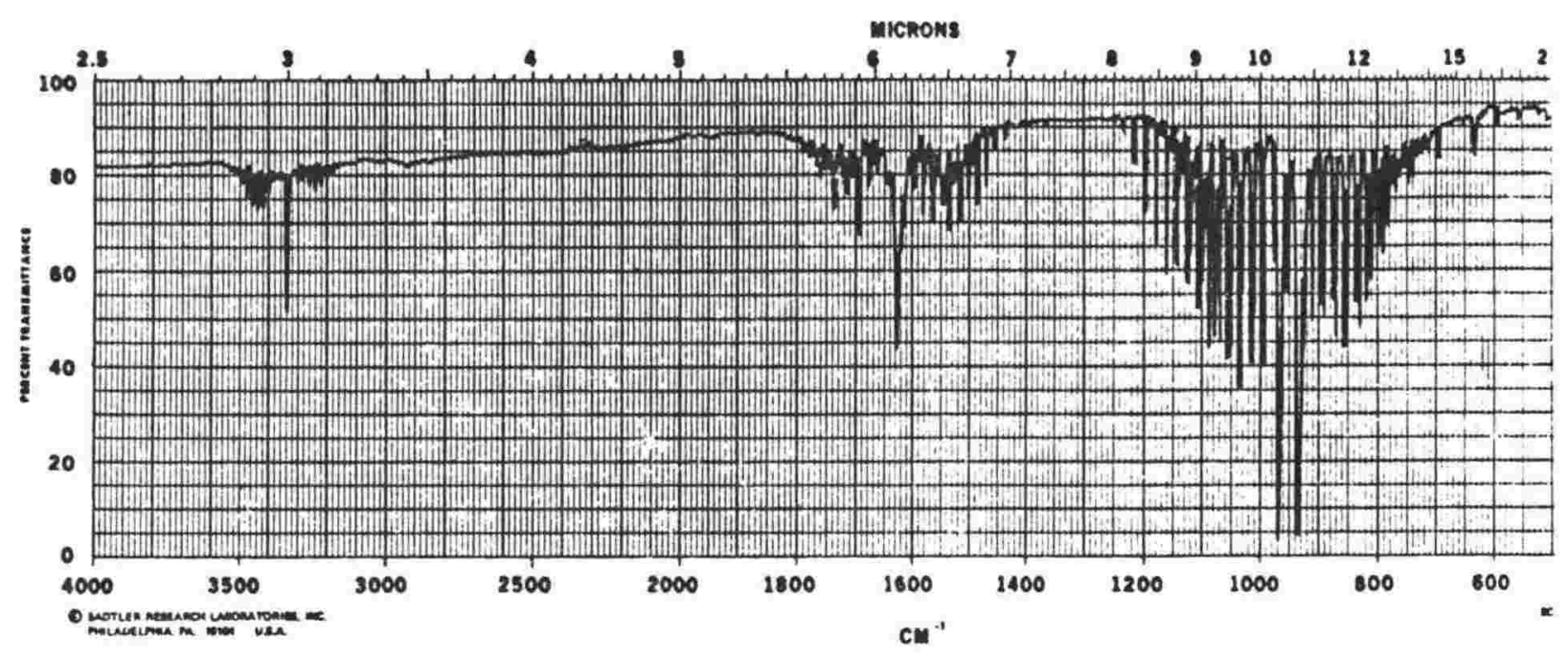

Figure 7.20 Gas phase ammonia (from Stadtler Research Laboratories (47)).

After holding the wafer at $150^{\circ} \mathrm{C}$ for 12 minutes, the spectrum obtained is shown in figure $7.18 \mathrm{C}$ and its difference spectrum in figure $7.19 \mathrm{C}$. Tga work (23) has shown that at this temperature only $\mathrm{NH}_{3}$ in a $1: 1$ association with the zeolite $\mathrm{Al}$ remains. The difference spectrum shows that the Bronsted hydroxyls have been lost (negative peak at $3601 \mathrm{~cm}^{-1}$ ). The resultant hydroxyl peak associated with the $\mathrm{NH}_{3}$ has broadened and shifted to lower wavenumber with a maximum at $3359 \mathrm{~cm}^{-1}$. Heating the wafer further to $200^{\circ} \mathrm{C}$ results in desorption of the ammonia (figures $7.18 \mathrm{D}$ and 7.19D). After heating to $400^{\circ} \mathrm{C}$ and cooling to $150^{\circ} \mathrm{C}$ the original spectrum was obtained (figure 7.18E).

A small peak at $3652 \mathrm{~cm}^{-1}$ was present in the spectrum after complete $\mathrm{NH}_{3}$ desorption and is probably due to an $\mathrm{AlOH}$ species in the zeolite channels produced by previous heating of the wafer. The small peaks at 2968 and $2933 \mathrm{~cm}^{-1}$ are due to hydrocarbons from backstreaming of the vacuum pump. (In later experiments this was avoided by flushing the cell with dry $\mathrm{N}_{2}$ at one atmosphere pressure, instead of evacuation). 


\subsubsection{Pyridine on $\mathrm{H}+\mathrm{ZSM}-5$ :}

Source: BDH AR.

\subsubsection{A Introduction:}

Pyridine has long been used as a probe molecule to determine the relative amounts of Bronsted and Lewis sites in acid zeolites. The original work was mainly carried out on the faujasites, this is reviewed in chapter 6 .

Pyridine was used in an IR study of the acidity of H+ZSM-5 by Topsoe et al. (29). In the two samples studied they found Bronsted and a smaller number of Lewis acid sites. The pyridine associated with the Bronsted sites was more readily thermally desorbed than that associated with Lewis sites.

Sayed et al. (30) used the IR spectra of sorbed pyridine to study the properties of a series of $\mathrm{H}+\mathrm{ZSM}-5$ catalysts dealuminated by calcination and acid washing. The ratio of Bronsted to Lewis sites ([B]/[L]) was calculated from the spectra using the peak at $1545 \mathrm{~cm}^{-1}$ arising from protonated pyridine and the peak at $1490 \mathrm{~cm}^{-1}$ arising from both Bronsted and Lewis bonded pyridine, and the relative extinction coefficients for each component. This procedure was required to avoid possible interference of the Lewis bonded pyridine band at $1455 \mathrm{~cm}^{-1}$ with a band at $1440 \mathrm{~cm}-1$ due to physisorbed pyridine. The $[B] /[L]$ was measured versus pyridine desorption temperature and found to reach a maximum at $200^{\circ} \mathrm{C}$. This maximum increased with increasing zeolite dealumination. This was ascribed to Bronsted sites formed from silanol nests resulting from dealumination (30):

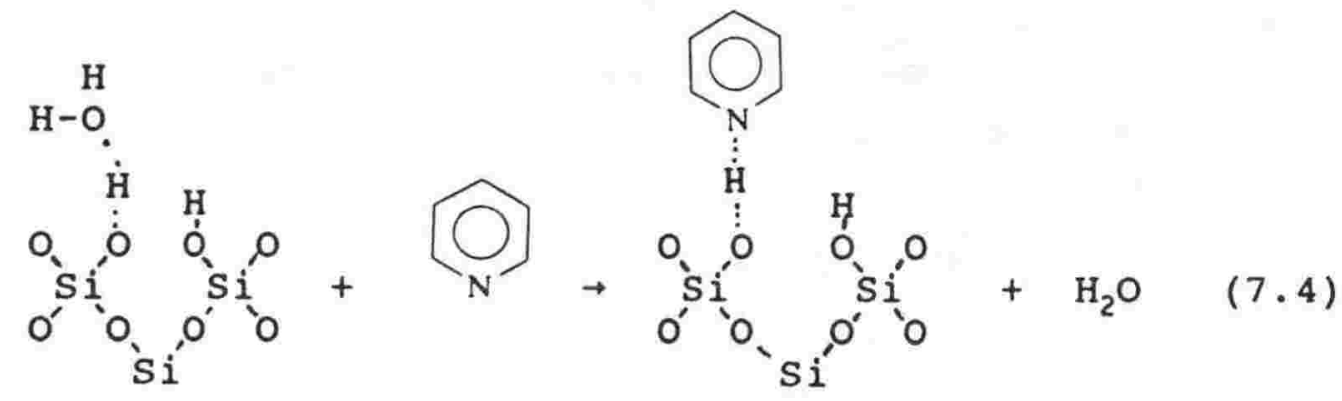


A study by $t d / m s$ and tga (23) showed that physisorbed pyridine desorbed up to $200^{\circ} \mathrm{C}$, with a higher temperature desorption between $400-700^{\circ} \mathrm{C}\left(\operatorname{Tmax}\right.$ at $\left.600^{\circ} \mathrm{C}\right)$ of pyridine, which was associated with the zeolite acid sites. No decomposition of the pyridine occured. Tga (23) showed this high temperature weight loss to correspond to 2.2 pyridine molecules per zeolite unit cell compared to 2.7 Al atoms per unit cell in the zeolite. This implied that not all the acid sites were accessible to pyridine.

\subsubsection{Results and discussion - pyridine on H+ZSM-5:}

Pyridine was sorbed on H+ZSM-5 (prep 816) held at $150^{\circ} \mathrm{C}$ to determine the effect of pyridine sorption on the Bronsted hydroxyl stretch. The spectra of increasing amounts of pyridine are shown in figure 7.21 and the corresponding difference spectra in figure 7.22. After injection into the FTIR cell of $15 \mathrm{ml}$ pyridine/air (fig 7.21C), further injection of pyridine (another $15 \mathrm{ml}$ ) resulted in no further changes to the spectrum. None of the silanol hydroxyls ( $3704 \mathrm{~cm}^{-1}$ ) had bonded, but all of the Bronsted acid sites (3610 $\mathrm{cm}^{-1}$ ) were gone. This implies all the Bronsted hydroxyls are accessible to pyridine, contradicting earlier tga results (23).

Heating the wafer to $300^{\circ} \mathrm{C}$, then recooling to $150^{\circ} \mathrm{C}$, resulted in the spectra in figures $7.21 \mathrm{E}$ and $7.22 \mathrm{E}$. The small peak at $3650 \mathrm{~cm}^{-1}$ reappeared, implying that pyridine had only been comparatively weakly bound at that site. Small reductions in the 1618 and $1453 \mathrm{~cm}^{-1}$ peaks were also observed. A peak at - $1455 \mathrm{~cm}^{-1}$ is traditionally assigned to Lewis bonded pyridine (45), implying that the hydroxyls contributing to the 3650 $\mathrm{cm}^{-1}$ peak are associated with Lewis sites. These may be AlOH species in the channels, with the Al behaving as a Lewis acid. This Lewis bound pyridine is less strongly bound than the Bronsted coordinated pyridine, in contrast with earlier results (29). 


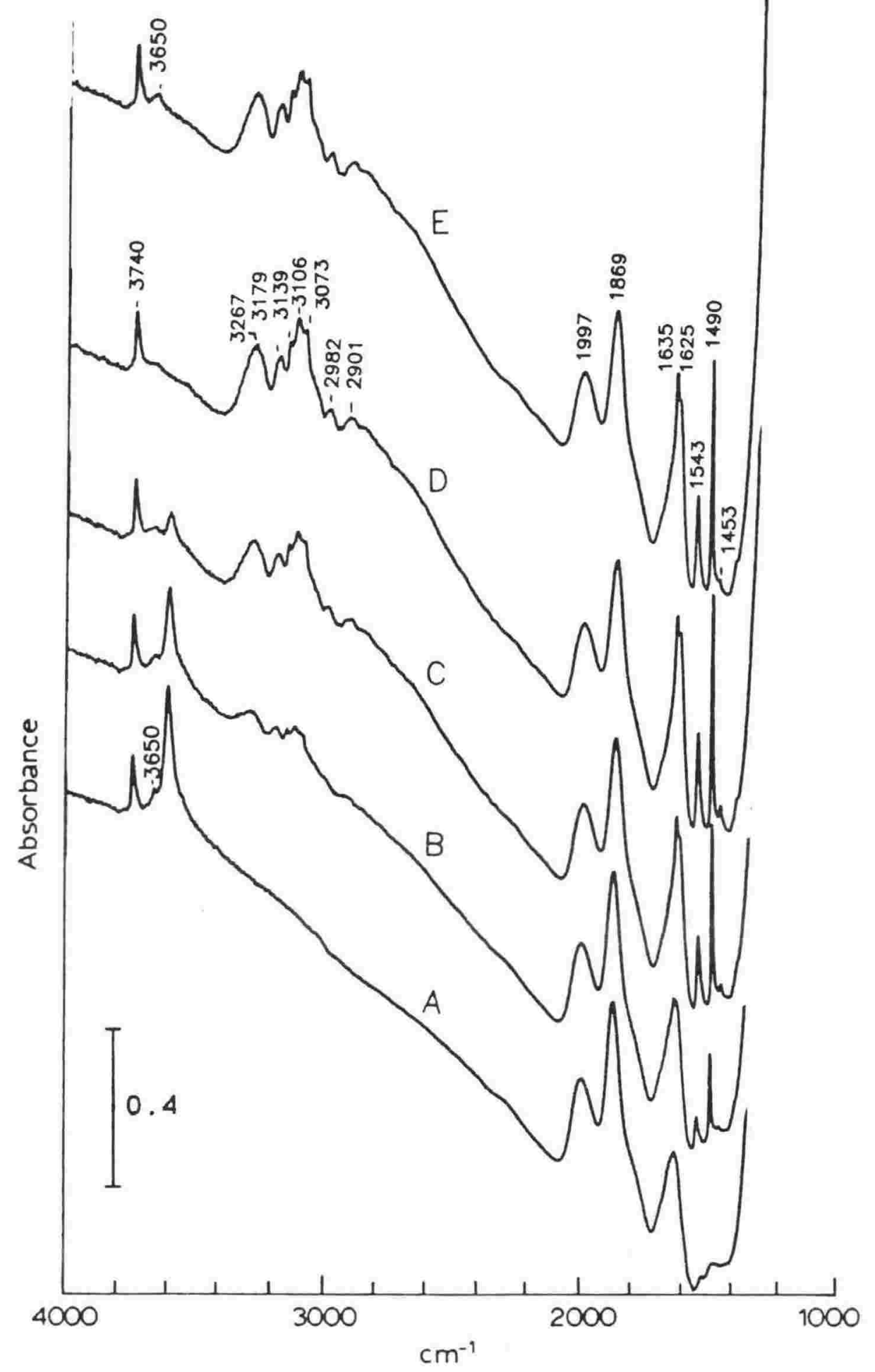

Figure 7.21. FTIR spectra of: A. Dry $\mathrm{H}+\mathrm{ZSM}-5$ held at $150^{\circ} \mathrm{C}$;

B. after addition of $5 \mathrm{ml}$ pyridine saturated air;

C. " " $10 \mathrm{ml} "$ " "

D. " " $15 \mathrm{ml} "$ " and

E. after heating to $300^{\circ} \mathrm{C}$, then cooling to $150^{\circ} \mathrm{C}$. 


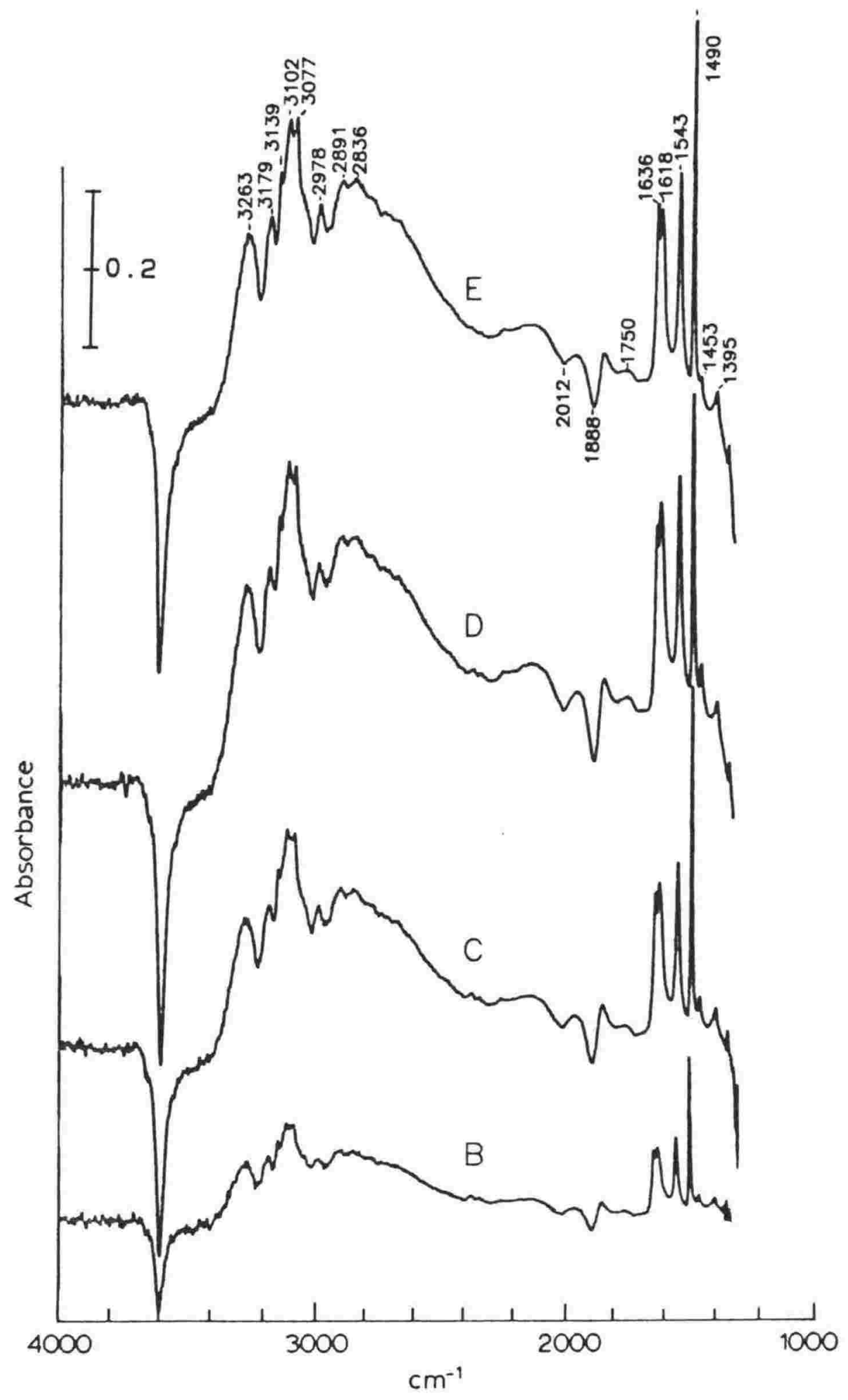

Figure 7.22. FTIR difference spectra corresponding to figure 7.21 . 
The main peak due to the Bronsted proton transferred towards pyridine is centred at $\sim 3265 \mathrm{~cm}^{-1}$. This peak is used in the correlation of $\Delta v$ versus proton affinity. There are also broad bands associated with the Bronsted proton under the $\mathrm{C}-\mathrm{H}$ stretching peaks. This was shown by an experiment on $\mathrm{H}+\mathrm{Y}$ held at $150^{\circ} \mathrm{C}$ (see chapter 6 ), in which $D_{2} O$ was added to the cell and exchange of the Bronsted proton occured. This broadness implies a wide range of energies for the bonded Bronsted proton.

\subsection{3 n-Propylamine on $\mathrm{H}+\mathrm{ZSM}-5$ :}

Source: BDH general purpose reagent $(>98 \%)$.

\subsubsection{A Introduction:}

$\mathrm{Td} / \mathrm{ms}$ results of $\mathrm{n}$-propylamine sorbed on $\mathrm{H}+2 \mathrm{SM}-5$ at room temperature are shown in figure 7.23 (this work).

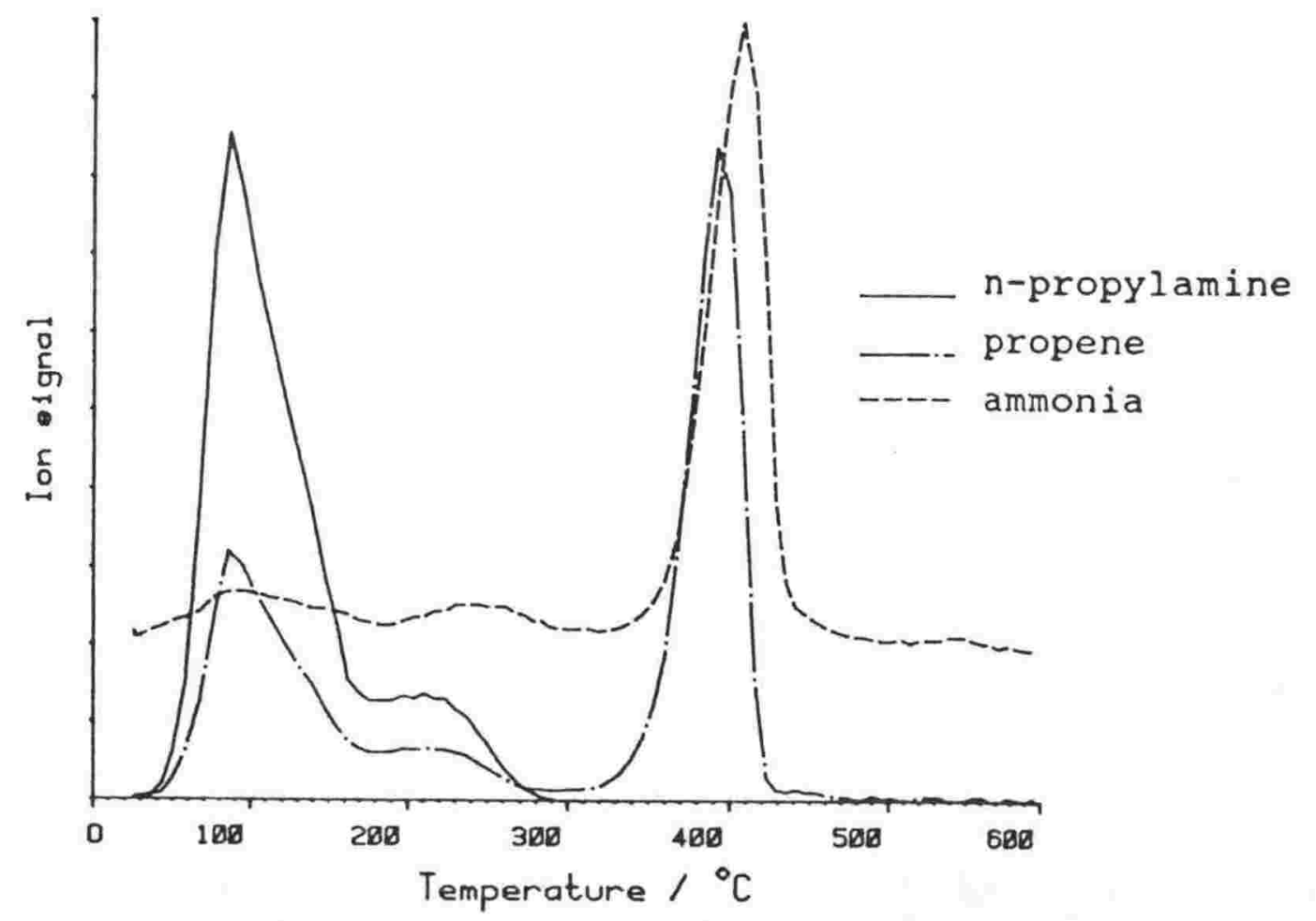

Figure $7.23 \mathrm{Td} / \mathrm{ms}$ of $\mathrm{n}$-propylamine sorbed on $\mathrm{H}+\mathrm{ZSM}-5$.

Unreacted, physisorbed amine desorbs up to $280^{\circ} \mathrm{C}$, followed by a propene and $\mathrm{NH}_{3}$ desorption $\left(\operatorname{Tmax}\right.$ at $400^{\circ} \mathrm{C}$ ) due to decomposition of $n$-propylamine bound on the Bronsted acid sites. Td/ms and tga work on a range of amines (23) showed that when amines are sorbed onto $\mathrm{H}+\mathrm{ZSM}-5$ at elevated 
temperatures further reaction of the amine occurs to give the dialkylamine and ammonia:

$$
\mathrm{RNH}_{2}+\mathrm{RNH}_{3}^{+} \mathrm{Z}^{-} \rightarrow \mathrm{R}_{2} \mathrm{NH}_{2}^{+} \mathrm{Z}^{-}+\mathrm{NH}_{3}
$$

For n-propylamine sorbed at $327^{\circ} \mathrm{C}$, just over half the n-propylamine reacted to di-n-propylamine. Td/ms showed that di-n-propylamine decomposed to propene and ammonia at a temperature $50^{\circ} \mathrm{C}$ higher than did n-propylamine.

Therefore the IR spectra of sorbed $n$-propylamine may show signs of further reaction with di-n-propylamine present or decomposition to propene and ammonia with sorbed ammonia, propene or further reaction products present.

\subsubsection{B FTIR Results:}

A wafer of $\mathrm{H}+\mathrm{ZSM}-5$ (prep 816 ) was held at $100^{\circ} \mathrm{C}$ and increasing amounts of n-propylamine injected into the FTIR cell. The resulting spectra are shown in figure 7.24 and the corresponding difference spectra in figure 7.25. The $n-$ propylamine bonds to the zeolite acid sites, as shown by the disappearance of the Bronsted $\mathrm{O}-\mathrm{H}$ stretch and appearance of a broadened $\mathrm{O}-\mathrm{H}$ band at $\sim 3287 \mathrm{~cm}^{-1}$. After the first injection of n-propylamine $(1 \mu l)$ only one third of the Bronsted hydroxyls have bonded and 'protonated' n-propylamine is observed (figures $7.24 \mathrm{~B}$ and $7.25 \mathrm{~B}$ ). The $\mathrm{C}-\mathrm{H}$ stretching region is similar to that of gas phase $n$-propylamine (figure 7.26), although peak intensities are slightly different. The fingerprint region shows bands that can be readily assigned to $n$-propylamine $(26,31,32)$. The band at $1610 \mathrm{~cm}^{-1}$ is due to an $\mathrm{NH}_{2}$ bend or $\mathrm{NH}_{3}{ }^{+}$asymm bend, a band at $1508 \mathrm{~cm}^{-1}$ is due to a $\mathrm{NH}_{3}^{+}$symm bend and bands at 1464 and $1391 \mathrm{~cm}^{-1}$ are due to $\mathrm{CH}_{2}$ bending modes.

Addition of a further $1 \mu l$ of $n$-propylamine results in bonding of two thirds of the Bronsted sites and the spectrum (not shown) is similar to that of figures 7.24 and $7.25 \mathrm{~B}$. The next $1 \mu l$ covers all the acid sites and changes appear in the spectrum (figures $7.24 \mathrm{C}$ and 7.25C). Figures 7.24D and 


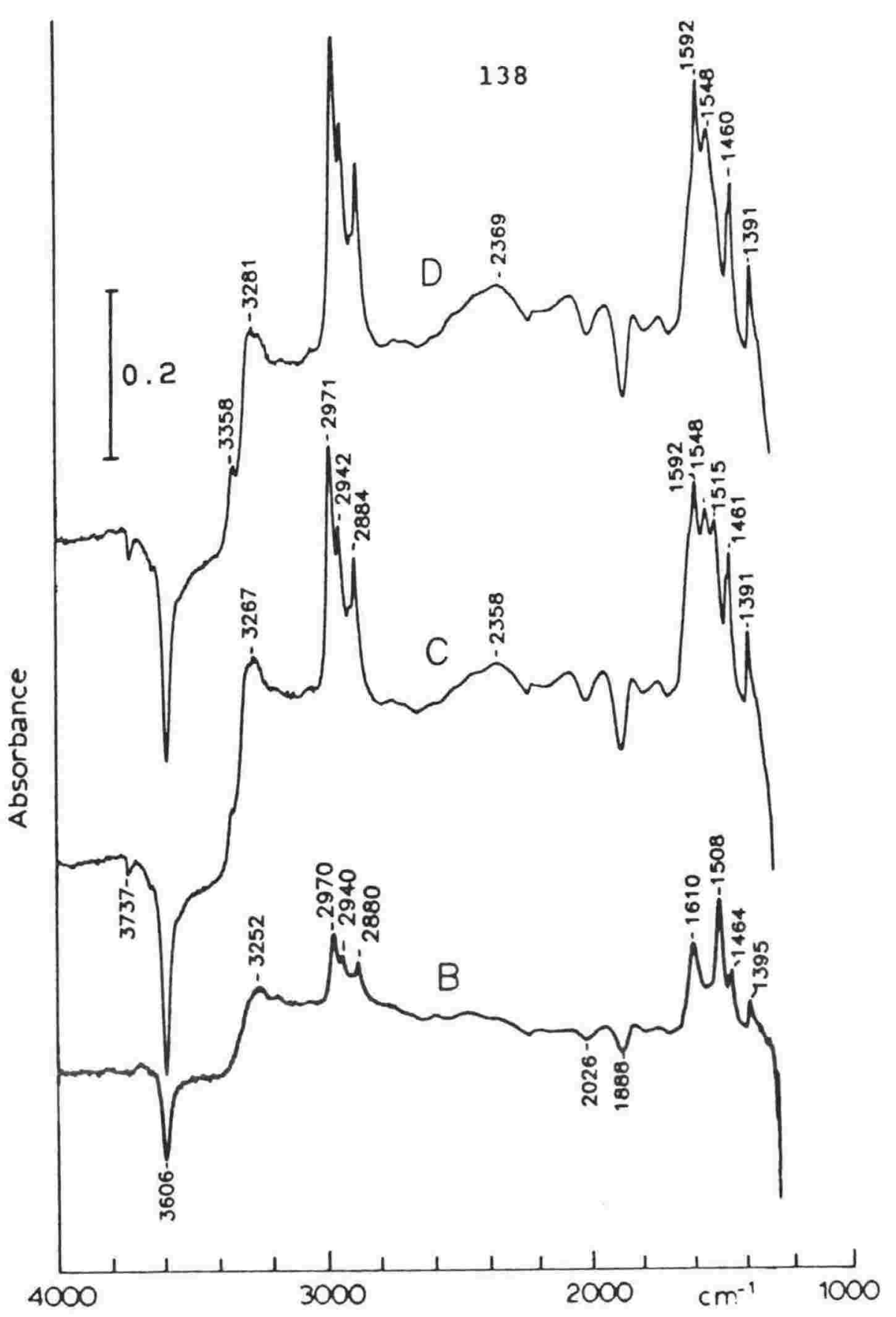

Figure 7.25 FTIR difference spectra of $\mathrm{H}+\mathrm{ZSM}-5$ after addition of $B$. $1 \mu 1$ n-propylamine

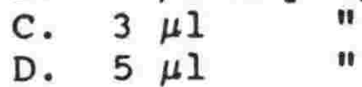

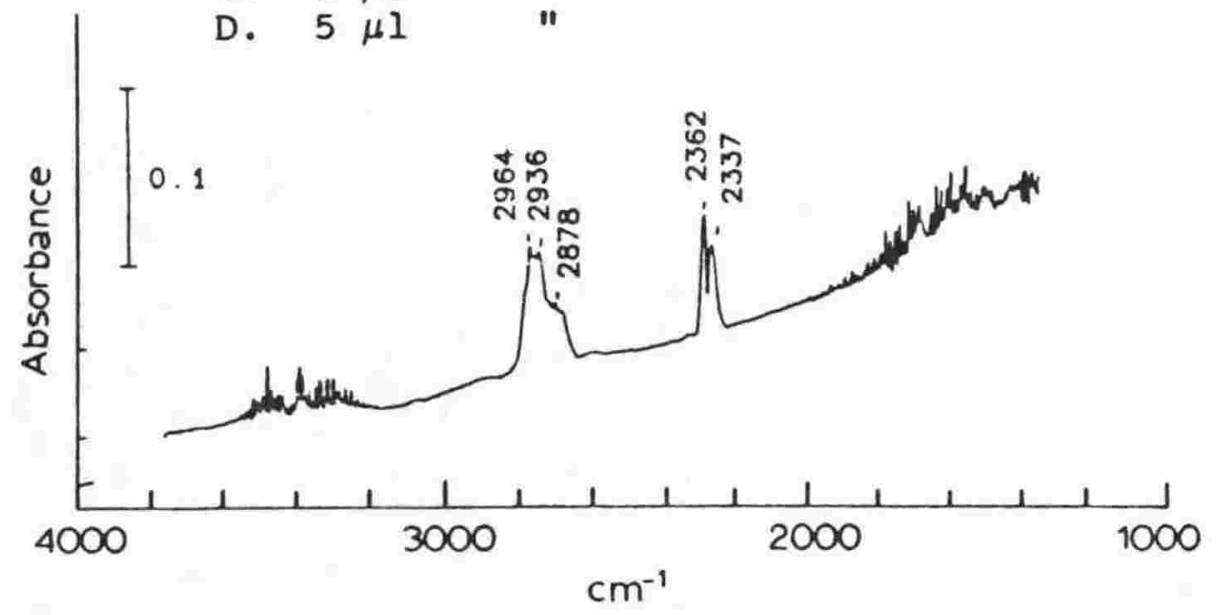

Figure 7.26 FTIR spectrum of gas phase n-propylamine. Gas phase water and $\mathrm{CO}_{2}$ were also present in the cell. 
7.25D show the spectrum after the addition of a further $2 \mu 1$ of n-propylamine. Flushing the cell for $80 \mathrm{~min}$ produces mor changes (figure 7.27A).

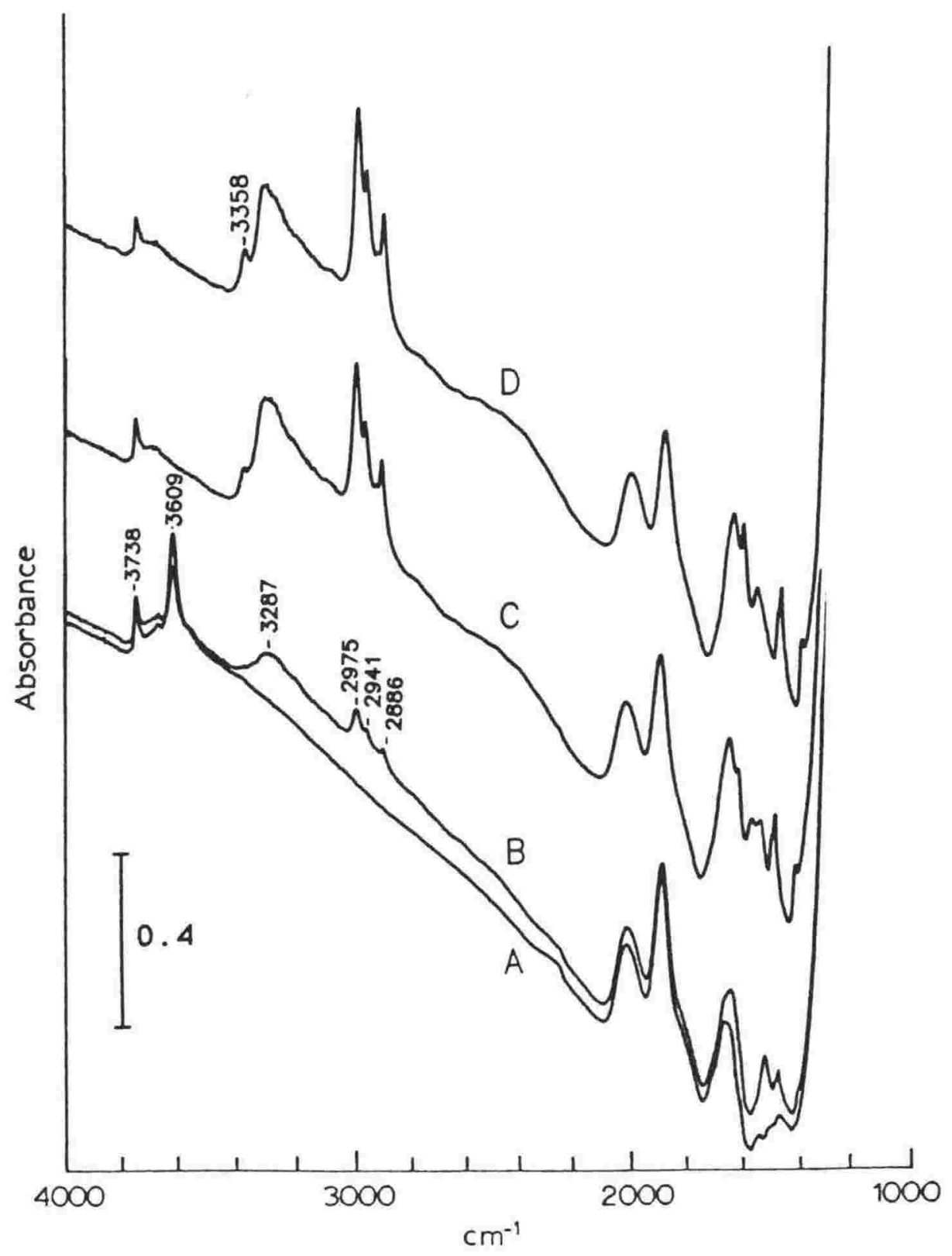

Figure 7.24 FTIR spectra of: A. $\mathrm{H}+\mathrm{ZSM}-5$ at $100^{\circ} \mathrm{C}$;

B. after addition of $1 \mu 1$ n-propylamine

$\begin{array}{lllll}\text { C. " } & \text { " } & \text { " } & 3 & \mu 1 \\ \text { D. } & \text { " } & \text { " } 11\end{array}$ 


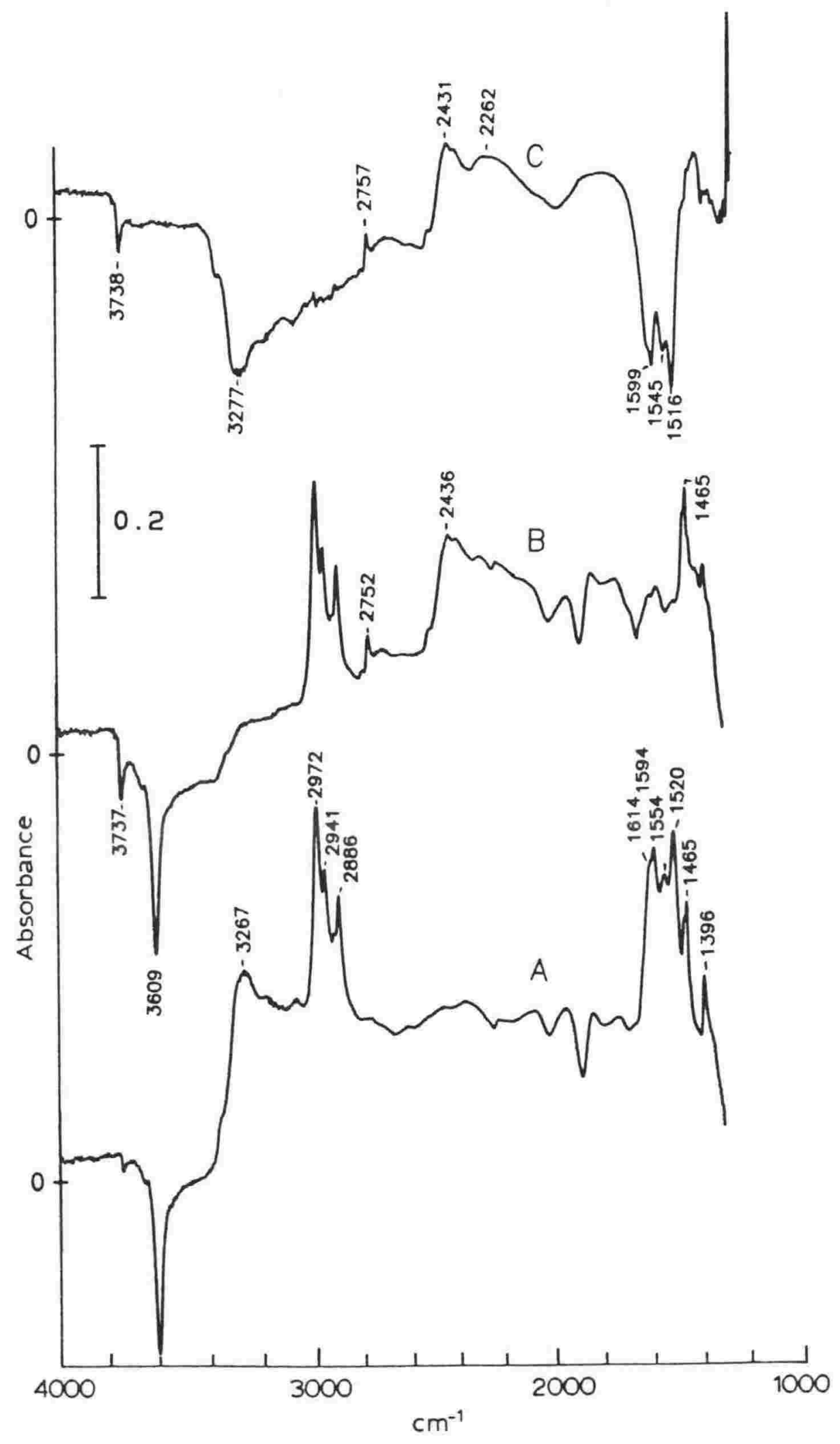

Figure 7.27 FTIR difference spectra: A. $5 \mu l$ n-propylamine sorbed then flushed $80 \mathrm{~min}$ at $100^{\circ} \mathrm{C} ; \mathrm{B}$. sample from $A$ after addition of three $1 \mu l$ pulses of $\mathrm{D}_{2} \mathrm{O}$ and $\mathrm{C}$. the difference spectrum B-A. 
In figures $7.24 \mathrm{C}, 7.24 \mathrm{D}, 7.25 \mathrm{C}$ and $7.25 \mathrm{D}$ a peak appears at $3358 \mathrm{~cm}^{-1}$ on the edge of the bonded hydroxyl band at a similar wavenumber to Bronsted hydroxyls bonded to ammonia. This almost disappears upon flushing (figure 7.27A), therefore is not ammonia as ammonia is more strongly bound and would have remained sorbed at $100^{\circ} \mathrm{C}$. The $\mathrm{C}-\mathrm{H}$ stretching region did not alter significantly. A broad band appeared at $-2360 \mathrm{~cm}^{-1}$ and the fingerprint region showed major changes, varying with the amount of sorbed n-propylamine. The bands assigned to $\mathrm{CH}_{2}$ bends (1464 and $1391 \mathrm{~cm}^{-1}$ ) stay at approximately the same wavenumber, just increasing in size. The region 1700 to $1500 \mathrm{~cm}^{-1}$, assigned to $\mathrm{NH}_{2}$ and $\mathrm{NH}_{3} \mathrm{~N}-\mathrm{H}$ bends shows a continual variation. If these changes were due to increasing amounts of physisorbed n-propylamine or di-n-propylamine, the $\mathrm{NH}_{2}$ bend at $1610 \mathrm{~cm}^{-1}$ should consistently increase. This is not observed.

$\mathrm{H} / \mathrm{D}$ exchange by addition of $\mathrm{D}_{2} \mathrm{O}$ into the cell at $100^{\circ} \mathrm{C}$ provided further information. The difference spectrum is shown in figure $7.27 \mathrm{~B}$, and the difference spectrum between figures $7.27 \mathrm{~B}$ and $7.27 \mathrm{~A}$ is shown in figure $7.27 \mathrm{C}$. An almost triangular shaped $\mathrm{O}-\mathrm{H}$ band ( $\max$ at $3263 \mathrm{~cm}^{-1}$ ) was lost with a corresponding $O-D$ band appearing ( $\max$ at $2431 \mathrm{~cm}^{-1}$ ). The $\mathrm{C}-\mathrm{H}$ stretching and bending regions were not altered, but the region assigned to $\mathrm{NH}_{2}$ or $\mathrm{NH}_{3}^{+}$bending was lost. This confirms their assignment.

The interactions that are occuring between the 'protonated' n-propylamine and further n-propylamine after the Bronsted sites have been bonded are complex and vary with time. Further work combining tga, $t d / m s$ and FTIR techniques could be done to show whether this effect is due to formation of hydrogen bonded amine dimers, or to reaction to ammonia and di-n-propylamine. 


\subsubsection{1,3 diaminopropane on H+Z8M-5:}

Source: Eastman practical grade.

1,3 Diaminopropane was used as a probe molecule because of its very high proton affinity $\left(979 \mathrm{~kJ} \mathrm{~mol}^{-1}\right.$ compared to $912 \mathrm{~kJ}$ $\mathrm{mol}^{-1}$ for $\mathrm{n}$-propylamine), and because it has two basic groups, one at each end of the molecule, which may lead to some interesting steric effects depending on the proximity of adjacent acid sites.

FTIR spectra for increasing amounts of 1,3 diaminopropane sorbed on $\mathrm{H}+\mathrm{ZSM}-5$ held at $150^{\circ} \mathrm{C}$ are shown in figure 7.28 . The corresponding difference spectra are shown in figure 7.29. The amine bonded to the Bronsted hydroxyls with a resultant very broad absorption from $\sim 3400$ to $\sim 2000 \mathrm{~cm}^{-1}$. Its maxima is approximately the same as for n-propylamine, not at lower wavenumber as might be expected from its higher proton affinity. The diaminopropane is therefore bonded in a similar manner to n-propylamine, with only one amine group bonded to the acid site. Steric limitations in the zeolite channels may prevent the full interaction of the second amine group that occurs in the gas phase, reducing its effective proton affinity. Interaction of the second amine group does occur, as shown by the much wider range of proton frequencies compared to the n-propylamine case.

The $\mathrm{C}-\mathrm{H}$ stretching region (around $2900 \mathrm{~cm}^{-1}$ ) is very indistinct (compared to the n-propylamine case), only appearing after addition of $1.25 \mu l$ of diaminopropane (figures $7.28 \mathrm{~B}$ and $7.29 \mathrm{~B}$ ). This may be because of the range of orientations of the diaminopropane molecules as they distort to minimise the energy of the second amine group.

In the difference spectra (figure 7.29) the fingerprint region $\left(\mathrm{NH}_{2}, \mathrm{NH}_{3}^{+}\right.$and $\mathrm{CH}_{2}$ bending) also shows broad peaks for the smaller additions of diaminopropane. With amounts of diaminopropane added greater than 1.25ul, these peaks sharpen. They also change with further addition of the amine. After addition of $3.25 \mu 1$ of diaminopropane and waiting one hour at $150^{\circ} \mathrm{C}$, the spectrum in figures $7.28 \mathrm{E}$ and 
7.29E was obtained. The variations observed are similar to those observed for n-propylamine due to interaction with more than one amine molecule per acid site.

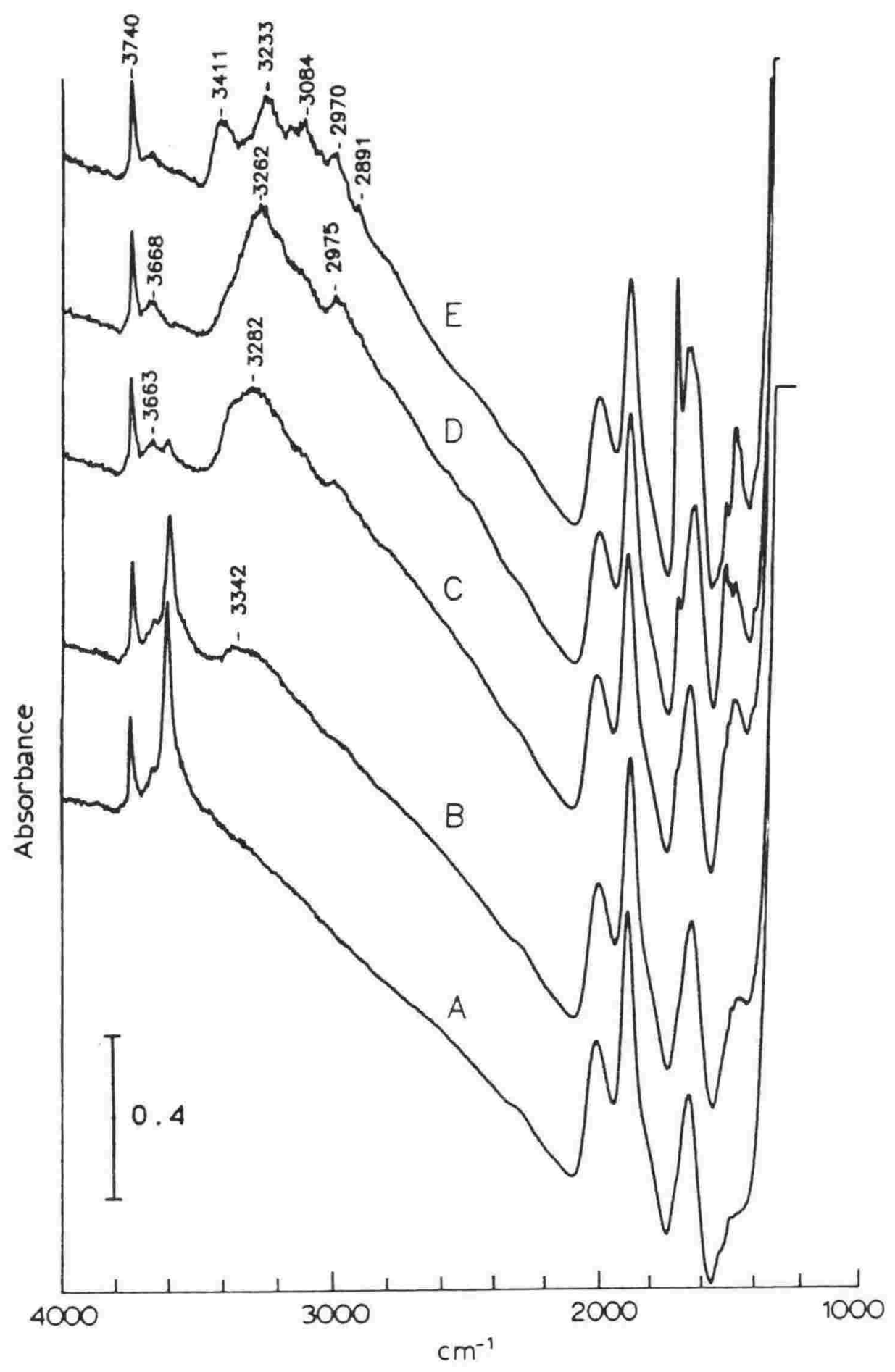

Figure 7.28 FTIR spectra of A. dry $\mathrm{H}+\mathrm{ZSM}-5$ at $150^{\circ} \mathrm{C}$;

B. after addition of $0.75 \mu 11,3$ diaminopropane;

C. " " $1.25 \mu l$

D. " " " $1.75 \mu 1$

E. "

" $3.23 \mu 1$

$n$

", then flushing $1 \mathrm{~h}$. 


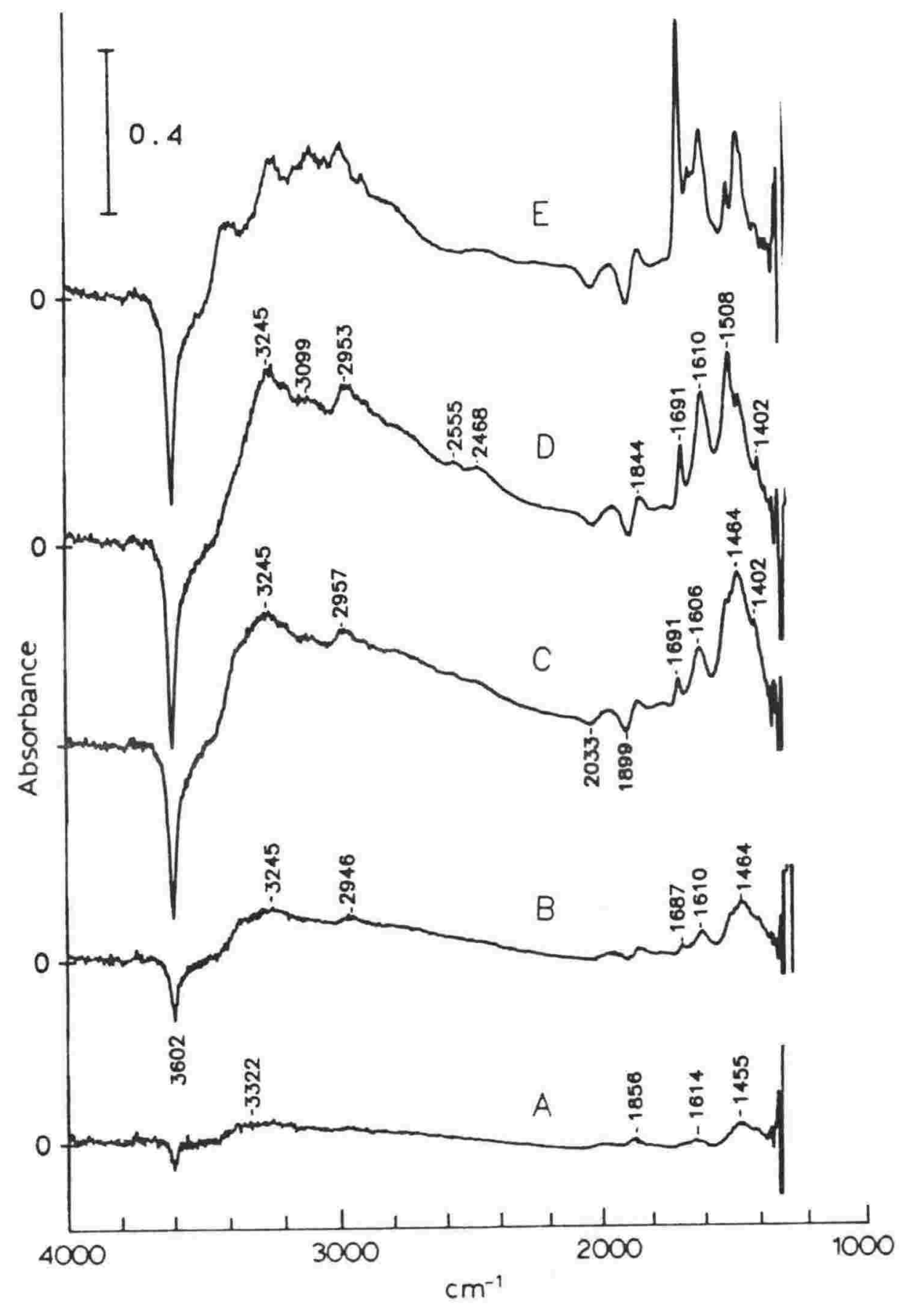

Figure 7.29 FTIR difference spectra of dry $\mathrm{H}+\mathrm{ZSM}-5$ at $150^{\circ} \mathrm{C}$ A. after addition of $0.25 \mu l 1,3 d$ iaminopropane;

$B, C, D$ and $E$ correspond to spectra in figure 7.28 . 


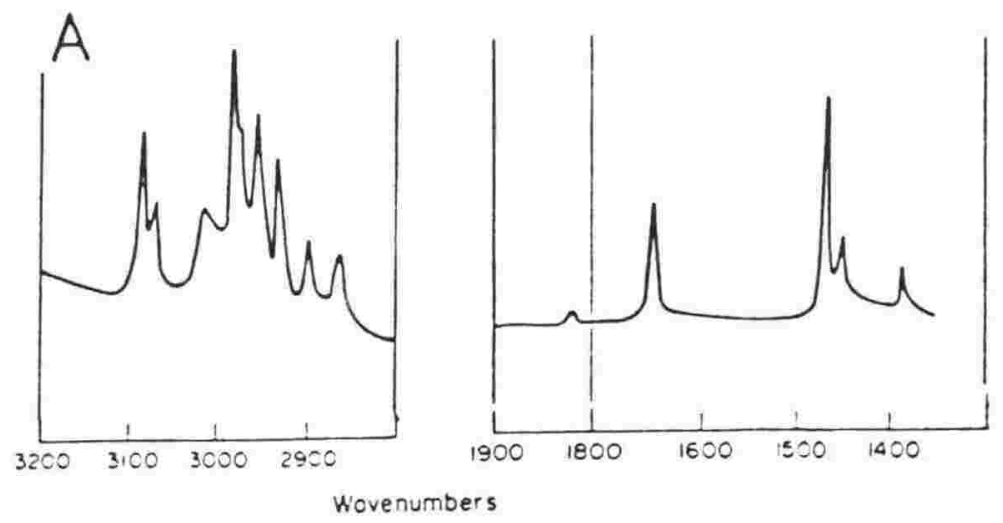

FTIR spectrum of propene sorbed on silica at $200 \mathrm{~K}$.

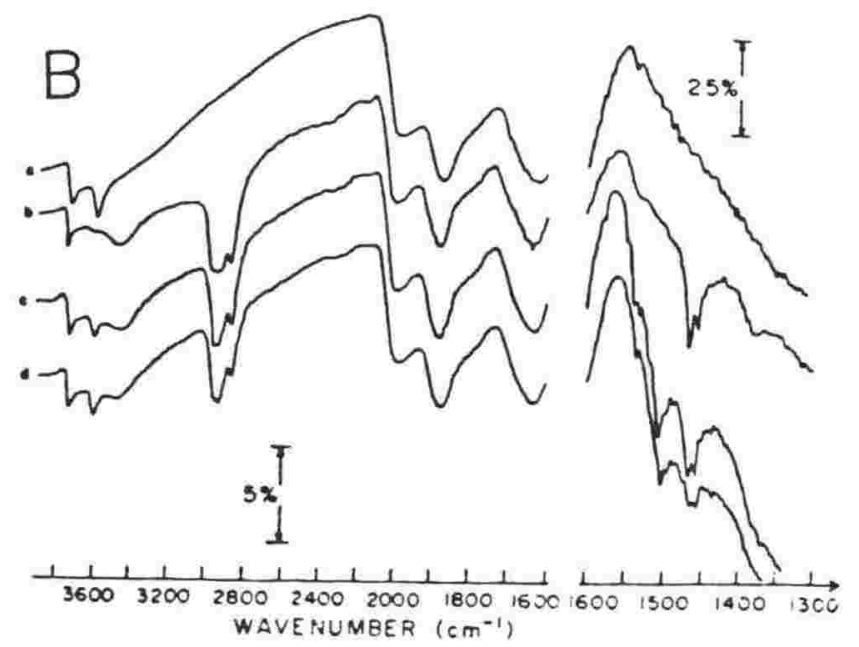

Transmission infrared spectra of propene adsorbed on $\mathrm{H}$ ZSM-5. The sample was exposed to 200 torr for $30 \mathrm{~s}$, followed by evacuation and heating to the following temperatures: (b) $293 \mathrm{~K}$, (c) 390 $\mathrm{K}$, and $(5) 440 \mathrm{~K}$.

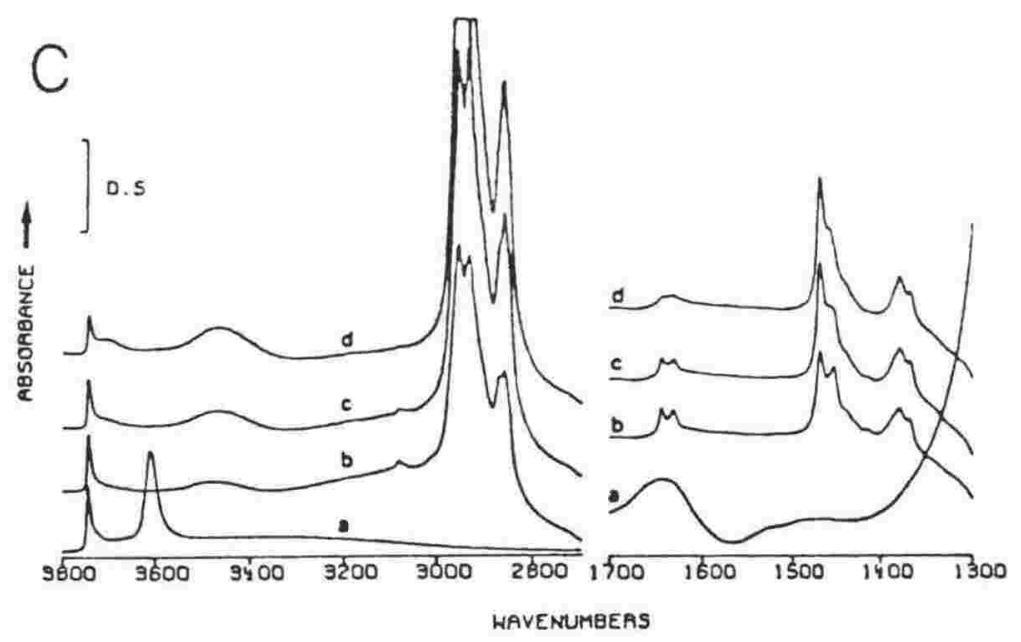

Infrared spectra of HZSM-5 zeolite: (a) Before propene adsorption. (b-d) At different times after propene adsorption and reaction at ambient temperature: (b) $1.5 \mathrm{~min}$, (c) $37 \mathrm{~min}$, (d) $4 \mathrm{~h} 13 \mathrm{~min}$. 


\section{CLASS B SORBANTS}

\subsection{FTIR of Alkenes sorbed on Bronsted Acid sites:}

\subsubsection{Introduction:}

An FTIR study of the molecular interactions of olefins with oxide surfaces has been carried out by Busca et al. (33) which included a study of alkenes on amorphous silica at $200 \mathrm{~K}\left(-73^{\circ} \mathrm{C}\right)$. Perturbation of the $\Delta v_{a_{H}}$ of surface silanol groups clearly indicated interaction with these sites. Comparison with gas phase spectra of the alkenes (33) showed that the $\cup \mathrm{C}=\mathrm{C}, \cup \mathrm{CH}_{2}=, \delta=\mathrm{CH}$ - and $\delta \mathrm{CH}_{2}=$ vibrational modes were significantly perturbed upon adsorption. The $v_{0 . H}$ band of surface silanols broadened and shifted to lower wavenumbers, the shift did not depend upon adsorption temperature, but was sensitive to the electron density on the olefin double bond, both increasing in the order: ethene < propene $=1$-butene $<2$-butenes. For ethene sorbed on $\mathrm{SiO}_{2}$, $v_{\mathrm{O} . \mathrm{H}}$ shifted $115 \mathrm{~cm}^{-1}$. They concluded the sorption of alkenes was through interaction of the $\pi$ electrons of the double bond with the surface hydroxyls.

Both Grady and Gorte (15) and Ghosh and Kydd (34) studied propene sorption on $\mathrm{H}+\mathrm{ZSM}-5$ at $20^{\circ} \mathrm{C}$. A comparison of their spectra (figure $7.30 \mathrm{~B}$ and $\mathrm{C}$ respectively) with those of unreacted propene sorbed on silica (figure 7.30A) (Busca et al.(33)) showed that propene completely reacted in less than 1.5 minutes at $20^{\circ} \mathrm{C}$. This was shown by loss of the $\mathrm{v}_{a} \mathrm{CH}_{2}$ at 3083 and $3067 \mathrm{~cm}^{-1}$ and the $V \mathrm{C}=\mathrm{C}$ at $1653 \mathrm{~cm}^{-1}$. 


\subsubsection{Ethene:}

Source: NZIG special gas

A wafer of dry $\mathrm{H}+\mathrm{ZSM}-5$ (figure 7.31A) was held in the FTIR cell at $21^{\circ} \mathrm{C}$ and $0.5 \mathrm{ml}$ ethene injected. A spectrum (figure 7.31B) and difference spectrum (figure 7.31C) were obtained immediately afterwards. Some of the ethene had bonded to the Bronsted acid sites, as shown by the reduction in intensity of the $3610 \mathrm{~cm}^{-1}$ band. A very broad band from $\sim 3600$ to $\sim 2900$ $\mathrm{cm}^{-1}$ appeared. Not enough ethene was sorbed to obtain frequencies for the $\mathrm{C}-\mathrm{H}$ stretches of sorbed ethene. Some gas phase ethene (figure 7.23A) was also present. Within 10 minutes the ethene had desorbed and was replaced by water that was present in trace amounts in the cell.

In an attempt to sorb more ethene into the zeolite, $20 \mathrm{ml}$ of ethene was injected and held in the cell over the sample for 20 minutes before flushing. The spectra at commencement of flushing are shown in figure $7.32 \mathrm{~B}$ and $7.32 \mathrm{D}$, and the spectrum after flushing for 4 minutes are shown in figure $7.32 \mathrm{C}$ and $7.32 \mathrm{E}$. Reaction had occured, as shown by changes in the $\mathrm{C}-\mathrm{H}$ stretching region, and water had also sorbed onto the sample.

Ethene therefore has a low affinity for $\mathrm{H}+\mathrm{ZSM}-5$ and is only weakly sorbed. However, once sorbed, it reacts further at room temperature. 


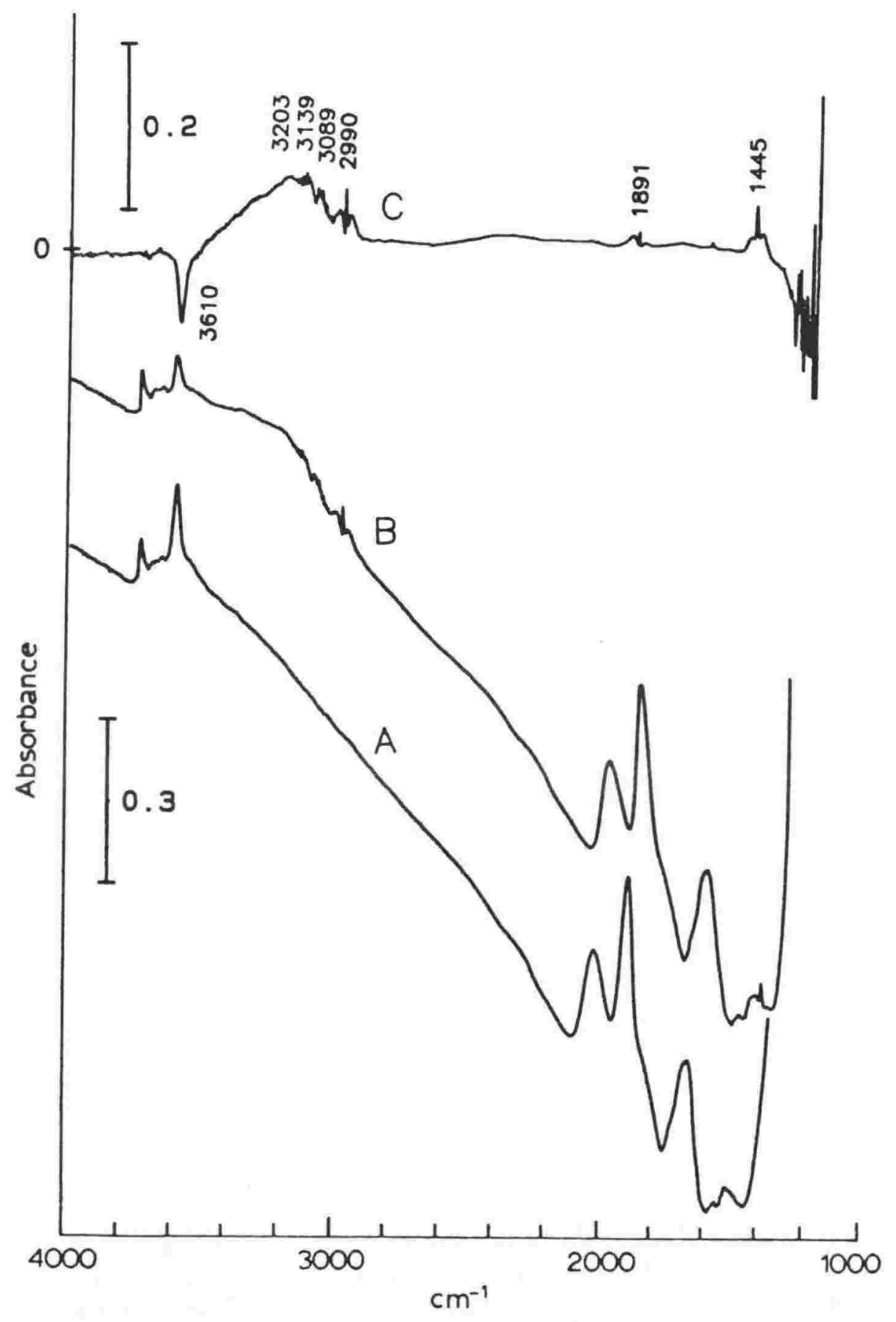

Figure 7.31 FTIR spectra of: A. dry $\mathrm{H}+\mathrm{ZSM}-5$ at $21^{\circ} \mathrm{C}$; B. immediately after addition of $0.5 \mathrm{ml}$ ethene and

C. the difference spectrum $(B-A)$. 


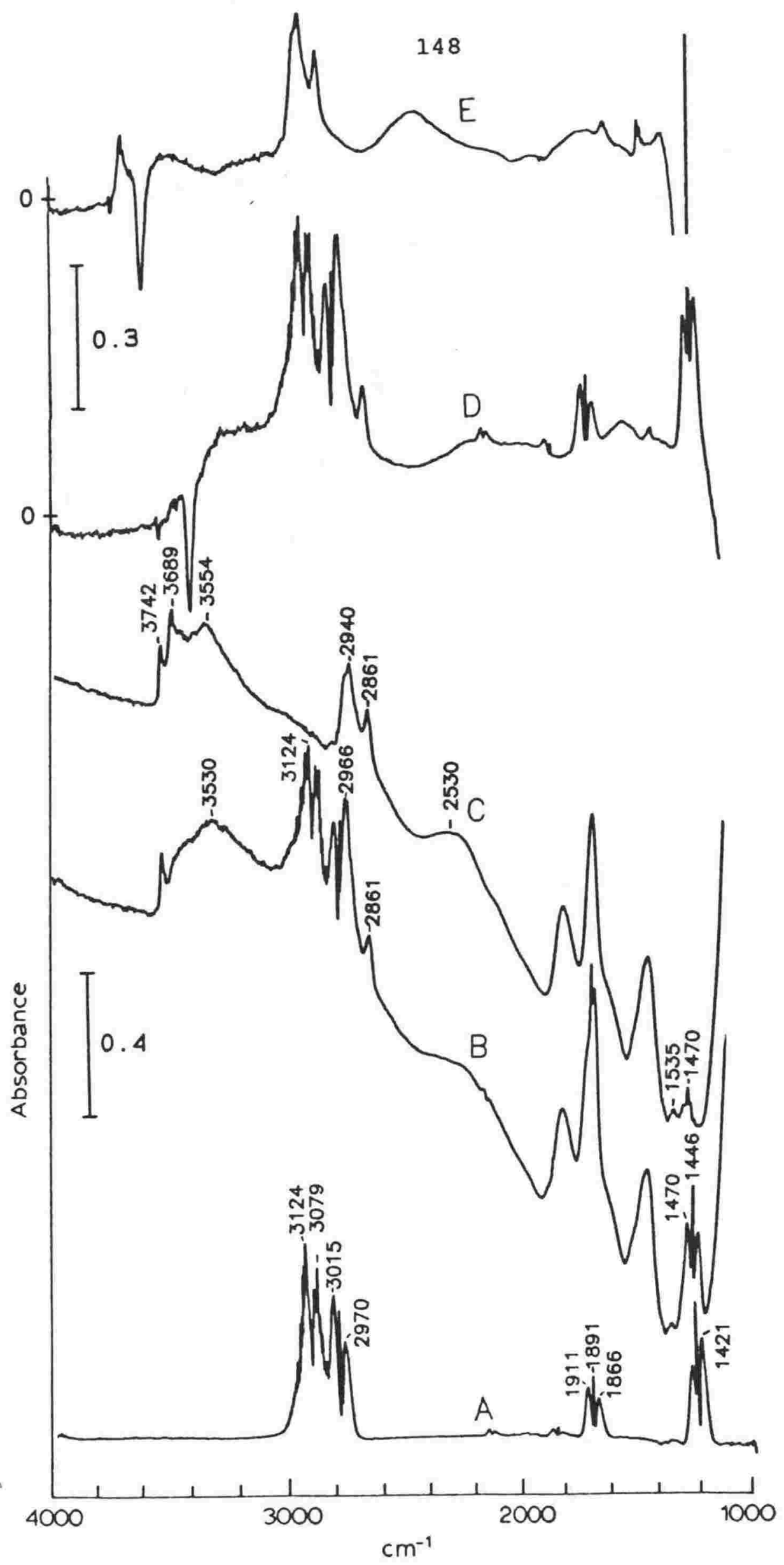

Figure 7.32 FTIR spectra at $21^{\circ} \mathrm{C}$ of: A. gas phase ethene; B. H+ZSM-5 after holding $20 \mathrm{ml}$ ethene in the FTIR cell for $20 \mathrm{~min} ; \mathrm{C}$. after flushing the cell for $4 \mathrm{~min}$ to remove gas phase ethene and the difference spectra: D. (B-figure 7.31A) and E. (C- figure 7.31A). 


\subsubsection{Propene:}

source: Matheson lecture bottle

The difference spectrum obtained after sorption of propene on $\mathrm{H}+\mathrm{ZSM}-5$ held at $80^{\circ} \mathrm{C}$ is shown in figure 7.33. A ccmparison with the spectrum of propene sorbed on silica at $-73^{\circ} \mathrm{C}$ (Busca et al.(33)) showed that reaction had occured. The resultant species is similar to that observed by Ghosh and Kydd (34). It is also similar to that of sorbed hexane, both in the $\mathrm{C}-\mathrm{H}$ stretching region and in the shape of the bonded hydroxyl peak. For alkenes and aromatics a broad flat hydroxyl band is observed, but for the reaction product and sorbed alkanes a more sharply defined peak is observed. This implies that the reaction product is more similar to an alkane than an alkene.

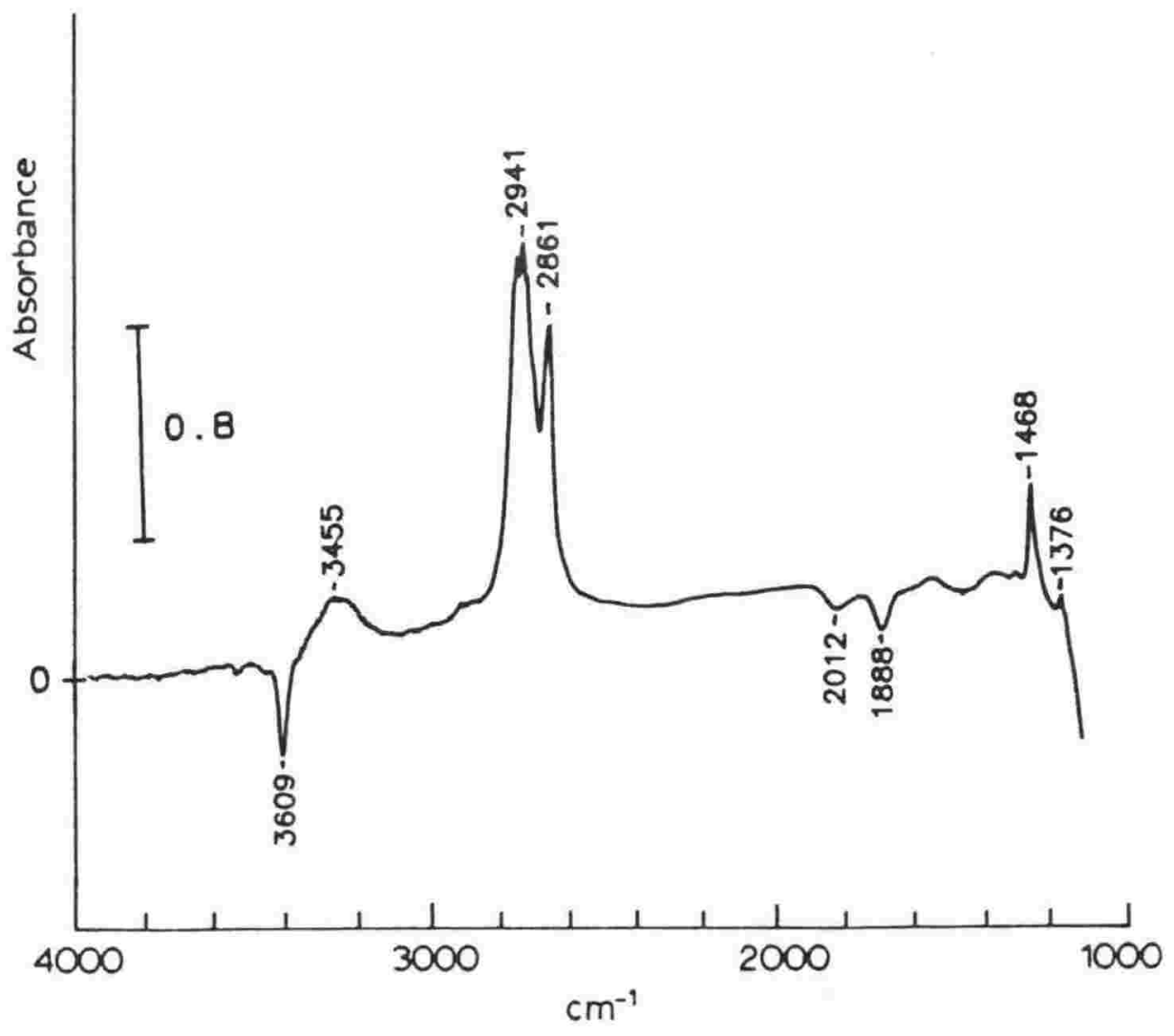

Figure 7.33 FTIR difference spectrum of propene sorbed on $\mathrm{H}+\mathrm{ZSM}-5$ held at $80^{\circ} \mathrm{C}$. 


\subsubsection{Isobutene:}

Source: Matheson lecture bottle

Isobutene sorbed on $\mathrm{H}+\mathrm{ZSM}-5$ held at $80^{\circ} \mathrm{C}$ also reacted rapidly. This can be seen by a comparison of the difference spectrum (figure 7.34B) with the spectrum of gas phase isobutene (figure $7.34 \mathrm{~A}$ ). The $\mathrm{C}-\mathrm{H}$ hydrogens of the resultant species showed $\mathrm{H} / \mathrm{D}$ exchange when $\mathrm{D}_{2} \mathrm{O}$ was passed through the sample. The spectrum in figure $7.34 \mathrm{C}$ shows the difference between the spectrum obtained after $\mathrm{D}_{2} \mathrm{O}$ addition and the spectrum obtained before. The bonded Bronsted $\mathrm{O}-\mathrm{H}$ peak $\left(-3453 \mathrm{~cm}^{-1}\right)$ has been lost and replaced by O-D $\left(-2555 \mathrm{~cm}^{-1}\right)$, and the intensity of the $\mathrm{C}-\mathrm{H}$ stretching region reduced. Resultant C-D stretches are observed $\left(\sim 2200 \mathrm{~cm}^{-1}\right)$. This exchange of $\mathrm{C}-\mathrm{Hs}$ shows that the hydrogens of the sorbed species are interacting/exchanging with the Bronsted proton. 


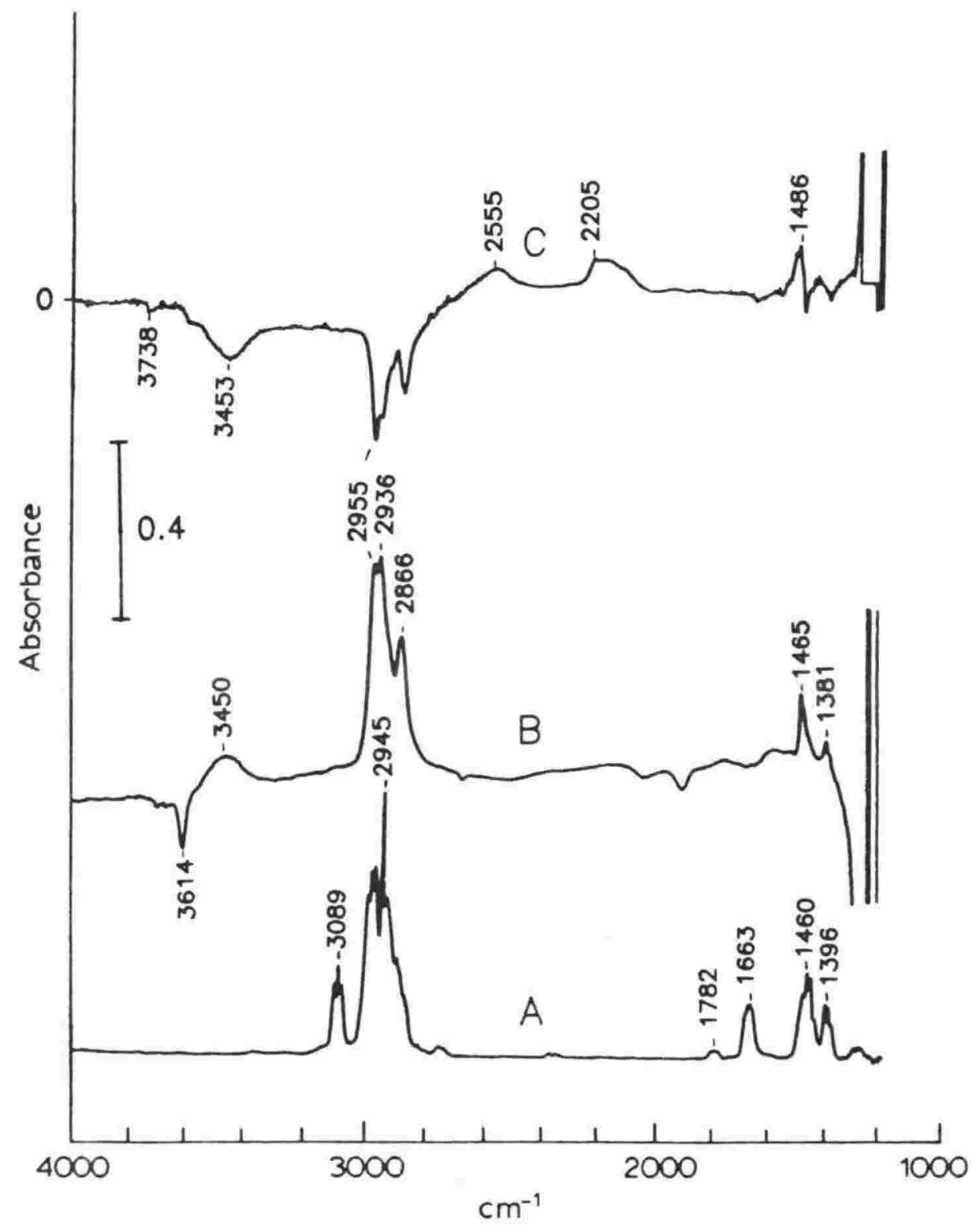

Figure 7.34 FTIR spectra: A. gas phase isobutene; B. the difference spectrum of isobutene sorbed on $\mathrm{H}+\mathrm{ZSM}-5$ held at $80^{\circ} \mathrm{C} ; \mathrm{C}$. the changes that occured to the difference spectrum upon addition of $\mathrm{D}_{2} \mathrm{O}$ to the FTIR cell. 


\subsubsection{Sorption of Benzene and Toluene on H+ZSM-5}

\subsubsection{A Introduction:}

IR spectroscopy of benzene has been used as a basic probe molecule to compare the acid strengths of $\mathrm{H}+\mathrm{ZSM}-5, \mathrm{H}+\mathrm{ZSM}-11$ and $\mathrm{H}+\mathrm{Y}$ (Jacobs et al.(3)). No spectra were published, but a table was presented of the frequency shifts and their relative intensities:

Table 7.2 Frequency shifts of hydroxyl bands, $\Delta v_{\mathrm{O}_{H}}$, in zeolites upon interaction with benzene. (from Jacobs et al. (3)).

$v_{\mathrm{O}-\mathrm{H}} \mathrm{Cm}^{-1} \quad \Delta v_{\mathrm{OH}} \mathrm{Cm}^{-1}$

$$
\mathrm{H}+\mathrm{ZSM}-5 \quad \mathrm{H}+\mathrm{ZSM}-11 \quad \mathrm{H}+\mathrm{Y}
$$

$\begin{array}{cccc}3740-3720 & 80 & 72 & 40 \\ 3610-3600 & - & 220 & - \\ & 300 & 300 & 326\end{array}$

For the H+ZSM-5 and $\mathrm{H}+\mathrm{ZSM}-11$ the shifted $3600 \mathrm{~cm}^{-1}$ band was split into at least two components, significantly different in position. They concluded that the $3600 \mathrm{~cm}^{-1}$ band stems from hydroxyls of different strength due to minor differences in local environment. No temperature of sorption was given, so these different bands may be due to physisorbed species (as observed for ammonia (7.4.1)).

Datka (36) studied the sorption of benzene and toluene on NaHY zeolites by IR. Only the HF hydroxyl bonded, shifting to a single broadened peak. Table 7.3 shows the shifts obtained: 
Table 7.3. The frequency shifts of the zeolite $0-\mathrm{H}$ band upon sorption of benzene and toluene (from Datka (36)).

$$
\Delta v_{0 . H} \mathrm{~cm}^{-1}
$$

adsorbate $\mathrm{NaHY}(\mathrm{H} / \mathrm{Na}=0.7) \quad \mathrm{NaHY}(\mathrm{H} / \mathrm{Na}=3.3)$

benzene

296

326

toluene

336

350

These results implied that the acid strength of the $3640 \mathrm{~cm}^{-1}$ $\mathrm{O}-\mathrm{H}$ groups increased with increase in $\mathrm{H}^{+}$concentration.

The $\mathrm{C}-\mathrm{H}$ stretching and combination bands in the region 3000 to $3100 \mathrm{~cm}^{-1}$ were greatly reduced in intensity compared to the solution values, probably due to displacement of the $\pi$ electrons and changes in the dipole moment derivative of the $\mathrm{C}-\mathrm{H}$ bond. The intensities of the $\mathrm{C}-\mathrm{C}$ stretching bands (1477 $\mathrm{cm}^{-1}$ for benzene and $1495 \mathrm{~cm}^{-1}$ for toluene) were not affected by sorption.

\subsubsection{B Results for benzene on $\mathrm{H}+\mathrm{ZSM}-5$ :}

Source: Mallinckrodt AR

The FTIR spectrum of benzene $(3 \mu \mathrm{l})$ sorbed on $\mathrm{H}+\mathrm{ZSM}-5$ held at $100^{\circ} \mathrm{C}$ is shown in figure $7.35 \mathrm{~B}$ and the difference spectrum in figure $7.35 \mathrm{C}$. A single, broad stretch was observed from $\sim 3600$ to $\sim 3000 \mathrm{~cm}^{-1}$. In comparison with the gas phase spectrum (figure 7.35D) the $\mathrm{C}-\mathrm{H}$ stretching region was reduced in intensity relative to the $\mathrm{C}-\mathrm{H}$ bend $\left(1480 \mathrm{~cm}^{-1}\right)$. The $\mathrm{C}-\mathrm{H}$ stretching band (36) (at $3092 \mathrm{~cm}^{-1}$ ) was at the same wavenumber, but the band at $3049 \mathrm{~cm}^{-1}$ (a combination band (36)) was split. This region is also different from benzene sorbed on NaHY which showed peaks at 3090,3078 and $3045 \mathrm{~cm}^{-1}$ (36). These differences are due to differences in the interactions of the benzene ring with its environment.

$\mathrm{H} / \mathrm{D}$ exchange was not possible as the benzene desorbed too rapidly at $80^{\circ} \mathrm{C}$. Lower temperatures could not be used as the $\mathrm{D}_{2} \mathrm{O}$ would then remain sorbed. 


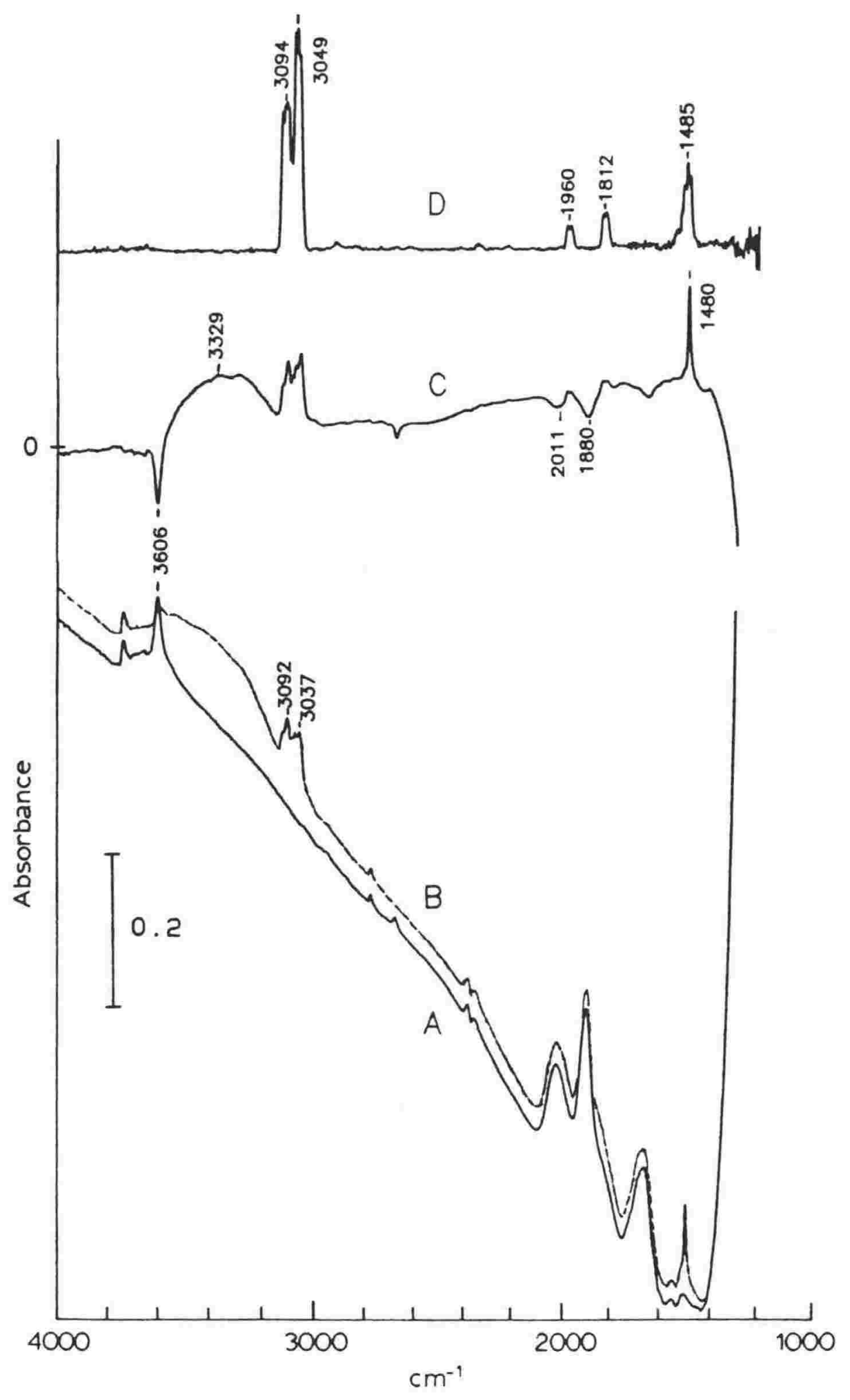

Figure 7.35 FTIR spectra of: A. dry $\mathrm{H} / \mathrm{D}+\mathrm{ZSM}-5$ at $100^{\circ} \mathrm{C}$; B. after addition of benzene; $C$. the difference spectrum $(B-A)$ and $D$. the spectrum of gas phase benzene. 
The experiment to sorb benzene at lower temperatures and obtain the spectrum of physisorbed benzene was not carried out due to lack of time. The reason for more than one hydroxyl peak observed by Jacobs et al. (3) has therefore not been clarified.

\subsubsection{Results for Toluene on H+zSM-5: \\ Source: BDH Analar}

The FTIR spectrum of toluene $(3 \mu \mathrm{l})$ sorbed on $\mathrm{H}+\mathrm{ZSM}-5$ held at $100^{\circ} \mathrm{C}$ is shown in figure $7.36 \mathrm{~B}$ and the difference spectrum in figure 7.37A. A very broad hydroxyl band from $\sim 3600$ to $\sim 2700$ $\mathrm{cm}^{-1}$ was observed. The $\mathrm{C}-\mathrm{H}$ stretching region was very weak, but a sharp ring C-C stretch (assigned by Datka (36)) was observed at $1500 \mathrm{~cm}^{-1}$. At this temperature not all the Bronsted hydroxyls were bonded and the toluene desorbed completely over a period of 20 minutes. H/D exchange by addition of $\mathrm{D}_{2} \mathrm{O}$ after addition of toluene was not successful due to this rapid desorption.

To determine if the $\mathrm{C}-\mathrm{H}$ hydrogens were interacting with the hydrogen bond, most of the Bronsted $\mathrm{O}-\mathrm{H}$ were converted to $\mathrm{O}-\mathrm{D}$ by passing $\mathrm{D}_{2} \mathrm{O}$ through the cell at $100^{\circ} \mathrm{C}$ (figure $7.36 \mathrm{C}$ ), then toluene was sorbed at $80^{\circ} \mathrm{C}$. The resultant spectrum is shown in figure $7.36 \mathrm{D}$ and difference spectrum in figure 7.37B. The Bronsted $\mathrm{O}-\mathrm{D}$ band disappeared and was replaced by a broad $\mathrm{O}-\mathrm{H}$ stretch. This was a result of some of the toluene exchanging $H / D$ with the $O-D$, then desorbing again resulting in a predominantly $\mathrm{O}-\mathrm{H}$ species. Very small $\mathrm{C}-\mathrm{D}$ peaks were observed showing some exchange had occured. The $\mathrm{C}-\mathrm{C}$ stretching region showed an additional peak at $1475 \mathrm{~cm}^{-1}$ perhaps due to an alteration in the ring bending mode.

\subsubsection{Conclusion:}

The similarity in spectra of sorbed benzene and toluene show that both are interacting with the zeolite Bronsted hydroxyls in the same manner - via the aromatic ring. The very broad hydroxyl band may be due to interaction of the entire ring rather than one specific site. 


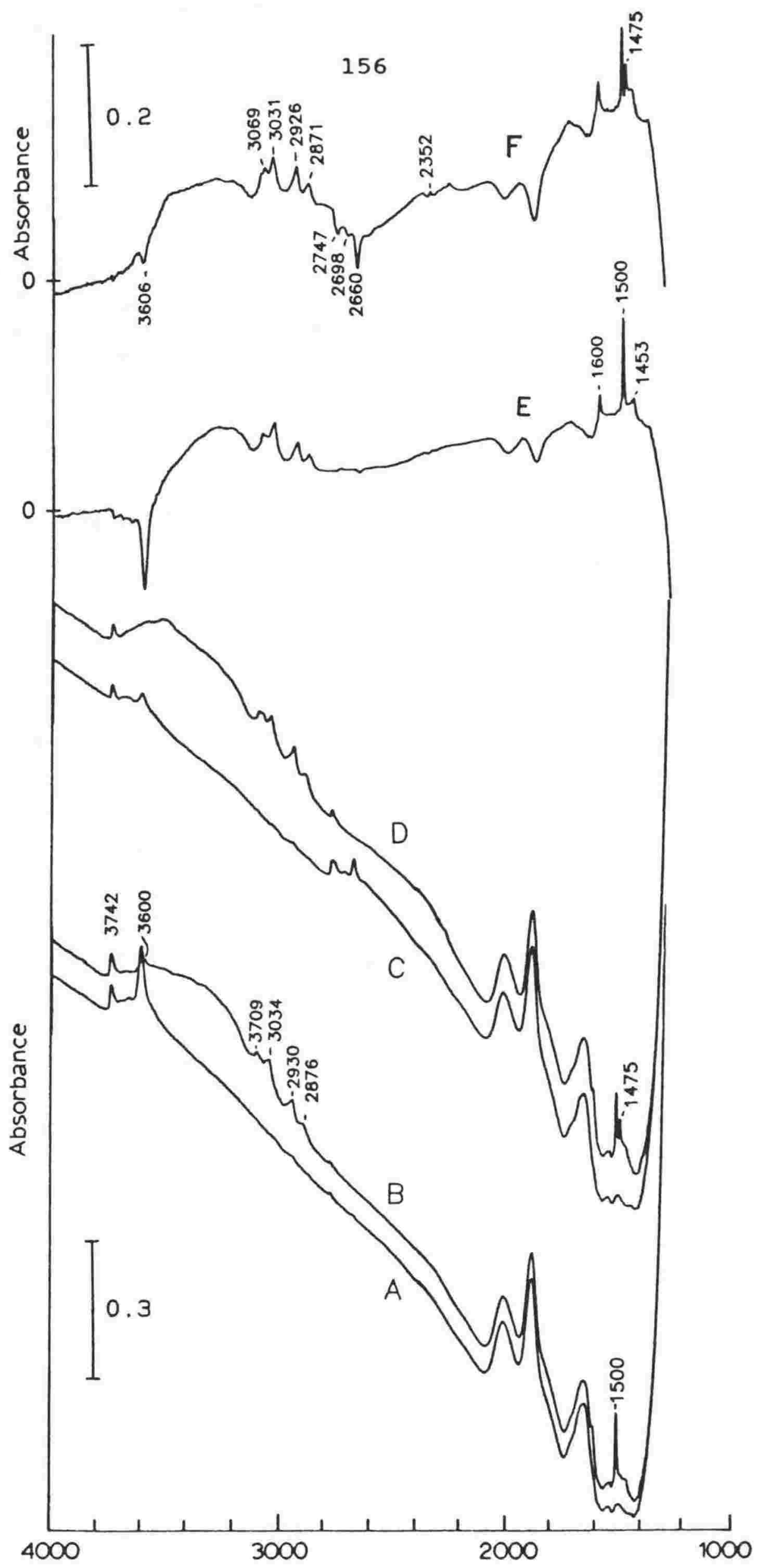

Figure 7.36 FTIR spectra of A. dry $\mathrm{H}+\mathrm{ZSM}-5$ at $100^{\circ} \mathrm{C}$;

B. after sorption of toluene; C. dry $\mathrm{D} / \mathrm{H}+$ at $80^{\circ} \mathrm{C}$ and D. after sorption of toluene.

FTIR difference spectra: E. toluene sorbed on $\mathrm{H}+\mathrm{ZSM}-5$ at $100^{\circ} \mathrm{C}$ and $\mathrm{F}$. toluene sorbed on $\mathrm{D} / \mathrm{H}^{+} \mathrm{ZSM}-5$ at $80^{\circ} \mathrm{C}$. 
CLASS C SORBANTS:

\subsection{Ethers on H+ZSM-5:}

\subsubsection{Introduction:}

In situ FTIR, accompanied by downstream gas chromatography of evolved gaseous products, has been used by Forester and Howe (18) to study the interaction of dimethylether (DME) on $\mathrm{H}+\mathrm{ZSM}-5$. Addition of DME at temperatures between $100^{\circ} \mathrm{C}$ and $200^{\circ} \mathrm{C}$ resulted in the loss of Bronsted hydroxyls and the appearance of broad intense bands at $\sim 2300$ and $\sim 1600 \mathrm{~cm}^{-1}$ and four new bands in the $\mathrm{C}-\mathrm{H}$ stretching region (3011, 2973, 2947 and $\left.2844 \mathrm{~cm}^{-1}\right)$. These were assigned to DME protonated by the zeolite.

The proton affinity difference between the conjugate base of the zeolite acid site and DME was estimated by Forester and Howe (18) by assigning the $2300 \mathrm{~cm}^{-1}$ band to the $v_{\mathrm{s}}{ }^{19} \mathrm{O}-\mathrm{H}-\mathrm{O}$ stretching vibration (of the zeolite-O-H-O $\left(\mathrm{CH}_{3}\right)_{2}$ complex) and the $1600 \mathrm{~cm}^{-1}$ band to the bending mode. The zeolite $\mathrm{O}-\mathrm{H}$ frequency shift upon bonding was comparable to that for adducts of $\mathrm{HCl}$ and $\mathrm{HBr}$ with trimethylamine (measured by Pimentel et al. (37) in solid Ar matrices) in which proton transfer is regarded as complete. The $\mathrm{C}-\mathrm{H}$ frequencies were also shifted upwards by 26 to $67 \mathrm{~cm}^{-1}$ relative to the neutral molecule in solution. Their conclusion (18) was that the DME is completely protonated by the zeolite, forming an ion pair.

Dimethylether and diethylether have been studied by IR in solid argon matrices in ether-alcohol complexes (Luck and Schremes (38)). One-to-one complexes were isolated of the type $\mathrm{R}_{2} \mathrm{O}$...HOR. The alcohol $\mathrm{O}-\mathrm{H}$ stretch was shifted by $\sim 210$ $\mathrm{cm}^{-1}$ to a single broadened peak. No broad multiple bands were observed as occur for ethers sorbed on H+ZSM-5. The spectrum of the $\mathrm{C}-\mathrm{H}$ stretching region did not change significantly between unassociated DME and 'protonated' DME. 
7.6.2 Results and discussion - DME sorbed on $\mathrm{H}+\mathrm{ZSM}-5$ :

Source: Matheson gas.

FTIR spectra of DME sorbed on $\mathrm{H}+2 \mathrm{ZM}-5$ (prep 816 ) held at $80^{\circ} \mathrm{C}$ are shown in figure 7.38 , with the difference spectra shown in figure 7.39. The DME bonds to the Bronsted hydroxyls, as shown by the loss of this peak. The difference spectra show the appearance of three broad bands - one under the $\mathrm{C}-\mathrm{H}$ stretches at $\sim 2900 \mathrm{~cm}^{-1}$, another at $\sim 2400 \mathrm{~cm}^{-1}$ and the third stronger and broader band between 1900 and $1300 \mathrm{~cm}^{-1}$. Superimposed upon this third broad band is a sharp negative and then positive peak at $1460 \mathrm{~cm}^{-1}$. In the gas phase spectrum of DME (figure 7.38D) there is a peak at $1453 \mathrm{~cm}^{-1}$ due to an asymetric $\mathrm{CH}_{3}$ bending mode (39) which is weaker than the $\mathrm{C}-\mathrm{H}$ stretching region, so the sharp positive band observed may be associated with this mode. The negative peak is also apparent on the non-difference spectra. It is not an artifact of the equipment as the same peak was observed by Forester (19), although not commented on.

As noted by Forester and Howe (18) the $\mathrm{C}-\mathrm{H}$ stretches have shifted to higher wavenumber, although the general shape of the peaks in this region is still similar to the gas phase spectrum. A comparison to that of $\mathrm{DME}$ in a solid $\mathrm{CD}_{3} O \mathrm{CD}_{3}$ solution (Allan et al. (39)) showed that the $2838 \mathrm{~cm}^{-1}$ band was $14 \mathrm{~cm}^{-1}$ higher (assigned to $v_{s} \mathrm{CH}_{2 \text { (out) }}+\mathrm{vCH}_{\text {(in) }}$ and the band at $2950 \mathrm{~cm}^{-1}$ was raised $57 \mathrm{~cm}^{-1}$. These changes are probably due to the sensitivity of the spectrum to the symmetry of the species (39), which could be different in the zeolite compared to the solid solution.

With increasing amounts of DME added, the spectra became more complicated in the $\mathrm{C}-\mathrm{H}$ stretching region, closely resembling the gas phase spectrum (figures $7.38 \mathrm{C}$ and $7.39 \mathrm{C}$ ). (The gas phase spectrum is more complicated because the hydrogen atoms are non-equivalent (Allan et al.(39))). A small amount of DME is associated with the SiO-H sites as the silanol peak (at $3740 \mathrm{~cm}^{-1}$ ) decreased in intensity. 


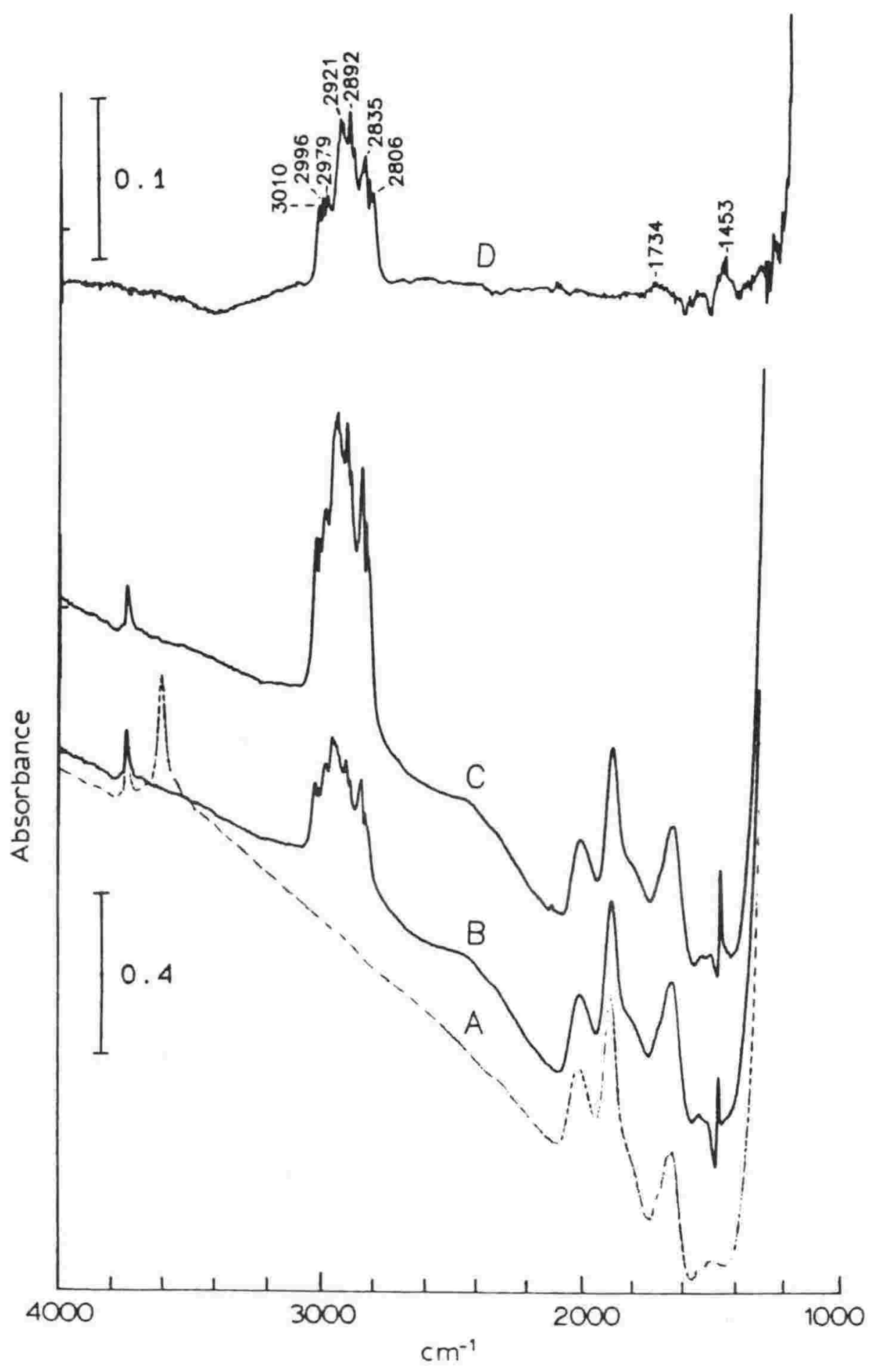

Figure 7.38. FTIR spectra of: A. dry $\mathrm{H}+\mathrm{ZSM}-5$ at $80^{\circ} \mathrm{C}$; B. after addition of $0.5 \mathrm{ml}$ DME; B. after addition of $2 \mathrm{ml}$ DME; D. gas phase DME. 


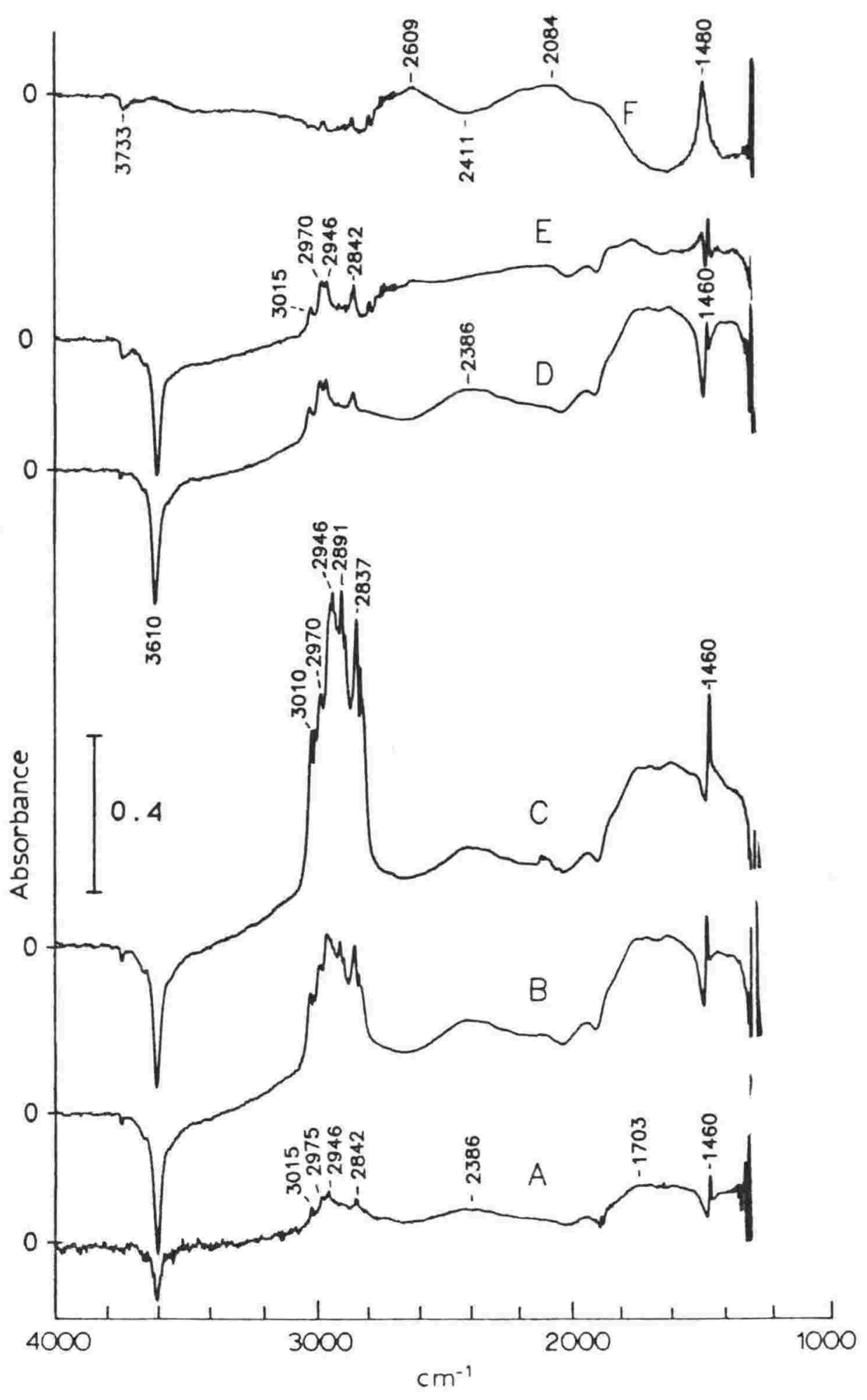

Figure 7.39. FTIR difference spectra:

A. after addition of $0.1 \mathrm{ml}$ DME at $80^{\circ} \mathrm{C}$;

B. " " " $0.5 \mathrm{ml} "$

C. " " $2.0 \mathrm{ml} "$

D. after flushing $20 \mathrm{~min}$ at $80^{\circ} \mathrm{C} ; \mathrm{E}$. after addition of two 1 $\mu 1$ pulses of $\mathrm{D}_{2} \mathrm{O}$ and $\mathrm{F}$. the difference spectrum (E-D). 
After flushing the cell for $20 \mathrm{~min}$ (figure $7.39 \mathrm{D}$ ), all the physisorbed and gas phase DME was removed, with the spectrum obtained very similar to that after initial sorption of DME (figure 7.39A). This shows that the sorbed species is not reacting significantly at this temperature.

Upon DME sorption the sharp Bronsted hydroxyl stretch disappeared, with broad bands appearing. The broad bands were shown to be due to exchangeable protons by a technique that was developed in this work. $D_{2} O$ was injected into the cell, with the sample held at a high enough temperature so that the $\mathrm{D}_{2} \mathrm{O}$ interacted with any labile protons, then desorbed. The difference spectrum before $D_{2} \mathrm{O}$ addition is shown in figure $7.39 \mathrm{D}$ and the difference spectrum after $\mathrm{D}_{2} \mathrm{O}$ addition in figure $7.39 \mathrm{E}$. The differences between these two spectra (figure 7.39E - 7.39D) is shown in figure 7.39F. The negative peaks in figure $7.39 \mathrm{~F}$ show the bands that were due to exchangeable protons. They have a very wide range of frequencies/energies with a sharp gap at $1480 \mathrm{~cm}^{-1}$. The $\mathrm{C}-\mathrm{H}$ stretching region is unaltered showing that the methyl groups were not interacting with the Bronsted proton.

To obtain further evidence on the identity of the sorbed DME species, td/ms was carried out. DME was sorbed onto a wafer on $\mathrm{H}+\mathrm{ZSM}-5$ in the FTIR cell held at $100^{\circ} \mathrm{C}$. The FTIR spectrum was recorded and shown to be the same as figure 7.39D. The FTIR cell was then connected to the ms system and an atmospheric pressure $t d / m s$ carried out. As shown in figure 7.40 the initial species to desorb was DME from $110^{\circ} \mathrm{C}$ ( $\operatorname{Tmax}$ at $190^{\circ} \mathrm{C}$ ). From $150^{\circ} \mathrm{C}$ methanol desorbed (Tmax at $205^{\circ} \mathrm{C}$ ), then a further reaction product (propene or propane) was observed (Tmax at $215^{\circ} \mathrm{C}$ ). That methanol was desorbed shows the reversibility of the methanol to DME reaction. Td/ms of methanol sorbed on $\mathrm{H}+\mathrm{ZSM}-5$ (figure 7.8 ) showed that methanol desorbed from $50^{\circ} \mathrm{C}\left(T \max\right.$ at $\left.135^{\circ} \mathrm{C}\right)$. Therefore, in the DME case, reaction to produce methanol from the sorbed DME species was the limiting factor, followed by rapid desorption of the methanol. 


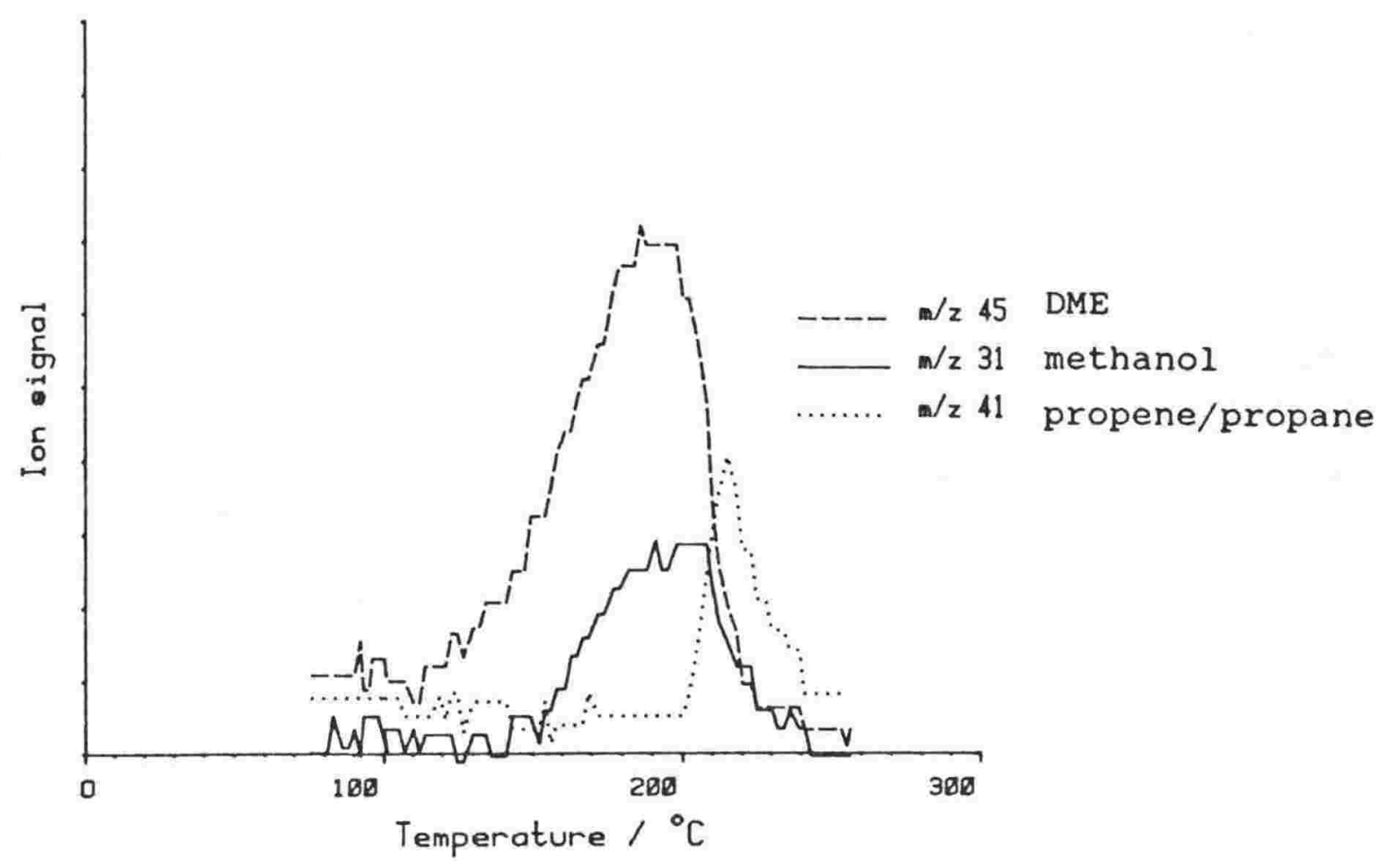

Figure 7.40. Td/ms of DME sorbed on H+ZSM-5, using the FTIR cell.

The observation of hydrocarbons at $>200^{\circ} \mathrm{C}$ is in agreement with Forester and Howe (18), who observed by FTIR a different sorbed species at temperatures $>200^{\circ} \mathrm{C}$. This species had the ability to methylate other species and was associated with hydrocarbon formation.

These $t d / m$ s results support the theory that DME is sorbed intact at the zeolite acid sites. 


\subsubsection{Diethylether on B+ZSM5}

Source: BDH AR.

Diethylether sorbed on $\mathrm{H}+\mathrm{ZSM} 5$ held at $80^{\circ} \mathrm{C}$ behaved similarly to the DME case. The difference spectra obtained with the addition of increasing amounts of diethylether are shown in figure $7.41 \mathrm{~A}$ and $\mathrm{B}$. The diethylether bonded to the Bronsted hydroxyl (shown by the negative $3610 \mathrm{~cm}^{-1}$ peak), and broad bands appeared. No significant changes occured in the spectra upon addition of further diethylether and waiting $\sim 5$ min (figure 7.41C). A comparison with the gas phase spectrum (obtained in the FTIR cell) (figure 7.41D) shows only minor changes in the $\mathrm{C}-\mathrm{H}$ asymmetric stretches $\left(2982\right.$ and $2938 \mathrm{~cm}^{-1}$ on $\mathrm{H}+\mathrm{ZSM}-5$ cf 2989 and $2949 \mathrm{~cm}^{-1}$ in the gas phase (assignments from Wieser et al. (40))), but a significant reduction in intensity and shift for the symmetric $\mathrm{C}-\mathrm{H}$ stretch $\left(2895 \mathrm{~cm}^{-1}\right.$ on $\mathrm{H}+\mathrm{ZSM}-5$ cf $2869 \mathrm{~cm}^{-1}$ for the gas phase). The $\mathrm{C}-\mathrm{H}$ bending region (1610 to $1358 \mathrm{~cm}^{-1}$ ) was quite different for diethylether sorbed on $\mathrm{H}+\mathrm{ZSM}-5$ showing a strong broad band cut by sharp negative peaks. By analogy with DME on $\mathrm{H}+\mathrm{ZSM}-5$, the broad band was probably due to the Bronsted proton interacting with the diethylether.

\subsubsection{Methylethylether on $\mathrm{H}+\mathrm{zSM}-5$ :}

The difference spectra of methylethylether sorbed on $\mathrm{H}+\mathrm{ZSM}-5$ held at ${ }^{\circ} \mathrm{C}$ from to $2000 \mathrm{~cm}^{-1}$ was published by Forester (19). This showed the same characteristics as observed for DME and diethylether. 


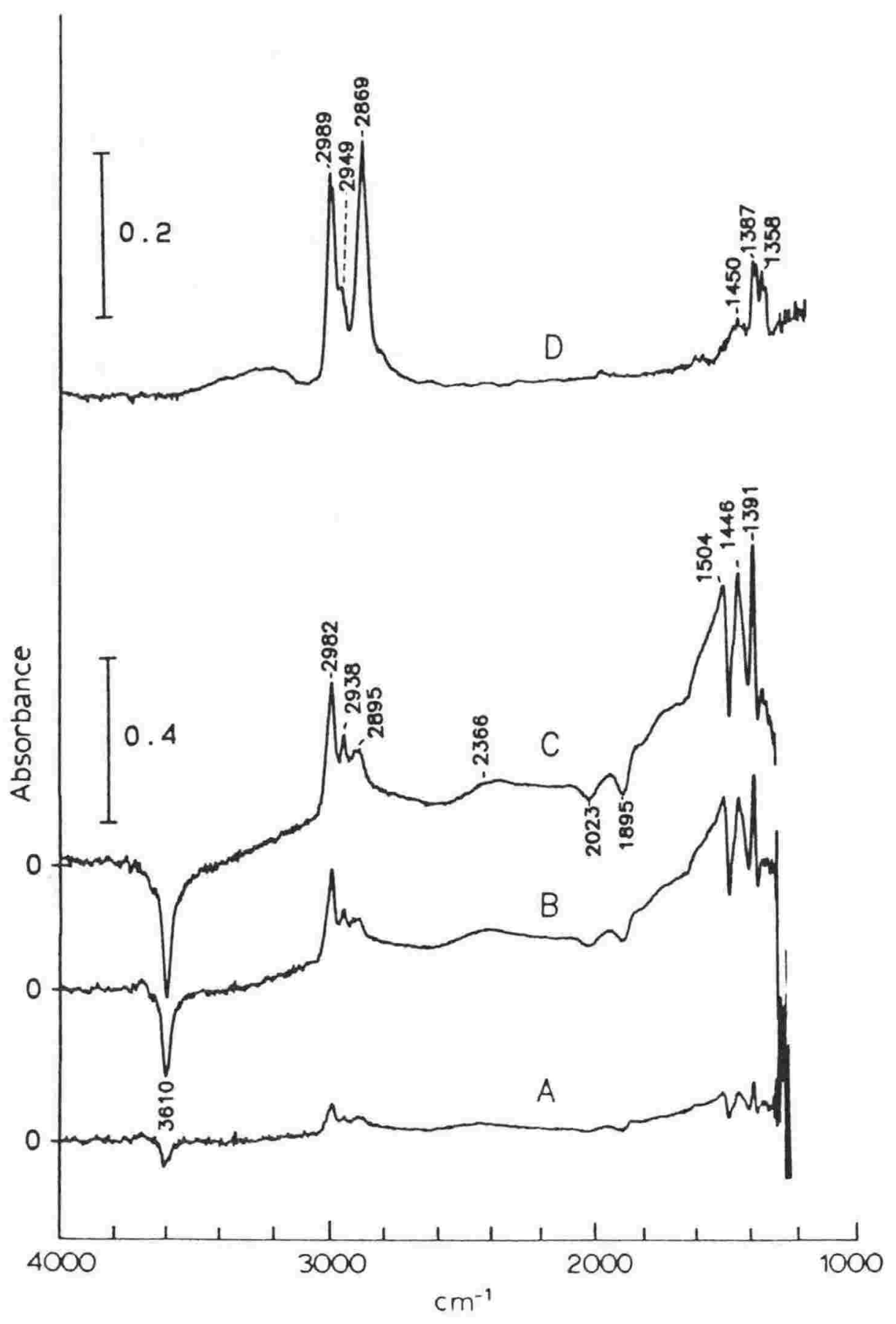

Figure 7.41. Difference FTIR spectra of:

A. after addition of $0.25 \mu \mathrm{l}$ diethylether on $\mathrm{H}+\mathrm{ZSM} 5$ at $80^{\circ} \mathrm{C}$;

B. " " " $0.75 \mu 1$ " " C. " " " $2.5 \mu l$ ", and flushed for 5 min; D. gas phase diethylether. 
7.6.5 Discussion:

All the ethers studied this far, symmetrical and unsymmetrical, show the same spectral characteristics when sorbed on $\mathrm{H}+\mathrm{ZSM}-5$.

The broad bands could be due to the proton affinity difference between the ether and conjugate base of $\mathrm{H}+\mathrm{ZSM}-5$ being similar so that the Bronsted proton is equally shared. In previous studies of complexes of organic acids and bases (eg. 7,11 ) this was the explanation given for the broad bands observed. An alternative is that the broad bands are a characteristic of the class of species sorbed. To determine the importance of the proton affinity difference, ethers of higher proton affinity were required. Proton affinities of ethers increase with increasing size and branching of the ether, so di-n-butyl ether and di-isopropylether were studied.

\subsubsection{Di-n-butylether on B+zSM-5:}

Source: BDH GR.

Di-n-butylether was sorbed on $\mathrm{H}+2 \mathrm{SM}-5$ held at $100^{\circ} \mathrm{C}$. The difference spectra are shown in figure 7.42. Again the Bronsted hydroxyl peak disappeared and was replaced by broad bands that were not as pronounced as in the case of the lighter ethers. $\mathrm{D}_{2} \mathrm{O}$ was passed through the wafer held at $110^{\circ} \mathrm{C}$, the difference spectrum between before and after $\mathrm{D}_{2} \mathrm{O}$ exposure is shown in figure 7.42C. A decrease in the broad bands from 3600 to $1200 \mathrm{~cm}^{-1}$ was observed. The $\mathrm{C}-\mathrm{H}$ stretching region also decreased in intensity, but this was due to desorption of some of the ether as no resultant C-D bands appeared. An absence of exchangeable proton stretching was again observed at $1480 \mathrm{~cm}^{-1}$.

After heating to $200^{\circ} \mathrm{C}$ at $10^{\circ} \mathrm{C} \mathrm{min}{ }^{-1}$, most of the ether had desorbed. The di-n-butylether was less strongly sorbed than ammonia which, under similar conditions, did not rapidly desorb until $250^{\circ} \mathrm{C}$. If the bonding was a simple acid - base proton transfer, this would imply that the di-n-butylether 
has a lower proton affinity than ammonia. However, there is no significant difference between the proton affinities for di-n-butylether and ammonia which are listed (2) as $852 \mathrm{~kJ}$ $\mathrm{mol}^{-1}$ and 853. $5 \mathrm{~kJ} \mathrm{~mol}^{-1}$ respectively. Further work would be required to resolve this discrepancy.

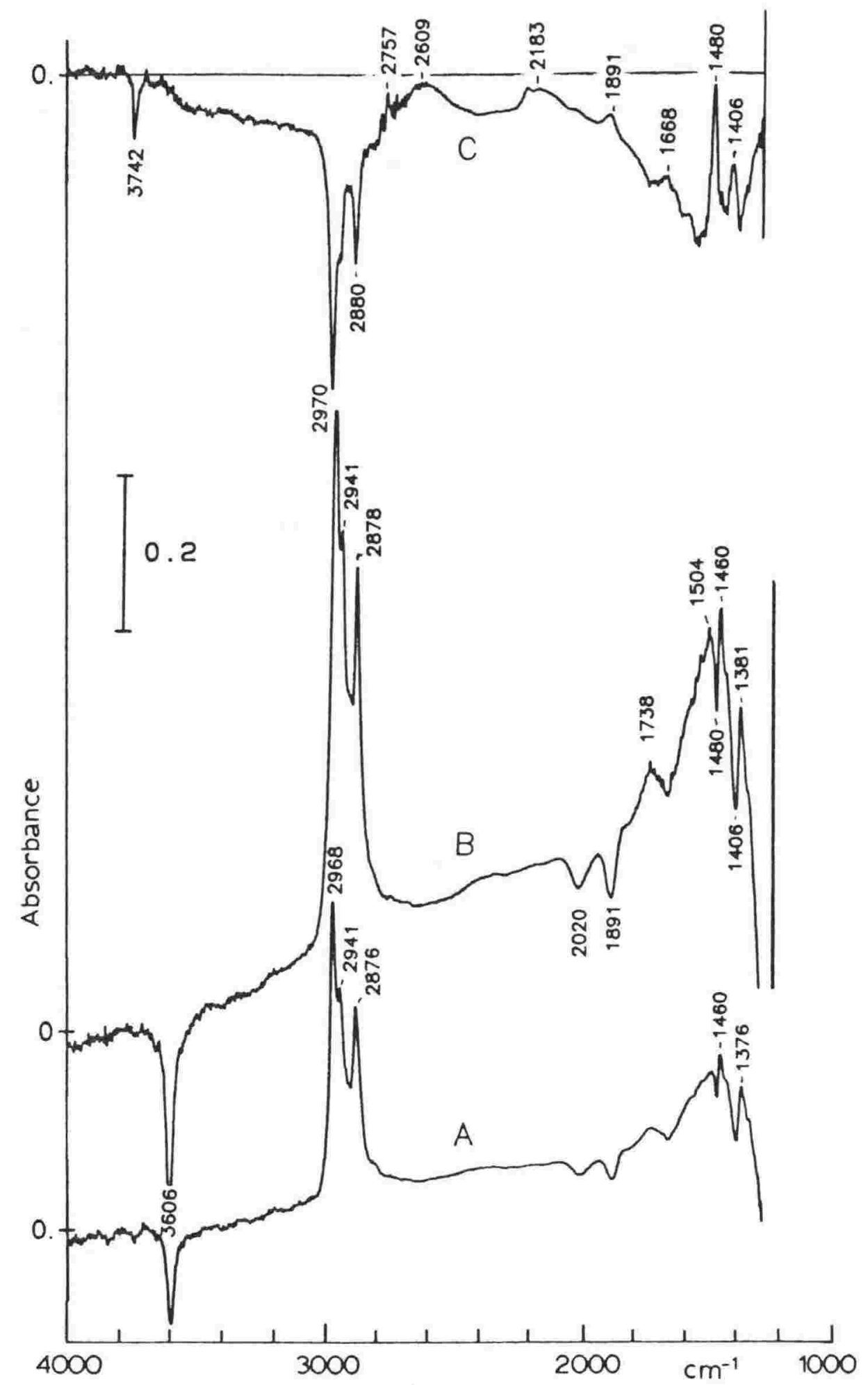

Figure 7.42. FTIR difference spectra of:

A. after addition of $1 \mu l$ di-n-butylether on $\mathrm{H}+\mathrm{ZSM}-5$ at $100^{\circ} \mathrm{C}$; B. after addition of $2 \mu \mathrm{l}$ di-n-butylether;

C. the differences due to $\mathrm{H} / \mathrm{D}$ exchange by $\mathrm{D}_{2} \mathrm{O}$ addition at $110^{\circ} \mathrm{C}$. 


\subsubsection{Di-isopropylether on $\mathrm{H}+\mathrm{ZSM}-5$ :}

Source: BDH technical grade

Di-isopropylether sorbed on $\mathrm{H}+\mathrm{ZSM}-5$ held at $80^{\circ} \mathrm{C}$ reacted within 4 minutes of sorption. This can be seen by a comparison of a spectrum of the di-isopropylether in the gas phase (figure $7.45 \mathrm{C}$ ) with that a di-isopropylether sorbed on the zeolite (figure 7.43B). The difference spectrum is shown in figure $7.44 \mathrm{~A}$. Both the $\mathrm{C}-\mathrm{H}$ stretching and bending regions show major changes from the gas phase ether. There is a strong similarity to that of the oligomer species formed from reaction of ethene or propene. Unlike the other sorbed ethers, a single broadened, hydroxyl stretch is observed, shifted by $66 \mathrm{~cm}^{-1}$. This is a similar shift to that observed for the product of ethene sorption, the propene reaction product is shifted further $\left(160 \mathrm{~cm}^{-1}\right)$. The di-isopropylether ether reaction product is therefore similar to that from ethene.

Further evidence of alkene formation was obtained by H/D exchange by addition of $\mathrm{D}_{2} \mathrm{O}$. The resultant changes are shown in figure 7.44B. The broadened, shifted Bronsted $0-\mathrm{H}$ peak (3465 $\mathrm{cm}^{-1}$ ) exchanged to $0-D\left(2564 \mathrm{~cm}^{-1}\right)$. The hydrocarbon hydrogens were also labile and a H/D exchange occured, with $C-D$ stretches appearing at $\sim 2213 \mathrm{~cm}^{-1}$. This exchange of $\mathrm{C}-\mathrm{Hs}$ was observed for sorbed alkene species, but not ethers that had sorbed unreacted.

Di-isopropylether was sorbed onto $\mathrm{H}+\mathrm{ZSM}-5$ held at $21^{\circ} \mathrm{C}$. The resultant difference spectrum is shown in figure 7.45A. Comparison with the spectrum of gas phase di-isopropylether shows that the ether was sorbed unreacted. Some ether bonded to the silanol sites, as shown by the negative peak at 3742 $\mathrm{cm}^{-1}$. Most of the Bronsted sites bonded, but no distinct, shifted hydroxyl band was observed. The hydroxyl stretch has therefore been spread over a very wide wavelength range, as observed for all ethers studied. The sample was heated at $10^{\circ} \mathrm{C} \mathrm{min}{ }^{-1}$ and reaction to the alkene type product had occured by $60^{\circ} \mathrm{C}$ (figure $7.45 \mathrm{~B}$ ). 


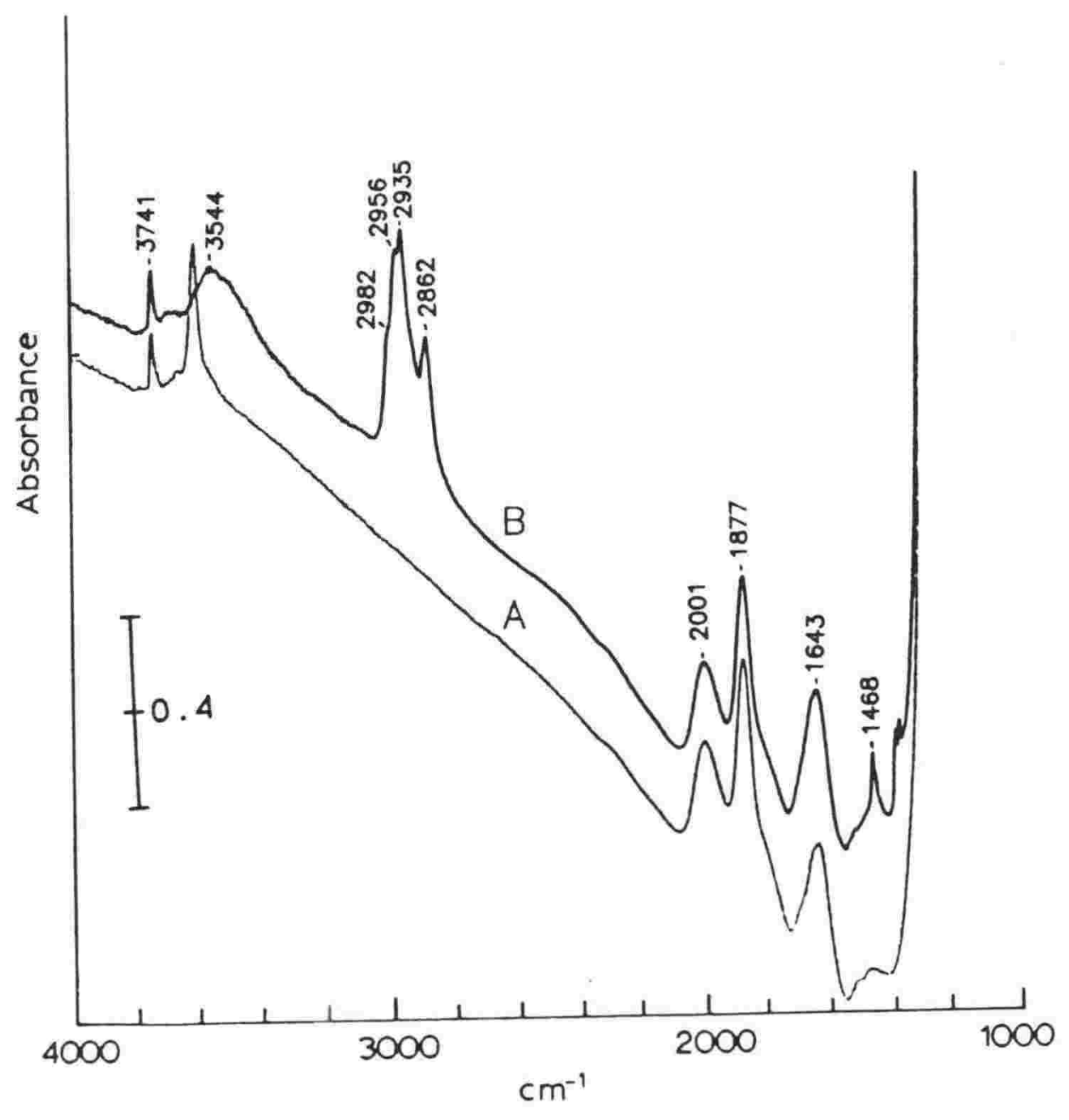

Figure 7.43. FTIR spectra of: A. dry $\mathrm{H}+\mathrm{ZSM}-5$ at $80^{\circ} \mathrm{C}$ and B. after addition of 1 kl di-isopropylether. 


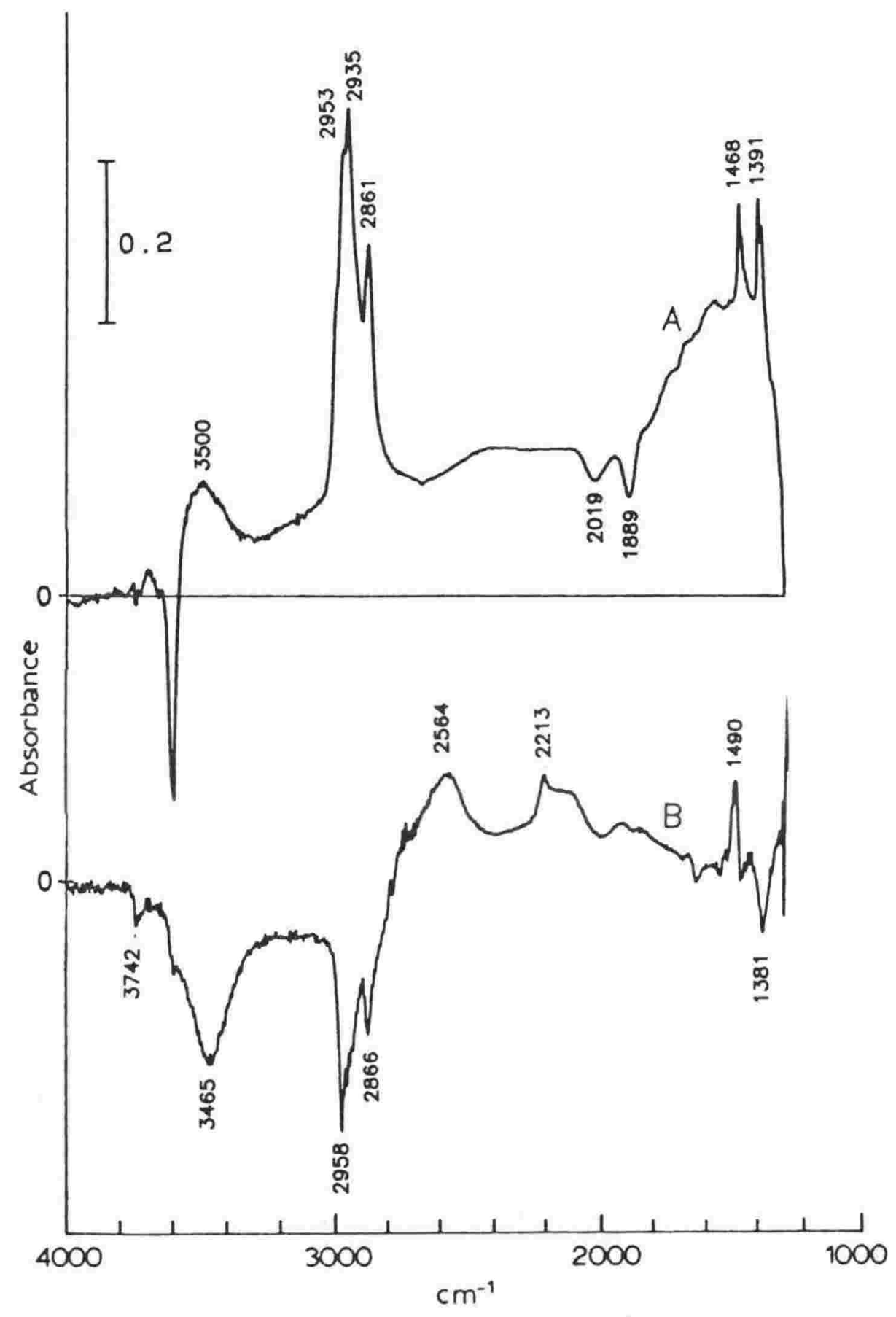

Figure 7.44. FTIR difference spectrum of A. diisopropylether on $\mathrm{H}+\mathrm{ZSM}-5$ at $80^{\circ} \mathrm{C}$ and $\mathrm{B}$. the changes due to $\mathrm{H} / \mathrm{D}$ exchange upon exposure to $\mathrm{D}_{2} \mathrm{O}$ at $100^{\circ} \mathrm{C}$. 


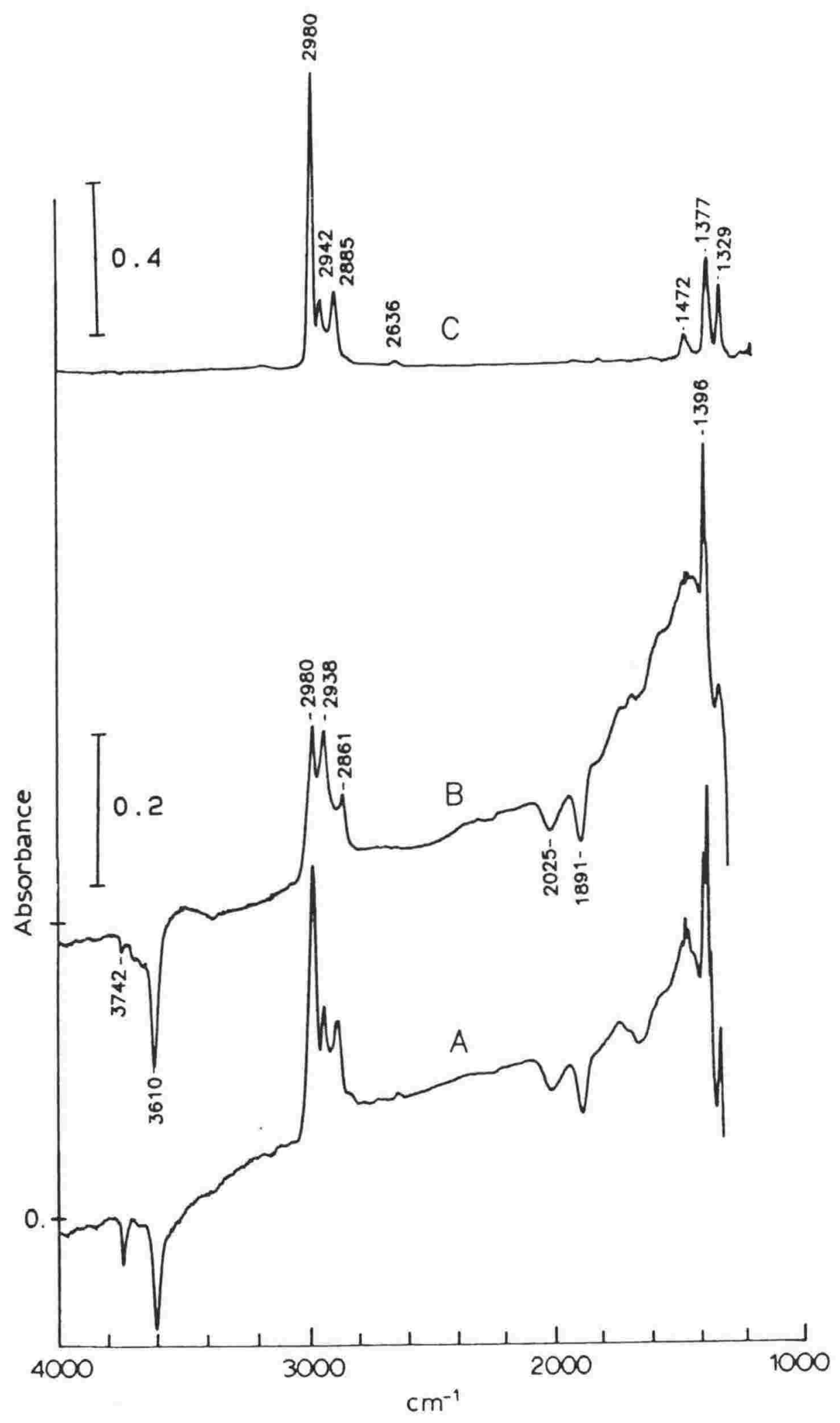

Figure 7.45. FTIR difference spectra of H+ZSM-5:

A. after addition of $1 \mu l$ di-isopropylether at $21^{\circ} \mathrm{C}$ and B. " " $2 \mu 1$ " then heating to $60^{\circ} \mathrm{C}$. C. gas phase di-isopropylether. 
7.6.8 Tetrahydrofuran (THF) on H+ZSM-5:

Source: freshly distilled over sodium.

The sorption of THF on $\mathrm{H}+\mathrm{ZSM}-5$ was studied because it has a proton affinity $27 \mathrm{~kJ} \mathrm{~mol} \mathrm{~kJ}^{-1}$ higher than DME, and to investigate the steric effect of a more accessible ether oxygen due to the ether having 'its arms tied behind its back'.

The difference spectrum of THF sorbed on $\mathrm{H}+\mathrm{ZSM}-5$ held at $80^{\circ} \mathrm{C}$ is shown in figure $7.46 \mathrm{~A}$. The THF has bonded to the Bronsted hydroxyl with broad bands formed. The $\mathrm{C}-\mathrm{H}$ region changed only slightly compared to the gas phase spectrum (figure 7.46C) implying that THF was sorbed unreacted. H/D exchange by addition of $\mathrm{D}_{2} \mathrm{O}$ at $100^{\circ} \mathrm{C}$ (figure $7.46 \mathrm{~B}$ ) shows clearly the the broad bands that are due to the exchangeable proton. 


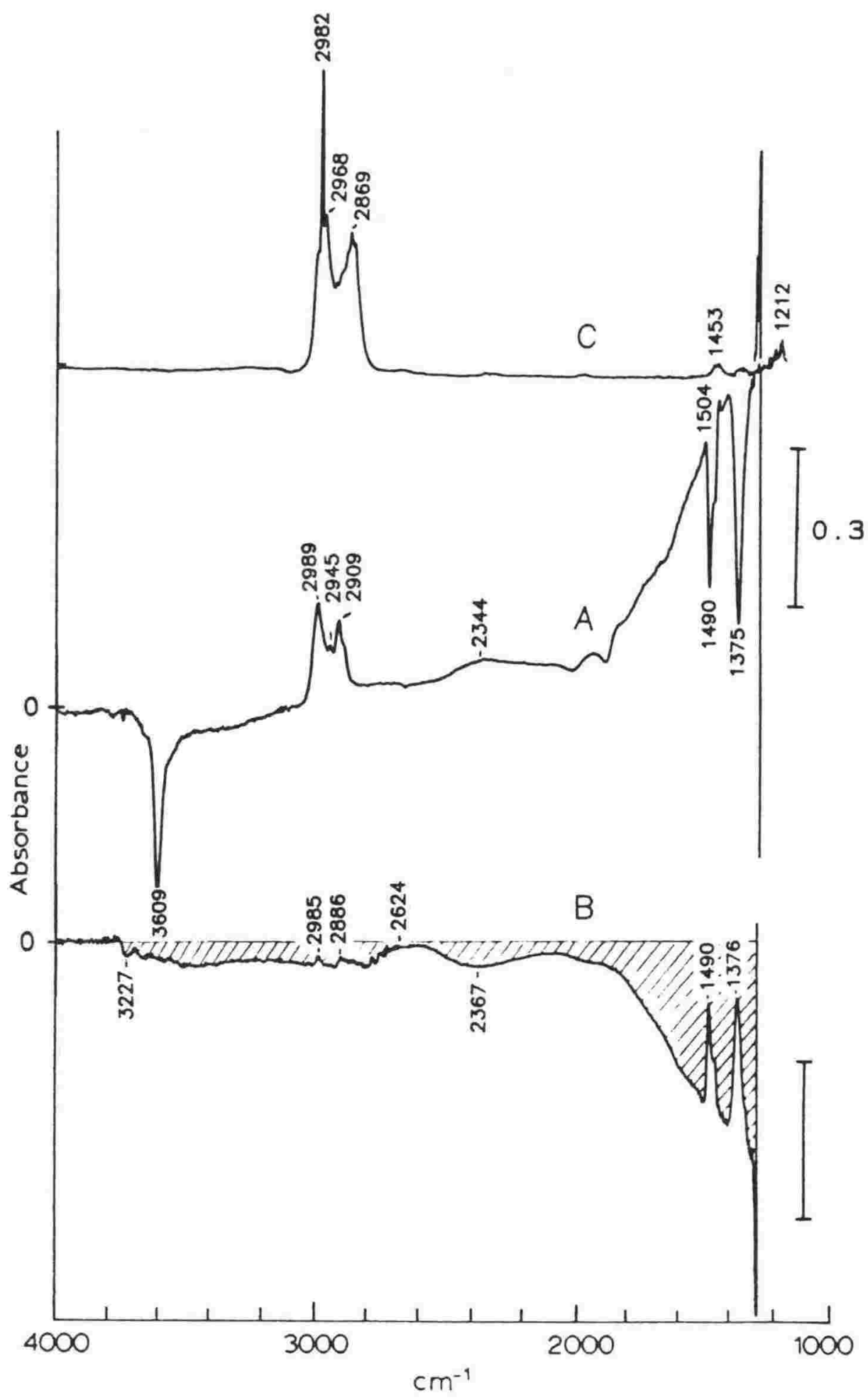

Figure 7.46. A. FTIR difference spectrum of $2 \mu l$ THF sorbed on $\mathrm{H}+\mathrm{ZSM}-5$ held at $80^{\circ} \mathrm{C} ; \mathrm{B}$. the changes that occured to spectrum $A$ after $H / D$ exchange by $D_{2} O$ addition at $100^{\circ} \mathrm{C}$ and C. gas phase THF. 


\subsection{Acetone on $\mathrm{H}+\mathrm{ZSM}-5$ :}

\subsubsection{Introduction:}

The IR spectra of acetone sorbed on alumina-magnesia mixed oxides was studied by Lercher et al. (41). They used the $0-\mathrm{H}$ frequency shift upon acetone adsorption to obtain an estimate of the $\mathrm{O}-\mathrm{H}$ acid strength. The frequency shift decreased from $290 \mathrm{~cm}^{-1}$ (for gamma- $\mathrm{Al}_{2} \mathrm{O}_{3}$ ) to $260 \mathrm{~cm}^{-1}$ (for $\mathrm{MgO}$ ) indicating decreasing acid strengths in that order. They did not publish their spectra or describe them in more detail.

Novakova et al. (42) studied the sorption of acetone on H+ZSM- 5 by tpd and FTIR. Tpd showed desorption of physisorbed acetone, then butene from about $230^{\circ} \mathrm{C}$, followed by aromatics (from $300^{\circ} \mathrm{C}$ ) and $\mathrm{C}_{6.7}$ dienes (from $350^{\circ} \mathrm{C}$ ). FTIR at room temperature showed bonding to the framework $\mathrm{O}-\mathrm{H}$ groups, with the disappearance of the $0-\mathrm{H}$ band at $3610 \mathrm{~cm}^{-1}$ and appearance of broad $\mathrm{O}-\mathrm{H}$ bands below $3000 \mathrm{~cm}^{-1}$. (A spectrum of these bands was not published, their spectra only covering the ranges 3800 to $3500 \mathrm{~cm}^{-1}$ and 1750 to $1350 \mathrm{~cm}^{-1}$ ). The $\mathrm{C}=0$ vibration, absorbing at $1740 \mathrm{~cm}^{-1}$ in the gas phase shifted to $1670 \mathrm{~cm}^{-1}$, indicating a partial loss of double bond character. Heating to $200^{\circ} \mathrm{C}$ resulted in reaction to give products of acetone condensation. At greater than $300^{\circ} \mathrm{C}$ further reaction occured to give a stable (to $500^{\circ} \mathrm{C}$ ) sorbed species with bands at 1644,1543 and $1511 \mathrm{~cm}^{-1}$. This was proposed (42) to be a species directly bonded to the lattice:<smiles>CC(=O)C=C(C)O[14C](=O)O[Na]</smiles>

\subsubsection{Results for acetone on H+ZSM-5:}

Source: Univar AR.

Sorption of acetone on to $\mathrm{H}+\mathrm{ZSM}-5$ held at $80^{\circ} \mathrm{C}$ results in the disappearance of the Bronsted hydroxyl and appearance of two broad bands at $\sim 2900$ and $\sim 2380 \mathrm{~cm}^{-1}$ (figure 7.47 ). The difference spectra (figure 7.48 ) show more clearly the 
changes in the fingerprint region. Figure $7.48 \mathrm{~A}$ shows the spectra obtained after addition of $1 \mu l$ of acetone. From 1800 to $1300 \mathrm{~cm}^{-1}$ there is a strong absorption upon which peaks due to $\mathrm{C}=0$ stretching (1699 and $1683 \mathrm{~cm}^{-1}$ ) and $\mathrm{C}-\mathrm{H}$ bending ( 1410 and $1373 \mathrm{~cm}^{-1}$ ) are observed. These are similar to, but a lot sharper than, those published by Novakova et al. (42). Some reaction of the acetone may have also occured, with small peaks appearing at 1617 and $1555 \mathrm{~cm}^{-1}$. These were assigned by Novakova et al (42) to $\mathrm{C}=0$ and $\mathrm{C}=\mathrm{C}$ stretches of acetone condensation products. However only carboxylate ions have a $\mathrm{C}=0$ stretch at such a low frequency (Williams \& Flemming (31)) (1610 to $1540 \mathrm{~cm}^{-1}$ ), so the assignment is uncertain. The only $\mathrm{C}=\mathrm{C}$ stretches at such a low wavenumber are those of $\mathrm{C}=\mathrm{C}$ bonds conjugated with $\mathrm{C}=0$ (1650 to $1580 \mathrm{~cm}^{-1}$ ) (31).

Addition of a further $2 \mu \mathrm{l}$ of acetone (figure 7.48B) shows some gas phase and perhaps physisorbed acetone present. The gas phase is apparent from the rotational fine structure in the $\mathrm{C}-\mathrm{H}$ stretching region $\left(\sim 3000 \mathrm{~cm}^{-1}\right)$. The 1720 and 1701 $\mathrm{cm}^{-1} \mathrm{C}=0$ stretches may be due to gas phase and physisorbed acetone respectively.

After a delay of $9 \mathrm{~min}$ in which the cell was being flushed, a further spectrum (figure $7.48 \mathrm{C}$ ) showed that reaction continued with a major peak appearing at $1548 \mathrm{~cm}^{-1}$. This is significantly different from the spectrum obtained at $300^{\circ} \mathrm{C}$ by Novakova et al. (42), so may be an intermediate species.

Acetone and its reaction products sorbed on $\mathrm{H}+\mathrm{ZSM}-5$ are all bonded to the Bronsted acid sites in the same manner, showing two broad bands ( 2900 and $\sim 2380 \mathrm{~cm}^{-1}$ ) and a stronger broad absorption (1800 to $1300 \mathrm{~cm}^{-1}$ ). For the unreacted acetone the bonding is through the carboxylate oxygen and is therefore still via an oxygen for the reaction products. Further work (tdms and FTIR) would be required to identify the reaction products. 


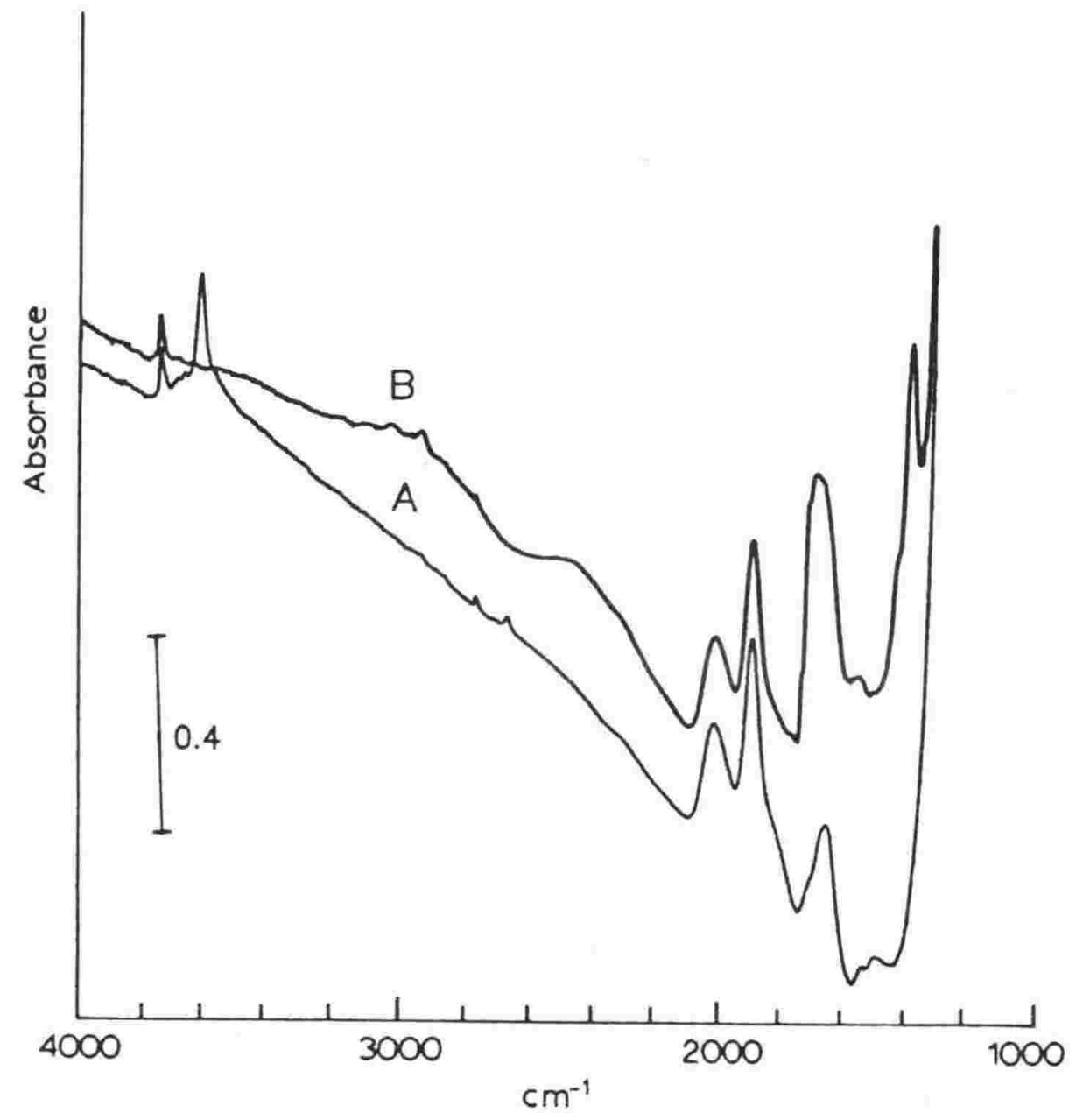

Figure 7.47. FTIR spectra of: A. dry $\mathrm{H}+\mathrm{ZSM}-5$ held at $80^{\circ} \mathrm{C}$ and $B$. after addition of $1 \mu$ lacetone. 


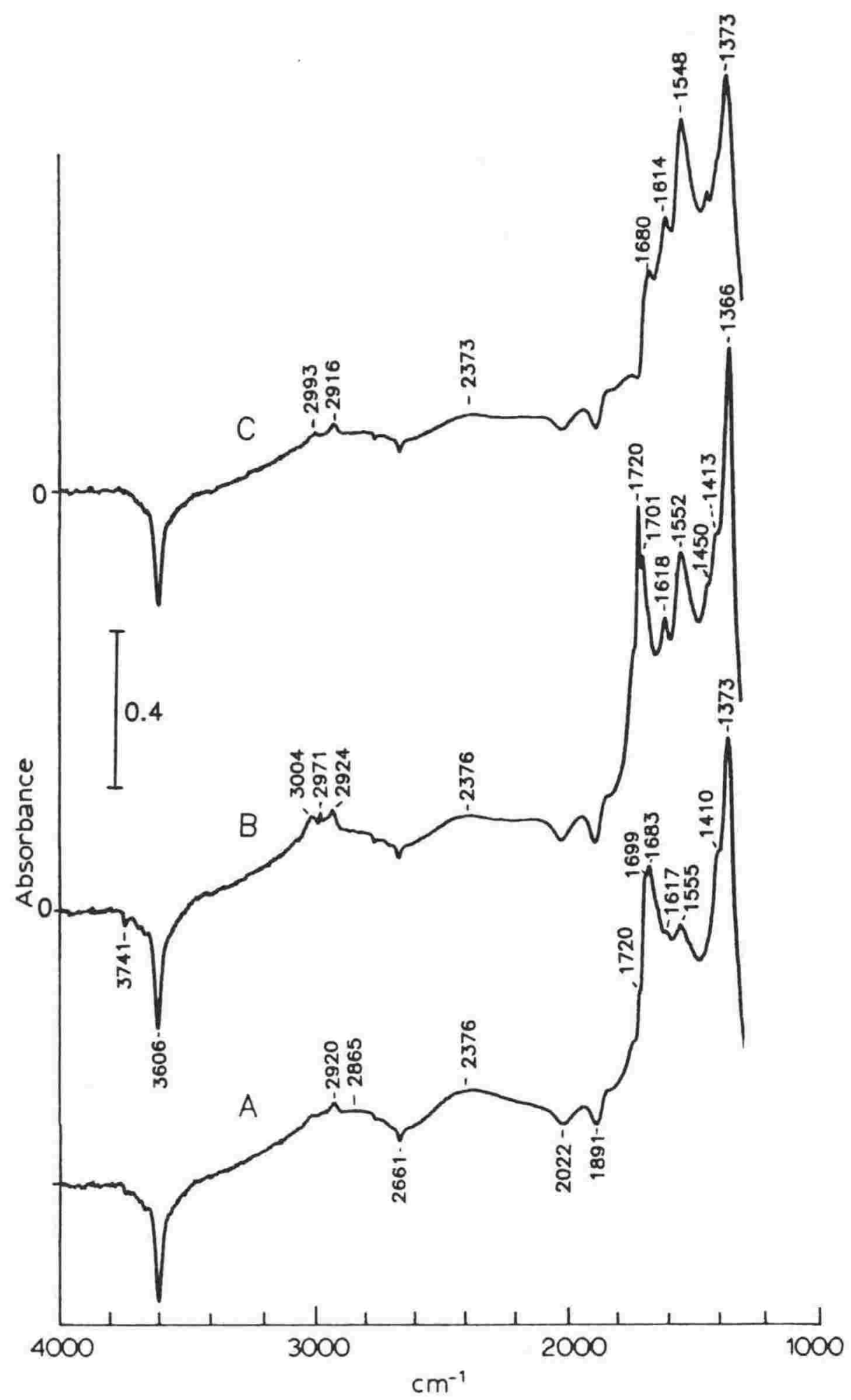

Figure 7.48. FTIR difference spectra of $\mathrm{H}+\mathrm{ZSM}-5$ :

A. after addition of $1 \mu^{\mu 1}$ acetone at $80^{\circ} \mathrm{C}$;

C. after flushing the sample in spectrum B for $9 \mathrm{~min}$. 
7.8 n-Butraldehyde on H+Z8M-5:

Source: BDH GR.

n-Butraldehyde was sorbed onto $\mathrm{H}+\mathrm{ZSM}-5$ held at $60^{\circ} \mathrm{C}$. The spectra are shown in figure $7.49 \mathrm{~B}$ and $\mathrm{C}$ and the difference spectra in figure $7.50 \mathrm{~A}$ and $\mathrm{B}$. The aldehyde bonded to the Bronsted hydroxyl with the appearance of three broad bands at $\sim 2950$ and $\sim 2430 \mathrm{~cm}^{-1}$ and from $\sim 1700$ to $\sim 1350 \mathrm{~cm}^{-1}$.

To determine the frequencies of the bonded hydroxyls the sample was heated to $110^{\circ} \mathrm{C}$, then $\mathrm{D}_{2} \mathrm{O}$ passed through the cell. The changes that occured to the spectrum are shown in figure 7.50C. A broad range of frequencies from 3610 to $1200 \mathrm{~cm}^{-1}$ was lost. Some intensity in the $\mathrm{C}-\mathrm{H}$ stretching region was also lost, but this was due to desorption of n-butraldehyde rather than $H / D$ exchange as no corresponding $C-D$ frequency appeared.

As the sample was heated further to $200^{\circ} \mathrm{C}\left(\right.$ at $10^{\circ} \mathrm{C} \mathrm{min}^{-1}$ ) the $n$-butraldehyde that remained on the zeolite reacted. This was shown by changes in the $\mathrm{C}-\mathrm{H}$ stretching and bending regions (figures $7.49 \mathrm{D}$ and $7.50 \mathrm{D}$ ). By $300^{\circ} \mathrm{C}$ all the sorbed species had desorbed. 


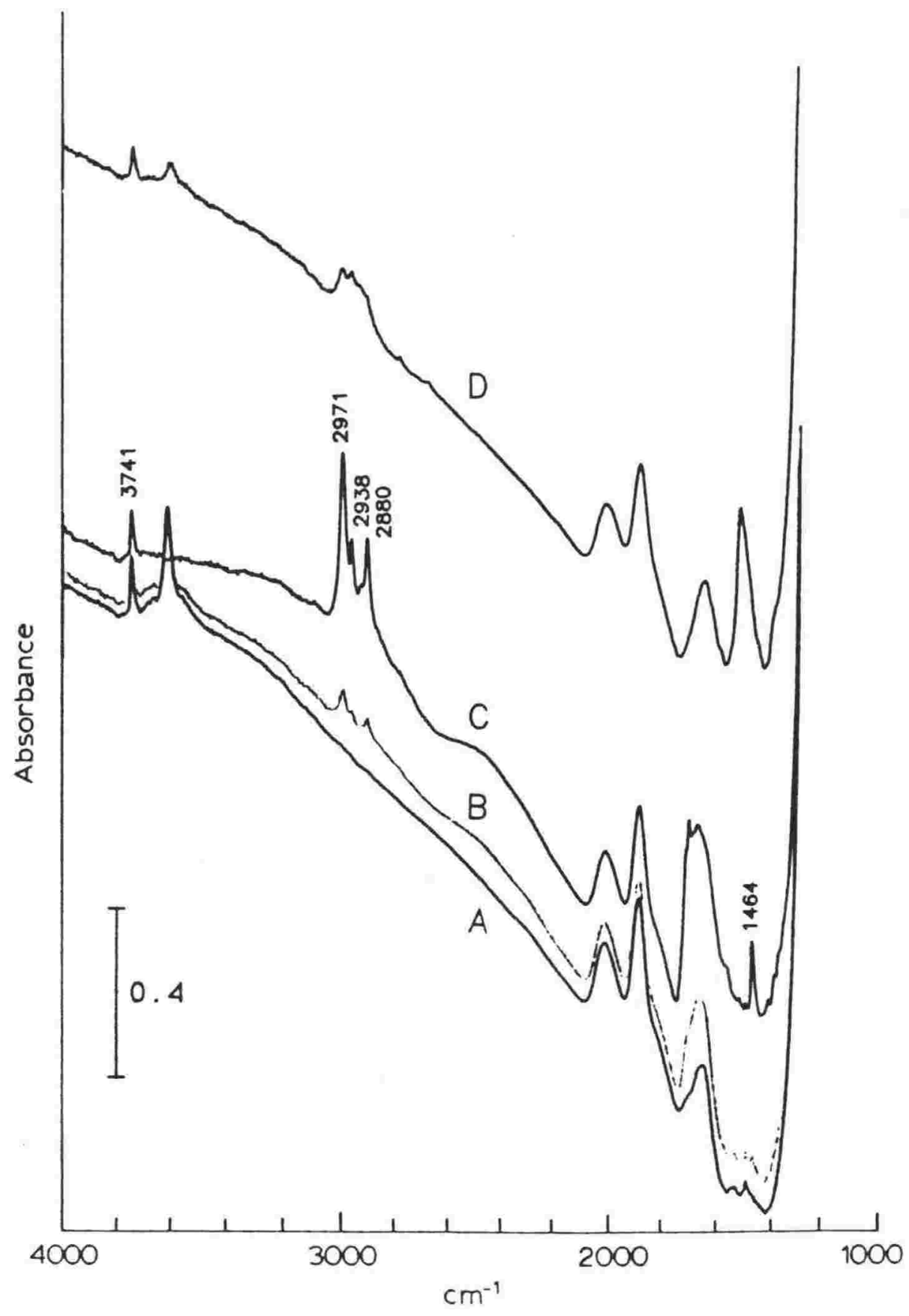

Figure 7.49. FTIR spectra of A. dry $\mathrm{H}+\mathrm{ZSM}-5$ at $60^{\circ} \mathrm{C}$; B. after addition of $1 \mu_{\mu 1}$ n-butraldehyde;

$\mathrm{C}$ after $\mathrm{D}_{2} \mathrm{O}$ "exchange at $110^{\circ} \mathrm{C}$, then heating to $200^{\circ} \mathrm{C}$. 


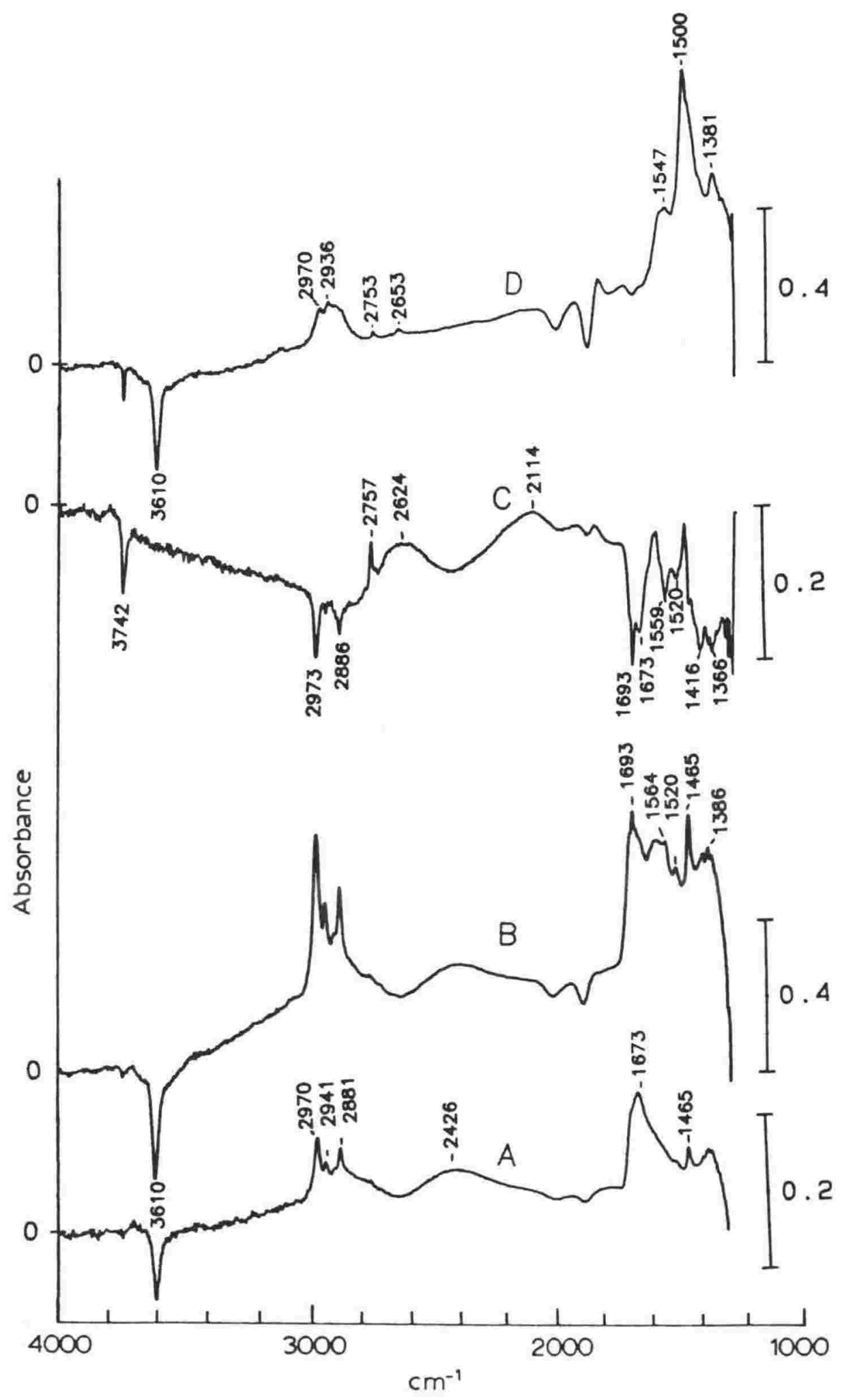

Figure 7.50. FTIR difference spectra of $\mathrm{H}+\mathrm{ZSM}-5$ :

A. after addition of $1 \mu_{41}$ n-butraldehyde

B. the changes that occured as a result of H/D exchange by $\mathrm{D}_{2} \mathrm{O}$ addition at $110^{\circ} \mathrm{C}$. Desorption of $\mathrm{n}$-butraldehyde also occured.

D. after $\mathrm{D}_{2} \mathrm{O}$ exchange, now at $200^{\circ} \mathrm{C}$. 


\subsection{Nitriles:}

\subsubsection{Previous IR studies of sorbed nitriles:}

The sorption of nitriles such as acetonitrile and benzonitrile has been used to estimate the strength of Lewis acid centres by the shift in the $v_{C=N}$ bands upon coordination (Ramis et al. (43), Paukshtis et al.(44)). However Paukshtis et al. (44) showed that for acetonitrile sorbed on $\mathrm{Ca}, \mathrm{Mn}$, $\mathrm{Co}, \mathrm{Ni}$, and $\mathrm{CrY}$ zeolites the shift did not correlate with the heat of sorption, so (in this case) the correlation was not valid.

Acetonitrile was sorbed on $\mathrm{HNaY}$ at $28^{\circ} \mathrm{C}$ by Mailer et al. (5) and shown to interact only with the $0-\mathrm{H}$ groups located in the large void spaces $\left(3650 \mathrm{~cm}^{-1}\right)$. The spectrum showed no distinct, shifted hydroxyl peak, but no further comments were made.

\subsubsection{Acetonitrile on H+ZSM-5:}

source: $B D H, H P L C$ grade

Acetonitrile was sorbed onto $\mathrm{H}+\mathrm{ZSM}-5$ held at $110^{\circ} \mathrm{C}$. The resultant spectrum is shown in figure $7.51 \mathrm{~B}$ and difference spectrum in figure $7.52 \mathrm{~B}$. Acetonitrile bonded to the acid sites, with the Bronsted $\mathrm{O}-\mathrm{H}$ peak disappearing and two broad bands appearing at $\sim 2796$ and $\sim 2405 \mathrm{~cm}^{-1}$. A very weak peak was observed in the $\mathrm{C}-\mathrm{H}$ stretching region, with the

characteristic $C \equiv N$ stretches at 2307 and $2282 \mathrm{~cm}^{-1}$. The $C \equiv N$ stretches are shifted to slightly higher wavenumber compared to the liquid phase (2293 and $2252 \mathrm{~cm}^{-1}$ (43)), but not as high as acetonitrile sorbed on $58 \mathrm{MOO}_{3}-\mathrm{TiO}_{2}$ (2323 and $2294 \mathrm{~cm}^{-1}$ ) (43) where association with Lewis acid was claimed to occur. However there is no significant shift from gas phase acetonitrile (at $2282 \mathrm{~cm}^{-1}$ ) (this work) or from acetonitrile sorbed on the pure $\mathrm{TiO}_{2}$ support (43).

Passing $\mathrm{D}_{2} \mathrm{O}$ through the sample wafer resulted in $\mathrm{H} / \mathrm{D}$ exchange and the spectrum shown in figure 7.51C. The changes that occured to the difference spectra (difference spectrum of 


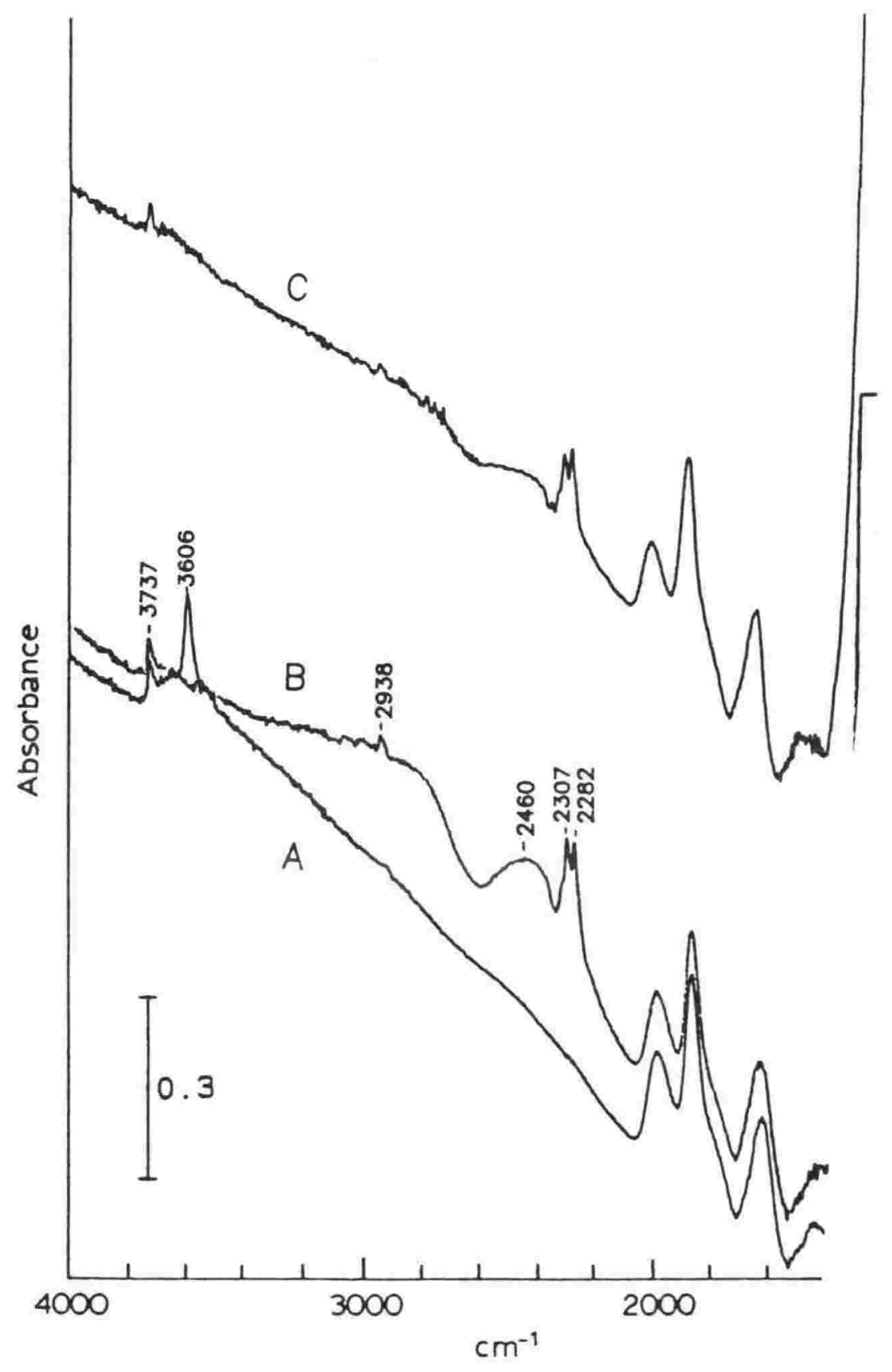

Figure 7.51. FTIR spectra of: A. dry $\mathrm{H}+\mathrm{ZSM}-5$ at $110^{\circ} \mathrm{C}$; B. after addition of ${ }_{\text {C. }} \frac{1}{\mu 1}$ acetonitrile; , then $1 \mu 1 \mathrm{D}_{2} \mathrm{O}$. 


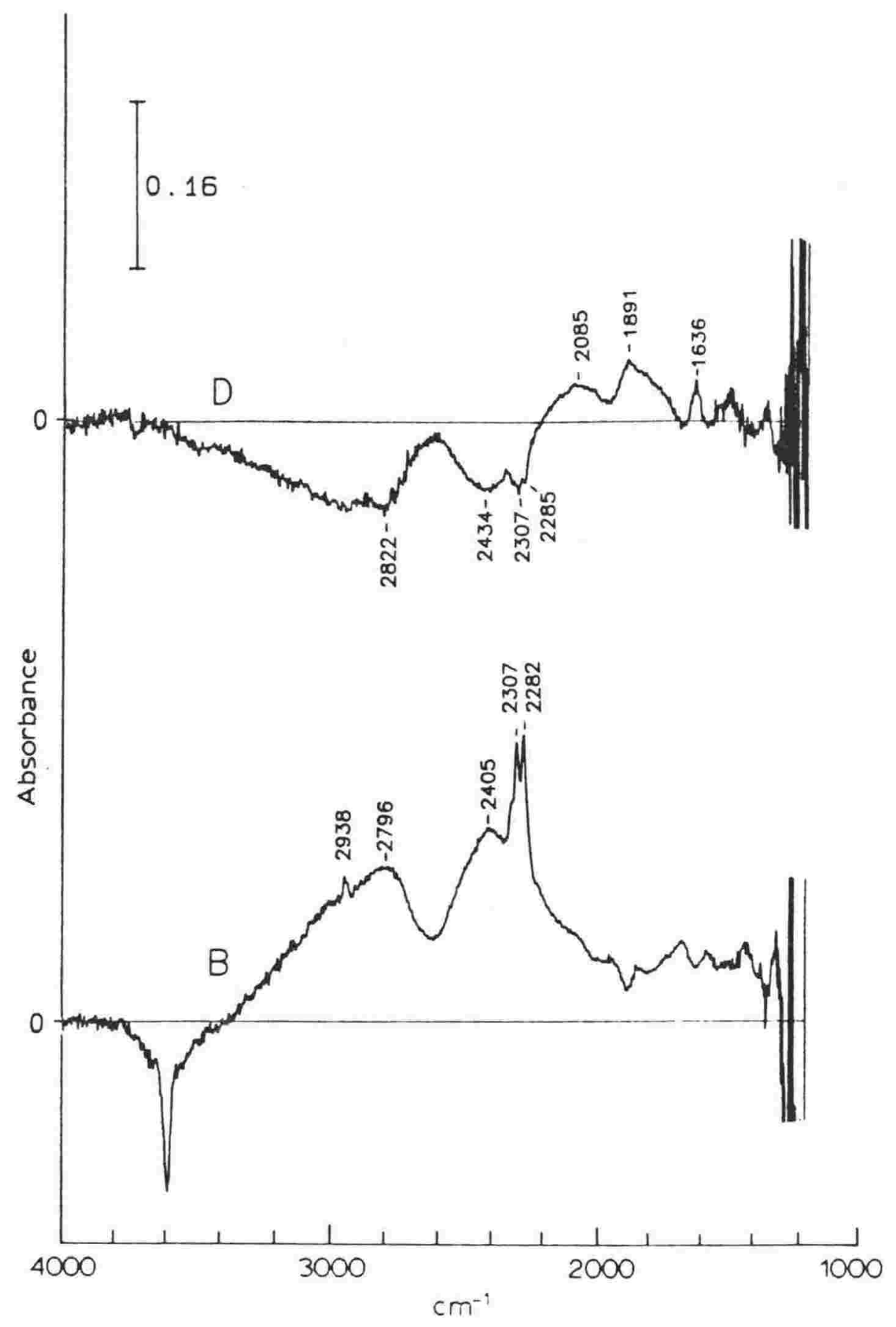

Figure 7.52. FTIR difference spectra of $\mathrm{H}+\mathrm{ZSM}-5$ B. after addition of $1 \mu 1$ acetonitrile at $110^{\circ} \mathrm{C}$;

C. the changes that occured to the difference spectra after $\mathrm{D}_{2} \mathrm{O}$ addition (difference spectrum of figure $7.51 \mathrm{C}-7.52 \mathrm{~B}$ ) 
figure 7.51C - figure 7.52B) is shown in figure 7.52D. The shape of the broad bands that are lost can be clearly seen with their deuterated equivalent bands appearing at $\sim 2085$ and $\sim 1891 \mathrm{~cm}^{-1}$. Some acetonitrile had also desorbed as shown by the negative peaks at 2307 and $2285 \mathrm{~cm}^{-1}$. Some exchange of the methyl group protons may have occured as the peak at 1636 $\mathrm{Cm}^{-1}$ may be due to $C-D$ stretches.

Strong bonding of acetonitrile to the zeolite Bronsted sites occurs, as acetonitrile remains sorbed at $110^{\circ} \mathrm{C}$ and the Bronsted hydroxyl stretch is lost. However the $\mathrm{C} \equiv \mathrm{N}$ group does not interact in the mode observed in the liquid phase or in the mode observed when sorbed on Lewis acid sites, as the $\mathrm{C} \equiv \mathrm{N}$ stretch does not shift. Further experimental and theoretical work to determine the reasons for this should provide some very interesting results.

\subsubsection{Benzonitrile on H+ZSM-5:}

source: Unilab Chemicals Ltd, LR.

Benzonitrile was sorbed on $\mathrm{H}+\mathrm{ZSM}-5$ held at $100^{\circ} \mathrm{C}$. The resultant spectrum is shown in figure $7.53 \mathrm{~B}$ and the difference spectra in figure 7.54B. A spectrum similar to the acetonitrile case was obtained with the zeolite Bronsted $0-\mathrm{H}$ stretch replaced by broad bands. In addition to the two broad bands at $\sim 2796$ and $\sim 2400 \mathrm{~cm}^{-1}$ there was a third broad band at $\sim 1500 \mathrm{~cm}^{-1}$. The $\mathrm{C}-\mathrm{H}$ stretching region showed a small peak at $3070 \mathrm{~cm}^{-1}$, with a strong, split $\mathrm{C} \equiv \mathrm{N}$ stretch at 2274 and $2240 \mathrm{~cm}^{-1}$.

The difference spectrum after $\mathrm{D}_{2} \mathrm{O}$ addition and flushing the cell for $10 \mathrm{~min}$ is shown in figure $7.54 \mathrm{C}$ and the difference between figure $7.54 \mathrm{~B}$ and $\mathrm{C}$ is shown in figure 7.54D. The broad bands in the region $\sim 3700$ to $-2200 \mathrm{~cm}^{-1}$ were replaced by bands in the region $\sim 2200$ to $\sim 1200 \mathrm{~cm}^{-1}$. The splitting in the $\mathrm{C} \equiv \mathrm{N}$ region was lost, along with marked changes in the ring bending region ( 1700 to $1200 \mathrm{~cm}^{-1}$ ). For a complete interpretation of these changes, further work is required. 


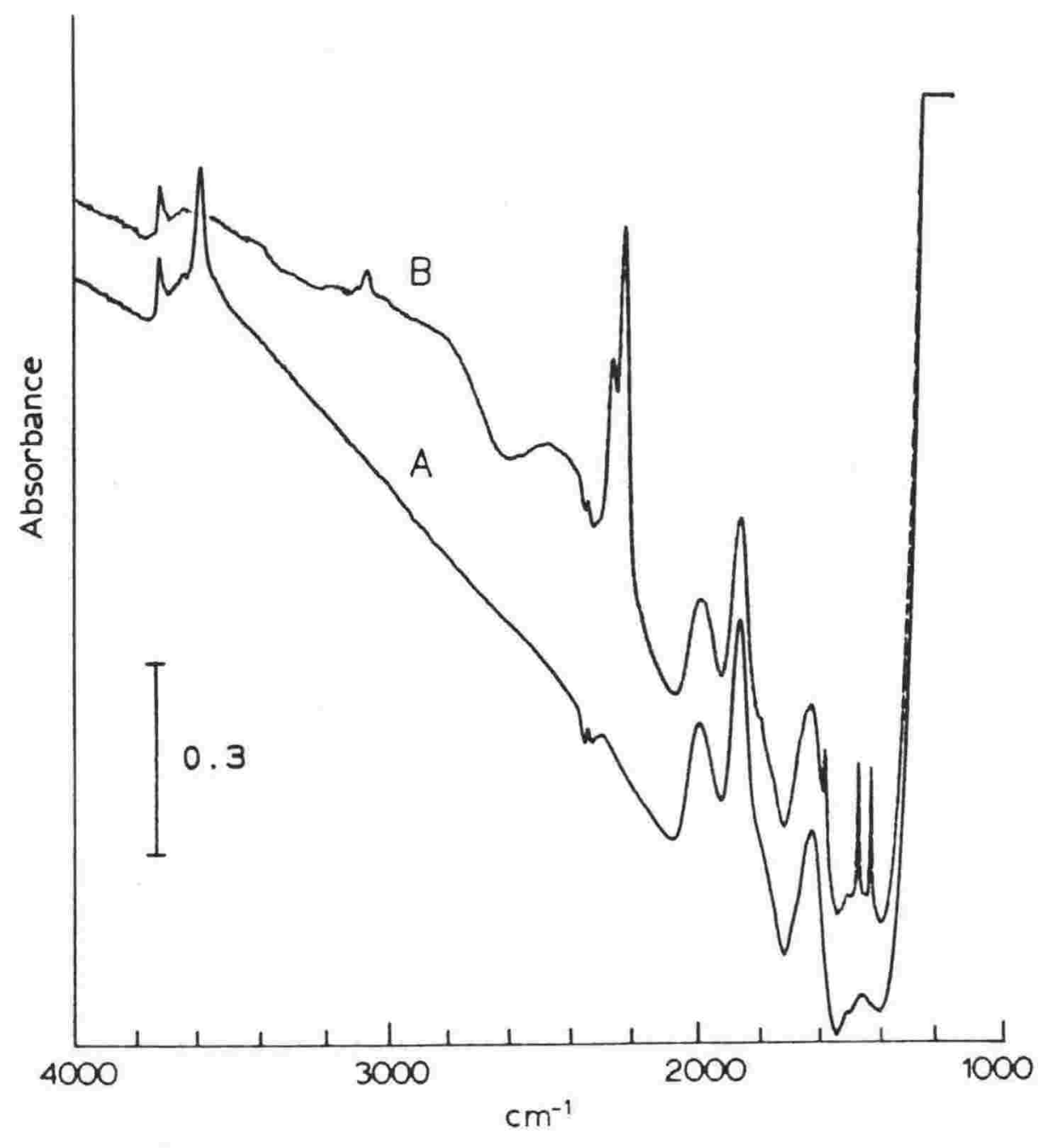

Figure 7.53. FTIR spectra of A. dry $\mathrm{H}+\mathrm{ZSM}-5$ at $100^{\circ} \mathrm{C}$ and B. after addition of $3 \mu l$ benzonitrile. 


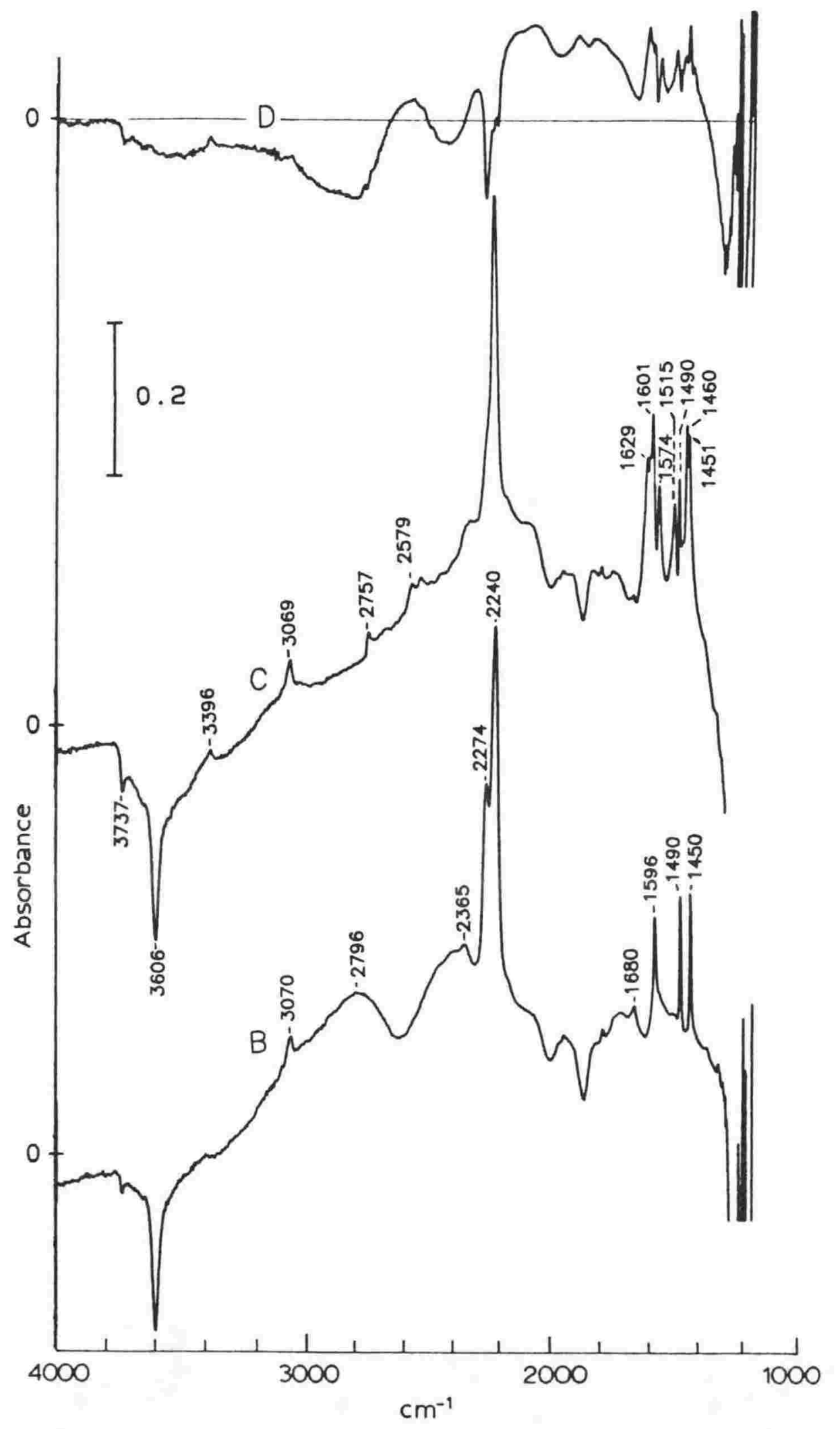

Figure 7.54. FTIR difference spectra of H+ZSM-5:

B. after addition of $3 \mu l$ benzonitrile at $100^{\circ} \mathrm{C}$;

C. after addition of $2 \mu \mathrm{I} \mathrm{D}_{2} \mathrm{O}$ and flushing the cell for 10 min; D. the changes the occured to the difference spectra after $H / D$ exchange (C-B). 


\subsection{Summary \& Discussion:}

A wide range of sorbants on $\mathrm{H}+\mathrm{ZSM}-5$ have been studied in order to determine whether the shift in the Bronsted hydroxyl band upon bonding $\left(\Delta v_{\mathrm{O} \cdot \mathrm{H}}\right)$ can be correlated with the proton affinity of the sorbant. The results are summarised in Table 7.4. The sorbants can be divided into three classes, each showing different bonding characteristics.

7.10.1 class A - distinct, shifted hydroxyl band:

A single, shifted hydroxyl band with a distinct maximum was observed for alkanes, alcohols, amines and carboxylic acids (which also showed broad bands similar to ethers). The common feature of this class is that they all interact with the zeolite Bronsted site through atoms with attached hydrogens. The merging of both the zeolite $\mathrm{O}-\mathrm{H}$ and sorbant $\mathrm{X}-\mathrm{H}$ stretches (for alcohols and amines) into a single $\mathrm{X}-\mathrm{H}$ stretching band implies that the proton/s from the sorbant and the zeolite have become equivalent or that one of these stretches has become extremely broad and effectively disappeared.

For the alcohols and amines there is no interaction of attached alkyl groups with the hydrogen bond as exchange from $C-H$ to $C-D$ does not occur upon $H / D$ exchange of the hydrogen bonded protons. 
Table 7.4

Sorbants studled on $\mathrm{H}+\mathrm{ZSM}-5$ - the maln features of the $\mathbb{R}$ spectrum attrlbutable to $\mathrm{v}_{\mathrm{o}+1}$ and their proton affinities.

CLASS A Sorbants

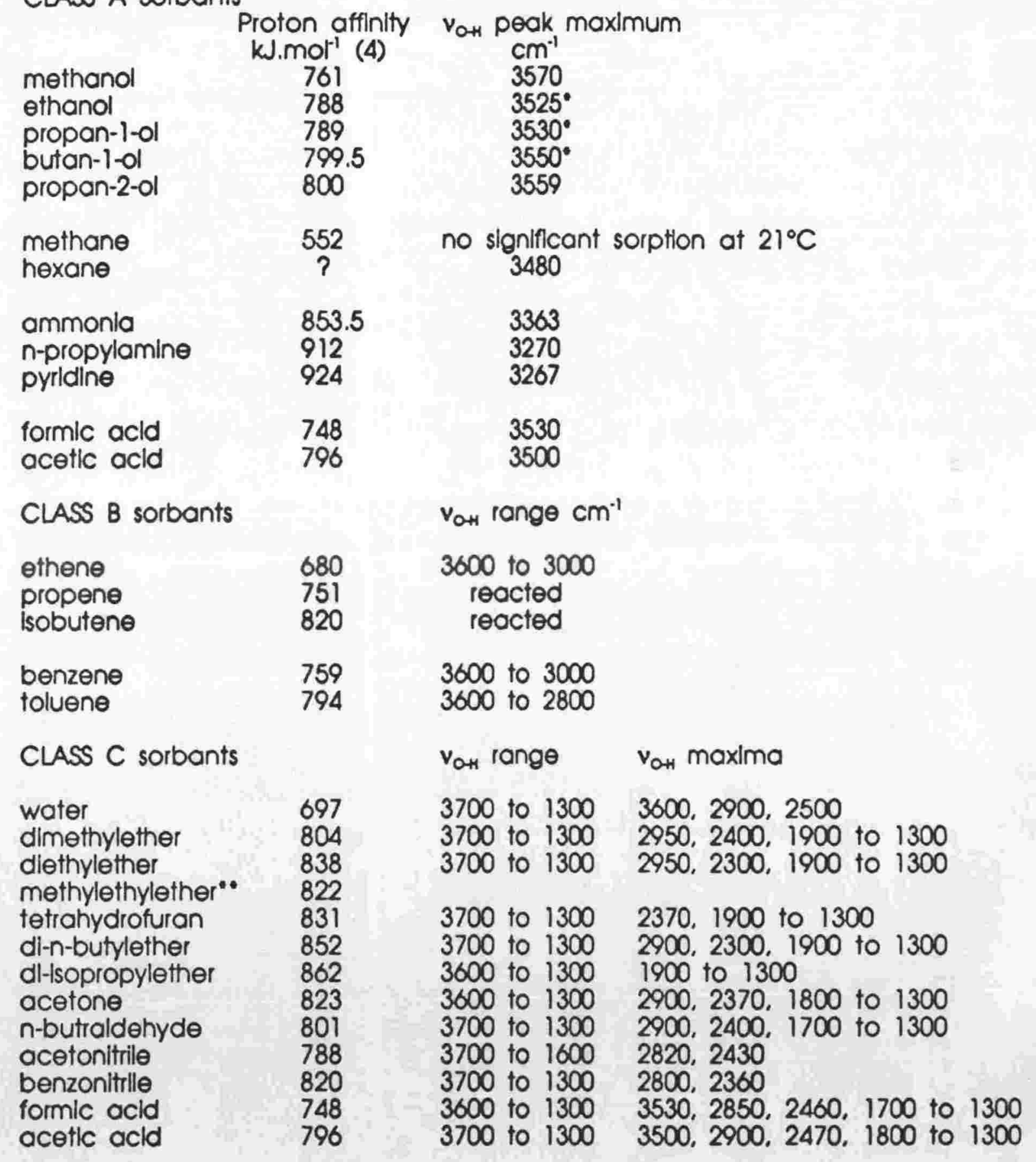


7.10.2 Class B - Single flat broad band due to hydrogen bonding:

Alkenes and aromatics sorbed on $\mathrm{H}+\mathrm{ZSM}-5$ show a hydroxyl stretch which is a broad, flat band from 3600 to $-2800 \mathrm{~cm}^{-1}$. Bonding is through the $\pi$ electrons of the double bond or aromatic ring. Alkenes sorbed in this manner are very reactive, with most reacting rapidly at room temperature. only ethene, the smallest alkene, remained unreacted long enough for a spectrum to be recorded. The reaction products of the sorbed alkenes (presumably oligomers) showed H/D exchange of the $\mathrm{C}-\mathrm{Hs}$ when $\mathrm{D}_{2} \mathrm{O}$ was passed through the sample. This shows that these hydrogens are interacting with the hydrogen bound to the zeolite. In other species (such as those in Class A) this exchange does not occur.

The sorbed aromatics, benzene and toluene, were more stable, not reacting at $100^{\circ} \mathrm{C}$. The $\mathrm{C}-\mathrm{H}$ hydrogens of toluene were interacting with the zeolite as C-D stretches were observed upon sorption of toluene on $\mathrm{D} / \mathrm{H}+\mathrm{ZSM}-5$.

7.10.3 class c - Very broad, diffuse hydrogen bonding.

Ethers, ketones, aldehydes, carboxylic acids, water and nitriles all showed a wide range of energies for the exchangeable Bronsted proton. The vibrational spectrum of the proton typically ranged from 3600 to $1200 \mathrm{~cm}^{-1}$, with two or three maxima.

Carboxylic acids showed features of both $A$ and $C$ classes. On top of the first broad band was a sharper peak which may be due to the $0-\mathrm{H}$ group bonding in a manner similar to the alcohols, while the $c=0$ group is similar to the ethers. This means that the acetic acid has not become a fully symmetric molecule, as would occur for complete protonation.

The common feature for these sorbants is that that they are all bonded through oxygen or nitrogen lone electron pairs. Except for water (which could be considered the simplest ether) there are no hydrogens on the bonding atom. The range 
The correlation is not accurate partially because of the small number of points, but mainly because the maxima are often at the top of broad peaks. A better correlation would be obtained using a single type of sorbant which has a wide range of proton affinities. Alkanes could be suitable for this as their proton affinity increases with increasing size. Sorbed alkanes also show a well defined $0-\mathrm{H}$ stretch which is only $\sim 300 \mathrm{~cm}^{-1}$ wide. However, the proton affinities of the larger alkanes have not yet been determined. A low temperature FTIR cell would also be required to study the lighter alkanes, as they readily desorb at room temperature. A similar study would then need to be carried out for alkanes hydrogen bonded with an acid with a known proton affinity (eg $\mathrm{HCl})$, perhaps using the frozen Ar matrix technique developed by Pimental (37).

\subsubsection{Estimation of the proton affinity of H+ZSM-5 by comparison with $\mathrm{HCl}$ and $\mathrm{HBr}$ in a solid $\mathrm{Ar}$ matrix:}

As described in the introduction to this chapter, work was carried out by Pimental et al. (37) on hydrogen bonding of $\mathrm{HCl}$ and $\mathrm{HBr}$ in solid Ar matrices. The shifts in proton stretching frequency obtained for a range of bases are shown in Table 7.5:

Table 7.5 Shifts in proton stretching wavenumber of bases upon hydrogen bonding with $\mathrm{HCl}$ and $\mathrm{HBr}$ in a solid Ar matrix (from Pimentel et al.(37)).

\begin{tabular}{cc}
$\mathrm{HCl}$ & \multicolumn{1}{c}{$\mathrm{HBr}$} \\
$v_{\mathrm{s}}=2854 \mathrm{~cm}^{-1}$ & $v_{\mathrm{s}}=2540 \mathrm{~cm}^{-1}$ \\
$\Delta v_{\mathrm{O}-\mathrm{H}}$ & $\Delta v_{\text {O-H }}$
\end{tabular}

$\begin{array}{lrr}\mathrm{H}_{2} \mathrm{O} & 314 & 230 \\ \mathrm{NH}_{3} & 2149 & 1150 \\ \left(\mathrm{CH}_{3}\right)_{3} \mathrm{~N} & 1260 & 690 \\ \left(\mathrm{CH}_{3}\right)_{2} \mathrm{O} & 574 & 840\end{array}$


of proton affinities covered by these sorbants is wide - from $788 \mathrm{~kJ} \mathrm{~mol}^{-1}$ for acetonitrile to $862 \mathrm{~kJ} \cdot \mathrm{mol}^{-1}$ for di-isopropylether. Di-isopropylether has a proton affinity higher than that of $\mathrm{NH}_{3}\left(853 \mathrm{kmol}^{-1}\right)$, which has a single shifted hydroxyl peak. This shows that the broad bands are not due to the case where the proton affinities of the acid and conjugate base are similar and the proton is equally shared between the two. Instead it is due to the type of bond formed with the Bronsted proton.

\subsubsection{Is a correlation of $\Delta v_{O . H}$ versus proton affinity possible?}

For the sorbants which show a single distinct $\mathrm{O}-\mathrm{H}$ maximum (class A) there is a correlation of increasing hydroxyl shift $\left(\Delta v_{\mathrm{OH}_{H}}\right)$ with increasing sorbant proton affinity. This is shown in figure 7.55 where the $0-\mathrm{H}$ maxima are plotted versus proton affinity.

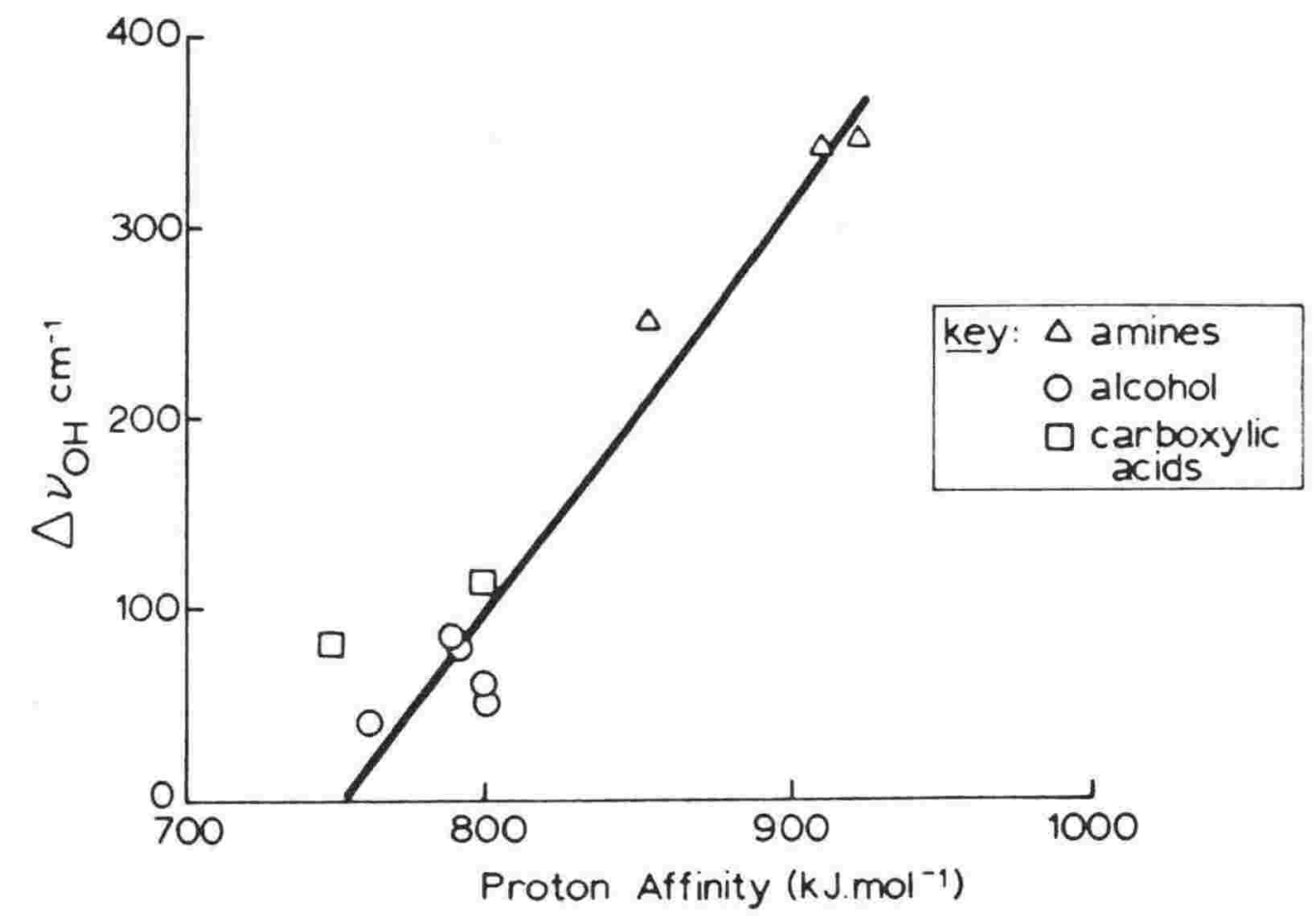

Figure 7.55. The shift in Bronsted hydroxyl stretching wavenumber $\left(\Delta v_{a-H}\right)$ upon sorption of a class $A$ base, versus the proton affinity of the base. 
Very large shifts are shown for both $\mathrm{HCl}$ and $\mathrm{HBr}$ bonded to $\mathrm{NH}_{3}$. This would imply that $\mathrm{H}+\mathrm{ZSM}-5$ was a weaker acid than $\mathrm{HCl}$ or $\mathrm{HBr}$ as a shift of only $247 \mathrm{~cm}^{-1}$ was observed for $\mathrm{NH}_{3}$ on $H+Z S M-5$. However, a closer study of their results shows that some of their assignments are dubious. For example, justification for assignments of the $v_{s}$ band for $\mathrm{H}_{3} \mathrm{~N} . \mathrm{HBr}$ was that it was the most prominent band and was broad $\left(80 \mathrm{~cm}^{-1}\right.$ half width). This band disappears upon allowing diffusion at $40 \mathrm{~K}$ and recooling to $15 \mathrm{~K}$. $\mathrm{NH}_{4} \mathrm{Cl}$ was also studied and the peak assigned to $v_{s}$ for $\mathrm{H}_{3} \mathrm{~N} . \mathrm{HCl}$ was not present. Their results could be reinterpreted to show that their study was of hydrogen bonding between acid and base separated in space by the frozen matrix. The physical separation would determine the extent of proton transfer. Annealing would enable the two species to associate, with the extent of proton transfer then governed by relative proton affinities.

Therefore a valid comparison can not be made of the relative proton affinities of $\mathrm{H}+\mathrm{ZSM}-5, \mathrm{HCl}$ and $\mathrm{HBr}$ based on this work.

\subsubsection{Estimation of Proton Affinity by bracketing:}

Proton affinities can be estimated by bracketing the unknown between two species with known proton affinities. One species has a higher proton affinity and no proton transfer is observed, the other has a lower proton affinity and proton transfer is observed (2). Proton affinities in the compilation of Lias et al. (2) are given at $27^{\circ} \mathrm{C}(300 \mathrm{~K})$. A comparison of $\mathrm{H}+\mathrm{ZSM}-5$ at the same temperature implies that its proton affinity is greater than $\mathrm{CH}_{4}\left(552 \mathrm{~kJ} . \mathrm{mol}^{-1}\right.$ ) (for which no proton transfer occurred) and less than or approximately equal to that of ethene $\left(680 \mathrm{~kJ}^{-\mathrm{mol}^{-1}}\right.$ ) (for which proton transfer did occur, but was only weakly sorbed). This implies that the proton affinity of $\mathrm{H}+2 \mathrm{SM}-5$ could be similar to that of $\mathrm{HCl}\left(564 \mathrm{~kJ} \cdot \mathrm{mol}^{-1}\right)$.

The bracketing technique has only been verified for proton transfer for some gas phase species. For a solid/gas interaction, sorption into the zeolite channels is required before bonding and this extra energy requirement could have 
the effect of increasing the apparent proton affinity (reducing apparent acidity).

\subsubsection{Bonding of physisorbed species:}

As sorbant is added at amounts greater than one molecule per zeolite Al, broad peaks additional to the bonded hydroxyl peak are observed at lower wave numbers in the IR spectrum. A good example is shown in the spectrum of sorbed ammonia $(7.4 .1)$. The Bronsted proton may have some association with the sorbant in the second and higher coordination shells. The greater distances would mean that the vibrational frequencies were lower, as is observed.

\subsection{REFERENCES:}

1. Walder R., Franklin J.L., Int. J. Mass Spec. and Ion Phys., 1980, 36, 85 .

2. Lias S.G., Liebman J.F. and Levin R.D., J. Phys. Chem. Ref. Data $1984,13,695$.

3. Jacobs P.A., Martens J.A., Weitkamp J. and Beyer H.K., Faraday Disc. Chem. Soc. 1981, 72, 353.

4. Rouxhet P.G. and Semples R.E., J. Chem. Soc. Faraday Trans. I, 1974, 2021.

5. Mailer W., Alekseev A.A., Yu V., Kazanskii V.B., Borovkov and Pfieffer G., Kinetics and Catalysis, 1983, 24, 1467.

6. Ault B.S., Steinback E. and Pimentel G.C., J. Phys. Chem., 1975, 79, 615 .

7. Hadzi D. and Kobilarov N., J. Chem. Soc. (A), 1966, 439.

8. Lindemann R. and Zundel G., J. Chem. Soc. Faraday Tran. II, $1972,68,979$.

9. Sessler W. and Zundel G., Z. Phys. Chem., 1972, 79, 180.

10. Janoschek R., Weidmann E.G., Pfeiffer H. and Zundel G., J. Am. Chem. Soc., 1972, 94, 2387.

11. Zundel G. and Nagyrevi A., J. Phys. Chem., 1978, 82, 685 .

12. Marlarski Z., Rospenk M., Sobczyk L. and Grech E., J. Phys. Chem., 1982, 86, 401. 
13. Wolny R., Koll A. and Sobczyk L., Can. J. Chem., 1985, 63,3568 .

14. Ison A. and Gorte R.J., J. Catal., 1984, 89, 150.

15. Grady M.C. and Gorte R.J., J. Phys. Chem., 1985, 89, 1305 .

16. Aronson M.T., Gorte R.J. and Farneth W.E., J. Catal., $1986,98,434$.

17. Aronson M.T., Gorte R.J. and Farneth W.E., J. Catal. $1987,105,455$.

18. Forester T.R. and Howe R.F., J. Am. Chem. Soc., 1987

19. Forester T.R., MSc Thesis Auckland University, New Zealand, 1985.

20. Papp H., Hinsen W., Do N.T. and Baerns M., Thermochimica Acta, $1984,82,137$.

21. Auroux A., Bolis V., Wierzchowski P., Gravelle P.C. and Vedrine P.C. 1978, 2544 .

22. Lok B.M., Marcus B.K. and Angell C.L., Zeolites, 1986, 6,185 .

23. Parker L.M., Bibby D.M. and Meinhold R.H., Zeolites, $1985,5,384$.

24. Earl W.L., Fritz P.O., Gibson A.A.V. and Lunsford J.H., J. Phys. Chem., 1987, 91, 2091.

25. Uytterhoeven J.B., Christner L.G and Hall W.K., J. Phys. Chem., 1965, 69, 2117.

26. Ghosh A.K. and Curthoys G., J. Chem. Soc., Faraday Trans. I, $1984,80,99$.

28. Datka J. and Tuznik E., J. Catal., 1986, 102, 43.

29. Topsoe N.Y., Pedsersen K., Derouane E.G., J. Catal., $1981,70,41$.

30. Sayed M.B., Kydd R.A. and Cooney R.P., J. Catal., 1984, 88,137 .

31. Williams D.H. and Flemming I. "Spectroscopic Methods in organic Chemistry", McGraw Hill, London, 1973..

32. Lemley A.T. and Lagowski J.J., J. Phys. Chem., 1974, 78, 708 .

33. Busca G., Ramis G., Lorenzelli V., Janin A. and Lavalley J., Spectrochimica Acta, 1987, 43A, 489 .

34. Ghosh A.K., Kydd R.A., J. Catal., 1986, 100, 
36. Datka J., J. Chem. Soc. Faraday Trans. I, 1981, 77, 511.

37. Ault B.S., Steinback E. and Pimentel G.C., J. Phys. Chem., 1975, 79, 615.

38. Luck W.A.P. and Schrems O., Spectrscopy Letters, 1980, 13,719 .

39. Allan A., MCKean D.C., Perchard J.P. and Josien M.L., Spectrochimica Acta, 1971, 27, 1409.

40. Wieser H., Laidlaw W.G., Krueger P.J. and Fuhrer H., Spectrochimica Acta, 1968, 24, 1055.

41. Lercher J.A., Colombier C., Vinek H. and Noller H., Imelik B. et al. Editors, "Catalysis by Acids and Bases" $1985,25$.

42. Novakova J., Kubelkova L., Jiru P., Beran S., Nedomova K. , Acta Physica et Chimica Aushaf, 1985, 31, 561.

43. Ramis G., Busca G. and Lorenzelli V., Applied Catal, $1987,32,305$.

44. Paukshtis E.A., Soltanov R.I. and Yurchenko E.N., React. Kinet. Catal. Lett., 1983, 23, 339.

45. Basil M.R., Kantner T.R. and Rhee K.H., J. Phys. Chem., $1964,68,3197$.

46. Lohse U., Loffler E., Hunger M., Stockner J. and Patzelova V., Zeolites, 1987, 7, 11.

47. IR spectrum from compilation by Stadler Research Laboratories Inc. 1974. 
CHAPTER 8: Bases sorbed on B+Mordenite and H+Y - a comparison with $\mathrm{H}+\mathrm{Z} 8 \mathrm{M}-5$ :

\subsection{Methanol on H+mordenite:}

$\mathrm{H}+$ mordenite (Strem lot\# 10282-51), dried by holding at $400^{\circ} \mathrm{C}$ for $30 \mathrm{~min}$, was held in the FTIR cell at $100^{\circ} \mathrm{C}$ (figure $8.1 \mathrm{~A}$ ) and $10 \mathrm{ml}$ of air saturated with methanol at $21^{\circ} \mathrm{C}$ was injected into the cell. The resultant spectrum is shown in figure 8.1B, with the difference spectrum shown in figure $8.1 \mathrm{C}$.

The Bronsted hydroxyl peaks for both $\mathrm{H}+\mathrm{ZSM}-5$ and $\mathrm{H}+$ mordenite occur at the same wavenumber $\left(-3610 \mathrm{~cm}^{-1}\right)$, implying similar acid strengths. After sorption of methanol, the shifted hydroxyl band was broader and the maximum at a slightly lower wavenumber compared to $\mathrm{H}+\mathrm{ZSM}-5$ (3559 cf $3574 \mathrm{~cm}^{-1}$ ). This implys $\mathrm{H}+$ mordenite may have slightly stronger acid sites with a wider range of acid strengths than $\mathrm{H}+\mathrm{ZSM}-5$.

The $\mathrm{C}-\mathrm{H}$ stretching region showed no significant differences from the $\mathrm{H}+\mathrm{ZSM}-5$ case. The peak observed at $1455 \mathrm{~cm}^{-1}$ in the gas phase spectrum of methanol (figure 7.10) appeared as a negative peak. The difference spectrum (figure $8.1 \mathrm{C}$ ) shows that there is a broad absorption from $\sim 3610$ to $-1200 \mathrm{~cm}^{-1}$, with maxima at $\sim 2416 \mathrm{~cm}^{-1}$ and between 1900 and $1200 \mathrm{~cm}^{-1}$. (The height of the broad bands has been exaggerated by the subtraction). Similar broad bands were observed for methanol on $\mathrm{H}+\mathrm{ZSM}-5$ at $80^{\circ} \mathrm{C}$ (figure 7.7). Broad bands were also observed for sorbed DME (figure 8.7), but the sharp, positive peak characteristic of sorbed DME was not observed, showing DME was not present. The sorbed species is the same as observed on $\mathrm{H}+\mathrm{ZSM}-5$, which was shown to be mainly methanol. 
196 


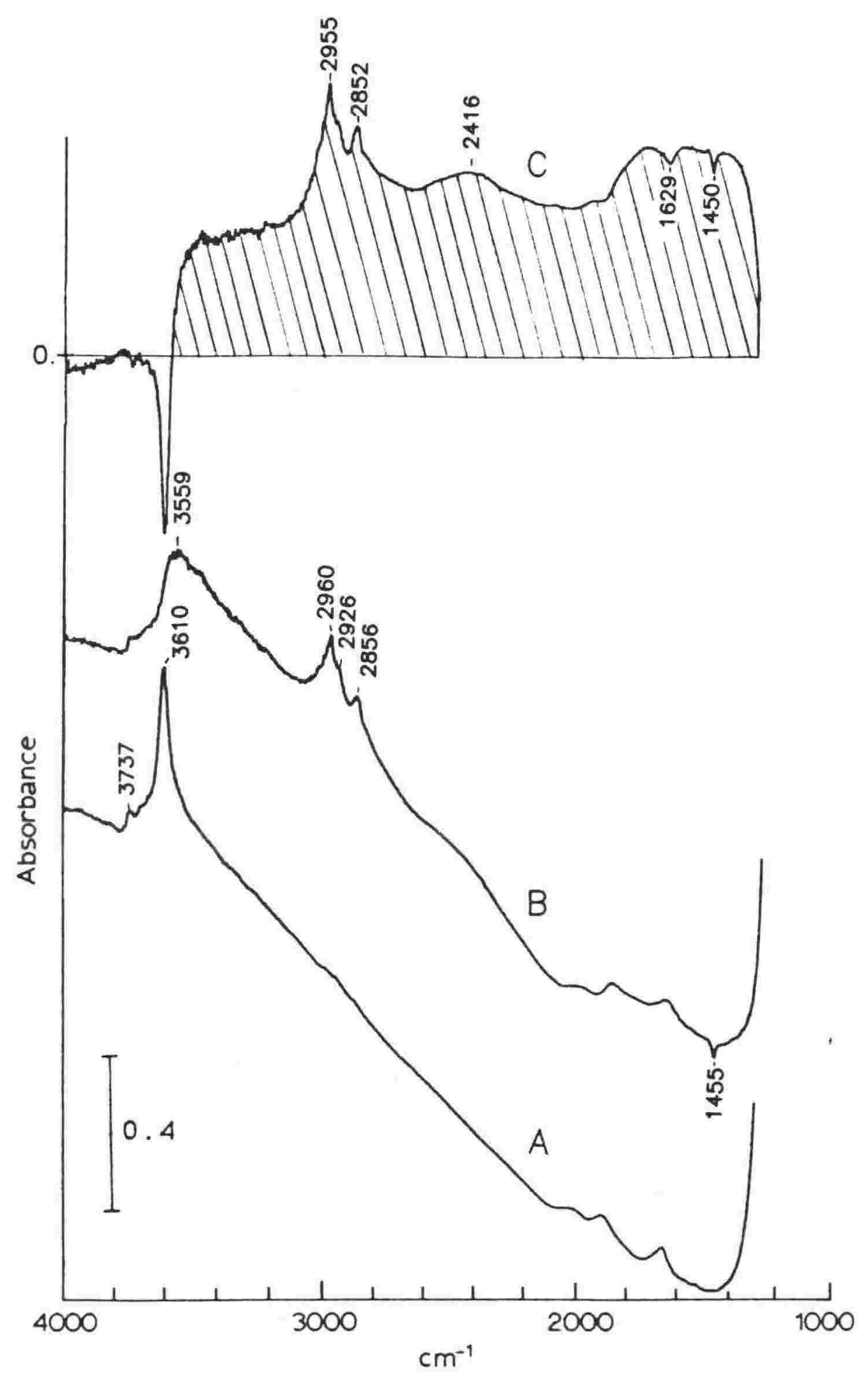

Figure 8.1 FTIR spectra of: A. dry H+mordenite held at $100^{\circ} \mathrm{C}$; B. after addition of $10 \mathrm{ml}$ methanol/air; $\mathrm{C}$. the difference spectrum (B-A). 


\subsection{Ammonia on H+mordenite:}

A dry wafer of $\mathrm{H}+$ mordenite was held at $150^{\circ} \mathrm{C}$ in a flow of dry nitrogen and its FTIR spectrum recorded (figure 8.2A). After injection of $10 \mathrm{ml} \mathrm{NH}$ gas into the cell, the resultant spectrum is shown in figure $8.2 \mathrm{~B}$. The absorbance of the sorbed ammonia was off-scale, so the sample was heated to $250^{\circ} \mathrm{C}$ at $10^{\circ} \mathrm{C} \mathrm{min} \min ^{-1}$ and held for $30 \mathrm{~min}$. The spectrum obtained after cooling to $150^{\circ} \mathrm{C}$ is shown in figure $8.2 \mathrm{C}$ and the difference spectrum in figure $8.2 \mathrm{D}$. Some of the Bronsted acid sites had been restored. The Bronsted proton associated with ammonia shows a peak at $3252 \mathrm{~cm}^{-1}$, with the bending mode of protonated ammonia at $1435 \mathrm{~cm}^{-1}$. This is similar to the $\mathrm{H}+\mathrm{ZSM}-5$ case (compare figure $7.18 \mathrm{C}$ with figure $8.2 \mathrm{D}$ ), but with the hydroxyl maximim $\sim 100 \mathrm{~cm}^{-1}$ lower. 


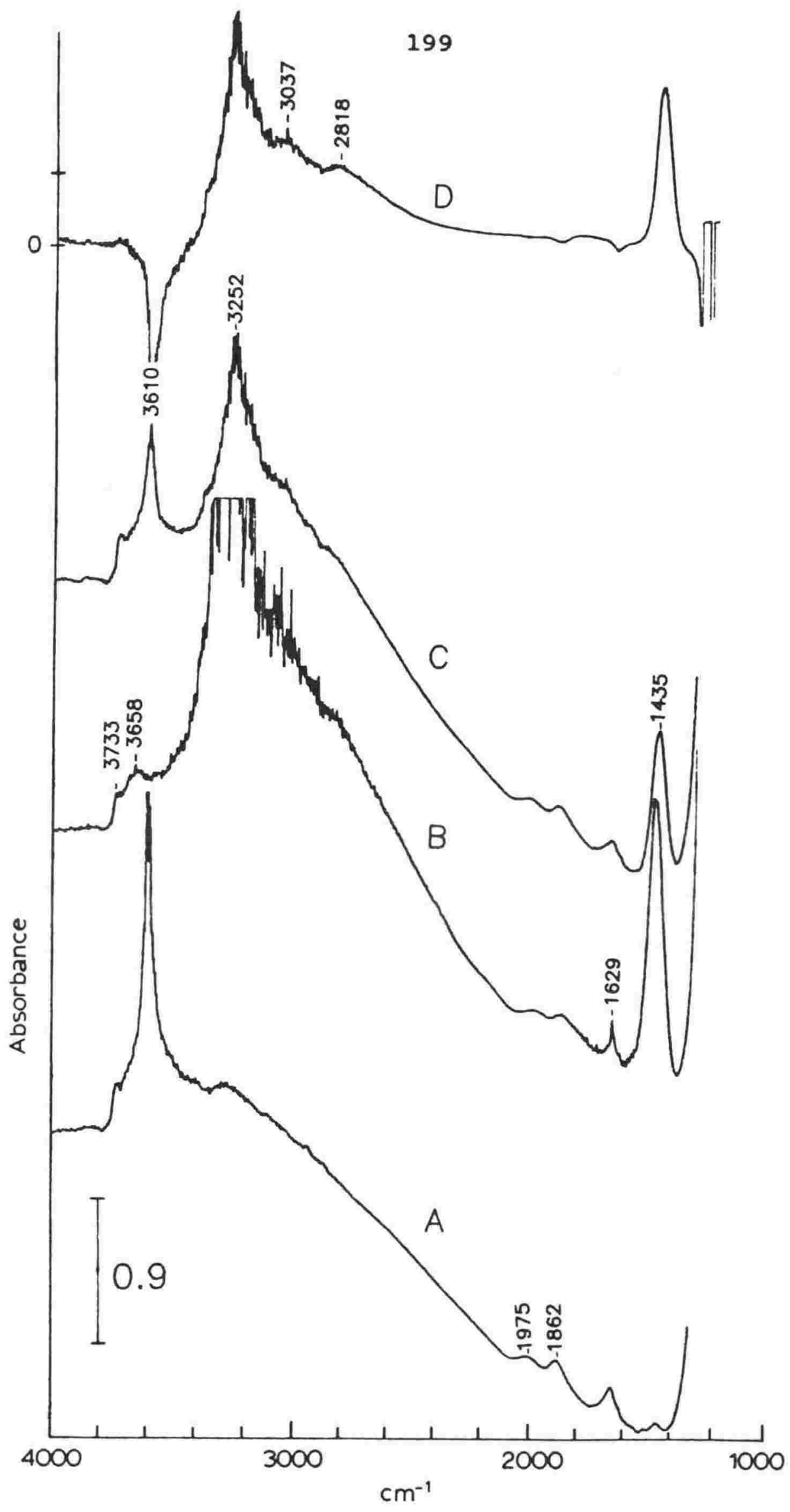

Figure 8.2 FTIR spectra of: A. dry H+mordenite at $150^{\circ} \mathrm{C}$; B. after addition of $10 \mathrm{ml} \mathrm{NH}_{3}$ gas; C. after heating to $250^{\circ} \mathrm{C}$ and holding $30 \mathrm{~min}$; D. the difference spectrum (C-A). 


\subsection{Pyridine on H+mordenite:}

FTIR spectra of increasing amounts of pyridine sorbed on a wafer of $\mathrm{H}+$ mordenite held at $150^{\circ} \mathrm{C}$ are shown in figure 8.3 . Further addition of pyridine after the spectrum in figure $8.3 \mathrm{C}$ was obtained caused no further changes. The difference spectrum (figure $8.3 \mathrm{C}$ - figure $8.3 \mathrm{~A}$ ) is shown in figure $8.4 \mathrm{~A}$.

In contrast with pyridine sorbed on $\mathrm{H}+\mathrm{ZSM}-5$, not all the Bronsted hydroxyls bonded strongly with pyridine. The hydroxyl peak only reduced in intensity, broadened and shifted slightly to $3599 \mathrm{~cm}^{-1}$. Some acid sites were therefore interacting only weakly with pyridine. Other acid sites interacted as for $\mathrm{H}+\mathrm{ZSM}-5$, with the main peak due to bonded hydroxyls shifted to $\sim 3250 \mathrm{~cm}^{-1}$, showing a slightly stronger interaction than $\mathrm{H}+\mathrm{ZSM}-5$. The remainder of the spectrum was very similar.

To determine the hydroxyl frequencies, $\mathrm{D}_{2} \mathrm{O}(2 \mu \mathrm{l})$ was injected into the FTIR cell so that $H / D$ exchange occured (figure 8.3D). The difference spectrum (between figure $8.3 D$ and 8.3C), figure 8.4B, shows these changes more clearly. Both the broad hydroxyl band at $\sim 3600 \mathrm{~cm}^{-1}$ and the band at $3250 \mathrm{~cm}^{-1}$ reduced in intensity along with a complex set of bands from $\sim 3200$ to $2800 \mathrm{~cm}^{-1}$. These bands are all due to stretches of exchangeable protons (zeolite $\mathrm{O}-\mathrm{H}$ and pyridine $\mathrm{N}-\mathrm{H}$ ). No defined C-D stretches appeared, showing lack of interaction of the $\mathrm{C}-\mathrm{H}$ bonds with Bronsted hydroxyls. A large increase in the peak at $1485 \mathrm{~cm}^{-1}$ and decreases in the peaks at $\sim 1630$ and $1541 \mathrm{~cm}^{-1}$ are due to differences in interaction of the $\mathrm{N}-\mathrm{H}$ and $\mathrm{N}-\mathrm{D}$ stretches with ring bending modes.

After heating to $500^{\circ} \mathrm{C}$, holding for 60 minutes and cooling, the pyridine had desorbed and both $\mathrm{OH}$ and $\mathrm{OD}$ Bronsted peaks were observed. 


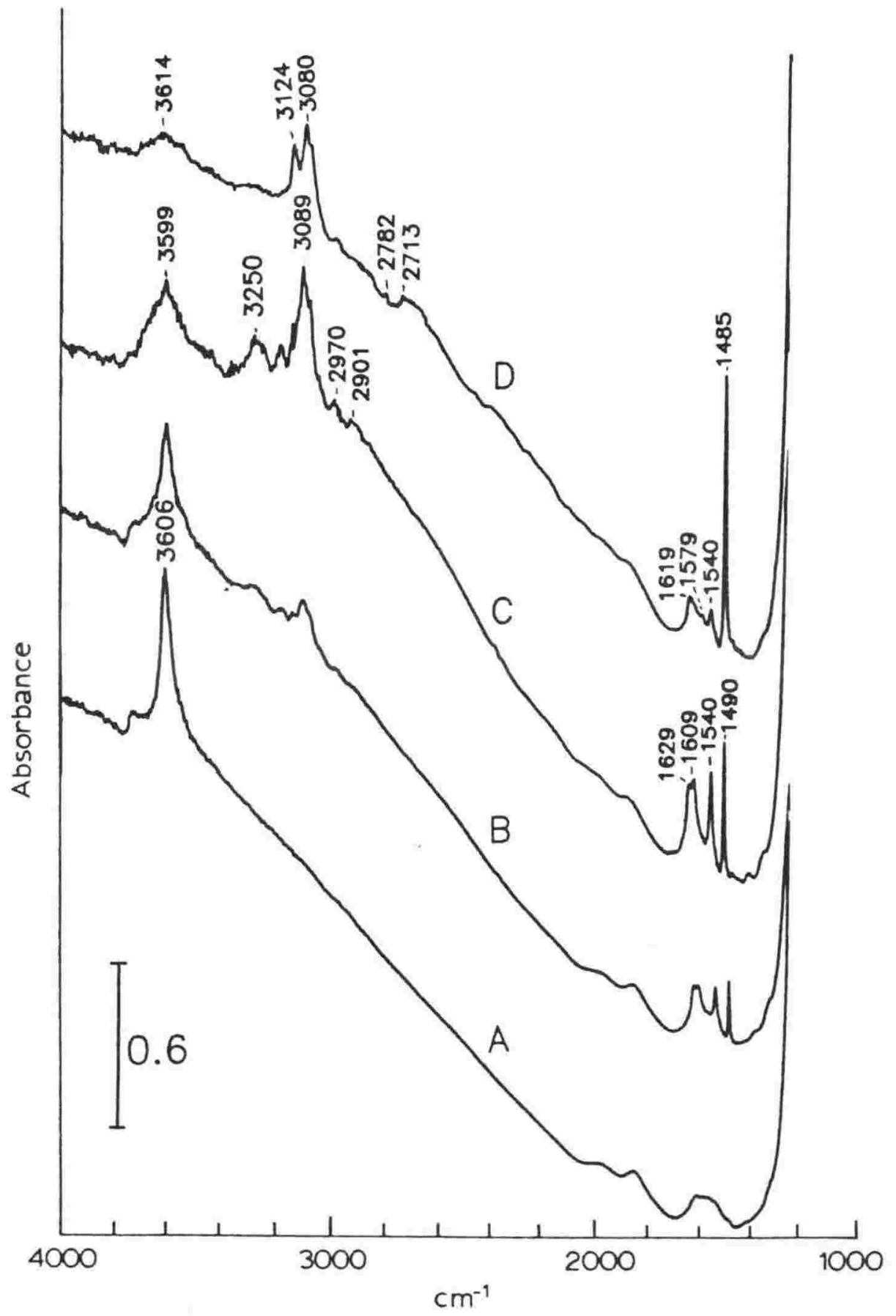

Figure 8.3 FTIR spectra of: A. dry H+mordenite at $150^{\circ} \mathrm{C}$; B. after addition of $5 \mathrm{ml}$ pyridine/air; $\mathrm{C}$. after addition of 23 $\mathrm{ml}$ pyridine/air and $\mathrm{D}$. after addition of $2 \mu \mathrm{I} \mathrm{D}_{2} \mathrm{O}$. 
202 


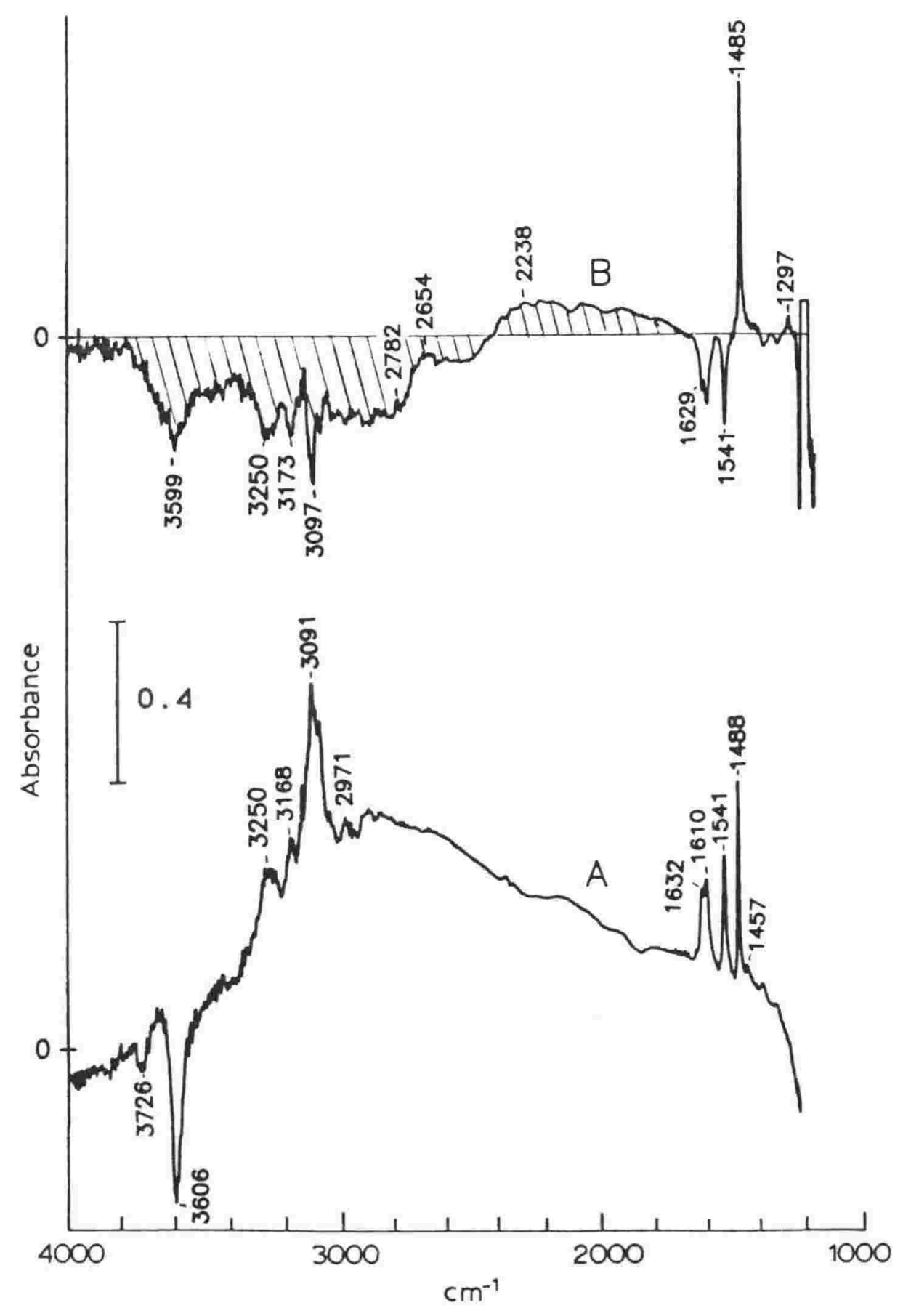

Figure 8.4 FTIR difference spectra of: A. after addition of $23 \mathrm{ml}$ pyridine/air and $\mathrm{B}$. after addition of $\mathrm{D}_{2} \mathrm{O}$ (figure 8.3D - figure $8.3 C$ ). 


\subsection{Propene on H+mordenite:}

Propene was sorbed onto dry $\mathrm{H}+$ mordenite held at $80^{\circ} \mathrm{C}$ (figure $8.5 \mathrm{~A})$. Figures $8.5 \mathrm{~B}$ and $8.5 \mathrm{D}$ show the maximum amount of propene that could be sorbed at $80^{\circ} \mathrm{C}$. Some of the Bronsted hydroxyls were still unassociated. Some gas phase or unreacted, sorbed propene was present, as shown by the band at $3109 \mathrm{~cm}^{-1}$. After flushing for 30 minutes with $20 \mathrm{ml} \mathrm{min} \mathrm{m}^{-1}$ dry $\mathrm{N}_{2}$, the spectrum in figure $8.5 \mathrm{C}$ and the difference spectrum in figure $8.5 \mathrm{E}$ was obtained. The sorbed propene had reacted, as no band at $3109 \mathrm{~cm}^{-1}$ was present. Not all the Bronsted hydroxyls were bonded as some of the original peak remained.

A comparison of $\mathrm{H}+\mathrm{ZSM}-5$ and $\mathrm{H}+$ mordenite showed some differences in the spectra of the reaction products. The main difference is that for $\mathrm{H}+\mathrm{ZSM}-5$ the broadened hydroxyl band has a maximum at $3455 \mathrm{~cm}^{-1}$, whereas for $\mathrm{H}+$ mordenite it is centred at $3609 \mathrm{~cm}^{-1}$. This implys that the reaction products of different proton affinities have formed. Further work would be required to establish this. 


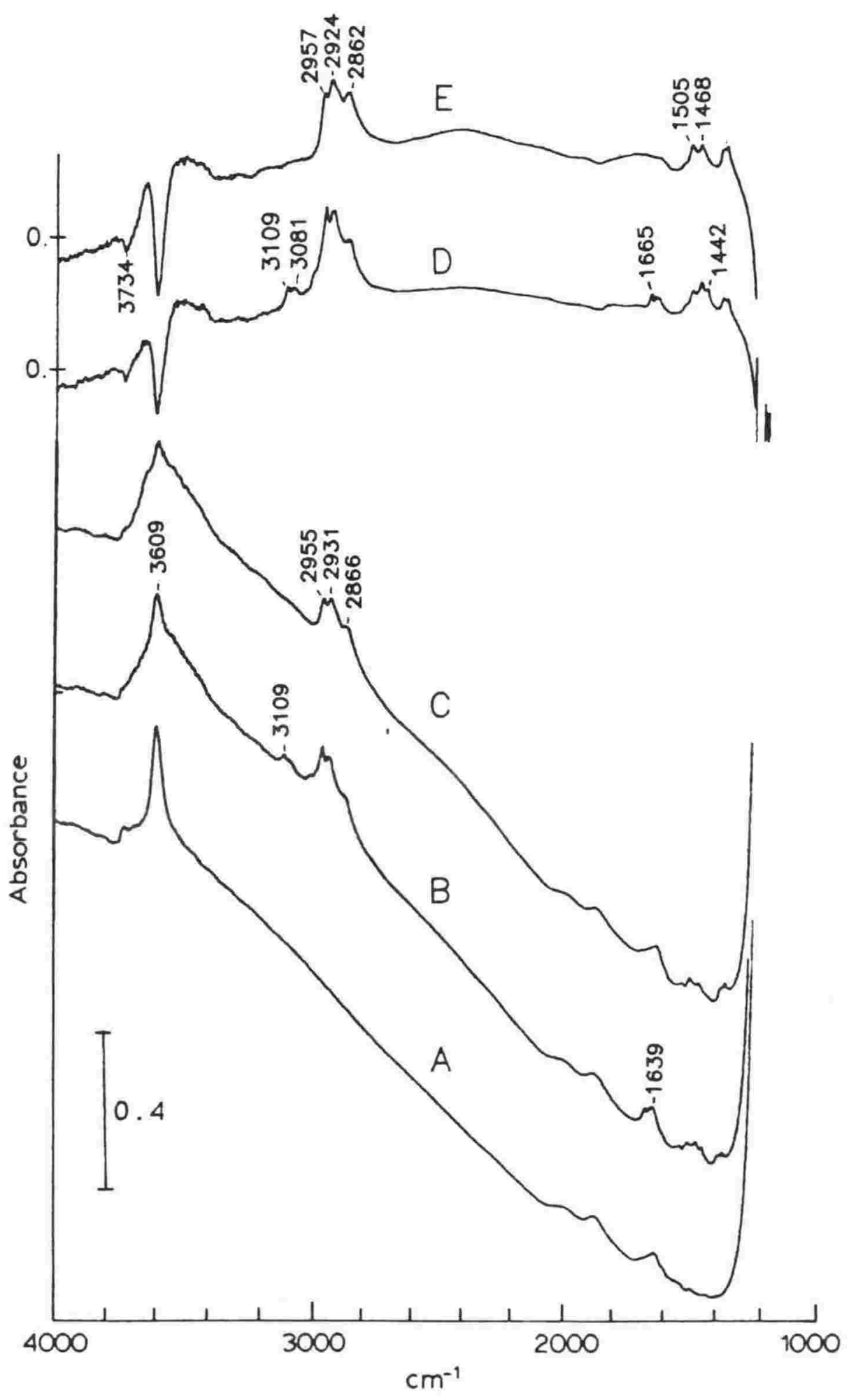

Figure 8.5 FTIR spectra of: A. dry H+mordenite at $80^{\circ} \mathrm{C} ; \mathrm{B}$. after addition of $2.5 \mathrm{ml}$ propene gas; C. $30 \mathrm{~min}$ later;

D. difference spectrum (B-A) and $E$. difference spectrum (CA) . 


\subsection{Toluene on H+mordenite:}

Toluene $(2 \mu \mathrm{l})$ was sorbed onto a dry wafer of $\mathrm{H}+$ mordenite held at $100^{\circ} \mathrm{C}$ (figure $8.6 \mathrm{~A}$ ). The resultant spectra are shown in figures $8.6 \mathrm{~B}$ and $\mathrm{C}$. The results are similar to those obtained for toluene on $\mathrm{H}+\mathrm{ZSM}-5$, except the broad hydroxyl band is more intense, noisier and has peaks superimposed. These peaks are significant, as the peaks at 3208,2931 and $2876 \mathrm{~cm}^{-1}$ coincide with the $\mathrm{C}-\mathrm{H}$ stretches observed for the H+ZSM-5 case. They may correspond to prefered orientations of the toluene molecules for bonding to the acid sites. Another difference from $\mathrm{H}+\mathrm{ZSM}-5$ is that not all the Bronsted hydroxyls appear to have bonded. 

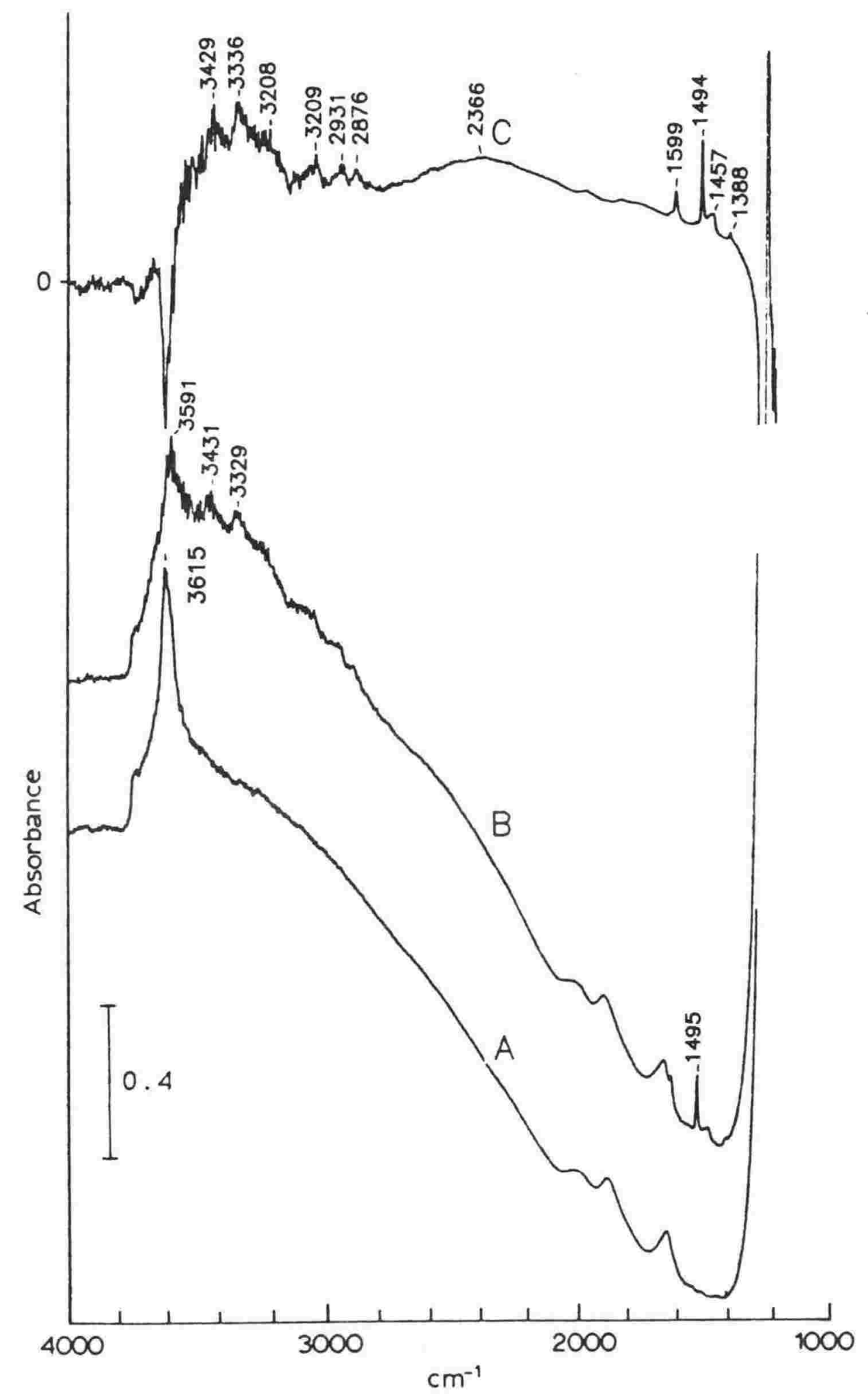

Figure 8.6 FITR spectra of: A. dry $\mathrm{H}+$ mordenite at $100^{\circ} \mathrm{C} ; \mathrm{B}$. after addition of $2 \mu l$ toluene; C. difference spectrum (BA) . 


\subsection{Dimethylether (DME) on H+mordenite:}

DME was sorbed onto a dry wafer of $\mathrm{H}+$ mordenite held at $80^{\circ} \mathrm{C}$ (figure $8.7 \mathrm{~A}$ ). The resultant spectra are shown in figures 8.7B and D. After holding for 15 minutes in flowing $\mathrm{N}_{2}$, the spectra obtained are shown in figures $8.7 \mathrm{C}$ and $\mathrm{E}$. The spectrum after sorption of DME was similar to that for H+ZSM5 , except that not all the Bronsted acid sites appeared to have bonded. There remained a broad band with a maximum at $3634 \mathrm{~cm}^{-1}$. This may be due to acid sites sterically not accessible to DME.

After flushing for 15 minutes, the $\mathrm{C}-\mathrm{H}$ stretching region decreased in intensity, although no Bronsted hydroxyl peaks reappeared. This was due to removal of gas phase and physisorbed DME. 


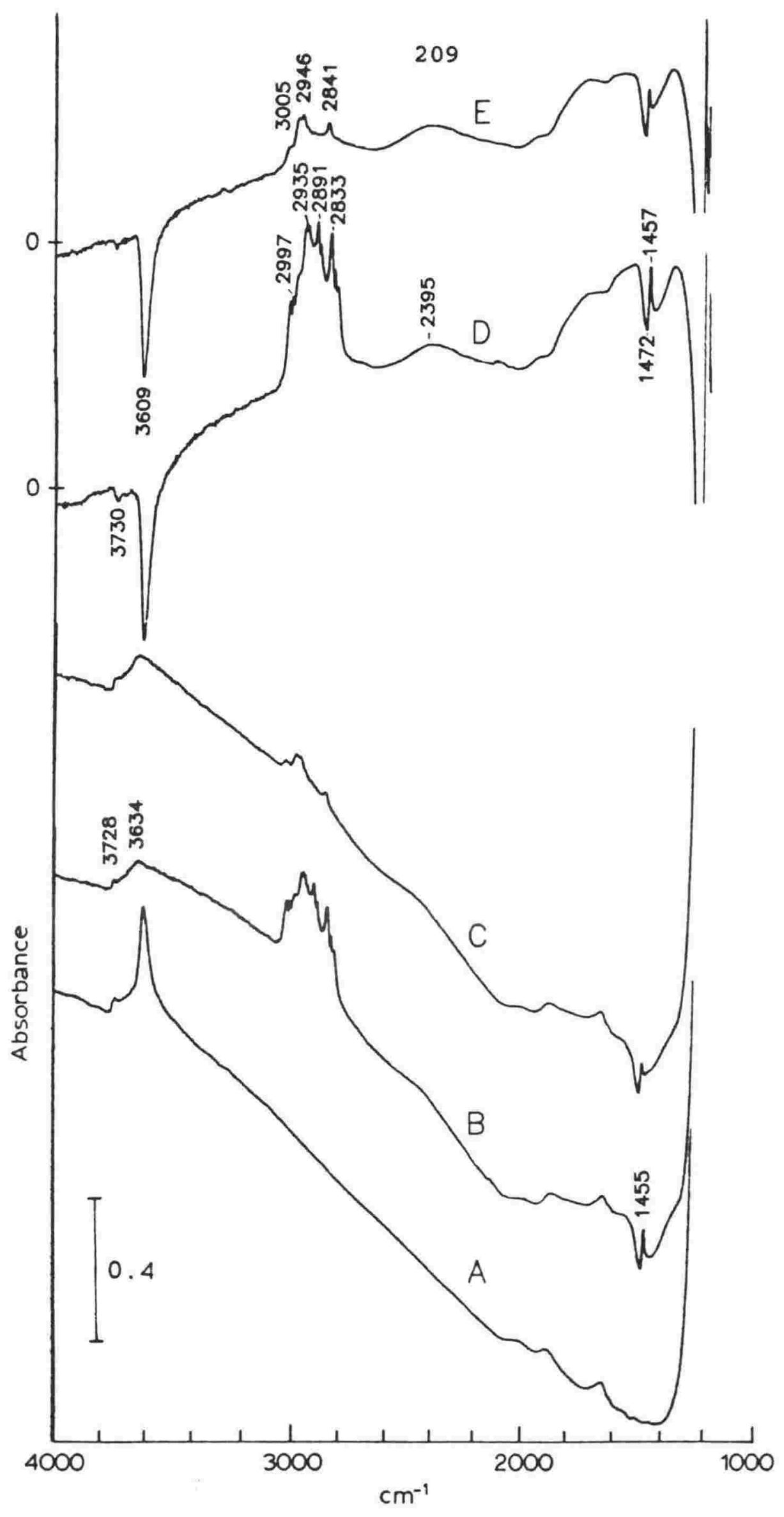

Figure 8.7 FTIR spectra of: A. dry H+mordenite at $80^{\circ} \mathrm{C}$ B. after addition of $1.5 \mathrm{ml}$ DME; C. after waiting $15 \mathrm{~min}$; D. difference spectrum (B-A); E. difference spectrum (C-A). 


\subsection{Acetone on Btmordenite:}

The FTIR spectra for acetone sorbed on a dry wafer of $\mathrm{H}+$ mordenite held at $80^{\circ} \mathrm{C}$ are shown in figures 8.8 and 8.9 . After heating to $150^{\circ} \mathrm{C}$, the difference spectrum in figure $8.9 \mathrm{D}$ was obtained. The spectra in $8.9 \mathrm{~A}$ and $\mathrm{B}$ are similar to that obtained for acetone on $\mathrm{H}+\mathrm{ZSM}-5$ (figure 7.47). A difference is that on $\mathrm{H}+\mathrm{ZSM}-5$ no distinct band in the hydroxyl stretching region remains, with broad bands over the entire spectrum range observed. However, for H+mordenite, a broad hydroxyl band was also observed (see figures $8.8 \mathrm{~B}$ and $\mathrm{C}$ ) probably due to acid sites that were not accessible enough to acetone for complete bonding to occur. Their environment is still affected by the acetone, as shown by the broadening of the hydroxyl peak.

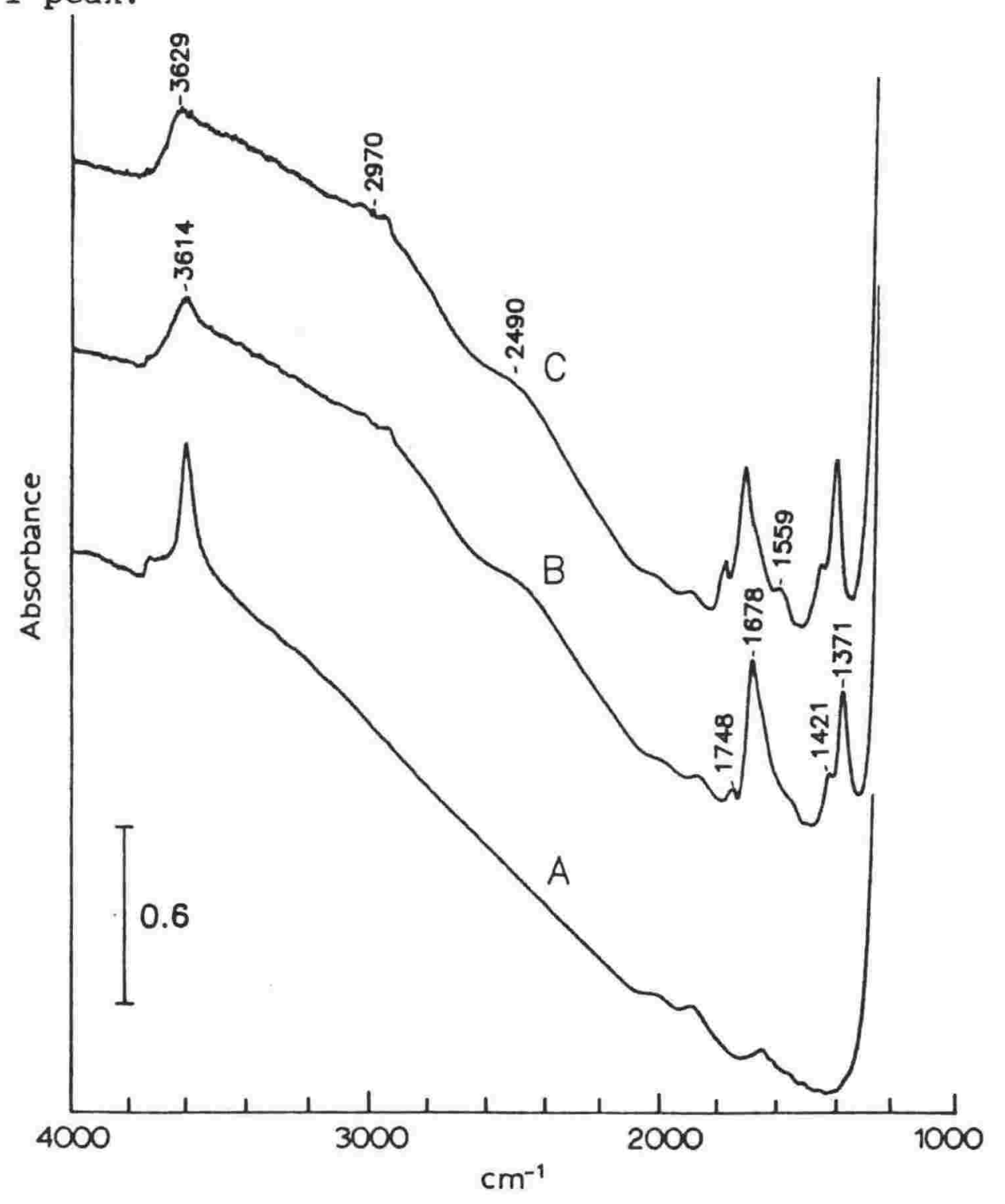

Figure 8.8 FTIR spectra of: A. dry $\mathrm{H}+$ mordenite at $80^{\circ} \mathrm{C}$;

B. after addition of $1 \mu l$ acetone and $C$. after addition of 3 HI acetone. 


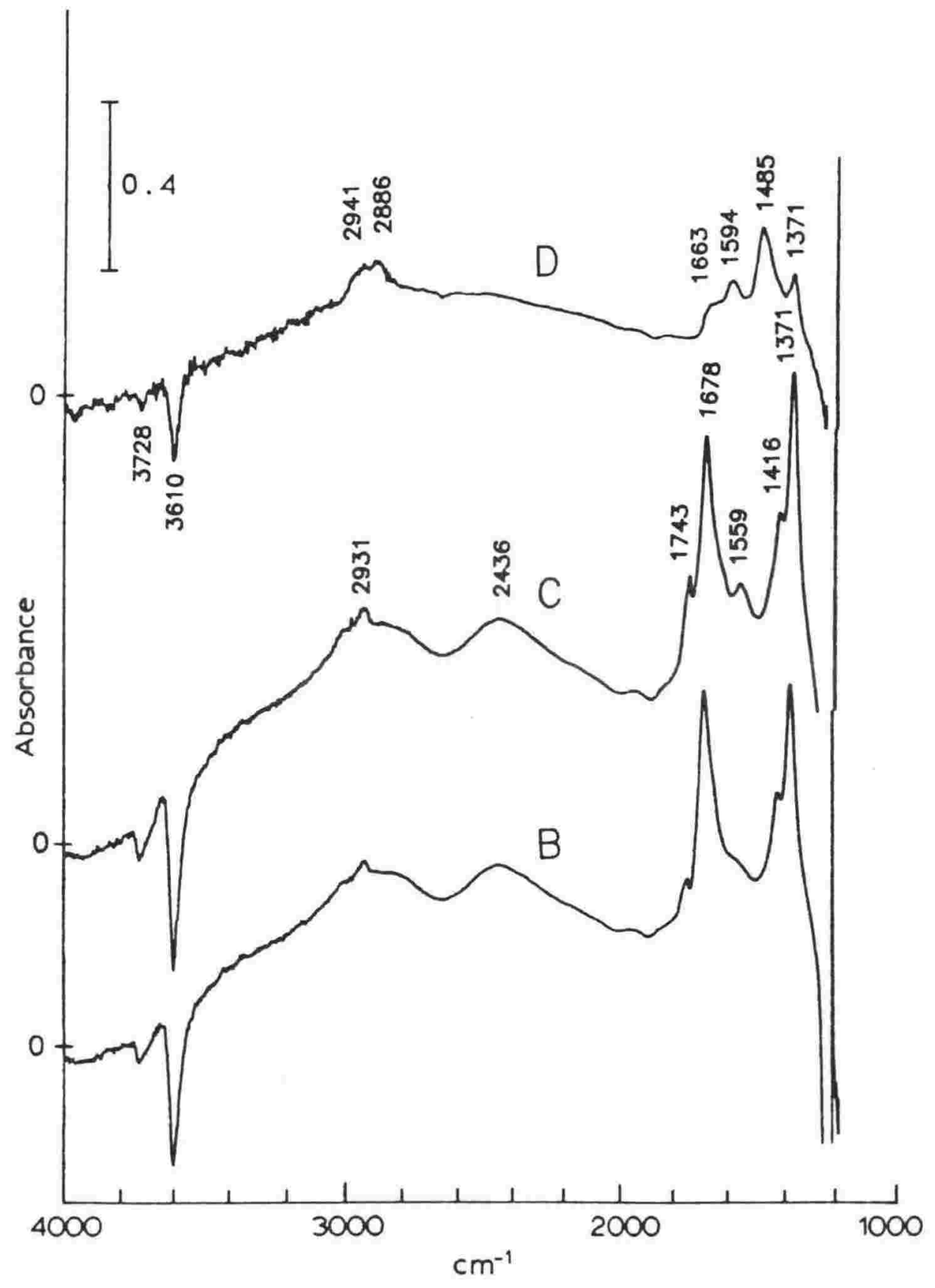

Figure 8.9 FTIR difference spectra of H+mordenite: B. after addition of $1 \mu l$ acetone; C. after addition of $3 \mu l$ acetone and $\mathrm{D}$. after heating to $150^{\circ} \mathrm{C}$. 


\subsection{Ammonium $Y$ (Ammonia on $\mathrm{H}+\mathrm{Y}$ ):}

The spectrum of ammonia desorbing from $\mathrm{NH}_{4} \mathrm{Y}$ in a $20 \mathrm{ml} \mathrm{min}{ }^{-1}$ dry $\mathrm{N}_{2}$ flow at $20^{\circ} \mathrm{C}, 150^{\circ} \mathrm{C}, 200^{\circ} \mathrm{C}, 250^{\circ} \mathrm{C}$ and $350^{\circ} \mathrm{C}$ are shown in figures $8.10 \mathrm{~A}, \mathrm{~B}, \mathrm{C}, \mathrm{D}$ and $\mathrm{E}$ respectively.

A $20^{\circ} \mathrm{C}$ there is a large off-scale absorption due to sorbed ammonia with some water also present. (The presence of water is shown by its bending mode at $1649 \mathrm{~cm}^{-1}$ ). After heating to $150^{\circ} \mathrm{C}$, the Bronsted hydroxyl peaks at 3643 and $3543 \mathrm{~cm}^{-1}$ have started to appear. There is a complex of bands in the hydroxyl stretching region. Further desorption does not result in a single hydroxyl maximum (as was observed for H+ZSM-5 and H+mordenite). Four maxima prevent assignment to hydroxyls associated with particular acid sites. The LF and HF hydroxyl peaks appear together, showing that the set of bands is due to ammonia on both these sites, probably with a range of energies. 


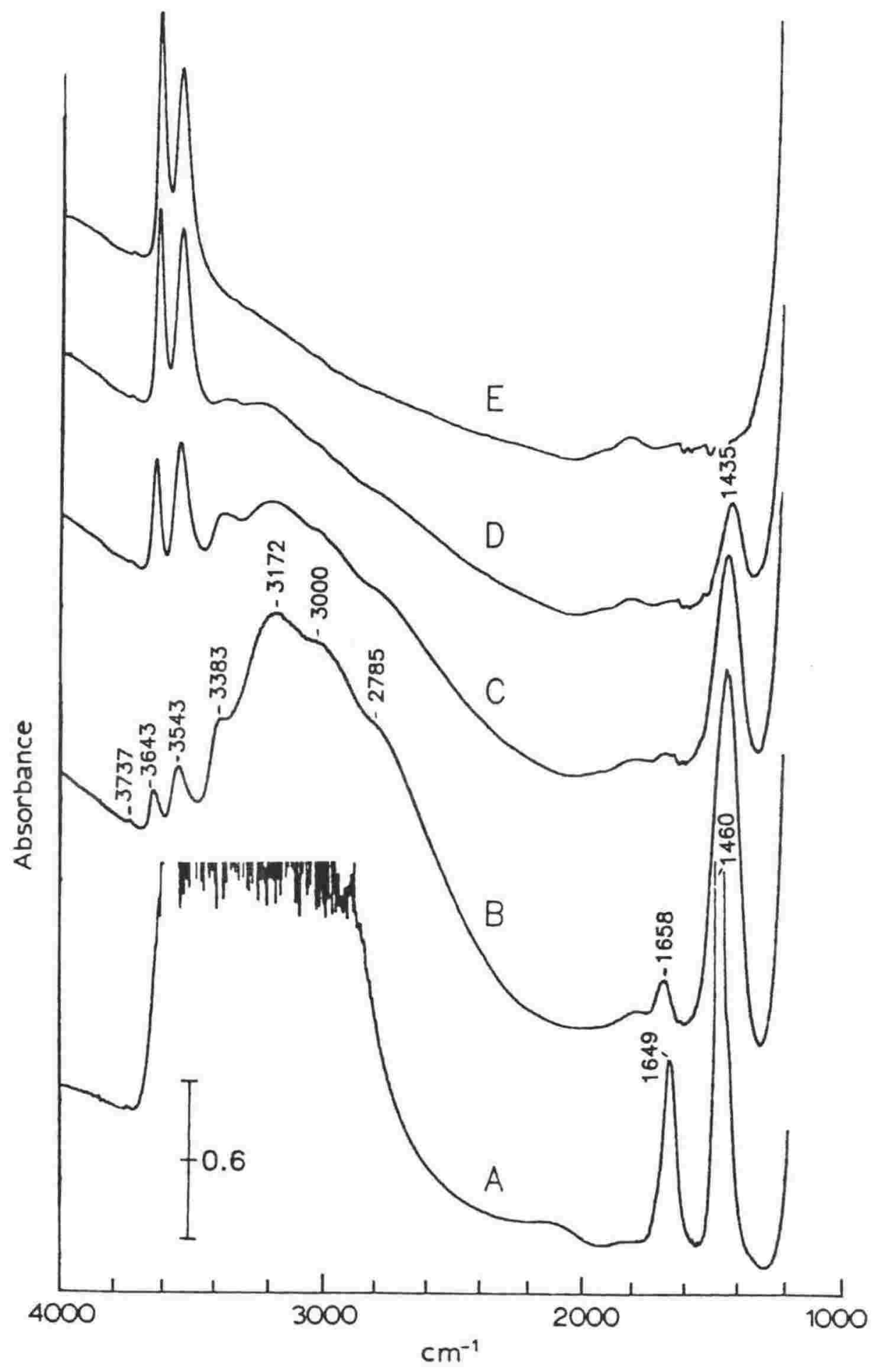

Figure 8.10 FTIR spectra of: A. $\mathrm{NH}_{4} \mathrm{Y}$ at $20^{\circ} \mathrm{C} ; \mathrm{B}$. at $150^{\circ} \mathrm{C}$; C. at $200^{\circ} \mathrm{C} ;$ D. $250^{\circ} \mathrm{C}$ and E. $350^{\circ} \mathrm{C}$. 


\subsection{Dimethylether (DME) on $\mathrm{H}+\mathrm{Y}$ :}

DME was sorbed onto dry $\mathrm{H}+\mathrm{Y}$ held at $80^{\circ} \mathrm{C}$ (figure $8.11 \mathrm{~A}$ ). (The $\mathrm{H}+\mathrm{Y}$ was obtained by heating $\mathrm{NH}_{4} \mathrm{Y}$ to $350^{\circ} \mathrm{C}$ in $30 \mathrm{~min}$, holding $30 \mathrm{~min}$, then cooling). The spectrum obtained is shown in figure 8.11B, and shows the maximum amount of DME that could be sorbed at this temperature. A proportion of both the LF and HF hydroxyls remained unbonded. Decreasing the sample temperature to $40^{\circ} \mathrm{C}$ (figure $8.11 \mathrm{C}$ ) enabled more DME to be sorbed, with the LF hydroxyls becoming completly bonded. At $25^{\circ} \mathrm{C}$, (figure $8.11 \mathrm{D}$ ) more DME was sorbed. Not all the HF hydroxyls were bonded, but the peak was broadened, showing weak interaction with DME.

Broad hydroxyl bands are observed, as for DME on H+ZSM-5 and $\mathrm{H}+$ mordenite, but with stronger maxima at $\sim 2900,2436$ and 1822 $\mathrm{cm}^{-1}$. The strong flat band from $\sim 2000$ to $1300 \mathrm{~cm}^{-1}$ for $\mathrm{ZSM}-5$ and mordenite is not apparent. Instead of a sharp negative, then positive peak at $\sim 1460 \mathrm{~cm}^{-1}$ there is a strong positive peak at $1458 \mathrm{~cm}^{-1}$. The difference in these bands must reflect the different environment inside the zeolite for the Bronsted proton.

Heating the sample at $10^{\circ} \mathrm{C} \mathrm{min} \mathrm{m}^{-1}$ resulted in the DME desorbing by $200^{\circ} \mathrm{C}$, with the original $\mathrm{H}+\mathrm{Y}$ spectrum obtained. 


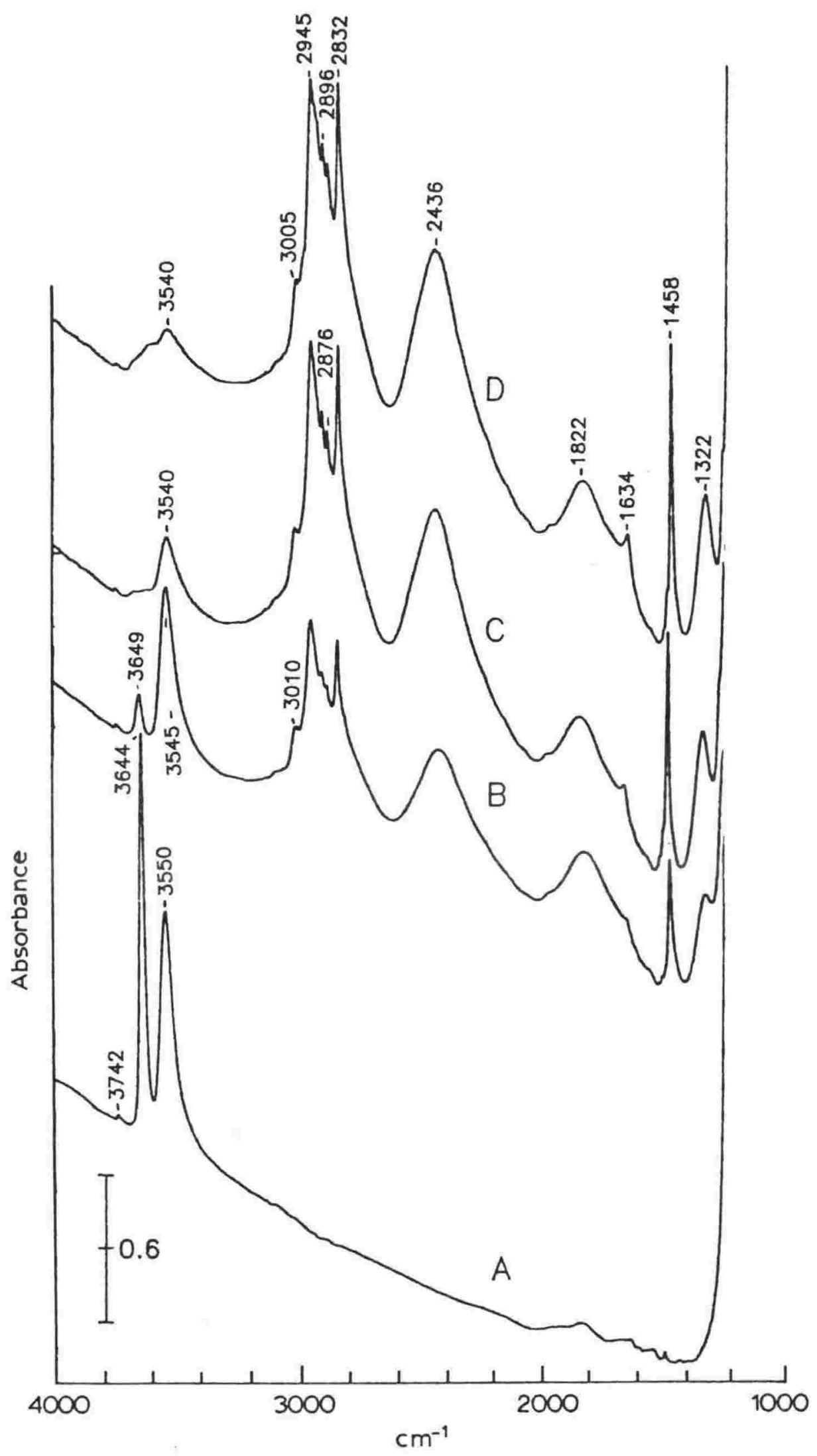

Figure 8.11 FTIR spectra of: A. dry $\mathrm{H}+\mathrm{Y}$ at $80^{\circ} \mathrm{C}$; B. after addition of $3 \mathrm{ml}$ DME gas at $80^{\circ} \mathrm{C}$; $\mathrm{C}$. after addition of a further $3 \mathrm{ml}$ DME at $40^{\circ} \mathrm{C}$ and $\mathrm{D}$. after addition of a further 3 $\mathrm{ml}$ DME at $25^{\circ} \mathrm{C}$. 


\subsection{Conclusions:}

A range of bases were sorbed on $\mathrm{H}+$ mordenite. Their behaviour was very similar to that observed for $\mathrm{H}+\mathrm{ZSM}-5$, with the sorbants falling into the same classes as described in Chapter 7. For Class A sorbants the shifts of the strongly bonded hydroxyls $\left(\Delta v_{\mathrm{OH}}\right)$ upon sorption are shown in Table 8.1 and plotted in figure 8.12 .

Table 8.1 Class A sorbants on $\mathrm{H}+$ mordenite - bonded $\mathrm{v}_{\mathrm{O}-\mathrm{H}}$ peak maxima.

methanol

ammonia

$$
v_{\mathrm{OH}}\left(\mathrm{cm}^{-1}\right) \quad \Delta v_{\mathrm{O} \cdot \mathrm{H}}\left(\mathrm{cm}^{-1}\right)
$$

pyridine

$$
3559
$$

of the sorbants studied only methanol and ammonia bonded strongly with all the Bronsted sites. Steric limitations restricted the larger sorbants to strong interactions with only some of the Bronsted sites. The larger sorbants (such as pyridine) interacted with the remainder of the acid sites, broadening the hydroxyl peak, presumably by a weaker, more long distance interaction.

Pyridine and ammonia show similar $v_{0 . H}$, and no correlation of $v_{\mathrm{OH}_{H}}$ with base proton affinity. This may result from the differences in steric accessibility to the acid sites. This restricts the possibility of determining a correlation for mordenite to small class A bases. A comparison of $v_{0 . H}$ upon ammonia sorption for $\mathrm{H}+2 \mathrm{SM}-5$ and $\mathrm{H}+$ mordenite implys that $\mathrm{H}+$ mordenite has sites of greater acid strength (for bonding ammonia).

The spectra of sorbed bases on $\mathrm{H}+\mathrm{Y}$ were more complicated because of the two types of Bronsted hydroxyls. For example, with sorbed ammonia, the shifted hydroxyl peaks could not be assigned to either the HF or LF acid sites as four bands were observed. Thus a correlation with sorbant proton affinity 
was not attempted. Diffuse, broad bands were observed for the Class C sorbant, DME, as occured for DME on $\mathrm{H}+2 \mathrm{SM}-5$ and H+mordenite. However, these bands were different in shape and position, implying a different environment for the Bronsted protons associated with DME in $\mathrm{H}+\mathrm{Y}$.

The behaviour of sorbants in three general classes, as described in chapter 7 for $\mathrm{H}+\mathrm{ZSM}-5$, is also observed for $\mathrm{H}+$ mordenite and $\mathrm{H}+\mathrm{Y}$.

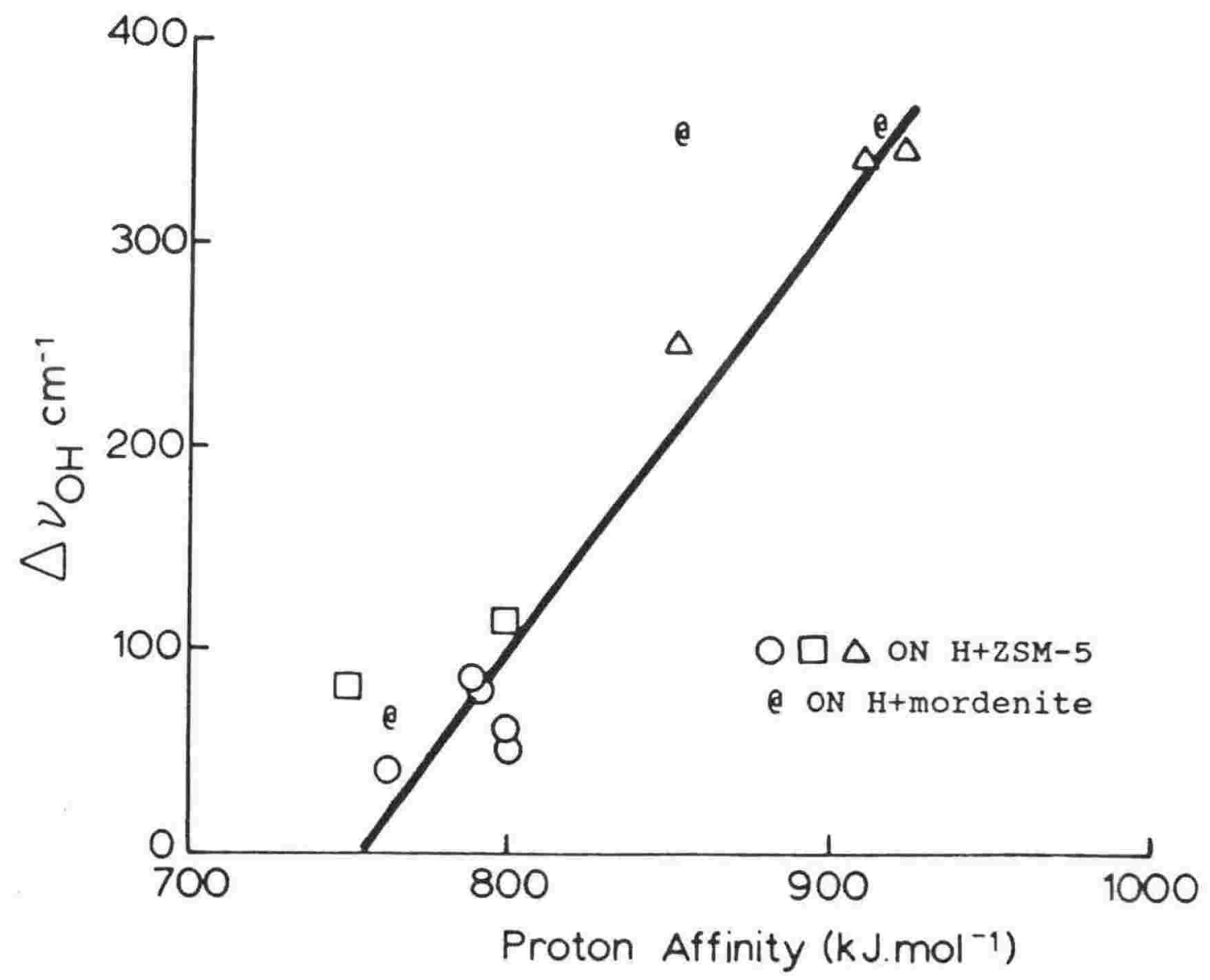

Figure 8.12. Correlation of $\Delta v_{a H}$ versus the proton affinity of the sorbed base for $\mathrm{H}+\mathrm{ZSM}-5$ with the data for $\mathrm{H}+$ mordenite from Table 8.1 superimposed (shown by $e^{2}$ ). 
CHAPTER 9: CARBOXYLIC ACIDS ON ALKALI EXCHANGED ZEOLITES:

\subsection{Introduction:}

The reactions of acetic acid over acid zeolites have been previously studied $(1,2)$. However, no results have been reported on the sorption and reactions of carboxylic acids over alkali-exchanged zeolites.

An initial td/ms experiment in which acetic acid was desorbed from $\mathrm{Na}+\mathrm{ZSM}-5$ resulted in the observation that ketene (ethenone) was produced between 250 and $550^{\circ} \mathrm{C}$ with a maximum at $370^{\circ} \mathrm{C}$ (figure 9.1). This was an important result, as ketene is produced industrially from gas phase pyrolysis of acetic acid at 700 to $800^{\circ} \mathrm{C}$ under reduced pressure $(0.1$ to 0.5 atm), with an organic phosphate acting as an acid catalyst (3):

$$
\mathrm{CH}_{3}-\mathrm{C}_{\mathrm{OH}}^{\prime \mathrm{O}} \stackrel{700-800^{\circ} \mathrm{C}}{\rightarrow} \quad \mathrm{CH}_{2}=\mathrm{C}=\mathrm{O}+\mathrm{H}_{2} \mathrm{O}
$$

The observation of ketene at temperatures ca $400^{\circ} \mathrm{C}$ lower than the industrial process, from reaction of acetic acid over an alkali metal exchange catalyst, implied that there may be a cost saving in using the zeolite catalyst. In the pyrolysis reaction, methane, carbon monoxide, carbon dioxide and ethene are produced as by-products. Reaction conditions and products are difficult to control, and a plant is only economic if it is run on a relatively large scale. However, these large scale plants do achieve high yields of ketene ( 90 to $95 \%$ ). The use of zeolite catalysts could in principle enable small plants for the production of ketene on-site, just prior to use. Ketene is a highly reactive acetylating agent, and a review of its chemistry and industrial uses is given in Kirk-othmer Chemical Encylopedia (4).

Further experimental work was then carried out to investigate the potential of this reaction. A range of carboxylic acids 
was investigated to determine the generality of the reaction in the production of higher ketenes:

$$
\underset{\mathrm{R}^{\prime \prime}}{\mathrm{R}} \mathrm{CH}-\mathrm{C}^{\prime}=0 \mathrm{OH} \rightarrow \underset{\mathrm{R}^{\prime}}{\mathrm{C}} \mathrm{C}=\mathrm{C}=\mathrm{O}+\mathrm{H}_{2} \mathrm{O}
$$

In-situ reaction of the ketene with another reactant, while still sorbed on the zeolite, was investigated as a means of avoiding problems of isolating the ketene product, and to perhaps utilise the shape selective properties of zeolites to control product distributions.

A survey of the range of possible ketene producing catalysts and an investigation into the mechanism of the ketene formation were carried out, and are described in chapter 10.

A search of Chemical Abstracts resulted in only one reference to the observation of ketene produced below $500^{\circ} \mathrm{C}$. This was in a study by Gonzalez et al. (5) of the reaction of acetic acid to acetone over $\mathrm{TiO}_{2}$ (anatase), where ketene was proposed as an intermediate. Ketene was not observed in the desorbed products. The only evidence for its presence was based on IR spectra. This was despite the fact that the strong characteristic $v_{c=0}$ shift for ketene at $2150 \mathrm{~cm}^{-1}$ was not observed. It was suggested that the ketene acted as a strong Lewis base, with the $v_{c=0}$ band shifted to $1730 \mathrm{~cm}^{-1}$ (at which frequency a small band was observed). The proposed reaction scheme (5) was:

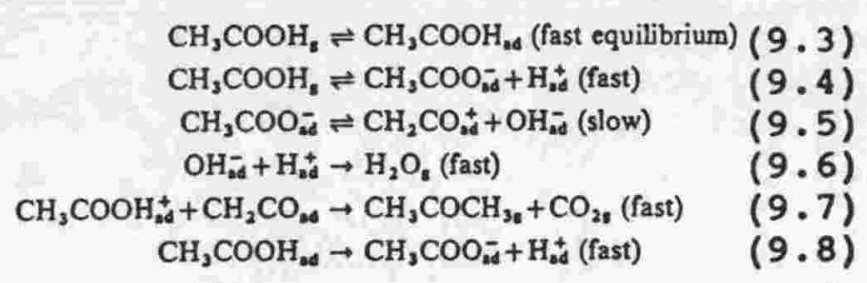

Ketene is formed from sorbed acetate (9.5). This scheme implies that both Bronsted basic (to enable $\mathrm{H}^{+}$ad $(9.4)$ ) and Bronsted acidic sites (to enable $\mathrm{OH}^{\circ}(9.5)$ ) are present. The mechanism also requires the presence of Lewis acid sites for sorption of ketene and acetic acid. This scheme does not seem feasible because of the requirement for three different 
sorption sites which would need to be adjacent for reaction to occur. The mechanism for the reaction of $\mathrm{CH}_{2} \mathrm{CO}_{\mathrm{ad}}{ }^{+}$is also not given.

RESULTS AND DI8CU8SION:

9.2 Reaction of acetic acid over H+28M-5:

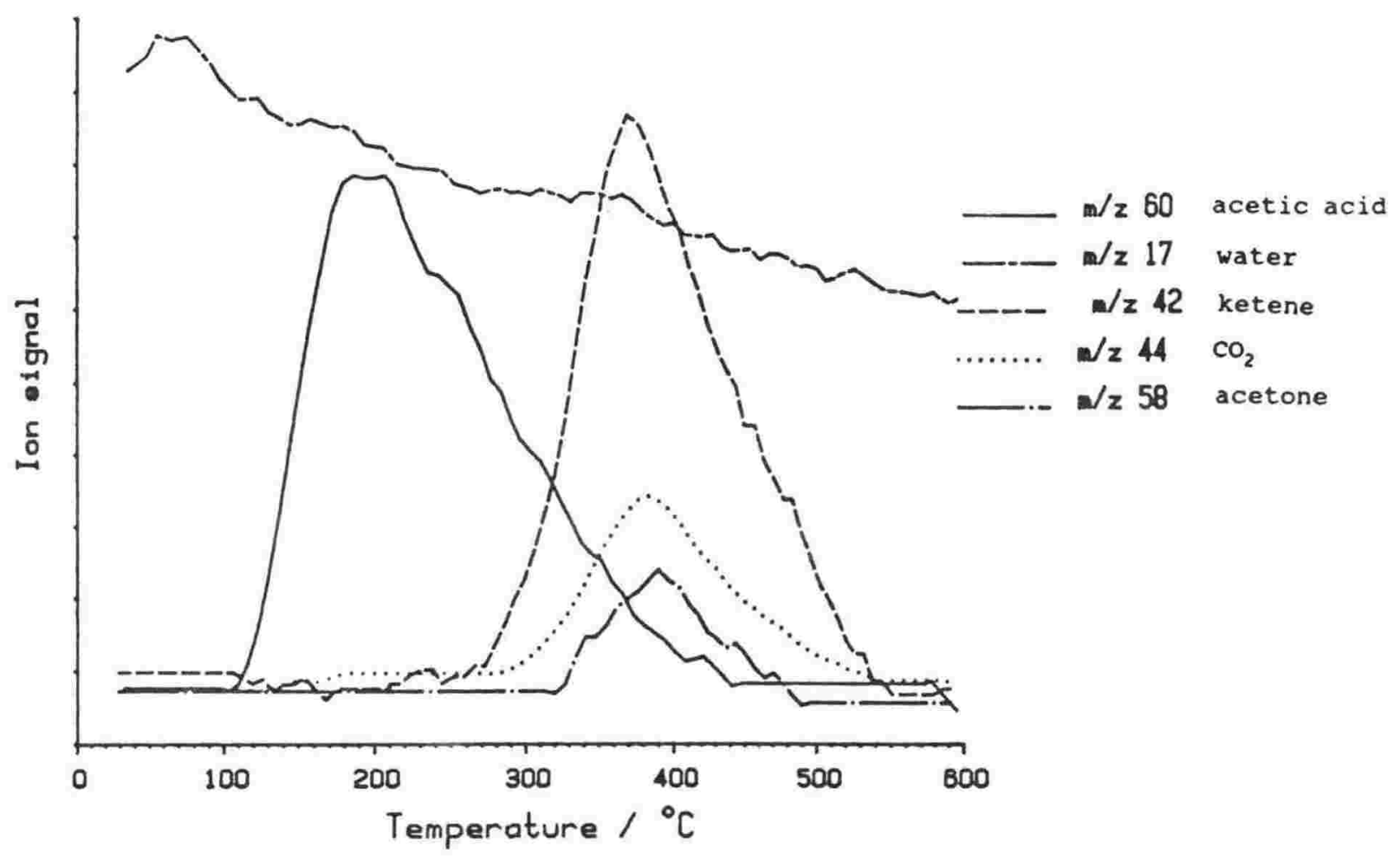

Figure $9.1 \mathrm{Td} / \mathrm{ms}$ of acetic acid sorbed on $\mathrm{Na}+\mathrm{ZSM}-5$.

The results of the low pressure td/ms experiment that lead to the observation of the ketene producing reaction are shown in figure 9.1. Acetic acid was sorbed on Na+ZSM-5 (prep 915) held at $150^{\circ} \mathrm{C}$ then heated at $10^{\circ} \mathrm{C} \mathrm{min}{ }^{-1}$. Physisorbed acetic acid desorbed frc $150^{\circ} \mathrm{C}$ to $440^{\circ} \mathrm{C}$. The ion signals corresponding to the published mass spectrum for ketene (6) were observed to reach a maximum at $370^{\circ} \mathrm{C}$, and are represented 
by the $\mathrm{m} / \mathrm{z} 42$ ion signal. Acetone $(\mathrm{m} / \mathrm{z} 58)$ and $\mathrm{CO}_{2}(\mathrm{~m} / \mathrm{z} 44)$ both reached maxima at $390^{\circ} \mathrm{C}$. This sequence of product evolution suggested that the acetic acid decomposed to ketene and water as shown in equation 9.1 .

Ketene probably reacted further with the remaining acetic acid. The reaction of ketene with acetic acid in the liquid phase gives acetic anhydride (3):

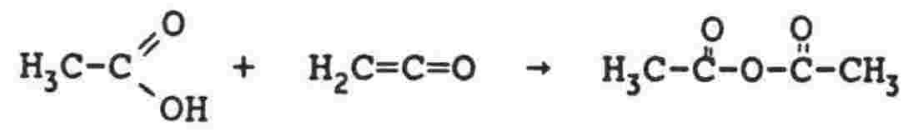

The mass spectrum of acetic anhydride is similar to acetic acid and has no significant molecular ion (6). This means that it can not be unambigously identified by mass spectrometry unless significant quantities are present compared to acetic acid. In this example no significant acetic anhydride was produced. Instead, it appeared that ketene reacted with acetic acid to give acetone and carbon dioxide, as the evolution of $\mathrm{CO}_{2}$ coincided with the evolution of acetone:

$$
\mathrm{H}_{3} \mathrm{C}-\mathrm{C}=\mathrm{OH}_{2}=\mathrm{O}+\mathrm{C}=\mathrm{O} \rightarrow \mathrm{H}_{3} \mathrm{C}-\stackrel{\mathrm{C}}{\mathrm{C}}-\mathrm{CH}_{3}+\mathrm{CO}_{2}
$$

No significant water desorption peak was observed corresponding to the desorption of ketene. This implies water may have been evolved (equation 9.1) upon sorption of acetic acid with the ketene remaining sorbed, or that water reacted irreversibly with the zeolite, or that the water was not transfered to the mass spectrometer due to condensation, in the transfer line. 


\subsection{Reaction of formic acid over Natzsk-5:}

The analogous reaction of formic acid over $\mathrm{Na}+\mathrm{ZSM}-5$, compared to the reaction of acetic acid, would be:

$$
\mathrm{HC}_{\text {OH }}^{\prime \prime} \rightarrow \mathrm{C} \equiv \mathrm{O}+\mathrm{H}_{2} \mathrm{O}
$$

The td/ms of formic acid sorbed onto $\mathrm{Na}+\mathrm{ZSM}-5$ at $20^{\circ} \mathrm{C}$ is shown in figure 9.2. Physisorbed formic acid is desorbed with a maximum at $100^{\circ} \mathrm{C}$, followed by the expected carbon monoxide with a maximum at $250^{\circ} \mathrm{C}$. However, as for acetic acid, no water desorption peak was observed.

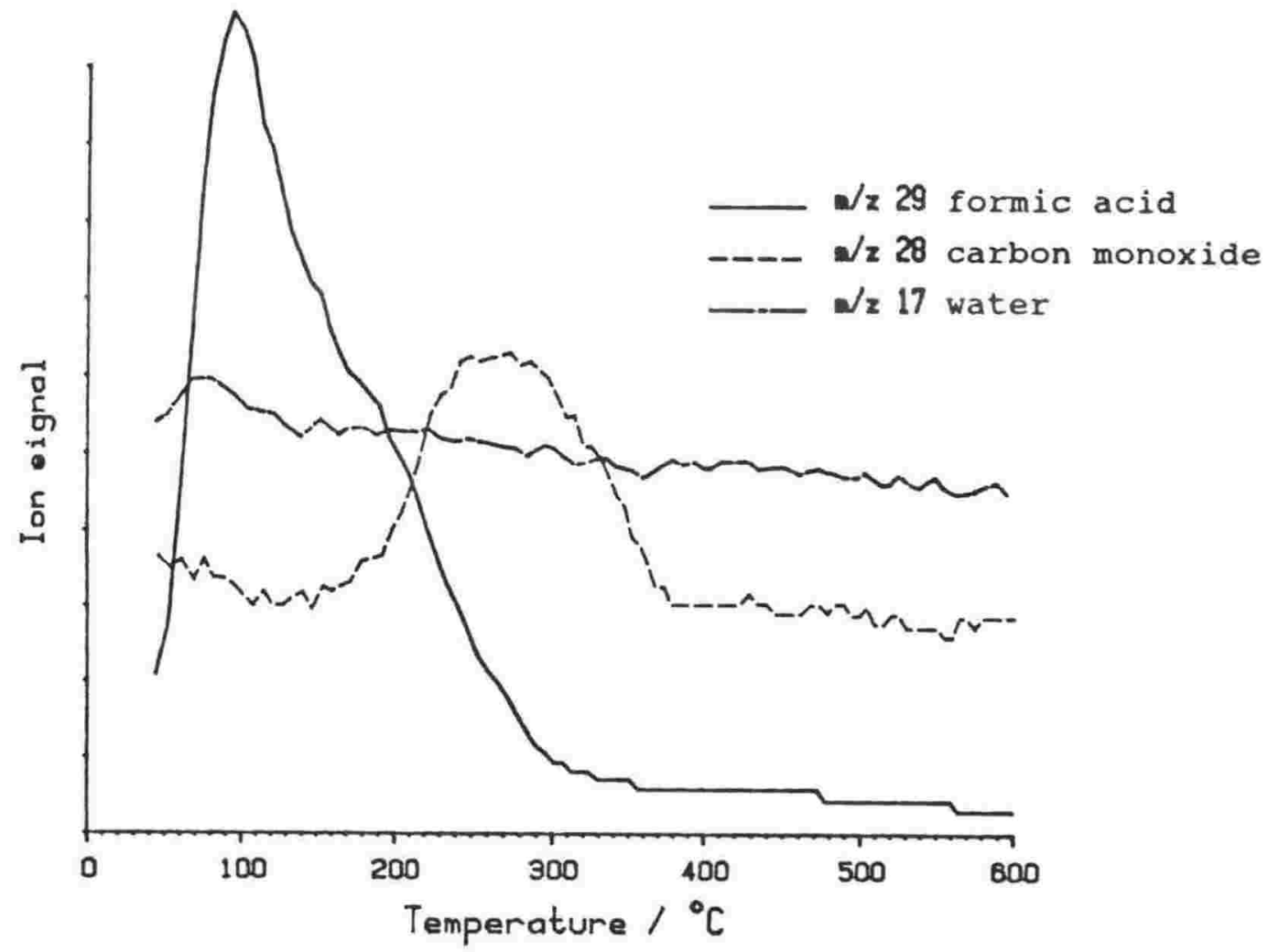

Figure $9.2 \mathrm{Td} / \mathrm{ms}$ of formic acid on $\mathrm{Na}+\mathrm{ZSM}-5$. 


\subsection{Reaction of propanoic acid over Na+z8M-5:}

Reactions of propanoic acid over Na+ZSM-5 analogous to those of acetic acid would be the production of the methylketene (propene-1-one) and water:

$$
\mathrm{H}_{3} \mathrm{C}-\mathrm{CH}_{2}-\mathrm{C}^{\prime \prime} \mathrm{OH} \rightarrow \mathrm{H}_{3} \mathrm{C}-\mathrm{C}=\stackrel{\mathrm{H}}{\mathrm{C}}=\mathrm{O}+\mathrm{H}_{2} \mathrm{O}
$$

This would be followed by reaction of the ketene with further propanoic acid to give pentane-3-one:

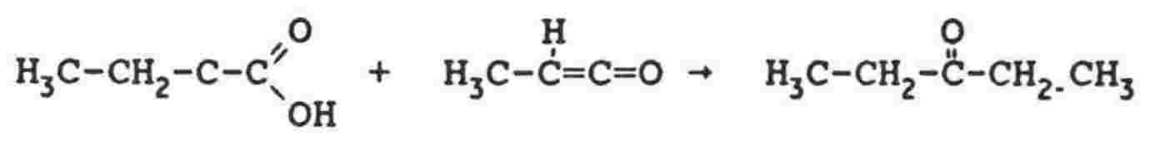

The ion signals observed during td/ms of propanoic acid sorbed on $\mathrm{Na}+\mathrm{ZSM}-5$ at $21^{\circ} \mathrm{C}$ are shown in figure 9.3.

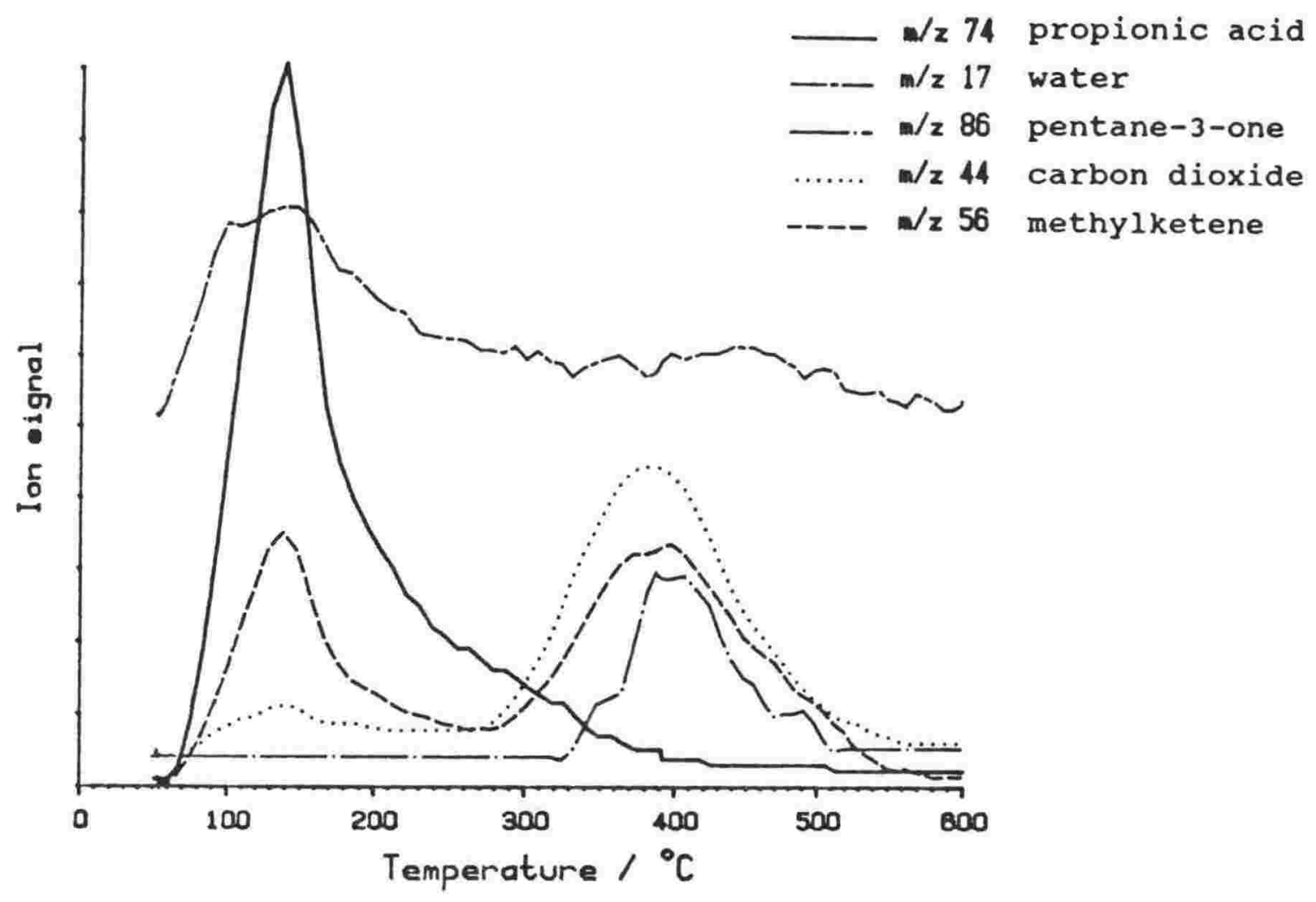

Figure $9.3 \mathrm{Td} / \mathrm{ms}$ of propionic acid on $\mathrm{Na}+\mathrm{ZSM}-5$.

Physisorbed propanoic acid desorbs with a maximum at $140^{\circ} \mathrm{C}$. An ion signal at $\mathrm{m} / \mathrm{z} 56$ is observed, which is probably due to the parent ion of methylketene (1-propene-1-one). A 
comparison of the mass spectrum obtained at $383^{\circ} \mathrm{C}$ with the published mass spectrum of methylketene (7) confirms this assignment. $\mathrm{CO}_{2}$ and pentane-3-one were also observed, the pentane-3-one being identified by comparison with its published mass spectrum (6).

\subsection{Reaction of 1so-butyric acid on $\mathrm{Li}+\mathrm{Y}$ :}

Dimethylketene is expected from the analogous reaction of iso-butyric acid over an alkali cation exchanged zeolite:

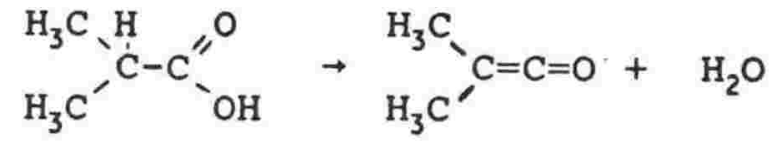

Further reaction to the ketone $(2,4$ dimethylpentan-3-one) may then occur:

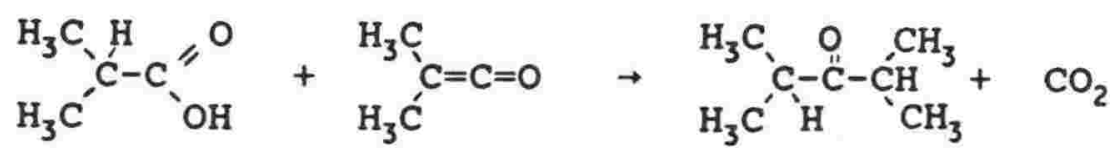

The td/ms results, of iso-butyric acid sorbed at room temperature on $\mathrm{L} \mathrm{I}+\mathrm{Y}$ are shown in figure 9.4. Unreacted isobutyric acid desorbed first, reaching a maximum at $220^{\circ} \mathrm{C}$. A product which, from its mass spectrum (7), was most likely dimethylketene desorbed with a maximum at $360^{\circ} \mathrm{C}$. No significant 2,4dimethylpentan-3-one was observed. Instead a large $\mathrm{m} / \mathrm{z} 28$ peak, most likely co, desorbed with Tmax at $370^{\circ} \mathrm{C}$. No peaks were observed in the mass spectrum other than those due to the acid and dimethylketene, so the remainder of the products from the reaction producing $c 0$ must have remained on the catalyst as coke. A small $\mathrm{CO}_{2}$ peak occured at higher temperatures $\left(\operatorname{Tmax}=550^{\circ} \mathrm{C}\right)$. Steric constraints most likely prevented the formation of the ketone. This is proof that the reaction takes place internally. 


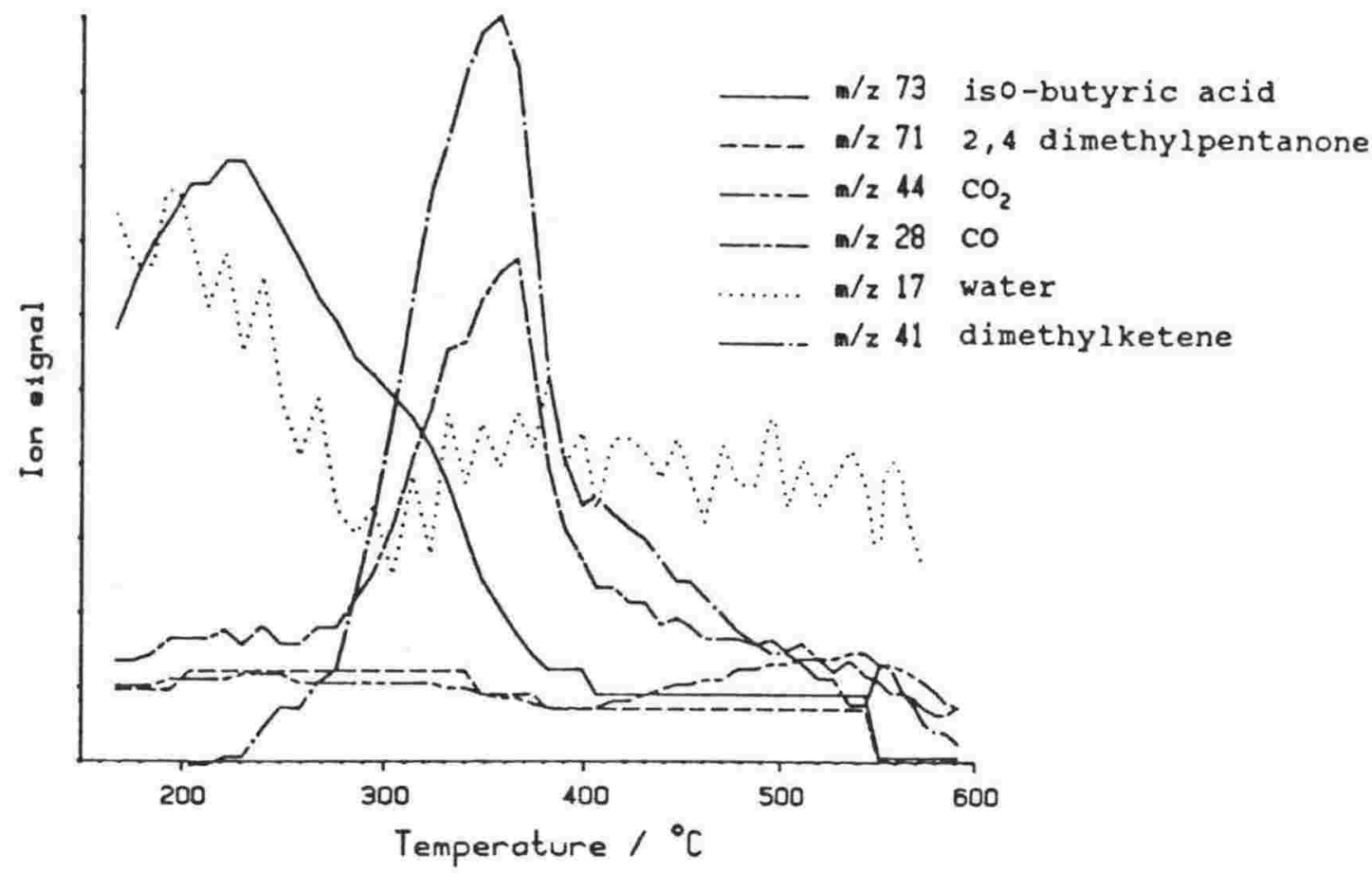

Figure 9.4 Td/ms of iso-butyric acid sorbed on $\mathrm{Li}+\mathrm{Y}$.

\subsection{Reaction of n-butyric acid on Li+Y:}

n-Butyric acid was sorbed on $\mathrm{Li}+\mathrm{Y}$ at room temperature in the same manner as for iso-butyric acid. The td/ms results are shown in figure 9.5. Physisorbed n-butyric acid and water desorbed first with a broad higher temperature $\left(200-600^{\circ} \mathrm{C}\right)$ desorption of n-butyric acid, presumably from basic sites. In contrast with the smaller carboxylic acids and iso-butyric acid, no reaction occured until greater than $420^{\circ} \mathrm{C}$ when $\mathrm{CO}_{2}$ and heptane-4-one appeared. There was also a small peak at $\mathrm{m} / \mathrm{z} 70$, perhaps due to ethylketene. The low reactivity of the n-butyric acid means that this is probably not a feasible route for producing ethylketene or heptane-4-one.

Decreasing reactivity of the carboxylic acids with increasing chain length was also observed for the conventional pyrolysis technique (4). No higher carboxylic acids were investigated. 


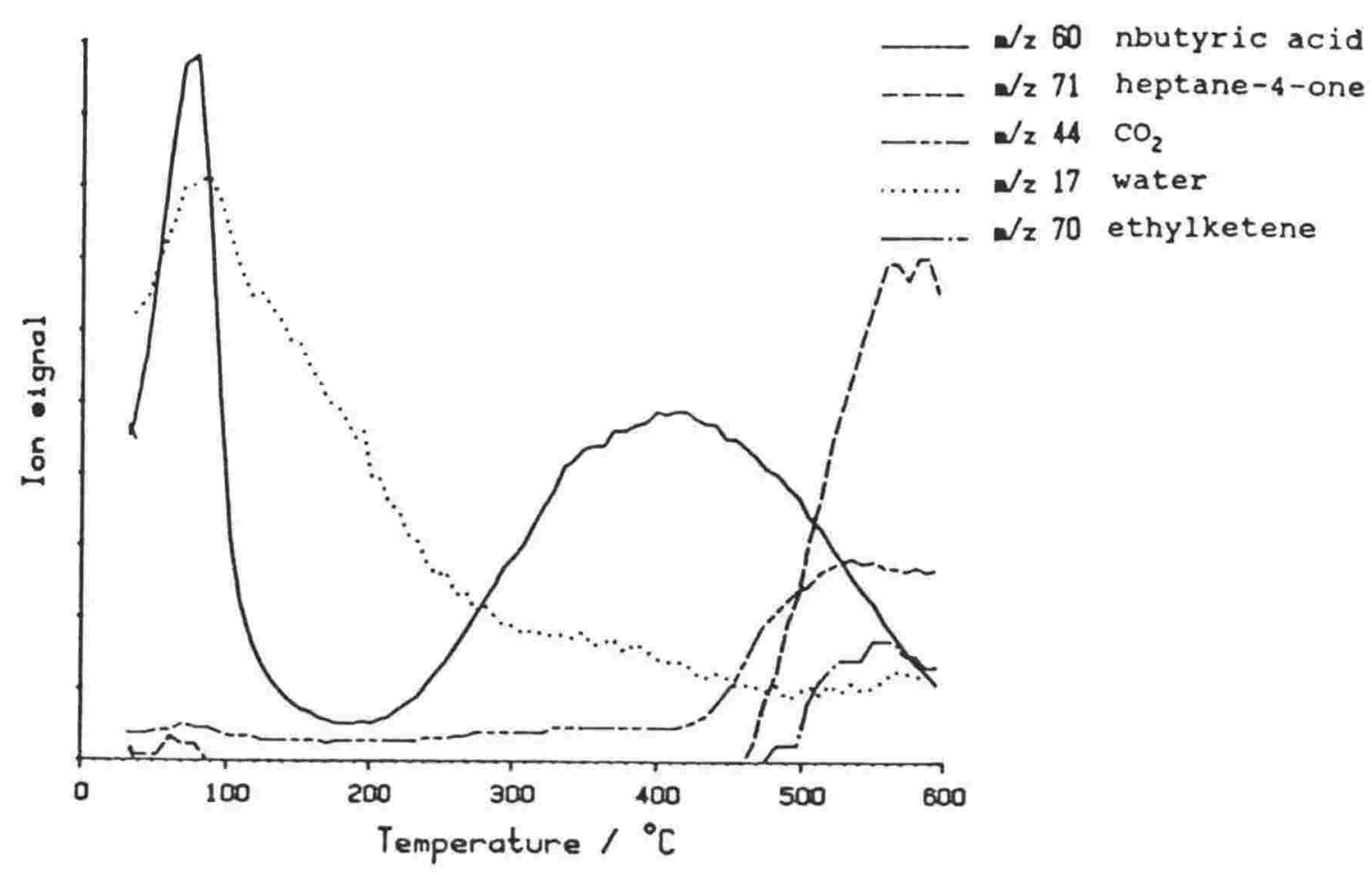

Figure $9.5 \mathrm{Td} / \mathrm{ms}$ of n-Butyric acid on Li+Y.

\subsection{Reaction of chloracetic acid on $\mathrm{Na}+\mathrm{X}$}

$\mathrm{Td} / \mathrm{ms}$ of chloracetic acid on $\mathrm{Na}+\mathrm{X}$ (figure 9.6) was carried out to determine whether the chlorinated ketene would be produced according the the scheme:

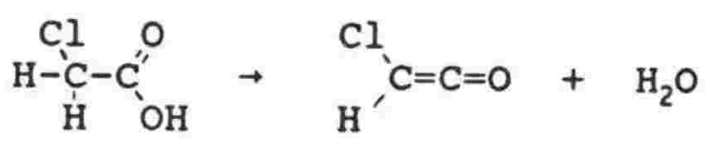

This would be a more useful acetylating agent for drug analysis by gas chromatography (10). The products desorbed were $\mathrm{CO}, \mathrm{CO}_{2}$ and formaldehyde, and coke was deposited on the zeolite. No chlorine was observed. The results suggest that the chlorinated ketene must be either too unstable to form, or to survive the conditions used. 


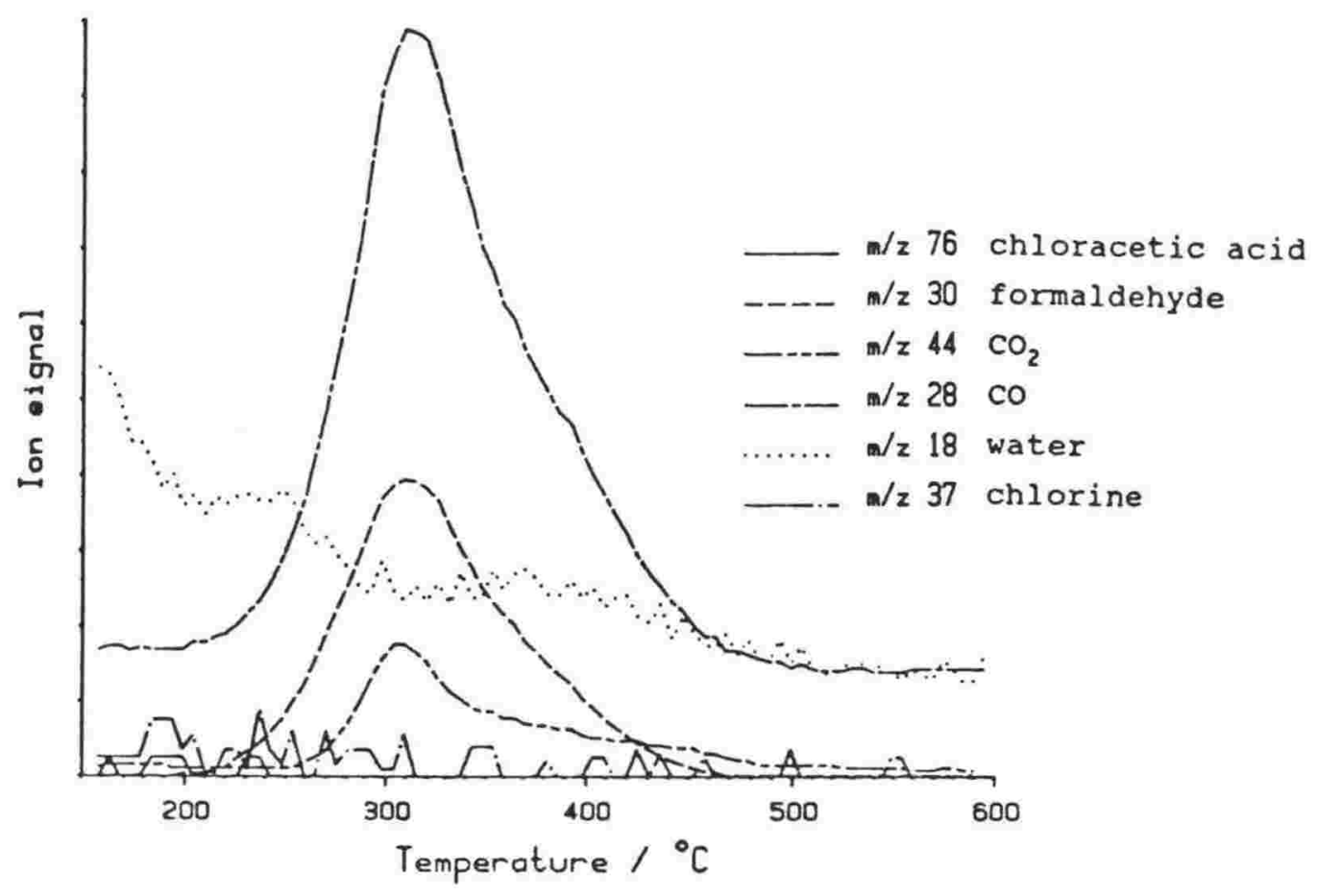

Figure 9.6 Td/ms of chloracetic acid on $\mathrm{Na}+\mathrm{X}$.

\subsection{Reaction of acetic acid over silicalite:}

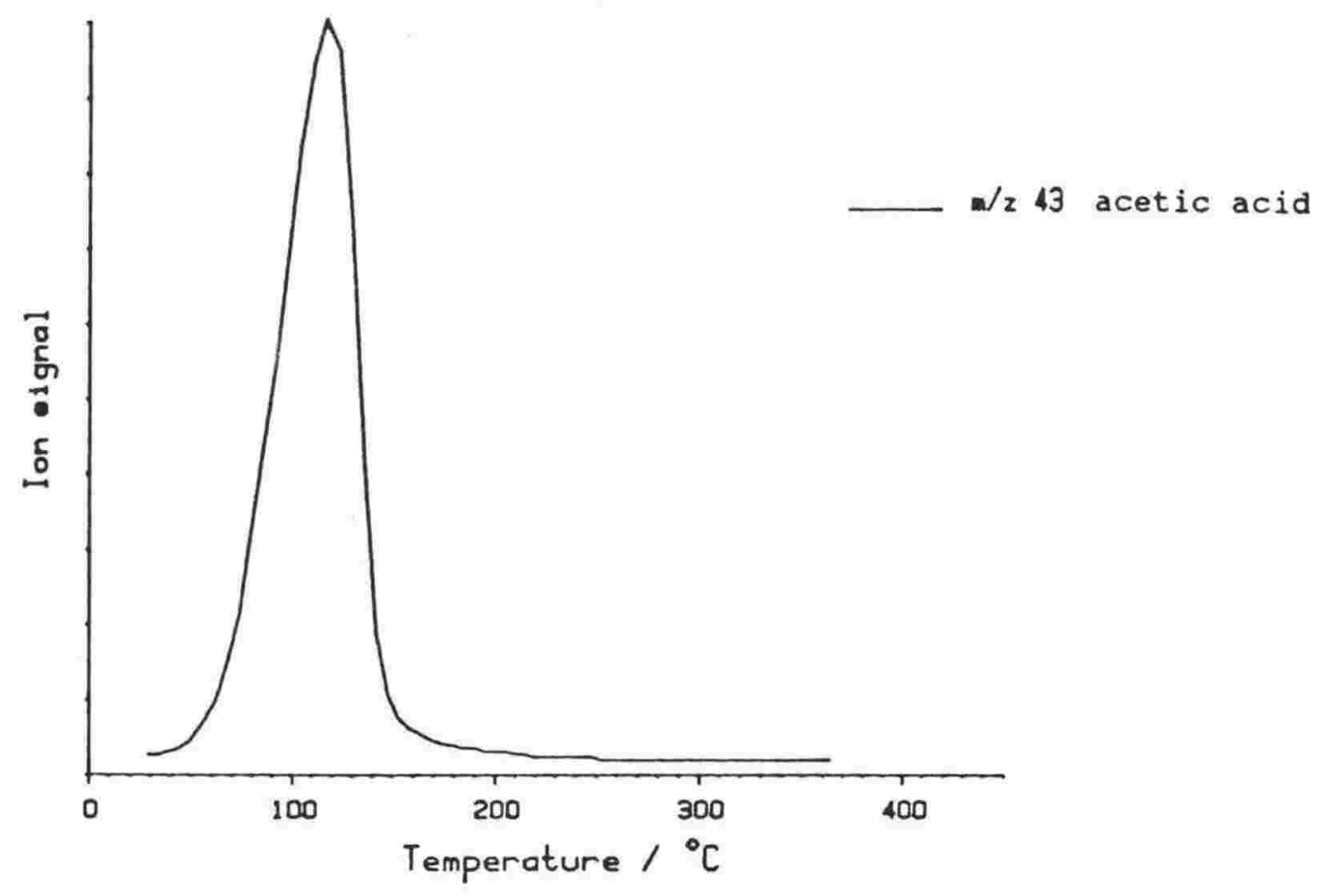

Figure $9.7 \mathrm{Td} / \mathrm{ms}$ of acetic acid on "Na+free" silicalite. 
$\mathrm{Td} / \mathrm{ms}$ showed that no acetic acid was sorbed onto "Na+ free" silicalite (the zero aluminium form of $2 S M-5$ ) when held at $150^{\circ} \mathrm{C}$. However, at $21^{\circ} \mathrm{C}$, acetic acid was sorbed upto $10.4 \%$ of the dry zeolite weight. This desorbed unreacted with a maximum at $110^{\circ} \mathrm{C}$ (figure 9.7) and shows the temperature range over which physisorbed acetic acid desorbs.

\subsection{Reaction of acetone over Na+z8M-5:}

An industrial alternative to synthesis of ketene by pyrolysis of acetic acid is the pyrolysis of acetone:

$$
\mathrm{H}_{3} \mathrm{C}-\stackrel{\mathrm{O}}{\mathrm{C}}-\mathrm{CH}_{3} \rightarrow \mathrm{H}_{2} \mathrm{C}=\mathrm{C}=\mathrm{O}+\mathrm{CH}_{4}
$$

This is carried out at 700 to $800^{\circ} \mathrm{C}$, at atmospheric pressure. The reaction is less endothermic than for acetic acid (3). The $t d / m s$ of acetone sorbed on Na+ZSM-5 was carried out to determine whether ketene could be formed from acetone over Na+ZSM-5. The results are shown in figure 9.8. Acetone was desorbed unreacted in two steps, with a small amount of ketene desorbed between 330 and $520^{\circ} \mathrm{C}$ ( $T \max$ at $460^{\circ} \mathrm{C}$ ). No other significant products were observed. Most of the acetone had desorbed before the ketene was observed. The mini-reactor technique was then used so that a greater amount of acetone would be present at the higher temperatures to determine the efficiency of the reaction to ketene (see chapter $10.5 \cdot 2.6)$. 


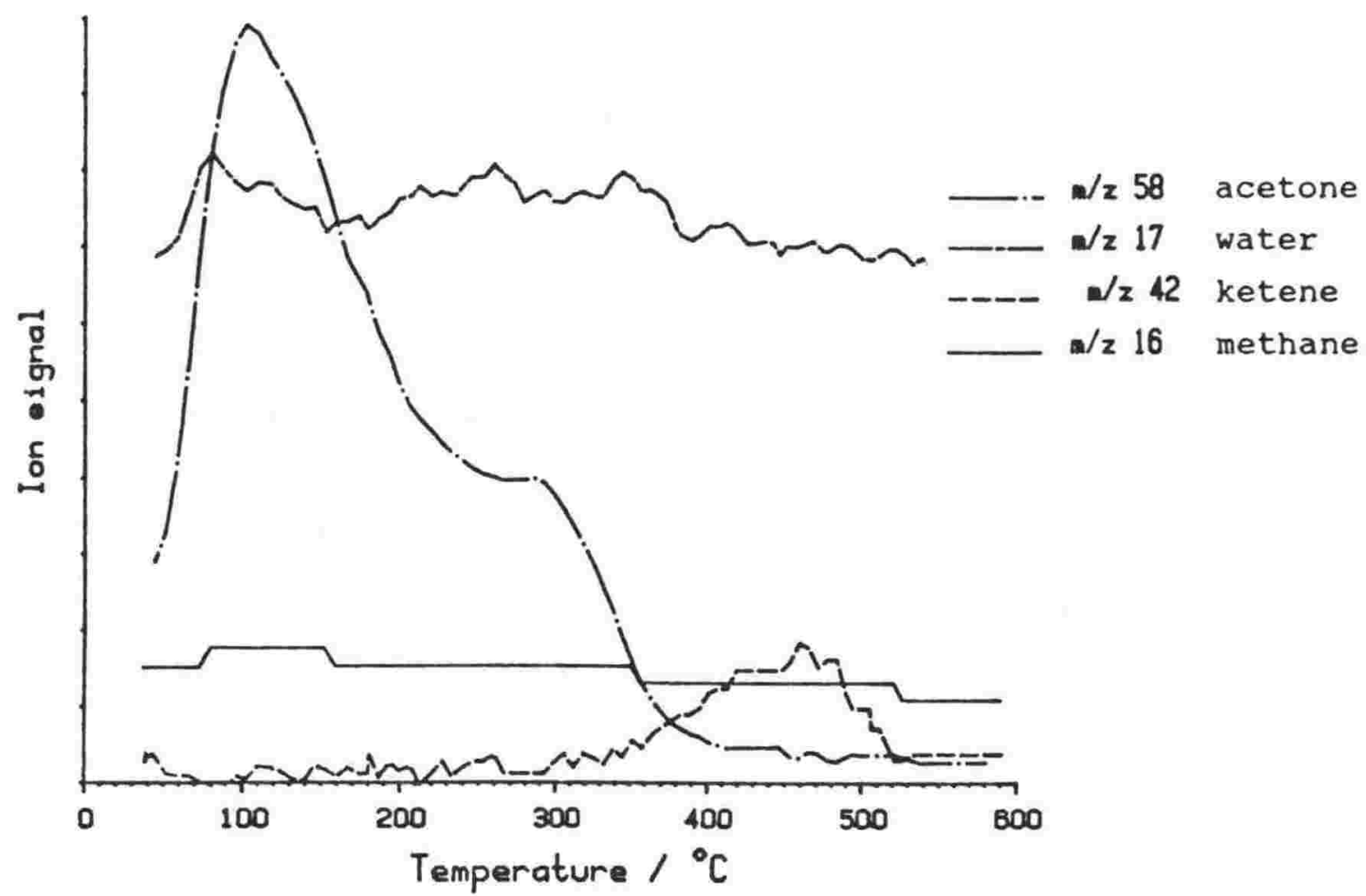

Figure $9.8 \mathrm{Td} / \mathrm{ms}$ of acetone sorbed on Na+ZSM-5.

\subsection{IN 8ITU REACTIONS OF KETENE8:}

Ketenes are highly reactive and toxic (ketene is as poisonous as $\mathrm{HCN}$ ) and therefore difficult to store and transport. For most industrial uses it is preferable to prepare the ketene just prior to further reaction (4).

Ketene prepared by zeolite catalysis could either be isolated from the process stream prior to further reaction, or the compound to be reacted with the ketene could be passed over the catalyst with the carboxylic acid reactant. Further reaction of the ketene would then be expected to occur rapidly, possibly inside the zeolite. This "in situ" reaction would have the advantage of eliminating the need to separate the ketene and the problems of handling a reactive material. The advantage of zeolite catalysed reactions their shape selective control over reaction pathways - could perhaps then be capitalised upon. A possible limitation is that the reactant introduced into the zeolite to react with 
the ketene must not react significantly with the zeolite at that temperature.

\subsection{In situ reactions of carboxylic acids and alcohols:}

A textbook method for ester preparation is by reaction of a ketene with an alcohol (8):

$$
\underset{R^{\prime}}{\mathrm{R}=\mathrm{C}=\mathrm{O}}+\mathrm{R}^{*} \mathrm{OH} \rightarrow \underset{\mathrm{R}^{\prime}}{\mathrm{C}}+\mathrm{C}^{\mathrm{R}} \mathrm{OR}^{*}
$$

Primary, secondary and tertiary alcohols supported on solid absorbants such as alumina have previously been shown to be acetylated by ketene in good yields (9). Methanol, ethanol and propanol were readily acetylated without a catalyst at room temperature. The in situ reaction of an alcohol with ketene was therefore investigated.

9.11.1 Reaction of acetic acid and methanol to methylacetate:

The reaction of acetic acid and methanol over Na+ZSM-5 was investigated to provide further evidence for the presence of ketene. The pulsed reactor technique (see chapter 2.2.3) was used with argon carrier gas at atmospheric pressure and the catalyst held at $330^{\circ} \mathrm{C}$. A $0.5 \mu \mathrm{l}$ injection of pure methanol produced unreacted methanol, water and dimethylether (pulse A figure 9.9). An injection of $0.5 \mu l$ of a $50 / 50$ methanol, acetic acid mixture produced an immediate desorption of unreacted methanol, water and dimethylether. This was followed by methylacetate, then acetone and $\mathrm{CO}_{2}$ as the methanol was depleted. 


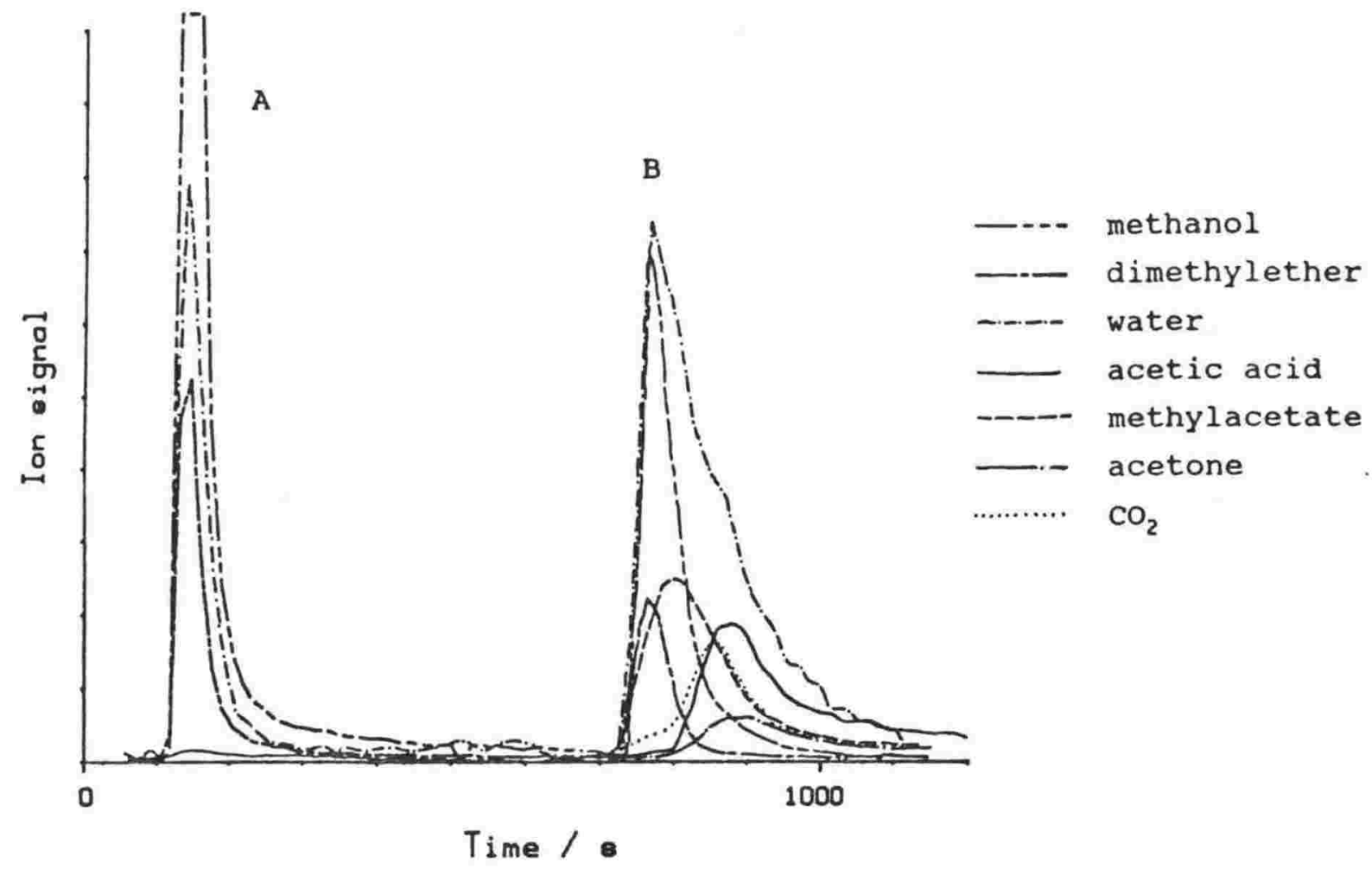

Figure 9.9 Products observed from pulsing reactants through $\mathrm{Na}+\mathrm{ZSM}-5$ held at $330^{\circ} \mathrm{C}$. Pulse A. $0.5 \mu l$ methanol only; pulse B. $0.5 \mu 1$ of $50 \%$ methanol/acetic acid.

The same reaction was also investigated with a constant flow of reactants using the mini-reactor setup containing $0.057 \mathrm{~g}$ Li+Y (figure 9.10). Methanol and acetic acid vapour were passed over the catalyst by flowing the argon carrier gas through an impinger containing acetic acid with a small amount of methanol, as the catalyst temperature was increased at $5^{\circ} \mathrm{C} \mathrm{min}{ }^{-1}$ from $150^{\circ} \mathrm{C}$. (The experimental conditions were: methanol/acetic acid/Ar flow $=10 \mathrm{ml} \mathrm{min}^{-1}, \mathrm{~N}_{2}$ flow $=7.5 \mathrm{ml}$ $\mathrm{min}^{-1}$ at atmospheric pressure). Methylacetate was observed between 220 and $520^{\circ} \mathrm{C}$, reaching a maximum at $320^{\circ} \mathrm{C}$. Ketene appeared at a higher temperature than with acetic acid alone (Tmax at $450^{\circ} \mathrm{C}$ ), indicating that at lower temperatures it was most likely being consumed by reaction with methanol. From $370^{\circ} \mathrm{C}, \mathrm{CO}_{2}$ and methane rapidly increased, with a smaller amount of acetone also observed. Very little reaction of methanol to dimethylether (DME) occurred. From $540^{\circ} \mathrm{C}$ hydrogen was observed. 


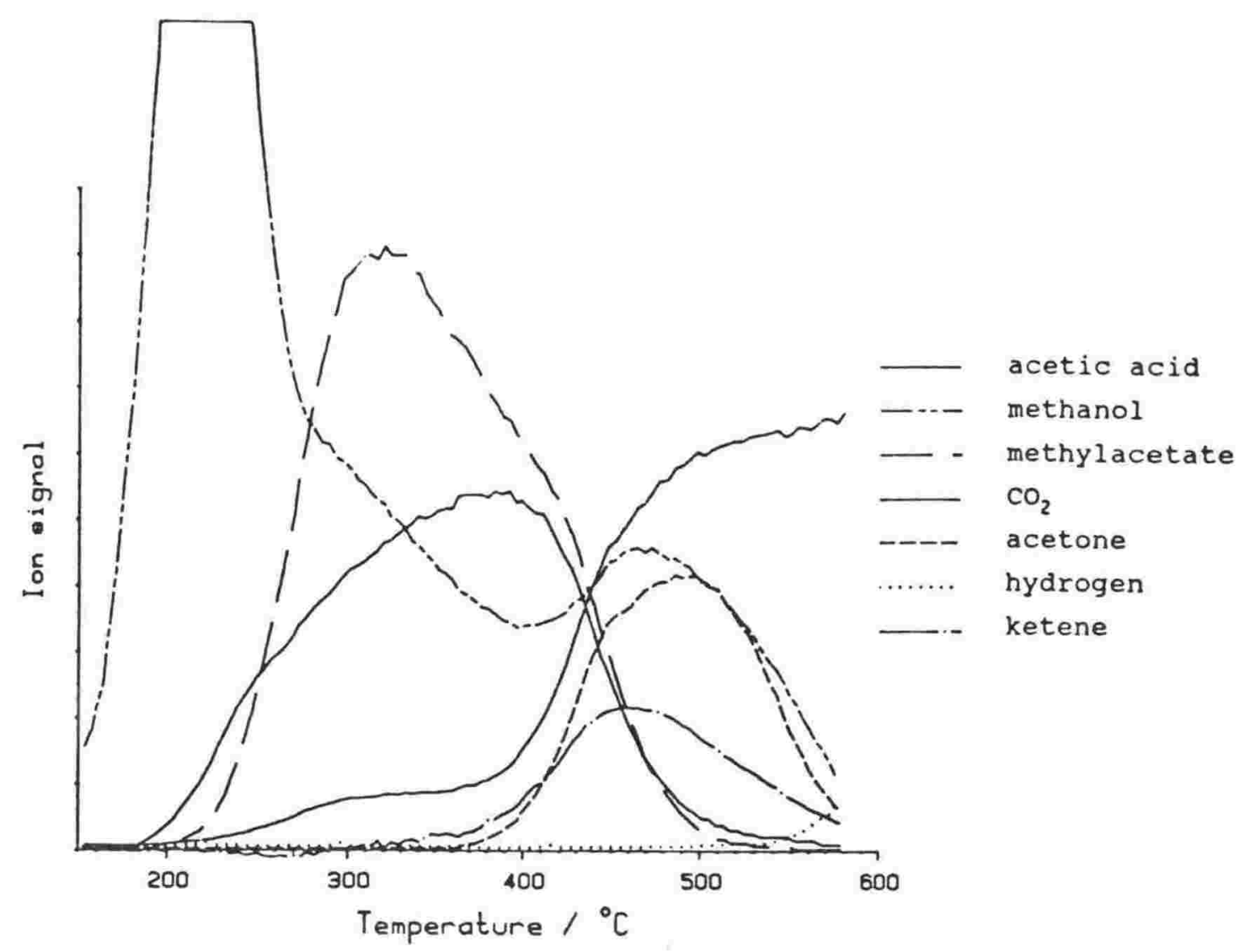

Figure 9.10 Mini-reactor experiment - methanol and acetic acid vapour passed through $\mathrm{Li}+\mathrm{Y}$ heated at $5^{\circ} \mathrm{C} \mathrm{min}^{-1}$.

To determine the reaction products of methanol alone over $\mathrm{Li}+\mathrm{Y}$, the mini-reactor experiment was carried out with methanol in the impinger cooled to $3^{\circ} \mathrm{C}$ by an ice bath to reduce its vapour pressure. (The experimental conditions were: methanol/Ar flow $=10 \mathrm{ml} \mathrm{min}^{-1}, \mathrm{~N}_{2}$ flow $=4 \mathrm{ml} \mathrm{min}{ }^{-1}$, heating rate $10^{\circ} \mathrm{C} \mathrm{min}^{-1}$, atmospheric pressure, $0.48 \mathrm{~g} \mathrm{Li}+\mathrm{Y}$ in the reactive filter). Figure 9.11 shows that methanol reacted from $\sim 300^{\circ} \mathrm{C}$ to form DME. Above $500^{\circ} \mathrm{C}$ the DME decreased with the formation of $\mathrm{CO}_{2}$, hydrogen, and ethene.

Comparison with figure 9.10 shows that the presence of acetic acid in the reactant stream resulted in preferential reaction to methylacetate, with very little DME and no formaldehyde observed and hydrogen formation only occuring from $540^{\circ} \mathrm{C}$. This shows that the reaction of methanol and acetic acid on $\mathrm{Na}+\mathrm{ZSM}-5$ and $\mathrm{Li}+\mathrm{Y}$ to give methylacetate is facile, occuring in preference to thermal decomposition reactions. 


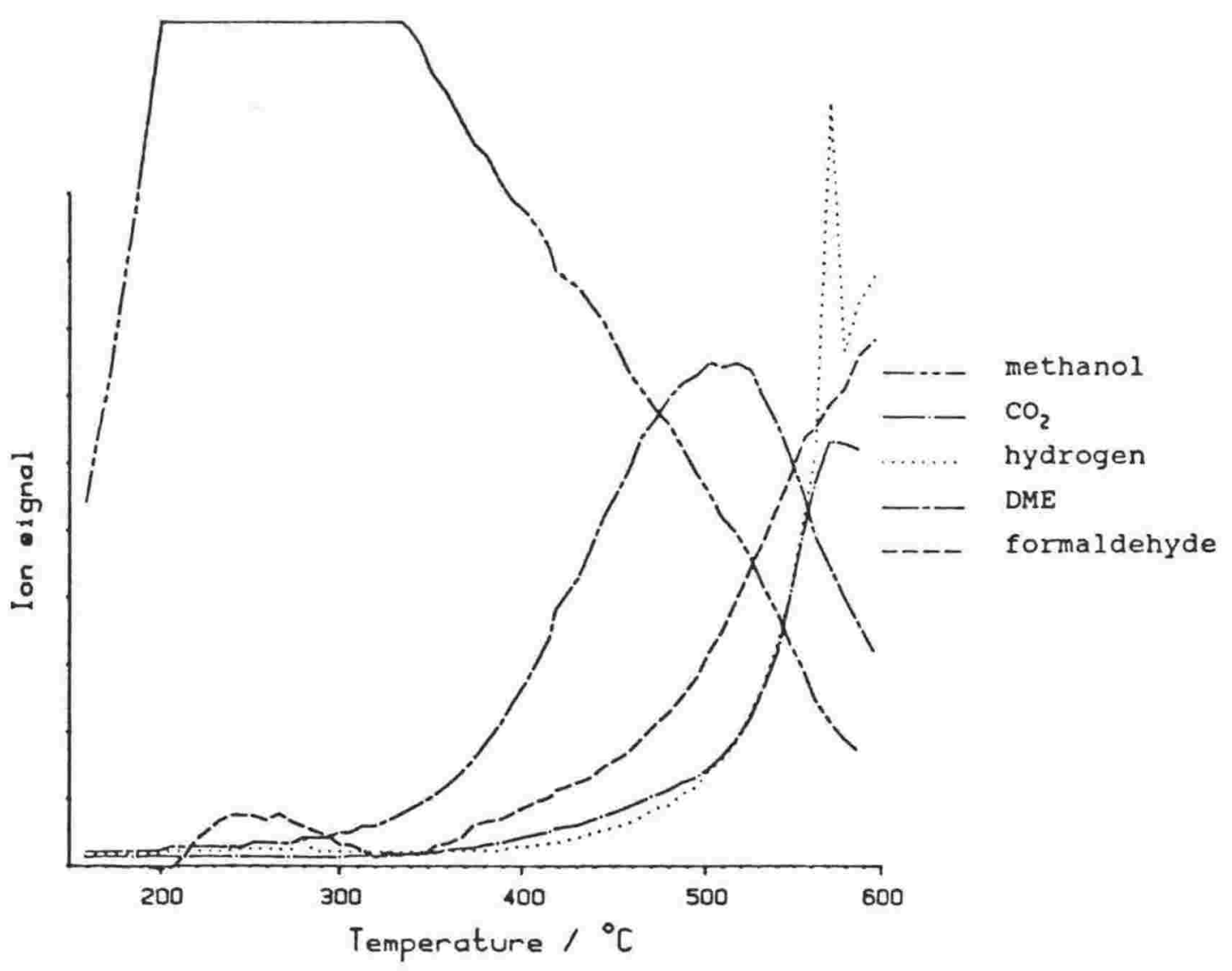

Figure 9.11 Mini-reactor experiment - methanol vapour passed through $\mathrm{Li}+\mathrm{Y}$ heated at $10^{\circ} \mathrm{C} \mathrm{min}^{-1}$.

\subsubsection{Acetic acid and Ethanol to give Ethylacetate:}

The mini-reactor with $0.05 \mathrm{~g} \mathrm{LiY} \mathrm{in} \mathrm{the} \mathrm{reactive} \mathrm{filter} \mathrm{was}$ used to investigate the variation in reaction products of ethanol and acetic acid with catalyst temperature. The impinger contained acetic acid $(0.5 \mathrm{ml})$ and ethanol $(0.05$ $\mathrm{ml}$ ). (The experimental conditions were: ethanol/acetic acid/Ar flow $=6.5 \mathrm{ml} \mathrm{min} \mathrm{m}^{-1}, \mathrm{~N}_{2}$ diluent flow $=6 \mathrm{ml} \mathrm{min}{ }^{-1}$, heating rate $2^{\circ} \mathrm{C} \mathrm{min}^{-1}$, atmospheric pressure). The results are shown in figure 9.12. At temperatures below $200^{\circ} \mathrm{C}$, mainly ethanol was observed with the acetic acid being sorbed onto the zeolite. At $260^{\circ} \mathrm{C}$ both ethylacetate and acetic acid reached a maximum. Further ethylacetate production at higher temperatures was limited by reaction of ethanol to ethene (and water). From $350^{\circ} \mathrm{C}, \mathrm{CO}_{2}$ and acetone increased rapidly, followed by an increase in methane from $460^{\circ} \mathrm{C}$. 


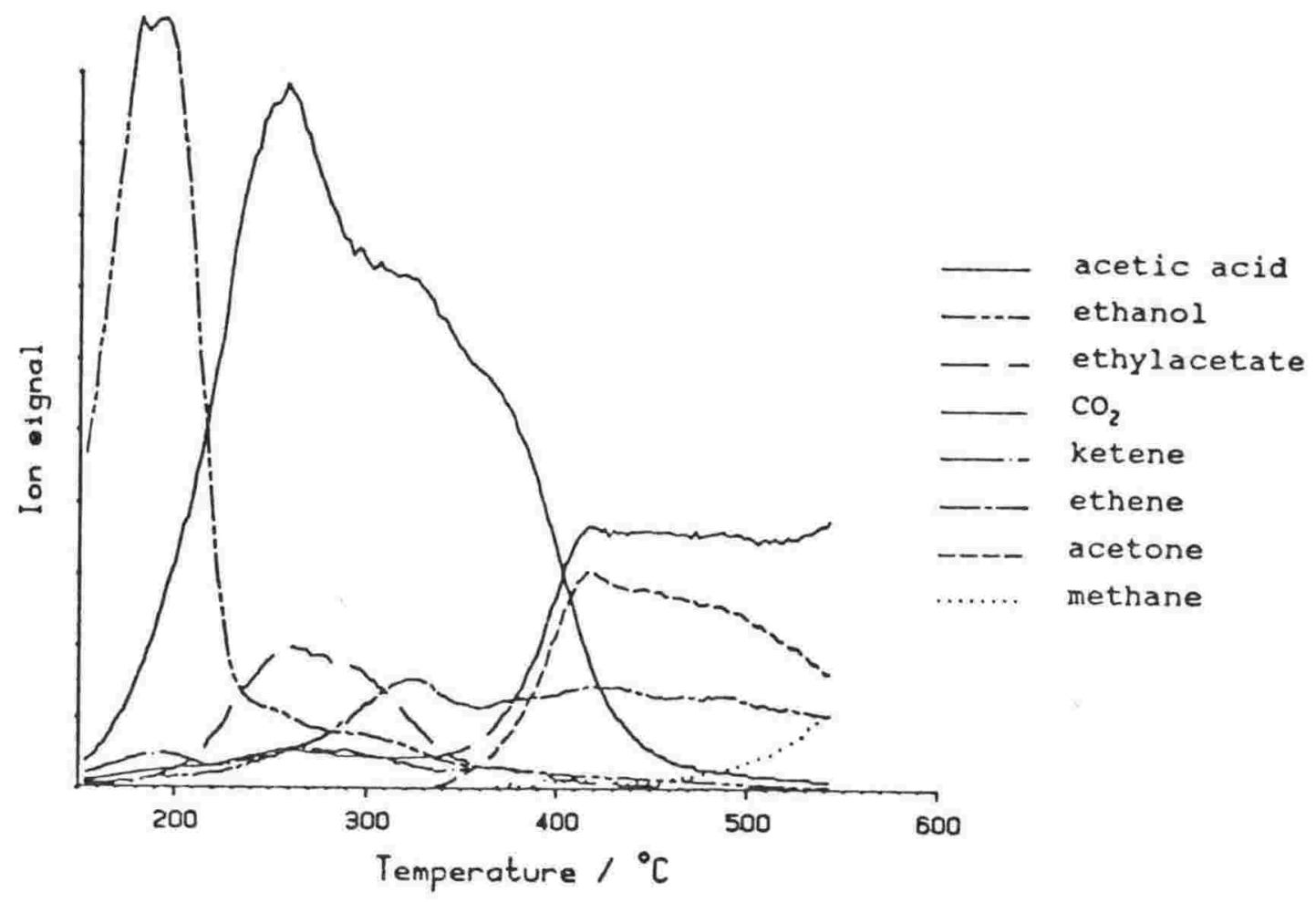

Figure 9.12 Mini-reactor experiment - ethanol and acetic acid vapour passed through $\mathrm{Li}+\mathrm{Y}$ heated at $2^{\circ} \mathrm{C} \mathrm{min}^{-1}$.

For comparison, the reaction products of ethanol alone over $\mathrm{Li}+\mathrm{Y}$ were studied using the mini-reactor. Ethanol was placed in the impinger in iced water $\left(2.5^{\circ} \mathrm{C}\right)$ to reduce vapour pressure. (The experimental conditions were: ethanol/Ar flow $=8 \mathrm{ml} \mathrm{min}^{-1}, \mathrm{~N}_{2}$ diluent flow $=6.5 \mathrm{ml} \mathrm{min}^{-1}$, atmospheric pressure, $0.048 \mathrm{~g} \mathrm{Li}+\mathrm{Y}$, heating rate $5^{\circ} \mathrm{C} . \mathrm{min}^{-1}$ from $150^{\circ} \mathrm{C}$ ). Figure 9.13 shows reaction of ethanol from $230^{\circ} \mathrm{C}$, with ethene being the main product observed. The ion signals are scaled by their relative sensitivity factors so that they are proportional to concentration. The reaction produced ethene and water in equal quantities:

$$
\mathrm{H}_{3} \mathrm{C}-\mathrm{CH}_{2}-\mathrm{OH} \rightarrow \mathrm{CH}_{2}=\mathrm{CH}_{2}+\mathrm{H}_{2} \mathrm{O}
$$

A small amount of $\mathrm{CO}_{2}$ was also observed. The reaction of ethanol to ethene over the catalyst reduces the selectivity of the acetylation reaction and the possible usefulness of the in situ reaction for the production of esters. 


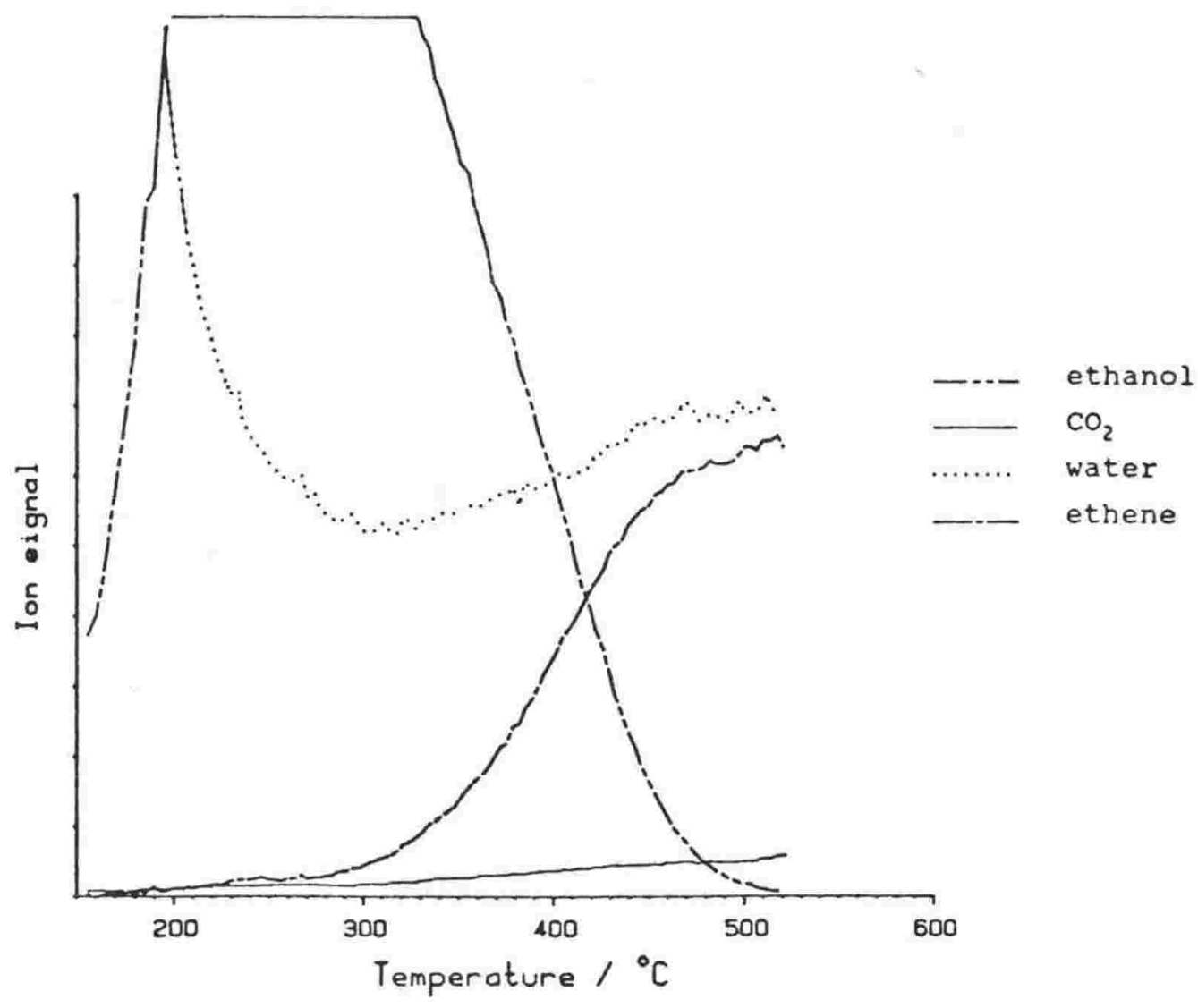

Figure 9.13 Mini-reactor experiment - ethanol vapour passed through $\mathrm{Li}+\mathrm{Y}$ heated at $5^{\circ} \mathrm{C} \mathrm{min}^{-1}$.

The reaction of ethanol and acetic acid to produce ethylacetate is a well known acid catalysed reaction. A range of catalysts such as niobic acid, $\mathrm{H}+\mathrm{ZSM}-5, \mathrm{SiO}_{2}-\mathrm{Al}_{2} \mathrm{O}_{3}$, and solid super acids $\mathrm{ZrO}_{2}-\mathrm{SO}_{4}{ }^{2-}$ and $\mathrm{TiO}_{2}-\mathrm{SO}_{4}{ }^{2-}$ (11) are effective. The active sites were proposed as protonic (Bronsted) acid sites on silica-alumina, and Lewis acid sites on alumina (12). Ketene has not been observed or proposed as an intermediate for these reactions. Therefore the use of alkali exchanged zeolites may provide an alternative reaction pathway to the acetate. 


\subsection{In situ reaction of acetic acid and dimethylamine:}

The product of acetylation of dimethylamine is dimethylacetamide:

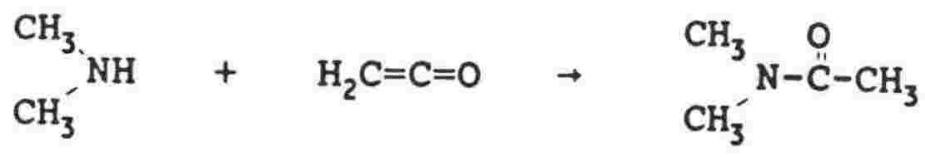

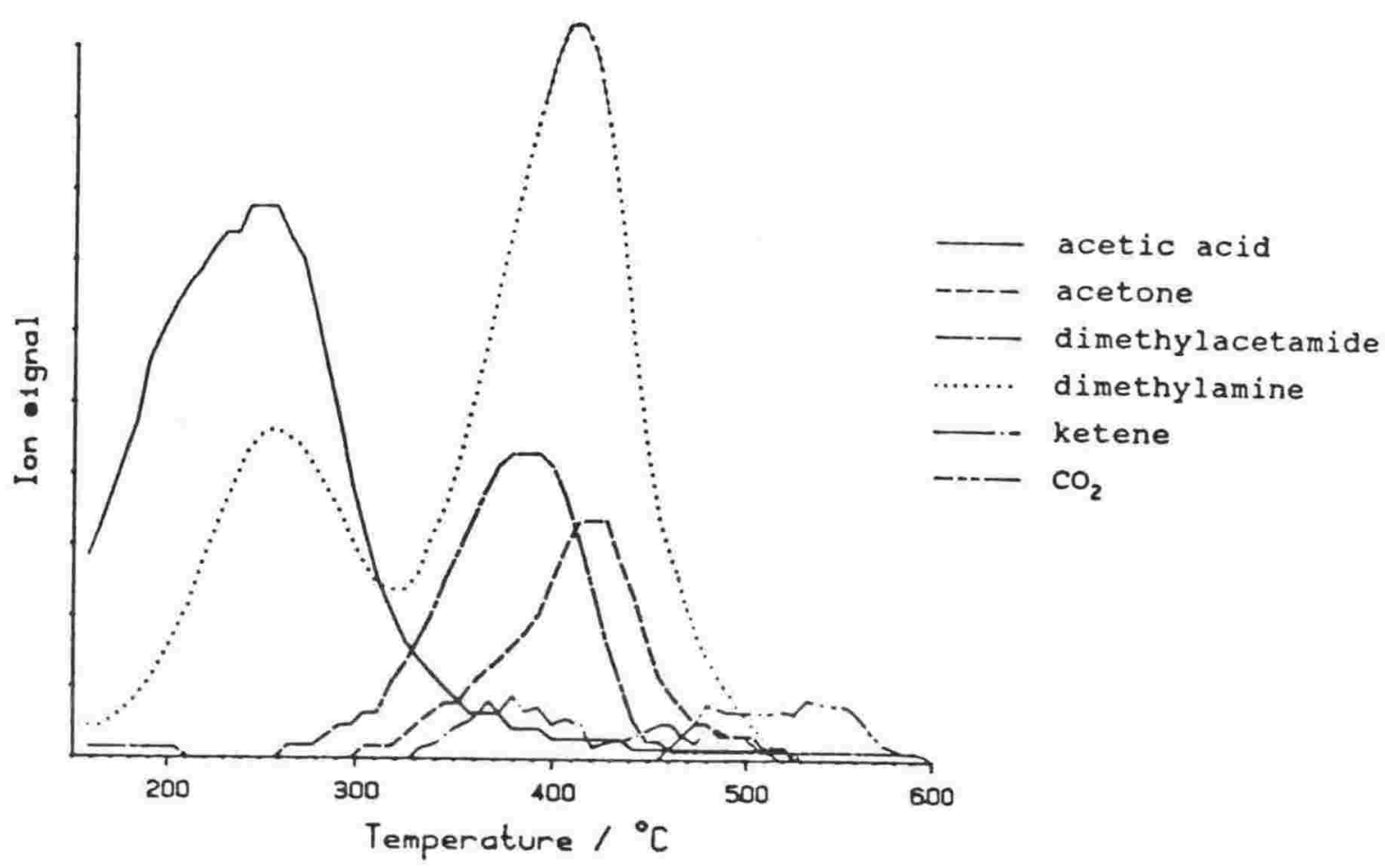

Figure $9.14 \mathrm{Td} / \mathrm{ms}$ of dimethyamine and acetic acid sorbed on $\mathrm{Li}+\mathrm{Y}$.

An initial experiment was carried out to determine if this reaction occured. Dimethylamine (25-30\% solution) and glacial acetic acid were mixed in a beaker. Reaction occured to give the salt with a vigorous effervescence. A slight excess of acetic acid was added after the fizzing ceased. Approximately $10 \mu l$ of this solution was placed in the $t d / m s$ tube, just behind the $\mathrm{Li}+\mathrm{Y}$ which was in the reactive filter. Low pressure td/ms was then carried out, the results are shown in figure 9.14 . Between $100^{\circ} \mathrm{C}$ and $300^{\circ} \mathrm{C}$ acetic acid and some amine desorbed. From $300^{\circ} \mathrm{C}$, with a maximum at $380^{\circ} \mathrm{C}$, dimethylacetamide was observed, along with unreacted amine, ketene and $\mathrm{CO}_{2}$. At a slightly higher temperature (with a 
maximum of $420^{\circ} \mathrm{C}$ ) acetone desorbed. This initial experiment verified that reaction 9.19 occurs readily.

Further work was carried out by Ian Miller (13) who passed gas phase acetic acid and dimethylamine through $\sim \mathrm{g} \mathrm{Na}+\mathrm{Y}$ held at $\sim 380^{\circ} \mathrm{C}$ at atmospheric pressure. Dimethylacetamide was the major liquid product. This in situ reaction is potentially useful because of the ease of preparation of dimethylacetamide without major side products.

\subsection{In situ reaction of acetic acid and Dimethoxymethane:}

The reaction of ketene with dimethoxymethane (methylal) gives methyl-3-methoxypropionate, an intermediate for the formation of acrylic esters (2):

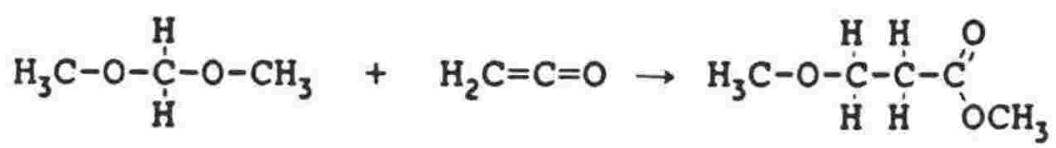

This reaction was investigated by injecting a 50:50 mixture by volume of dimethoxymethane and acetic acid into the pulsed reactor held at $350^{\circ} \mathrm{C}$ and atmospheric pressure. However, instead of propionate, methylacetate and lighter molecules were observed. It was then shown that dimethoxymethane decomposed over $\mathrm{Na}+2 \mathrm{SM}-5$ by injection of pure dimethoxymethane. The products identified were formaldehyde, dimethylether and methanol. The decomposition to give formaldehyde and dimethylether can be written:

$$
\mathrm{H}_{3} \mathrm{C}-\mathrm{O}-\underset{\dot{\mathrm{H}}}{\stackrel{\mathrm{H}}{\mathrm{H}}}-\mathrm{O}-\mathrm{CH}_{3} \rightarrow \mathrm{H}_{3} \mathrm{C}-\mathrm{O}-\mathrm{CH}_{3}+\mathrm{H}_{2} \mathrm{C}=\mathrm{O}
$$

Methanol may have been produced by the further reaction of water with dimethyether. 


\subsection{In situ reaction of acetic acid and Phenol:}

Ketene has been reported to react readily with even hindered phenols provided the phenol is supported on a solid adsorbent (14):

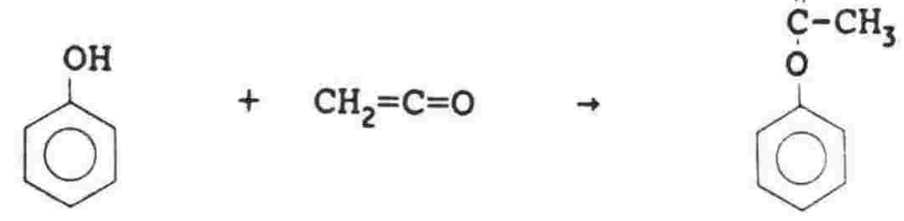

An attempt was made to determine whether acetylation of phenol by ketene produced from acetic acid could be carried out in situ. Phenol is a solid at room temperature, with a low vapour pressure. Phenol crystals dissolved as they were placed in the impinger with a small amount of acetic acid. However the phenol vapour pressure was too low to be detected by the mass spectrometer, even after the impinger and connecting lines were warmed, so the mini-reactor technique could not be used.

Instead a $t d / m s$ experiment was tried in which a small drop of phenol and acetic acid were placed on an $11.6 \mathrm{mg}$ sample of $\mathrm{Na}+\mathrm{Y}$. This was heated to $150^{\circ} \mathrm{C}$ and held under low pressure argon flow to remove excess material not strongly sorbed. The results from the subsequent $t d / m s$ run are shown in figure 9.15. Unreacted acetic acid desorbed followed by most of the phenol between $150^{\circ} \mathrm{C}$ and $350^{\circ} \mathrm{C}$. There was then a ketene peak ( $\max =360^{\circ} \mathrm{C}$ ) at the same temperature observed as for acetic acid alone, and a $\mathrm{CO}_{2}$ peak with a higher maximum ( $T \max =480^{\circ} \mathrm{C}$ ) than for acetic acid alone $\left(\max =390^{\circ} \mathrm{C}\right)$. No acetone was observed. This implied that the presence of phenol had hindered the formation of acetone. No significant acetic acid phenyl ester was observed. A small amount may have formed and not been identified as its mass spectrum is very similar to that of phenol except for the molecular ion at $\mathrm{m} / \mathrm{z} 136$ which has an intensity of only $14 \%$ of the largest ion signal $(\mathrm{m} / \mathrm{z} 94)$. However, the reaction of ketene with phenol is facile, so the most likely reason for lack of reaction here was that the bulk of the phenol had desorbed before any significant amount of ketene was formed. In order to determine whether this reaction will occur in situ a 
technique for controlled vapourisation of phenol is required to give a constant flow of phenol over the catalyst.

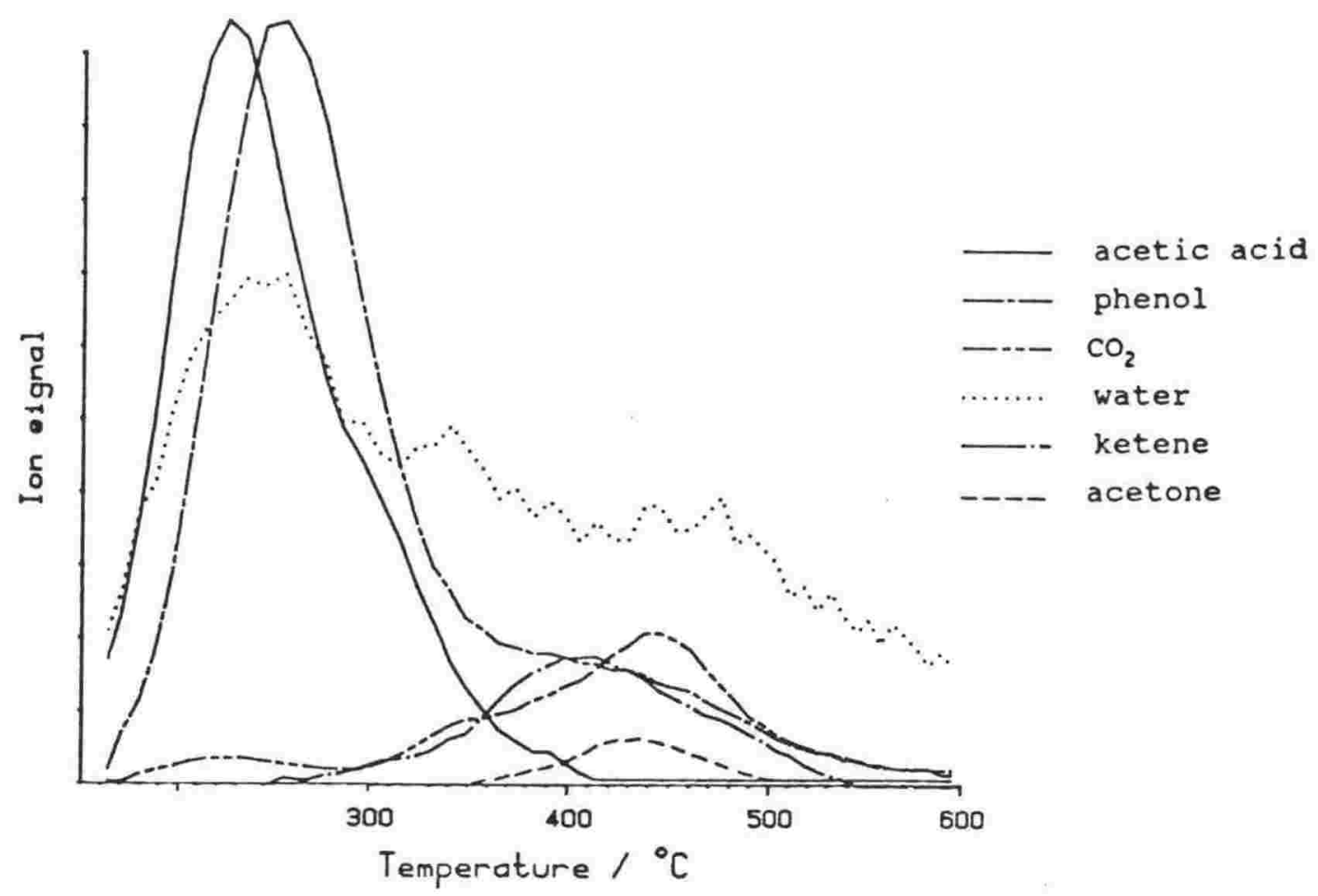

Figure $9.15 \mathrm{Td} / \mathrm{ms}$ of acetic acid and phenol sorbed on $\mathrm{Li}+\mathrm{Y}$. 


\subsection{CONCLUSIONB:}

The reaction of a small chain carboxylic acid to its corresponding ketene occurs as a general reaction over the alkali metal exchanged zeolites investigated here. This was observed for acetic acid, propanoic acid and iso-butyric acid. n-Butyric acid showed low reactivity, in line with the general observation of decreasing reactivity with increasing chain length observed for the conventional pyrolysis reaction.

The expected products of the in situ acetylation reactions of ketene with alcohols and dimethylamine were observed. The acetylation occured readily with few side reactions if the reactant itself did not react readily with the catalyst. For example, methanol and dimethylamine were readily acetylated, whereas dimethoxymethane reacted over the catalyst before any acetylation could occur.

Although the expected in situ reactions with ketene were observed, this does not prove that the reactions did occur via ketene.

\subsection{REFERENCES:}

1. Chang C.D. and Silvestri A.J., J. Catal., 1977, 47, 249.

2. Servotte Y., Jacobs J. and Jacobs P.A., Acta Physica et Chemica Aushaf, 1985, 31, 609.

3. Kirk-othmer Encyclopedia of Chemical Technology, 3rd Edition, John Wiley and Sons, 1980, 1, 155.

4. Kirk-othmer Encyclopedia of Chemical Technology, 3 rd Edition, John Wiley and Sons, 1980, 13, 874.

5. Gonzalez F., Munuera G., Prieto J.A., J. Chem. Soc. Faraday Trans. 1, 1978, 76, 1517.

6. Eight Peak Index of Mass Spectra, 2nd Ed., Mass Spectrometry Data Centre, 1974.

7. Maquestiau, Flammang R. and Pauwels P., Org. Mass Spec. $1983,18,547$.

8. Allinger N.L. Cava M.P., De Jongh D.C., Johnson C.R., Lebel N.A. and Stevens C.L. "Organic Chemistry", Worth Publishers Inc., New York, 1971. 
9. Chihara T., Takagi Y., Teratani S. and Ogawa H., Chem Lett., 1982, 1451.

10. Dickson S., Toxicology section, Chemistry Division, DSIR, personal communication,.

11. Chen Z, Iizuka T. and Tanabe K., Japan Chem. Lett., 1984,1085 .

12. Mochida T., Yasuhide A., Kato A. and Seiyama T., J. Catal., 1971, 21, 263.

13. Miller I. Carina Chemicals Laboratory, Lower Hutt, New Zealand, personal communication,.

14. Chihara T., Teratani S. and Ogawa H. J. Am. Chem. Soc. Chem. Comm., 1981, 1120. 
CHAPTER 10: The Nature of the Ketene Producing Reaction

\section{$10.1 \mathrm{Td} / \mathrm{ms}$ survey of possible catalysts for ketene production:}

The td/ms technique was used for a rapid, qualitative determination of the ketene producing ability of a range of catalysts. The main aim was to determine which catalysts could produce ketene for a possible patent application. zeolites with a wide variety of structures as well as sodium and calcium acetates, microporous aluminium phosphates (AlPO's), amorphous aluminosilicates and pillared clays were surveyed. These were exchanged with the cations $\mathrm{Li}^{+}, \mathrm{Na}^{+}, \mathrm{K}^{+}$, $\mathrm{Rb}^{+}, \mathrm{Cs}^{+}, \mathrm{Ca}^{++}, \mathrm{Zn}^{++}$and $\mathrm{La}^{3+}$. The results are given in Appendix II.

\section{Summary of results from Appendix II:}

Thermal decomposition of sodium and calcium acetates resulted in desorption of acetone and some $\mathrm{CO}_{2}$. A small amount of ketene was observed, probably from the thermal decomposition of acetone. Therefore a substrate or catalyst appears to be required for any major ketene production. A microporous crystalline structure is not a requirement for this catalyst as it was shown that amorphous aluminosilicates produced some ketene. However, the environment inside the zeolite micropores influences strongly the relative proportions of ketene and $\mathrm{CO}_{2}$ and acetone. The particular catalyst structure and exchanged cation can therefore be chosen to optimise ketene production.

All zeolites produced ketene to differing degrees, except those in which sorption of acetic acid was sterically prevented. The temperature of the maximum for ketene desorption did not follow any trends with variation of the zeolite, but remained within the range $330^{\circ} \mathrm{C}$ to $430^{\circ} \mathrm{C}$, with the mode at $370^{\circ} \mathrm{C}$. There was only one exception, $\mathrm{Li}^{+}$chabazite, which had a maximum at $480^{\circ} \mathrm{C}$. 
244 
All the cations investigated in exchanged zeolites were also effective in producing some ketene. The largest pore zeolites ( $\mathrm{X}$ and $\mathrm{Y}$ ) with the smallest alkali metal cations $\left(\mathrm{Li}^{+}\right.$and $\mathrm{Na}^{+}$) gave the best ketene yields, as the competing reaction to acetone and $\mathrm{CO}_{2}$ occurred $-60^{\circ} \mathrm{C}$ higher than did the ketene producing reaction. With increasing cation size, the temperature of the reaction to acetone and $\mathrm{CO}_{2}$ decreased, while that for ketene desorption remained approximately constant. This resulted in a decrease in the amount of ketene with an increase in acetone and $\mathrm{CO}_{2}$ production.

Thus the temperature of the ketene forming reaction is not very sensitive to either zeolite structure or exchanged cation.

An increase in cation size results in a decrease in Lewis acidity and an increase in basicity (1). Thus the acetone and $\mathrm{CO}_{2}$ forming reaction occurred at a higher temperature the stronger the Lewis acidity of the cation.

Catalysts exchanged with multiply charged cations (eg Ca ${ }^{++}$, $\mathrm{Zn}^{++}$and $\mathrm{La}^{3+}$ ) showed acidic as well as basic properties with the production of alkenes. This is a result of reaction with water to produce polyhydroxides and acid sites.

\section{CONCLUSIONS from the TD/MS SURVEY (Appendix II):}

The $t d / m s$ survey indicates that the 'best' catalysts for ketene production are the largest pore zeolites (faujasites) exchanged with the smallest cations $\left(\mathrm{Li}^{+}\right.$and $\left.\mathrm{Na}^{+}\right)$. This is because the temperature of reaction to ketene varies little with different catalysts, but the competing reaction to acetone and $\mathrm{CO}_{2}$ occurs at higher temperatures. Thus more ketene is observed. 
10.2 The effect of catalyst composition on ketene production - a study using the mini-reactor technique:

A mini-reactor technique was developed in which the acetic acid flow rate was held constant while the catalyst temperature was increased (see chapter 2). Results were compared with those obtained from td/ms experiments in which the acetic acid concentration varied with temperature, depending upon how strongly it was sorbed on the catalyst.

\subsubsection{Na+zSM-5:}

$\mathrm{Na}^{+}$exchanged $\mathrm{ZSM}-5(0.04 \mathrm{~g})$ was placed in the reactive filter held in a constant flow of gas phase acetic acid at atmospheric pressure. The flow rate of Ar through the impinger was $7 \mathrm{ml} \mathrm{min}{ }^{-1}$ which was diluted by a $12 \mathrm{ml} \mathrm{min}{ }^{-1} \mathrm{~N}_{2}$ flow. Assuming that the Ar was saturated with acetic acid at its room temperature $\left(22^{\circ} \mathrm{C}\right)$ vapour pressure, the mass flow rate of acetic acid through the catalyst was $0.5 \mathrm{~g} \mathrm{~g}^{-1} \mathrm{~h}^{-1}$. The partial pressure of acetic acid in the gas stream was 5 Torr.

The species observed as the catalyst temperature was increased from $350^{\circ} \mathrm{C}$ at $2^{\circ} \mathrm{C} \mathrm{min} \mathrm{m}^{-1}$, plotted in approximate mole ratios (see chapter 2), are shown in figure 10.1. Unreacted acetic acid decreased with temperature as the reaction products ketene, acetone and $\mathrm{CO}_{2}$ increased. Ketene and acetone reached a maxima at $\sim 400^{\circ} \mathrm{C}$, then decreased as reaction to methane and $\mathrm{CO}_{2}$ became dominant at higher temperatures. At all temperatures more acetone and $\mathrm{CO}_{2}$ were produced than ketene. 


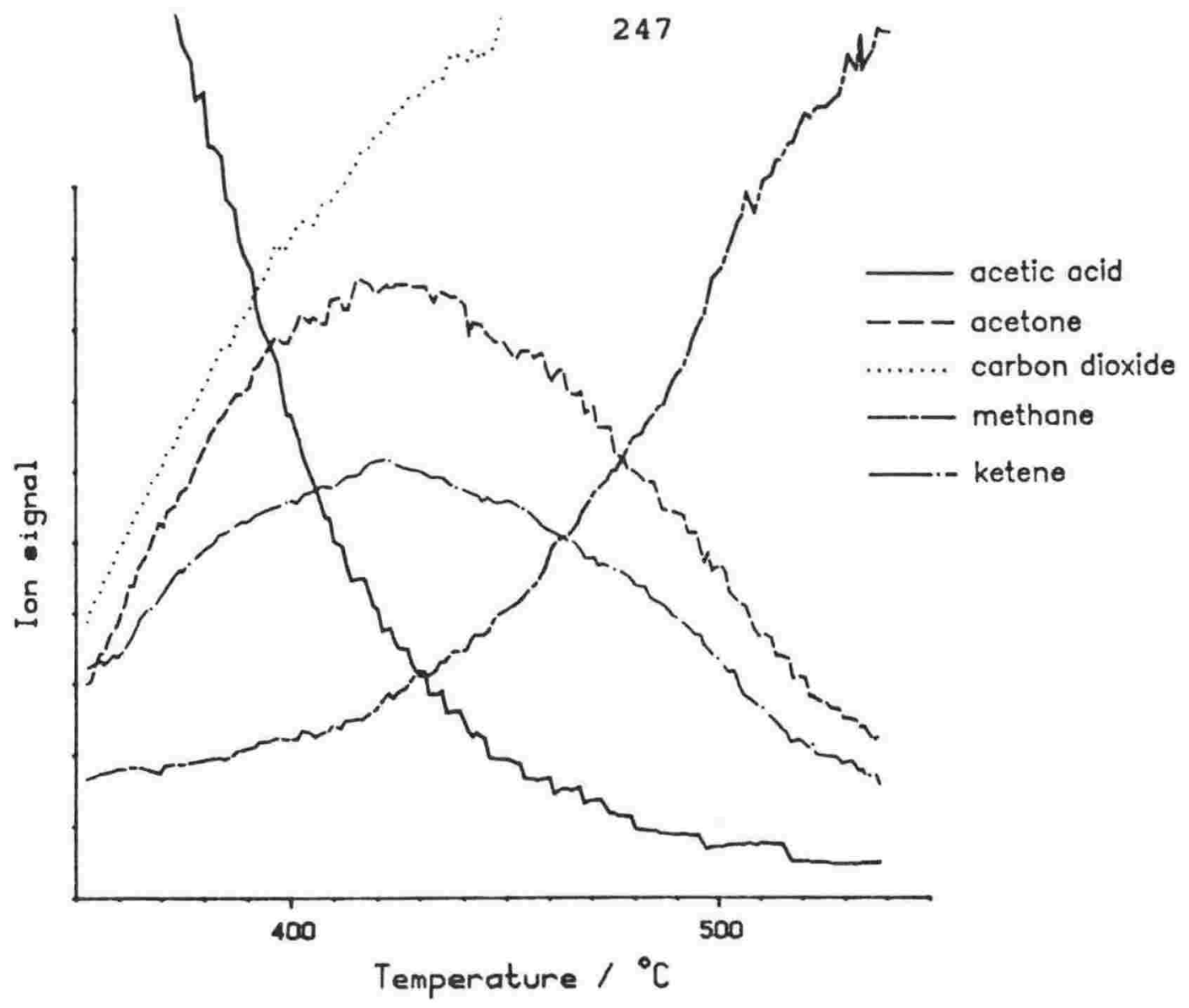

Figure 10.1. Reaction products of acetic acid over $\mathrm{Na}+\mathrm{ZSM}-5$ versus temperature. The ion signals are scaled to show approximate mole ratios.

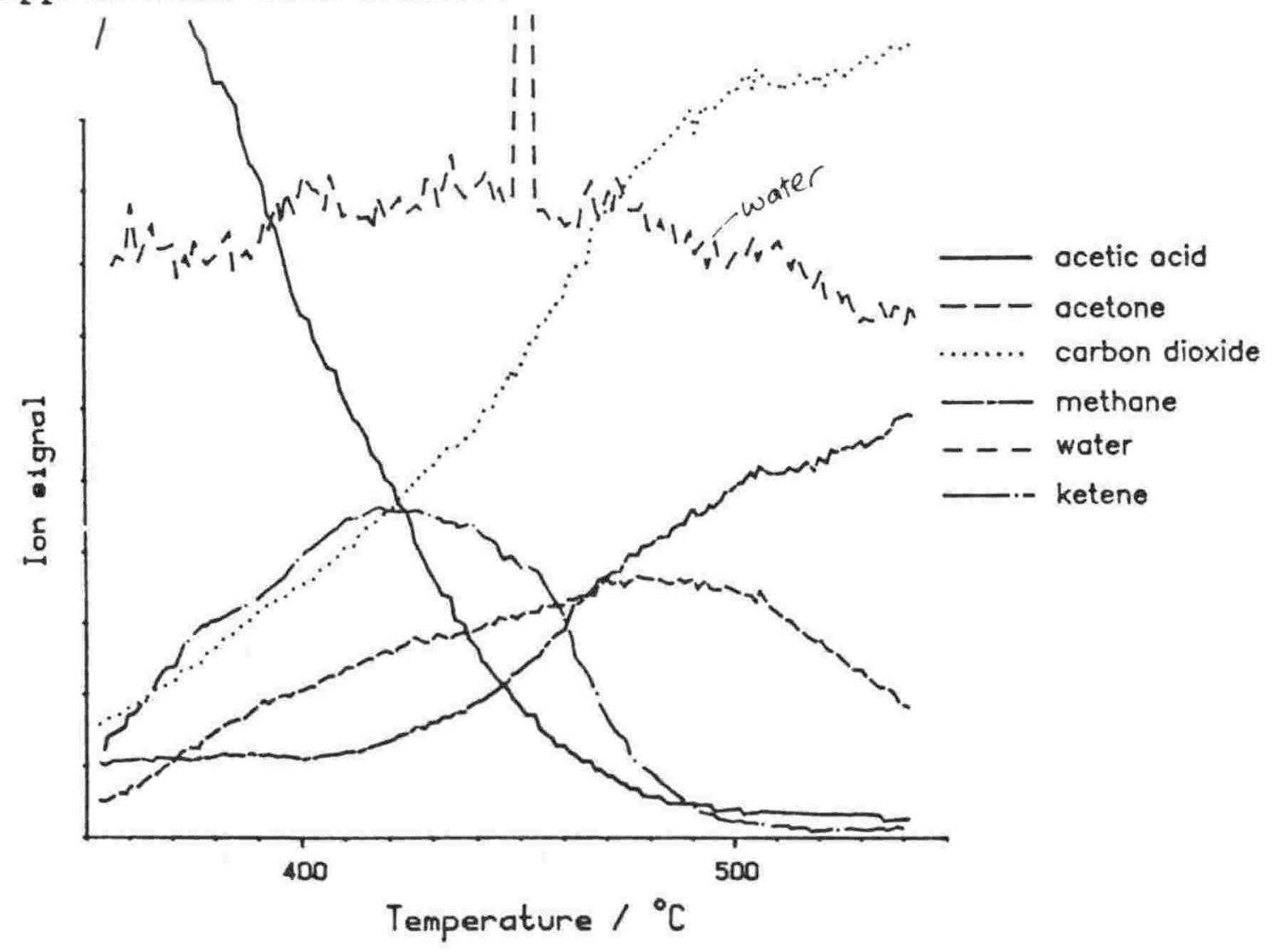

Figure 10.2. Reaction products of acetic acid over $\mathrm{Na}+\mathrm{Y}$ (sample A) versus temperature. The ion signals are scaled to show approximate mole ratios. 
Similar conditions were used for $\mathrm{Na}+\mathrm{Y}$ (sample $\mathrm{A}$ ) as for $\mathrm{Na}+\mathrm{ZSM}-5$, to allow a comparison to be made. (The experimental conditions were: acetic acid/Ar flow rate $=6$ $\mathrm{ml} \min ^{-1}, \mathrm{~N}_{2}$ diluent flow rate $11 \mathrm{ml} \mathrm{min}^{-1}$, catalyst weight $0.056 \mathrm{~g}$, acetic acid mass flow rate $0.36 \mathrm{~g} \mathrm{~g}^{-1} \mathrm{~h}^{-1}$, heating rate $\left.2^{\circ} \mathrm{C} \mathrm{min}^{-1}\right)$. The results are shown in figure 10.2. Acetic acid showed a similar decline with temperature compared to $\mathrm{Na}+\mathrm{ZSM}-5$, but a greater proportion of ketene was observed in the products, reaching a maximum at $\sim 420^{\circ} \mathrm{C}$. Increases in $\mathrm{CO}_{2}$ and acetone were delayed with acetone reaching a maximum at $-480^{\circ} \mathrm{C}$ (compared with $420^{\circ} \mathrm{C}$ for Na+ZSM- 5). The same differences were also observed in $t d / m s$ of acetic acid from these catalysts. The amount of water observed was not equal to the amount of ketene observed. This may have been due to condensation occuring when the amount of water exceeded its vapour pressure. The rate of increase in methane with temperature was similar for both catalysts. Methane was not observed in the $t d / m s$ experiments, presumably because of the lack of free acetic acid at higher temperatures.

\subsubsection{A comparison of two samples of Na+Y (Sample A - as recieved Linde $Y$ and sample $B$ - exchanged in 1 M NaCl)}

Further $t d / m s$ work (not shown here) gave results which showed variations in the relative amounts of ketene, acetone and $\mathrm{CO}_{2}$ for the same catalyst, depending upon treatment during ion exchange.

The mini-reactor experiment for $\mathrm{Na}+\mathrm{Y}$ (sample A) was repeated using the following conditions: acetic acid/Ar flow $=7.5 \mathrm{ml}$ $\mathrm{min}^{-1}$, Ar diluent flow $=9 \mathrm{ml} \mathrm{min}^{-1}$, catalyst weight $0.038 \mathrm{~g}$, heating rate $2^{\circ} \mathrm{C} \mathrm{min}{ }^{-1}$. The results obtained (figure 10.3) are very similar to those of figure 10.2, showing the experiment to be reproducible. In figure 10.3 evolved water was observed, in almost equal quantities to the ketene, but 


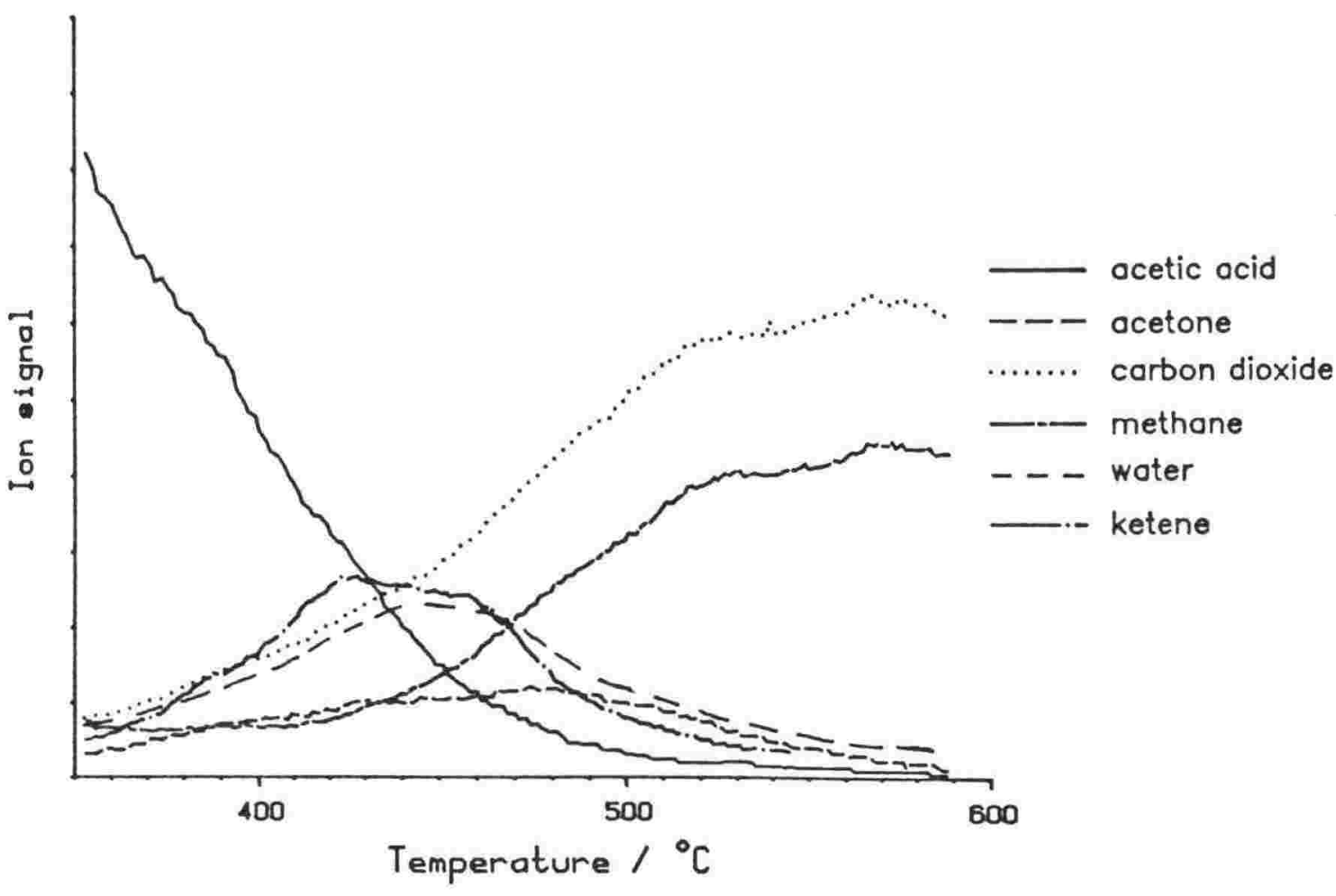

Figure 10.3. Reaction products of acetic acid over $\mathrm{Na}+\mathrm{Y}$ (sample A) versus temperature. The ion signals are scaled to show approximate mole ratios.

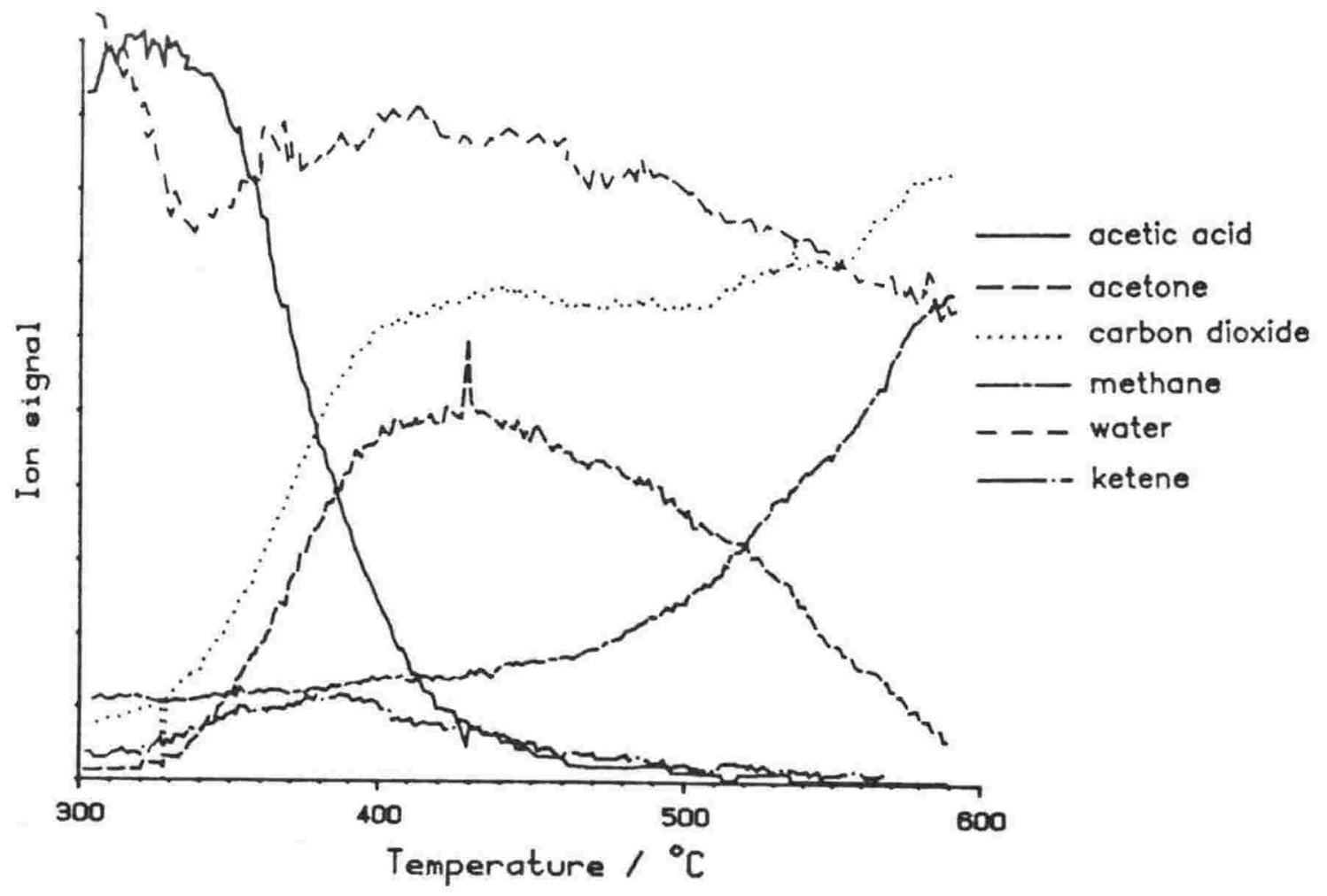

Figure 10.4. Reaction products of acetic acid over $\mathrm{Na}+\mathrm{Y}$ (sample B) versus temperature. The ion signals are scaled to show approximate mole ratios. 
slightly delayed. This may have been the result of pretreatment of the interface between the reactor and the mass spectrometer so that less water was sorbed than previously $(10.2 .2)$.

For $\mathrm{Na}+\mathrm{Y}$ (sample B), which had been exchanged in $\mathrm{NaCl}$ solution (as described in 11.2), very different results (figure 10.4) were obtained under similar experimental conditions (acetic acid/Ar flow $=7.5 \mathrm{ml} \mathrm{min}{ }^{-1}$, Ar diluent flow $=9.7 \mathrm{ml} \mathrm{min}{ }^{-1}$, catalyst weight $0.046 \mathrm{~g}$ and heating rate $\left.2^{\circ} \mathrm{C} \min ^{-1}\right)$. Only a small proportion of ketene was formed compared to a large amount of $\mathrm{CO}_{2}$ and acetone.

Analysis of the two samples (see Appendix I) showed that for sample $\mathrm{A}$ the mole ratio $\mathrm{Na} / \mathrm{Al}=0.84$ and for sample $\mathrm{B} \mathrm{Na/AI}=$ 0.92. It is not known whether the additional $\mathrm{Na}^{+}$is associated with zeolite $\mathrm{Al}$ sites or as $\mathrm{NaCl}$ in the channels, but the additional Nat in sample B is possibly related to the favoured production of acetone and $\mathrm{CO}_{2}$.

\subsubsection{Cs+Na+Y:}

The mini-reactor experiment was carried out because the previous $t d / m s$ results (appendix II) showed a large proportion of ketene and small acetone and $\mathrm{CO}_{2}$ peaks, contrary to the general trend for higher acetone and $\mathrm{CO}_{2}$ production with increasing cation size. The $\mathrm{Cs}+\mathrm{Na}+\mathrm{Y}$ was prepared from $\mathrm{Na}+\mathrm{Y}$ by exchange as described in to 11.2. Analysis (see appendix I) showed a Cs/Na mole ratio of 1.9 .

Figure 10.5 shows the results for $\mathrm{Cs}+\mathrm{Na}+\mathrm{Y}$ using the following experimental conditions: acetic acid/Ar flow $=5.5 \mathrm{ml} \mathrm{min}{ }^{-1}$, Ar diluent flow $=20.5 \mathrm{ml} \mathrm{min}{ }^{-1}$, catalyst weight $=0.05 \mathrm{~g}$, WHSV $=0.3 \mathrm{~g} \mathrm{~g}^{-1} \mathrm{hr}^{-1}$, partial pressure of acetic acid $=3.2$ Torr, heating rate $=5^{\circ} \mathrm{C} \mathrm{min}^{-1}$. Only a small amount of ketene was observed with acetone and $\mathrm{CO}_{2}$ being the dominant products. This is in agreement with the general trend observed in the $t d / m s$ experiments. The mini-reactor is therefore a better technique for comparing different catalysts. The anomaly in the $t d / m s$ result may have been due to how the acetic acid was 
sorbed on different sites in the zeolite, some sites favouring ketene, and the other favouring acetone.

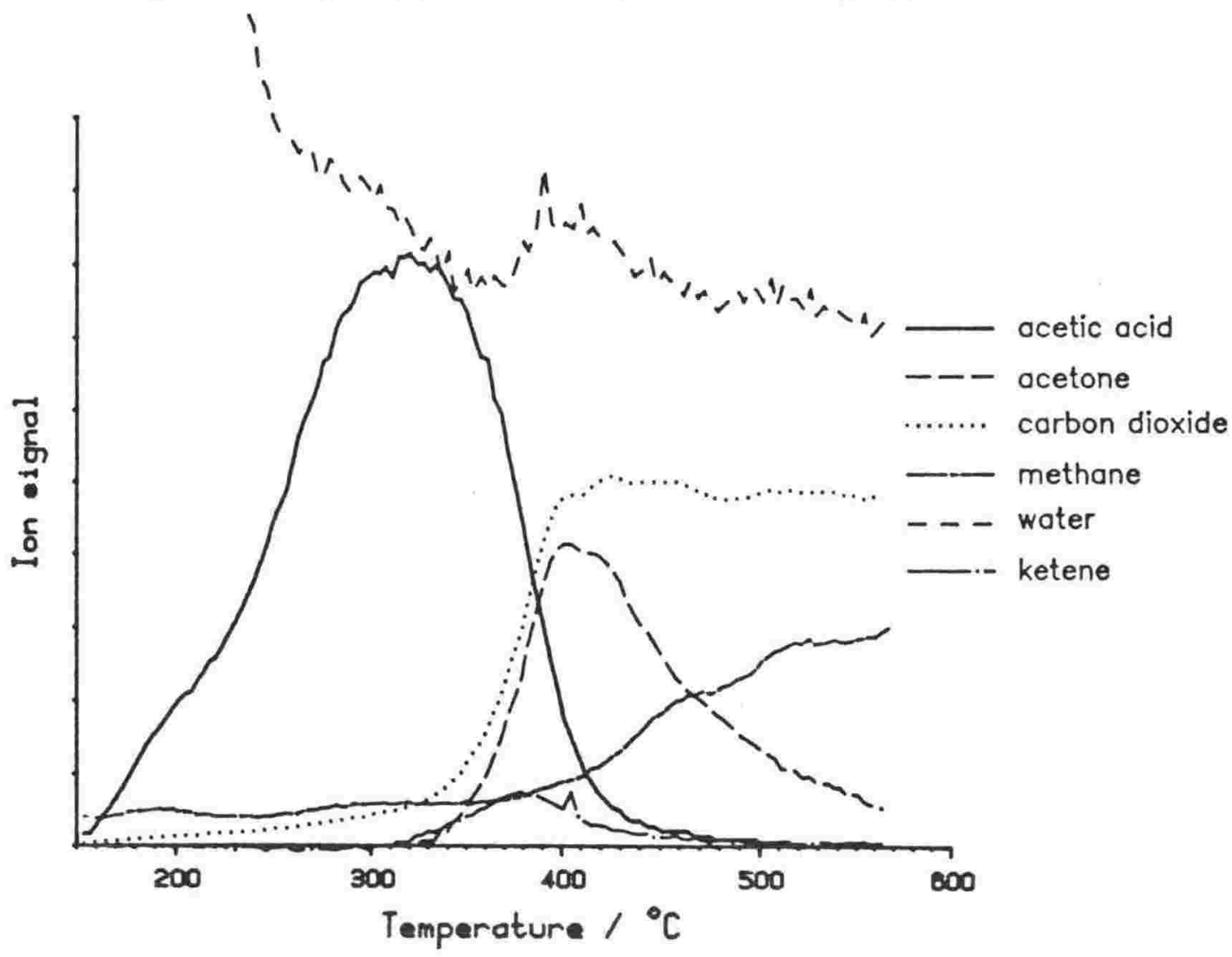

Figure 10.5. Reaction products of acetic acid over Cs+Na+Y versus temperature. The ion signals are scaled to give approximate mole ratios. 
10.2 .5 SUMMARY:

The mini-reactor technique technique confirms that the relative amounts of ketene and competing products vary with catalyst used. The general trends observed by the $t d / m s$ technique with catalyst were also observed by the mini-reactor technique. The catalysts exchanged with the smaller cations produced the greater proportions of ketene.

\section{Different exchange procedures for the same catalyst also} result in the production of different proportions of ketene. This may depend upon the number of cations in the channels that are not associated with zeolite Al.

The td/ms technique was useful for a rapid survey of potential catalysts, but the mini-reactor technique gave more consistent results as there was only one main reaction variable (temperature). The mini-reactor also models more closely the conditions that would be found in a larger scale reactor, so would be the prefered technique in any further catalyst surveys. 
10.3 In situ-FTIR - an investigation into the reactive species sorbed on the catalyst and gas phase products.

\subsubsection{Background on IR spectra of acetic acid sorbed on similar surfaces:}

IR studies of acetic acid sorbed on alkali exchanged zeolites do not appear to have been published, but studies have been reported on acetic acid sorbed on surfaces with Lewis acidic properties.
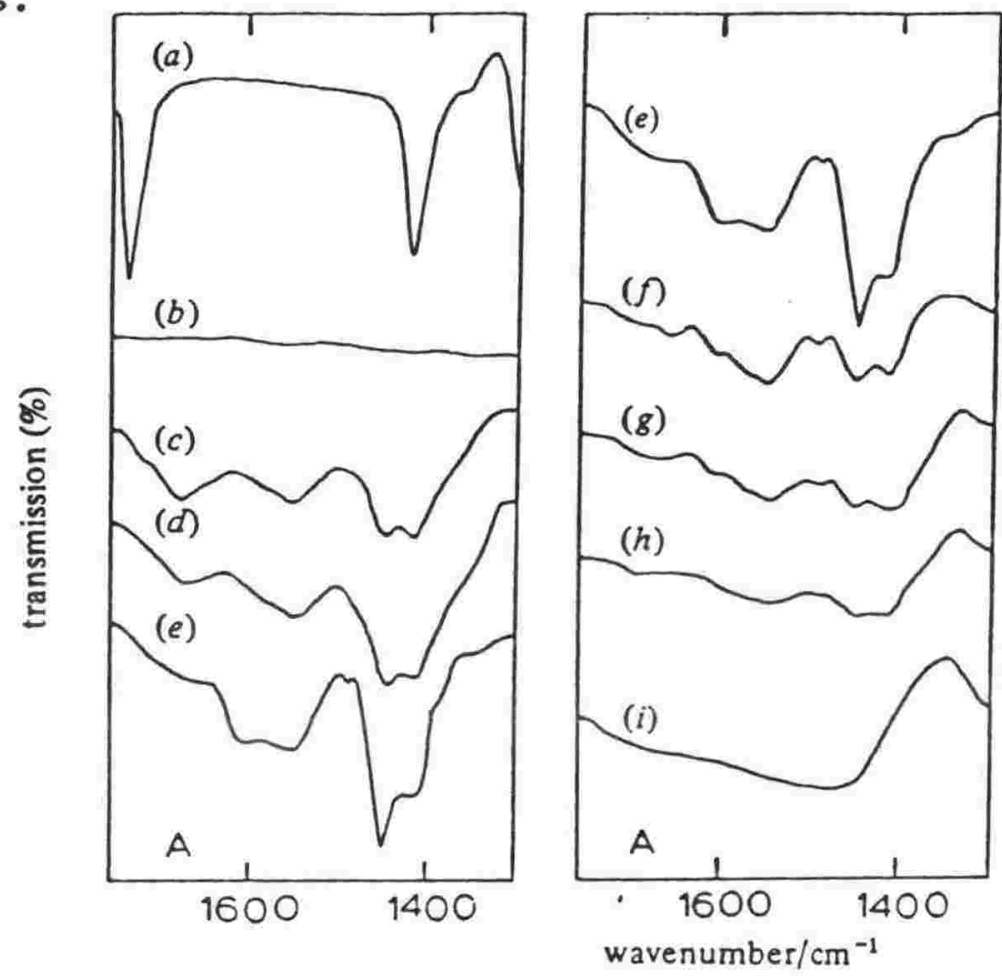

(A) (a) Spectrum of acetic acid vapour $\left(1.3 \mathrm{kN} \mathrm{m}^{-2}\right) ;(b)-(i)$ spectra of $(\mathrm{VO})_{2} \mathrm{P}_{2} \mathrm{O}_{7}$ after (b) evacuation $(17 \mathrm{~h}, 673 \mathrm{~K}),(c)$ contact with acetic acid vapour at the saturated vapour pressure of acetic acid at $213 \mathrm{~K},(d)$ contact with the s.v.p. of acetic acid at $233 \mathrm{~K},(e)$ contact with acetic acid vapour $\left(2 \mathrm{kN} \mathrm{m}^{-2}\right)$ and evacuation $(1 \mathrm{~h})$ at $c a .300 \mathrm{~K},(f 453 \mathrm{~K},(\mathrm{~g}) 553 \mathrm{~K},(h) 653 \mathrm{~K}$ and $(i) 693 \mathrm{~K}$.

Figure 10.6. IR spectra of acetic acid on anhydrous vanadyl pyrophosphate obtained by Puttock and Rochester (2).

Acetic acid sorbed on the surface of anhydrous vanadyl pyrophosphate (VO) ${ }_{2} \mathrm{P}_{2} \mathrm{O}_{7}$ at $27^{\circ} \mathrm{C}$ was studied by Puttock and Rochester (2). Their spectra are shown in figure 10.6. Bands at 1720 (shoulder) and $1680 \mathrm{~cm}^{-1}$ were assigned to $\mathrm{C}=0$ stretching of undissociated adsorbed acetic acid. Bands at 1600 and $1450 \mathrm{~cm}^{-1}$ and 1550 and $1420 \mathrm{~cm}^{-1}$ were assigned to two types of surface acetate. Sorption of deuterated acetic acid did not change the wavenumbers of these bands confirming their assignment to $\mathrm{c}-\mathrm{O}$ stretches. 
The IR spectrum of acetic acid sorbed on anhydrous $\mathrm{TiO}_{2}$ anatase at $20^{\circ} \mathrm{C}$ obtained by Gonzalez et al. (3) is shown in figure 10.7. (see also chapt 9.1). The acetic acid bonded to the surface hydroxyls at 3730 and $3680 \mathrm{~cm}^{-1}$ and a very broad band appeared at $\sim 3200 \mathrm{~cm}^{-1}$. In the $\mathrm{v}_{\mathrm{c}-0}$ region the band at $1675 \mathrm{~cm}^{-1}$ was assigned to "molecularly adsorbed species tightly bonded to the surface in a co-ordinative form". This band desorbed upon heating (fig $10.7 \mathrm{c}$ ). The remaining bands were assigned to sorbed acetate.

Ketene vapour was held over this "carboxylated surface" at $20^{\circ} \mathrm{C}$ and the resultant spectrum is shown in figure 10.8. The additional peaks were assumed to belong to sorbed ketene and they concluded that the adsorbed ketene "acts as a strong Lewis base, as suggested by the displacement of the $\mathrm{v}_{\mathrm{c}-0}$ band of gaseous ketene from 2150 to $1730 \mathrm{~cm}^{-1}$ ". This is very large shift $\left(420 \mathrm{~cm}^{-1}\right)$, and is greater than that observed for sorption and reaction of acetic acid to acetate $\left(320 \mathrm{~cm}^{-1}\right)$. There may, however, be an alternative conclusion as reaction of the ketene may have occurred upon sorption.

In this work, acetic acid was sorbed onto alkali exchanged zeolites and studied by FTIR to determine the species that are present upon sorption and reaction of acetic acid. 


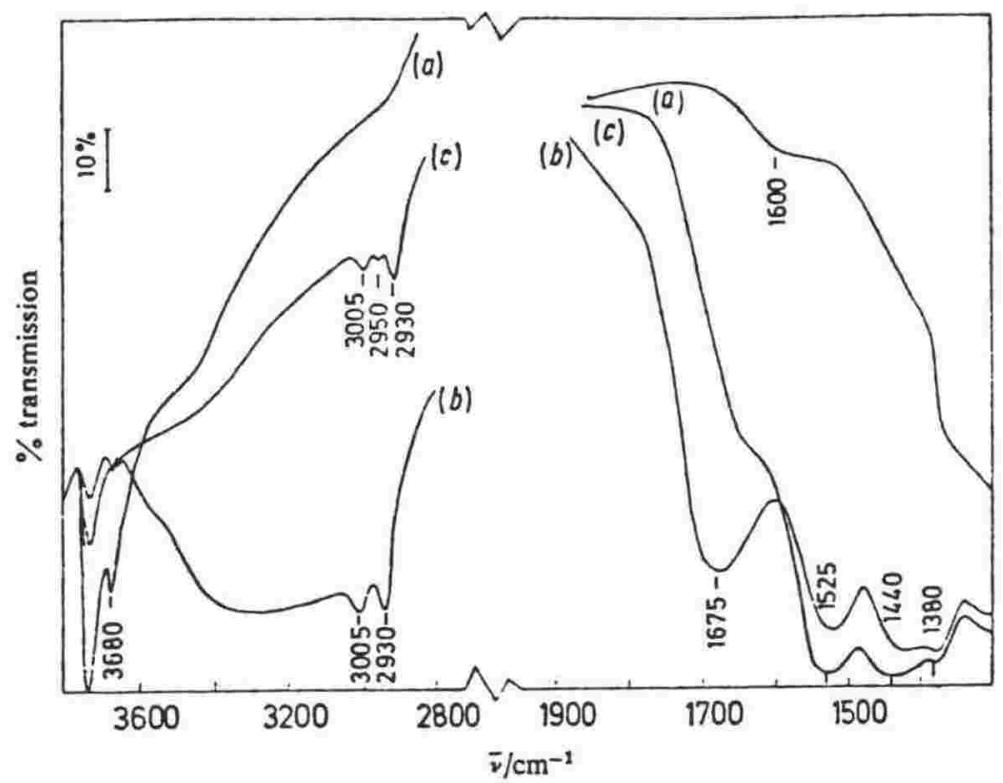

I.r. spectra of $\mathrm{TiO}_{2}$, anatase: (a) " standard surface"; (b) after adsorption at $20^{\circ} \mathrm{C}$ of $\mathrm{CH}_{3} \mathrm{COOH}$ vapour up to 1.15 molecule $\mathrm{nm}^{-2} ;($ c $)$ outgassed $15 \mathrm{~min}$ at $150^{\circ} \mathrm{C}$

Figure 10.7. IR spectra of acetic acid sorbed on anhydrous $\mathrm{TiO}_{2}$ anatase at $20^{\circ} \mathrm{C}$, obtained by Gonzalez et al. (3).

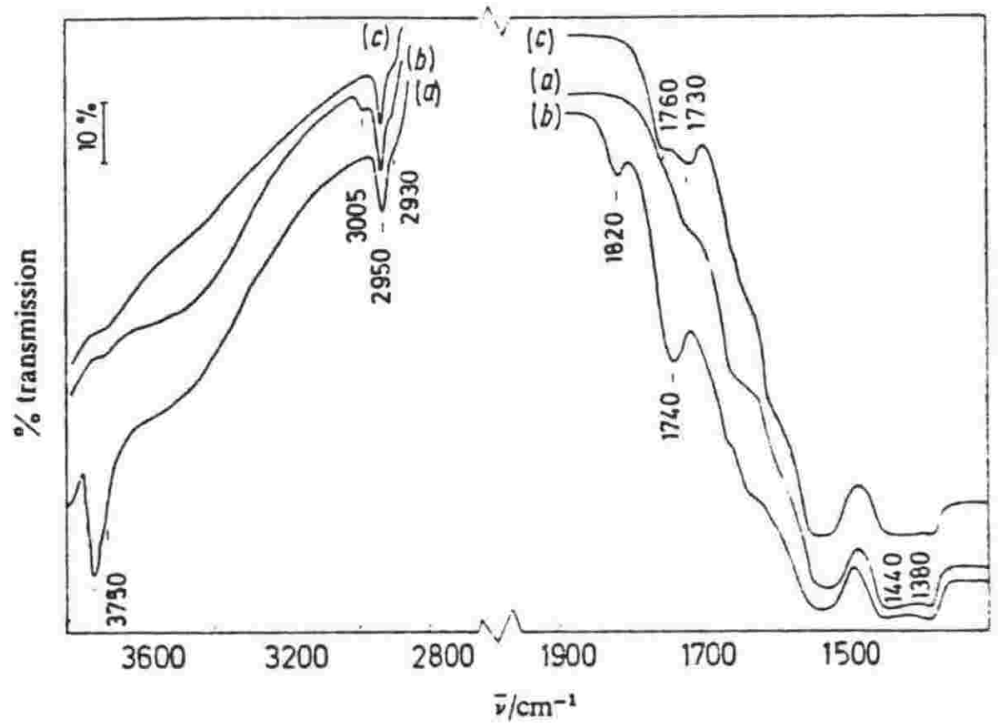

I.r. spectra of $\mathrm{TiO}_{2}$, anatase: (a) "carboxylated surface" ; (b) after saturative adsorption at $20^{\circ} \mathrm{C}$ with ketene vapours; (c) outgassed $20 \mathrm{~min}$ at $250^{\circ} \mathrm{C}$.

Figure 10.8. IR spectrum of ketene sorbed onto a "carboxylated surface" of $\mathrm{TiO}_{2}$ anatase at $20^{\circ} \mathrm{C}$ obtained by Gonzalez et al. (3). 


\subsubsection{Acetic acid sorbed on Li+28M-5 at $200^{\circ} \mathrm{C}$.}

Acetic acid $(2 \mu l)$ was sorbed onto a wafer of dry Li+ZSM-5 (prep 816) held at $200^{\circ} \mathrm{C}$ and flushed with dry $\mathrm{N}_{2}(25 \mathrm{ml}$ $\left.\mathrm{min}^{-1}\right)$. The spectrum of dry $\mathrm{Li}+\mathrm{ZSM}-5$ is shown in figure $10.9 \mathrm{~A}$ and the spectrum immediately after addition of acetic acid is shown in figure 10.9B. The difference spectrum (between $10.9 \mathrm{~B}$ and $10.9 \mathrm{~A}$ ) is shown in figure 10.9C. Peaks at 3582 , 1800 and $1776 \mathrm{~cm}^{-1}$ due to gas phase acetic acid (see Table $3.2)$, were observed along with a smaller peak at $1721 \mathrm{~cm}^{-1}$ due to sorbed acetic acid. After flushing for $40 \mathrm{~min}$ only three strong peaks at 1612,1569 (shoulder) and $\sim 1430 \mathrm{~cm}^{-1}$ remained. The difference spectrum is shown in figure 10.9D. The peak at $1612 \mathrm{~cm}^{-1}$ was the most intense and was off-scale.

No significant peaks were observed in the hydroxyl stretching region, with even the few silanols originally present having reacted (as indicated by the disappearance of the band at $3742 \mathrm{~cm}^{-1)}$. Lithium hydroxide was therefore not formed.

No sorbed or gas phase ketene was observed. The IR bands of ketene in the region studied are listed in Table 10.1. The strongest band is the $\mathrm{c}=0$ stretch at $2151 \mathrm{~cm}^{-1}$.

\section{Table 10.1 IR absorption bands of ketene (4)}

$\begin{array}{ccc}\text { Band } & \text { Mode } & \text { Wavenu } \\ & & \\ 1 & \mathrm{C}-\mathrm{H} \text { stretch } & 3069 \\ 2 & \mathrm{C}=\mathrm{O} \text { stretch } & 2150 \\ 3 & \mathrm{CH}_{2} \text { bend } & 1388 \\ 4 & \mathrm{C}=\mathrm{C} \text { stretch } & 1120 \\ 5 & \mathrm{C}-\mathrm{H} \text { stretch } & 3166\end{array}$

Heating to $460^{\circ} \mathrm{C}$ at $10^{\circ} \mathrm{C} \mathrm{min}{ }^{-1}$ resulted in almost complete desorption of the sorbed species and the reappearance of the $\mathrm{Si}-\mathrm{OH}$ peak. 


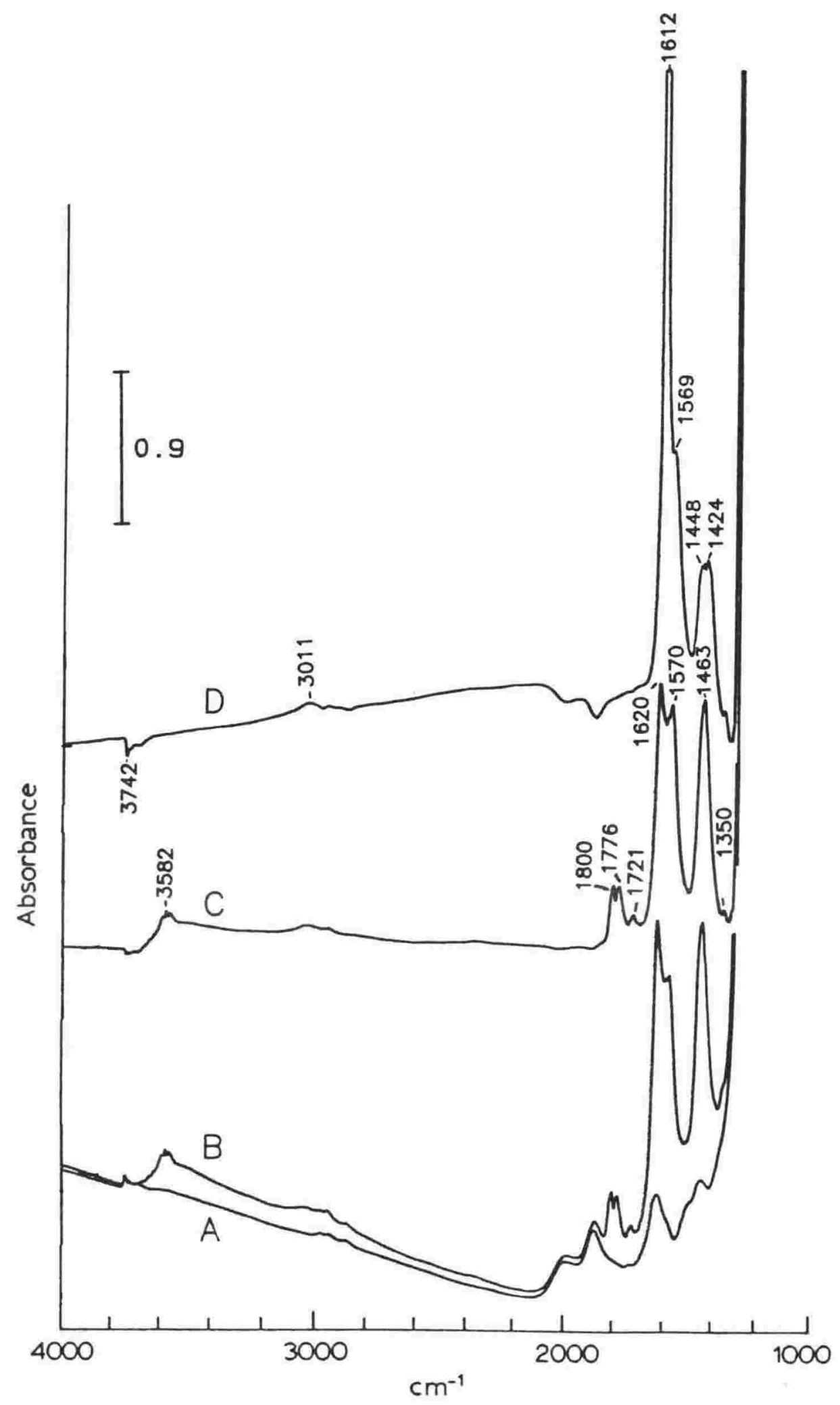

Figure 10.9. Acetic acid sorbed on $\mathrm{Li}+\mathrm{ZSM}-5$ at $200^{\circ} \mathrm{C}$.

A. Before sorption; B. After sorption of acetic acid; C. Difference spectrum (B-A); D. Difference spectrum after flushing the FTIR cell for $40 \mathrm{~min}$. 
10.3.2.2 Acetic acid sorbed on $\mathrm{Li}+\mathrm{Y}$ at $150^{\circ} \mathrm{C}$ :

A wafer of $\mathrm{Li}+\mathrm{Y}$ was dried by heating to $350^{\circ} \mathrm{C}$ in flowing dry $\mathrm{N}_{2}\left(30 \mathrm{ml} \mathrm{min}^{-1}\right)$, then cooled to $150^{\circ} \mathrm{C}$. The difference spectra (from the dry $\mathrm{L} i+\mathrm{Y}$ ) obtained upon addition of increasing amounts of acetic acid $(0.5,1$ and $2 \mu l$ (total)) are shown in figure 10.10 A, B, and $C$. The first peaks observed were at 1584 and $1402 \mathrm{~cm}^{-1}$ with peaks at 1658,1723 and a shoulder at $\sim 1770 \mathrm{~cm}^{-1}$ later increasing.

The sample was then heated to $200^{\circ} \mathrm{C}$, and the difference spectrum after $2 \mathrm{~min}$ is shown in figure $10.10 \mathrm{D}$. After 40 min flushing at $200^{\circ} \mathrm{C}$, the only remaining strong peaks were at 1550 and $1421 \mathrm{~cm}^{-1}$ (figure $10.10 \mathrm{E}$ ). The sample was then heated at $10^{\circ} \mathrm{C} \mathrm{min}$ min $^{-1}$ to $500^{\circ} \mathrm{C}$ with the $\mathrm{N}_{2}$ flow off and the cell sealed in an attempt to determine the gas phase desorption products. $\mathrm{CO}_{2}$ was the only product observed with peaks at 2361 and $2327 \mathrm{~cm}^{-1}$. The 1584 and $1405 \mathrm{~cm}^{-1}$ peaks only gradually decreased, with small peaks remaining at $500^{\circ} \mathrm{C}$ (figure 10.10 F).

The sample wafer was black, due to coke formation. This was removed by heating the wafer at $450^{\circ} \mathrm{C}$ in air for $30 \mathrm{~min}$. 


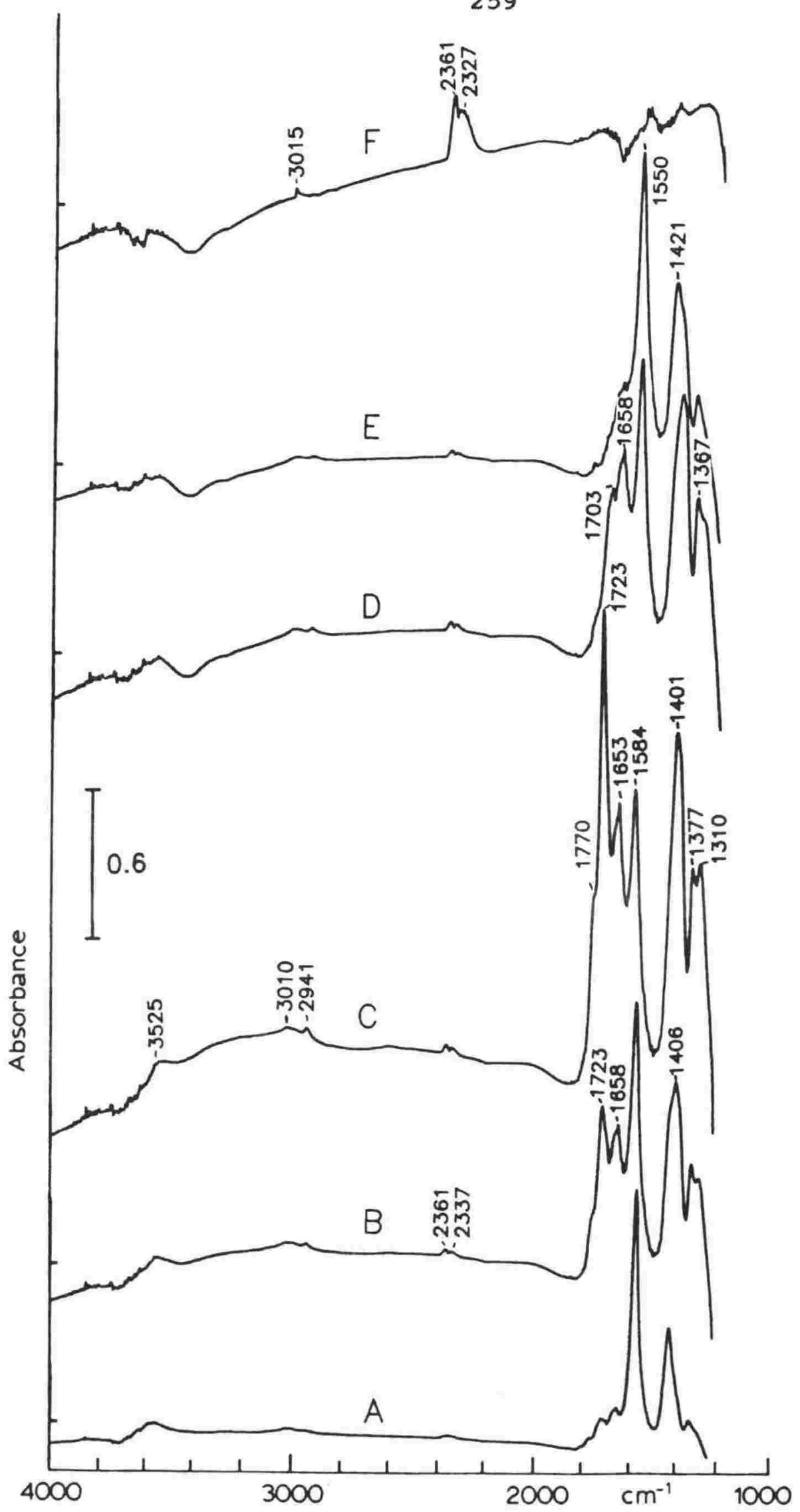

Figure 10.10. Acetic acid sorbed on $\mathrm{Li}+\mathrm{Y}$ at $150^{\circ} \mathrm{C}$. Difference spectra after addition of: A. $0.5 \mu l$ acetic acid; B. $1 \mu l$ acetic acid; C. $2 \mu l$ acetic acid; D. after 2 min flushing at $200^{\circ} \mathrm{C} ; \mathrm{E}$. after $40 \mathrm{~min}$ at $200^{\circ} \mathrm{C} ; \mathrm{F}$. after heating sealed FTIR cell to $500^{\circ} \mathrm{C}$. 
The spectra obtained upon addition of increasing amounts of the deuterated acetic acid on $\mathrm{Li}+\mathrm{Y}$ (from the previous experiment) are shown in figure $10.11 \mathrm{~A}, \mathrm{~B}$ and $\mathrm{C}(0,0.5 \mu \mathrm{l}$ and $1.5 \mu l$ respectively). (The gas phase spectrum of the deuterated acetic acid is shown in figure 3.8 ). The initial spectrum (figure 10.11 A) shows the presence of residues from the previous experiment. The peaks in the $\mathrm{O}-\mathrm{H}$ stretching region shifted to the $O-D$ stretching region, showing $H / D$ exchange. Peaks due to the strongly sorbed species (1570 and $1421 \mathrm{~cm}^{-1}$ ) appeared first, with peaks at $1713,1658, \sim 1383$ and 1322 increasing after addition of more acetic acid. Heating to $200^{\circ} \mathrm{C}$ and $320^{\circ} \mathrm{C}$ (figures $10.11 \mathrm{D}$ and $\mathrm{E}$ ) resulted in the desorption of the less strongly bound species with peaks remaining at 1570 and $1426 \mathrm{~cm}^{-1}$. These are similar to the non-deuterated case (1584 and 1405), showing that these peaks are due to $\mathrm{C}=0$ stretches. No major hydroxyl peaks are associated with the remaining sorbed species. 


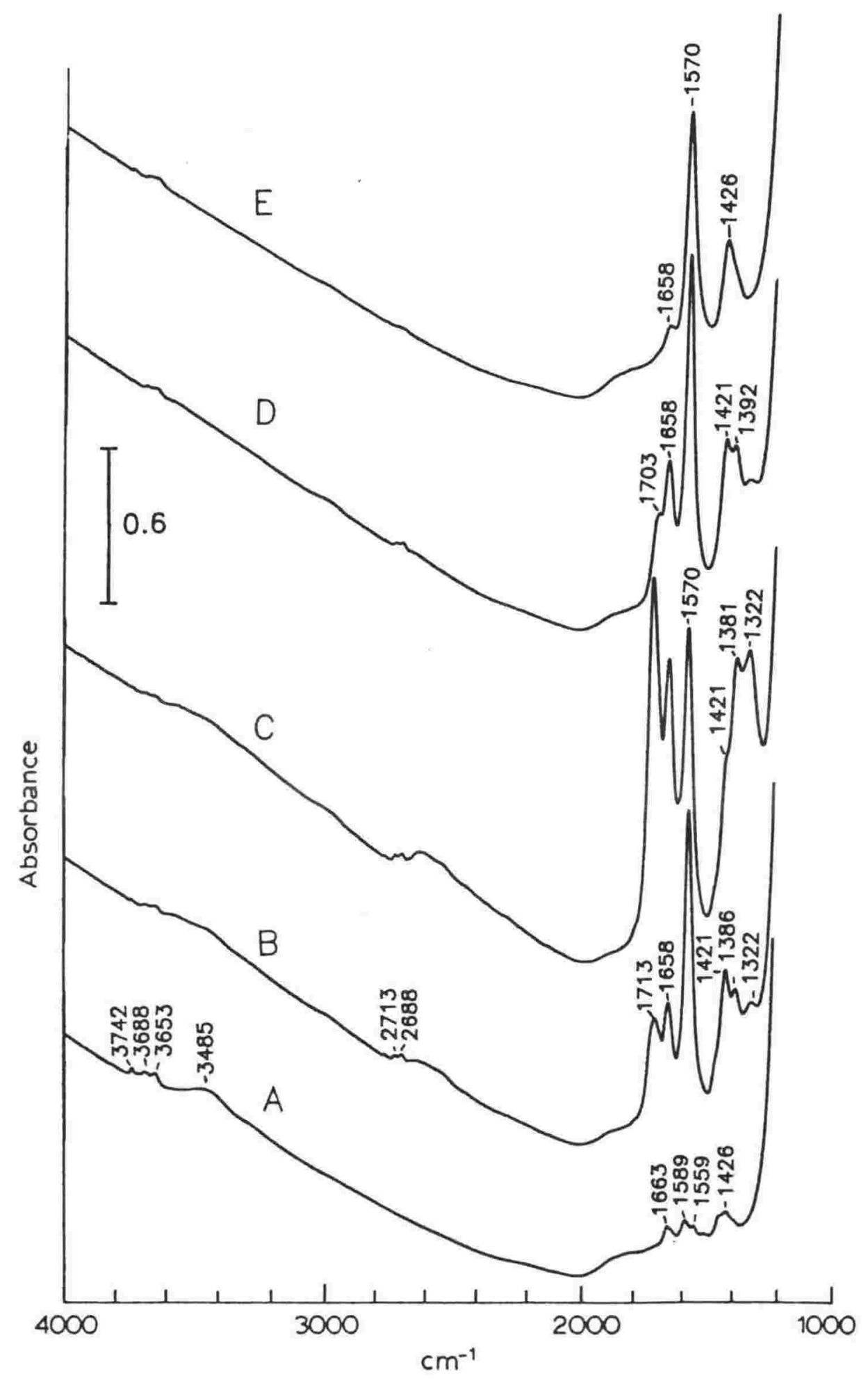

Figure 10.11. Deuterated acetic acid sorbed on $\mathrm{Li}+\mathrm{Y}$ at $150^{\circ} \mathrm{C}$.

A. spectrum before sorption; B after addition of $0.5 \mu l$ acetic acid; C. after addition of $1.5 \mu l$ acetic acid; $D$. after heating to $200^{\circ} \mathrm{C}$ and $\mathrm{E}$. after heating to $320^{\circ} \mathrm{C}$. 


\subsubsection{4 sodium Acetate:}

The spectrum of sodium acetate was obtained to compare with that of the stable species formed on the alkali-exchanged zeolites. A KBr pellet was prepared containing $\sim 1 \%$ AR sodium acetate hydrate. The pellet thickness was less than $1 \mathrm{~mm}$ so that it fitted into the FTIR cell sample holder, with room to spare for expansion when heated. The spectrum of sodium acetate hydrate is shown in figure $10.12 \mathrm{~A}$, and the spectrum of sodium acetate, obtained after heating at $90^{\circ} \mathrm{C}$ for $30 \mathrm{~min}$., is shown in figure $10.12 \mathrm{~B}$.

Dry sodium acetate showed two strong peaks at 1579 and 1420 $\mathrm{cm}^{-1}$ and weak $\mathrm{C}-\mathrm{H}$ stretches at 3000 and $2936 \mathrm{~cm}^{-1}$. These peaks are close to those observed for the strongly bound species on the zeolite, confirming that it is an acetate species.

The hydrated sodium acetate showed additional peaks in the carboxylate stretching region (1712 and $1639 \mathrm{~cm}^{-1}$ ), perhaps due to sorbed acetic acid species. The acetate peaks were shifted to a slightly lower wavenumber (1564 and $1410 \mathrm{~cm}^{-1}$ ). There was also a strong set of bands in the hydroxyl stretching region. 


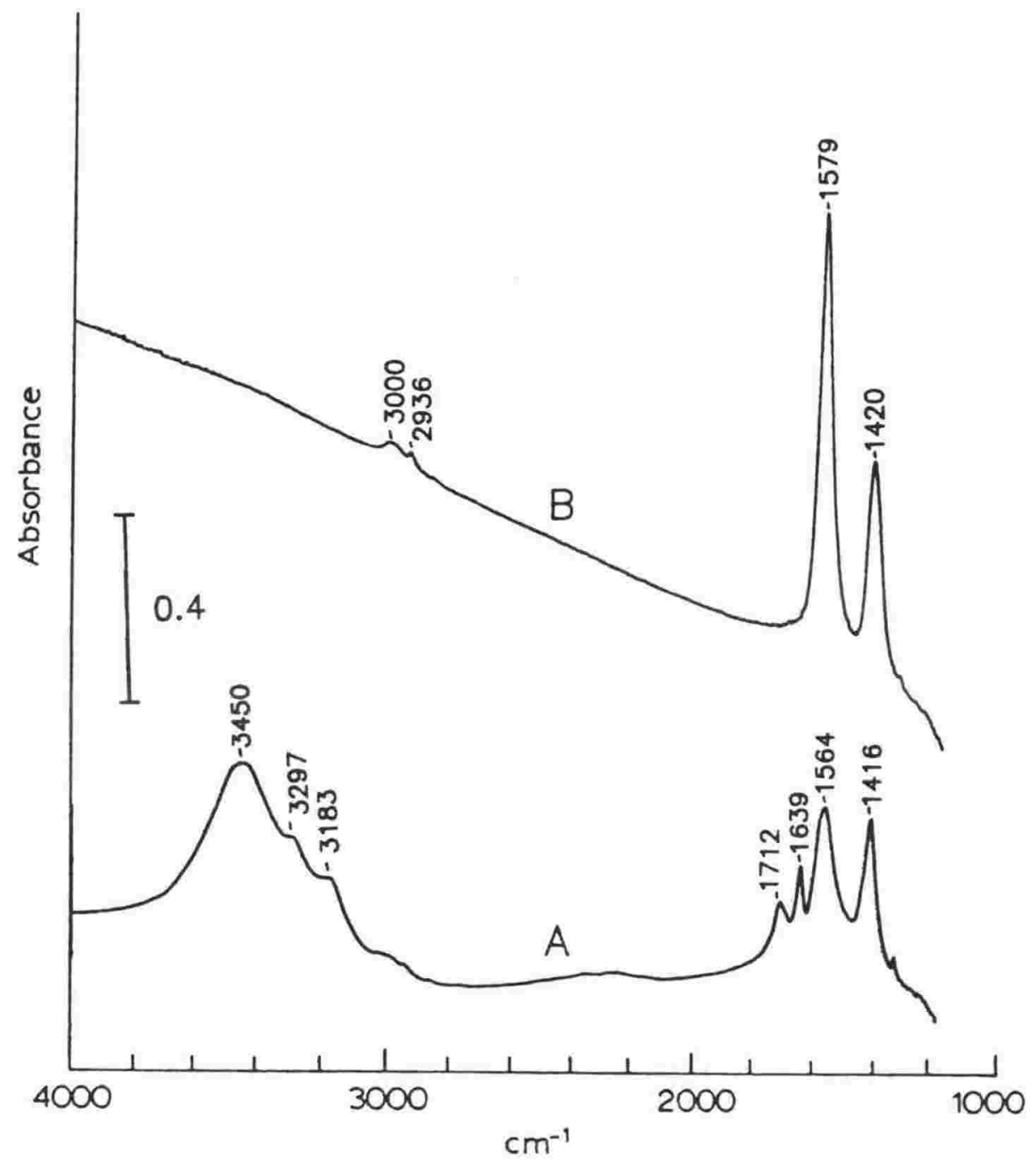

Figure 10.12. Sodium acetate in $\mathrm{KBr}$.

A. sodium acetate hydrate; B. anhydrous sodium acetate. 
Td/FTIR experiments were carried out to mimic the conditions of the $t d / m s$ experiments and to determine which sorbed species was resposible for ketene formation.

\subsubsection{Td/FTIR of acetic acid on Na+Y at atmospheric pressure:}

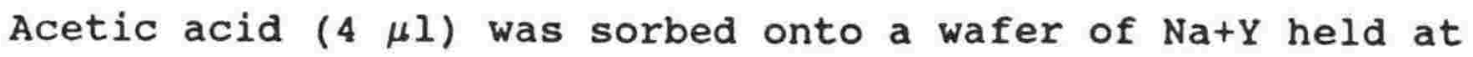
$150^{\circ} \mathrm{C}$ and atmospheric pressure with a $25 \mathrm{ml} \mathrm{min}^{-1}$ flow of He gas. The cell was flushed for about 15 minutes, then heated at $10^{\circ} \mathrm{C} \mathrm{min}{ }^{-1}$ to $550^{\circ} \mathrm{C}$. Spectra obtained at $150^{\circ} \mathrm{C}, 300^{\circ} \mathrm{C}$ and $450^{\circ} \mathrm{C}$ are shown in figure $10.13 \mathrm{~A}, \mathrm{~B}$ and $\mathrm{C}$. The absorbances of the major peaks were measured from these spectra (and others at intermediate temperatures) and plotted versus sample temperature. The results are shown in figure 10.14. Above $450^{\circ} \mathrm{C}$, emission from the sample became a major effect, causing changes in positions and intensities of the peaks. The peak at $\sim 1720 \mathrm{~cm}^{-1}$ is due to a sorbed acetic acid species which desorbs by $200^{\circ} \mathrm{C}$. The broad hydroxyl band $\left(\sim 3560 \mathrm{~cm}^{-1}\right)$ and a peak at $\sim 1670 \mathrm{~cm}^{-1}$ desorb more slowly, up to $350^{\circ} \mathrm{C}$ and $400^{\circ} \mathrm{C}$ respectively. These perhaps result from a more stongly sorbed form of acetic acid. The two strongest peaks at 1584 and $1401 \mathrm{~cm}^{-1}$, which were off-scale for most of the run, desorbed last. These have been shown earlier to be due to acetate anions.

After the run, the wafer was a mid-brown colour. This was heated at $350^{\circ} \mathrm{C}$ in air for about 1 hour until the wafer became almost white. 


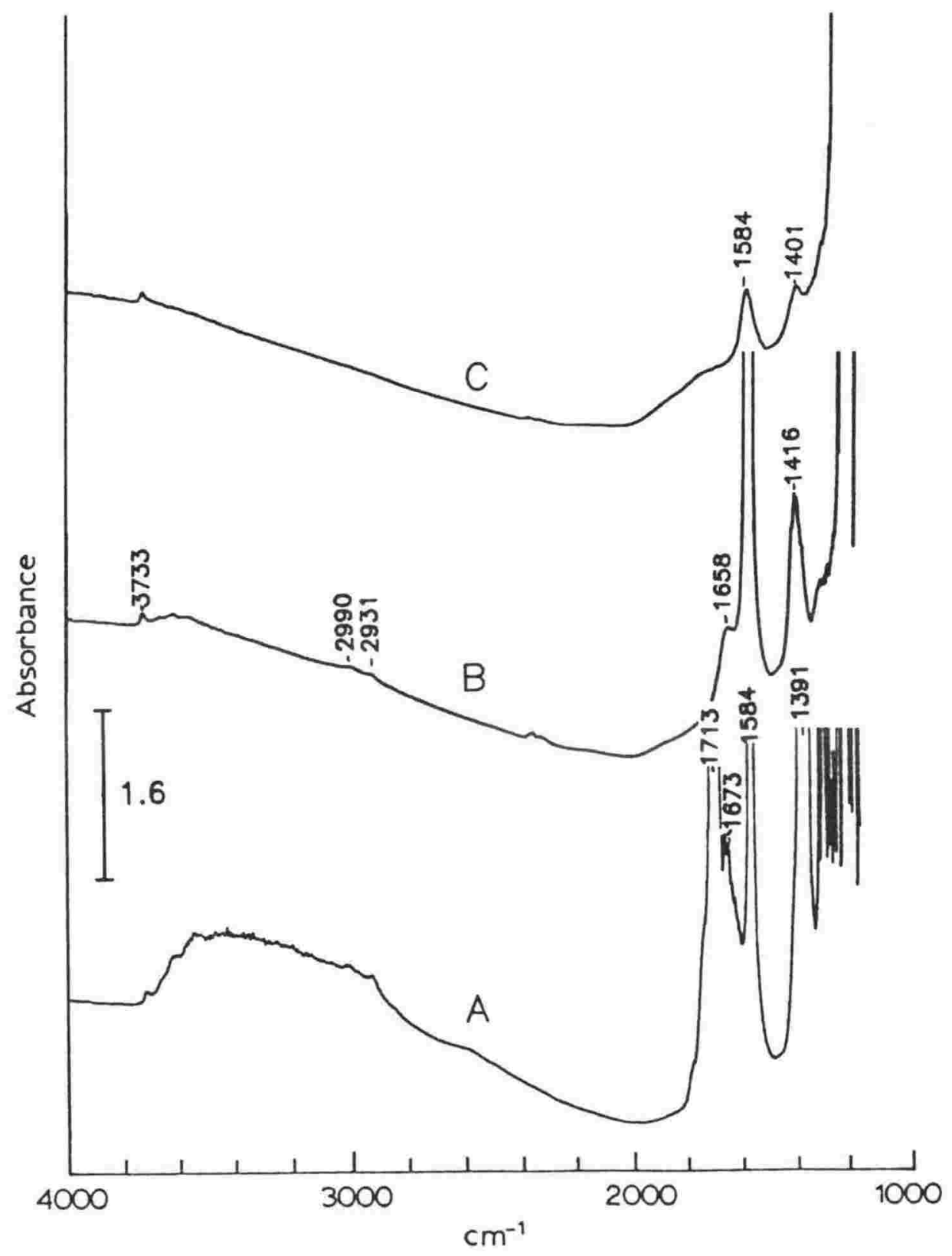

Figure 10.13. Thermal desorption of acetic acid form Na+Y at atmospheric pressure. FTIR spectra obtained at: A. $150^{\circ} \mathrm{C}$; B. $300^{\circ} \mathrm{C}$ and C. $450^{\circ} \mathrm{C}$. 

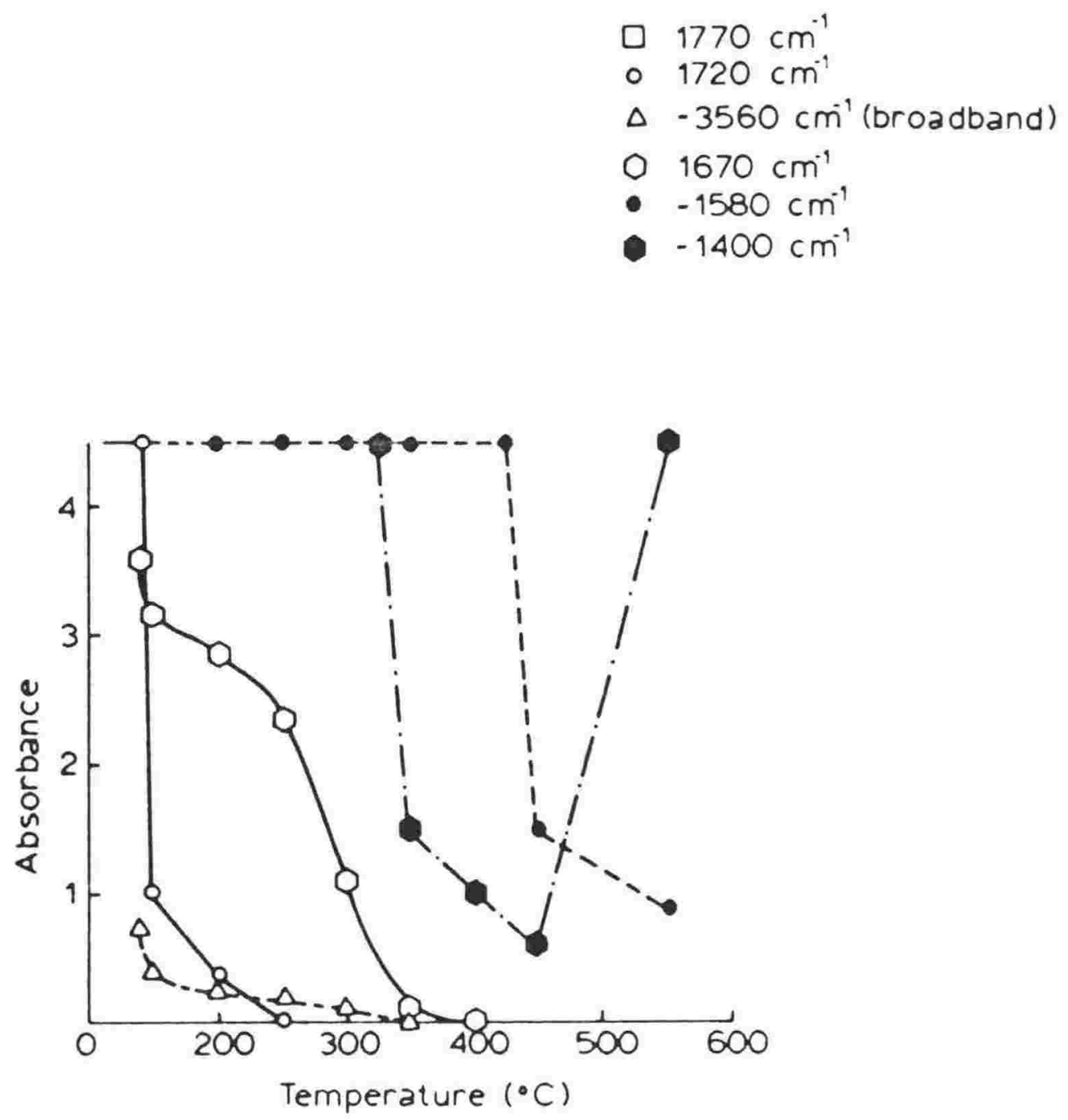

Figure 10.14. Thermal desorption of acetic acid from $N a+Y$ at atmospheric pressure. Absorbances of FTIR peaks versus temperature. 


\subsubsection{Td/FTIR of acetic acid on NatY under vacuum:}

The td/FTIR experiment was then repeated with no carrier gas, but the cell evacuated, to determine the effect of pressure. Acetic acid $(4 \mu \mathrm{l})$ was injected into the cell containing $\mathrm{Na}+\mathrm{Y}$ held at $150^{\circ} \mathrm{C}$, followed by evacuation for 5 minutes. The cell was then sealed in an attempt to observe any desorbed volatiles, and the temperature increased at $10^{\circ} \mathrm{C} \mathrm{min} \mathrm{m}^{-1}$. spectra obtained at $150^{\circ} \mathrm{C}, 250^{\circ} \mathrm{C}, 300^{\circ} \mathrm{C}$ and $400^{\circ} \mathrm{C}$ are shown in figure $10.15 \mathrm{~A}, \mathrm{~B}, \mathrm{C}$ and $\mathrm{D}$ respectively. A plot of the major ion signals versus sample temperature is shown in figure 10.16. There are no major differences from the experiment carried out at atmospheric pressure.

Two peaks at 2163 and $2134 \mathrm{~cm}^{-1}$, the correct wavenumbers for gas phase ketene, were observed at $300^{\circ} \mathrm{C}$ (at $\mathrm{A}$ in figure 10.16). Peaks at 2360 and $3015 \mathrm{~cm}^{-1}$ assigned to gas phase $\mathrm{CO}_{2}$ and methane increased from $350^{\circ} \mathrm{C}$, as the ketene decreased (at B in figure 10.16). Gas phase ketene was observed as the broad band at $\sim 3560 \mathrm{~cm}^{-1}$ and the peak at $1670 \mathrm{~cm}^{-1}$ were decreasing in intensity. Ketene evolution may therefore be associated with one or both of these peaks. The intense peak at $\sim 1400 \mathrm{~cm}^{-1}$ decreases in intensity as increasing amounts of gas phase methane and $\mathrm{CO}_{2}$ are observed, probably as a result of acetate decomposition. 


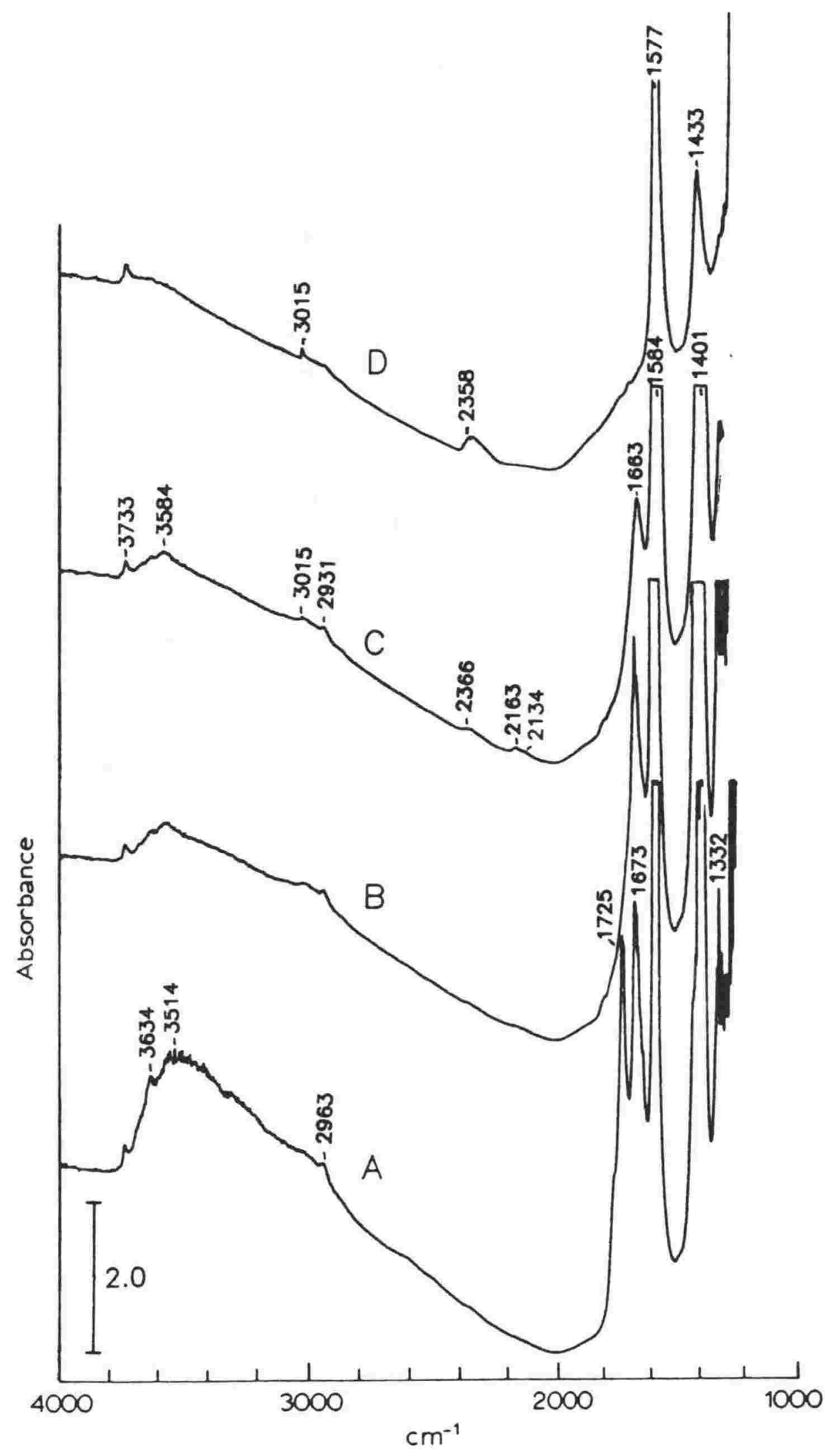

Figure 10.15. Thermal desorption of acetic acid from $\mathrm{Na}+\mathrm{Y}$ into the evacuated, sealed FTIR cell. FTIR spectra recorded at: A. $150^{\circ} \mathrm{C}$; B. $250^{\circ} \mathrm{C} ; \mathrm{C} .300^{\circ} \mathrm{C}$ and D. $400^{\circ} \mathrm{C}$. 

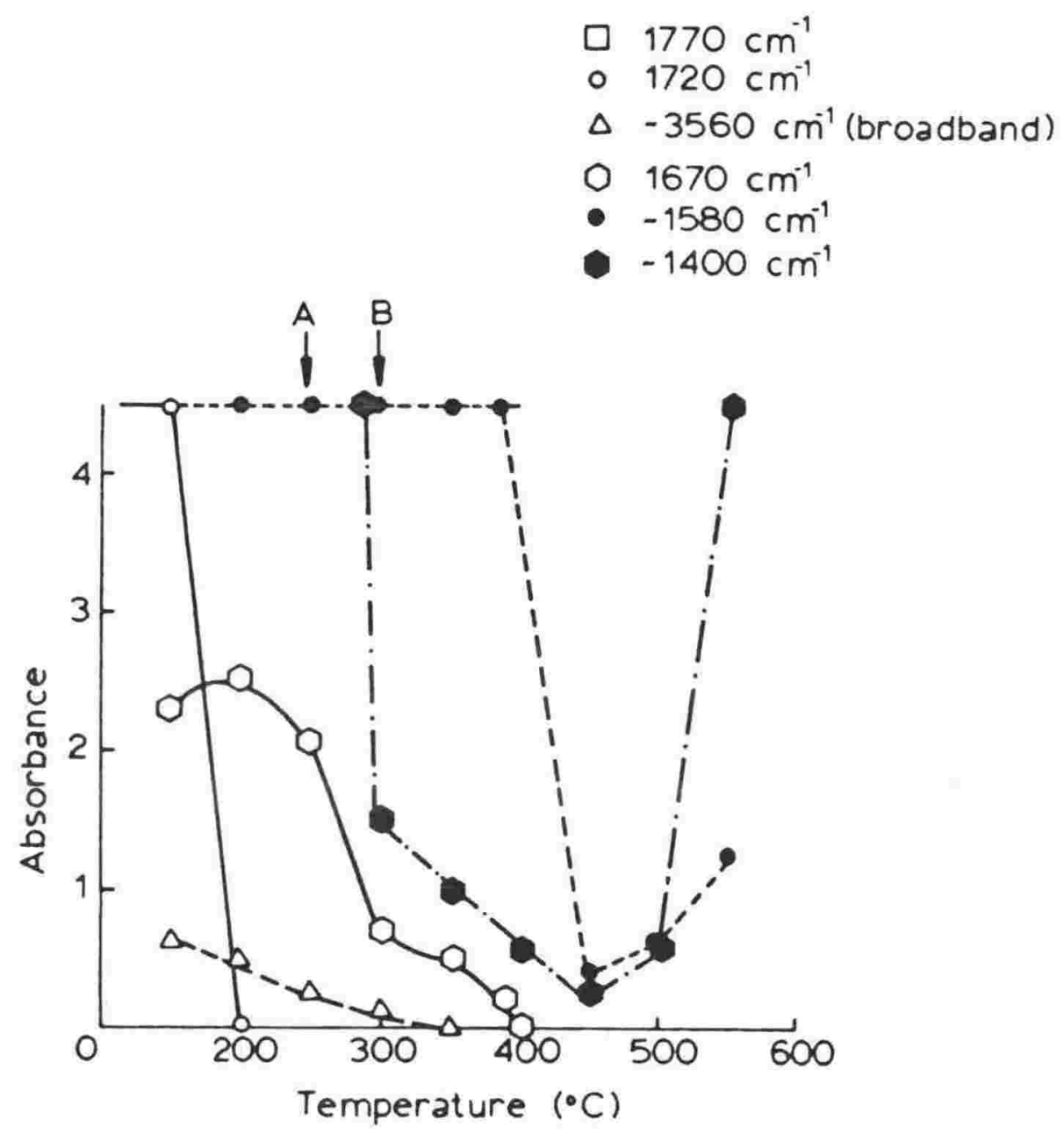

Figure 10.16. Thermal desorption of acetic acid from $\mathrm{Na}+\mathrm{Y}$ into the evacuated, sealed FTIR cell. Absorbances of FTIR peaks versus NaY temperature. 
10.3.2.8 Td/FTIR of acetic acid sorbed on Na+Y diluted with silicalite-1:

To reduce the intensities of the off-scale peaks, $\mathrm{Na}+\mathrm{Y}$ was diluted with silicalite-1, which has a low Al content $(0.3$ mole $\%$ ) and should have few strong sorption sites for acetic acid. (A ratio of about $1: 20 \mathrm{Na}+\mathrm{Y}$ to silicalite was taken). The wafer was heated to $350^{\circ} \mathrm{C}$, then cooled to $150^{\circ} \mathrm{C}$ under vacuum. It showed a trace of sorbed acetic before the experiment was started (figure $10.17 \mathrm{~A}$ ). Acetic acid $(2 \mu 1)$ was injected into the cell. and the spectrum, shown in figure 10.17B, obtained. Further acetic acid was injected to give 4 $\mu 1$ total and the spectrum shown in figure 10.17C. The silanol peak of the silicate had not reduced significantly in size, showing that acetic acid was not sorbed at these sites. Gas phase acetic acid, monomer and dimer (1800 and $1770 \mathrm{~cm}^{-1}$ ) was observed along with sorbed acetic acid (a broad hydroxyl band and peaks at $1722,1670 \mathrm{~cm}^{-1}$ ). The peaks due to acetate ( 1580 and $1400 \mathrm{~cm}^{-1}$ ) were greatly reduced compared to those of $\mathrm{Na}+\mathrm{Y}$ alone. The peak at $1400 \mathrm{~cm}^{-1}$ was swamped by a strong silica peak at higher temperatures.

The cell was evacuated, sealed and heated at $10^{\circ} \mathrm{C} \mathrm{min}^{-1}$. spectra obtained at $200^{\circ} \mathrm{C}, 300^{\circ} \mathrm{C}, 350^{\circ} \mathrm{C}$ and $410^{\circ} \mathrm{C}$ are shown in figures $10.18 \mathrm{D}, \mathrm{E}, \mathrm{F}, \mathrm{G}$ and $\mathrm{H}$ respectively. The changes in the major absorbance peaks with temperature are shown in figure 10.19 .

A major difference between the $\mathrm{Na}+\mathrm{Y}$ and the $\mathrm{Na}+\mathrm{Y}$ in $\mathrm{SL}-\mathrm{I}$ is that for $\mathrm{Na}+\mathrm{Y}$ no peak at $1770 \mathrm{~cm}^{-1}$ is present at $150^{\circ} \mathrm{C}$. On $\mathrm{Na}+\mathrm{Y} / \mathrm{SL}-1$ this peak remained at $250^{\circ} \mathrm{C}$ and is therefore not due to the gas phase acetic acid dimer species, which has a $\mathrm{C}=\mathrm{O}$ stretch at the same wavenumber. It is probably due to a sorbed acetic acid species on the silicalite, bonded to a degree similar to the gas phase dimer, since the $v_{c=0}$ shift from free acetic acid is the same. This species was also 


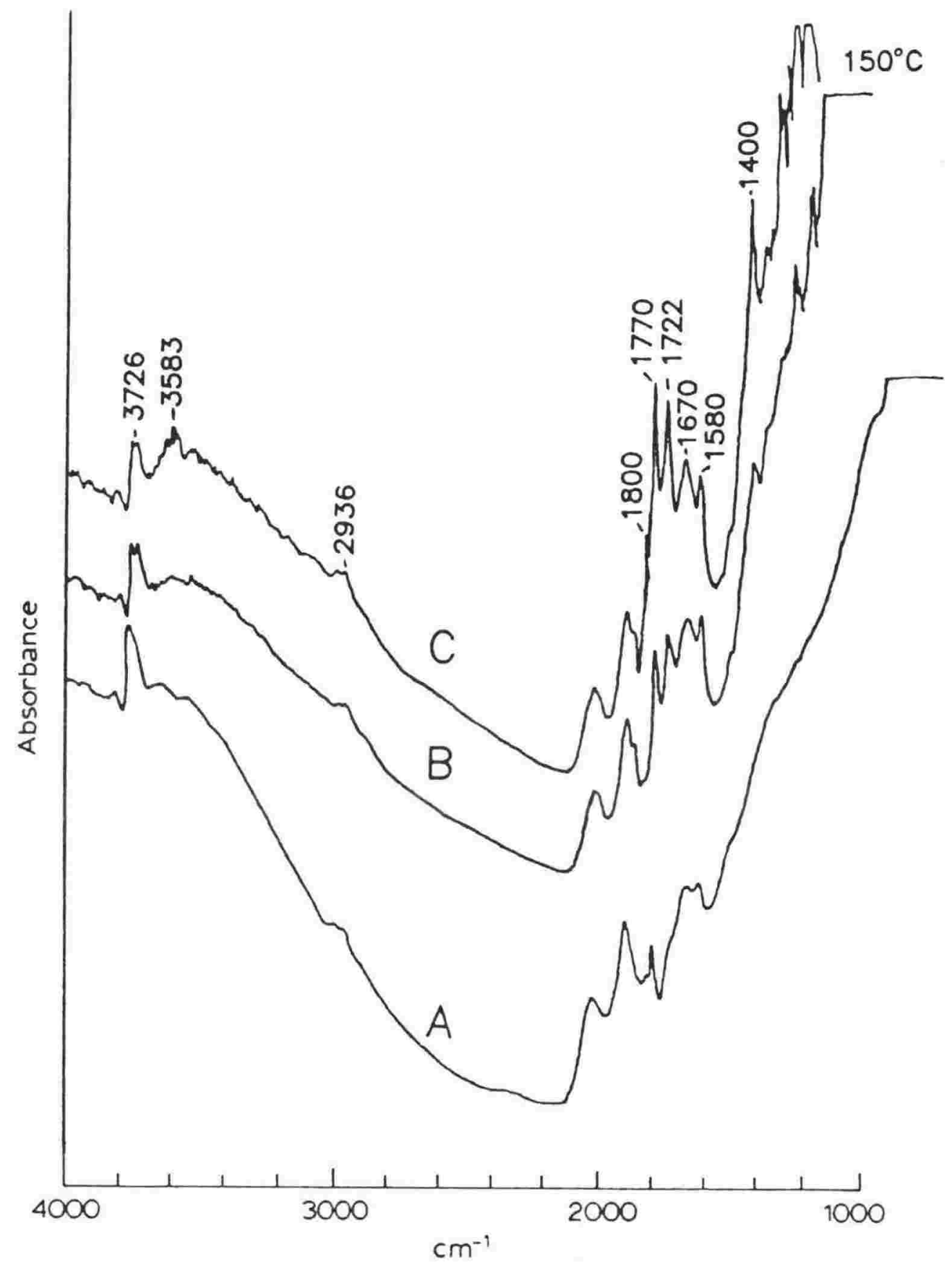

Figure 10.17. Addition of acetic acid to $\mathrm{Na}+\mathrm{Y}$ in silicalite1 at $150^{\circ} \mathrm{C}$. A. trace of acetic acid sorbed; B. $2 \mu 1$ acetic acid sorbed; C. $4 \mu \mathrm{l}$ acetic acid sorbed. 


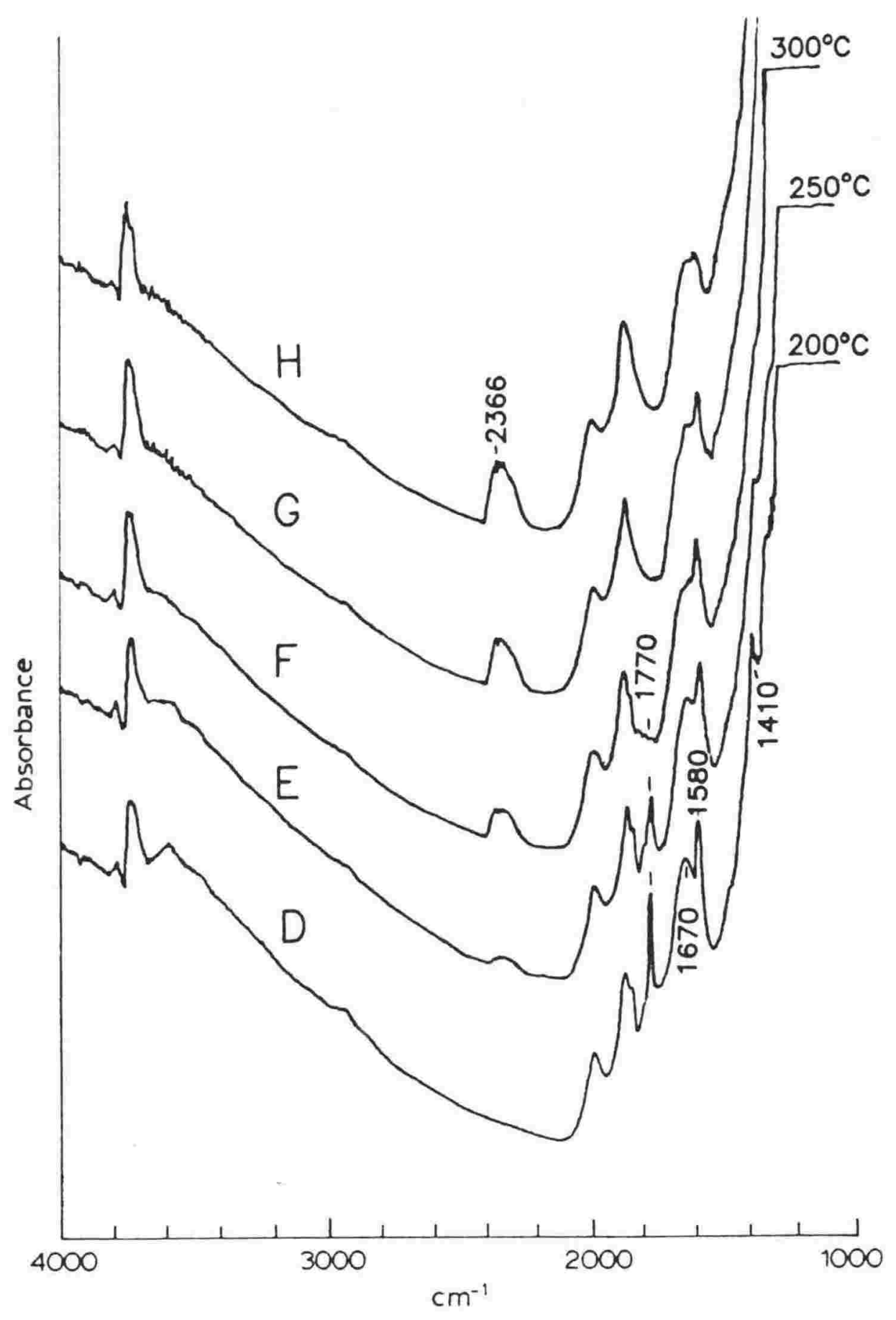

Figure 10.18. Thermal desorption of acetic acid from $\mathrm{Na}+\mathrm{Y}$ in silicalite-1 into the evacuated, sealed FTIR cell. FTIR spectra recorded at increasing temperature: D. $200^{\circ} \mathrm{C}$; E. $250^{\circ} \mathrm{C} ; \mathrm{F}$. $300^{\circ} \mathrm{C} ; \mathrm{G} .350^{\circ} \mathrm{C}$ and $\mathrm{H} .410^{\circ} \mathrm{C}$. 
bonded more strongly than the species with the peak at 1722 $\mathrm{cm}^{-1}$ as this desorbed by $200^{\circ} \mathrm{C}$.

The peaks at $\sim 1665$ and $1770 \mathrm{~cm}^{-1}$, from sorbed acetic acid desorbed in the temperature range that ketene was observed by td/ms. Gas phase ketene was not observed by FTIR as its position was obscured by silicalite-1 overtone bands.

Thermal decomposition of the acetate species is not associated with ketene formation (as shown in 10.4 and 11.3.1). Therefore ketene is probably formed from a sorbed acetic acid species with a IR peak at $\sim 1665 \mathrm{~cm}^{-1}$ in the carboxyl stretching region. The sorbed species observed in silicalite with a peak at $1770 \mathrm{~cm}^{-1}$ may also be associated with reaction to ketene (see 10.5.2). Further work is required to determine more fully the nature of these sorbed species.

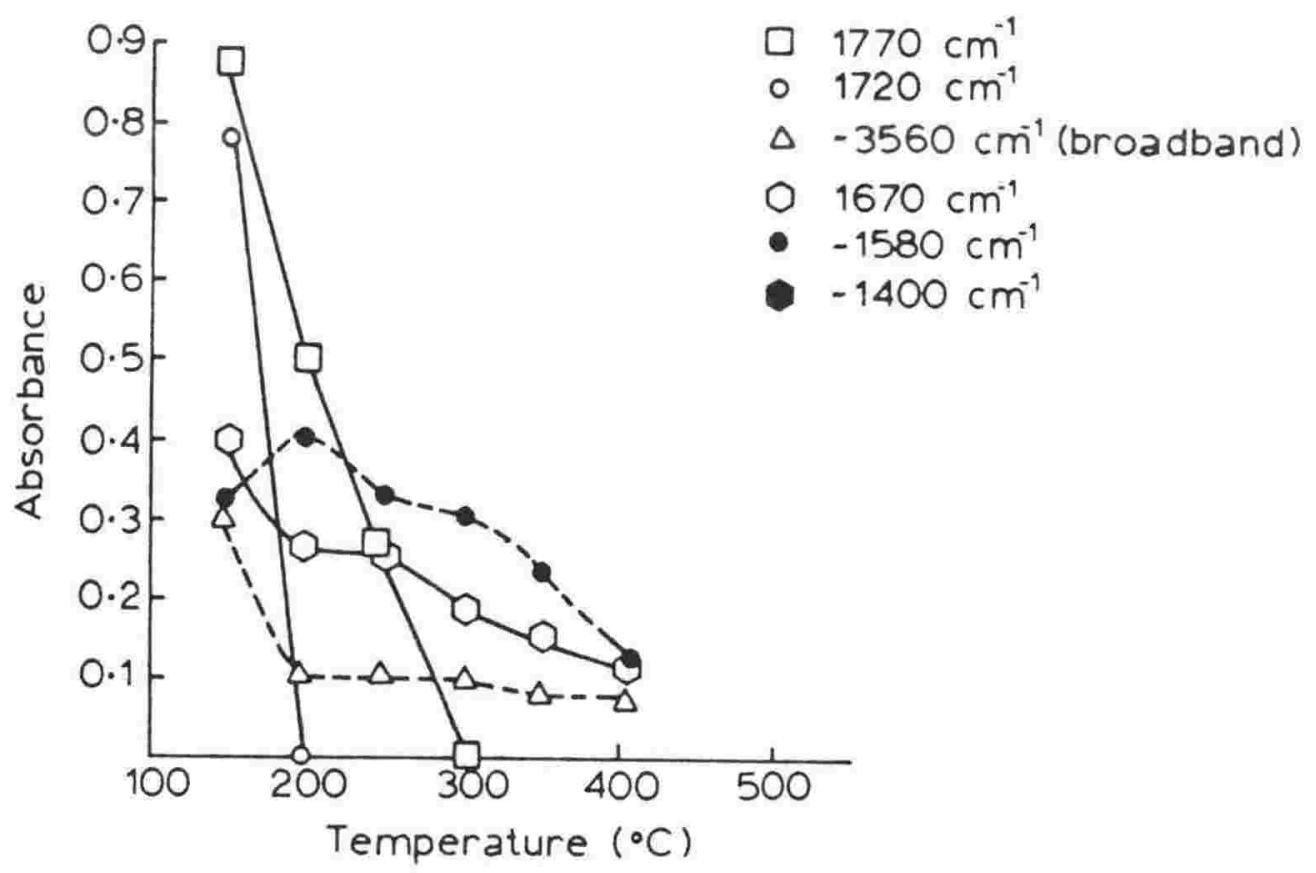

Figure 10.19. Thermal desorption of acetic acid from $\mathrm{Na}+\mathrm{Y}$ in silicalite-1, evacuated. Absorbances of FTIR peaks versus sample temperature. 


\section{Mini-reactor/FTIR of acetic acid over NatY:}

The FTIR in situ cell was set up as a mini catalytic reactor

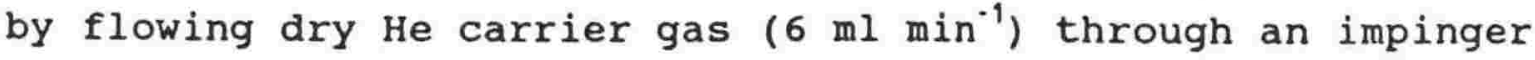
containing acetic acid, then past the sample wafer in the in situ cell. This gave a constant flow rate of acetic acid. The cell was held at constant temperature and the changes in sorbed and gas phase species were observed with time.

\section{$10.3 .2 .9 \mathrm{Na}+\mathrm{Y}$ at $300^{\circ} \mathrm{C}$ :}

The results for $\mathrm{Na}+\mathrm{Y}$ (sample B) held at $300^{\circ} \mathrm{C}$ are shown in figure 10.20. Initially only acetate species (1584 and 1401 $\mathrm{cm}^{-1}$ ) formed as shown in figure $10.20 \mathrm{~A}$, recorded 2 minutes after the addition of acetic acid to the carrier gas. After 8 minutes, (figure $10.20 \mathrm{~B})$, gas phase $(3579,1802$ and 1777 $\mathrm{cm}^{-1}$ ), physisorbed $\left(1733 \mathrm{~cm}^{-1}\right.$ ) and a more strongly sorbed (1663 $\mathrm{cm}^{-1}$ ) species were also observed. Gas phase $\mathrm{CO}_{2}\left(2361 \mathrm{~cm}^{-1}\right)$, water $\left(\sim 3800 \mathrm{~cm}^{-1}\right)$ and ketene (2163 and $\left.2124 \mathrm{~cm}^{-1}\right)$ were observed. Their band shapes showed rotational fine structure, which is only observed for gas phase species. After $18 \mathrm{~min}$ (figure $10.20 \mathrm{C}$ ) all peaks, except $\mathrm{CO}_{2}$, had increased in intensity. No significant unshifted acetone peaks were observed $\left(2971,1720 \mathrm{~cm}^{-1}\right.$ (see chapter 7.7.2)). This is discussed in 10.3.4.

After $22 \mathrm{~min}$ reaction time (between spectra $10.20 \mathrm{C}$ and D) a gas sample was taken and later analysed by mass spectrometry. Helium (the carrier gas), air, $\mathrm{CO}_{2}$ and acetone, but no ketene or acetic acid were observed. This does not agree with the composition of the gas phase species observed by FTIR, implying that the acetic acid and ketene originally present sorbed onto the walls of the container or reacted further. To avoid this and obtain meaningful results rapid on-line gas analysis is required. 


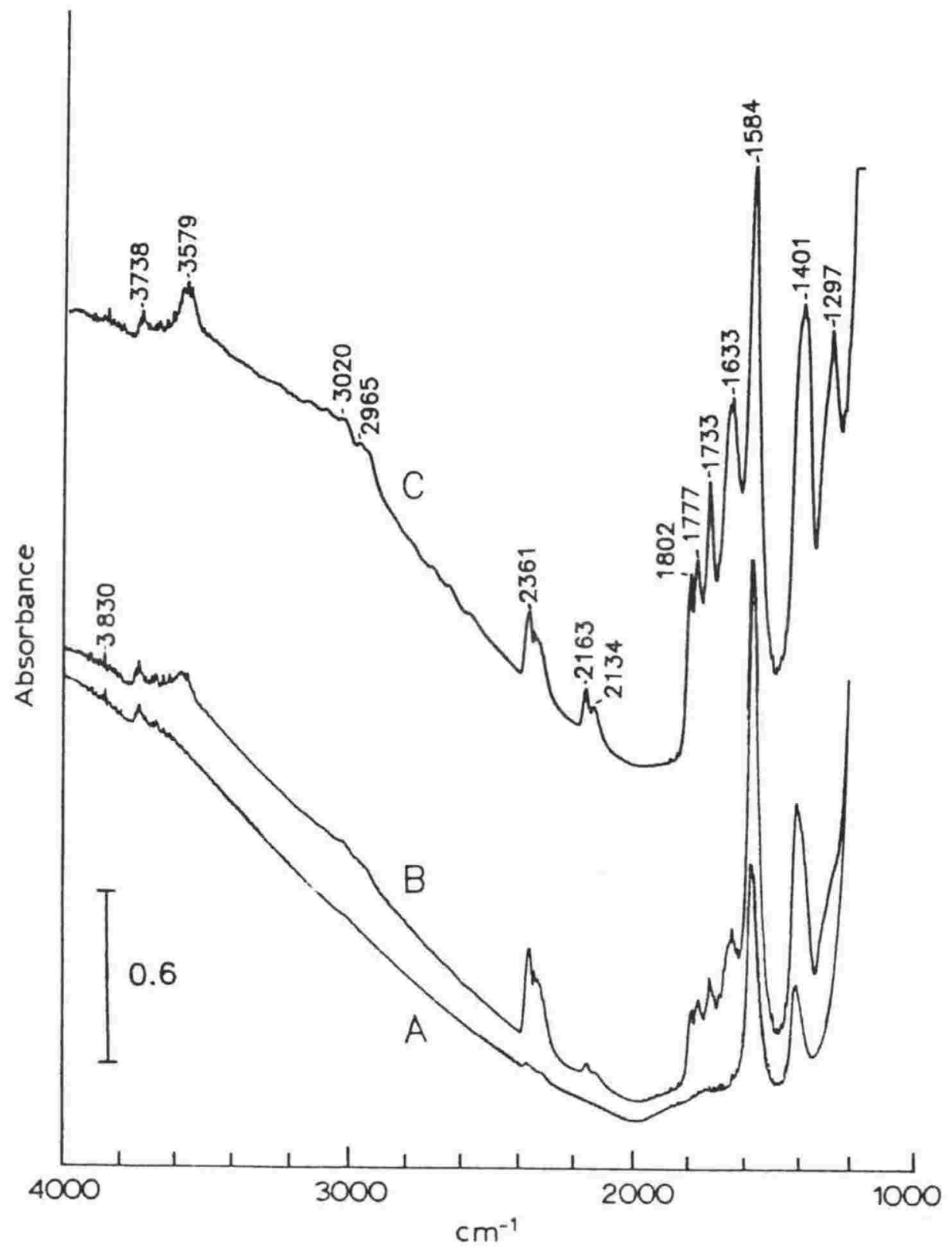

Figure 10.20. FTIR spectra obtained at different times for a constant flow of acetic acid throuygh $\mathrm{Na}+\mathrm{Y}$ held at $300^{\circ} \mathrm{C}$. A. after $2 \mathrm{~min}$; B. $8 \mathrm{~min} ;$ c. $18 \mathrm{~min}$. 


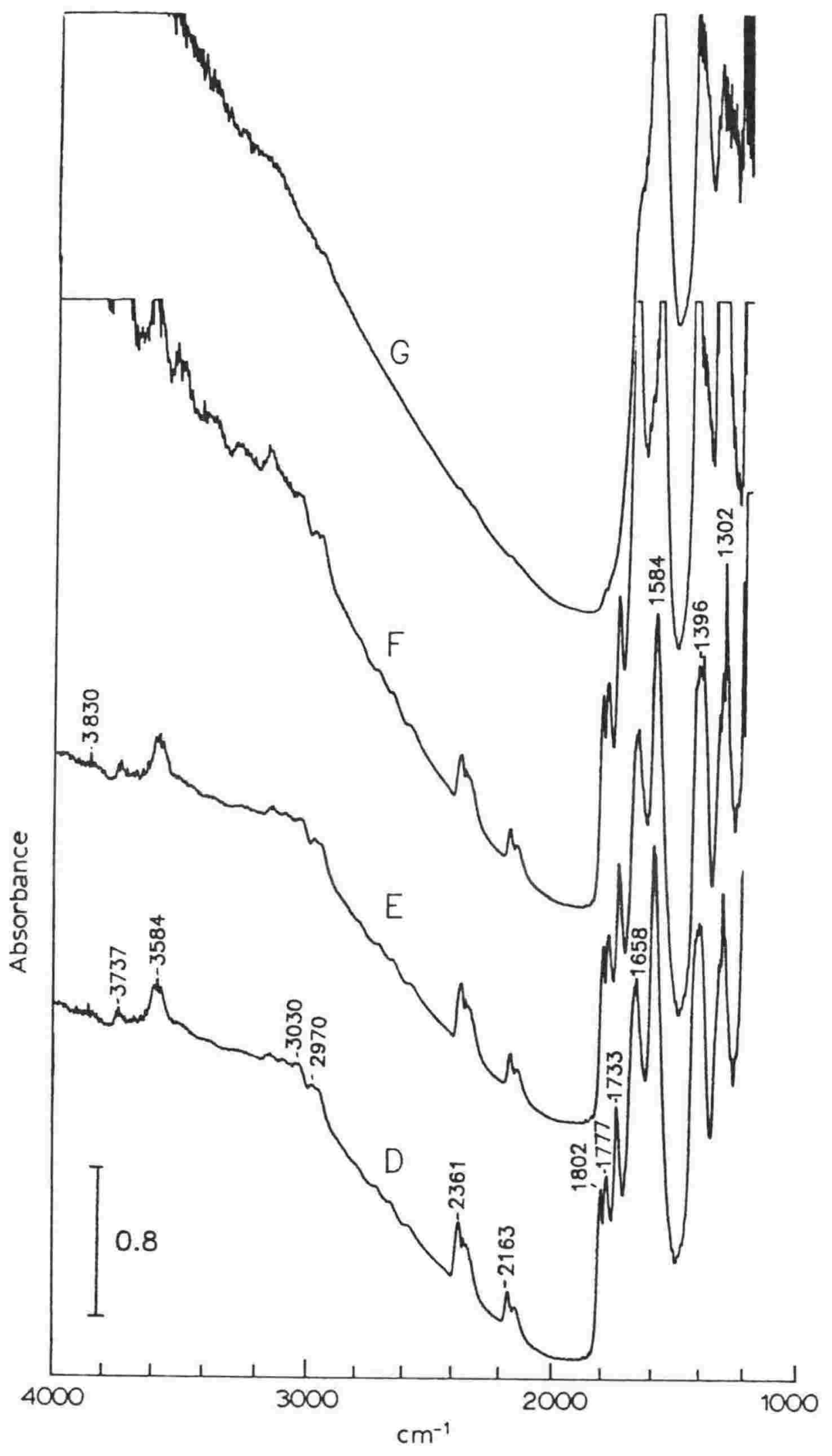

Figure 10.20 cont. D. after $46 \mathrm{~min}$. E. after $56 \mathrm{~min} ; \mathrm{F}$. after $166 \mathrm{~min}$ and $G$. after flushing the gas phase species away. 
Coke was also built up as the reaction proceeded. This was shown by an increase in the overall absorbance of the sample and increasingly noisy spectra over the $2.75 \mathrm{~h}$ experiment duration. Spectra were recorded after 46, 56 and $166 \mathrm{~min}$ and shown in figure $10.20 \mathrm{D}, \mathrm{E}$, and $\mathrm{F}$ respectively. The ketene and $\mathrm{CO}_{2}$ peaks reached an almost steady concentration, only decreasing slightly with time.

At the conclusion of the experiment the cell was flushed with helium $\left(60 \mathrm{ml} \mathrm{min}^{-1}\right)$ for $5 \mathrm{~min}$. The gas phase and weakly sorbed species were flushed away leaving only the two acetate peaks (figure $10.20 \mathrm{G}$ ). The catalyst had become dark grey. This was heated in air at $400^{\circ} \mathrm{C}$ for $\sim 1 \mathrm{~h}$ until almost white and used in the following experiment.

\section{$10 \cdot 3 \cdot 2 \cdot 10 \mathrm{Na}+\mathrm{Y}$ at $350^{\circ} \mathrm{C}$ :}

The results for acetic acid over $\mathrm{Na}+\mathrm{Y}$ held at $350^{\circ} \mathrm{C}$ are shown in figure 10.21. Initially, the acetate peaks increased in intensity and gas phase $\mathrm{CO}_{2}$ was observed (figure 10.21 A). Spectra were recorded at reaction times of 15,35 and $55 \mathrm{~min}$ and are shown in figures $10.21 \mathrm{~B}, \mathrm{C}$ and $\mathrm{D}$. Only when gas phase (1802 and $1777 \mathrm{~cm}^{-1}$ ) and sorbed (shoulder at $1649 \mathrm{~cm}^{-1}$ and $1733 \mathrm{~cm}^{-1}$ ) acetic acid species appeared, was gas phase ketene observed. A distinct gas phase methane peak (3020 $\mathrm{cm}^{-1}$ ) and associated band structure was observed. The peaks due to gas phase and weakly sorbed acetic acid were smaller than at $300^{\circ} \mathrm{C}$, implying more rapid reaction. As the reaction proceeded coke built up on the sample resulting in increased background absorbance. After reaching steady state, the $\mathrm{CO}_{2}$ and ketene peaks decreased only slightly. 


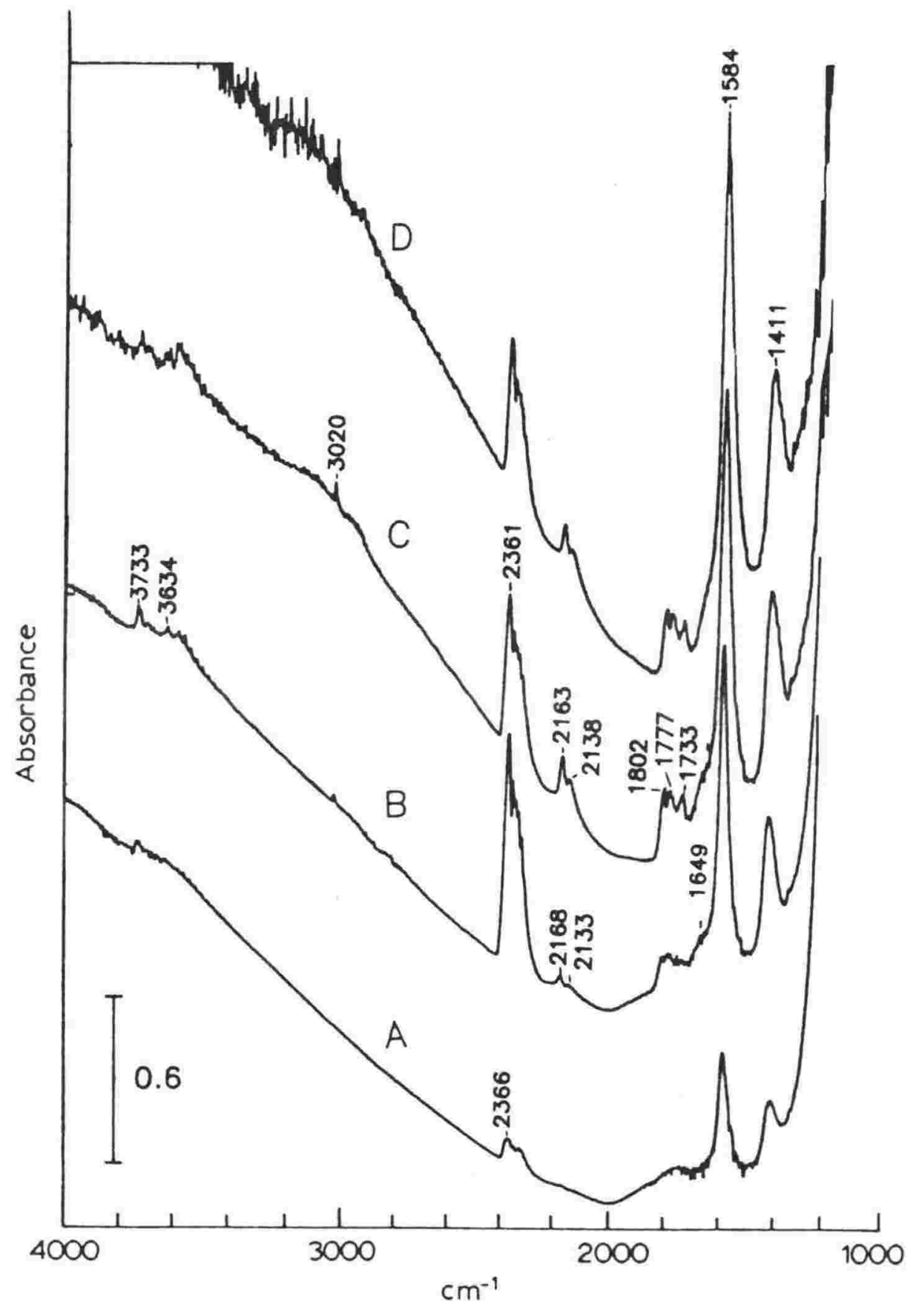

Figure 10.21. FTIR spectra obtained a different times for a constant flow of acetic acid through $\mathrm{Na}+\mathrm{Y}$ at $350^{\circ} \mathrm{C}$.

A. after $2 \mathrm{~min}$; B. $15 \mathrm{~min} ; \mathrm{C} .35 \mathrm{~min}$ and D. $55 \mathrm{~min}$. 
$10.3 \cdot 2.11 \mathrm{Na}+\mathrm{Y}$ at $400^{\circ} \mathrm{C}$ :

Spectra were recorded after 0, 2, 17, 37 and 57 minutes reaction time of acetic acid over $\mathrm{Na}+\mathrm{Y}$ at $400^{\circ} \mathrm{C}$ and are shown in figure $10.22 \mathrm{~A}, \mathrm{~B}, \mathrm{C}, \mathrm{D}$ and $\mathrm{E}$ respectively. The first trace of ketene is observed with the first traces of gas phase and sorbed acetic acid species. The 'steady state' reached shows a greater proportion of gas phase $\mathrm{CO}_{2}$ and methane to ketene than at lower temperatures. Only very small gas phase water peaks were observed. After $1 \mathrm{~h} 5 \mathrm{~min}$, the cell was flushed with pure He for $10 \mathrm{~min}$. Only the peaks due to sorbed acetate remained (figure $10.22 \mathrm{~F}$ ). Coke had accummulated on the sample, turning the wafer black. 


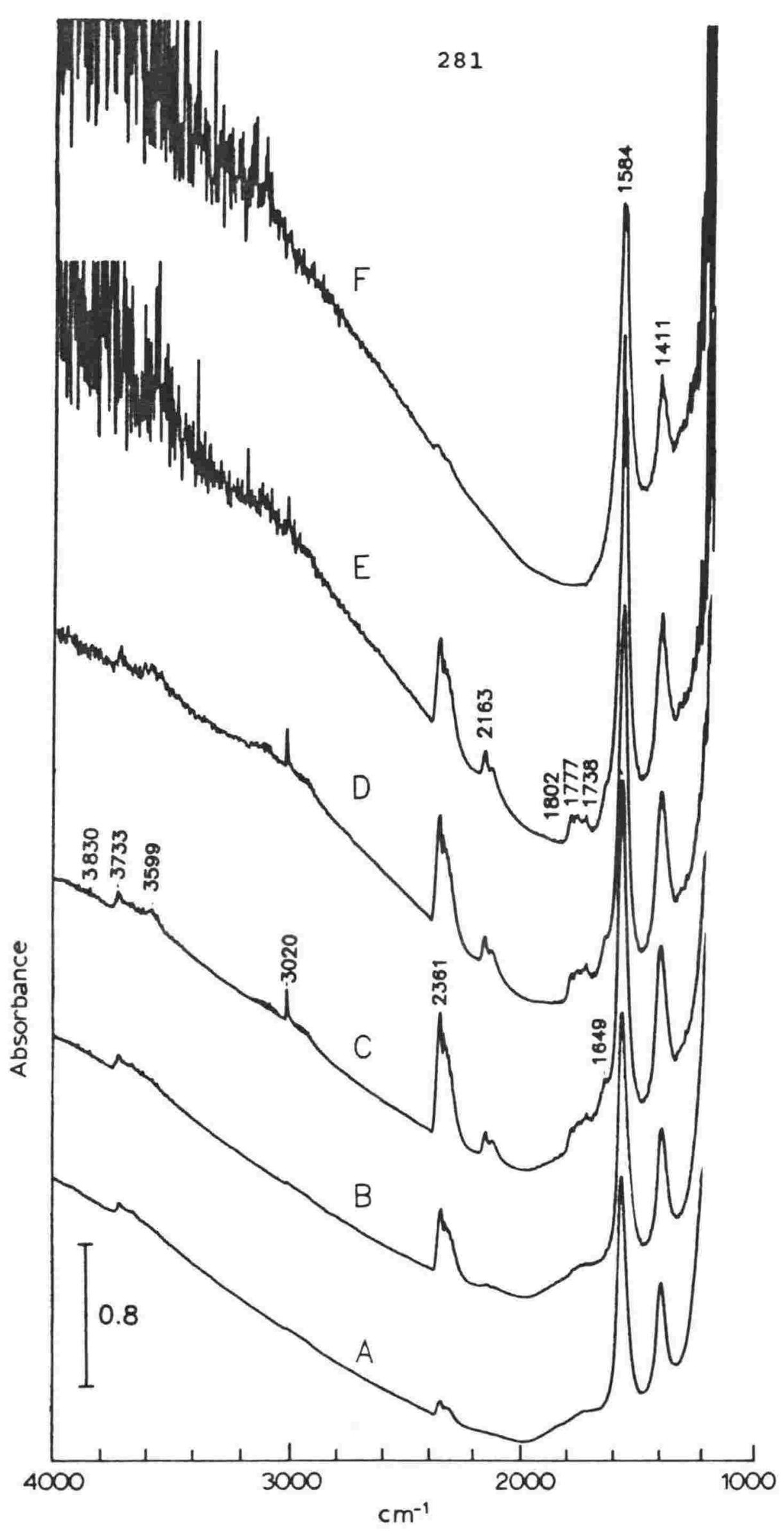

Figure 10.22. FTIR spectra obtained at different reaction times for a constant flow of acetic acid through $\mathrm{Na}+\mathrm{Y}$ held at $400^{\circ} \mathrm{C}$. A. after $0 \mathrm{~min}$; B. $2 \mathrm{~min} ; \mathrm{C} .17 \mathrm{~min} ; \mathrm{D} .37 \mathrm{~min} ; \mathrm{E}$. $57 \mathrm{~min}$; F. after flushing for $10 \mathrm{~min}$. 


\subsection{3 summary of FTIR results:}

1. The first acetic acid to contact the catalyst reacts to form a strongly bound acetate species. This does not desorb until heated to greater than $400^{\circ} \mathrm{C}$, when its decomposition results in $\mathrm{CO}_{2}$ and methane in the gas phase.

2. Ketene was only observed in the gas phase suggesting that it desorbs very rapidly upon formation.

3. The presence of ketene was linked to that of a sorbed acetic acid species, not the acetate species.

4. On Na+Y two different sorbed acetic acid species were observed with IR peaks in the $\mathrm{C}=0$ stretching region at 1724 and $1670 \mathrm{~cm}^{-1}$. The species with the peak at $1670 \mathrm{~cm}^{-1}$ was more strongly sorbed and remained sorbed at higher temperatures.

5. Acetic acid sorbed on $\mathrm{Na}+\mathrm{Y} / \mathrm{silicalite}$ showed an additional sorbed species, with a peak in the $\mathrm{C}=0$ stretching region at $1770 \mathrm{~cm}^{-1}$, the same frequency as the gas phase acetic acid dimer. It must therefore be bonded to the sorbate to a similar degree as the dimer bonding.

6. Gas phase water was observed by FTIR from the decomposition of acetic acid to ketene and water.

7. No significant gas phase or sorbed acetone was observed. 


\subsubsection{Discussion:}

Gas phase acetone was not observed in either the td/FTIR experiment with the cell sealed, or in the mini-reactor FTIR experiments. Gas phase acetone has a band with rotational fine structure centred at $2971 \mathrm{~cm}^{-1}$ in the $\mathrm{C}-\mathrm{H}$ stretching region and a peak at $1720 \mathrm{~cm}^{-1}$ in the $\mathrm{C}=0$ stretching region (see chapter 7.7 .2 figure $7.48 \mathrm{~B}$ ). When sorbed, the $\mathrm{C}=0$ stretch of acetone should shift to lower wavenumbers. However, no peaks were observed that could be readily assigned to sorbed acetone. An example is the spectrum recorded at $400^{\circ} \mathrm{C}$ in a td/FTIR experiment (figure 10.16 D). When the only sorbed species was the acetate, which was (from $t d / m s$ results) decomposing to acetone, $\mathrm{CO}_{2}$ and methane, no acetone was observed, only gas phase methane and $\mathrm{CO}_{2}$. While acetone should have been present, it was not detected by FTIR.

Some gas phase water was observed in the mini-reactor FTIR experiments, with a band of rotational fine structure centred at $1830 \mathrm{~cm}^{-1}$. Water is expected as a product of decomposition of acetic acid to ketene and water. This confirms that water is evolved, implying that sorption/condensation of water in the transfer lines may have prevented its detection in some mass spectrometry experiments.

In a separate experiment a very strong (off-scale) IR absorbance at $1612 \mathrm{~cm}^{-1}$ was observed for acetic acid sorbed on $\mathrm{Li}+\mathrm{ZSM}-5$ at $200^{\circ} \mathrm{C}$, after flushing to remove gas phase and physisorbed acetic acid. This was not observed on $\mathrm{Li}+\mathrm{Y}$ or $\mathrm{Na}+\mathrm{Y}$. The $1612 \mathrm{~cm}^{-1}$ peak may be due to a strongly sorbed acetic acid species, similar to that at $-1658 \mathrm{~cm}^{-1}$ (figure 10.10), observed for the $\mathrm{Li}+\mathrm{Y}$ case. Further $t d / \mathrm{ms}$ and td/FTIR work is required to clarify this. 
10.4. Mini-reactor/ms experiment to determine if $\mathrm{Na}^{*}$ ions are catalysts for ketene production:

A td/ms experiment (11.3.1) had shown that thermal decomposition of sodium acetate did not produce ketene. A mini-reactor/ms experiment was carried out to determine whether ketene could be formed under dynamic conditions over $\mathrm{Na}^{+}$ions with a continuous flow of acetic acid. This would further clarify the role of the alkali cation in exchanged zeolites in ketene production.

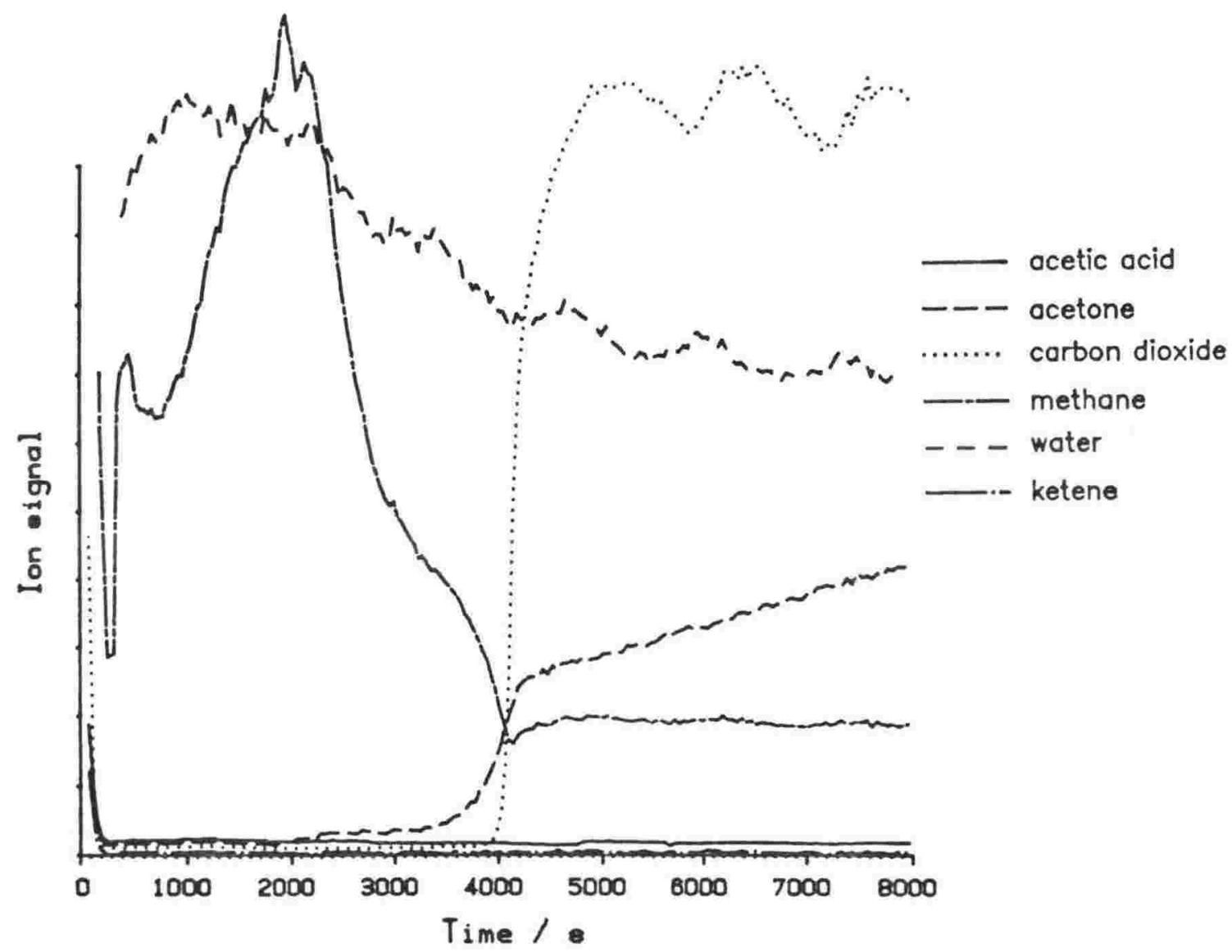

Figure 10.23. Reaction products of acetic acid over $\mathrm{NaOH}$ on kao wool at $400^{\circ} \mathrm{C}$ versus reaction time.

Kao wool was placed in $\mathrm{NaOH}$ solution and held at $90^{\circ} \mathrm{C}$ until dry. Some of the kao wool partially dissolved and the resultant crusty mixture was ground and placed in the reactive filter supported by fresh kao wool. The reactor was heated to $400^{\circ} \mathrm{C}$ and acetic acid saturated Ar ( $7 \mathrm{ml} \mathrm{min}^{-1}$ ) flowed through the sample. A large amount of water was evolved and condensed on cooler parts of the reactor. Only water and methane were observed by mass spectrometry for the 
first hour, then acetone and $\mathrm{CO}_{2}$ were observed (figure 10.23). No acetic acid or ketene was observed.

Probable reactions that were occuring in the first hour were reaction of acetic acid with $\mathrm{NaOH}$ to produce methane and sodium carbonate:

$\mathrm{CH}_{3}-\mathrm{C}_{\mathrm{OH}}^{\prime \prime}+2 \mathrm{NaOH} \rightarrow \mathrm{CH}_{4}+\mathrm{Na}_{2} \mathrm{CO}_{3}$

and acetic acid reacting with $\mathrm{NaOH}$ to produce sodium acetate and water:

$\mathrm{CH}_{3}-\mathrm{C}_{\mathrm{OH}}^{\prime \prime}+\mathrm{NaOH} \rightarrow \mathrm{CH}_{3}-\underset{\mathrm{O}}{\stackrel{\mathrm{C}}{\mathrm{O}}-\mathrm{Na}^{+}}+\mathrm{H}_{2} \mathrm{O}$

After about one hour, perhaps due to consumption of the reactive sodium base, the products observed change markedly. $\mathrm{CO}_{2}$ becomes the dominant product, with some acetone. Decomposition of sodium acetate to acetone and $\mathrm{CO}_{2}$ occurred:

$2\left(\mathrm{CH}_{3}-\mathrm{C}_{20}^{\prime}-\mathrm{Na}^{+}\right) \rightarrow \mathrm{CH}_{3}-\underset{\mathrm{O}}{\mathrm{C}}-\mathrm{CH}_{3}+\mathrm{CO}_{2}+\mathrm{Na}_{2} \mathrm{O}$

Further $\mathrm{CO}_{2}$ may have been produced by reaction of sodium carbonate with acetic acid:

$2\left(\mathrm{CH}_{3}-\mathrm{C}_{\mathrm{OH}}^{\prime \prime}\right)+\mathrm{Na}_{2} \mathrm{CO}_{3} \rightarrow 2\left(\mathrm{CH}_{3}-\mathrm{C}_{\mathrm{O}}^{\prime \prime}-\mathrm{Na}^{+}\right)+\mathrm{CO}_{2}+\mathrm{H}_{2} \mathrm{O}$

Carbon formed on the silica walls of the reactor with a mirror-like finish and the kao wool became pitch black, implying thermal decomposition of the sodium acetate to 'coke' and $\mathrm{CO}_{2}$ ('coke-a-cola').

No ketene was observed, showing that reaction of acetic acid with $\mathrm{Na}^{+}$ions does not produce ketene. 
10.5. Further investigation into the mechanism of ketene formation using the mini-reactor/ms:

10.5.1 Effect of partial pressures of reactants and products on ketene formation:

To further investigate the mechanism of ketene formation experiments to determine the effect of partial pressures of reactants and products were required. Initial investigations were carried out at a catalyst temperature of $400^{\circ} \mathrm{C}$, varying the amount of gas diluting the acetic acid/Ar gas stream in through the mini-reactor containing $\mathrm{Na}+\mathrm{Y}$. These showed that at lower acetic acid partial pressures, the proportion of ketene compared to acetone and $\mathrm{CO}_{2}$ increased. The reaction to produce ketene may therefore be first order with respect to acetic acid, while the reaction to produce acetone and $\mathrm{CO}_{2}$ may require the reaction of two molecules of acetic acid.

An experiment was also carried out, adding $\mathrm{CO}_{2}$ into the reactant gas stream. The results indicated that the additional $\mathrm{CO}_{2}$ suppressed acetone formation more than ketene. This implied that the reaction to produce ketene may not be associated with the reaction that produces $\mathrm{CO}_{2}$ and acetone.

However, better control over gas flows (using mass flow controllers rather than flowmeters and needle valves) would required to obtain quantitative results and confirm the conclusions.

\subsubsection{Is a catalyst required for ketene formation?:}

10.5.2.1 Catalytic effects of the reactor itself are often significant in catalytic reactions and an experiment was carried out to determine the importance of this. The mini-reactor was held at a constant temperature $\left(400^{\circ} \mathrm{C}\right)$ with a constant flow of acetic acid. The products were observed with $\mathrm{Na}+\mathrm{Y}$ catalyst in the mini-reactor and without. The amount of ketene reduced by $2 / 3$, but was not reduced to zero upon removal of catalyst. Catalysis could have occured on 
the walls of the reactor, with traces of catalyst or cations perhaps being important.

\subsubsection{Products observed with an empty mini-reactor:}

To determine the products produced with no catalyst, the mini-reactor experiments (of 10.2) were reproduced with an empty reactive filter. A constant flow of acetic acid (acetic acid $/$ Ar flow $=6 \mathrm{ml} \mathrm{min}{ }^{-1}$, Ar diluent flow $=12 \mathrm{ml}$ $\mathrm{min}^{-1}$ ) passed through the mini reactor which was heated at $2^{\circ} \mathrm{C}$ $\mathrm{min}^{-1}$ from $350^{\circ} \mathrm{C}$. The results (figure 10.24) show ketene as the major product. A smaller proportion of ketene is produced at lower temperature compared to Na+Y (figure 10.2). For example at $400^{\circ} \mathrm{C}$ with no catalyst the ratio of ketene to acetic acid and other products is 0.11 , and for $\mathrm{Na}+\mathrm{Y}$ the ratio is 0.23 . However, with increasing temperature, competing products (acetone, $\mathrm{CO}_{2}$ and methane) increase for $\mathrm{Na}+\mathrm{Y}$ reducing the amount of ketene, whereas with no catalyst the amount of ketene increases up to $500^{\circ} \mathrm{C}$ with no major competing products. No acetone was observed. After $560^{\circ} \mathrm{C}$, $\mathrm{CO}_{2}$ and methane increased with a decline in the amount of ketene.

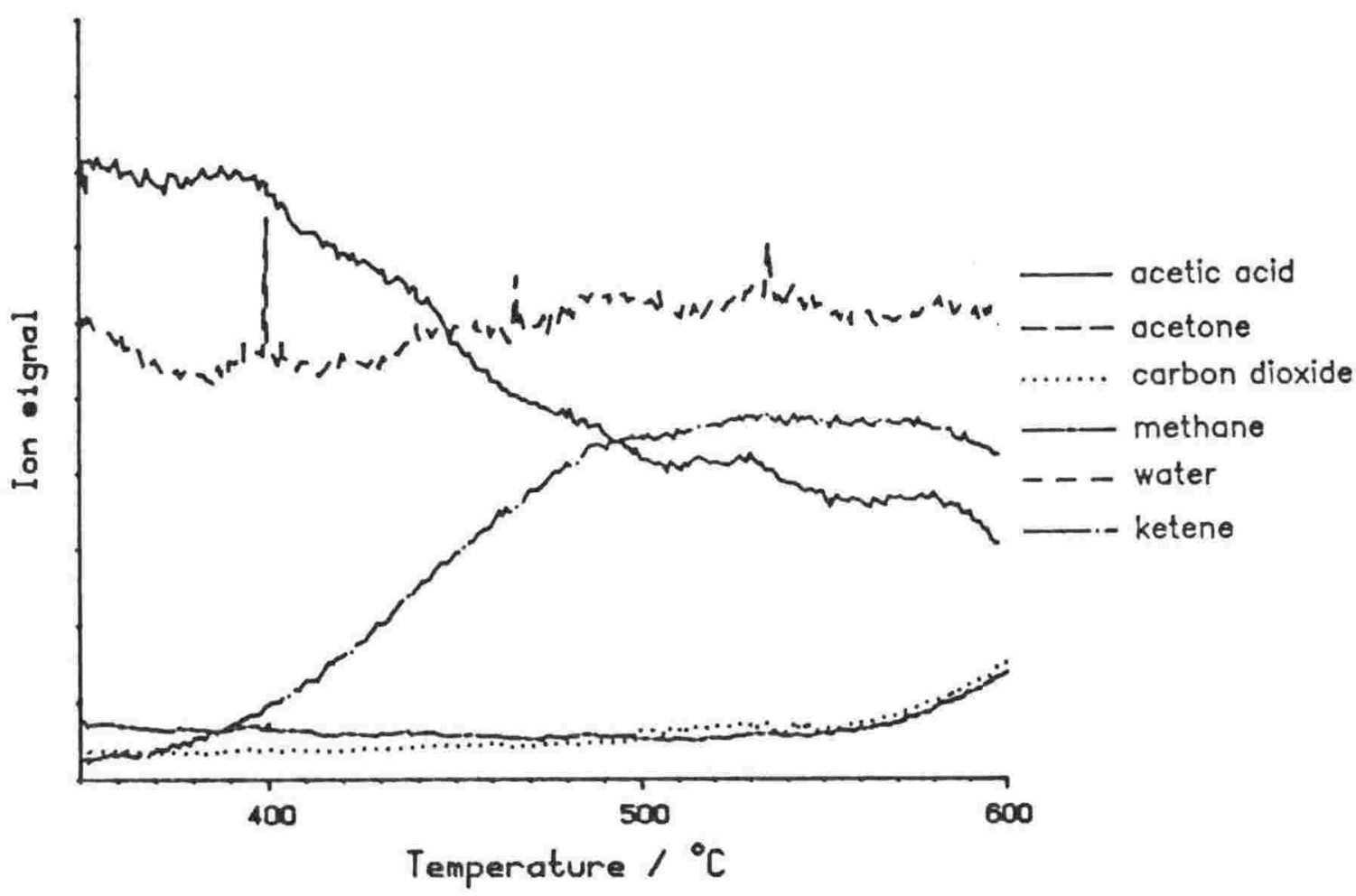

Figure 10.24. Reaction products of a constant flow of acetic acid through the "empty" mini-reactor versus temperature. 
To determine whether the reaction observed in the empty minireactor was due to gas phase thermal decomposition of acetic acid or was enhanced by surfaces, a further set of mini-reactor experiments was carried out:

10.5.2.3 With kao wool in the reactive filter to determine the effect of the kao wool support. (acetic acid/Ar flow $=6$ $\mathrm{ml} \mathrm{min}{ }^{-1}$, Ar diluent flow $=12 \mathrm{ml} \mathrm{min}^{-1}$, heating rate $2^{\circ} \mathrm{C}$ $\left.\min ^{-1}\right)$.

10.5.2.4 With Si wool to determine the effect of a surface with a similar area as kao wool, but without the aluminium content of the kao wool. (acetic acid/Ar flow $=5.5 \mathrm{ml}$ $\mathrm{min}^{-1}$, Ar diluent flow $=12 \mathrm{ml} \mathrm{min}{ }^{-1}$, heating rate $5^{\circ} \mathrm{C} \mathrm{min}^{-1}$ ).

10.5.2.5 With Si wool and silicalite-1 (prep 737) supported by $\mathrm{Si}$ wool to determine the effect of a large surface area zeolite without the active sites caused by substitution of Al for $\mathrm{Si}$ in the structure. (acetic acid/Ar flow $=6 \mathrm{ml} \mathrm{min}{ }^{-1}$,

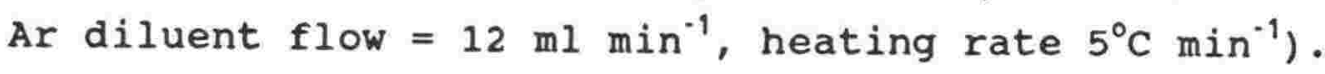

The results are shown in figures $10.25,10.26$ and 10.27 respectively. The ion signals have been scaled by their relative sensitivity factors, so are proportional to concentration. They have also been scaled to constant mass spectrometer system sensitivity $\left({ }^{36} \mathrm{Ar}=3000\right)$, so that a direct comparison of ion signals can be made between runs.

Figure 10.25 shows that the presence of kao wool increased the extent of conversion of acetic acid to ketene, compared to the empty reactor, resulting in an almost complete conversion at $550^{\circ} \mathrm{C}$ compared to about $50 \%$ conversion in its absence. No other products increased significantly.

With Si wool instead of kao wool (figure 10.26) the extent of conversion was significantly less. Comparison with the empty reactor shows a slight increase in the amount of ketene produced, although this may have been due to a higher acetic acid concentration during the run. 
Addition of silicalite-1 (figure 10.27) greatly increased the extent of reaction of acetic acid. The amount of ketene evolved was only slightly less than the amount formed using kao wool only. An additional reaction to acetone and $\mathrm{CO}_{2}$ occurred, which was not observed in the other cases. This was probably due to the $0.058 \mathrm{Na}^{+}$content of the silicalite (see Appendix I), causing reaction to acetone and $\mathrm{CO}_{2}$ via acetate formation.

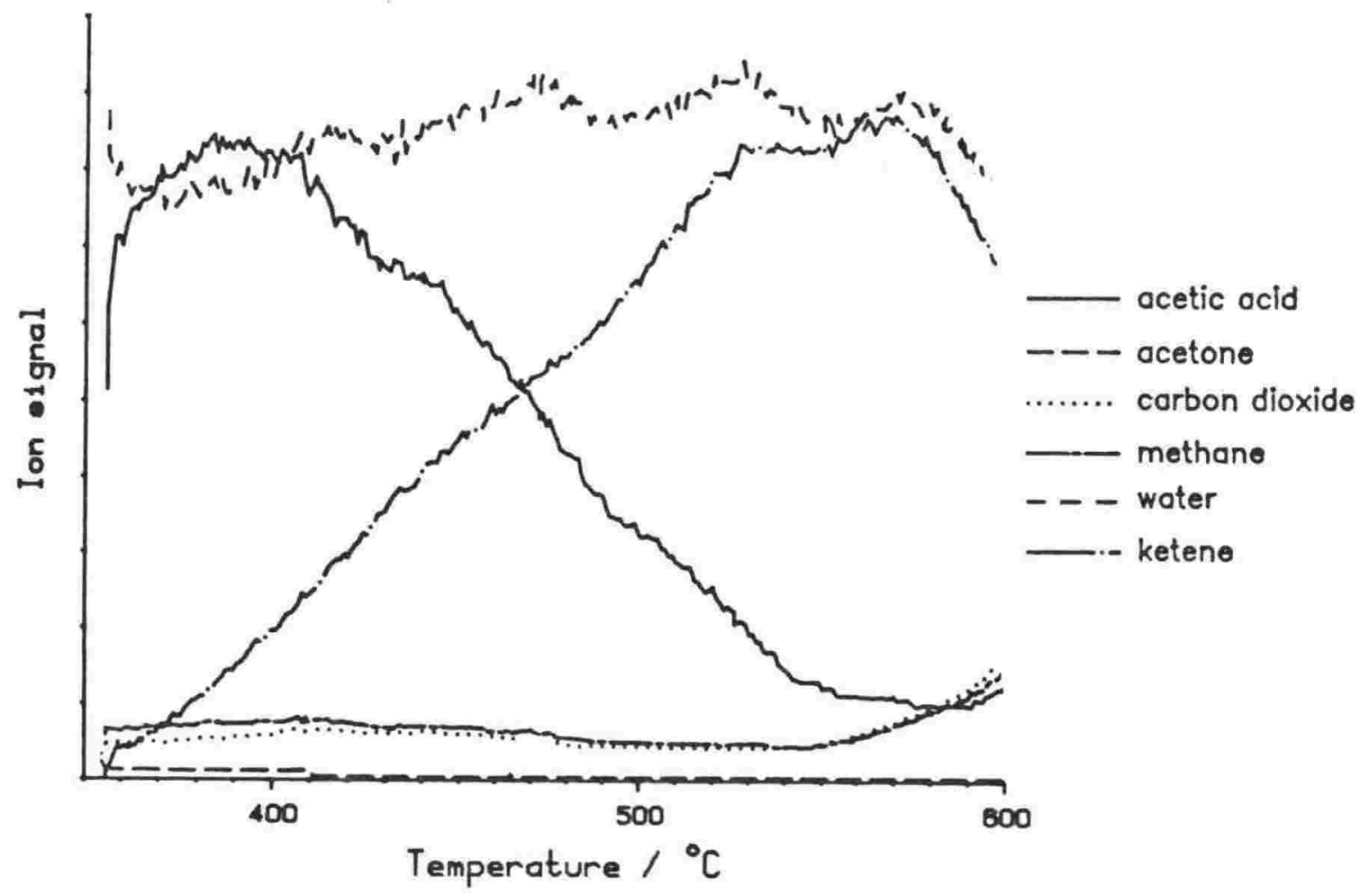

Figure 10.25. Reaction products of a constant flow of acetic acid through the mini-reactor containing kao wool versus temperature. 


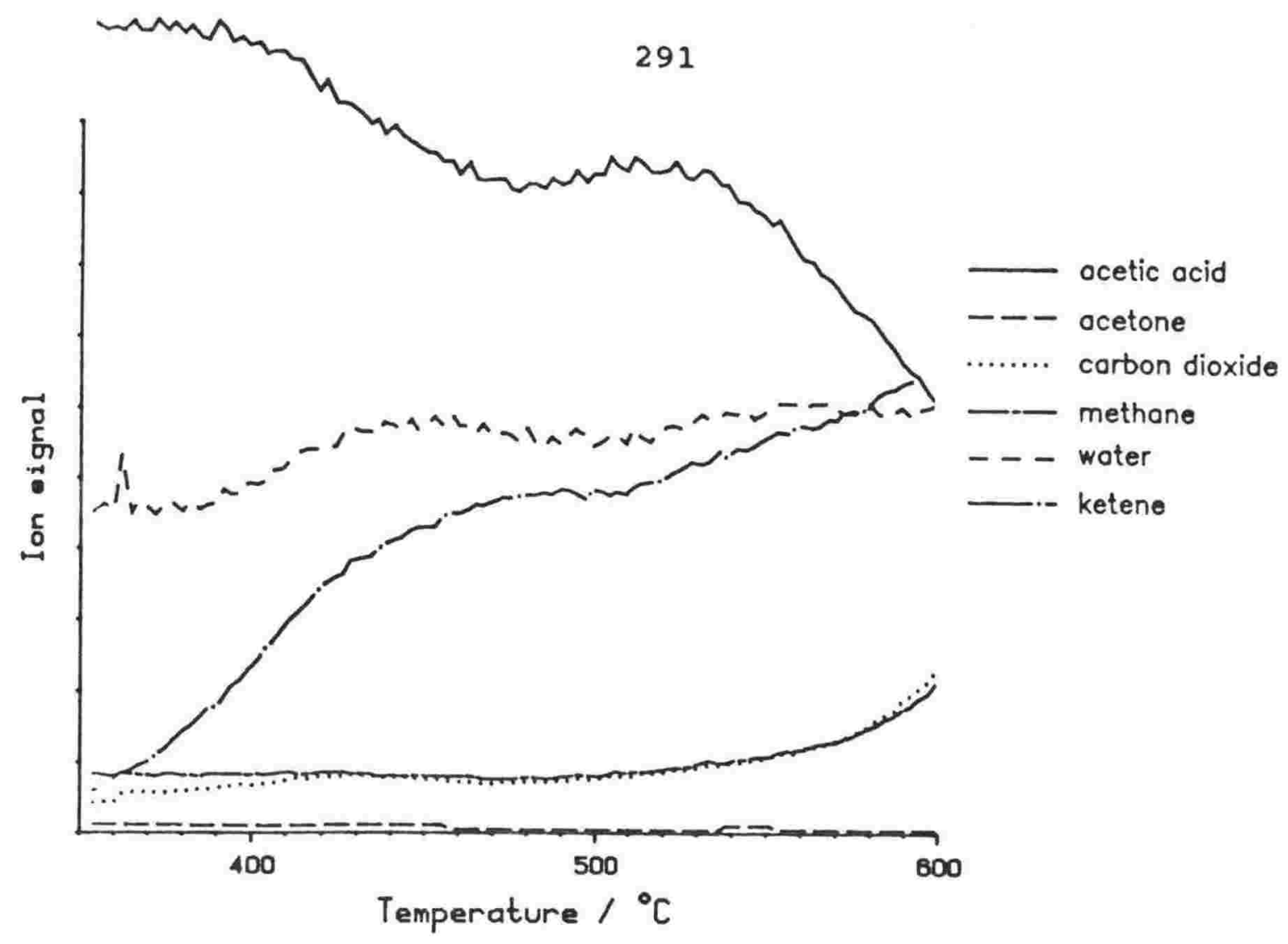

Figure 10.26. Reaction products of a constant flow of acetic acid through the mini-reactor containing silica wool versus temperature.

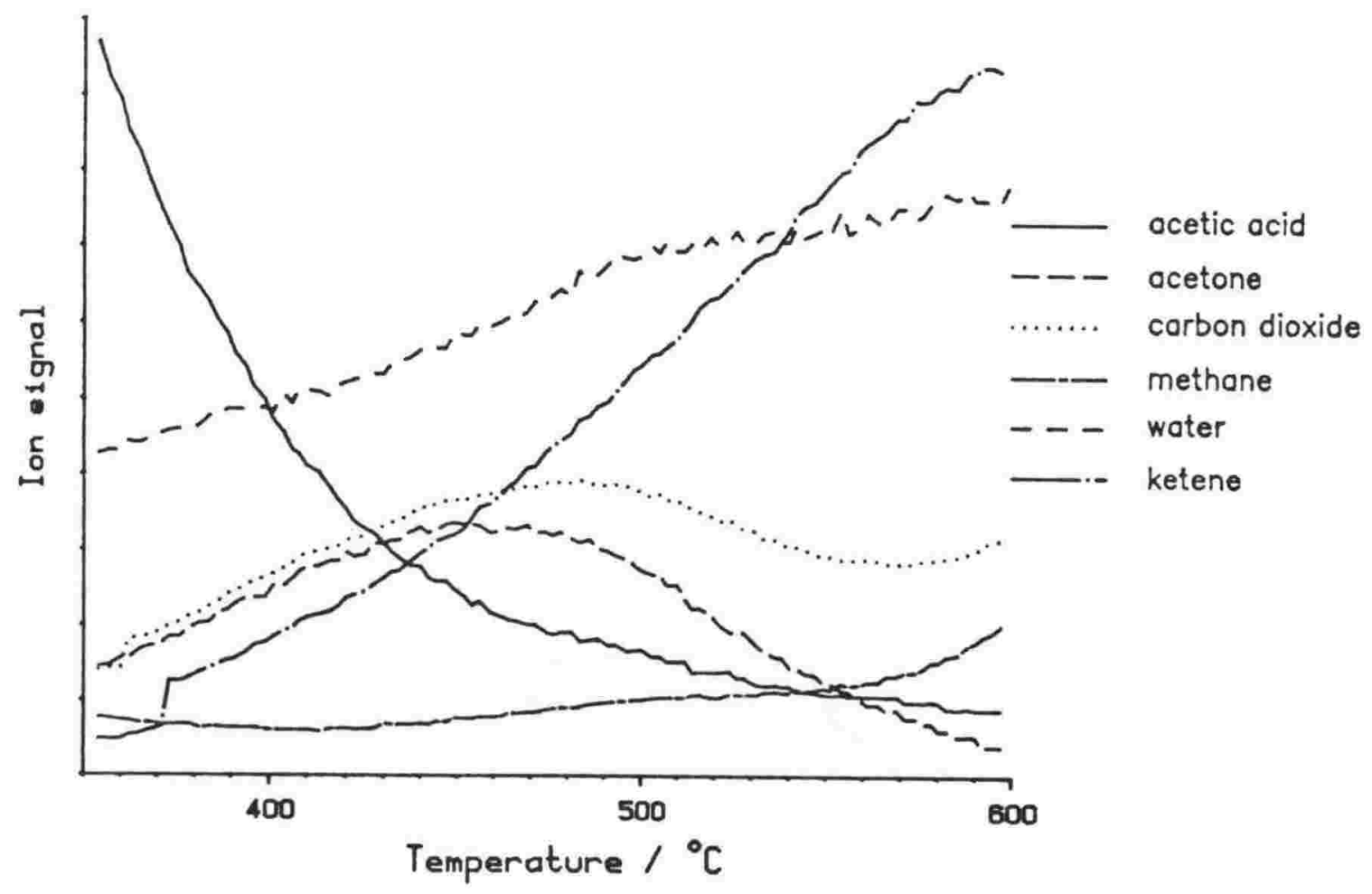

Figure 10.27. Reaction products of acetic acid through the mini-reactor containing silicalite-1 supported by $\mathrm{Si}$ wool versus temperature. 


\subsubsection{Reaction of acetone over LitY:}

The thermal decomposition of acetone to ketene and methane (equation 9.17) has a lower heat of reaction $\left(81 \mathrm{~kJ} \mathrm{~mol}^{-1}\right.$ at $25^{\circ} \mathrm{C}$ (5)) than the decomposition of acetic acid to ketene and water $\left(142 \mathrm{~kJ} \mathrm{~mol}^{-1}(10)\right)$. If the extent of reaction of acetic acid to ketene observed in the 'empty' mini-reactor is merely the low temperature end of the gas phase thermal decomposition, then a similar experiment with acetone should result in a greater amount of ketene produced.

The mini-reactor experiment with acetone in the impinger at $3^{\circ} \mathrm{C}$ was carried out $(0.5 \mathrm{~g} \mathrm{Li}+\mathrm{Y}$, acetone $/ \mathrm{Ar}$ flow $=7.5 \mathrm{ml}$ min-1, Ar diluent flow $=13 \mathrm{ml} \mathrm{min}^{-1}$, heating rate $5^{\circ} \mathrm{C} \mathrm{min}^{-1}$ ). The results are shown in figure 10.28. The acetone concentration decreased, but no major gaseous products were observed. There was a small amount of $\mathrm{CO}_{2}$ and methane and perhaps a trace of ketene. A significant proportion of the acetone may have reacted to form 'coke', as the catalyst was black at the end of the run.

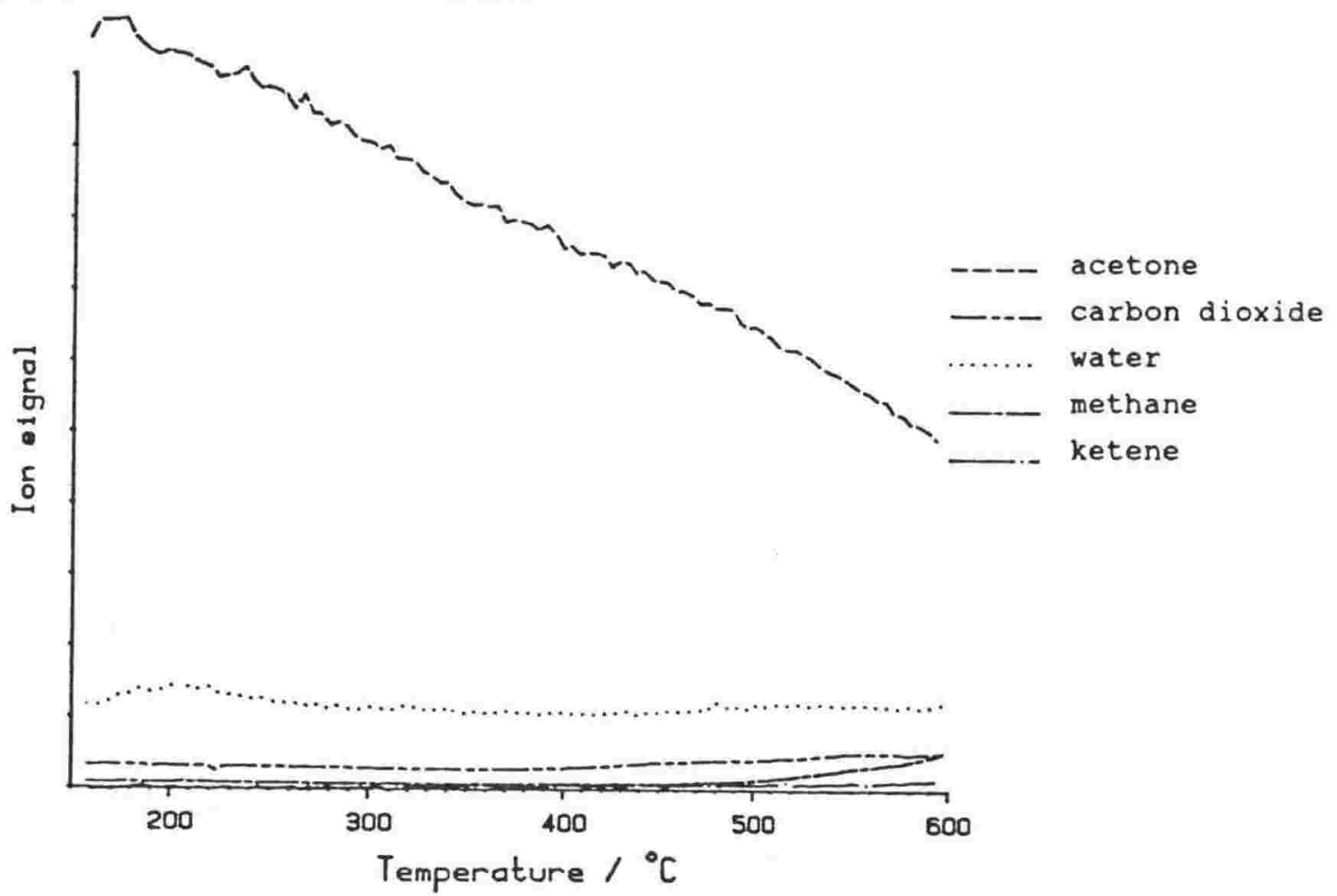

Figure 10.28. Reaction products of acetone over $\mathrm{Li}+\mathrm{Y}$ versus temperature. 


\subsection{Discussion:}

These experiments show that ketene production is independant of the reaction to acetone and $\mathrm{CO}_{2}$ since no acetone was observed in figures 10.24, 10.25 and 10.26. Acetone and $\mathrm{CO}_{2}$ production result from acetate decomposition which is formed by reaction of acetic acid with an alkali metal cation. The presence of alkali metal cations is therefore required to produce acetone. This also agrees with the results of the $t d / m s$ survey - that the temperature of ketene evolution remained constant, while the temperature of acetone and $\mathrm{CO}_{2}$ depended on the exchanged cation. As the Lewis acidity of the exchanged cation increases (cation size decreases), the stability of the acetate-alkali metal complex increases (6) and decomposition to acetone and $\mathrm{CO}_{2}$ occurs at a higher temperature. The reaction of acetic acid to acetate could be written:

$\mathrm{CH}_{3}-\mathrm{C}_{\mathrm{OH}}^{\prime \prime}+\mathrm{Na}^{+}$-zeolite $-\mathrm{CH}_{3}-\mathrm{C}_{\prime}^{\prime \prime}\left(-\mathrm{Na}^{+}+\mathrm{H}^{+}\right.$-zeolite (10.5)

However, the reaction does not occur in this manner as no resultant zeolite hydroxyl stretches due to acid sites were observed by FTIR. The cation/acetate complex may still associated with the zeolite acid sites or the acetate may have formed only on cations not associated with zeolite Al. Experiments with a zeolites containing different amounts of intercalated salts may be able to determine this.

Conversion of acetic acid to ketene occurs without a catalyst present in the reactive filter. The reaction may either be a gas phase thermal reaction or the walls of the silica reactor may be providing a catalytic surface for the reaction, or a combination of both. Increasing the surface area by addition of $\mathrm{Si}$ wool to the reactive filter only slightly increased the amount of ketene produced. However, addition of kao wool resulted in a major increase in ketene. This may have been due to a difference in surface areas between the $\mathrm{Si}$ and kao wools, or due to weak acid sites associated with the aluminium content of the kao wool aiding adsorption of the acetic acid and subsequent reaction. silicalite-1, which 
has a very high surface area was only slightly less effective at producing ketene than kao wool due to some competing reaction to acetone and $\mathrm{CO}_{2}$ (from reaction with the small amount of $\mathrm{Nat}$ and/or zeolite Al sites).

Therefore the reaction to ketene may occur both to some extent in the gas phase and on surfaces, as increasing the surface area increases conversion. A surface which readily sorbs acetic acid, but does not have strong active sites which produce acetone and $\mathrm{CO}_{2}$ is therefore the best for producing ketene.

That reaction of acetone does not give significant ketene under the same conditions, despite having a lower heat of reaction, supports the hypothesis that the acetic acid to ketene reaction is not simply a gas phase reaction. This also agrees with the FTIR results in which ketene was only observed in the gas phase when a strongly bound form of acetic acid was observed on the catalyst.

Further evidence that these catalysts were performing a significant function comes from earlier work. Industrially, the synthesis of ketene is carried out at temperatures between 700 to $800^{\circ} \mathrm{C}$. Rate constants for production of ketene from acetic acid were investigated by Padmanabhan et al. who found optimal conditions at $750^{\circ} \mathrm{C}, 100$ Torr pressure and $0.3 \%$ triethyl phosphate (acid catalyst) concentration. They stated that 'thermodynamic calculations have indicated that ketene formation is feasible at $900 \mathrm{~K}\left(627^{\circ} \mathrm{C}\right)$ and above'. Their initial runs on the thermal cracking of acetic acid in a fluidised bed of quartz at atmospheric pressure from 600 to $750^{\circ} \mathrm{C}$ without a catalyst resulted in products such as $\mathrm{CO}, \mathrm{CO}_{2}$, $\mathrm{H}_{2}, \mathrm{C}_{n} \mathrm{H}_{m}$ and $\mathrm{CH}_{4}$ together with a carbon deposit. Therefore their further experiments were carried out using a catalyst.

Child and Hay (8) studied the thermodynamics of the thermal decomposition of acetic acid in the vapour phase. They confirmed that the reaction of acetic acid to ketene and water is endothermic with a heat of reaction of $130 \mathrm{~kJ} \mathrm{~mol}^{-1}$ at $300^{\circ} \mathrm{C}$. The equilibrium obtained after holding acetic acid in 
a closed vessel for 20 hours at $330^{\circ} \mathrm{C}$ resulted in only $1.7 \%$ reaction to ketene, $0.6 \%$ of which had reacted further to acetic anhydride. At temperatures greater than $330^{\circ} \mathrm{C}$, several additional products were observed by gas chromatography, so no work was done at higher temperatures.

The mini-reactor and $t d / m s$ techniques therefore give greater ketene concentrations and fewer side products than that achieved for acetic acid at equilibrium. This supports the hypothesis that the ketene produced in this work is, to a significant extent, catalysed by surfaces.

Further work is required to determine the nature of the sites upon which sorption of acetic acid results in reaction to ketene. They are not alkali metal cations as reaction results in acetate formation. They are also not Bronsted acid sites as reaction over acid catalysts results in conversion to acetone, isobutene, $\mathrm{CO}_{2}$, then aromatic hydrocarbons (9). FTIR showed that the species associated with the observation of ketene, for acetic acid sorbed on $\mathrm{Na}+\mathrm{Y}$, had its carbonyl stretch shifted from $1800 \mathrm{~cm}^{-1}$ (gas phase) to $\sim 1670 \mathrm{~cm}^{-1}$. This shows strong bonding, perhaps to the alkali metal cation associated with zeolite Al sites which behave as Lewis acids:

$$
\mathrm{CH}_{3}-\mathrm{C}_{\mathrm{OH}}^{\mathrm{O}^{\delta-}} \mathrm{Na}+\ldots \text { zeolite }
$$

An argument against the association of acetic acid with the alkali cation is the observation that the $t d / m s$ survey showed that ketene evolution was almost independant of the exchanged cation. This implys that there must be additional sorption sites in the zeolite. These additional sites may be similar to sites on kao wool, over which ketene was produced. Kao wool is an amorphous silica alumina derived from kaolin and may have weak Lewis acid sorption sites due to its aluminium content.

FTIR work on acetic acid sorbed on silicalite alone has not been carried out. FTIR of a mixture of $\mathrm{Na}+\mathrm{Y}$ in silicalite showed an additional peak of sorbed acetic acid at $\sim 1770$ 
$\mathrm{cm}^{-1}$, perhaps due to acetic acid sorbed on silicalite. The strength of sorption would be similar to that of acetic acid associated with another molecule of acetic acid in the dimer, as the carbonyl stretching peak occurs at the same wavenumber. Acetic acid did not bond to the silanol hydroxyls as their FTIR peak did not decrease significantly. The sorption sites on and within silicalite that enable acetic acid to react to ketene must therefore be sites associated with the silicalite structure, perhaps due to defects. 


\subsection{CONCLUSIONS: The Mechanism of ketene formation at low temperatures (less than $600^{\circ} \mathrm{C}$ ).}

1. Ketene is formed by decomposition of acetic acid sorbed on various surfaces at temperatures above $350^{\circ} \mathrm{C}$. The extent of reaction to ketene observed is much greater than the possible equilibrium concentrations from gas phase reaction at these temperatures, therefore catalysis is occuring. Increasing the surface area increases the conversion.

2. Catalysis occurs on surface sites which sorb acetic acid, without causing reaction to acetate. Kao wool, silicalite and zeolites are examples of surfaces which have these sites.

3. Alkali metal exchanged zeolites have a high surface area and sites for sorption of acetic acid, producing a greater proportion of ketene at low temperatures (less than $450^{\circ} \mathrm{C}$ ) than with no catalyst present. However the alkali metal cations also react with the acetic acid to produce the acetate ion, which further reacts to form acetone and $\mathrm{CO}_{2}$. This competing reaction reduces the amount of ketene observed. With increasing Lewis acidity of the exchanged cation, the reaction to acetone and $\mathrm{CO}_{2}$ becomes less favourable and occurs at a higher temperature, increasing the amount of ketene produced. The zeolites exchanged with the smaller cations $\left(\mathrm{Li}^{+}, \mathrm{Na}^{+}\right)$consequently produced the most ketene.

4. Decomposition of acetic acid to methane and $\mathrm{CO}_{2}$ was also increased by the presence of alkali metal exchanged zeolites.

5. The 'best' catalyst for producing ketene at low temperatures is therefore a high surface area material with no strong acidic or basic sites such as kao wool or silicalite. 
10.8 Re-investigation of In situ-reactions:

In situ reactions (see Chapter 9) were re-investigated to obtain more information on the mechanism and to determine the best catalyst, in light of the results that showed that ketene production was optimal on surfaces with no strong active sites.

The acetylation of methanol to methylacetate (chapter 9.11.1) was investigated further. Acetic acid and methanol were placed in the reactive filter of the mini-reactor setup and their vapours passed through the mini-reactor.

The experiment was carried out for:

10.8.1. The empty mini-reactor to determine if a catalyst is necessary as the reaction of ketene and methanol may occur readily in the gas phase. (acetic acid/methanol/Ar flow $=6$ ml $\mathrm{min}^{-1}$, Ar diluent flow $=12 \mathrm{ml} \mathrm{min}^{-1}$, heating rate $=2{ }^{\circ} \mathrm{C}$ $\left.\min ^{-1}\right)$.

10.8.2. With $\mathrm{si}$ wool in the reactive filter to determine the effect of an increase in surface area. (acetic acid/methanol/Ar flow $=6 \mathrm{ml} \mathrm{min}{ }^{-1}$, Ar diluent flow $=12 \mathrm{ml}$ $\mathrm{min}^{-1}$, heating rate $=5^{\circ} \mathrm{C} \mathrm{min}^{-1}$ ).

10.8.3. With $\mathrm{Si}$ wool and silicalite-1 to determine the effect of a larger surface area with slight catalytic activity. $(0.043 \mathrm{~g}$ silicalite, acetic acid/methanol $/ \mathrm{Ar}$ flow $=$ $6.5 \mathrm{ml} \mathrm{min}^{-1}$, Ar diluent flow $12.5 \mathrm{ml} \mathrm{min}^{-1}$, heating rate $5^{\circ} \mathrm{C}$ $\left.\min ^{-1}\right)$.

10.8.4. With LiY and kao wool to determine the effect of an active catalyst. $\quad(0.057 \mathrm{~g} \mathrm{LiY,} \mathrm{acetic} \mathrm{acid/methanol} / \mathrm{Ar}$ flow = $10 \mathrm{ml} \mathrm{min}^{-1}, \mathrm{~N}_{2}$ diluent flow $=7.5 \mathrm{ml} \mathrm{min}{ }^{-1}$, heating rate $5^{\circ} \mathrm{C}$ $\left.\min ^{-1}\right)$.

The results are presented in figures 10.29 to 10.32 . 


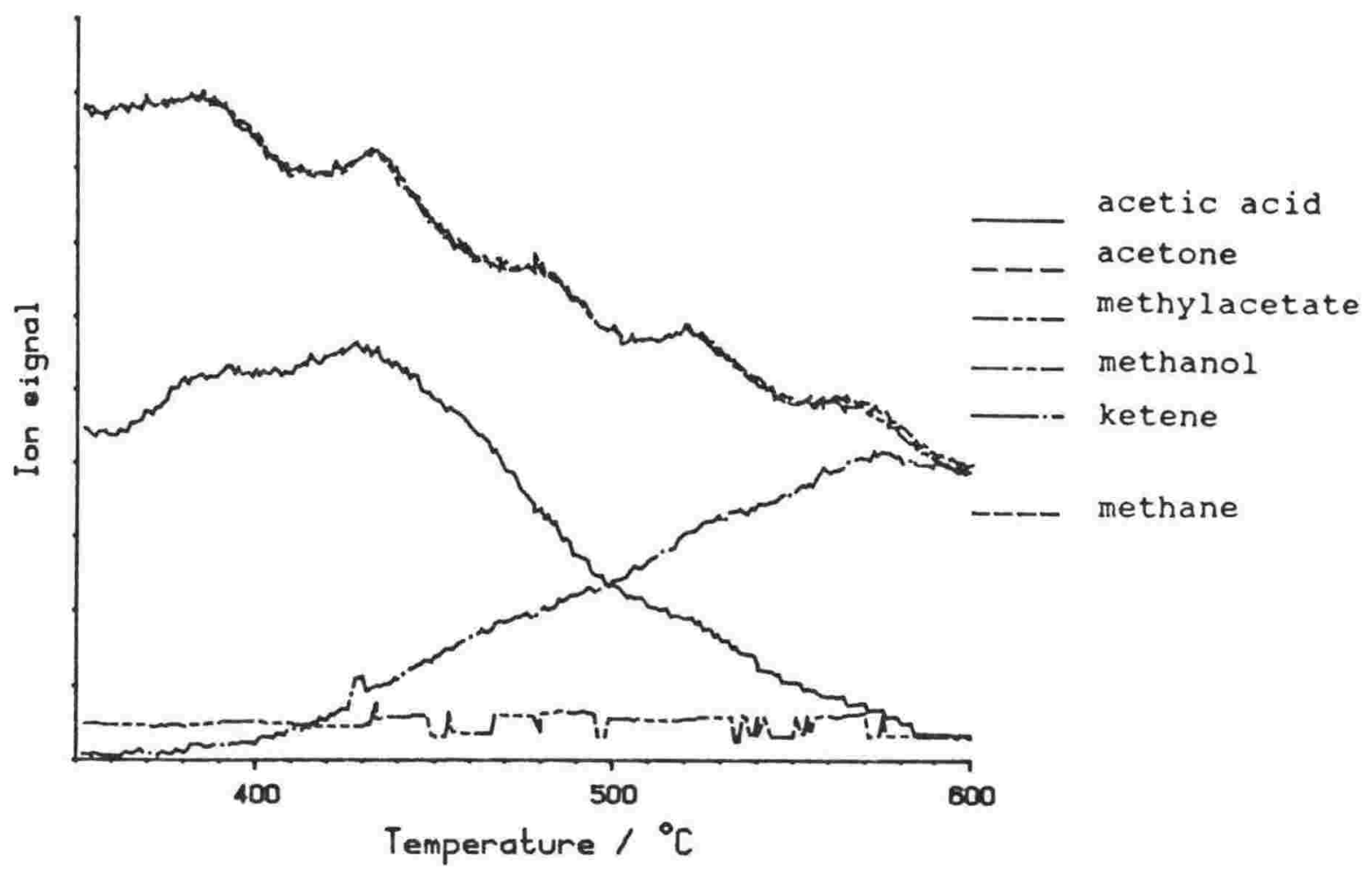

Figure 10.29. Reaction products of acetic acid and methanol vapours in the empty mini-reactor versus temperature.

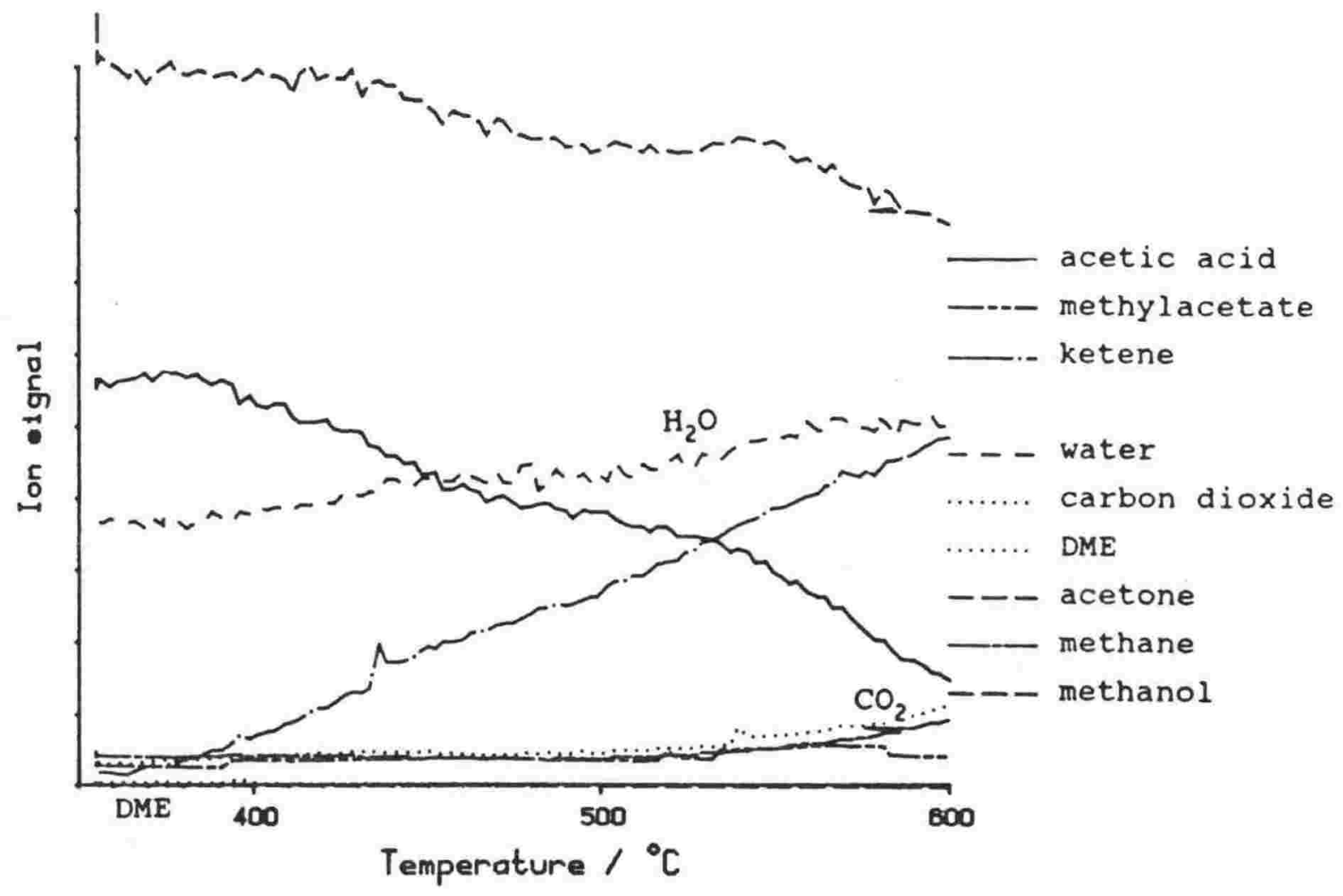

Figure 10.30. Reaction products of acetic acid and methanol in the mini-reactor containing silica wool, versus temperature. 


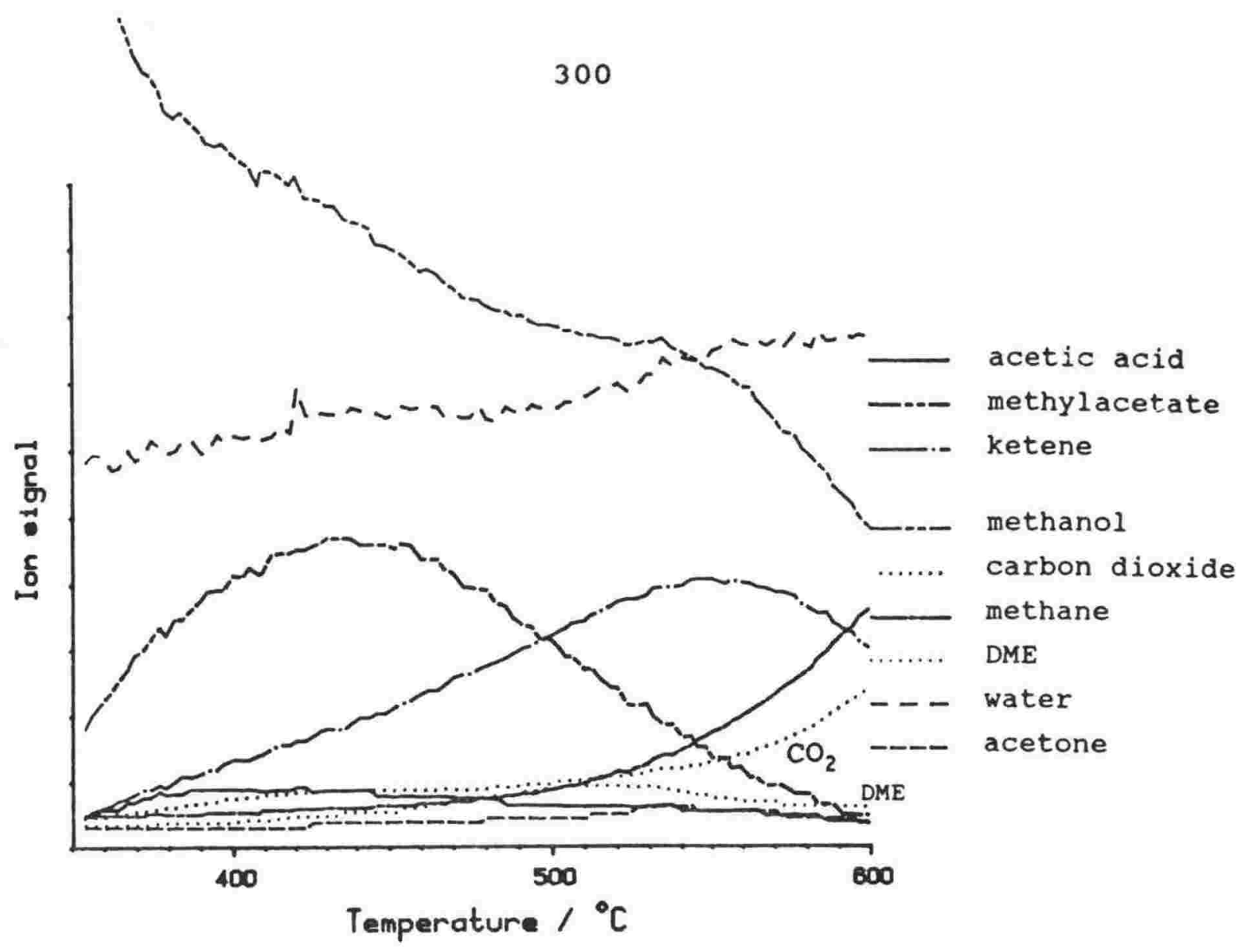

Figure 10.31. Reaction products of acetic acid and methanol in the mini-reactor containing silicalite-1 supported by silica wool, versus temperature.

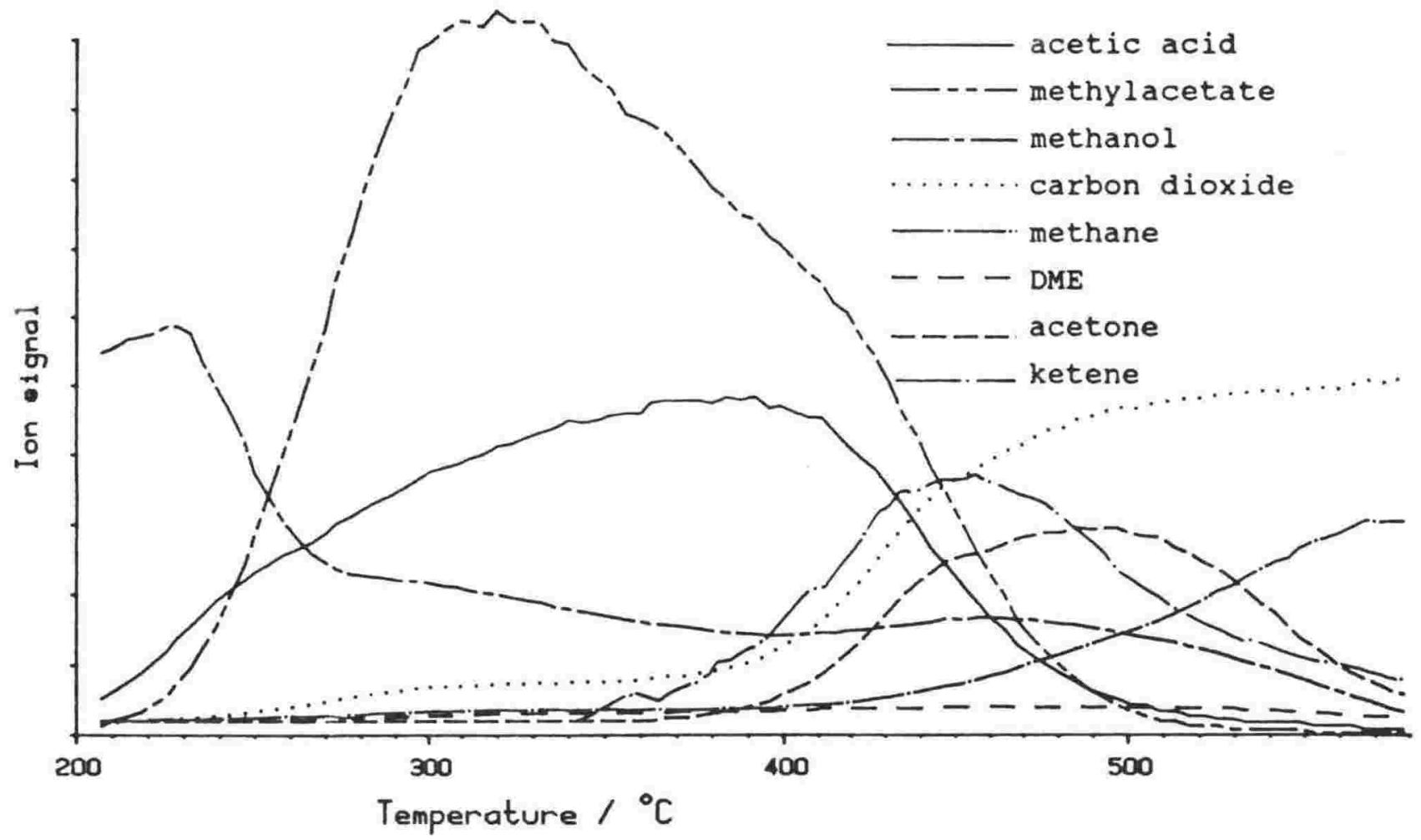

Figure 10.32. Reaction products of acetic acid and methanol in the mini-reactor containing $\mathrm{Li}+\mathrm{Y}$ supported by kao wool, versus temperature. 
With no catalyst, or just si wool, only a trace of methylacetate was observed at all temperatures (figures 10.29 and 10.30). Ketene was produced in amounts similar to those obtained when no methanol was present, showing no significant gas phase reaction of ketene and methanol. No dimethylether or acetone were observed.

With silicalite present (figure 10.31), methylacetate was produced with a maximum at about $430^{\circ} \mathrm{C}$. Very little unreacted acetic acid was observed and the amount of ketene produced was less than the case when no methanol was present. Small amounts of dimethylether and acetone were observed.

With a more active catalyst (LiY) (figure 10.32), methyl acetate was produced at a lower temperature $\left(\operatorname{Tmax}\right.$ at $300^{\circ} \mathrm{C}$ ). From $360^{\circ} \mathrm{C}$, acetone and $\mathrm{CO}_{2}$ increased, becoming the dominant products. Ketene was observed with a maximum at $450^{\circ} \mathrm{C}$.

A catalyst with a high sorptive capacity is required for methanol to be acetylated, therefore this reaction occurs on a surface. From these results it is not possible to determine whether LiY or silicalite-1 would be the better catalyst. Silicalite-1 produced fewer by-products, but methylacetate was observed at a lower temperature over LiY than over silicalite. 


\subsubsection{Reaction of methanol with sodium acetate.}

One explanation for these results is that methanol is acetylated by reaction with ketene, another explanation is that methanol is reaction with acetate. The reaction of methanol with sodium acetate to give methyl acetate can be written:

$\mathrm{CH}_{3} \mathrm{OH}+\mathrm{CH}_{3}-\mathrm{C}_{\mathrm{O}}^{\prime \prime \prime}-\mathrm{Na}^{+} \rightarrow \mathrm{CH}_{3}-\mathrm{C}_{\mathrm{OCH}_{3}}^{\prime \prime}+\mathrm{NaOH}$

This possibility was investigated using the mini-reactor $/ \mathrm{ms}$ technique. Sodium acetate hydrate $(0.023 \mathrm{~g})$ was placed in the reactive filter, held in place with $\mathrm{Si}$ wool and dried at $150^{\circ} \mathrm{C}$. Methanol flowed from the impinger through the reactor. (methanol/Ar flow $=5 \mathrm{ml} \mathrm{min}{ }^{-1}$, Ar diluent flow $=12.5 \mathrm{ml}$ $\mathrm{min}^{-1}$, heating rate $=5^{\circ} \mathrm{C} \mathrm{min}^{-1}$ ). The results are shown in figure 10.33. Excess methanol was present at all temperatures (not plotted scaled to relative concentration as the ion signal was too intense). No major products were observed until about $400^{\circ} \mathrm{C}$ when a large amount of acetone (not plotted scaled to relative concentration), some $\mathrm{CO}_{2}$ and methane were observed from the reaction and decomposition of sodium acetate. Coke was also deposited as the reactive filter was pitch black after the run. Only a small amount of methyl acetate was observed between $350^{\circ} \mathrm{C}$ and $500^{\circ} \mathrm{C}$.

This experiment confirms that the reaction of methanol with acetate is not the major reaction path to methylacetate. The acetylation therefore either occurs via reaction of sorbed methanol with a sorbed acetic acid species or via reaction of sorbed methanol with sorbed ketene. 


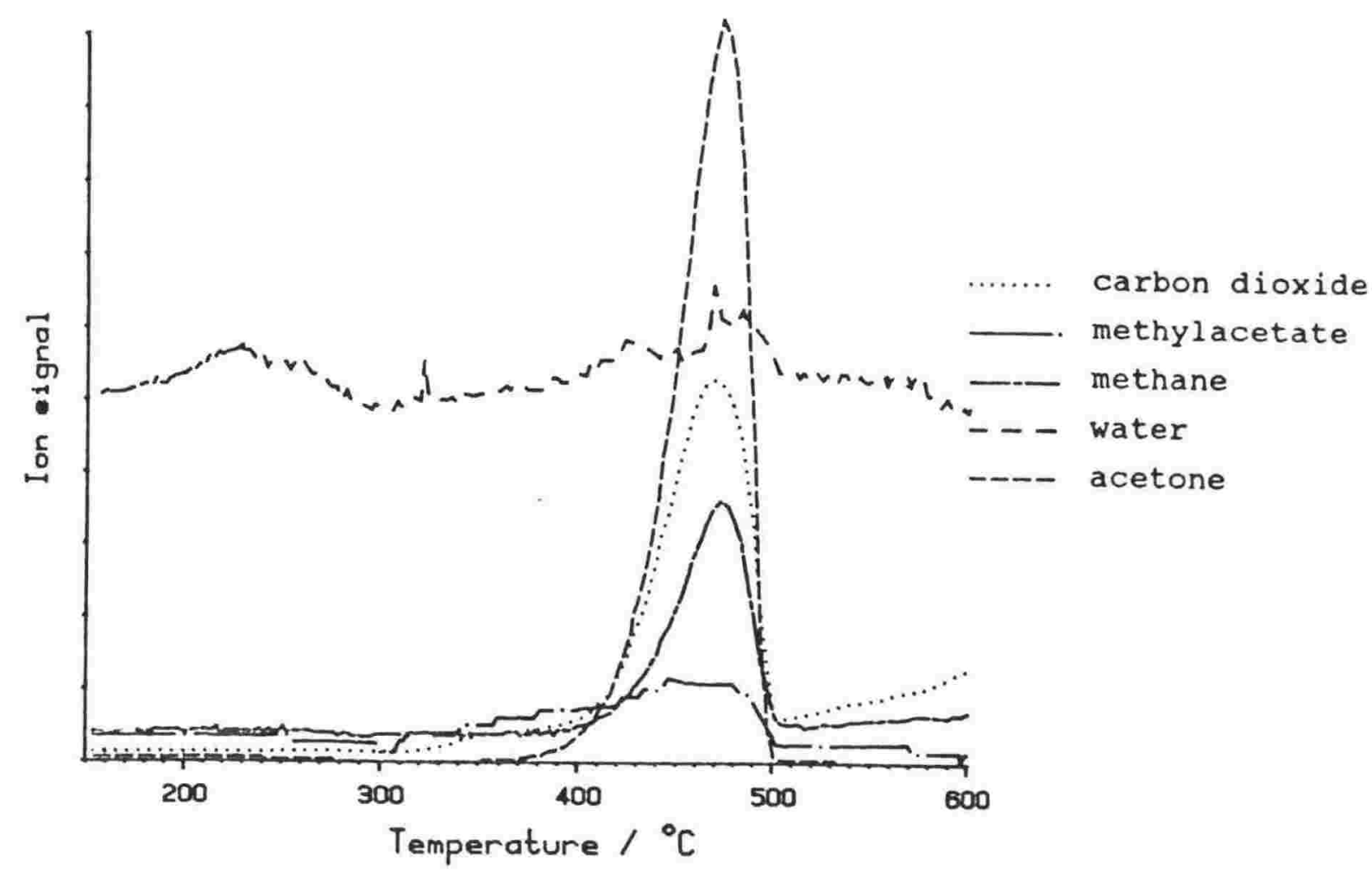

Figure 10.33. Reaction products of methanol over sodium acetate versus temperature.

\subsubsection{CONCLUSION: Acetylation of methanol.}

1. The acetylation of methanol by acetic acid requires a catalyst with a high sorptive capacity such as silicalite or LiY. Therefore this reaction occurs on a surface.

2. The acetylation does not occur by reaction of methanol with acetate formed on the catalyst.

3. Therefore acetylation occurs either by reaction of methanol with a sorbed acetic acid species or with sorbed ketene. 


\section{Chapter 10 REFERENCES:}

1. Barthomeuf D., J. Phys. Chem., 1984, 88, 42 .

2. Puttock S.J. and Rochester C.H., J. Chem. Soc. Faraday Trans. 1, 1986, 82, 3013.

3. Gonzalez F., Munuera G., Prieto J.A., J. Chem. Soc. Faraday Trans. 1, 1978, 74, 1517.

4. Halverson F. and Williams V.Z., J. Chem. Phys., 1947, 15,552 .

5. calculated from:

$\Delta \mathrm{H}_{\text {reaction }}=\mathrm{H}_{f}\left(\mathrm{CH}_{4(g)}+\right.$ ketene $\left._{(g)}\right)-\mathrm{H}_{f}\left(\right.$ acetone $\left._{(g)}\right)$.

Heats of formation for $\mathrm{CH}_{4}$ and ketene obtained form 'Circular of National Bureau of Standards 500' US Govt. Printing office, 1952. Heat of formation of acetone from Chao J., and Zwolinski B.J., J. Phys Chem. Ref. Data, 1976, 5, 319.

6. Duval C., "Inorganic Thermogravimetric Analysis", Elesvier, Amsterdam, 1963.

7. Padmanabhan N., Deshpande P.K., Kuloor N.R., Ind. Eng. Chem. Process Des. Dev. 1968, 7, 511.

8. Child W.C. and Hay A.J. 1964, 68, 182.

9. Chang C.D. and Silverstri A.J. J. Catal, 1977, 47, 249 .

10. Kirk-othmer Encylopedia of Chemical Technology, 3rd Edition, John Wiley and Sons, 1980. 
sample origin:

H+ZSM-5 prep 915, H+ZSM-5 prep 800 and Silicalite 1 were synthesised using a tetrapropylammonium bromide template as described by Parker et al. (1).

H+ZSM-5 prep 816 was synthesised using a tetrapropylammonium bromide template, as described in a patent application (2).

Zeolite Y - Linde Y, SK40, Union Carbide, lot no. 9680801014.

Sample Composition:

Sample weight $\%$ Al Al atoms/zeolite unit cell

H+ZSM-5 prep $915 \quad 1.20 \pm .04 \quad 2.52 \pm .08$

H+ZSM-5 prep $816 \quad 1.48 \pm .05 \quad 3.11 \pm 0.1$

H+ZSM-5 prep $800 \quad 0.62 \pm .02 \quad 1.3 \pm .04$

These samples were analysed by fusion in $\mathrm{HF} / \mathrm{H}_{2} \mathrm{SO}_{4}$, dissolved in dilute $\mathrm{HNO}_{3}$, then determined by $\mathrm{AA}$ spectrometry.

Sample wt $\% \mathrm{Al}$ wt $\% \mathrm{Na}$ wt $\% \mathrm{Cs}$ mole ratio $\mathrm{Na} / \mathrm{Al}$

$\begin{array}{llllll}\mathrm{Na}+\mathrm{Y} & \mathrm{A} & 8.5 & 6.05 & - & 0.84 \\ \mathrm{Na}+\mathrm{Y} & \mathrm{B} & 9.9 & 7.97 & - & 0.92 \\ \mathrm{Li}+\mathrm{Y} & & 9.6 & 3.03 & - & 0.37 \\ \mathrm{Cs}+\mathrm{Y} & 7.56 & 2.17 & 23.1 & \end{array}$
silicalite 1
0.14
0.02

These samples were analysed by fusion in lithium salts, followed by AA spectrometry, carried out by N.J. Baxter.

\section{References:}

1. Parker L.M., Bibby D.M. and Meinhold R.H., Zeolites, $1985,5,384$.

2. European Patent Application 0028516. 


\section{APPENDIX II: SURVEY OF POSSIBLE CATALYSTS FOR KETENE PRODUCTION.}

\subsection{INTRODUCTION :}

The $t d / m s$ technique was chosen for this survey because it was simple and rapid (taking about one and a half hours to test each catalyst), and gave a reasonably clear indication of the possible usefulness of the catalyst. The relative amounts of ketene and other products could be determined over a wide temperature range. However only qualitative comparisons were obtained as two variables were changed at once - the amount of acetic acid on the catalyst and the temperature. Using $\mathrm{td} / \mathrm{ms}$ also gave an indication of the strength of sorption of acetic acid on each catalyst.

Zeolites with a wide variety of structures as well as crystalline aluminium phosphates, amorphous aluminosilicates and pillared clays were surveyed. These were exchanged with the cations $\mathrm{Li}^{+}, \mathrm{Na}^{+}, \mathrm{K}^{+}, \mathrm{Rb}^{+}, \mathrm{Cs}^{+}, \mathrm{Ca}^{++}, \mathrm{Zn}^{++}$and $\mathrm{La}^{3+}$.

\subsection{METHOD:}

Each catalyst was treated in a similar manner. The catalysts were exchanged in $\sim 1 \mathrm{M}$ solutions of the chloride salt, filtered then exchanged for another two days in fresh solution. They were then filtered, rinsed lightly with distilled water and dried at $80^{\circ} \mathrm{C}$. This resulted in the bulk of the cations being exchanged. (Complete exchange may not have occured, especially for those structures with cations in hindered positions).

About $10 \mathrm{mg}$ of the catalyst was placed in the td/ms tube, heated to $150^{\circ} \mathrm{C}$ and evacuated via the gas handling rig. Acetic acid was then sorbed (as detailed in chapter 2) and a low pressure td/ms experiment run from $150^{\circ} \mathrm{C}$ to $600^{\circ} \mathrm{C}$. The $\mathrm{td} / \mathrm{ms}$ results are plotted with the ion signals scaled by their approximate sensitivity factors so that they show relative concentrations (except for water in some cases). The ion signal at $\mathrm{m} / \mathrm{z} 42$, with the contributions from acetic 
acid and acetone removed, was been used for ketene. The ion signals $\mathrm{m} / \mathrm{z} 60, \mathrm{~m} / \mathrm{z} 58, \mathrm{~m} / \mathrm{z} 44, \mathrm{~m} / \mathrm{z} 17$ and $\mathrm{m} / \mathrm{z} 56$ are representative of acetic acid, acetone, $\mathrm{CO}_{2}$, water and alkene respectively unless stated in the figure legend.

\subsection{INORGANIC SALTS:}

\subsubsection{Sodium carbonate:}

Source: BDH Analar.

This simple inorganic salt was studied to determine whether a catalyst support played a role in ketene production. Acetic acid was added, at room temperature to sodium carbonate.

Effervescence occurred as $\mathrm{CO}_{2}$ was evolved with the formation of sodium acetate:

$2\left(\mathrm{CH}_{3}-\mathrm{C}^{\prime \prime} \mathrm{OH}\right)+\mathrm{Na}_{2} \mathrm{CO}_{3} \rightarrow 2\left(\mathrm{CH}_{3}-\mathrm{C}_{\mathrm{O}}^{\prime \prime}-\mathrm{Na}^{+}\right)+\mathrm{CO}_{2}+\mathrm{H}_{2} \mathrm{O}$

$\mathrm{Td} / \mathrm{ms}$ (figure 11.1) showed a loss of excess acetic acid, some water and further $\mathrm{CO}_{2}$ between room temperature and $170^{\circ} \mathrm{C}$.

Between $380^{\circ} \mathrm{C}$ and $590^{\circ} \mathrm{C}$ there was a large acetone evolution as the decomposition of sodium acetate occured. After the onset of the acetone peak other products were observed. These were minor with the relative amounts (calculated by integration under the ion signal peaks and scaling by the relative sensitivity factors) were acetone $84.7 \%, \mathrm{CO}_{2} 6.4 \%$, water $4.1 \%$, $\mathrm{CH}_{4} 2.3 \%$ and ketene $2.5 \%$. The reactions that occured were:

$2\left(\mathrm{CH}_{3}-\mathrm{C}_{\stackrel{1}{1}}^{\left.\stackrel{\mathrm{O}}{\mathrm{O}}-\mathrm{Na}^{+}\right)} \rightarrow \mathrm{H}_{3} \mathrm{C}-\underset{\mathrm{O}}{\mathrm{C}}-\mathrm{CH}_{3}+\mathrm{Na}_{2} \mathrm{CO}_{3}\right.$

or

$$
\rightarrow \mathrm{H}_{3} \mathrm{C}-\underset{\mathrm{O}}{\mathrm{C}}-\mathrm{CH}_{3}+\mathrm{CO}_{2}+\mathrm{coke}+2(\mathrm{NaOH} \text { or } \mathrm{NaO})
$$

$$
+\mathrm{H}_{2} \mathrm{O}
$$


The reaction was non-stoichiometric with a black deposit remaining after the run, indicating that "coke" was formed. The small amounts of ketene and methane observed were probably thermal decomposition products of acetone:

$$
\mathrm{CH}_{3}-\underset{\mathrm{O}}{\mathrm{C}}-\mathrm{CH}_{3} \rightarrow \mathrm{CH}_{2}=\mathrm{C}=\mathrm{O}+\mathrm{CH}_{4}
$$

A small amount of ketene was also observed in the mini-reactor experiment with acetone (see chapter 9.9).

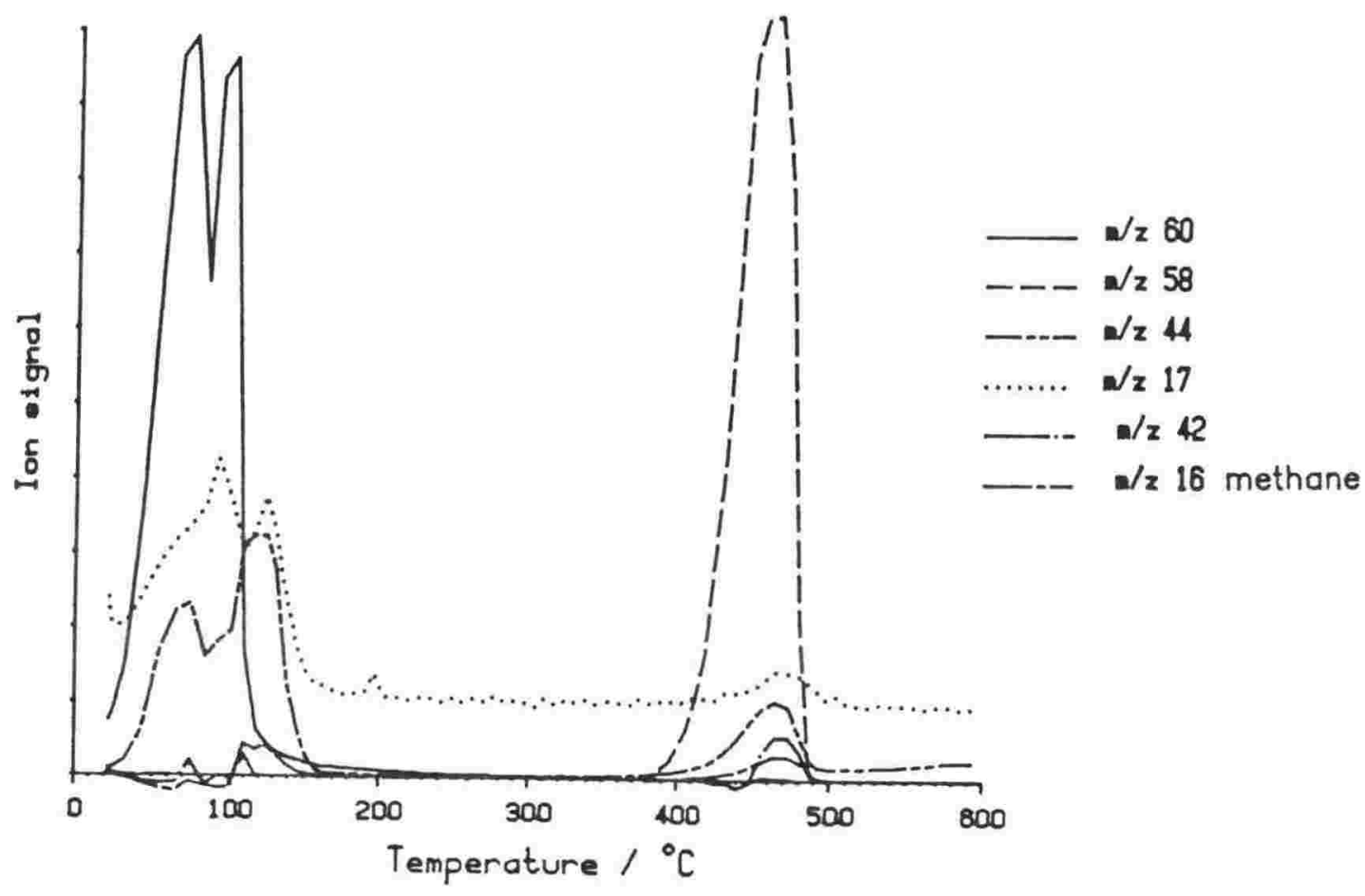

Figure 11.1. Td/ms of acetic acid on sodium carbonate.

\subsubsection{Calcium carbonate:}

Source: BDH Analar.

Addition of acetic acid to calcium carbonate at room temperature resulted in only a slight reaction with no significant effervesence observed. $\mathrm{Td} / \mathrm{ms}$ (figure 11.2) showed that most of the calcium carbonate had remained unreacted, decomposing to $\mathrm{CO}_{2}$ and $\mathrm{CaO}$ from $500^{\circ} \mathrm{C}$. The unreacted acetic acid had desorbed below $100^{\circ} \mathrm{C}$. Acetone from decomposition of calcium acetate, evolved from $350^{\circ} \mathrm{C}$ to $480^{\circ} \mathrm{C}$, along with a small amount of $\mathrm{CO}_{2}$, reacting in a similar fashion to sodium acetate (equation 11.2). 
No significant water evolution was observed, but a small amount of ketene (most likely from the thermal decomposition of acetone) and a slightly smaller amount of methane (not plotted) were observed.

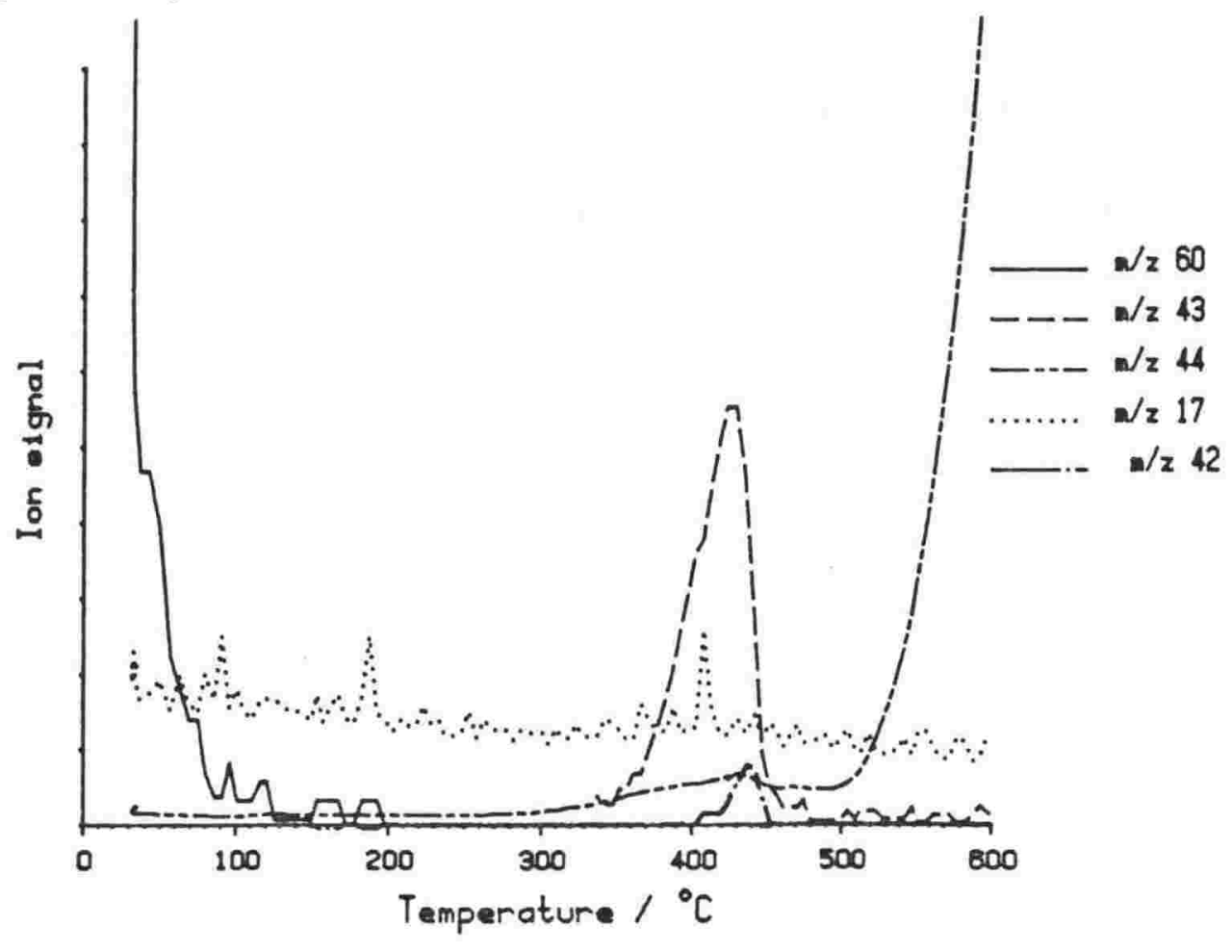

Figure 11.2. Td/ms of acetic acid on calcium carbonate.

\subsection{ZEOLITE A:}

Source: Na+A, Linde, (Union Carbide), lot no. 9350770001-S-1

Zeolite $A$ is a small pore catalyst with a 3 dimensional channel system of 8 -membered rings $4.1 \AA$ in diameter (1). The acetic acid molecule was not sorbed into the $\mathrm{Na}^{+}, \mathrm{K}^{+}$or $\mathrm{Ca}^{++}$forms, but a small amount did sorb into the $\mathrm{Li}^{+}$form. During $t d / m s$ of $\mathrm{Li}^{+} \mathrm{A}$ (figure 11.3) a small amount of ketene and a larger amount of $\mathrm{CO}_{2}$ desorbed. No acetone was observed. The catalyst became a cream colour, showing that only a small amount of coke had been deposited, probably due to the limited amount of acetic acid sorbed. 


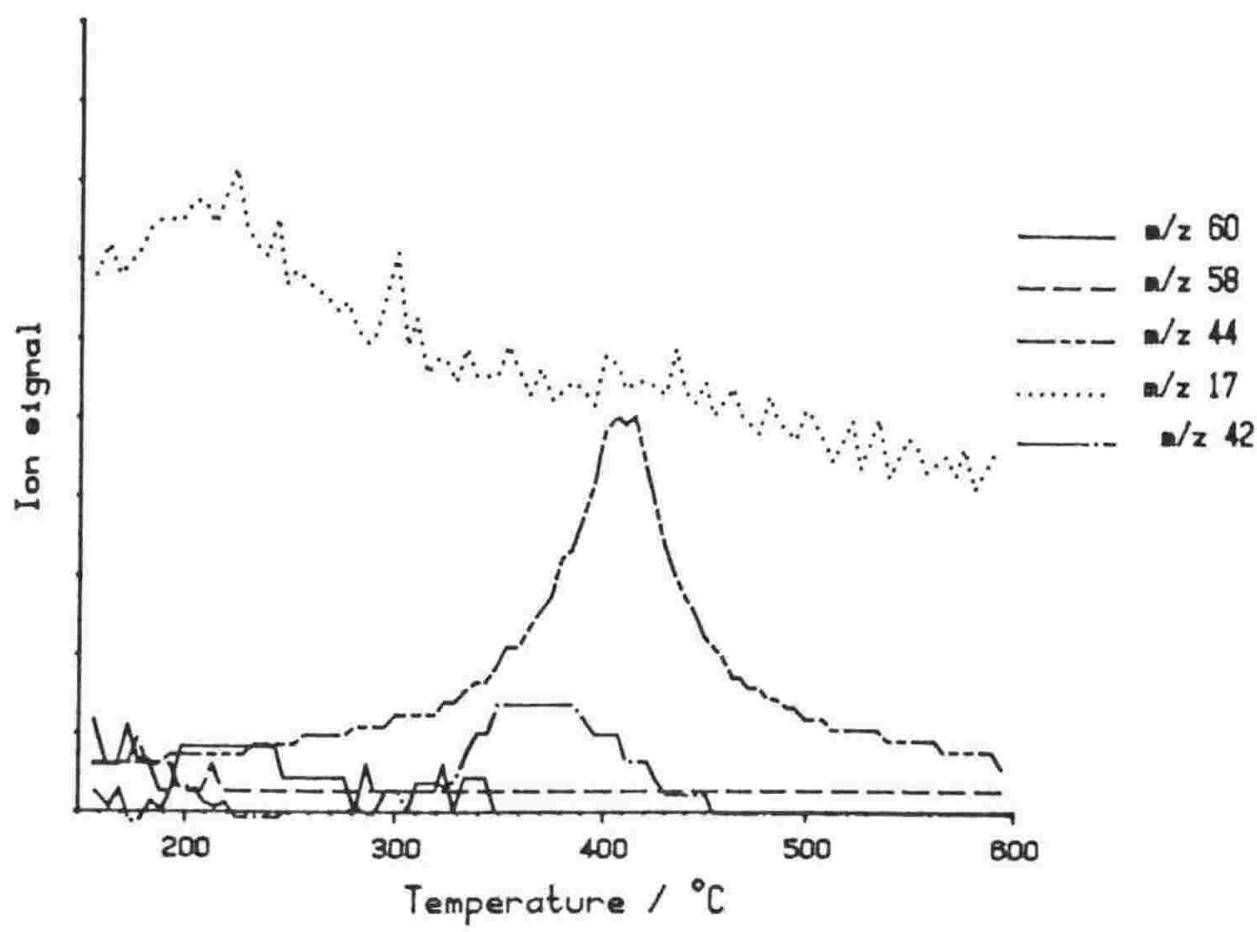

Figure 11.3. Td/ms of acetic acid sorbed on $\mathrm{Li}^{+} \mathrm{A}$.

\subsection{MORDENITE:}

Source: Na+Mordenite, Strem, lot no. 10282-51.

Mordenite has a two dimensional channel system, one set of channels with $6.7 \times 7.0 \AA$ openings and the other $2.9 \times 5.7 \AA$. The small channel is too small for diffusion of molecules greater the $\mathrm{O}_{2}$ and $\mathrm{N}_{2}$, therefore the channels available for diffusion of acetic acid and reaction products are essentially one dimensional. These may be subject to stacking faults and appear to be partially blocked by cations larger than $\mathrm{Li}^{+}$.

of the cation exchanged forms tried $\left(\mathrm{Li}^{+}, \mathrm{Na}^{+}, \mathrm{K}^{+}, \mathrm{Rb}^{+}\right.$and $\mathrm{Ca}^{++}$) only the $\mathrm{Li}^{+}$exchanged mordenite produced significant ketene (figure 11.4) and was a light tan colour after the run. The major product was $\mathrm{CO}_{2}$. With the larger cations the main product desorbed was $\mathrm{CO}_{2}$ with a small amount of acetone. (See for example the $\mathrm{td} / \mathrm{ms}$ of $\mathrm{Na}$ exchanged mordenite figure 11.5). The zeolites were a green/brown colour after the $t d / m s$ runs due to decomposition of acetic acid to coke and $\mathrm{CO}_{2}$. The amount of $\mathrm{CO}_{2}$ evolved decreased with increasing 



\subsection{CHABAZITE:}

Source: Linde AW 500, Union Carbide, lot no. 9395800046-S-3.

Chabazite (1) contains a 3-dimensional channel system consisting of large ellipsoidal cavities joined through rings of 8 ( $\mathrm{Si}$ or $\mathrm{Al}$ ) atoms $(3.6 \times 3.7 \AA)$.

For $\mathrm{Li}^{+}$chabazite (figure 11.6), ketene was produced at high temperatures (between $330^{\circ} \mathrm{C}$ and $570^{\circ} \mathrm{C}$ with a maximum at $480^{\circ} \mathrm{C}$ ). This implies the formation of a very stable acetic acid $\mathrm{Li}^{+}$chabazite complex. In addition to ketene production, a small amount of acetone and a large amount of $\mathrm{CO}_{2}$ and methane desorbed. Pyrolysis reactions producing $\mathrm{CH}_{4}$ and $\mathrm{CO}_{2}$ were dominant above $500^{\circ} \mathrm{C}$. Coke also formed with the zeolite changing from light brown to dark grey. In chabazite different sized cations are likely to be in different sites (1) which may account for the marked difference in td/ms results between $\mathrm{Li}^{+}$chabazite and $\mathrm{Na}^{+}$chabazite. For $\mathrm{Na}^{+}$chabazite (figure 11.7), ketene desorbed between $240^{\circ} \mathrm{C}$ and $580^{\circ} \mathrm{C}$ with a maximum at $355^{\circ} \mathrm{C}$, a lower temperature than for $\mathrm{Li}^{+}$chabazite, and similar to most other zeolites. $\mathrm{CO}_{2}$ was again the major product with very little acetone. Some methane desorbed with a maximum at $520^{\circ} \mathrm{C}$. The $\mathrm{K}^{+}$exchanged chabazite (figure 11.8) showed a similar ketene desorption ( Tmax at $355^{\circ} \mathrm{C}$ ) to the $\mathrm{Na}^{+}$case but without the large $\mathrm{CO}_{2}$ peak. The $\mathrm{Rb}^{+}$exchanged form (figure 11.9) also showed a dominant ketene peak, but shifted to higher temperature (Tmax at $385^{\circ} \mathrm{C}$ ). Both samples turned grey due to coke formation.

The $\mathrm{Ca}^{2+}$ and $\mathrm{La}^{3+}$ exchanged forms showed similar behaviour, evolving a large amount of $\mathrm{CO}_{2}$ and a small amount of ketene in a broad step from $280^{\circ} \mathrm{C}$ to $600^{\circ} \mathrm{C}$. (See figure 11.10 for the $\left.\mathrm{Ca}^{++} \mathrm{td} / \mathrm{ms}\right)$. Between $350^{\circ} \mathrm{C}$ and $600^{\circ} \mathrm{C}$ butenes, and perhaps lower alkenes, desorbed. Alkenes are products typical of the reaction of acetic acid over proton-exchanged acid zeolites, implying that these catalysts posses "acidic" as well as "basic" properties. 


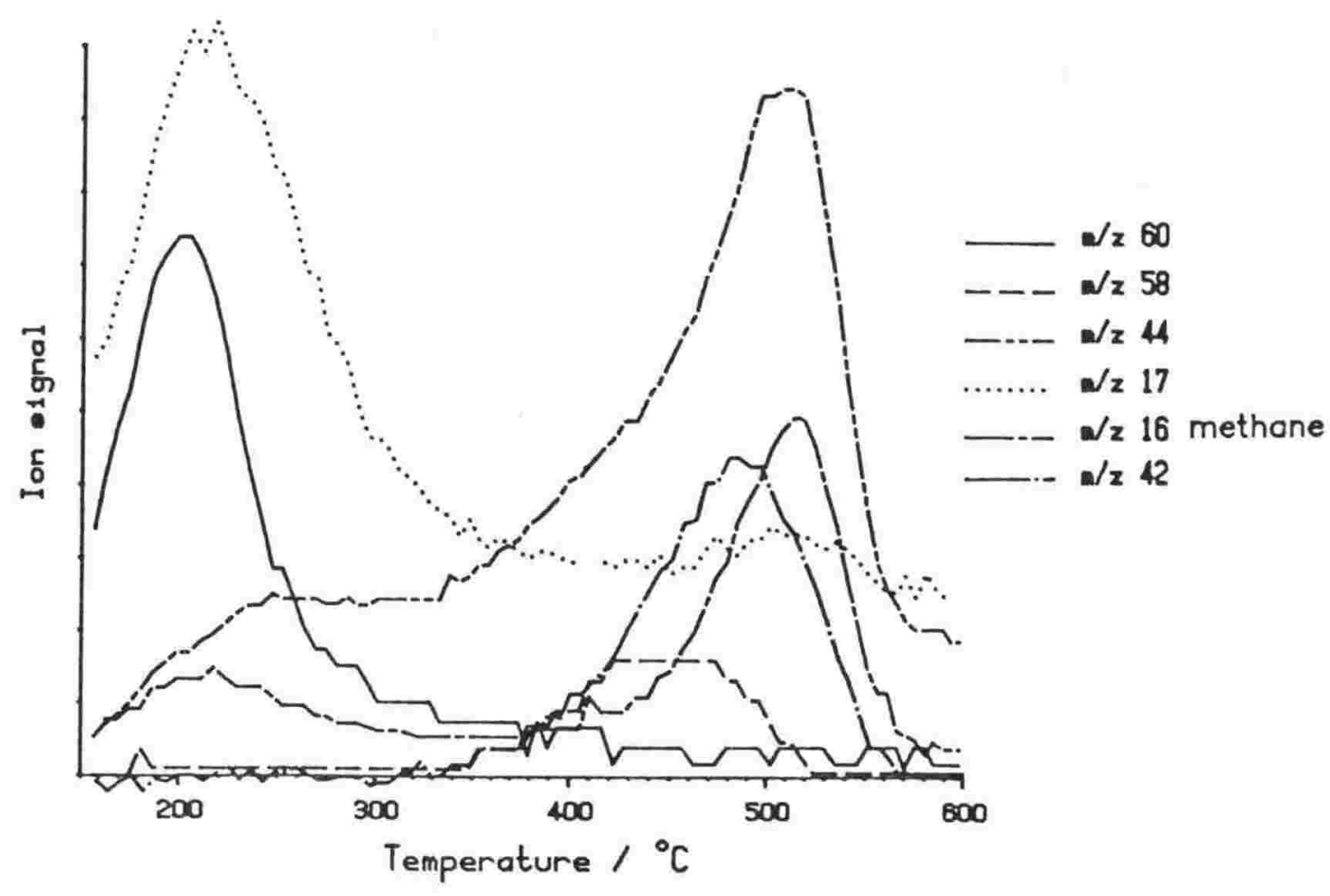

Figure 11.6. Td/ms of acetic acid sorbed on Li+chabazite.

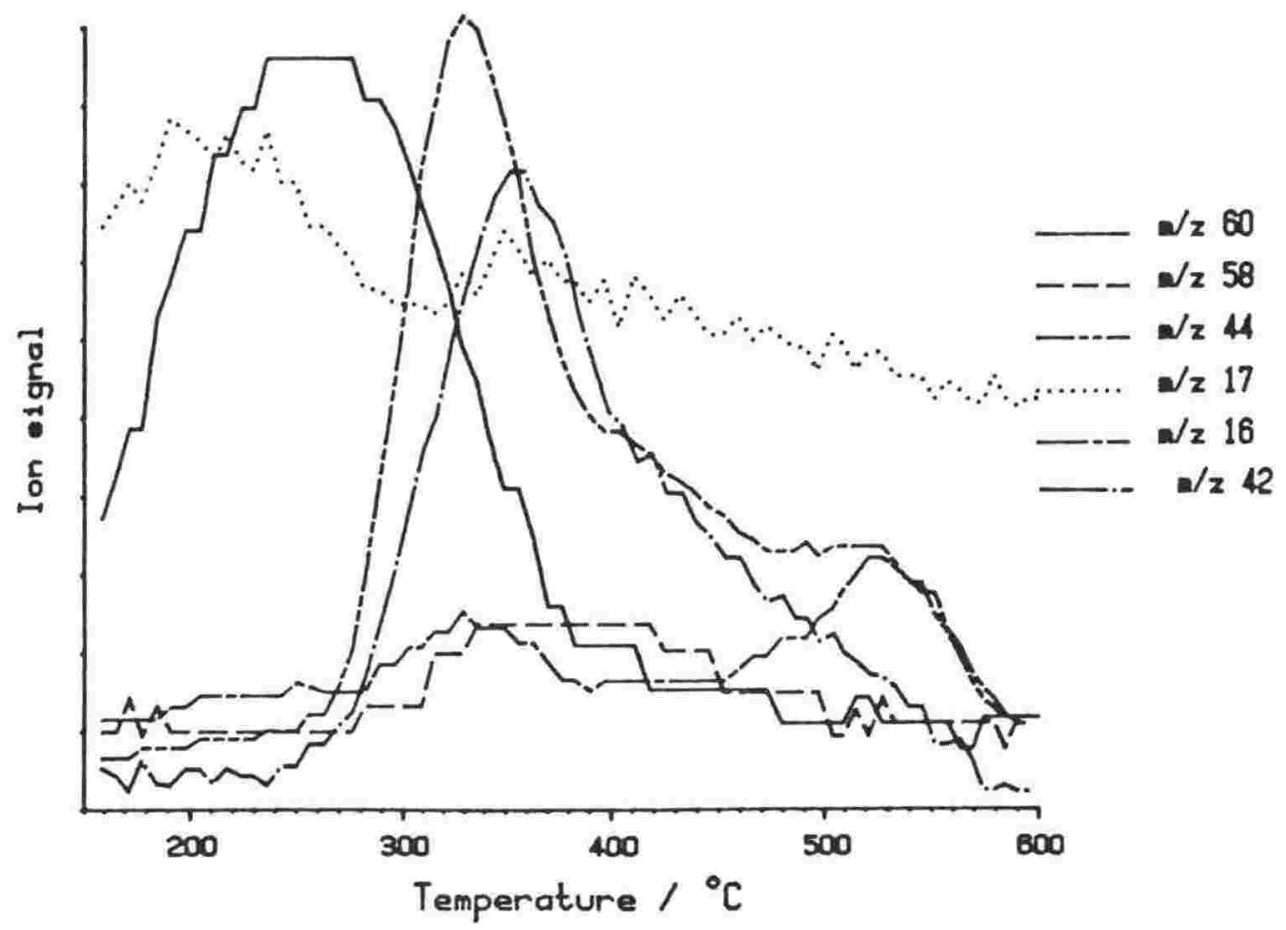

Figure 11.7. Td/ms of acetic acid sorbed on Natchabazite. 


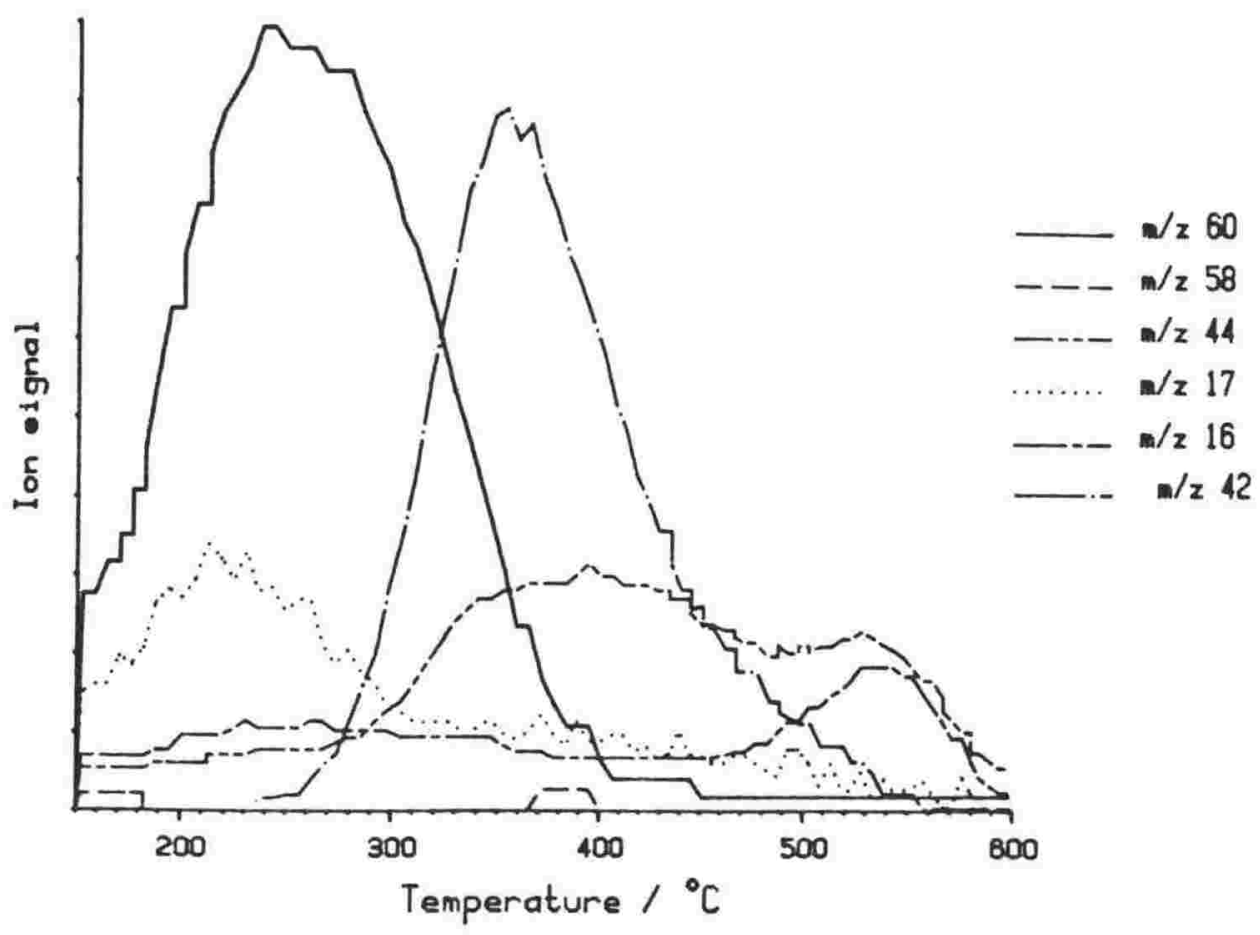

Figure 11.8. Td/ms of acetic acid sorbed on K+chabazite.

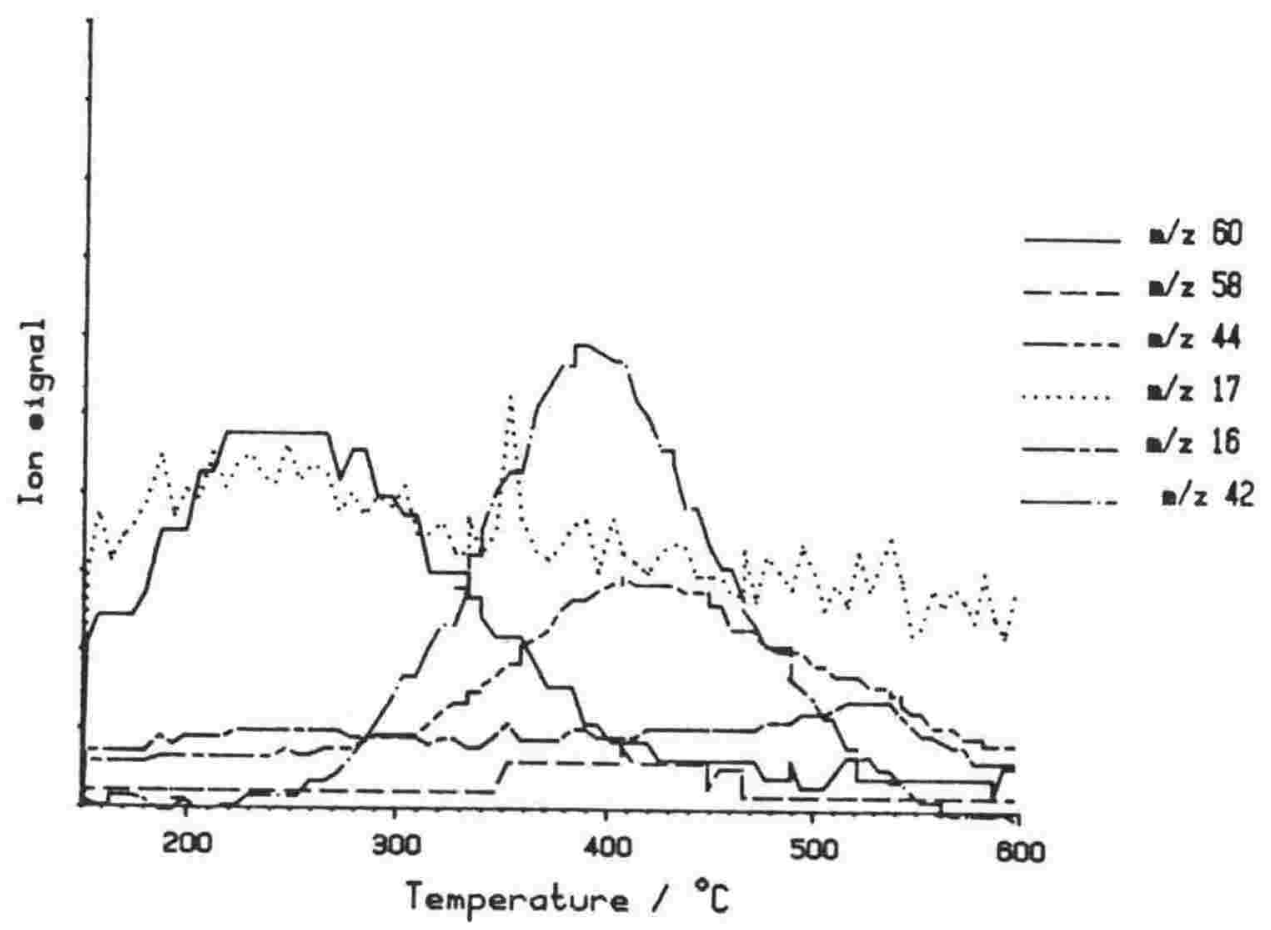

Figure 11.9. Td/ms of acetic acid sorbed on Rb+chabazite. 


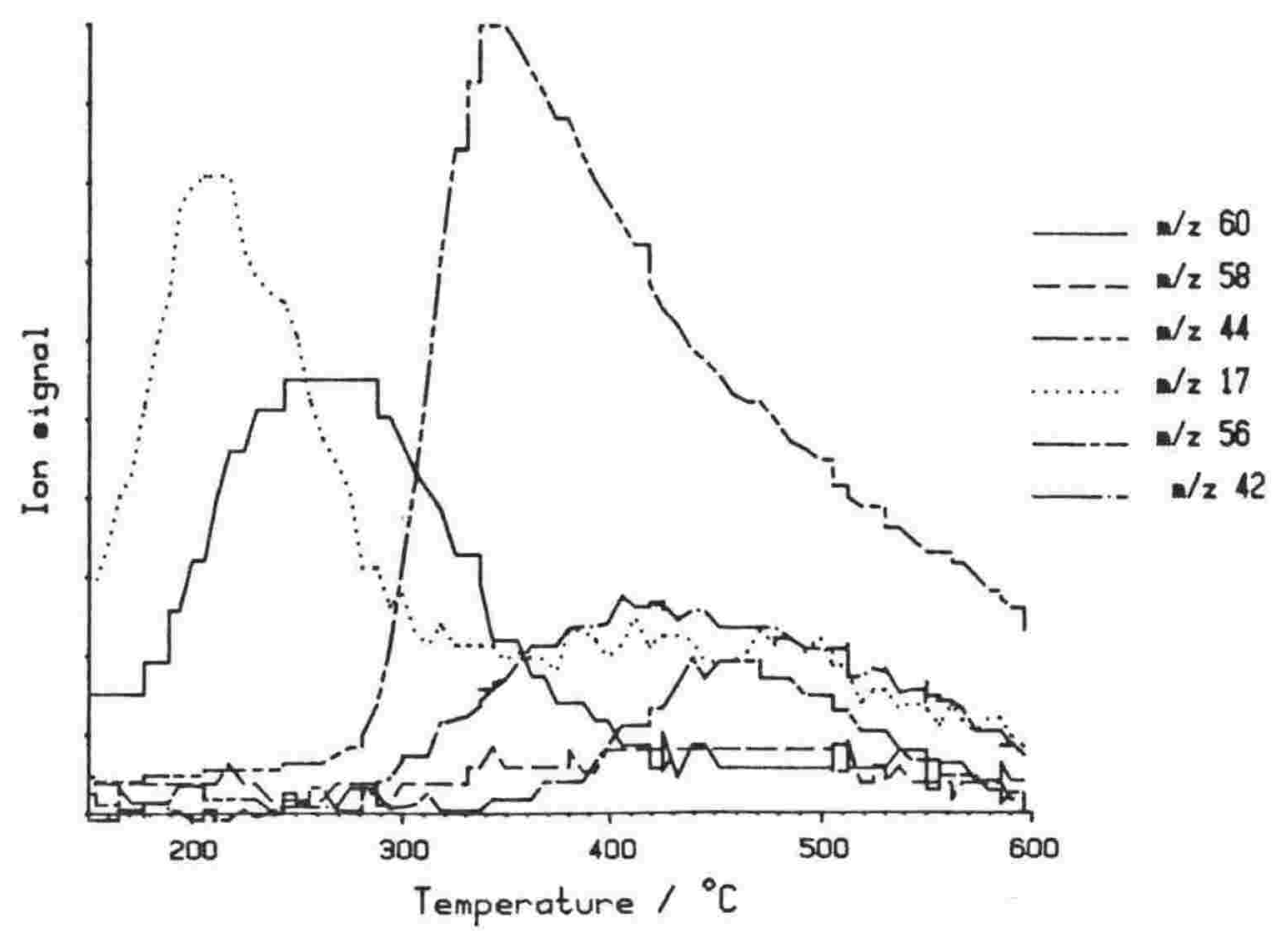

Figure 11.10. $\mathrm{Td} / \mathrm{ms}$ of acetic acid sorbed on $\mathrm{Ca}^{2+}$ chabazite.

\subsection{The FAUJASITES: Zeolites $X, Y$ and Ultrastable $Y$ :}

The zeolites $\mathrm{X}$ and $\mathrm{Y}$ have the same structure but vary in aluminium content $(1,2)$. Zeolite $X$ has 96 to $77 \mathrm{Al}$ per unit cell and zeolite $Y$ has 76 to $48 \mathrm{Al}$ per unit cell. The faujasite structure contains the largest void volume of the zeolites studied, with large cavities linked through 6-rings (2.2 $\AA$ diameter) and 12-rings (7.4 \& diameter). The 12-rings form a three dimensional channel structure. Six cation sites have been identified with the position of the cation depending on cation concentration and extent of hydration. 


\subsubsection{Zeolite $\mathrm{x}$ :}

Source: $\mathrm{Na}+\mathrm{X}$ BDH LR.

The main product from $t d / m s$ of acetic acid from $\mathrm{Li}^{+} \mathrm{X}$ was ketene (figure 11.11). This desorbed between $270^{\circ} \mathrm{C}$ and $500^{\circ} \mathrm{C}$ with a sharp maximum at $370^{\circ} \mathrm{C}$, acetone and $\mathrm{CO}_{2}$ desorbed with a maximum at $460^{\circ} \mathrm{C}$. With increasing cation size, from $\mathrm{Na}+\mathrm{X}$ to $\mathrm{Cs}+\mathrm{X}$, the maximum of the ketene desorption peak (Tmax) remained within $20^{\circ} \mathrm{C}$ of $370^{\circ} \mathrm{C}$, while the maxima of the acetone and $\mathrm{CO}_{2}$ desorption decreased. For $\mathrm{Na}+\mathrm{X}$, the temperature difference between the ketene $\operatorname{Tmax}\left(380^{\circ} \mathrm{C}\right)$ and the acetone $\operatorname{Tmax}\left(425^{\circ} \mathrm{C}\right)$ was $45^{\circ} \mathrm{C}$ and significant ketene was produced (figure 11.12). However, for $\mathrm{K}+\mathrm{X}$, acetone and $\mathrm{CO}_{2}$ desorbed with a much lower Tmax of $380^{\circ} \mathrm{C}$ and the reaction proceeded markedly in favour of acetone and $\mathrm{CO}_{2}$ (figure 11.13), with only a small amount of ketene produced. The $\mathrm{Rb}+\mathrm{X}$ and $\mathrm{Cs}+\mathrm{X}$ cases (figure 11.15) were very similar to the $\mathrm{K}+\mathrm{X}$ case. Thus in this case, the smallest cation $\left(\mathrm{Li}^{+}\right)$exchanged $\mathrm{x}$ was the best ketene producing catalyst.

$\mathrm{Td} / \mathrm{ms}$ of acetic acid on $\mathrm{Ca}^{++} \mathrm{X}$ (figure 11.16) also produced acetone and $\mathrm{CO}_{2}\left(\operatorname{Tmax}\right.$ at $490^{\circ} \mathrm{C}$ and $475^{\circ} \mathrm{C}$ respectively) and some ketene $\left(\operatorname{Tmax}\right.$ at $\left.450^{\circ} \mathrm{C}\right)$. Ketene desorbed at a higher temperature than from the alkali metal exchanged zeolite. only a trace of butene desorbed from $460^{\circ} \mathrm{C}$.

Acetic acid $t d / m s$ from $\mathrm{La}^{3+} \mathrm{x}$ (figure 11.17) showed a large $\mathrm{CO}_{2}$ desorption, with a small amount of ketene and a smaller amount of acetone. In addition, butene and perhaps other light alkenes, were observed. 


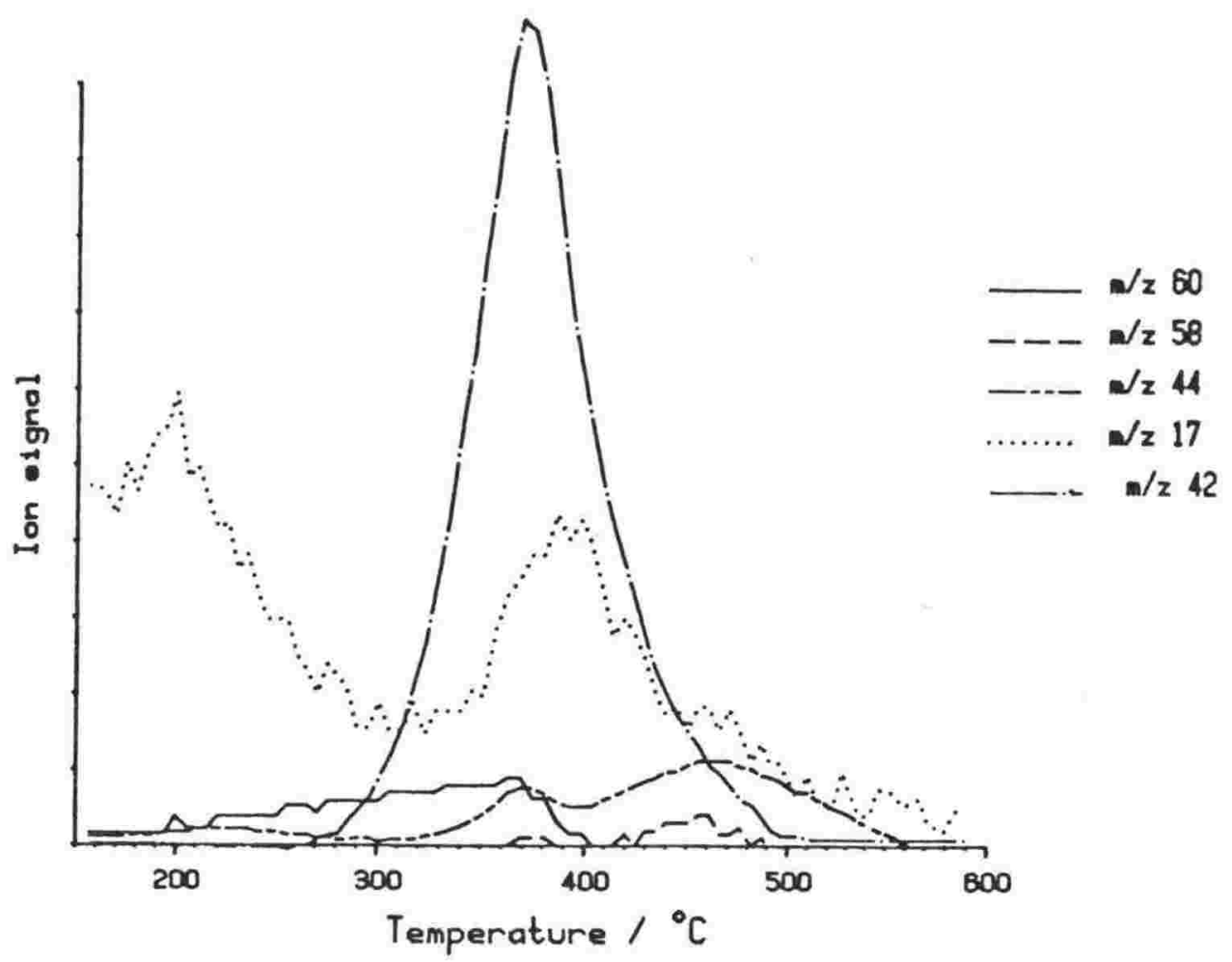

Figure 11.11. Td/ms of acetic acid sorbed on $\mathrm{Li}+\mathrm{X}$.

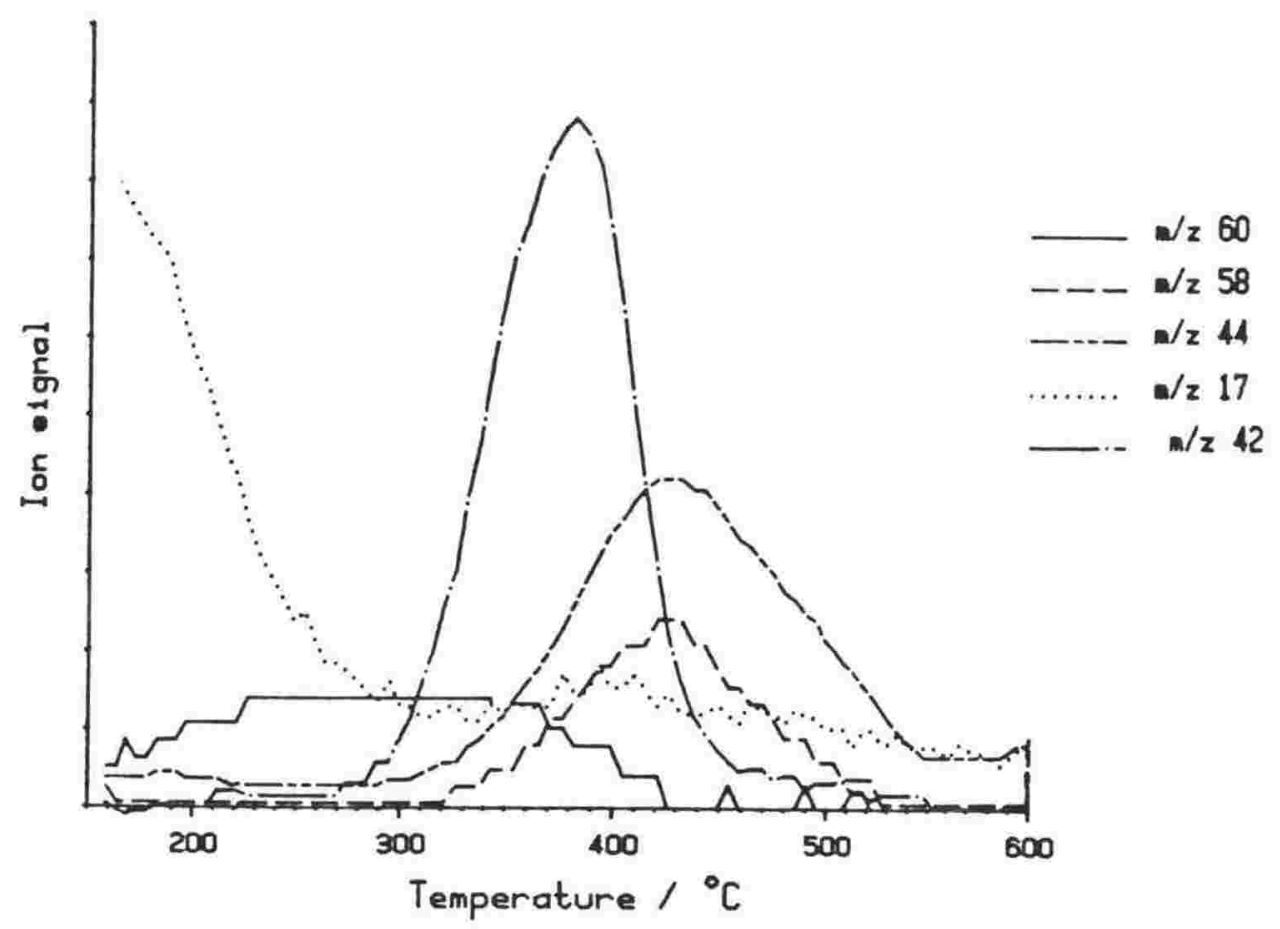

Figure 11.12. Td/ms of acetic acid sorbed on $\mathrm{Na}+\mathrm{X}$. 


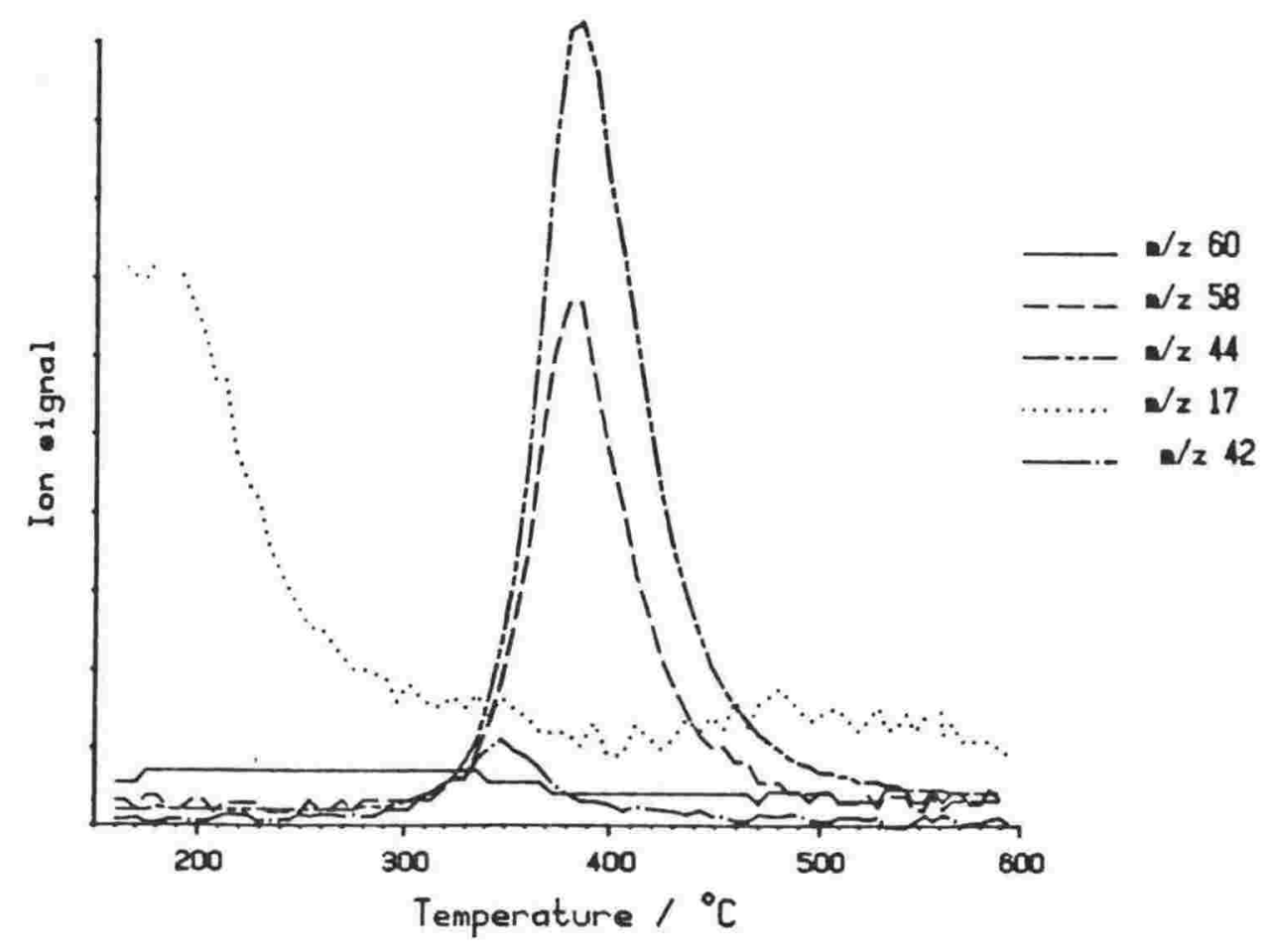

Figure 11.13. Td/ms of acetic acid sorbed on $\mathrm{K}+\mathrm{X}$.

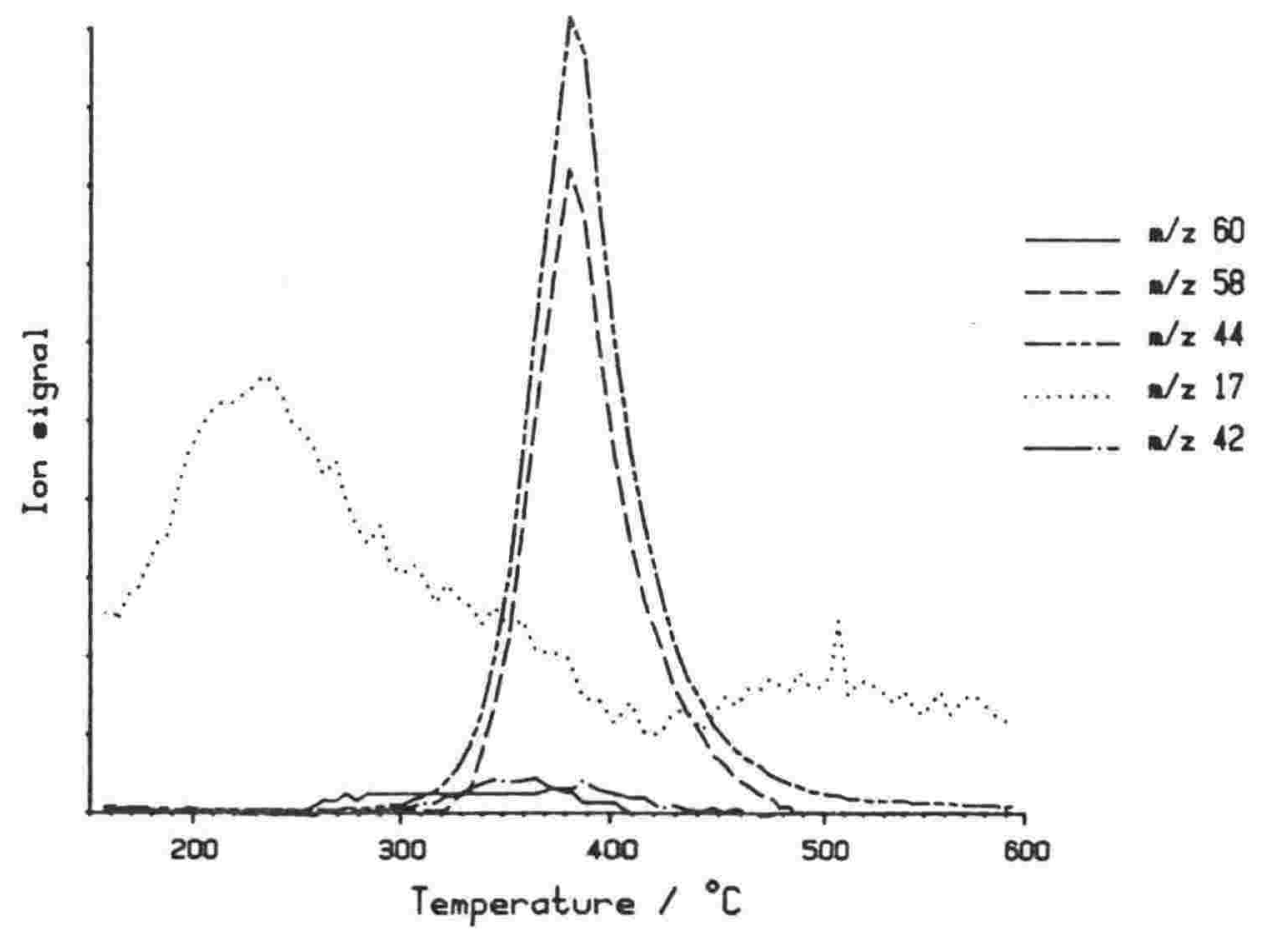

Figure 11.14. Td/ms of acetic acid sorbed on $\mathrm{Rb}+\mathrm{X}$. 


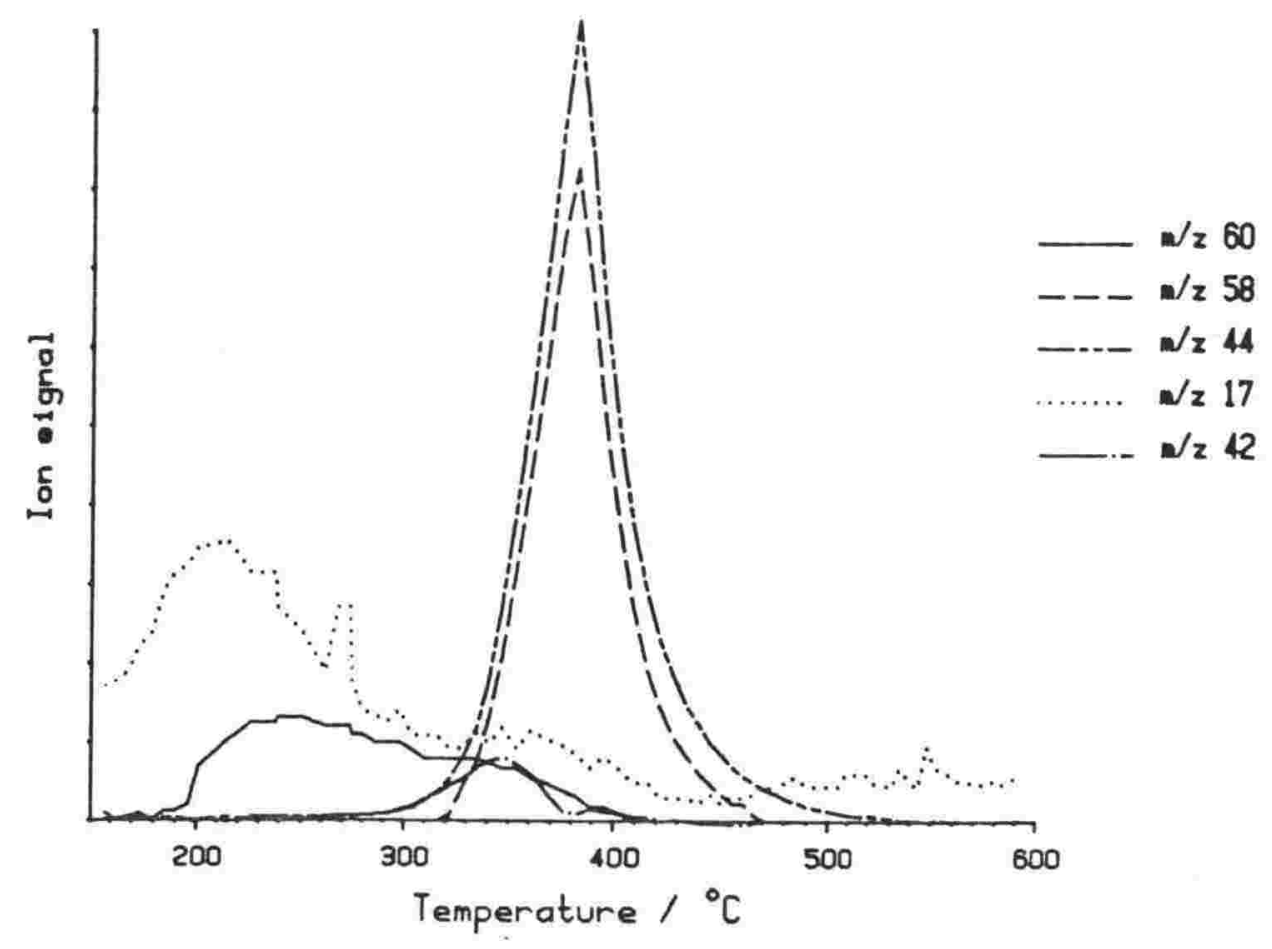

Figure 11.15. Td/ms of acetic acid sorbed on Cs+X.

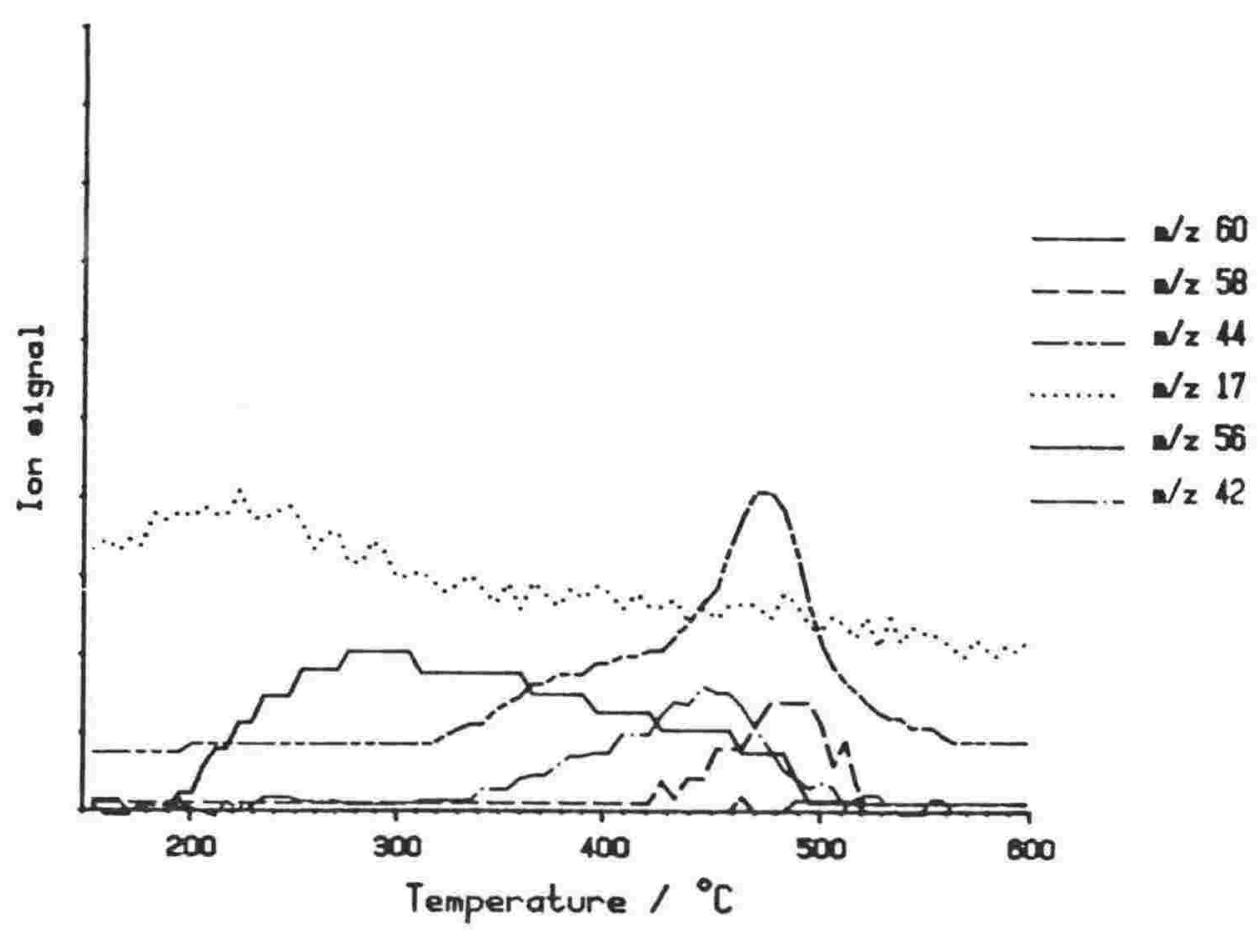

Figure 11.16. Td/ms of acetic acid sorbed on $\mathrm{Ca}^{++} \mathrm{X}$. 


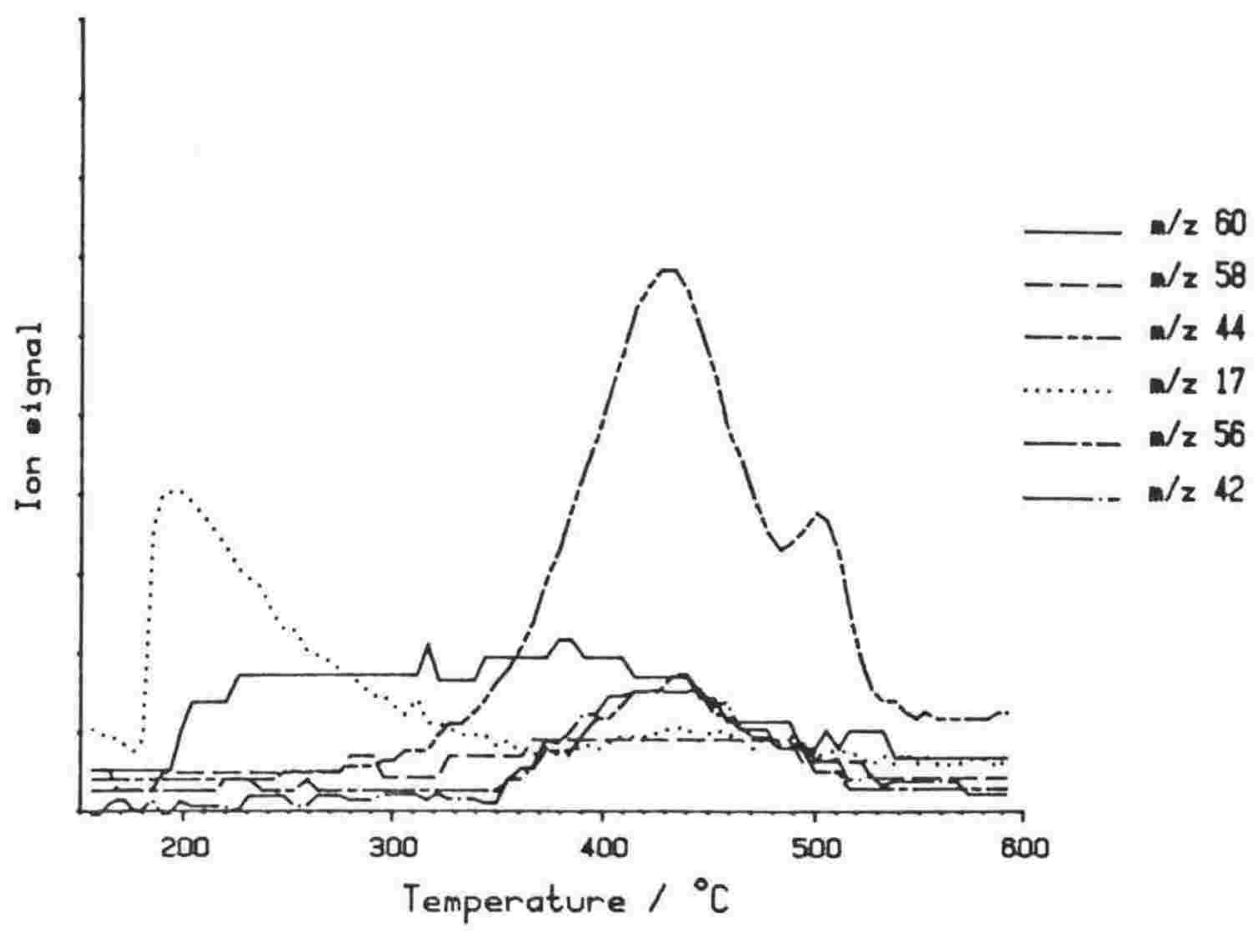

Figure 11.17. Td/ms of acetic acid sorbed on $\mathrm{La}^{3+} \mathrm{X}$.

\subsubsection{Zeolite Y:}

Source: NaY, Linde SK40, Union Carbide, lot no. 9680801014.

As for zeolite $x$, the smallest cation exchanged form was the best catalyst for producing ketene. For Li+Y (figure 11.8), the competing reaction to produce acetone and $\mathrm{CO}_{2}$ occured $75^{\circ} \mathrm{C}$ higher $\left(\operatorname{Tmax}\right.$ at $415^{\circ} \mathrm{C}$ ) than the reaction to produce ketene (Tmax at $340^{\circ} \mathrm{C}$ ). With increasing cation size, Tmax for ketene desorption decreased from $410^{\circ} \mathrm{C}\left(\mathrm{Li}+\mathrm{Y}\right.$ ) to $375^{\circ} \mathrm{C}$ ( $\mathrm{Rb}+\mathrm{Y}$ (figures $11.19,11.20,11.21))$. This meant that the amount of acetone and $\mathrm{CO}_{2}$ produced increased at the expense of ketene production. However the larger cation exchanged forms (greater than $\mathrm{Na}+\mathrm{Y}$ ) produced much more ketene than the equivalent $X$ forms. $C s+Y$ did not follow this trend, but produced a large proportion of ketene and small $\mathrm{CO}_{2}$ and acetone peaks (figure 11.22) The td/ms experiment was repeated and found to be reproducible. This was further investigated using the mini-reactor technique (see chapter $10.2 .4)$. 


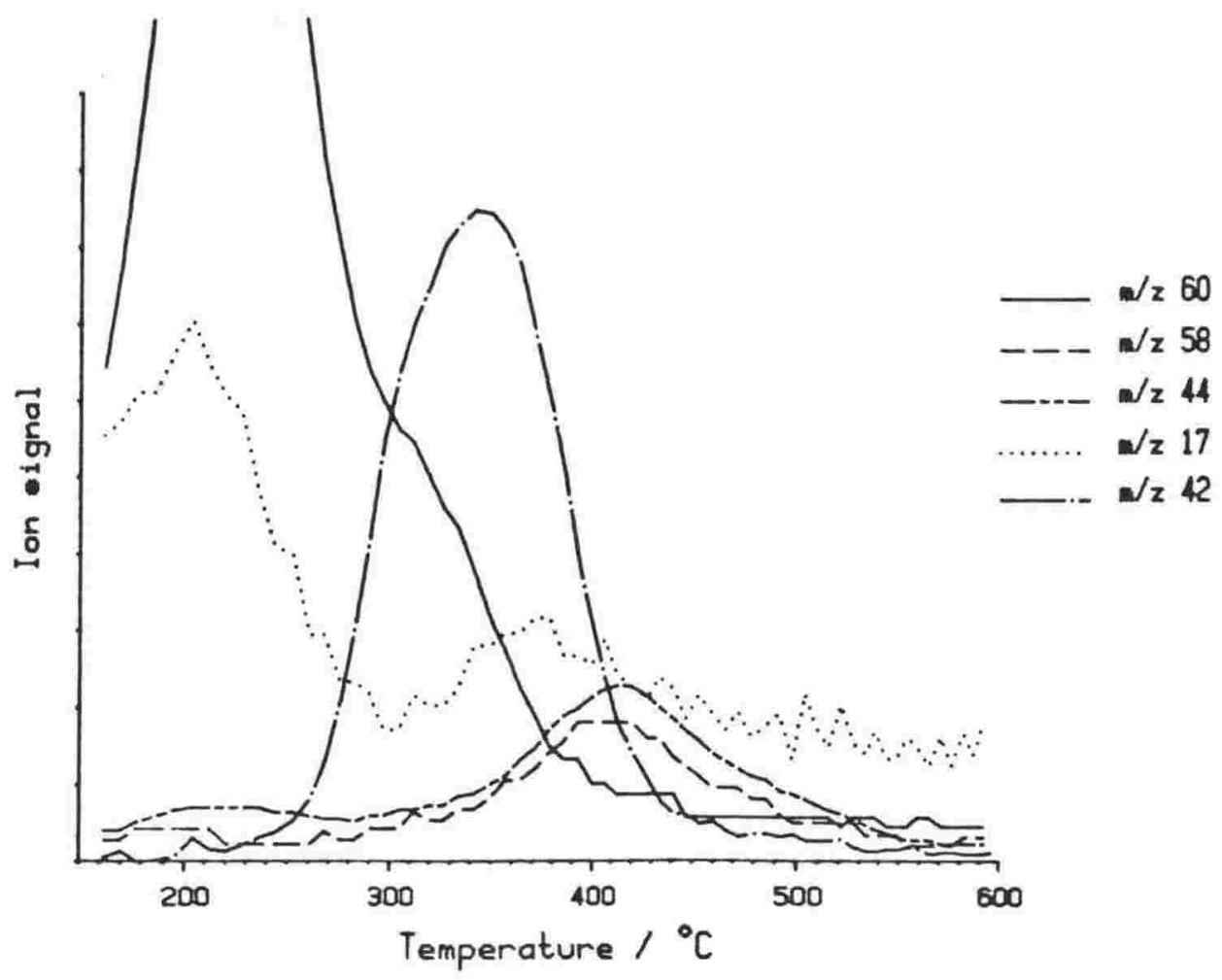

Figure 11.18. Td/ms of acetic acid sorbed on Li+Y.

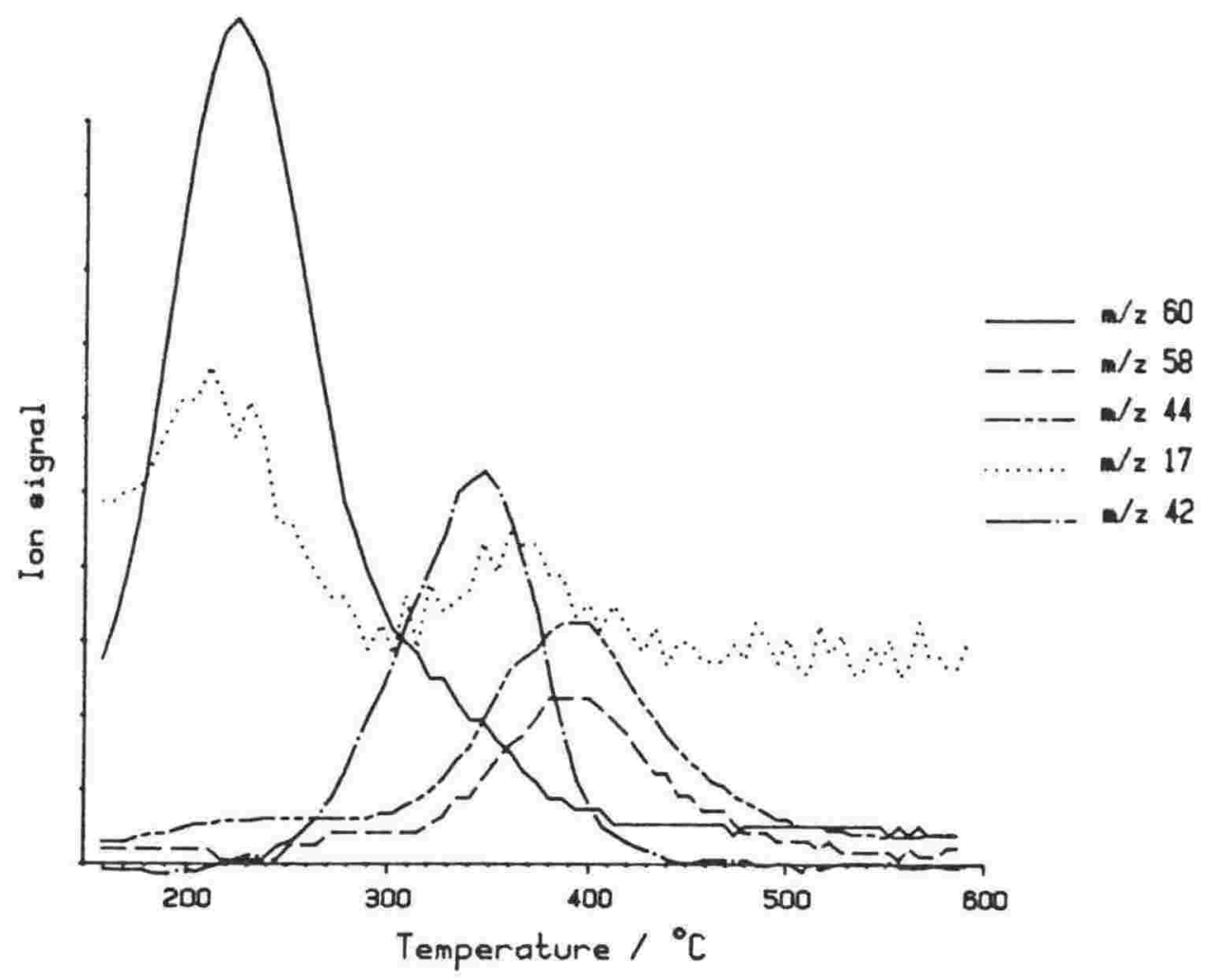

Figure 11.19. Td/ms of acetic acid sorbed on Na+Y. 


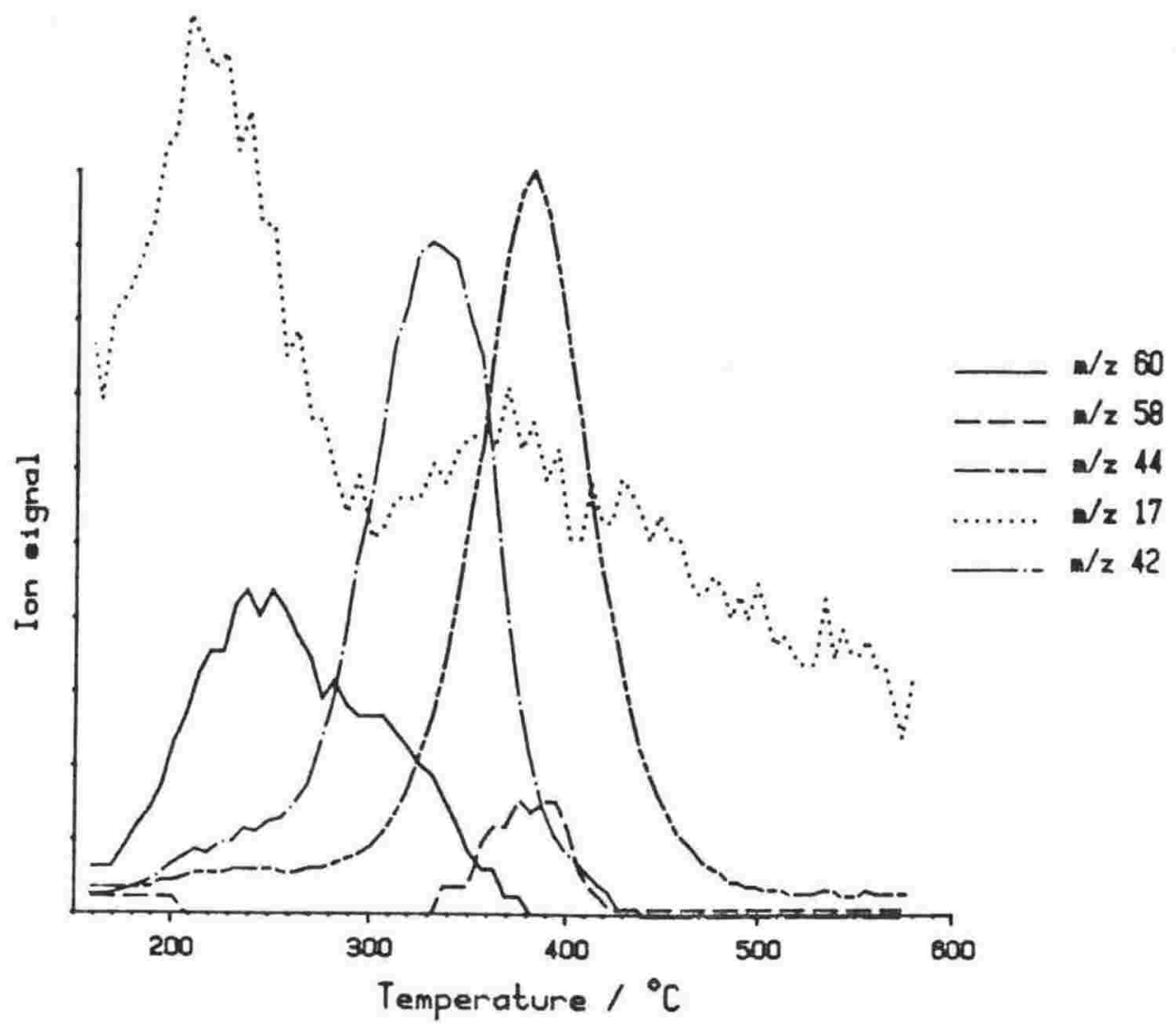

Figure 11.20. Td/ms of acetic acid sorbed on $\mathrm{K}+\mathrm{Y}$.

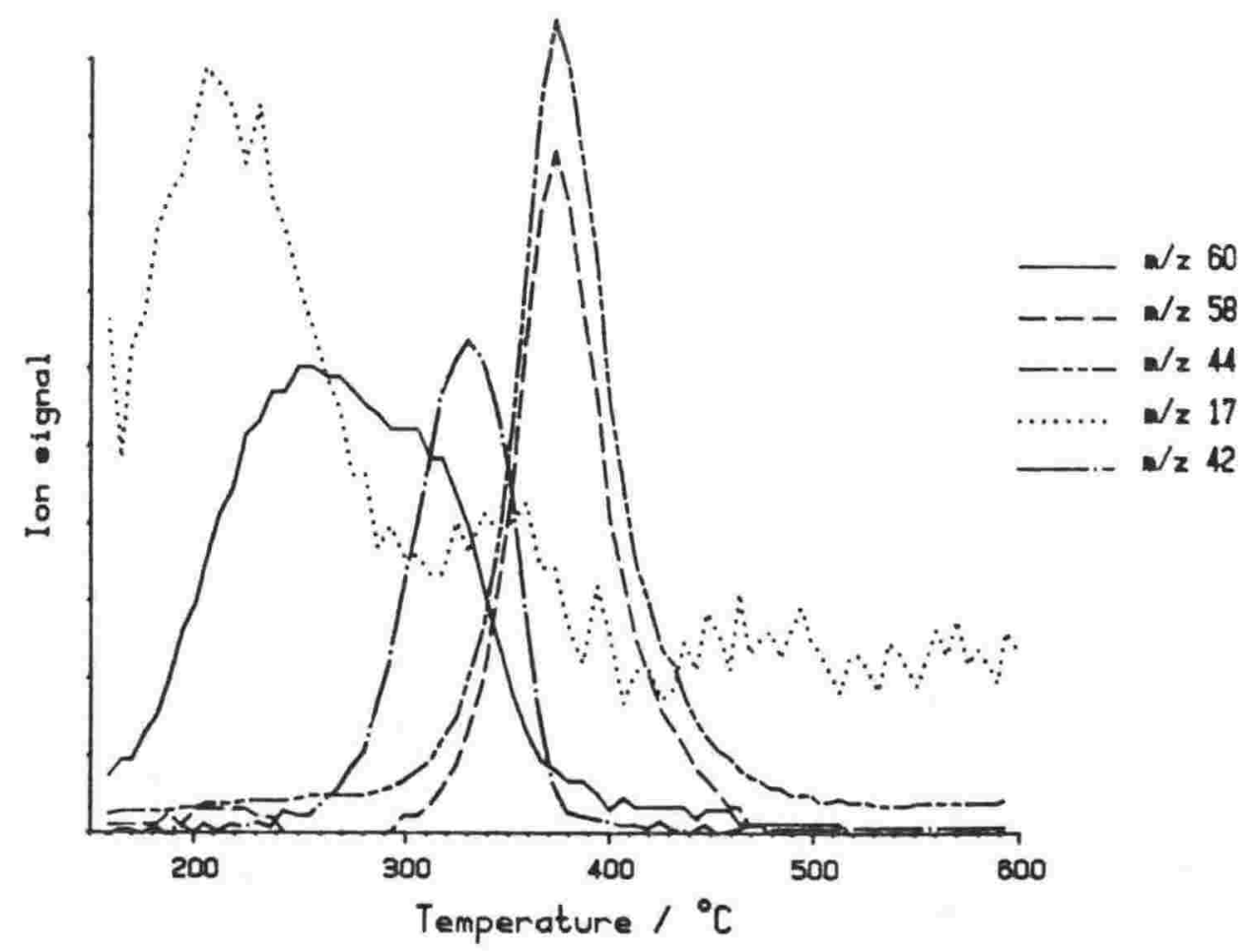

Figure 11.21. $\mathrm{Td} / \mathrm{ms}$ of acetic acid sorbed on $\mathrm{Rb}+\mathrm{Y}$. 


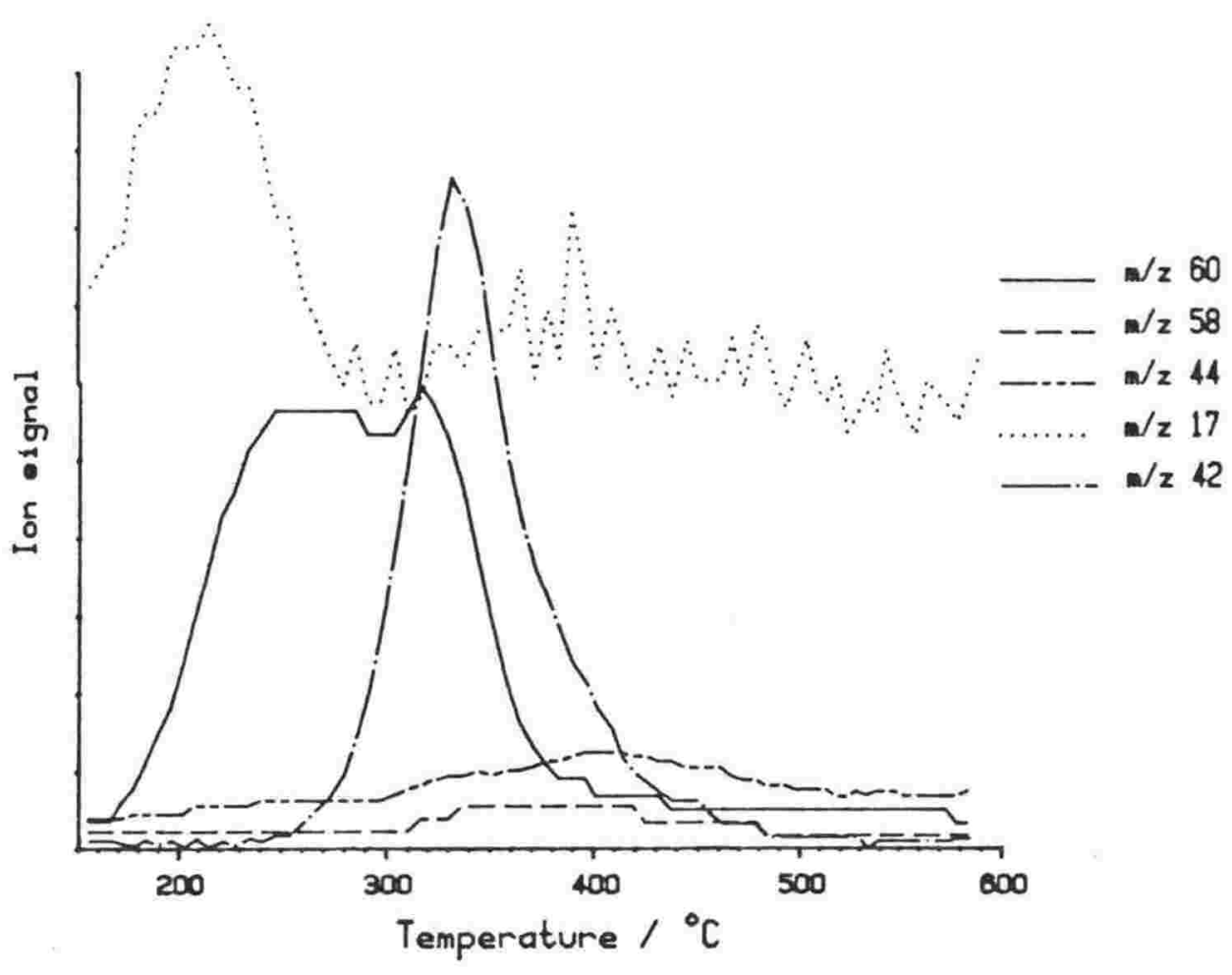

Figure 11.22. Td/ms of acetic acid sorbed on $\mathrm{Cs}+\mathrm{Y}$.

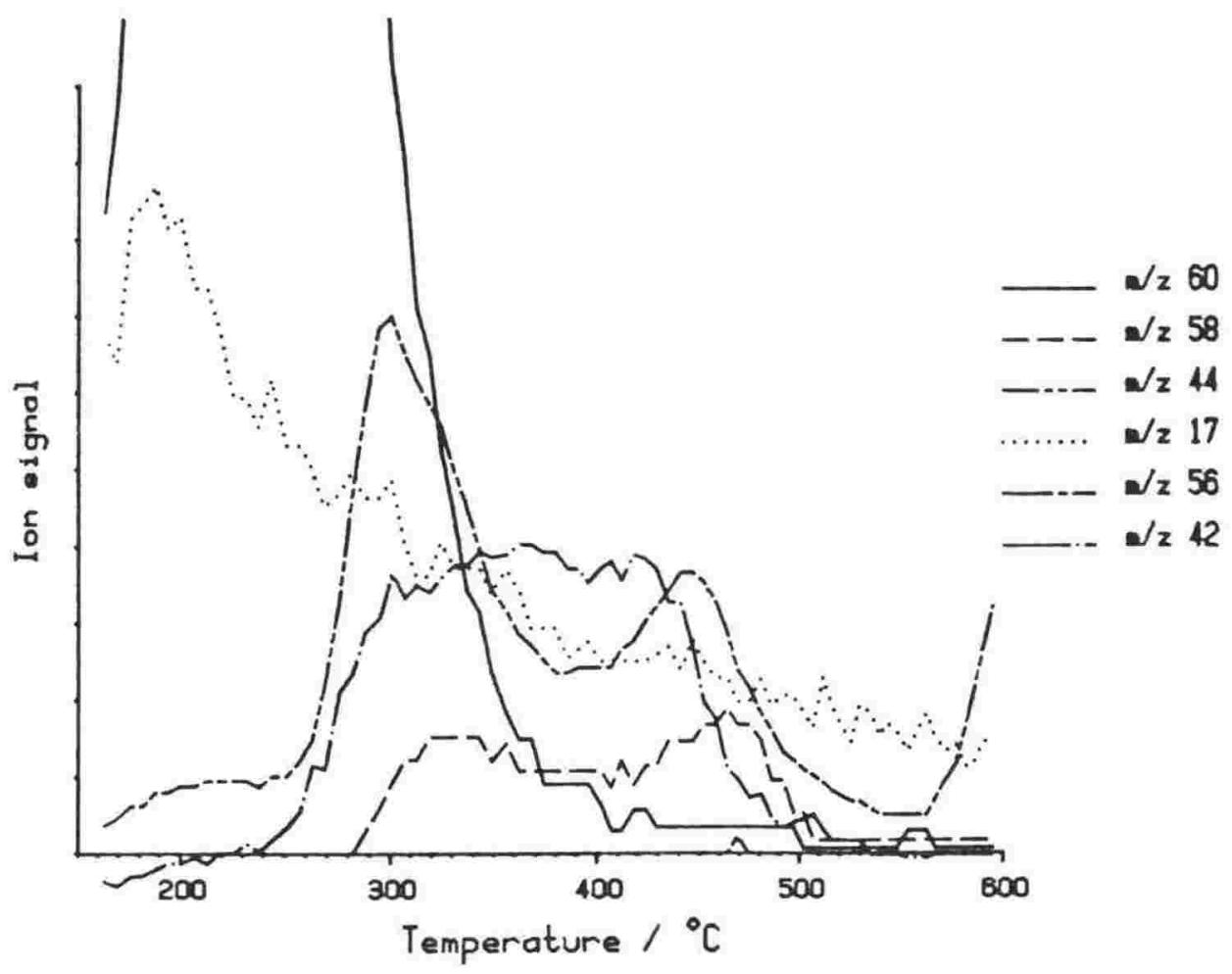

Figure 11.23. Td/ms of acetic acid sorbed on $\mathrm{Ca}^{4+} \mathrm{Y}$. 
The $\mathrm{Ca}^{2+}$ exchanged $\mathrm{Y}$ form (figure 11.23) produced $\mathrm{CO}_{2}$ and acetone in two peaks (Tmax at $310^{\circ} \mathrm{C}$ and $440^{\circ} \mathrm{C}$ ), and a broad ketene desorption from $240^{\circ} \mathrm{C}$ to $500^{\circ} \mathrm{C}$. No significant alkenes were observed.

The major product from $t d / m s$ of acetic acid sorbed on $\mathrm{La}^{3+} \mathrm{Y}$ (figure 11.25) was $\mathrm{CO}_{2}$. In addition lesser amounts of ketene, acetone and water were produced together with some butene.

$\mathrm{Td} / \mathrm{ms}$ of acetic acid sorbed on $\mathrm{Zn}^{2+}$ exchanged $\mathrm{Y}$ showed a large low temperature water desorption, with a smaller high temperature water desorption. A small amount of unreacted acetic acid desorbed with two maxima at $230^{\circ} \mathrm{C}$ and $340^{\circ} \mathrm{C}$. Aside from water, ketene was the major product, but its desorption coincided with that of $\mathrm{CO}_{2}$, acetone and butene (Tmax at $380^{\circ} \mathrm{C}$ ). The coincidence of these peaks implies that this catalyst would produce a large proportion of reaction products other than ketene when used in a isothermal reactor. The alkene produced implies that $\mathrm{Zn}^{2+}$, along with the other multiply charged cations has some acidic nature.

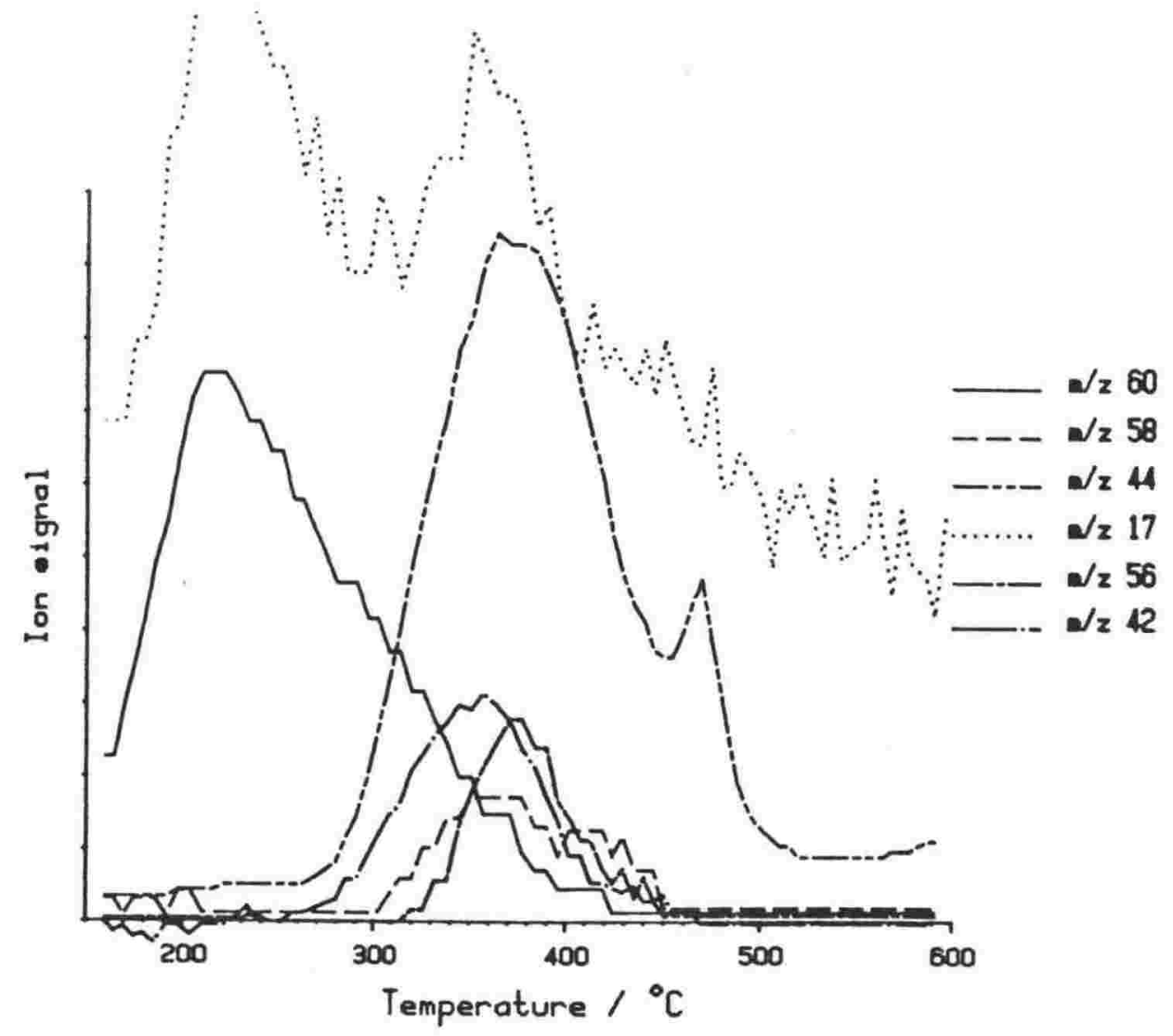

Figure 11.24. Td/ms of acetic acid sorbed on $\mathrm{La}^{3+} \mathrm{Y}$. 


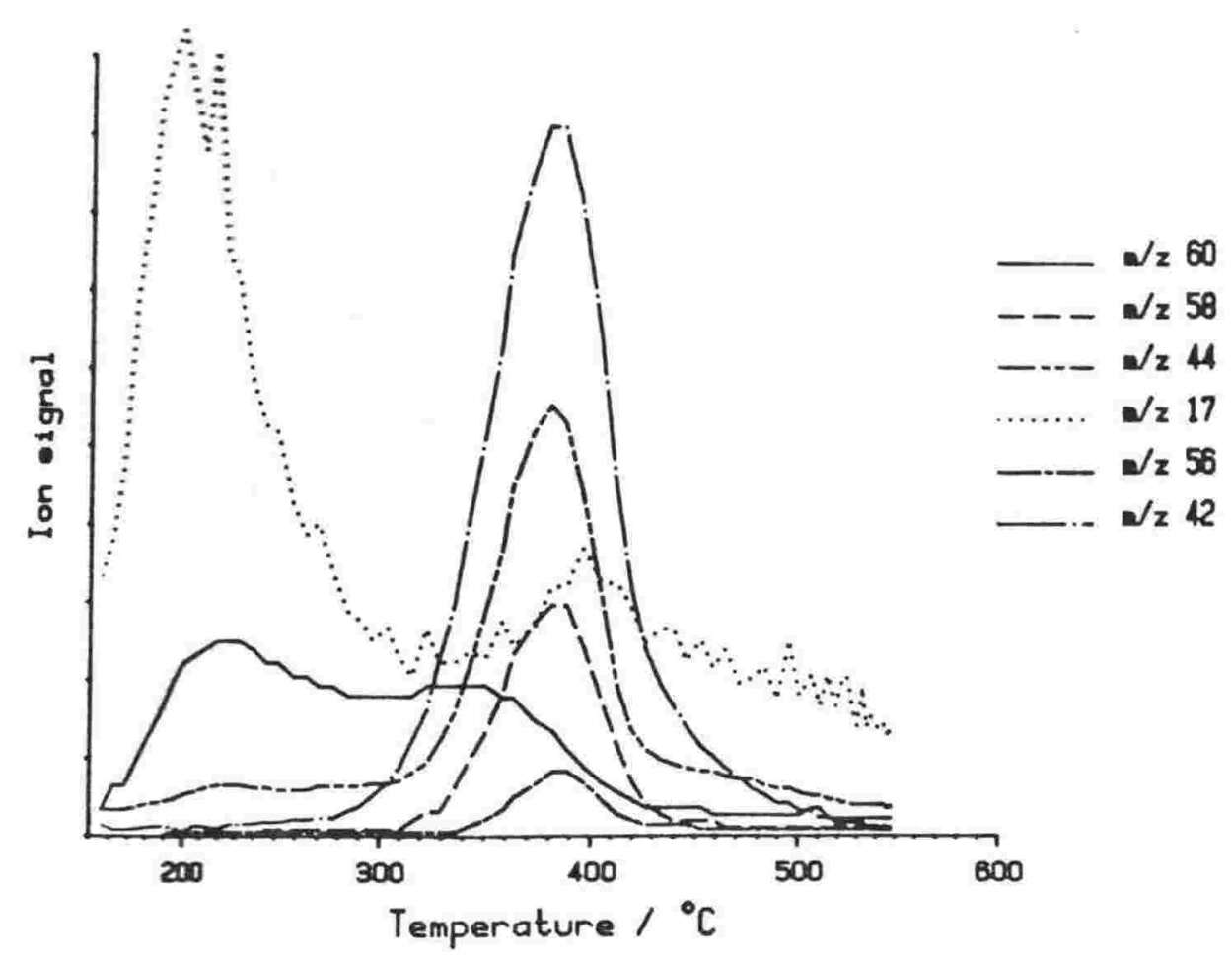

Figure 11.25. Td/ms of acetic acid sorbed on $\mathrm{Zn}^{2+} \mathrm{Y}$.

The acid $\left(\mathrm{H}^{+}\right)$exchanged form was prepared by exchange of $\mathrm{Na}^{+} \mathrm{Y}$ in $\mathrm{NH}_{4} \mathrm{NO}_{3}$ solution in a similar manner used for all other cations. The sample was then heated to $600^{\circ} \mathrm{C}$ at $10^{\circ} \mathrm{C} \cdot \mathrm{min}^{-1}$ in the td/ms tube in $\mathrm{Ar}$ atmosphere to drive off $\mathrm{NH}_{3}$, leaving $\mathrm{H}+\mathrm{Y}$. Acetic acid was then sorbed and a td/ms run (figure 11.26). There was a broad ketene desorption (Tmax at $370^{\circ} \mathrm{C}$ ) followed by a broad $\mathrm{CO}_{2}$ desorption (Tmax at $440^{\circ} \mathrm{C}$ ). Butene and some acetone were also observed.

The exchange procedure used gives incomplete exchange and the reamining $\mathrm{Na}^{+}$ions may have given rise to the mixture of 'basic' (ketene and acetone) and 'acidic' (butene) products. Further exchange of the $\mathrm{NH}_{4}{ }^{+} \mathrm{Y}$ in $\mathrm{NH}_{4} \mathrm{NO}_{3}$ solution resulted in removal of more sodium (observed qualitatively by flame photometry). The sample was then exchanged a further two times at $80^{\circ} \mathrm{C}$ to minimise the $\mathrm{Na}^{+}$content. Conversion to the $\mathrm{H}+\mathrm{Y}$ form and $t d / m s$ of sorbed acetic acid was then repeated. The results (figure 11.27) show no significant differences from the temperatures and proportions of products observed 
from figure 11.26. Further exchange of $\mathrm{H}^{+}$for $\mathrm{Na}^{+}$therefore did not effect the amount of ketene produced. Later work on the interaction of $\mathrm{H}+\mathrm{Y}$ with water (chapter 5) showed structural collapse upon desorption of sorbed water. This means that the $\mathrm{H}+\mathrm{Y}$ sample used here may have collapsed, with the ketene formed on the amorphous aluminosilicalite.

In general, the presence of Bronsted acid sites resulted in the appearance of butene in the products and an increased amount of $\mathrm{CO}_{2}$.

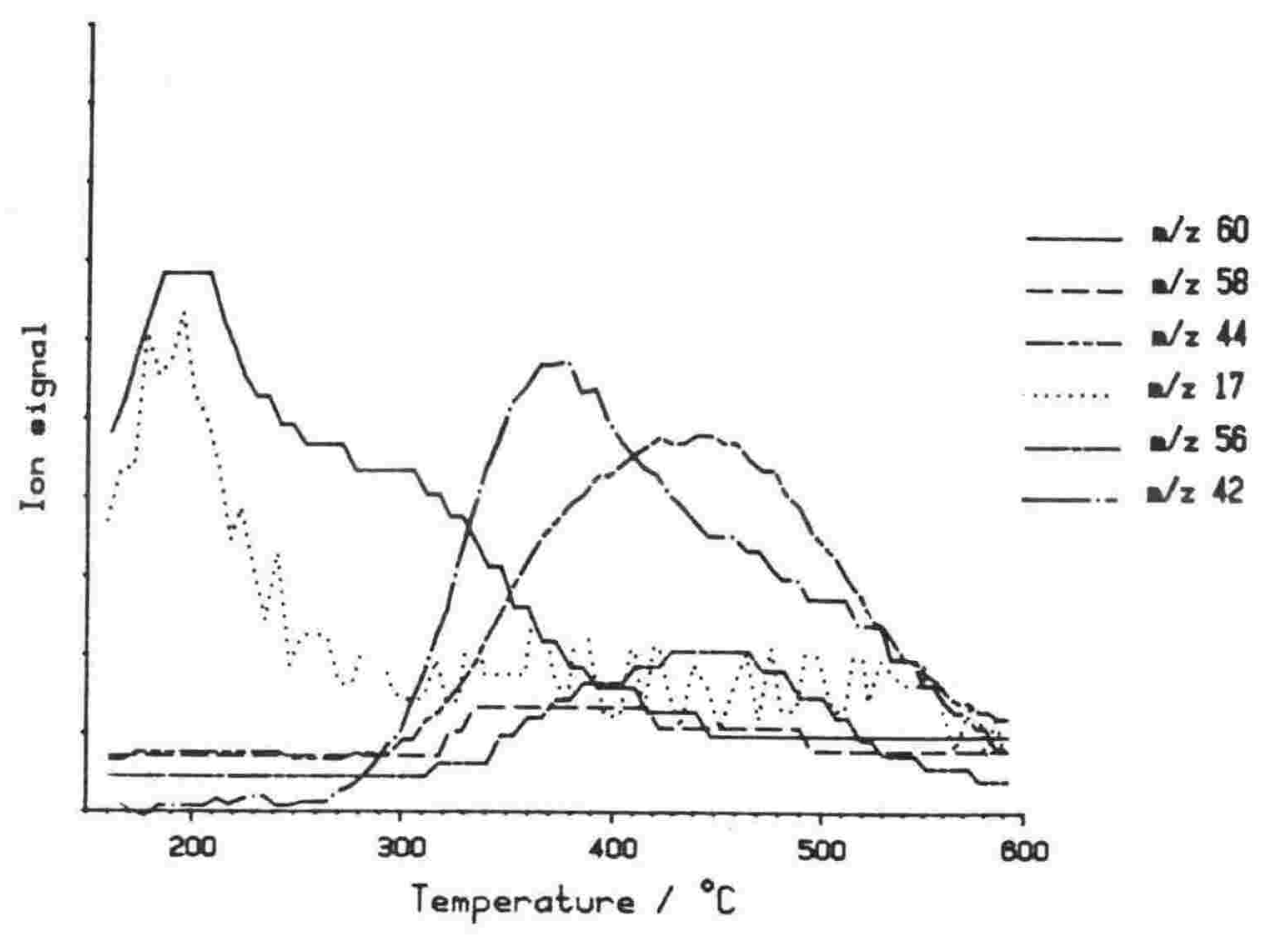

Figure 11.26. Td/ms of acetic acid sorbed on $\mathrm{H}+\mathrm{Y}$ (sample $\mathrm{A}$ ). 


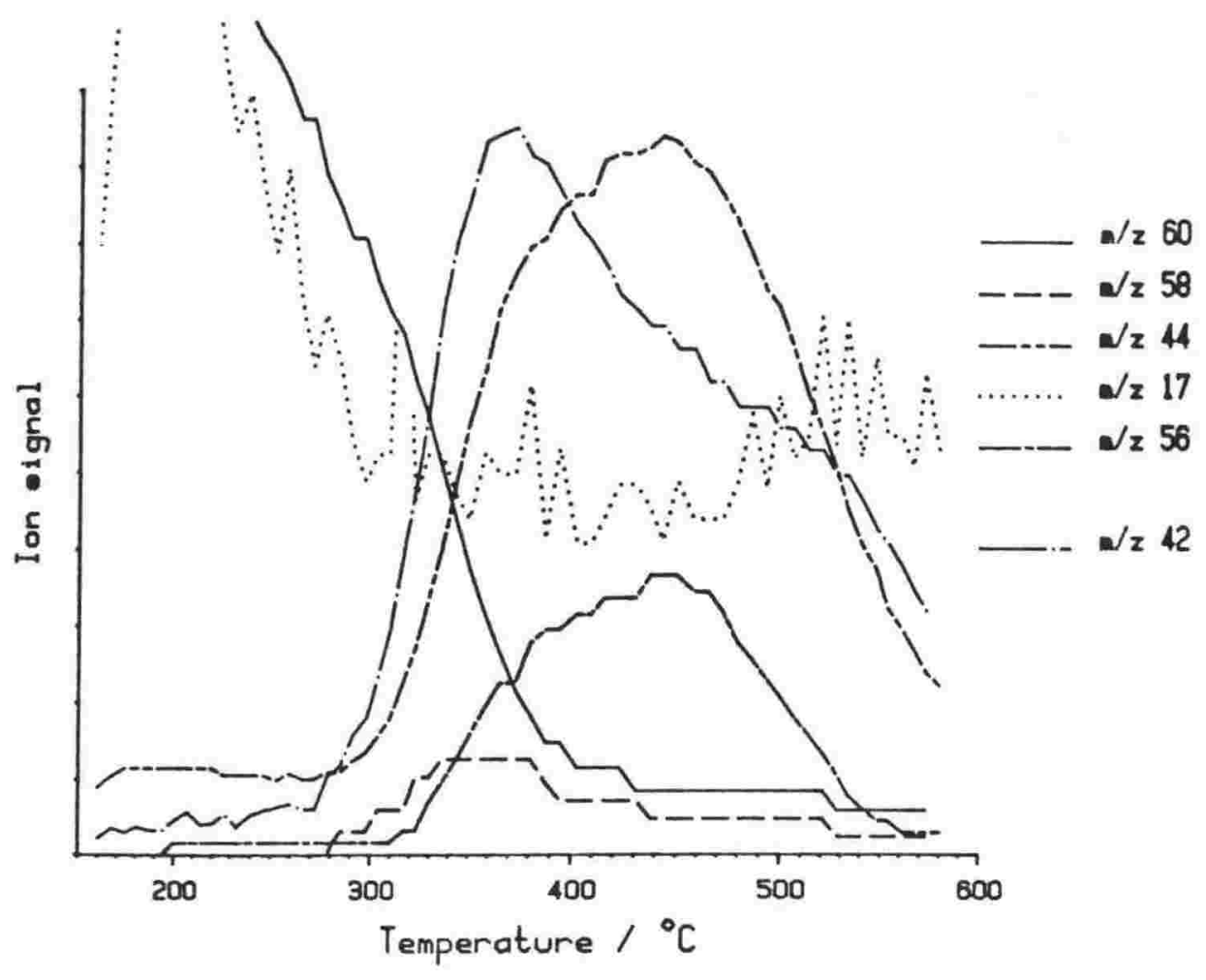

Figure 11.27. Td/ms of acetic acid sorbed on $\mathrm{H}+\mathrm{Y}$ (sample $\mathrm{C}$ ).

\section{7 .3 ULTRASTABLE Y:}

For the faujasites $\mathrm{X}$ and $\mathrm{Y}$, decreasing the alumiuium concentration (from $X$ to $Y$ ) decreased the temperature at which ketene desorbed. For zeolite $\mathrm{Y}$ the maxima for $\mathrm{Li}^{+}, \mathrm{Na}^{+}$, $\mathrm{K}^{+}$and $\mathrm{Rb}^{+}$were all within $330^{\circ} \mathrm{C}$ to $350^{\circ} \mathrm{C}$. For zeolite $\mathrm{X}$ the maxima for $\mathrm{Li}+, \mathrm{Na}+$ and $\mathrm{K}+$ were between 370 to $385 \mathrm{C}$. Ultrastable $\mathrm{Y}$ has an even lower Al concentration and was tested to determine whether ketene would be produced at a lower temperature making it an even better catalyst.

Ultrastable $\mathrm{Y}$ was obtained by steaming $\mathrm{NH}_{4}{ }^{+} \mathrm{Y}$ at $700^{\circ} \mathrm{C}$ for 1 hour (3). This resulted in the removal of Al from the framework and a decrease in the unit cell dimensions (verified by Xray powder diffraction (3)). Displaced Al remains in the channels as an aluminium oxide and may be responsible for Lewis acidity (4).

The number of moles of $\mathrm{NH}_{3}$ desorbed during $t d / m s$ of an $\mathrm{NH}_{4}{ }^{+}$ exchanged zeolite is equal to the number of acid sites (5), while the temperature of desorption gives an indication of 
the acid strength of the zeolite. Figure 11.28 shows $t d / m s$ of the $\mathrm{NH}_{4}^{+}$forms of $X, Y$ and ultrastable $Y$. The number of acid sites decreases in that order, while the temperature of desorption and therefore the acidity increases.

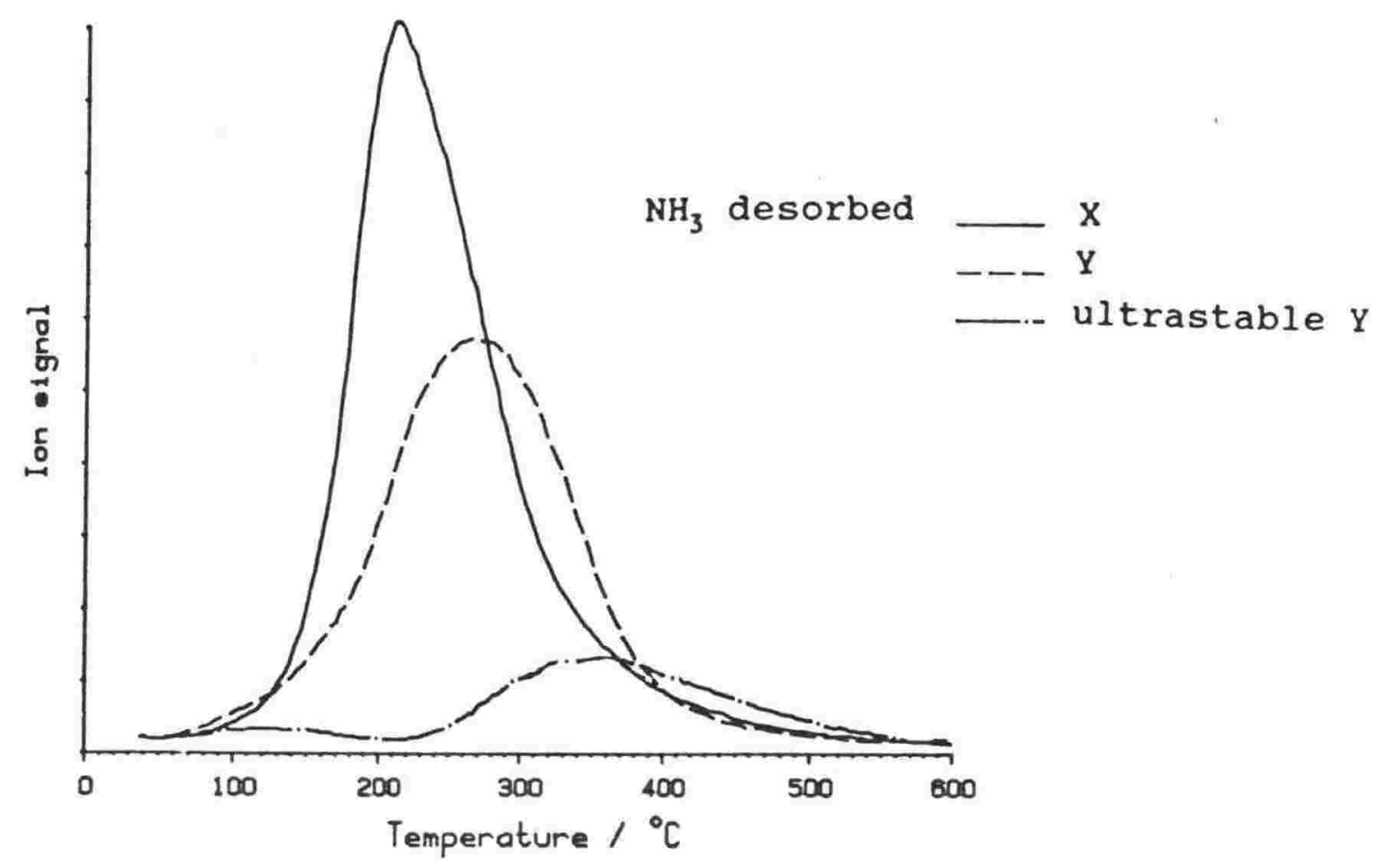

Fig. 11.28. Td/ms of the $\mathrm{NH}_{4}{ }^{+}$forms of $\mathrm{X}, \mathrm{Y}$ and ultrastable $\mathrm{Y}$.

The Lit exchanged ultrastable Y (figure 11.29) showed ketene desorption $\left(\operatorname{Tmax}\right.$ at $\left.380^{\circ} \mathrm{C}\right)$ with a greater amount of acetone and $\mathrm{CO}_{2}$ desorbed $\left(\mathrm{Tmax}\right.$ at $\left.410^{\circ} \mathrm{C}\right)$. In addition, butene desorbed, which implied that some acid sites were still present. The Li ${ }^{+}$USY sample was then heated at $500^{\circ} \mathrm{C}$ for one hour to perhaps cause movement of $\mathrm{Li}^{+}$and $\mathrm{H}^{+}$ions. This was then re-exchanged in Licl solution to remove any further $\mathrm{H}^{+}$ that had become available for exchange. A repeat $t d / m s$ experiment (figure 11.30) gave results that were very similar to $\mathrm{H}^{+} \mathrm{Na}^{+} \mathrm{Y}$ (figures 11.26 and 11.27). This implied an increase in the "acidic" nature of the catalyst. 


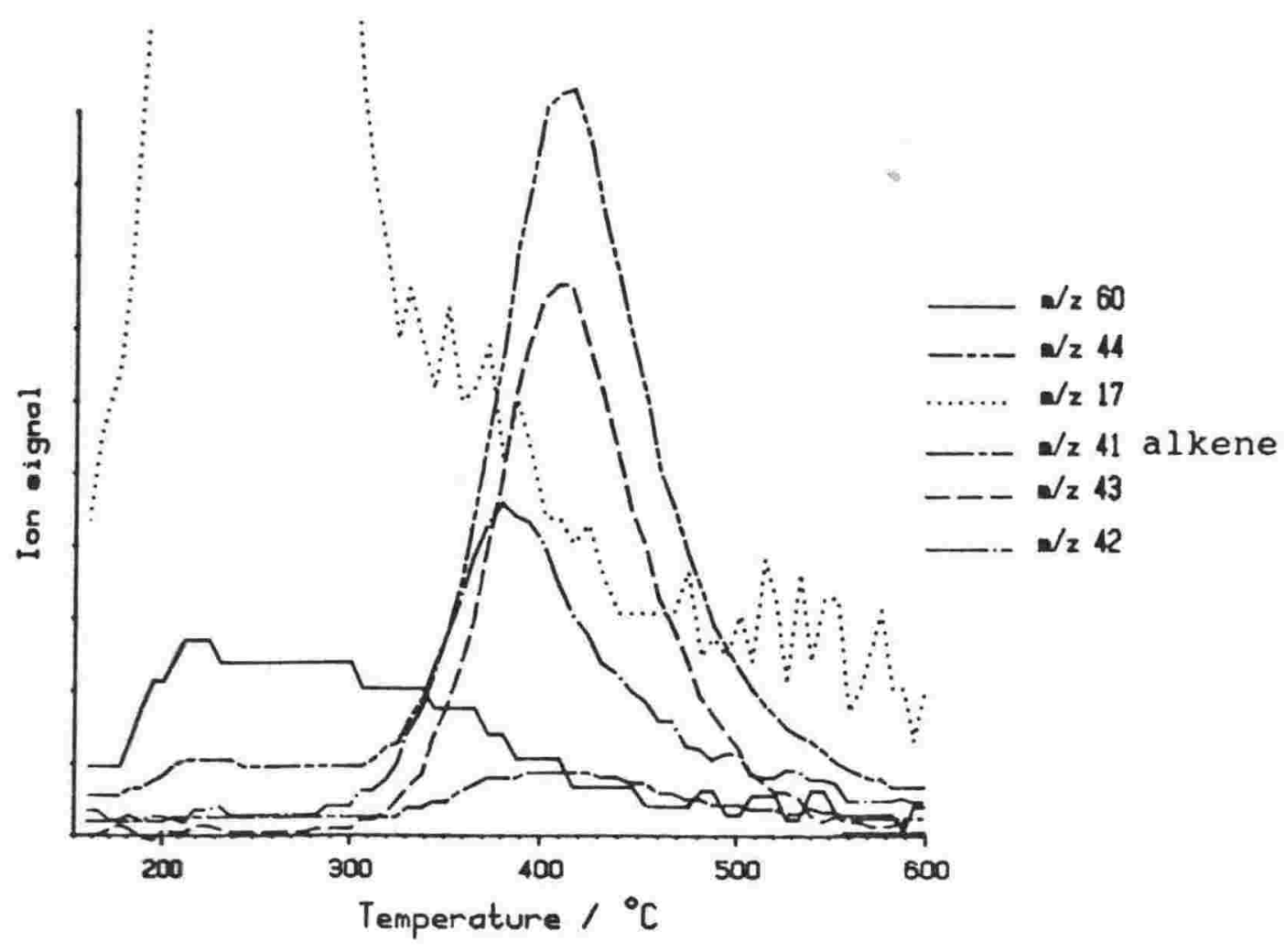

Figure 11.29. Td/ms of acetic acid on Litultrastable $\mathrm{Y}$.

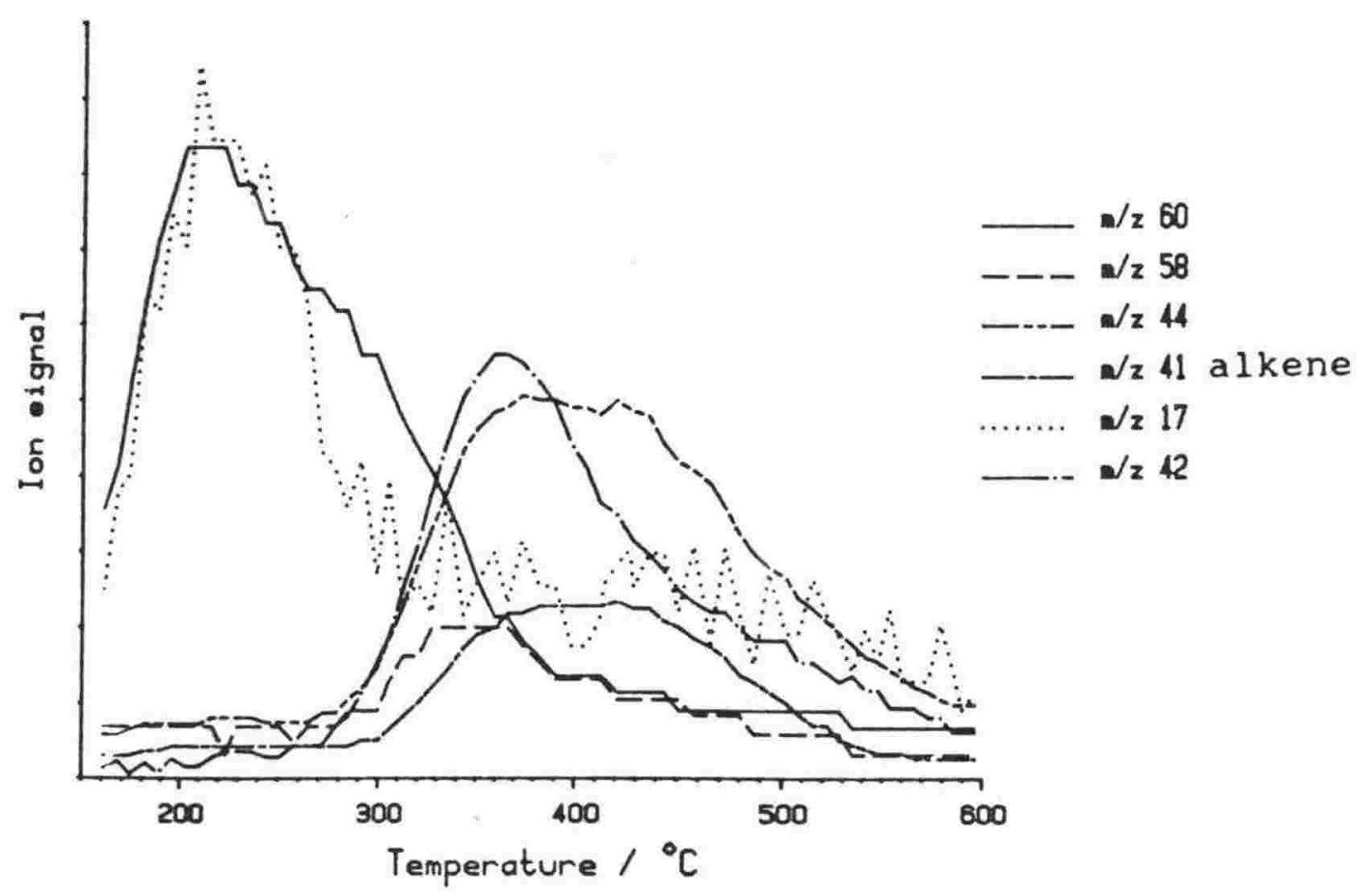

Figure 11.30. Td/ms of acetic acid on Li+ultrastable $\mathrm{Y}$, further exchanged in $\mathrm{LiCl}$. 
The Na+USY showed no acetone and a slight ketene desorption the major products were $\mathrm{CO}_{2}$ and butene (figure 11.31). For $\mathrm{K}^{+} \mathrm{USY}, \mathrm{CO}_{2}$ and acetone were the major products, then ketene and butene (figure 11.32). This was similar to Li+USY. The $\mathrm{Cs}^{+}$form was similar to $\mathrm{K}^{+} \mathrm{USY}$ (figure 11.33), the $\mathrm{Rb}^{+}$form (figure 11.34) showed a decreased ketene desorption. Both showed no significant acetone desorption.

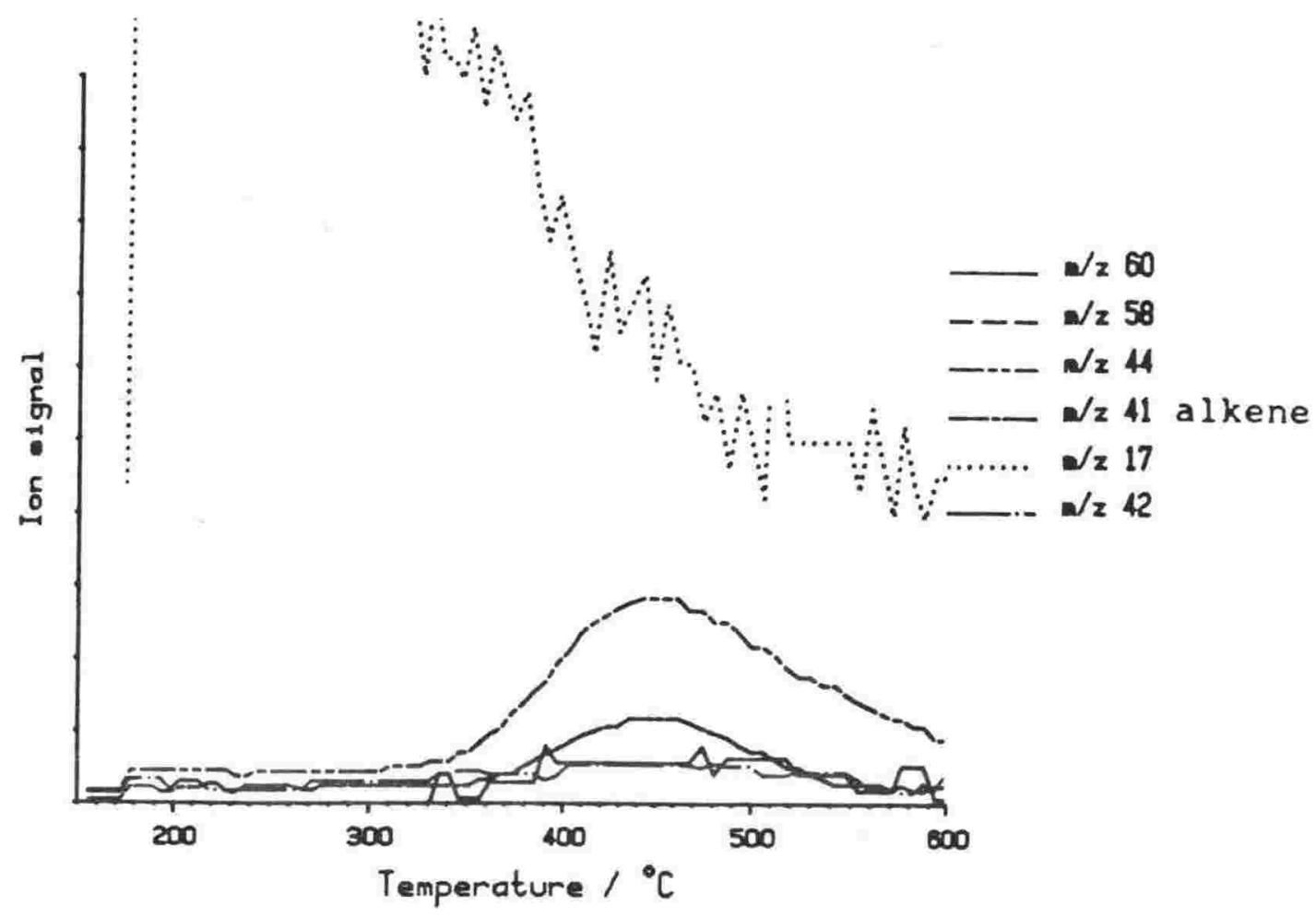

Figure 11.31. Td/ms of acetic acid on Natultrastble $\mathrm{Y}$.

The formation of the ultrastable $Y$ produced a catalyst with basic (produced ketene) and acidic (produced butene) properties. Further heating increased the acidic nature, which may have been due to aluminium oxide in the channels. It was not possible to evaluate the effect of decreasing the cation concentration from $Y$ to USY as the steric effects of descreasing the unit cell size and the presence of acid sites (due to Al oxide?) within the zeolite predominated. The combined effect was an increase in $\mathrm{CO}_{2}$ and butene production and a reduction in the proportion of ketene produced. 


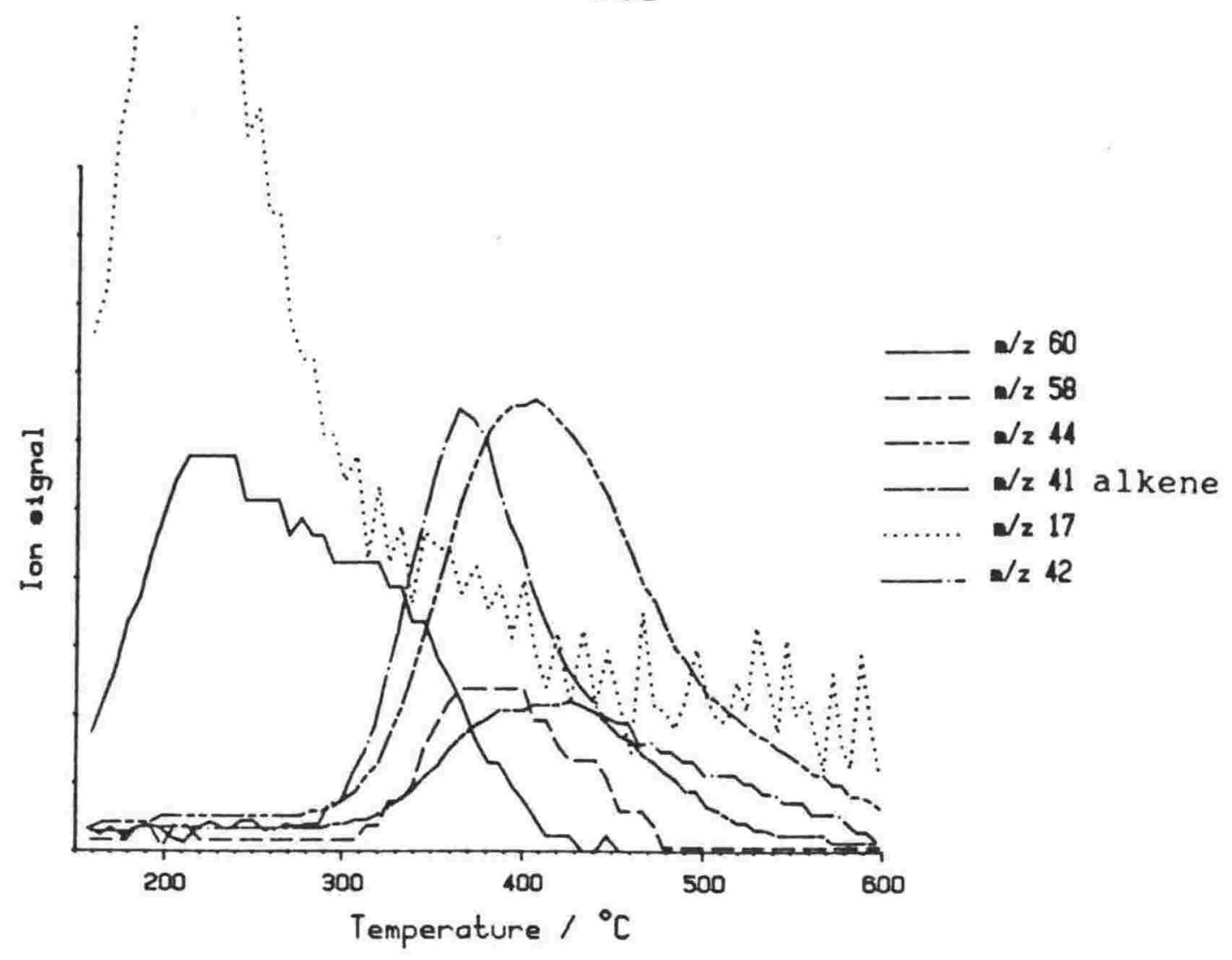

Figure 11.32. Td/ms of acetic acid on K+ultrastable Y.

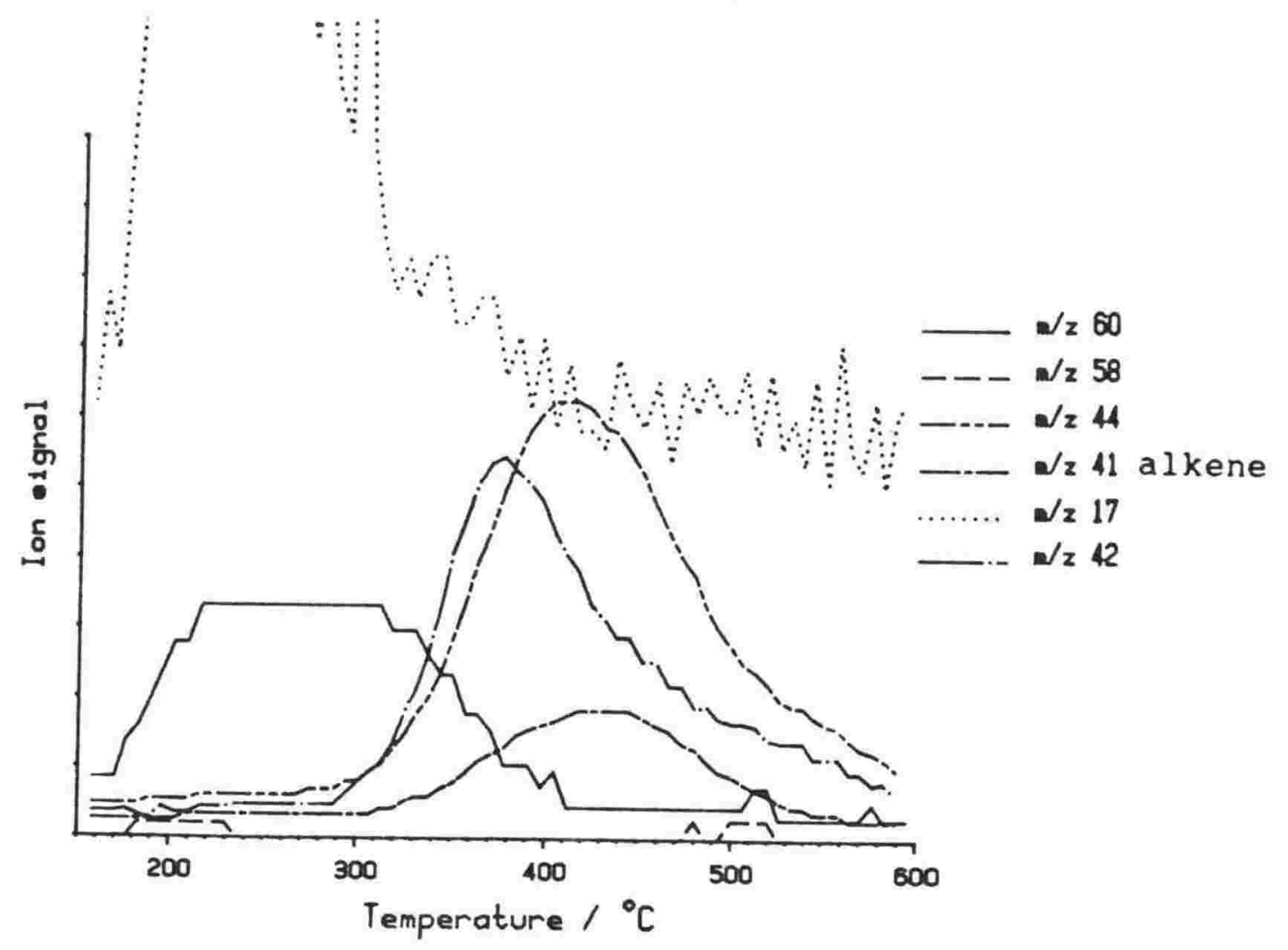

Figure 11.33. Td/ms of acetic acid on Cstultrastable Y. 


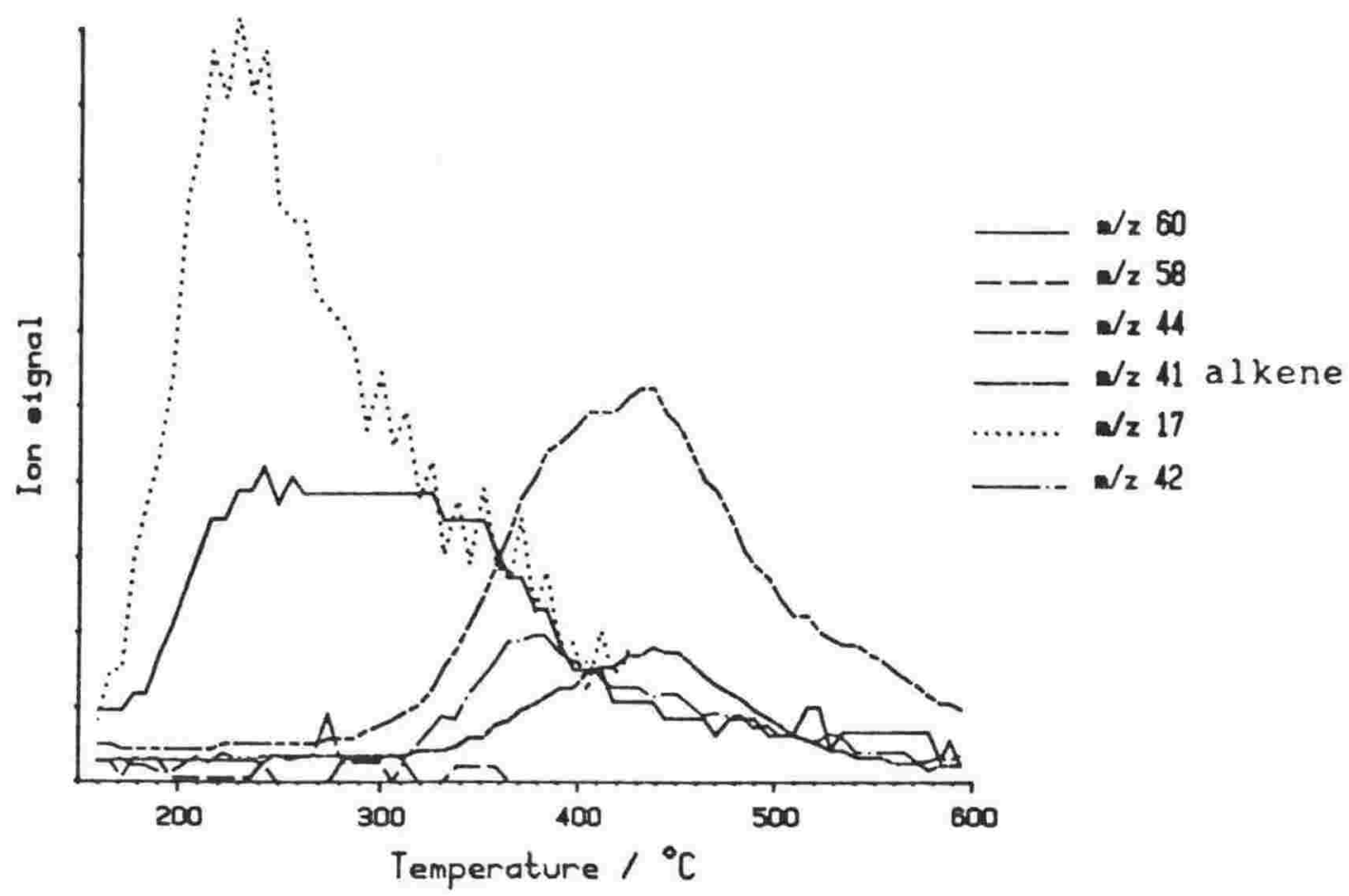

Figure 11.34. Td/ms of acetic acid on Rb+ultrastable $\mathrm{Y}$.

\section{$11.8 \mathrm{ZSM}-5$ :}

Source: synthesised according to (5) (prep 915).

Zeolite ZSM-5 has a three dimensional channel system consisting of two intersecting channel systems with 10 membered ring openings. One channel system is sinusoidal and has near circular ( 5.4 to $5.6 \AA$ ) openings. The other channel system is straight with elliptical openings (5.1 x $5.6 \AA$ ). At the intersections of the two channels additional space is available for sorbants. ZSM-5 has a low aluminium content, typically 3 Al/unit cell $(2,6)$.

$\mathrm{Td} / \mathrm{ms}$ of acetic acid sorbed on $\mathrm{H}+\mathrm{ZSM}-5$ showed acetic acid desorption, with the main reaction products being $\mathrm{CO}_{2}$ and ethene $\left(T \max\right.$ at $\left.240^{\circ} \mathrm{C}\right)$. Small amounts of methane and acetone were also observed. Just above background level was a broad ketene desorption from $220^{\circ} \mathrm{C}$ to $540^{\circ} \mathrm{C}$.

$\mathrm{Td} / \mathrm{ms}$ of acetic acid on $\mathrm{Li}+\mathrm{ZSM}-5$ resulted in a broad ketene desorption from $280^{\circ} \mathrm{C}$ to $550^{\circ} \mathrm{C}$ with $\mathrm{Tmax}$ at $350^{\circ} \mathrm{C} . \mathrm{CO}_{2}$ desorbed over a wide temperature range from $180^{\circ} \mathrm{C}$ to $570^{\circ} \mathrm{C}$ 
with a peak at $350^{\circ} \mathrm{C}$. Between $300^{\circ} \mathrm{C}$ and $500^{\circ} \mathrm{C}$, acetone desorbed and some of the $\mathrm{CO}_{2}$ evolution would have been associated with this. The $\mathrm{CO}_{2}$ that desorbed at lower temperatures must have been strongly sorbed, probably associated with the lithium cations. It was not as strongly bound as lithium carbonate, which, according to Duval (7), is stable up to $428^{\circ} \mathrm{C}$.

$\mathrm{Td} / \mathrm{ms}$ of Na+ZSM-5 showed a large desorption of ketene (Tmax at $370^{\circ} \mathrm{C}$ ) and a smaller amount of $\mathrm{CO}_{2}$ and acetone ( $\mathrm{Tmax}$ at $390^{\circ} \mathrm{C}$ ). There was a water desorption before the ketene peak which was small compared to the amount of ketene.

ZSM-5 exchanged with the larger cations $\mathrm{K}+, \mathrm{Rb}+$ and $\mathrm{Cs}+$ sorbed very little acetic acid at $150^{\circ} \mathrm{C}$. $\mathrm{K}^{+} \mathrm{ZSM}-5$ (figure 11.38), $\mathrm{Cs}^{+} \mathrm{ZSM}-5$ and $\mathrm{Rb}^{+} \mathrm{ZSM}-5$ (figure 11.39) showed only a small amount of ketene, with no other major products.

$\mathrm{Ca}^{2+} \mathrm{ZSM}-5$ (figure 11.40) showed desorption of unreacted acetic acid and low temperature ( Tmax at $250^{\circ} \mathrm{C}$ ) $\mathrm{CO}_{2}$ desorption accompanied by a small amount of acetone and a slightly smaller amount of butene. There was only a trace of ketene. 


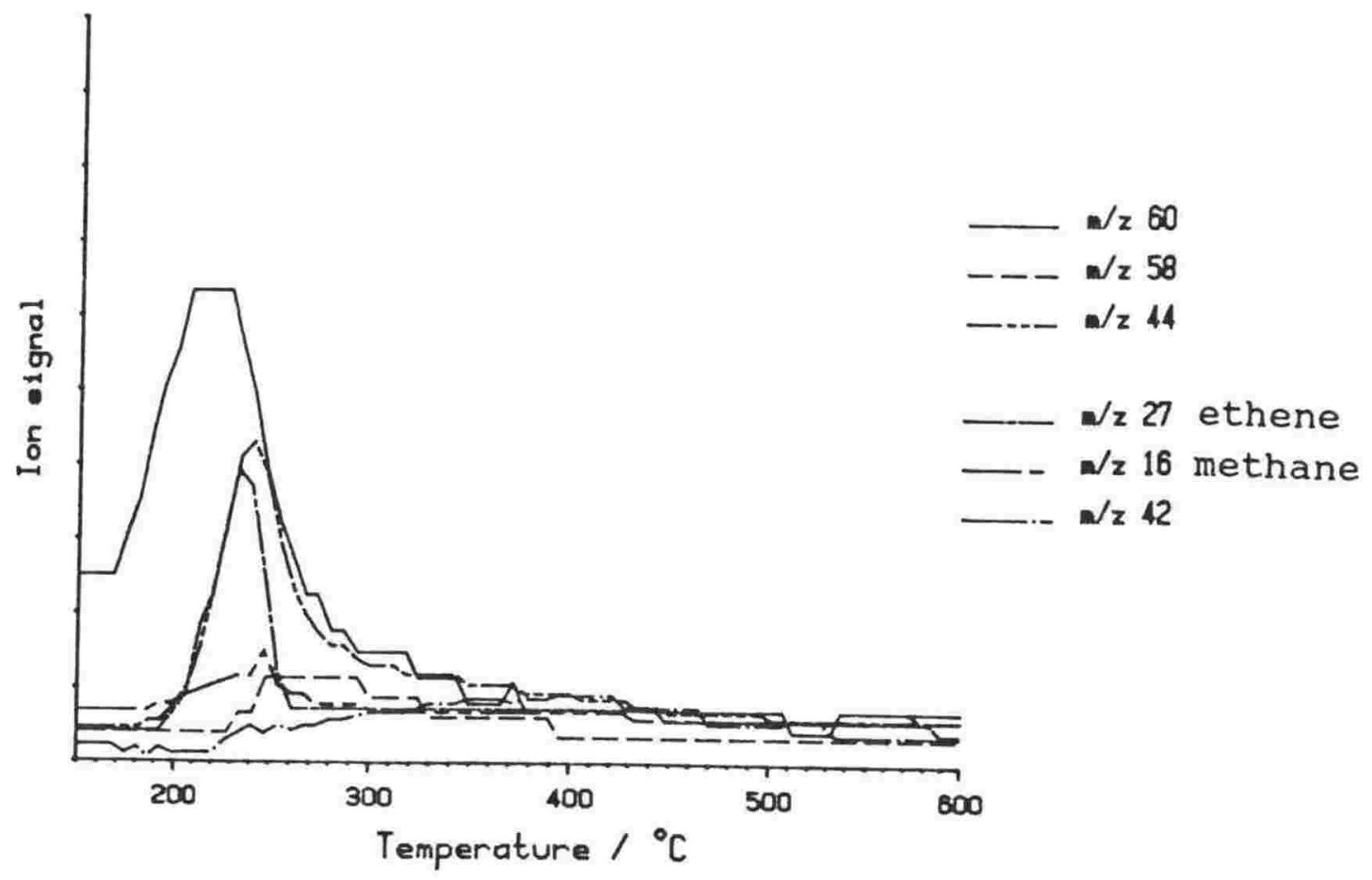

Figure 11.35. Td/ms of acetic acid on $\mathrm{H}+\mathrm{ZSM}-5$.

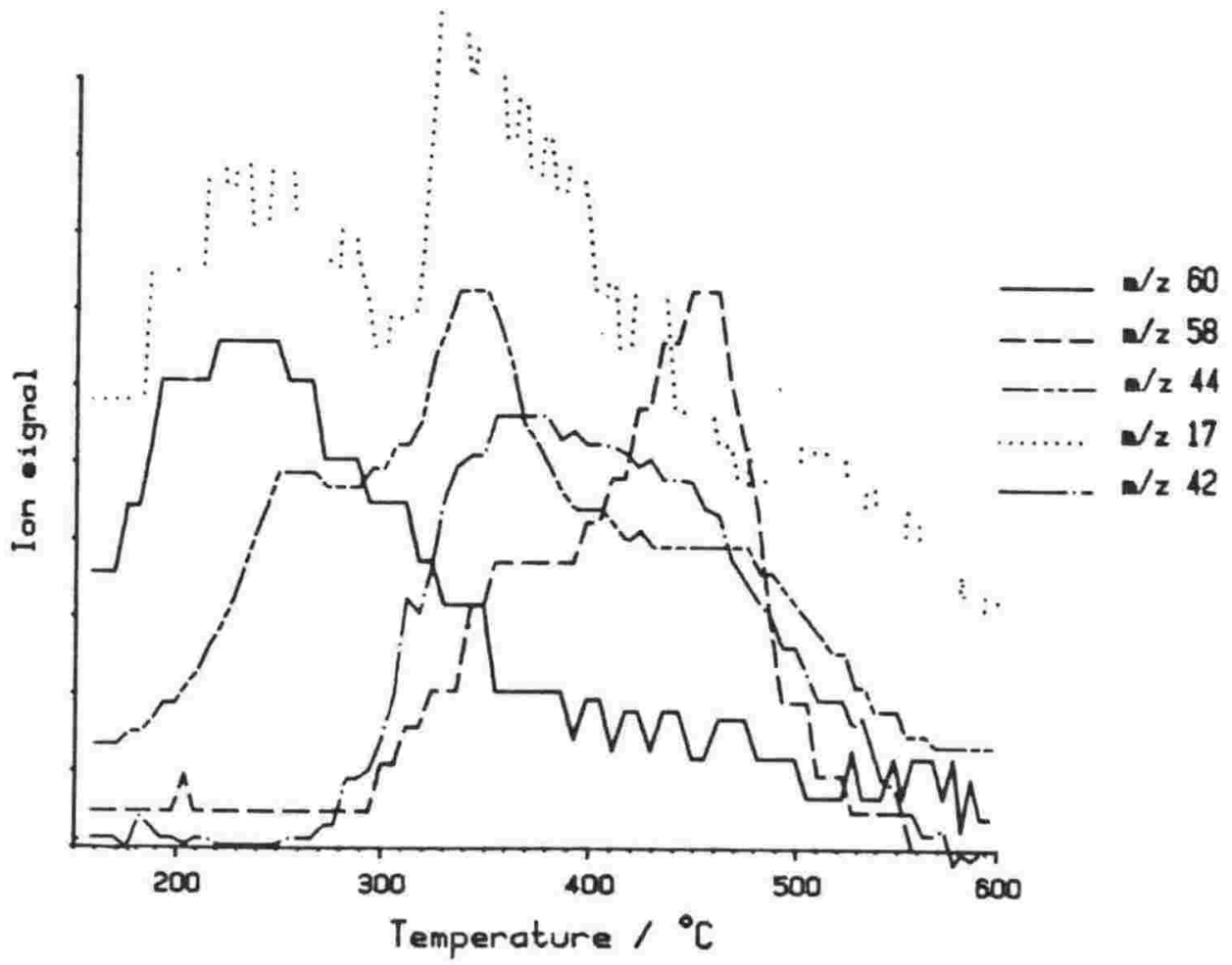

Figure 11.36. Td/ms of acetic acid on Li+ZSM-5. 


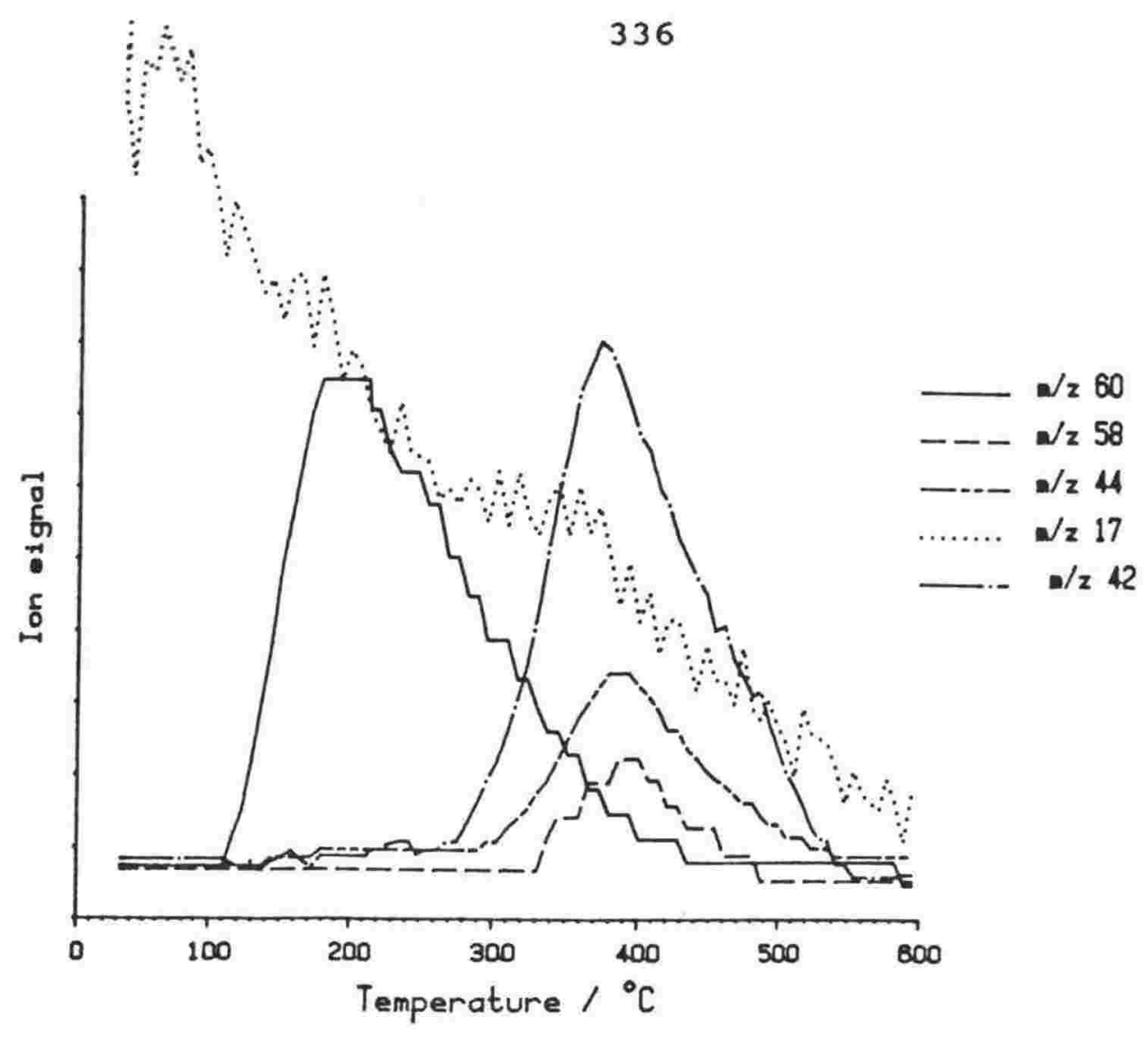

Figure 11.37. Td/ms of acetic acid on Na+2SM-5.

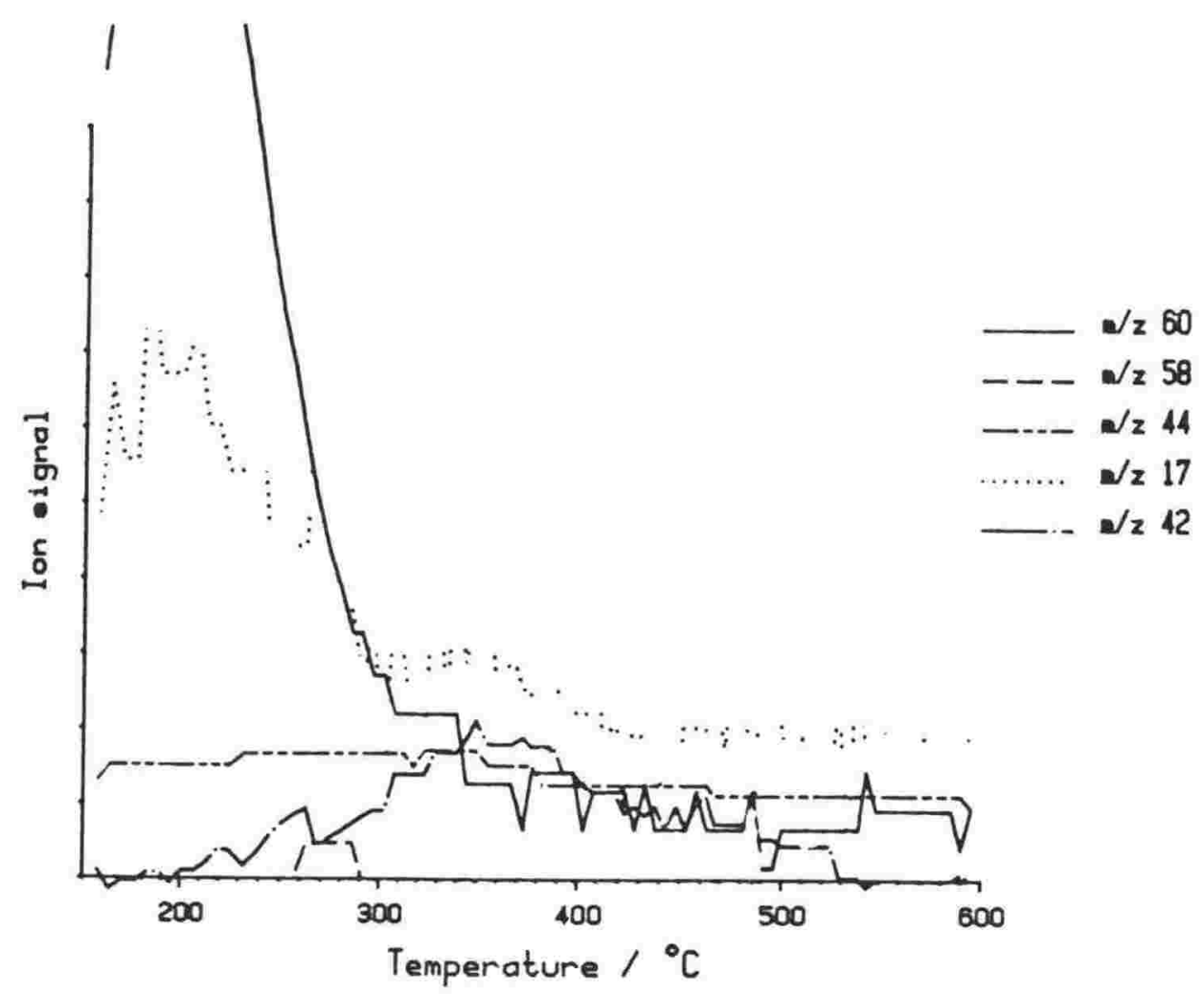

Figure 11.38. Td/ms of acetic acid on $\mathrm{K}+\mathrm{ZSM}-5$. 


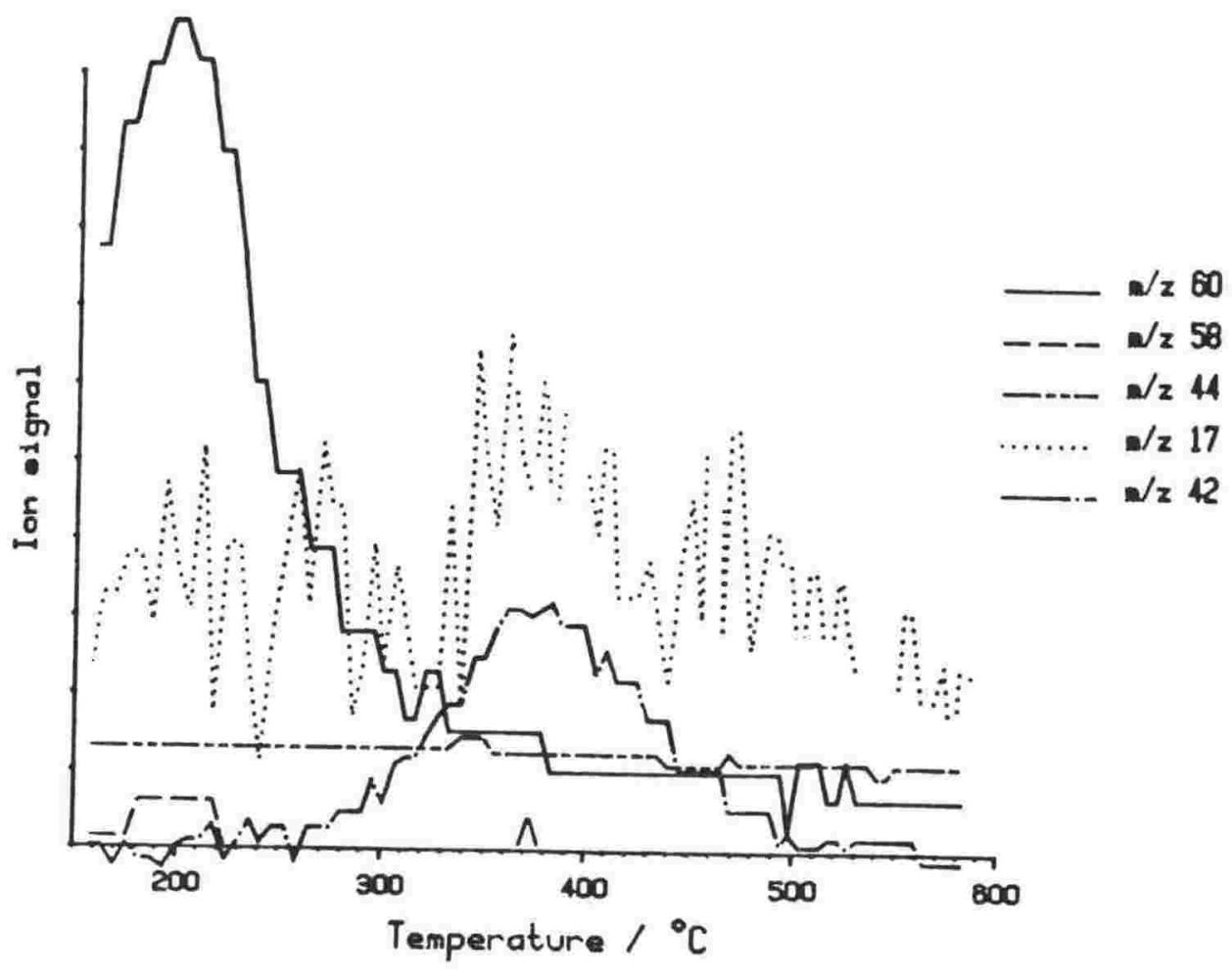

Figure 11.39. Td/ms of acetic acid on Rb+ZSM-5.

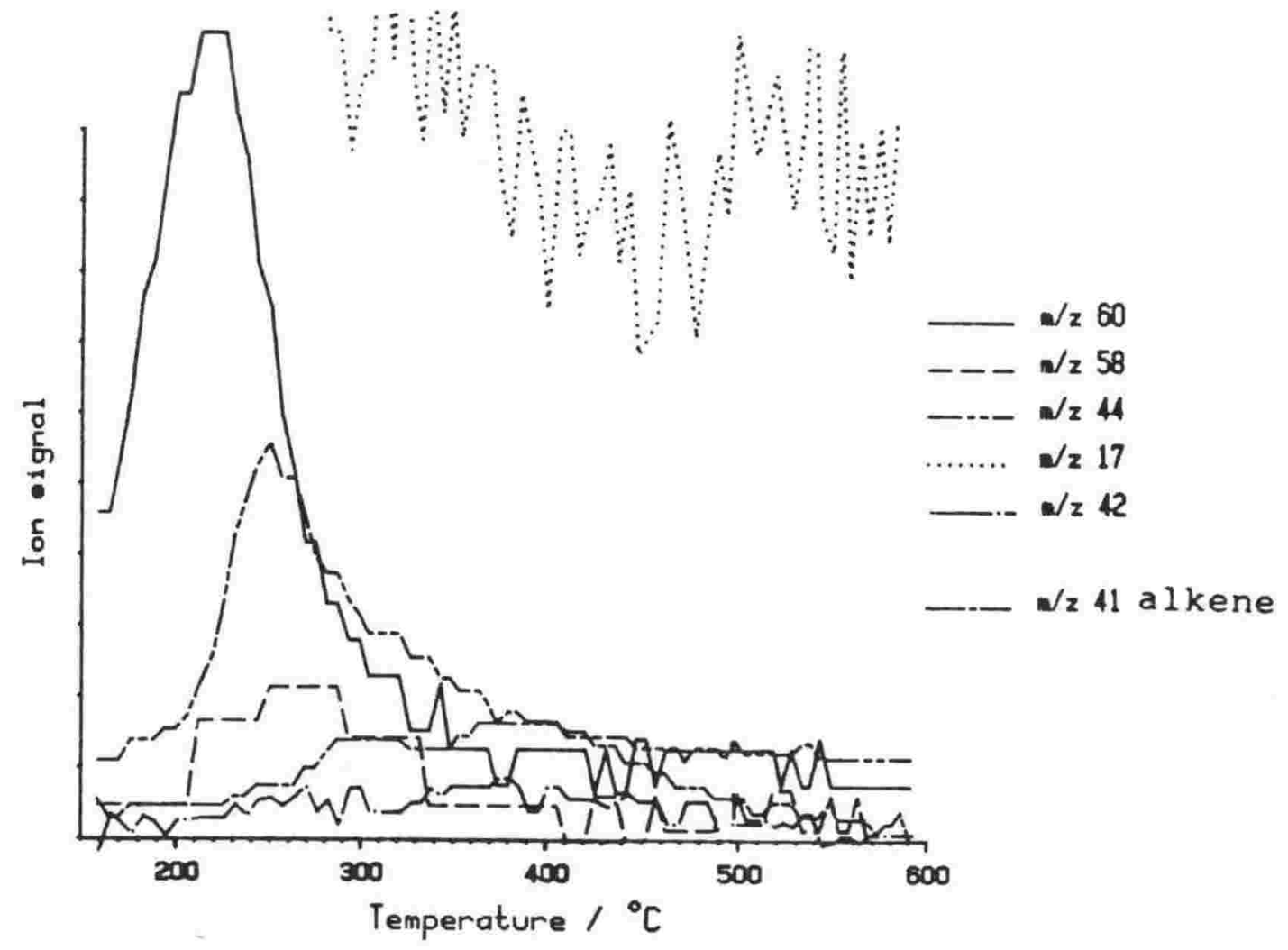

Figure 11.40. Td/ms of acetic acid on $\mathrm{Ca}^{2+} \mathrm{ZSM}-5$. 


\subsection{ALUMINIUM PHOSPHATES:}

Source: supplied by N.J. Tapp according to (8).

Microporous aluminium phosphates (AlPOs) ( 8 ) have three dimensional framework structures in many ways analogous to zeolites where the $\mathrm{SiO}_{2}$ and $\mathrm{AlO}_{2}$ tetrahedra are replaced by alternating $\mathrm{AlO}_{2}^{-}$and $\mathrm{PO}_{2}^{+}$units. Substitution of $\mathrm{Al}$ into the zeolite framework results in the generation of acidic sites, while in AlPO's substitution of $S i$ (for $P$ ) or Co (for Al) into the lattice similarly results in acidic sites. The AlPO studied (AlPO\#5) has a unique framework with no analogous zeolite structure. It has a one dimensional channel system with a pore diameter of $8 \AA(12$ membered rings) $(8,9)$. The unsubstituted AlPO\#5 was expected to have a neutral framework with no ion exchange capacity. However sodium ions did exchange into the lattice, possibly due to defects in the structure.

$\mathrm{Td} / \mathrm{ms}$ of acetic acid on $\mathrm{Na}^{+} \mathrm{AlPO} \#$ (figure 11.41) showed ketene production $\left(\operatorname{Tmax}\right.$ at $430^{\circ} \mathrm{C}$ ), along with small amounts of $\mathrm{CO}_{2}$ (Tmax at $430^{\circ} \mathrm{C}$ ) and acetone. The Si substituted AlPO\#5 (figure 11.42) also showed ketene, but with a much greater amount of acetone and $\mathrm{CO}_{2}$ produced compared to the unsubstituted form. The cobalt substituted AlPO\#5 (figure 11.43) produced $\mathrm{CO}_{2}$ and acetone with less ketene. 


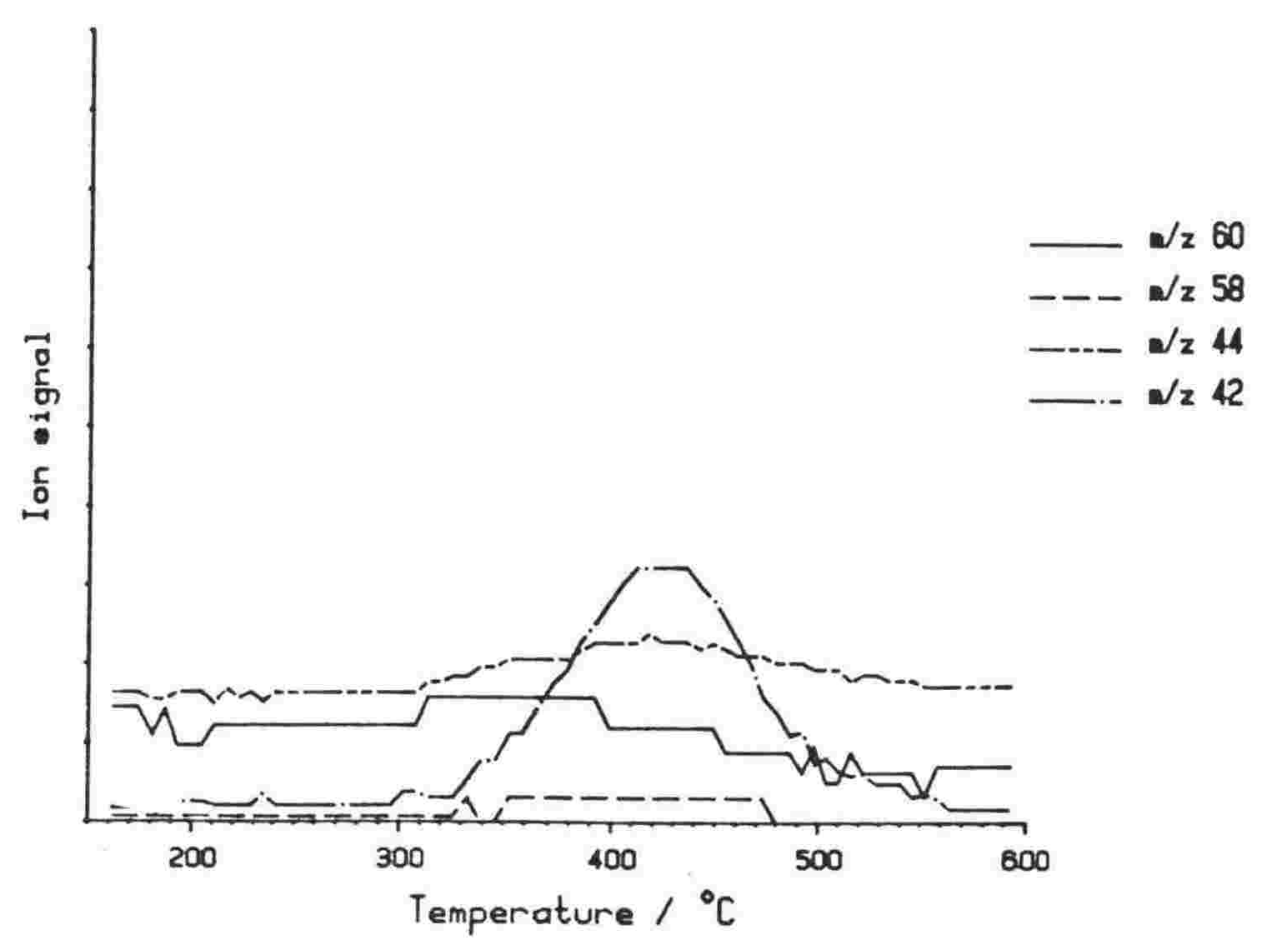

Figure 11.41. Td/ms of acetic acid on Na+AlPO (unsubstituted).

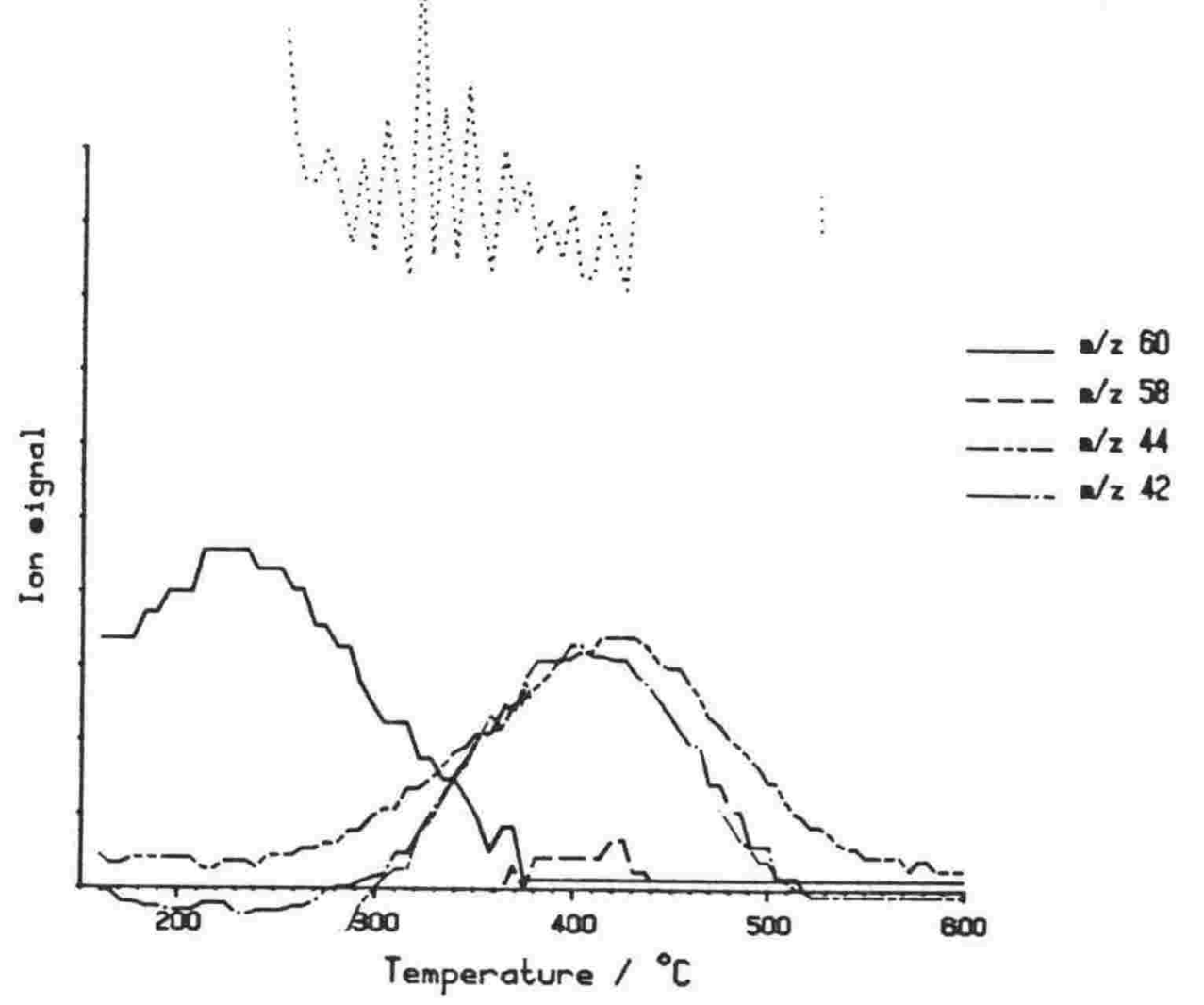

Figure 11.42. Td/ms of acetic acid on Na+AlPO (Si substituted). 


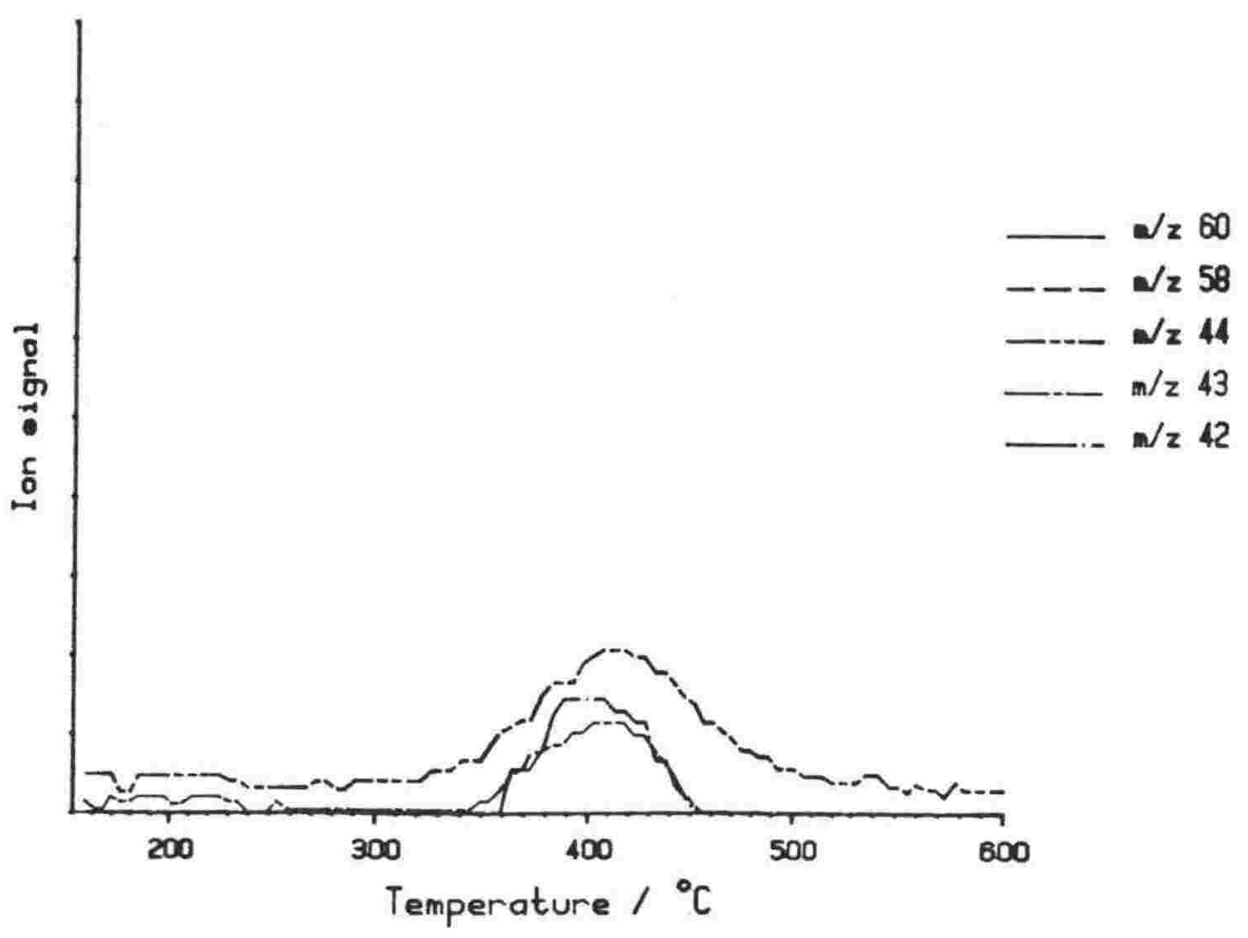

Figure 11.43. Td/ms of acetic acid on Na+AlPO (Co substituted).

\subsection{PILLARED CLAY8:}

Source: synthesied by D. McLauchlan according to (10).

Pillared clays have a layered structure (11) with individual sheets separated by an interlayer space within which reside charge balancing exchangeable cations. Layer spacings are $\sim 18 \AA$ with the clay having a thickness of $9.6 \AA$ and the pillar height estimated at $8.4 \AA$. They have a high surface area of about $250 \mathrm{~m}^{2} \mathrm{~g}^{-1}$ and are stable to about $500^{\circ} \mathrm{C}$.

$\mathrm{Td} / \mathrm{ms}$ of hectorite pillared with iron oxide (figure 11.44) showed a large desorption of unreacted acetic acid and a small amount of ketene with $T \max$ at $340^{\circ} \mathrm{C}$. There was a $\mathrm{CO}_{2}$ desorption with $\mathrm{Tmax}$ at $270^{\circ} \mathrm{C}$ and a $\mathrm{CO}_{2}$ and acetone desorption with $T \max 350^{\circ} \mathrm{C}$. XRD showed a significant reduction in the Xray intensity of the peak due to the spacing between the pillared layers. This was probably due to structural collapse that occurs at temperatures greater than $500^{\circ} \mathrm{C}$.

Al pillared montmorillonite showed no major desorption above $300^{\circ} \mathrm{C}$ except for water (figure 11.45). However a small amount 
of ketene was observed, which, at temperatures less than $500^{\circ} \mathrm{C}$, was greater than the amount of $\mathrm{CO}_{2}$. No acetone was observed.

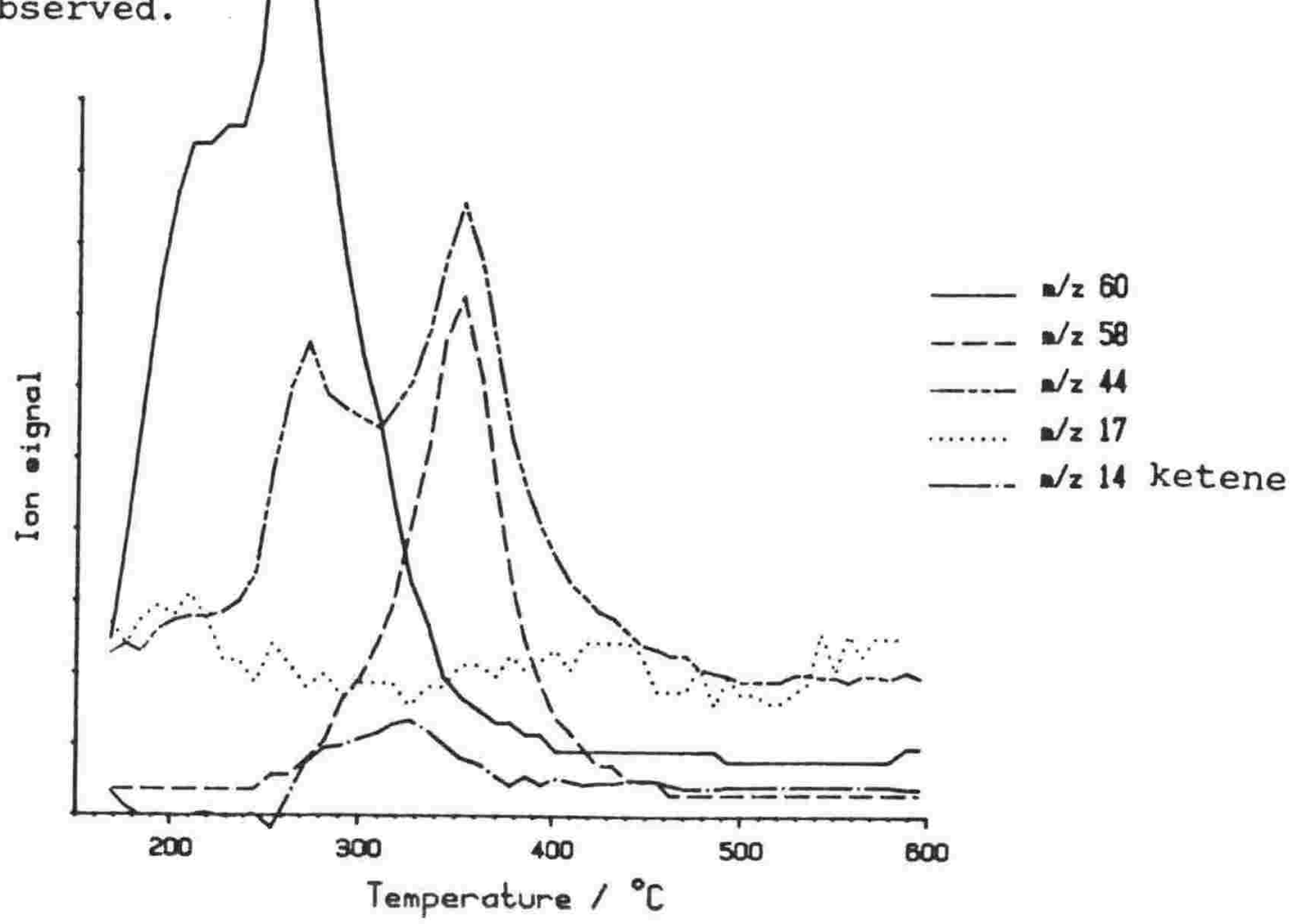

Figure 11.44. Td/ms of acetic acid on Hectorite Iron oxide.

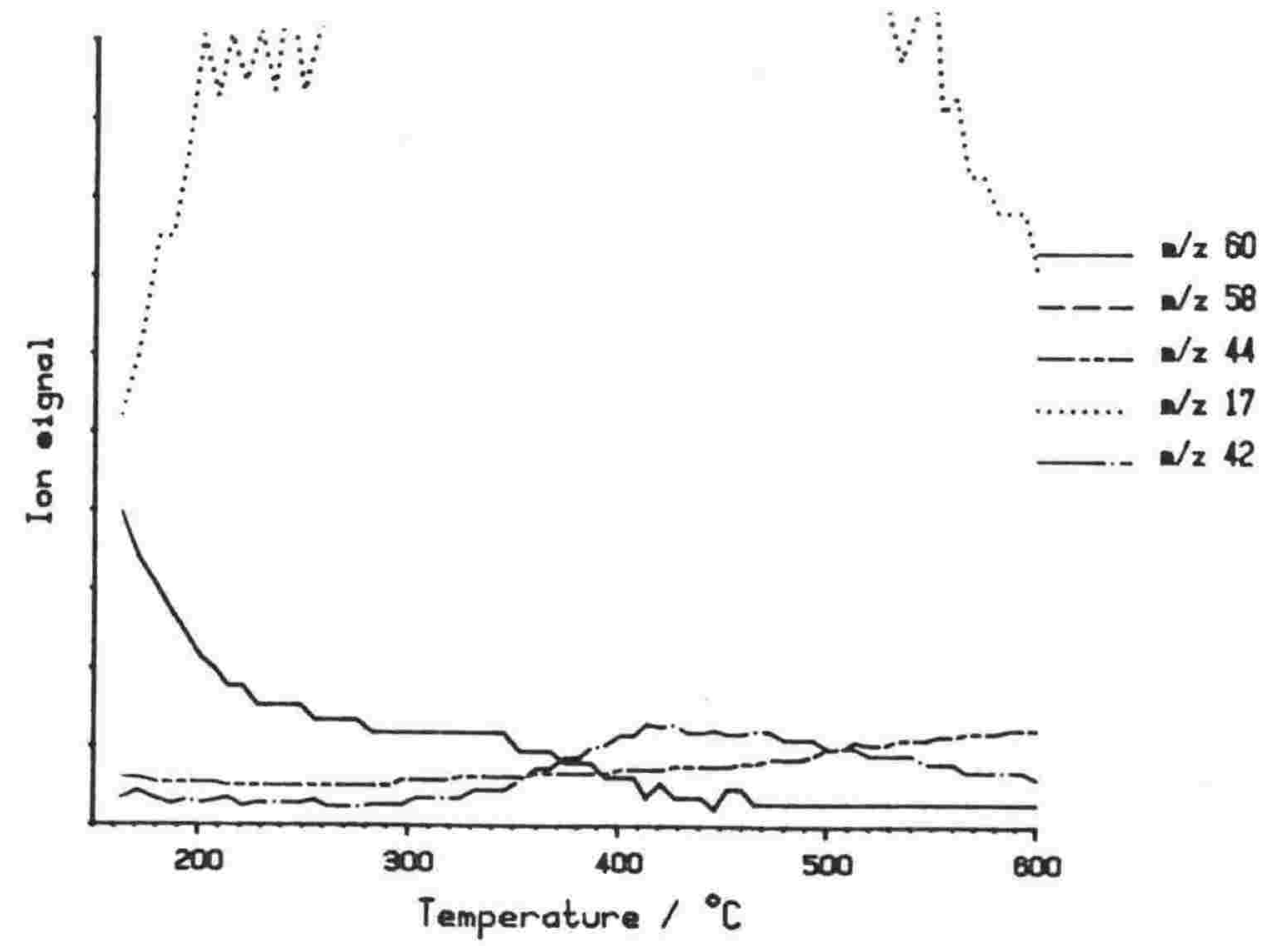

Figure 11.45. Td/ms of acetic acid on Al pillared Montmorillonite. 


\subsection{Amorphous aluminosilicates:}

Source: synthesised according to (12).

Amorphous aluminosilicates have acid sites with a wide range of acid strengths and lack the three dimensional porous lattice structure of zeolites (12).

An amorphous aluminosilicate was prepared from ethylsilicate and aluminium nitrate according to (12). Td/ms (figure 11.46) of the $\mathrm{NH}_{4}^{+}$exchanged aluminosilicate showed a broad $\mathrm{NH}_{3}$ desorption (from 280 to $600^{\circ} \mathrm{C}$ with $\operatorname{Tmax}$ at $390^{\circ} \mathrm{C}$ ) implying a wide range of acid site strengths, with some acid sites of high acid strength, similar to zeolites.

$\mathrm{Td} / \mathrm{ms}$ of acetic acid from Li+aluminosilicate (figure 11.46) showed only a small ketene peak and a slightly larger $\mathrm{CO}_{2}$ peak. There was a very large water desorption with two maxima at $340^{\circ} \mathrm{C}$ and $470^{\circ} \mathrm{C}$. Further exchange in Licl solution for two days, followed by a repeat $t d / m s$ reproduced this result. A comparison of the $t d / m s$ plots for water and ammonia shows that water is lost at only a slightly lower temperature than ammonia. This implies that the Li+aluminosilicate has an affinity for water similar to that for ammonia. The acetic acid, when sorbed at $150^{\circ} \mathrm{C}$, seemed to have displaced very little of the bound water. This may be because it had reacted to form $\mathrm{LiOH}$.

High temperature water desorption was not observed for aluminosilicates exchanged with $\mathrm{Na}^{+}, \mathrm{K}^{+}$or $\mathrm{Ca}^{2+}$. These three cases were similar (figures 11.48, 11.49, 11.50), with the major product being $\mathrm{CO}_{2}$ and a broad desorption of ketene from $300^{\circ} \mathrm{C}$ to $600^{\circ} \mathrm{C}\left(\operatorname{Tmax}\right.$ at $\left.\sim 380^{\circ} \mathrm{C}\right)$. Butene also desorbed (Tmax at $420^{\circ} \mathrm{C}$ ) then methane $\left(\operatorname{Tmax}\right.$ at $\left.540^{\circ} \mathrm{C}\right)$. Methane and $\mathrm{CO}_{2}$ were produced from the decomposition of the catalyst-acetic acid complex at temperatures above $450^{\circ} \mathrm{C}$. Butene desorption showed that some acidic behaviour remained. The $\mathrm{K}^{+}$exchanged catalyst may be the best out of these three as, in this case, more ketene was produced than $\mathrm{CO}_{2}$ at $380^{\circ} \mathrm{C}$. 


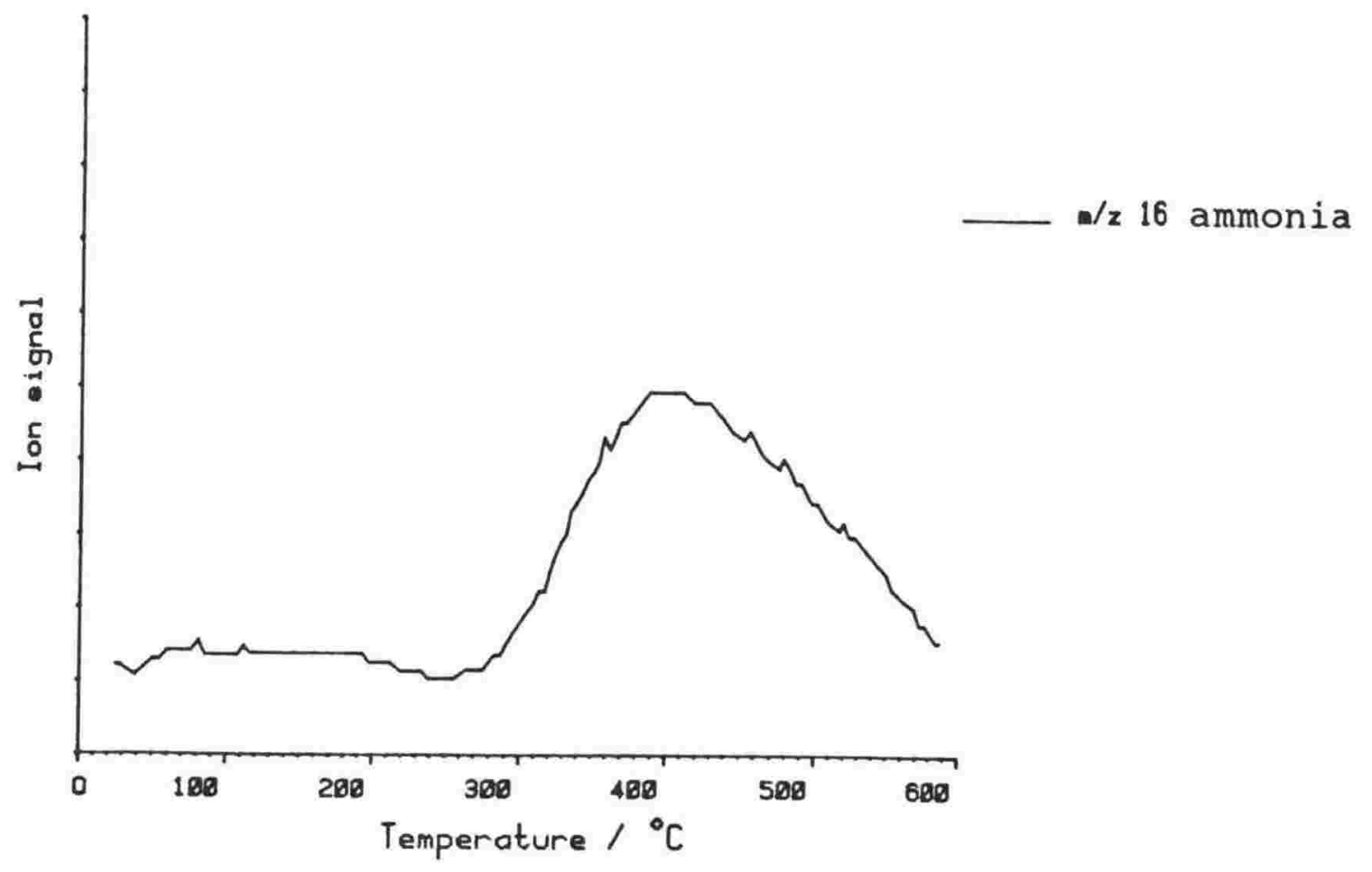

Figure 11.46. Td/ms of $\mathrm{NH}_{4}^{+}$exchanged alumino-silicate.

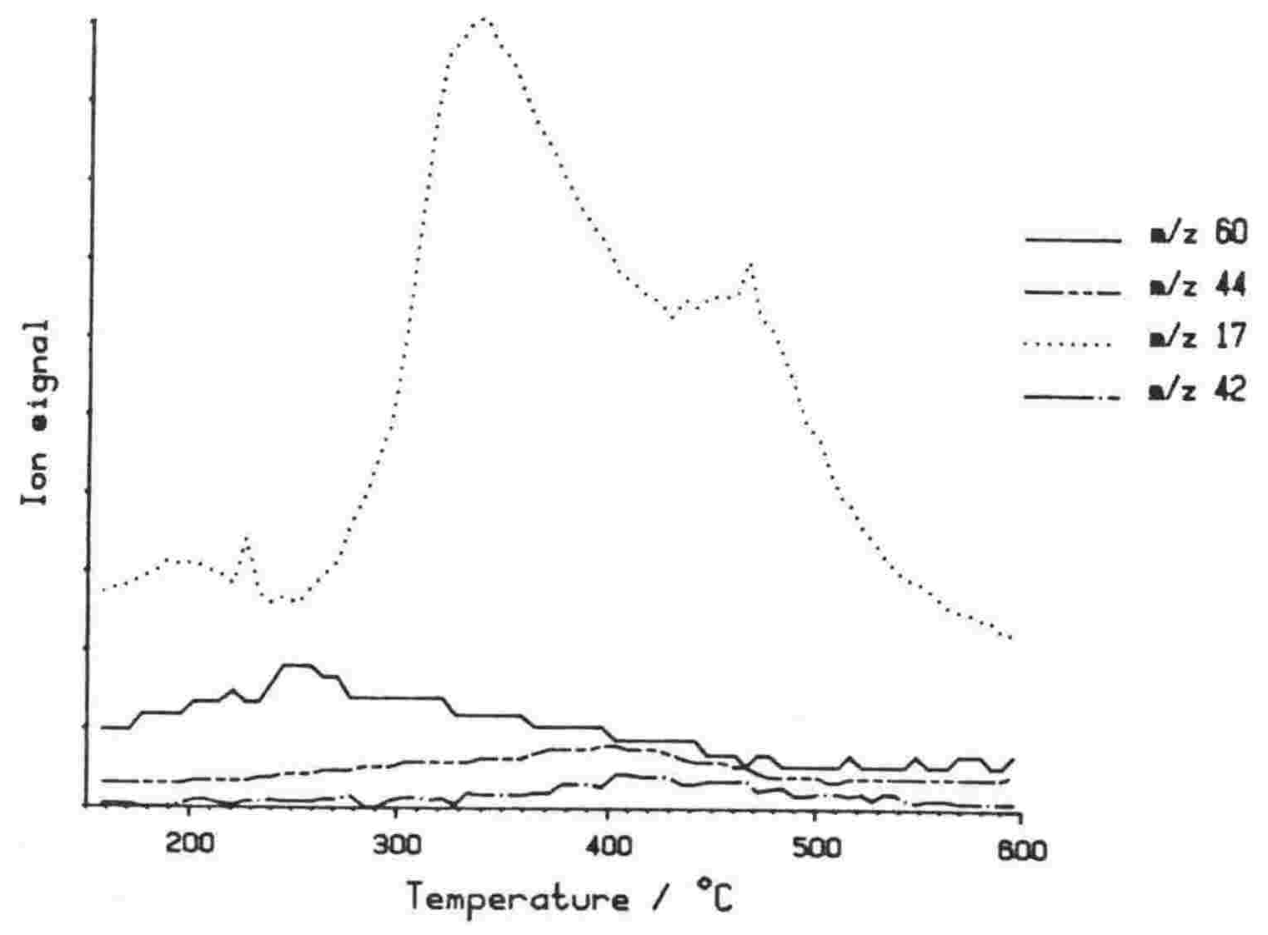

Figure 11.47. Td/ms of acetic acid on Litalumino-silicate. 


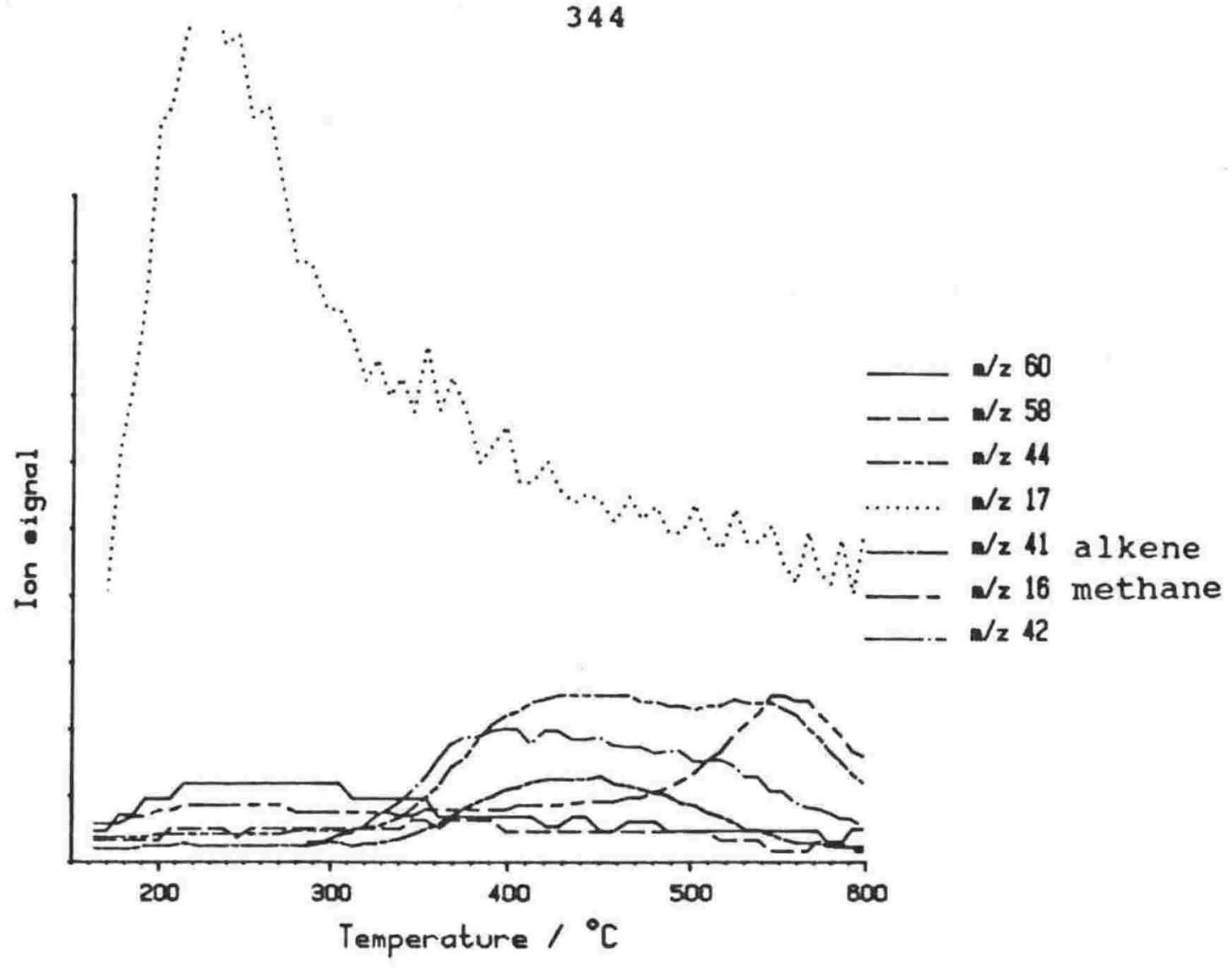

Figure 11.48. Td/ms of acetic acid on Natalumino-silicate.

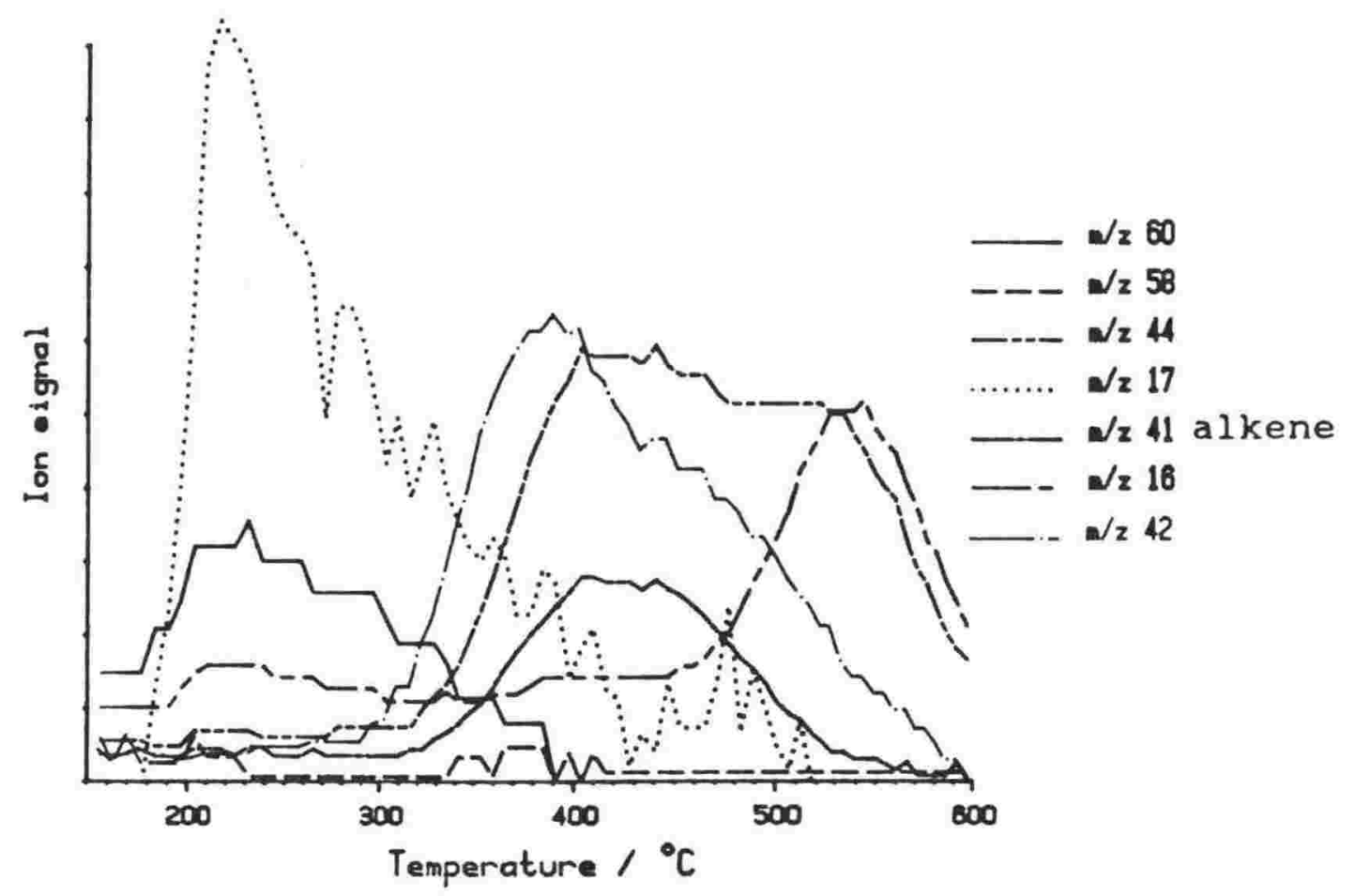

Figure 11.49. Td/ms of acetic acid on K+alumino-silicate. 


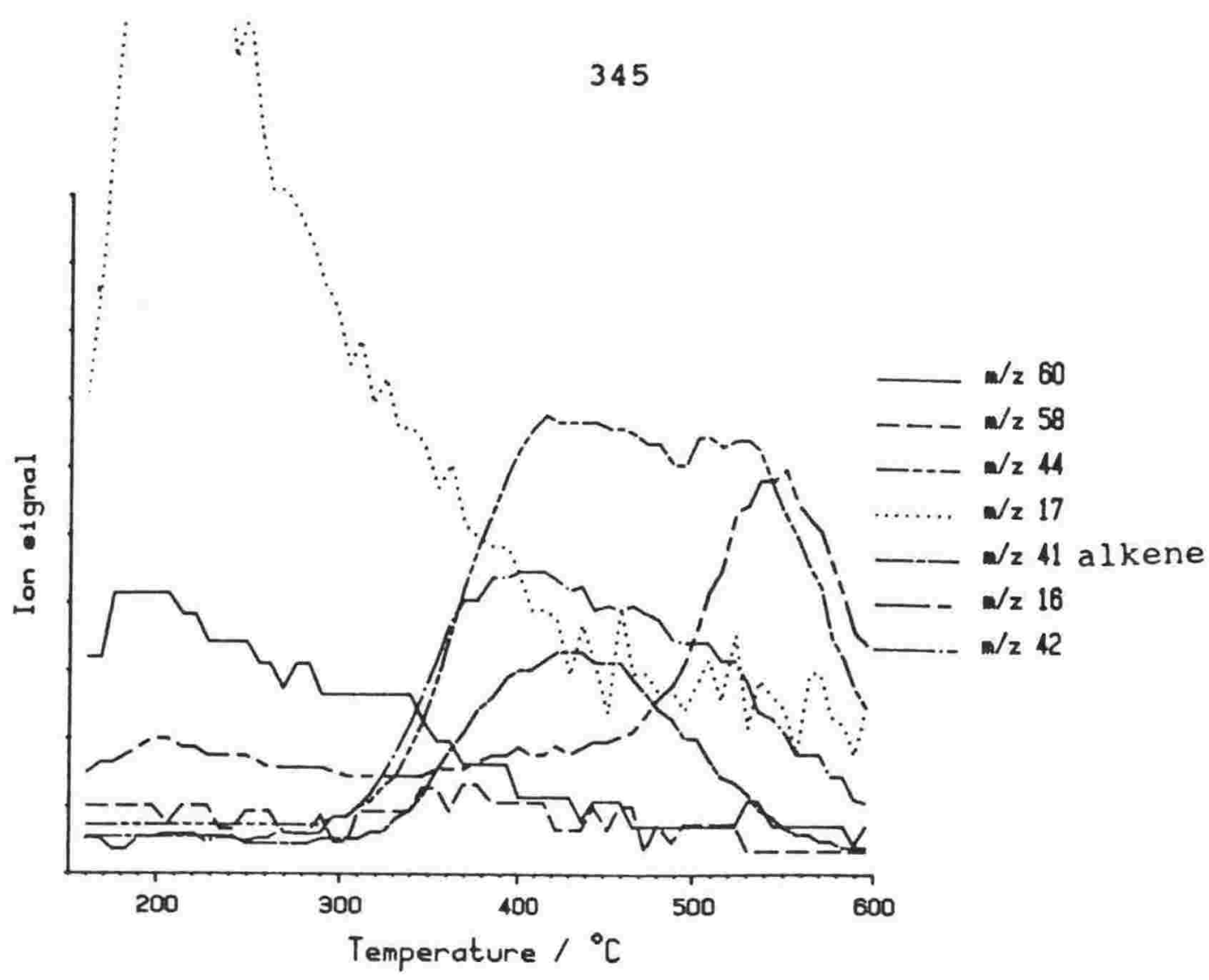

Figure 11.50. Td/ms of acetic acid on $\mathrm{Ca}^{2+}$ alumino-silicate.

\subsection{Titanium Dioxide (Anatase):}

Source: Baker Analysed reagent.

Acetic acid on titanium dioxide in the anatase form has previously been studied by IR and a sorbed ketene species proposed, although ketene was not observed in the reaction products (13).

No acetic acid could be sorbed onto the $\mathrm{TiO}_{2}$ anatase used here without pretreatment. Following the proceedure given in (13), the $\mathrm{TiO}_{2}$ was fired overnight at $350^{\circ} \mathrm{C}$ then immediately weighed into the $t d / m s$ tube and heated to $350^{\circ} \mathrm{C}$ under vacuum for 10 minutes. After cooling to $150^{\circ} \mathrm{C}$, acetic acid was sorbed. The $t d / m s$ is shown in figure 11.51. Very little acetic acid was strongly sorbed, but there was a barely significant ketene desorption along with a small amount of acetic acid and $\mathrm{CO}_{2}$. A drop of acetic acid was placed on the $\mathrm{TiO}_{2}$ sample after this run and another $t d / m s$ carried out. Almost all the acetic acid desorbed below $80^{\circ} \mathrm{C}$. There was no significant ketene production, only a small acetic acid and $\mathrm{CO}_{2}$ desorption. 
These results agree with the observation that some ketene could be formed on $\mathrm{TiO}_{2}$ anatase, but also show that the amounts observed in the products are insignificant. They suggest that careful pre-treatment of the catalyst is necessary to achieve any sorptive capacity.

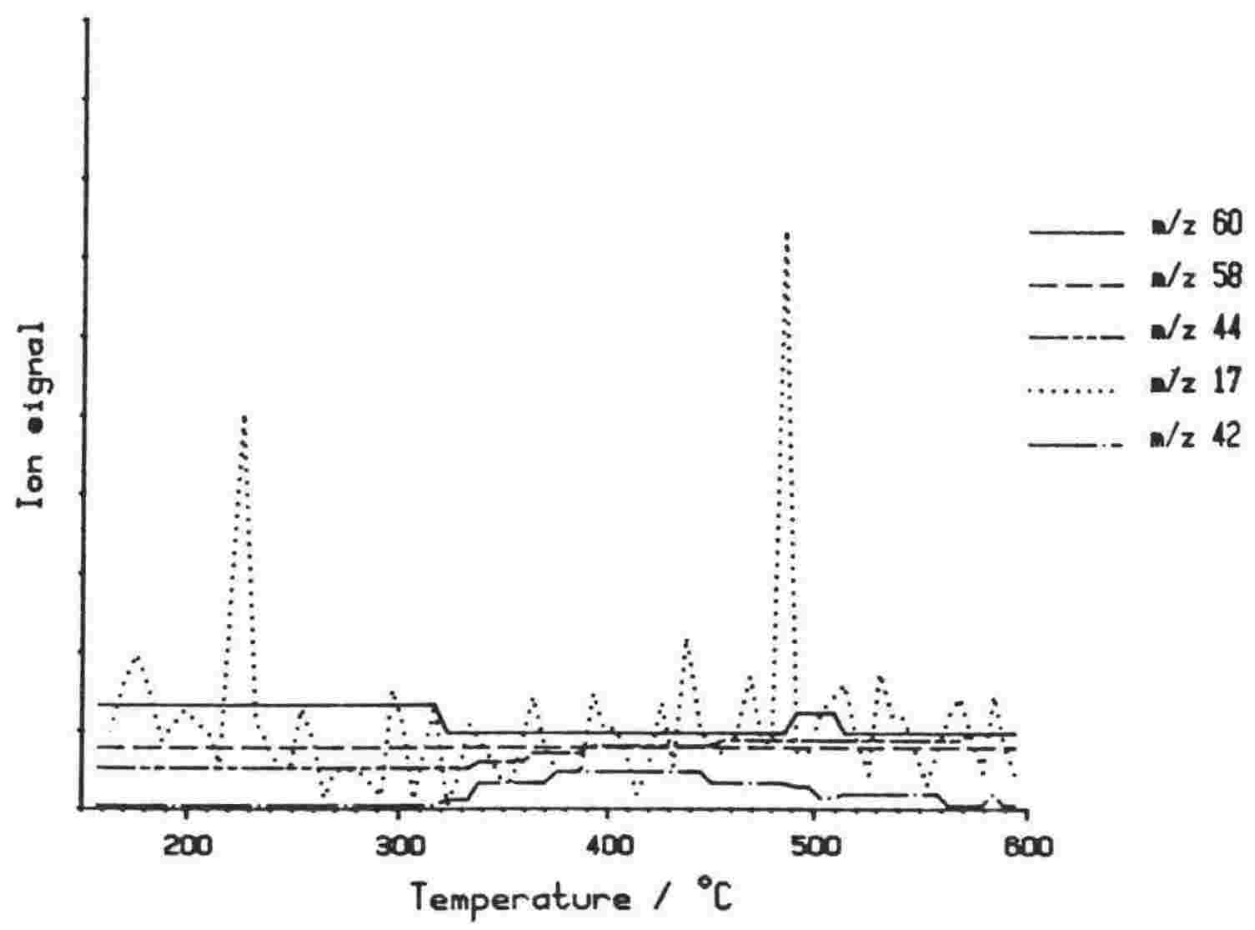

Figure 11.51. Td/ms of acetic acid on $\mathrm{TiO}_{2}$ anatase.

FOR DISCUSSION AND CONCLUSIONS BEE CHAPTER 10. 


\subsection{REFERENCES :}

1. Breck, D.W., 'Zeolite Molecular Sieves', Wiley, New York, 1974.

2. Ward, J.W., Applied Industrial Catalysis, 1984, 3, 271.

3. MCDaniel C.V., and Maher P.K., 'Zeolite Chemistry and Catalysis', Rabo J.A. Ed., American Chemical Society Monograph 171, 1976, 285.

4. Shannon R.D., Gardner K.H., Staley R.H., Bergeret G., Gallezot P. and Auroux A., J. Phys. Chem., 1985, 89, 4779.

5. Parker L.M., Bibby D.M., and Meinhold R.H., Zeolites, $1985,5,384$.

6. Kokotailo G.T., Lawton S.L., Olson D.H. and Meier W.M., Nature, 1978, 272, 437.

7. Duval C., 'Inorganic Thermogravimetric Analysis', Elsevier, Amsterdam, 1963.

8. Tapp N.J., PhD Thesis, Victoria University, New Zealand, 1988 .

9. Bennett J.M., Cohen J.P., Flanigen E.M., Pluth J.J. and Smith J.V., Am Chem. Soc. Sym. Ser., 1983, 218, 109.

10. Brindley G.W. and Yamanaka S., American Mineralogist, $1979,64,830$.

11. Tennakoon D.T.B., Jones W. and Thomas J.M., J. Chem. Soc. Faraday Trans 1, 1986, 82, 3081.

12 Bourne K.H., Cannings F.R. and Pitkethly R.C., J. Phys. Chem., 1970, 74, 2197.

13. Gonzalez F., Munuera G., Prieto J.A. J. Chem. Soc. Faraday Trans. 1, 1978, 76, 1517. 
APPENDIX III: LIST OF PUBLICATIONS FROM THIS THESIS

1. Parker L.M. "Sorption of acetic acid on H+ZSM-5", Studies in Surface Science and Catalysis, Bibby D.M. et al. editors, Elsevier, Amsterdam, 1988, 36, 589.

2. Parker L.M., Bibby D.M. and Burns G.R., "Interaction of water with the zeolite HY, studied by FTIR", accepted for publication in Zeolites, 1989.

3. Parker L.M., Bibby D.M. and Burns G.R., "FTIR spectra of bases sorbed on H+ZSM-5 - a study of hydrogen bonding", to be presented at the International Zeolite Conference, Amsterdam, 1989 and published in the proceedings.

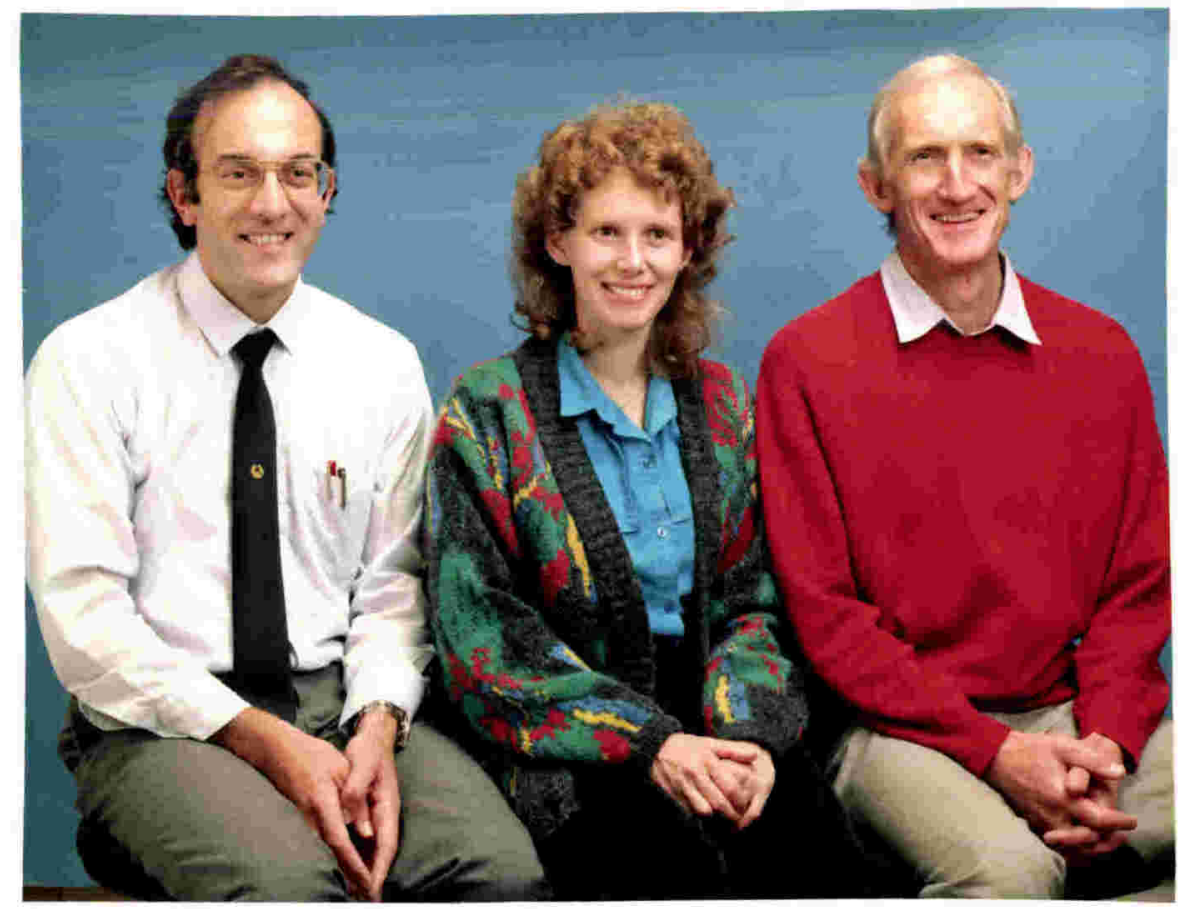

Dave Bibby, Linda Parker and Gary Burns, May 1989. 